\title{
PSDF
}

Power Systems Development Facility

Technical Progress Report

Gasification Test Run TC07

December 11, 2001 April 5, 2002

DOE Cooperative Agreement Number of What DE-FC21-90MC25140
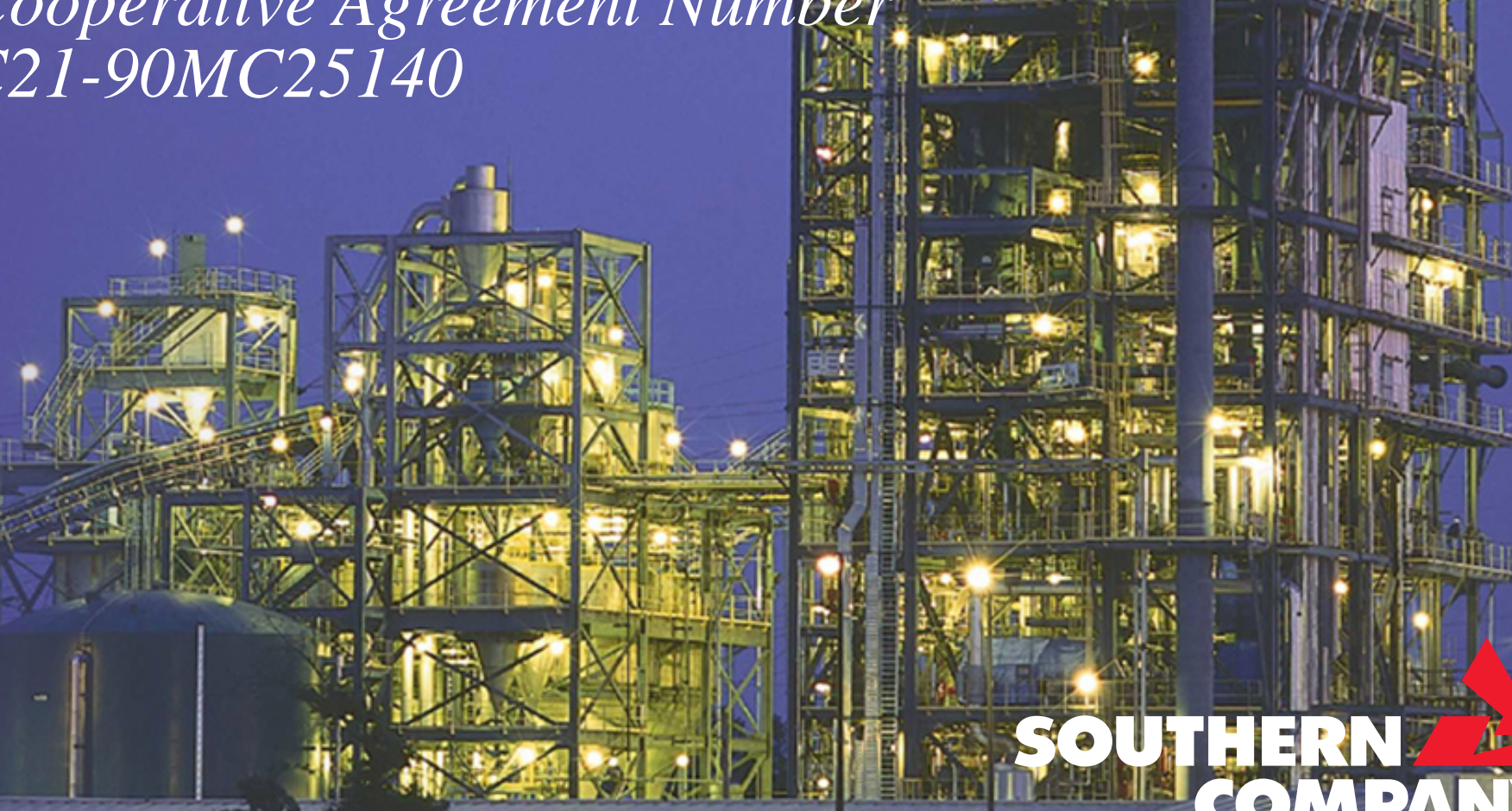

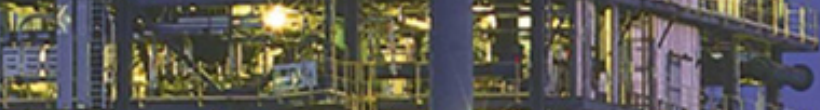
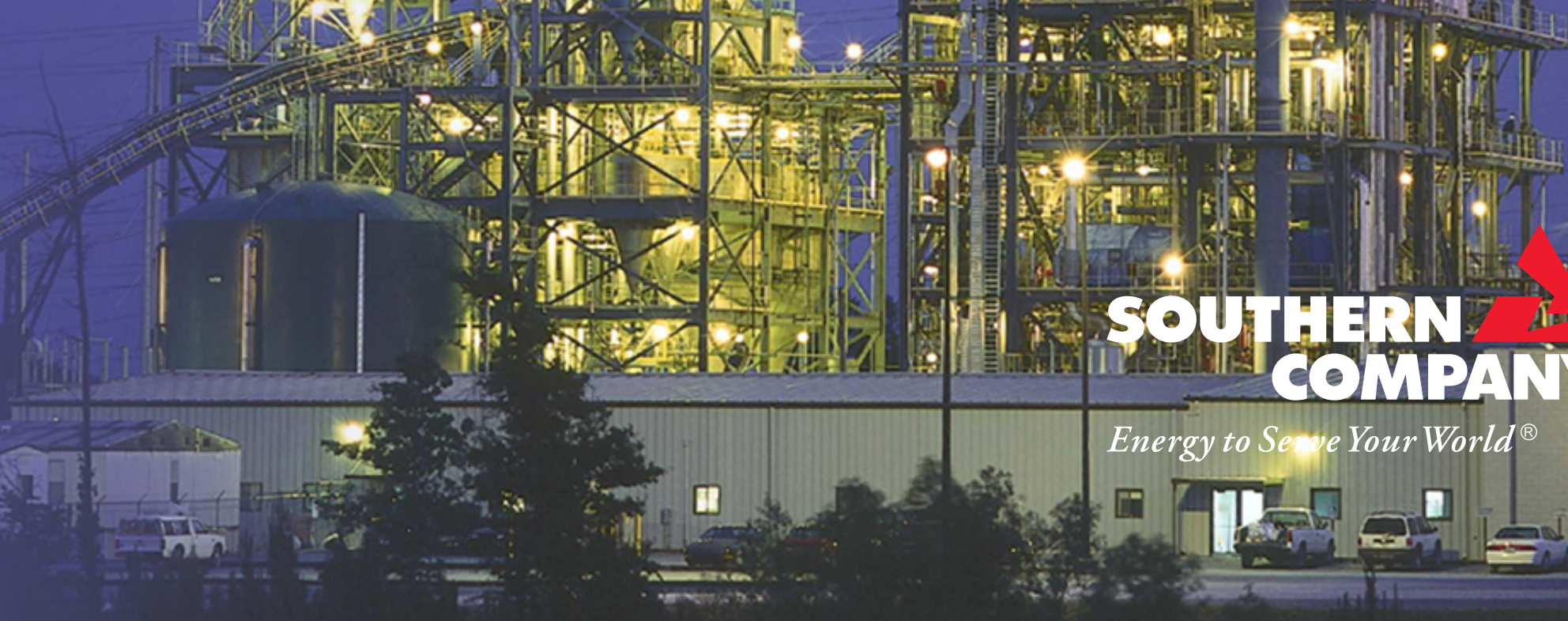

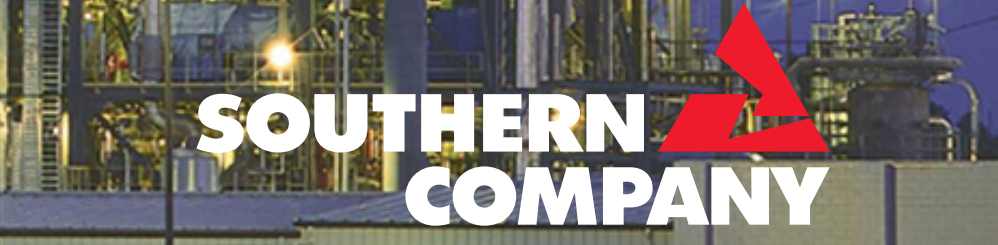

Energy to Se re Your World ${ }^{\circledR}$ 


\title{
POWER SYSTEMS DEVELOPMENT FACILITY TECHNICAL PROGRESS REPORT
}

\author{
GASIFICATION TEST RUN TC07
}

DECEMBER 11, 2001 - APRIL 5, 2002

DOE Cooperative Agreement Number

DE-FC21-90MC25140

\author{
Prepared by: \\ Southern Company Services, Inc. \\ Power Systems Development Facility \\ P.O. Box 1069 \\ Wilsonville, AL 35186 \\ Tel: 205-670-5840 \\ Fax: 205-670-5843 \\ http://psdf.southernco.com
}

February 2003 


\section{POWER SYSTEMS DEVELOPMENT FACILITY}

\section{DISCLAIMER}

This report was prepared as an account of work sponsored by an agency of the United States Government. Neither the United States Government nor any agency thereof, nor any of their employees, nor Southern Company Services, Inc., nor any of its employees, nor any of its subcontractors, nor any of its sponsors or cofunders, makes any warranty, expressed or implied, or assumes any legal liability or responsibility for the accuracy, completeness, or usefulness of any information, apparatus, product, or process disclosed, or represents that its use would not infringe privately owned rights. Reference herein to any specific commercial product, process, or service by trade name, trademark, manufacturer or otherwise, does not necessarily constitute or imply its endorsement, recommendation, or favoring by the United States Government or any agency thereof. The views and opinions of authors expressed herein do not necessarily state or reflect those of the United States Government or any agency thereof.

Available to the public from the National Technical Information Service, U.S. Department of Commerce, 5285 Port Royal Road, Springfield, VA 22161. Phone orders accepted at (703) 487-4650. 


\begin{abstract}
This report discusses Test Campaign TC07 of the Kellogg Brown \& Root, Inc. (KBR) Transport Reactor train with a Siemens Westinghouse Power Corporation (Siemens Westinghouse) particle filter system at the Power Systems Development Facility (PSDF) located in Wilsonville, Alabama. The Transport Reactor is an advanced circulating fluidized-bed reactor designed to operate as either a combustor or a gasifier using a particulate control device (PCD). The Transport Reactor was operated as a pressurized gasifier during TC07. Prior to TC07, the Transport Reactor was modified to allow operations as an oxygen-blown gasifier.

Test Run TC07 was started on December 11, 2001, and the sand circulation tests (TC07A) were completed on December 14, 2001. The coal-feed tests (TC07B-D) were started on January 17, 2002 and completed on April 5, 2002. Due to operational difficulties with the reactor, the unit was taken offline several times. The reactor temperature was varied between 1,700 and $1,780^{\circ} \mathrm{F}$ at pressures from 200 to 240 psig. In TC07, 679 hours of solid circulation and 442 hours of coal feed, 398 hours with PRB coal and 44 hours with coal from the Calumet mine, and 33 hours of coke breeze feed were attained. Reactor operations were problematic due to instrumentation problems in the LMZ resulting in much higher than desired operating temperatures in the reactor. Both reactor and PCD operations were stable and the modifications to the lower part of the gasifier performed well while testing the gasifier with PRB coal feed.
\end{abstract}




\section{ACKNOWLEDGMENT}

The authors wish to acknowledge the contributions and support provided by various project managers: Jim Longanbach (DOE), Neville Holt (EPRI), Cheryl Chartier (KBR), Zal Sanjana (Siemens Westinghouse), and Vann Bush (SRI). Also, the enterprising solutions to problems and the untiring endeavors of many personnel at the site during commissioning of the transport reactor train in gasification mode of operation are greatly appreciated. The project was sponsored by the U.S. Department of Energy National Energy Technology Laboratory under contract DE-FC21-90MC25140. 


\section{CONTENTS}

$\underline{\text { Section }}$

$\underline{\text { Page }}$

Inside Cover

Disclaimer

Abstract

Acknowledgment

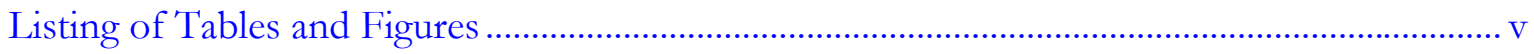

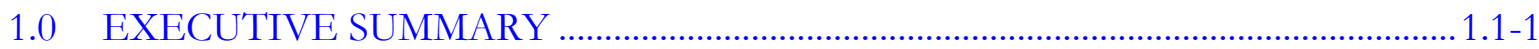

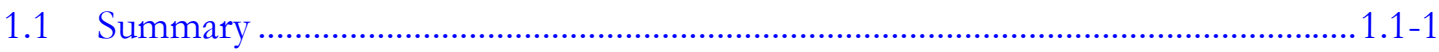

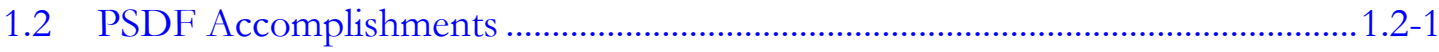

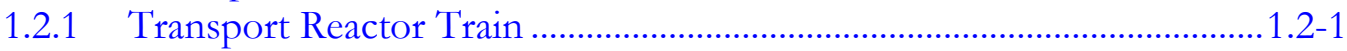

1.2.2 Particulate Control Device ....................................................................1.2-3

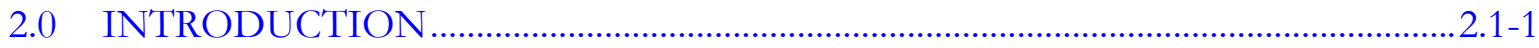

2.1 Power Systems Development Facility ....................................................................... 2.1

2.2 Transport Reactor System Description ...................................................................2.2.

2.3 Siemens Westinghouse Particulate Control Device...................................................2.3-1

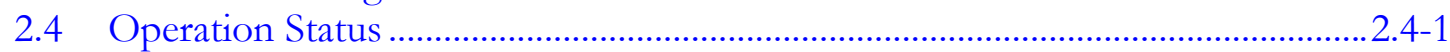

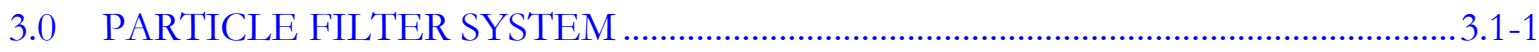

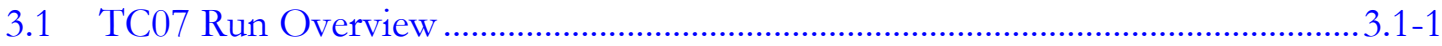

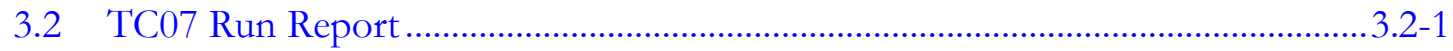

3.2.1 TC07B and TC07C ......................................................................................

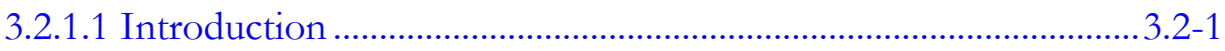

3.2.1.2 Test Objectives ....................................................................................

3.2.1.3 Major Operating Events.................................................................... 3.2-2

3.2.1.4 Run Summary and Analysis .........................................................3.2-4

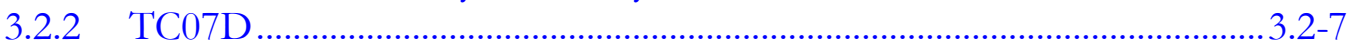

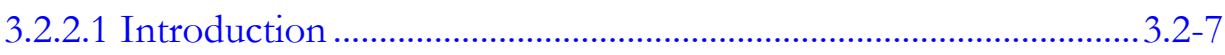

3.2.2.2 Test Objectives ....................................................................... 3.2-7

3.2.2.3 Major Operating Events................................................................ 3.2-8

3.2.2.4 Run Summary and Analysis ............................................................. 3.2-9

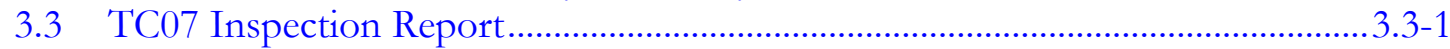

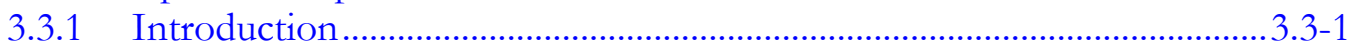

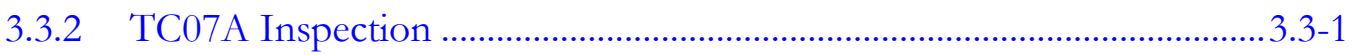

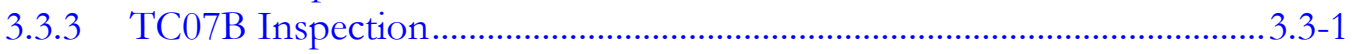

3.3.4 TC07C Inspection...............................................................................3.3-2

3.3.4.1 TC07C Filter Elements.................................................................3.3-2

3.3.4.2 TC07C Gasification Ash Deposition ...............................................3.3-4

3.3.4.3 TC07C Filter Element Gaskets ...........................................................3.3-6

3.3.4.4 TC07C Failsafe Inspection ……...................................................3.3-6 


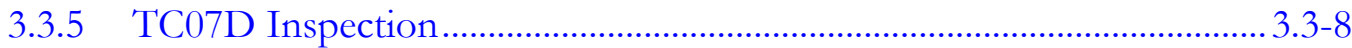

3.3.5.1 TC07D Filter Elements .................................................................

3.3.5.2 TC07D Gasification Ash Deposition.............................................. 3.3-11

3.3.5.3 TC07D Filter Element Gasket.....................................................3.3-11

3.3.5.4 TC07D Failsafe Devices …………..........................................3.3-12

3.3.5.5 Auxiliary Equipment...................................................................3.3-15

3.3.5.6 Fine Solids Removal System Inspection......................................3.3-16

3.4 TC07 Gasification Ash Characteristics and PCD Performance ..............................3.4-1

3.4.1 In situ Sampling ......................................................................................... 3.4

3.4.1.1 PCD Inlet Particle Mass Concentrations .......................................3.4-2

3.4.1.2 PCD Outlet Particle Mass Concentrations ......................................3.4-2

3.4.1.3 Syngas Moisture Content ........................................................... 3.4-3

3.4.1.4 Real-Time Particle Monitoring ......................................................3.4-4

3.4.2 Sampling of PCD Dustcakes and Consolidated Deposits .........................3.4-5

3.4.2.1 Physical Properties of In situ Samples and Dustcakes ..................3.4-6

3.4.2.2 In situ Particulate Samples ................................................................. 3.4-6

3.4.2.3 Dustcake Samples .................................................................................. 3.4-7

3.4.2.4 Chemical Composition of In situ Samples and Dustcakes ...........3.4-8

3.4.2.5 In situ Particulate Samples ............................................................... 3.4-8

3.4.2.6 Dustcake Samples ............................................................................ 3.4-9

3.4.2.7 Particle-Size Analysis of In situ Samples ...................................... 3.4-10

3.4.3 Laboratory Measurements of Gasification Ash Drag ..............................3.4-11

3.4.4 Analysis of PCD Pressure Drop................................................................... 12

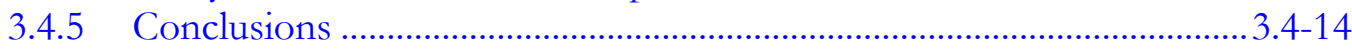

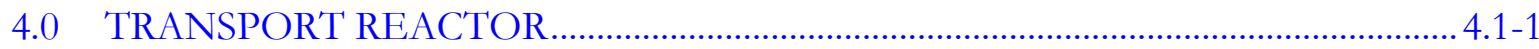

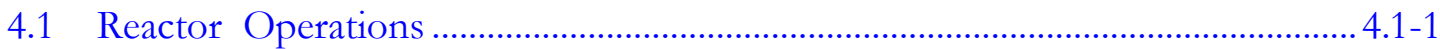

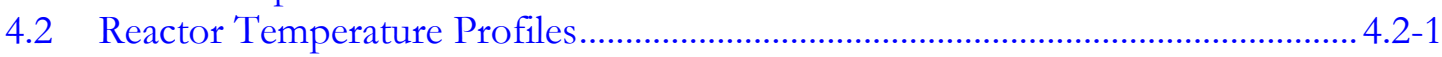

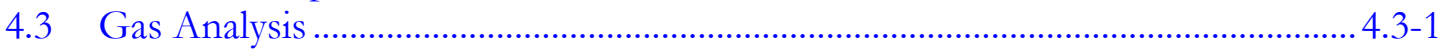

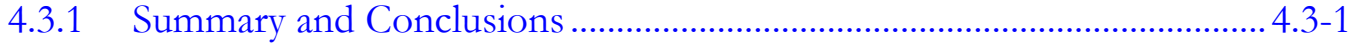

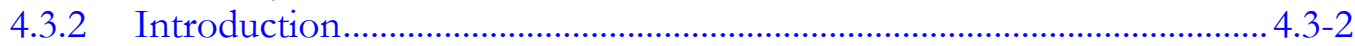

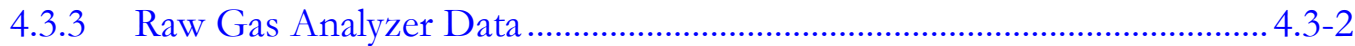

4.3.4 Gas Analysis Results............................................................................. 4.3-5

4.3.5 Nitrogen and Adiabatic Corrected Synthesis

4.3.6 Synthesis Gas-Water Gas-Shift Equilibrium ............................................. 4.3-9

4.3.7 Synthesis Gas Combustor Oxygen, Carbon, and

Hydrogen Balance Calculations .................................................................. 4.3-9

4.3.8 Sulfer Emissions ..................................................................................... 4.3-11

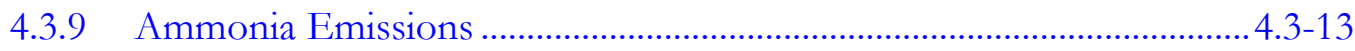

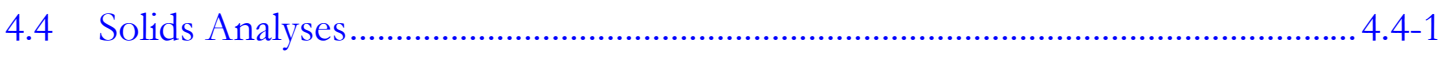

4.4.1 Summary and Conclusions ........................................................................... 4.

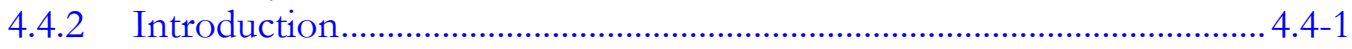

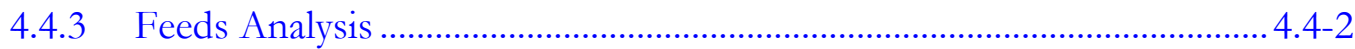

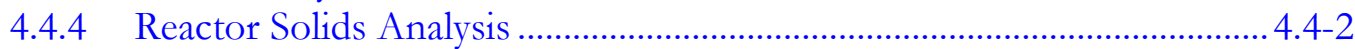

4.4.5 Reactor Products Solids Analysis ................................................................. 4.4-4 


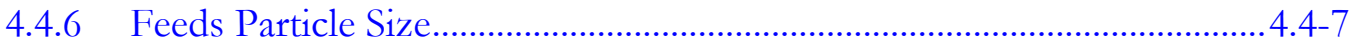

4.4.7 Reactor Solids Particle Size....................................................................4.4-8

4.4.8 Particle Size Comparison .............................................................................4.4.8

4.4.9 Standpipe and PCD Fines Bulk Densities...............................................4.4-9

4.5 Mass and Energy Balances ......................................................................................... 4.5-1

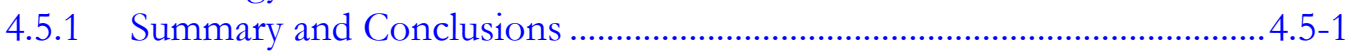

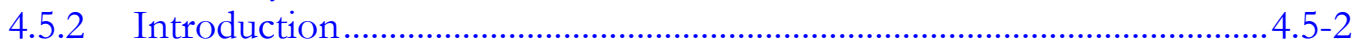

4.5.3 Feed Rates ............................................................................................ 4.5-2

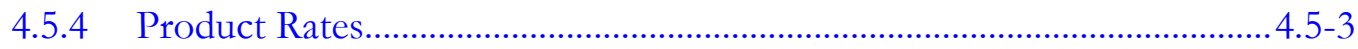

4.5.5 Coal Rates and Carbon Conversion ..............................................................4.5-4

4.5.6 Overall Material Balance ................................................................................... 4.5-6

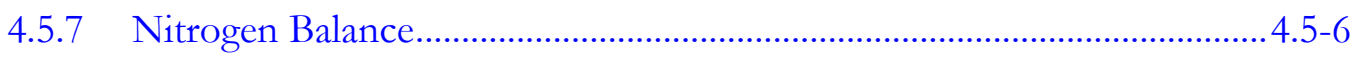

4.5.8 Sulfur Balance and Sulfur Removal.......................................................... 4.5-7

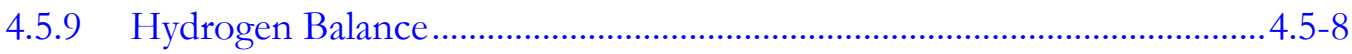

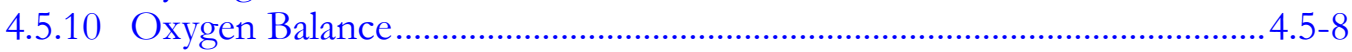

4.5.11 Calcium Balance ….....................................................................................

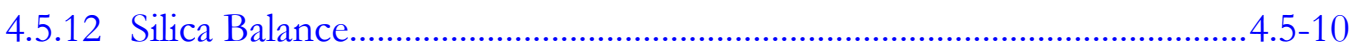

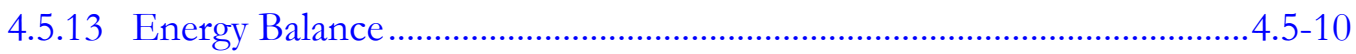

4.5.14 Gasification Efficiencies ........................................................................ 4.5-11

4.6 Iron Oxide Injection for $\mathrm{H}_{2} \mathrm{~S}$ Control.................................................................. 4.6-1

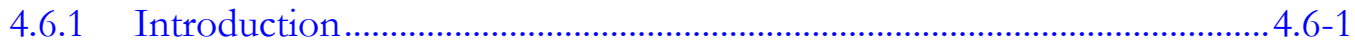

4.6.2 Key Reactions ....................................................................................... 4.6-2

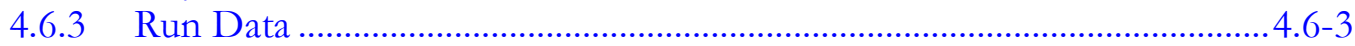

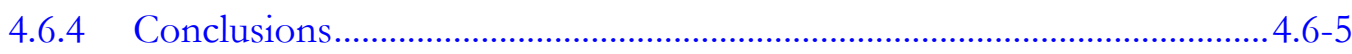

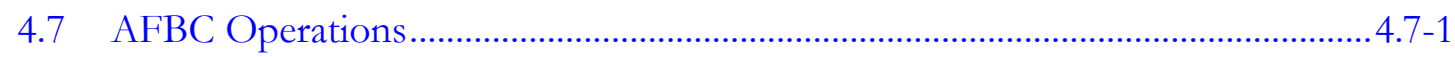

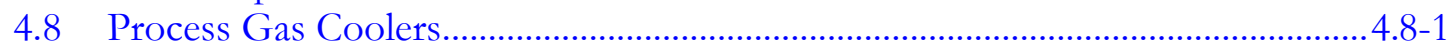

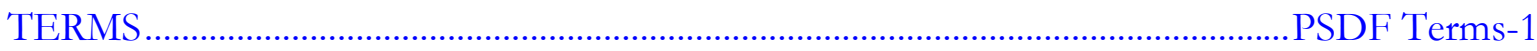




\section{Listing of Tables}

Table

$\underline{\text { Page }}$

2.2-1 Major Equipment in the Transport Reactor Train

$2.2-3$

2.2-2 Major Equipment in the Balance-of-Plant

2.2-4

3.2-1 TC07 B/C Run Statistics and Steady-State PCD Operating Parameters (January 17, 2002 Through February 9, 2002)

3.2-2 TC07D Run Statistics and Steady-State PCD Operating Parameters (March 21, 2002 Through April 5, 2002)

PCD Inlet and Outlet Particulate Measurements From TC07

Physical Properties of TC07 In situ Samples

Physical Properties of TC07 Dustcake Samples

Chemical Composition of TC07D In situ Samples.

3.4-19

$3.4-5$

Chemical Composition of TC07 Dustcake Samples

3.4-20

3.4-6

TC07 Transient Drag Determined From PCD $\triangle \mathrm{P}$ and From Raptor

3.4-21

$4.1-1$

TC07 Operating Conditions

4.3-1 Operating Periods

4.6-1 Chemical and Physical Properties of Iron-Based Materials................................... 4.6-7 


\section{Listing of Figures}

Figure

$\underline{\text { Page }}$

2.2-1 Flow Diagram of the Transport Reactor Train in Gasification Mode

of Operation.

2.3-1 Siemens Westinghouse PCD FL0301

2.3-2

2.4-1 Operating Hours Summary for the Transport Reactor Train................................. 2.4-3

3.2-1 Filter Element Layout Implemented in TC07B and TC07C ...............................3.2-12

3.2-2 Filter Element Layout Implemented in TC07D .....................................................2.2-13

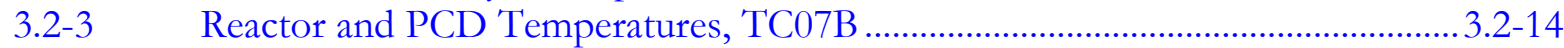

3.2-4 PCD Filter and Cone Temperatures, TC07B …......................................................2.2-15

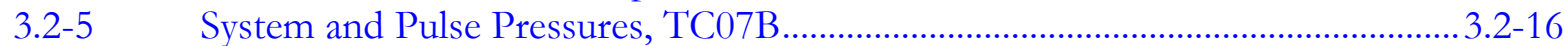

3.2-6 PCD Normalized Pressure Drop, TC07B ............................................................ 3.2-17

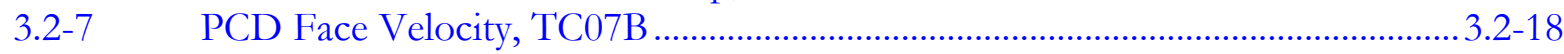

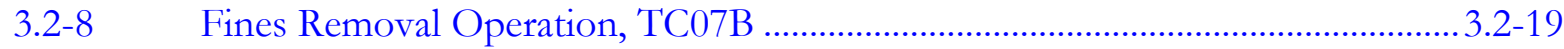

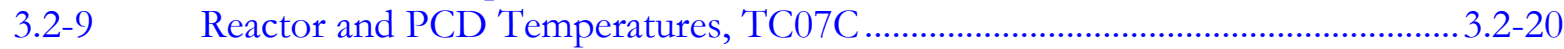

3.2-10 PCD Filter Element and Cone Temperatures, TC07C..........................................3.2-21

3.2-11 Pulse Pressures and System Pressure, TC07C …...................................................3.2-22

3.2-12 Normalized PCD Pressure Drop, TC07C .............................................................. 3.2-23

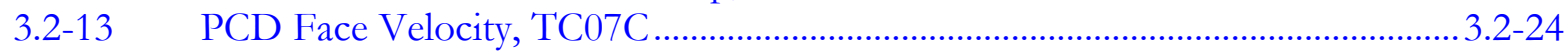

3.2-14 Fines Removal System Operation, TC07C .............................................................2.2-25

3.2-15 Reactor and PCD Temperatures, TC07D ….........................................................3.2-26

3.2-16 PCD Filter Element and Cone Temperatures, TC07D …...................................3.2-27

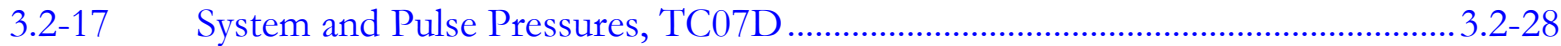

3.2-18 Normalized PCD Pressure Drop, TC07D .................................................................2.2-29

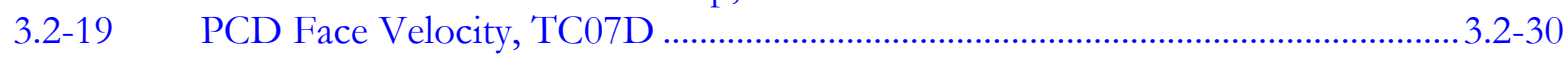

3.2-20 Fines Removal System Operation, TC07D ...........................................................2. 31

3.3-1 Failed Filter Element After TC07C (B-12) ........................................................3.3-18

3.3-2 Failed Filter Element After TC07C (B-14) ...........................................................3.3-19

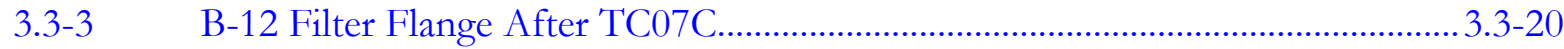

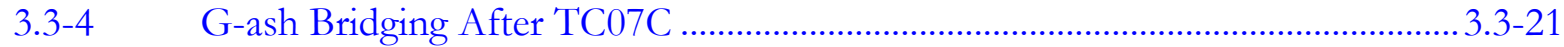

3.3-5 Location of $\mathrm{G}$-ash Bridging After TC07C.............................................................3.3-22

3.3-6 Location of Removed Filter Row Before TC07D .................................................. 3.3-23

3.3-7 Flow Curve for Blinded Pall Fuse After TC07C .....................................................3.3-24

3.3-8 PSDF Designed \#1 Flow Curve After TC07C......................................................3.3-25

3.3-9 PSDF Designed \#2 Flow Curve After TC07C....................................................3.3-26

3.3-10 PSDF Designed \#3 Flow Curve After TC07C.......................................................3.3-27

3.3-11 Filter Layout With Corresponding Exposure Hours ..............................................3.3-28

3.3-12 PCD Lower Plenum After TC07D ..........................................................................3.3-29

3.3-13 G-ash Build-up on Filter Holders After TC07D ...................................................3.3-30

3.3-14 G-ash Build-up on Upper Ash Shed After TC07D ...............................................3.3-31

3.3-15 G-ash Build-up on Support Brackets After TC07D ............................................3.3-32

3.3-16 Outlet Loading From PCD for All Gasification Runs ...........................................3.3-33 
3.3-17 PSDF Designed \#1 Flow Curve After TC07D ................................................... 3.3-34

$3.3-18$

PSDF Designed \#3 Flow Curve After TC07D

3.3-35

3.3-19

PSDF Designed \#5 Flow Curve After TC07D

3.3-36

$3.3-20$

PSDF Designed \#4 Flow Curve After TC07D

3.3-37

Simplified Schematic of the SRI Safeguard Device ................................................3.3-38

$3.3-21$

$3.3-22$

$3.3-23$

$3.3-24$

$3.3-25$

3.3-26

$3.3-27$

$3.3-28$

$3.3-29$

3.3-30

3.3-31

3.3-32

3.3-33

Simplified Schematic of Test Setup

$3.3-39$

Data From April 1, 2002, SGD Activation Test.

$3.3-40$

Receiver Pressure During April 1, 2002, SGD Activation Test

$3.3-41$

Flow Test Results for Combined SRI SGD Plus Backup PSDF Designed

Failsafe.

$3.3-42$

G-ash Resistance Probes Used During TC07D...

$3.3-43$

Resistance Probe Construction

$3.3-44$

Pitting on Back-Pulse Pipe After TC07D ................................................................3.3-45

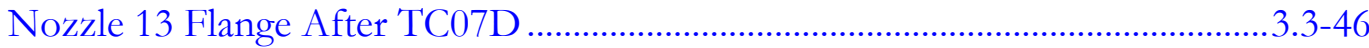

Nozzle 13 Refractory Erosion

$3.3-47$

Cracked Spheri Valve Seal After TC07D.

$3.3-48$

Erosion of FD0520 Vent Line After TC07D

$3.3-49$

FD0520 Vent-Line Flange

$3.3-50$

$3.4-1$

PCD Outlet Loadings Measured During GCT-4, TC06, and TC07

$3.4-22$

$3.4-2$

PCME Dustalert 90 Response During Startup Transient on

February 7, 2002

3.4-3 PCME Dustalert 90 Response During Filter Element Breakage on February 8, 2002

3.4-4 PCME Dustalert 90 Response During Startup Transient on March 23, 2002.

PCME Dustalert 90 Response With Low Particle Concentration

Comparison of PCME Response and Actual Particle Concentration ....

TC07 Inlet Particle-Size Distributions.....

Comparison of Average Inlet Particle-Size Distributions From TC07

and Other Gasification Runs

3.4-9 Effect of Particle Size on Drag of G-ash From TC07 and Other

Gasification Runs

3.4-10 Comparison of PCD Drag With RAPTOR Measurements.....

4.1-1 Lower Mixing Zone Spool Piece for Enriched Air and Oxygen-Blown

Operations

4.1-2 Compare the Effect of Standpipe Level on Circulation Rate in

TC07 and TC06

4.1-3 Compare the Effect of Dipleg Aeration on Circulation Rate in

TC07 and TC06

4.2-1 Transport Reactor Schematic.

$4.2-2$

TC07 Reactor Temperature Profile

4.2-3

Reactor Temperature Profile for Medium and High Solids

Circulation Rates

4.2-4 Standpipe Temperature Profiles for Low, Medium and High Solids Circulation Rates 
4.2-5 Temperature Profiles for TC07 and GCT4 ....................................................... 4.2-4

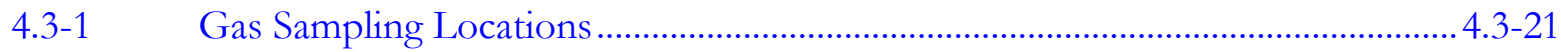

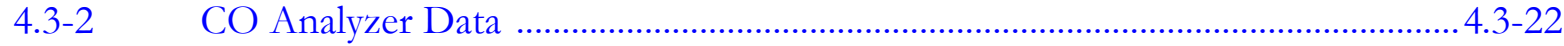

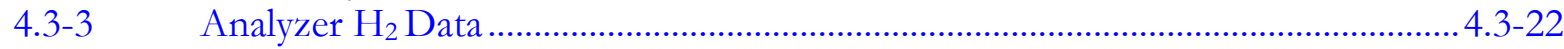

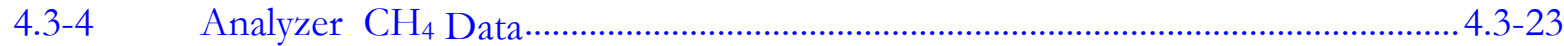

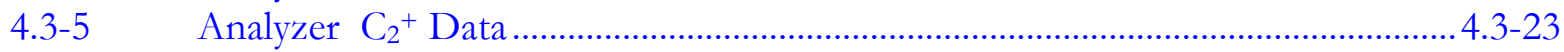

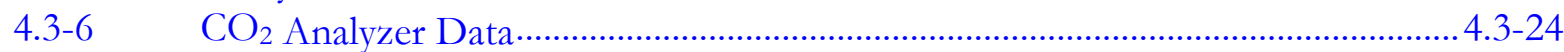

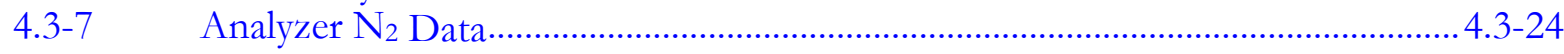

4.3-8 Sum of GC Gas Compositions (Dry) ........................................................................

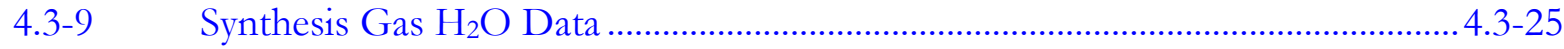

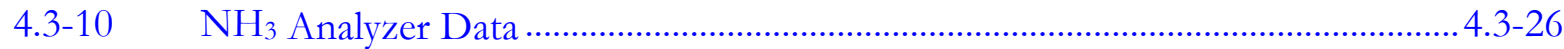

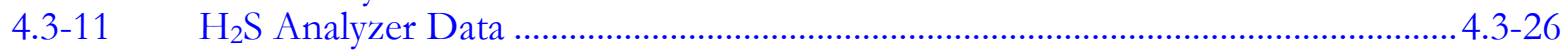

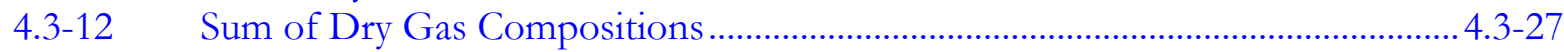

4.3-13 $\mathrm{H}_{2} \mathrm{O}$ Data...................................................................................................... 4.3-27

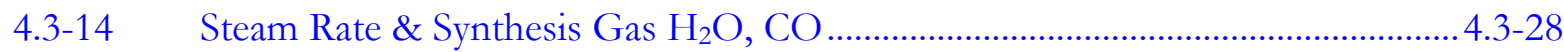

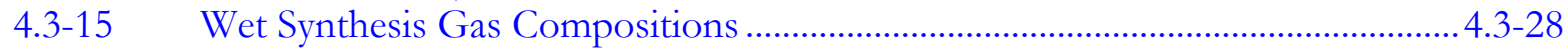

4.3-16 Synthesis Gas Lower Heating Values ..................................................................... 4.3-29

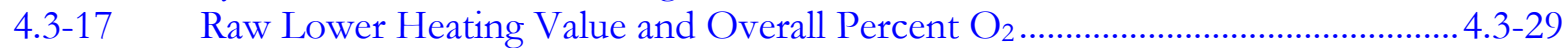

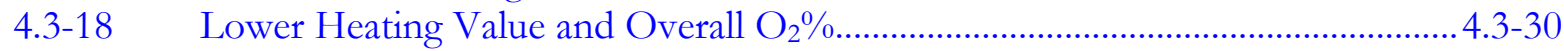

4.3-19 Water-Gas Shift Constant .................................................................................... 4.3-30

4.3-20 Synthesis Gas Combustor Outlet Oxygen.............................................................. 4.3-31

4.3-21 Synthesis Gas Combustor Outlet Carbon Dioxide ............................................... 4.3-31

4.3-22 Synthesis Gas Combustor Outlet Moisture.........................................................4.3-32

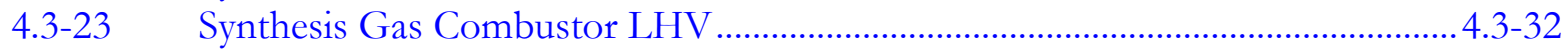

4.3-24 Sulfur Emissions ..................................................................................................... 4.3-33

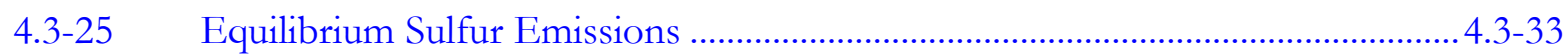

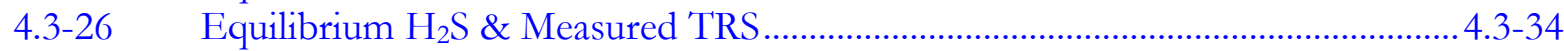

4.3-27 Corrected Equilibrium $\mathrm{H}_{2} \mathrm{~S} \&$ Maximum TRS ........................................................3-34

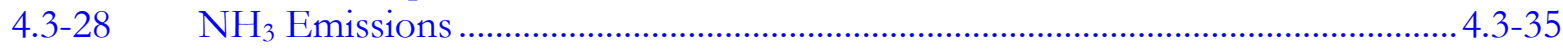

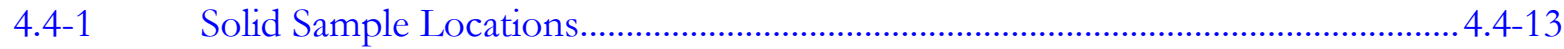

4.4-2 Coal Carbon \& Moisture .................................................................................... 4.4-13

4.4-3 Coal Sulfur \& Ash ............................................................................................ 4.4-14

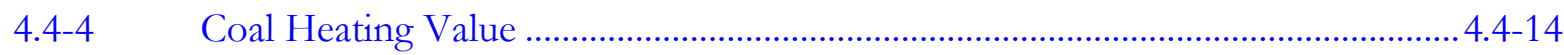

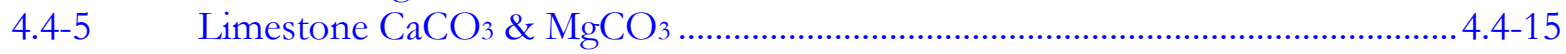

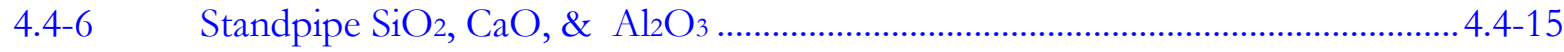

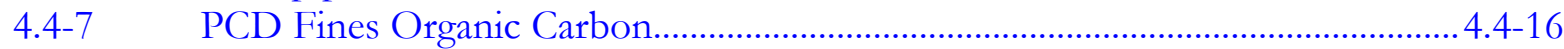

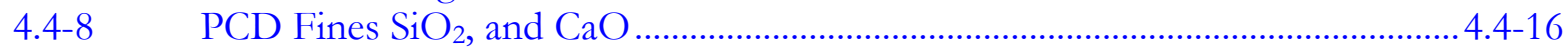

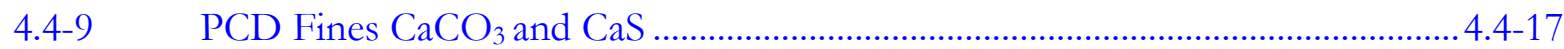

4.4-10 PCD Fines Calcination \& Sulfation.................................................................... 4.4-17

4.4-11 Coal Particle Size .................................................................................................. 4.4-18

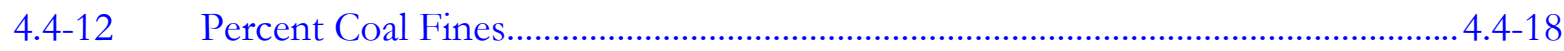

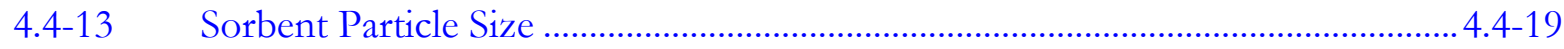

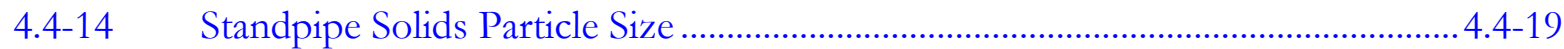

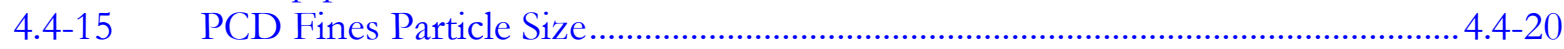

4.4-16 Particle Size Distribution............................................................................................ 4.4-20

4.4-17 Standpipe and PCD Fines Solids Bulk Density .................................................... 4.4-21 


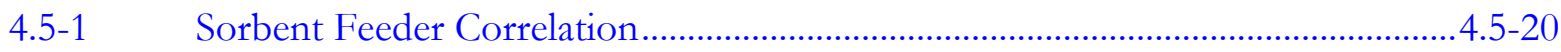

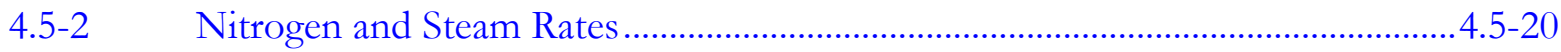

4.5-3 Air and Synthesis Gas Rates................................................................................ 4.5-21

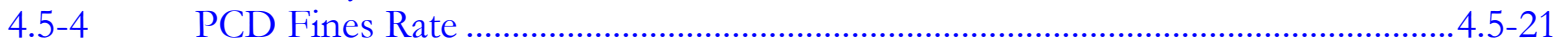

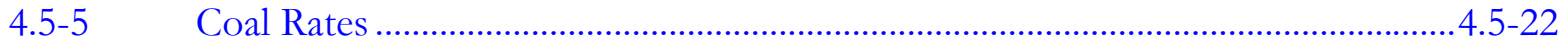

4.5-6 Carbon Conversion and Air-to-Coal Ratio .............................................................4.5-22

4.5-7 Carbon Conversion vs Riser Temperature ..........................................................4.5-23

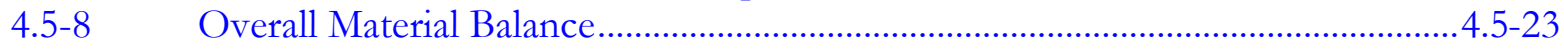

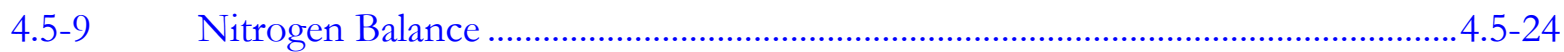

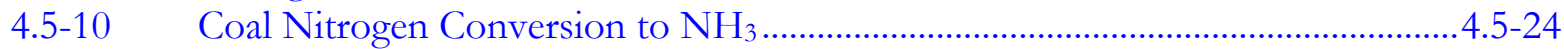

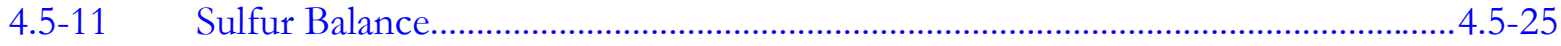

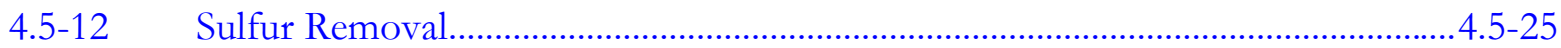

4.5-13 Sulfur Removal vs Steam Rate ............................................................................4.5-26

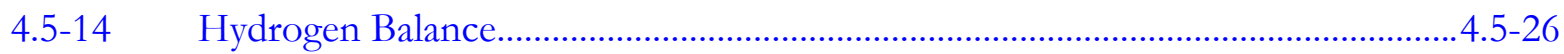

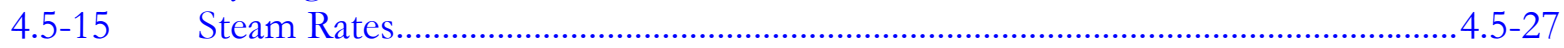

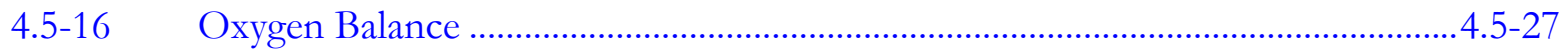

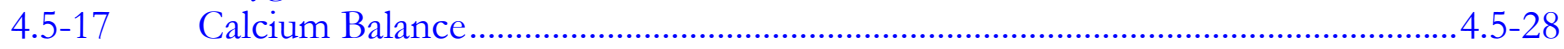

4.5-18 Calcination and Calcination Temperature ...........................................................4.5-28

4.5-19 Sulfur Emissions and Feeds Ca/S Ratio .................................................................4.5-29

4.5-20 Sulfur Emissions and PCD Solids Ca/S Ratio........................................................4.5-29

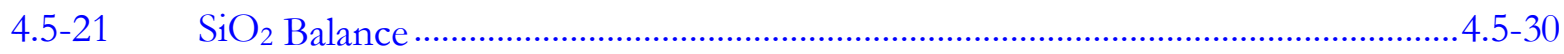

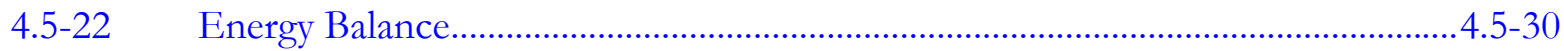

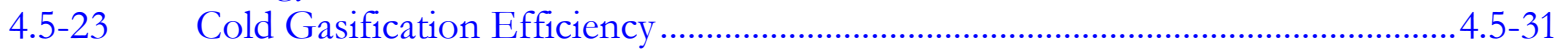

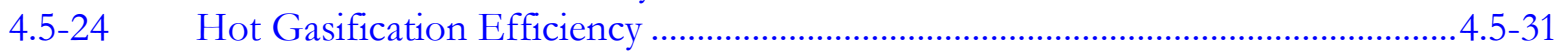

4.5-25 Nitrogen Corrected Cold Gasification Efficiency ……........................................... 4.5-32

4.6-1 The Syngas and TRS Concentrations During TC07D .............................................. 4.6-9

4.6-2 Actual and $\mathrm{CaO}-\mathrm{B}$ ased Equilibrium Concentrations of $\mathrm{H}_{2} \mathrm{~S}$..................................4.6-9

4.6-3 Effect of Using Flue Dust for Capturing $\mathrm{H}_{2} \mathrm{~S}$.......................................................4.6-10

4.6-4 Actual Concentrations of Water in the Syngas During Iron-Oxide Injection

Tests Versus Equilibrium Concentrations of Water for Reactions Shown .........4.6-10

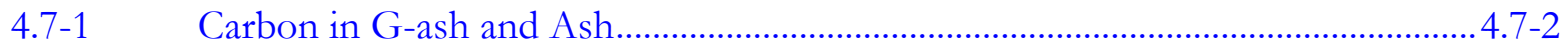

4.7-2 Temperature Profile of Bed .................................................................................... 4.7-2

4.8-1 HX0202 Heat Transfer Coefficient and Pressure Drop.......................................... 4.8-4

4.8-2 HX0402 Heat Transfer Coefficient and Pressure Drop .......................................... 4.8-4 


\subsection{EXECUTIVE SUMMARY}

\subsection{SUMMARY}

This report discusses Test Campaign TC07 of the Kellogg Brown \& Root, Inc. (KBR) Transport Reactor train with a Siemens Westinghouse Power Corporation (Siemens Westinghouse) particle filter system at the Power Systems Development Facility (PSDF) located in Wilsonville, Alabama. The Transport Reactor is an advanced circulating fluidized-bed reactor designed to operate as either a combustor or a gasifier using a particulate control device (PCD). The Transport Reactor was operated as a pressurized gasifier during TC07. Test Run TC07 was started on December 11, 2001, and the sand circulation tests (TC07A) were completed on December 14, 2001. The coal feed tests (TC07B-D) were started on January 17 and completed on April 5, 2002.

Prior to TC07, the Transport Reactor was modified to allow operations as an oxygen-blown gasifier. The combustor heat exchanger J-leg was removed and replaced with a spool piece designated as the lower mixing zone (LMZ). Air, oxygen, steam, and nitrogen can be added through the LMZ which operates like a bubbling fast-fluidized bed. TC07 was planned as a 500 -hour test run to evaluate the reactor modifications and characterize operations with a bituminous coal. A blend of four subbituminous coals from the Powder River Basin (PRB) and a bituminous coal from the Calumet mine in Alabama were tested with Bucyrus limestone from Ohio. The primary test objectives were:

- Reactor Operations - Evaluate effect of the LMZ on temperature profiles, solid circulation rates, operational stability, and process performance in air-blown mode and evaluate the effects on the LMZ of changes in circulation rate, velocity in the LMZ, and air/steam ratios in the LMZ.

- PCD Operations - Evaluate effect of the reactor modifications on PCD operations as well as testing of metallic filter elements and different failsafes.

- Characterization of Gasification Ash (g-ash, formerly referred to as char) Bridging - Develop a better understanding of the origin and growth of bridging. To aid in this understanding, several types of instrumentation were installed prior to the run. Pressure taps were installed inside two filters on the bottom plenum to determine the uniformity of backpulse pressure distribution. Also, additional filter thermocouples and newly developed resistance probes were added to monitor g-ash bridging presence and growth.

- Failsafe Device Testing - Test several types of failsafe devices to determine effectiveness. The Southern Research Institute (SRI) Safe Guard Device (SGD) was installed, along with a pressure tap to monitor the device position. PSDF-designed devices were installed above four filters, and the remaining filters contained Pall fuses. 
Secondary objectives included the following:

- Reactor Operations - Continue to evaluate the effect of reactor operating conditions on coal devolatilization, tar cracking, heat release, heat transfer, accelerated fuel particle heat-up rates, temperature profiles, and pressure balance.

- Process Performance - Continue to evaluate the effect of reactor operating parameters such as steam/coal ratio, solids-circulation rate, and reactor temperature on $\mathrm{CO} / \mathrm{CO}_{2}$ ratio, carbon conversion, synthesis gas composition, synthesis gas Lower Heating Value (LHV) and cold- and hot-gas efficiencies.

- Minimize Tar Formation - Continue to evaluate the effectiveness of using coke breeze as a transition fuel to eliminate tar formation during startup.

- Polishing Sorbents for $\mathrm{H}_{2} \mathrm{~S}$ Removal - Inject refuse iron oxide upstream of the PCD to evaluate its effectiveness in removing sulfur from the syngas.

- Filter Element Testing - Continue to expose metallic filter elements to gasification conditions. The types of filter elements installed were Pall Iron Aluminide, Hastelloy X, and HR-160.

- Particulate Sampling and Dustcake Characterization - Evaluate how the particulate loadings and properties, the pressure drop, and the transient drag are influenced by the LMZ, changes in coal-feed rate, and coal type.

Test Run TC07 was started on December 11, 2001, and the sand circulation tests (TC07A) were completed on December 14, 2001. The coal-feed tests (TC07B-D) were started on January 17, 2002 and completed on April 5, 2002. Due to operational difficulties with the reactor as discussed in section 4.1, the unit was taken offline several times. The reactor temperature was varied between 1,700 and $1,780^{\circ} \mathrm{F}$ at pressures from 200 to 240 psig. In TC07, 679 hours of solid circulation and 442 hours of coal feed, 398 hours with PRB coal and 44 hours with coal from the Calumet mine, and 33 hours of coke breeze feed were attained. Reactor operations were problematic due to instrumentation problems in the LMZ resulting in much higher than desired operating temperatures in the reactor. Both reactor and PCD operations were stable and the modifications to the lower part of the gasifier performed well while testing the gasifier with PRB coal feed. 


\subsection{PSDF ACCOMPLISHMENTS}

The PSDF has achieved over 4,985 hours of operation on coal feed and about 6,470 hours of solids circulation in combustion mode and 3,184 hours of solid circulation and 2,343 hours of coal feed in gasification mode of operation. The major accomplishments in TC06 and TC07 are summarized below. For accomplishments in GCT1-4, see technical progress report for TC06 Test Campaign. For combustion-related accomplishments, see the technical progress report for the TC05 Test Campaign.

\subsubsection{Transport Reactor Train}

The major accomplishments and observations in TC07 included the following:

Commercial:

- With subbituminous coal, more than 95-percent carbon conversion and $115 \mathrm{Btu} / \mathrm{scf}$ nitrogen-corrected syngas heating value can be attained. The projected syngas characteristics are sufficient to support existing pressurized syngas burners.

- The projected cold gas efficiency (syngas latent heat to feed heat) and hot gas efficiency (syngas latent + sensible heat to feed heat) for subbituminous coal ranged from 65 to 73 percent and from 87 to 98 percent, respectively. Commercial units can be designed with riser energy fluxes exceeding $100 \mathrm{MBtu} / \mathrm{hr} / \mathrm{ft}^{2}$ resulting in a compact gasifier loop that operates with a high circulation rate and has low erosion.

- Several areas still exist that need additional testing and evaluating such as the high loading disengager design, controllability of the gasifier, gasifier process operations, integration with the Piloted-Syngas Burner (PSB), and feed and ash removal system issues.

Process:

- After the initial problems with reactor operations due to incorrectly installed thermocouples in the LMZ, successful commissioning of the LMZ was completed. The operating envelope for steam and air flows through the LMZ to obtain stable reactor operations was defined. All steam and air flow controllers in the LMZ were tuned.

- Carbon conversions were between 90 and 98 percent, with most around 95 percent. The carbon conversion increased slightly with higher riser temperatures. The raw and corrected cold gasification efficiencies were around 60 and 70 percent, respectively. The hot gasification efficiency was over 90 percent.

- The coal rate ranged from 3,800 to $4,500 \mathrm{lb} / \mathrm{hr}$ and the air-to-coal ratio varied between 2.9 and 3.4.

- The overall mass balance was good between +1.5 and -5 percent. The nitrogen balance was excellent, with \pm 2 -percent error. The sulfur balance was acceptable for most of the run between -10 and +20 percent. The hydrogen and oxygen element balances were 
poor between -30 and 0 percent. The energy balance was acceptable at +3 to +10 percent.

- The carbon content of PCD solids during PRB operation indicates that there were several periods of good carbon conversion. The heating value of PCD solids ranged from 1,000 to $5,000 \mathrm{Btu} / \mathrm{lb}$.

- Even though carbon conversion averaged around 95 percent, the standpipe carbon content was between 0.1 and 0.3 wt percent for the steady operating periods due to high solids circulation rates in the gasifier loop. This amount of g-ash in circulating solids is sufficient to minimize combustion of the coal volatiles.

- The reactor experienced some of the highest circulation rates and riser densities ever observed in the Transport Reactor. These characteristics improved the temperature distribution in both the mixing zone and the riser and likely resulted in higher coal particle heat-up rates. At the same coal-feed rate, the temperature profile in the reactor changed significantly with the solids circulation rate.

- Standpipe solids contained small amounts of $\mathrm{CaS}$ and $\mathrm{CaCO}_{3}$; standpipe calcium was nearly completely calcined. The PCD fines calcium was typically 80 - to 90 -percent calcined.

- As ash accumulated in the gasifier, the standpipe solids particle size increased and the solids bulk density decreased. Due to short test run, the standpipe solids did not reach steady compositions with respect to $\mathrm{SiO}_{2}, \mathrm{CaO}, \mathrm{Al}_{2} \mathrm{O}_{3}$, and $\mathrm{MgO}$.

- In situ PCD inlet solids samples generally had the same chemical composition as the solids sampled from FD0520. PCD solids particle size was constant during PRB operation at around $10 \mu \mathrm{SMD}$. PCD solids bulk density was around $25 \mathrm{lb} / \mathrm{ft}^{3}$.

- Steam injection during TC07 was much more reliable than in previous test runs due to modifications to the superheated steam system. Steam flows varied from less than 300 to over 1,700 pph. At higher steam-flow rates, the hydrogen concentration increased in the syngas, along with hydrogen sulfide and moisture. At lower steam-flow rates, the carbon monoxide concentration was higher due to less steam dilution. All steam entered through the LMZ, and the majority was mixed with the entering air to moderate temperatures in the LMZ.

- Different types of iron oxide were tested to evaluate the ability to remove $\mathrm{H}_{2} \mathrm{~S}$ upstream of PCD. In certain tests, iron oxide was effective in lowering the $\mathrm{H}_{2} \mathrm{~S}$ syngas concentration, however the syngas water content was the dominant parameter in determining the minimum $\mathrm{H}_{2} \mathrm{~S}$ concentration.

- The ammonia $\left(\mathrm{NH}_{3}\right)$ concentration varied from 1,500 to 1,900 ppm and the fuel nitrogen conversion to $\mathrm{NH}_{3}$ was around 70 to 88 percent.

Equipment:

- The gasifier char/ash removal system (FD0510) operated well without any line plugging during gasification. 
- The sulfator (atmospheric fluidized-bed combustor - AFBC) performed well during the entire test, maintaining a uniform temperature throughout the bed. Sand was periodically added to the AFBC due to a loss of bed material. Since the high-carbon conversion in the Transport Gasifier significantly reduced the amount of remaining gash, the AFBC did not receive enough g-ash to maintain a high temperature. Thus, the AFBC required additional heating from its start-up burner and fuel oil injection system. Overall, the AFBC performed well.

- The coal feeder, for the most part, performed well. The major problems occurred when situations dictated that the coal mill shut down, allowing particle segregation that occurs when the coal silo level fluctuates over a large range.

- The gas analyzers were online for virtually the entire test run, presenting the best gas composition data from the Transport Reactor to date. The dry gas compositions added up to between 98 and 101 percent on a consistent basis. The moisture analyzer did not agree well with the batch sampling moisture tests.

\subsubsection{Particulate Control Device}

The highlights of PCD operation for TC07 are listed below.

- In TC07B and D, no bridging or filter failures occurred, and the pressure drop across the PCD tubesheet was controllable. During the bituminous coal-feed portion of TC07B, the major concern with PCD operation was the high-solids loading, which at times exceeded the capacity of the fines removal system.

- PCD operation was successful for most of TC07, although g-ash bridging and two filter failures occurred during the short, unstable run TC07C. The bridging was extensive, completely plugging the bottom plenum of filters, and likely added considerable mechanical stress to the filters. Unstable system conditions and the particle leakage resulting from the filter failures precipitated system shutdown.

- Outlet loading samples other than those taken after the instance of filter failures indicated good sealing of the filter vessel, with particle loading usually below 1 ppmw. Several samples showed outlet loading above the lower limit of detection of 0.1 ppmw; however, these samples appeared to be contaminated with large particles, many larger than $100 \mu \mathrm{m}$, suggesting that they did not come from a leak through the PCD.

- Several new tests were conducted during TC07, such as testing of the SRI Safe Guard Device and back-pulse intensity measurements. Additional instrumentation was installed in the filter vessel, including newly developed electrical resistance probes designed to identify the presence of g-ash bridging.

- During TC07B and D, the baseline pressure drop across the PCD tubesheet was lower than that seen in previous test runs. This difference is consistent with SRI lab measurements that showed a lower particle drag. 
- Because thermal transients continued to be an operational concern, particularly those resulting from reactor upsets, new logic was introduced to address this concern. Initially, a flaw in the logic caused excessive back-pulsing; however, after the logic was modified, it proved useful in controlling thermal transients.

- The metal filter elements performed well during TC07. Other than the two filters that failed during an off-coal period under extreme conditions in TC07C, there was no apparent loss of mechanical integrity of any filters. The three types of filters used include Iron Aluminide, Hastelloy X, and Haynes HR-160. 


\subsection{INTRODUCTION}

This report provides an account of the TC07 test campaign with the Kellogg Brown \& Root, Inc. (KBR) Transport Reactor and the Siemens Westinghouse Power Corporation (Siemens Westinghouse) filter vessel at the Power Systems Development Facility (PSDF) located in Wilsonville, Alabama, 40 miles southeast of Birmingham. The PSDF is sponsored by the U.S. Department of Energy (DOE) and is an engineering-scale demonstration of advanced coal-fired power systems. In addition to DOE, Southern Company Services, Inc., (SCS), Electric Power Research Institute (EPRI), and Peabody Energy are cofunders. Other cofunding participants supplying services or equipment currently include KBR, and Siemens Westinghouse. SCS is responsible for constructing, commissioning, and operating the PSDF.

\subsection{POWER SYSTEMS DEVELOPMENT FACILITY}

SCS entered into an agreement with DOE/National Energy Technology Laboratory (NETL) for the design, construction, and operation of a hot-gas, clean-up test facility for pressurized gasification and combustion. The purpose of the PSDF is to provide a flexible test facility that can be used to develop advanced power system components and assess the integration and control issues of these advanced power systems. The facility also supports Vision 21 programs to eliminate environmental concerns associated with using fossil fuels for producing electricity, chemicals, and transportation fuels. The facility was designed as a resource for rigorous, long-term testing and performance assessment of hot-stream clean-up devices and other components in an integrated environment.

The PSDF now consists of the following modules for systems and component testing:

- A Transport Reactor module.

- A hot-gas clean-up module.

- A compressor/turbine module.

The Transport Reactor module includes KBR Transport Reactor technology for pressurized combustion and gasification to provide either an oxidizing or reducing gas for parametric testing of hot particulate control devices. The Transport Gasifier can be operated in either air- or oxygen-blown modes. Oxygen-blown operations are primarily focused on testing and developing various Vision 21 programs to benefit gasification technologies in general. The hot-gas, clean-up filter system tested to date at the PSDF is the particulate control device (PCD) supplied by Siemens Westinghouse. The gas turbine is an Allison Model 501-KM gas turbine, which drives a synchronous generator through a speed reducing gearbox. The model 501-KM engine was designed as a modification of the Allison Model 501-KB5 engine to provide operational flexibility. Design considerations include a large, close-coupled external combustor to burn a wide variety of fuels and a fuel delivery system that is much larger than standard. 


\subsection{TRANSPORT REACTOR SYSTEM DESCRIPTION}

The Transport Reactor is an advanced circulating fluidized-bed reactor operating as either a combustor or as a gasifier, using a hot-gas, clean-up filter technology (particulate control devices or PCDs) at a component size readily scaleable to commercial systems. The Transport Reactor train operating in gasification mode is shown schematically in Figure 2.2-1. A taglist of all major equipment in the process train and associated balance-of-plant is provided in Tables 2.2-1 and 2.2-2.

The Transport Reactor consists of a mixing zone, a riser, a disengager, a cyclone, a standpipe, a loop seal, a solids cooler, and J-legs. The fuel, sorbent, steam, oxygen, and/or air are mixed together in the mixing zone, along with the solids from the standpipe. The mixing zone, located below the riser, has a slightly larger diameter compared to the riser. Provision is made to inject air at several different points along the riser to control the formation of $\mathrm{NO}_{\mathrm{x}}$ during combustion mode of operation. The gas and solids move up the riser together, make two turns and enter the disengager. The disengager removes larger particles by gravity separation. The gas and remaining solids then move to the cyclone, which removes most of the particles not collected by the disengager. The gas then exits the Transport Reactor and goes to the primary gas cooler and the PCD for final particulate clean-up. The solids collected by the disengager and cyclone are recycled back to the reactor mixing zone through the standpipe and a J-leg. In the combustion mode of operation, the solids cooler (not shown) controls the reactor temperature by generating steam and provides solids surge volume. A part of the solids stream from the standpipe flows through the solids cooler. The solids from the solids cooler then return to the bottom of the reactor mixing zone through another J-leg. The solids cooler is not used in gasification. The nominal Transport Reactor operating temperatures are 1,800 and $1,600^{\circ} \mathrm{F}$ for gasification and combustion modes, respectively. The reactor system is designed to have a maximum operation pressure of $294 \mathrm{psig}$ with a thermal capacity of approximately $21 \mathrm{MBtu} / \mathrm{hr}$ for combustion mode and $41 \mathrm{MBtu} / \mathrm{hr}$ for gasification mode.

For start-up purposes, a burner (BR0201) is provided at the reactor mixing zone. Liquefied propane gas (LPG) is used as start-up fuel. The fuel and sorbent are separately fed into the Transport Reactor through lockhoppers. Coal is ground to a nominal average particle diameter between 250 and $400 \mu$. Sorbent is ground to a nominal average particle diameter of 10 to $30 \mu$. Limestone or dolomitic sorbents are fed into the reactor for sulfur capture. The gas leaves the Transport Reactor cyclone and goes to the primary gas cooler which cools the gas prior to entering the Siemens Westinghouse PCD barrier filter. The PCD uses ceramic or metal elements to filter out dust from the reactor. The filters remove almost all the dust from the gas stream to prevent erosion of a downstream gas turbine in a commercial plant. The operating temperature of the PCD is controlled both by the reactor temperature and by an upstream gas cooler. For test purposes, 0 to 100 percent of the gas from the Transport Reactor can flow through the gas cooler. The PCD gas temperature can range from 700 to $1,600^{\circ} \mathrm{F}$. The filter elements are back-pulsed by high-pressure nitrogen (or air in combustion mode) in a desired time interval or at a given maximum pressure difference across the elements. There is a secondary gas cooler after the filter vessel, to cool the gas before discharging to the stack or thermal oxidizer (atmospheric syngas combustor). 
In a commercial process, the gas from the PCD would be sent to a gas turbine in a combined-cycle package. The flue gas or fuel gas is sampled for on-line analysis after traveling through the secondary gas cooler.

After exiting the secondary gas cooler, the gas is then letdown to approximately 2 psig through a pressure control valve. In gasification the fuel gas is then sent to the atmospheric syngas burner to burn the gas and oxidize all reduced sulfur compounds $\left(\mathrm{H}_{2} \mathrm{~S}, \mathrm{COS}\right.$, and $\mathrm{CS}_{2}$ ) and reduced nitrogen compounds $\left(\mathrm{NH}_{3}\right.$ and $\left.\mathrm{HCN}\right)$. The atmospheric syngas burner uses propane as a supplemental fuel. In combustion, the atmospheric syngas burner can be bypassed and fired on propane to make start-up steam. The gas from the atmospheric syngas burner goes to the baghouse and then to the stack.

The Transport Reactor produces both fine ash collected by the PCD and coarse ash extracted from the Transport Reactor standpipe. The two solid streams are cooled using screw coolers, reduced in pressure in lock hoppers, and then combined together. The combustion solids are suitable for commercial use or landfill as produced. In gasification, any fuel sulfur captured by sorbent should be present as calcium sulfide (CaS). The gasification ash is processed in the sulfator (atmospheric fluidized-bed combustor - AFBC) to oxidize the $\mathrm{CaS}$ to calcium sulfate $\left(\mathrm{CaSO}_{4}\right)$ and burn any residual carbon on the ash. The waste solids are then suitable for commercial use or disposal. Neither the AFBC nor the atmospheric syngas burner would be part of a commercial process. In a commercial process, the gasification ash (formerly referred to as char) can be landfilled, utilized, or burned in an atmospheric or pressurized fluidized-bed combustor to recover the solids heat value. 
Table 2.2-1

Major Equipment in the Transport Reactor Train

\begin{tabular}{|l|l|}
\hline TAG NAME & \multicolumn{1}{|c|}{ DESCRIPTION } \\
\hline BR0201 & Reactor Start-Up Burner \\
\hline BR0401 & Thermal Oxidizer (Atmospheric Syngas Burner - ASB) \\
\hline BR0602 & Sulfator Start-Up/PCD Preheat Burner \\
\hline C00201 & Main Air Compressor \\
\hline C00401 & Recycle Gas Booster Compressor \\
\hline C00601 & Sulfator Air Compressor \\
\hline CY0201 & Primary Cyclone in the Reactor Loop \\
\hline CY0207 & Disengager in the Reactor Loop \\
\hline CY0601 & Sulfator Cyclone \\
\hline DR0402 & Steam Drum \\
\hline DY0201 & Feeder System Air Dryer \\
\hline FD0206 & Spent Solids Screw Cooler \\
\hline FD0210 & Coal Feeder System \\
\hline FD0220 & Sorbent Feeder System \\
\hline FD0502 & Fines Screw Cooler \\
\hline FD0510 & Spent Solids Transporter System \\
\hline FD0520 & Fines Transporter System \\
\hline FD0530 & Spent Solids Feeder System \\
\hline FD0602 & Sulfator Solids Screw Cooler \\
\hline FD0610 & Sulfator Sorbent Feeder System \\
\hline FL0301 & PCD - Siemens Westinghouse \\
\hline FL0302 & PCD - Combustion Power \\
\hline FL0401 & Compressor Intake Filter \\
\hline HX0202 & Primary Gas Cooler \\
\hline HX0203 & Combustor Heat Exchanger \\
\hline HX0204 & Transport Air Cooler \\
\hline HX0402 & Secondary Gas Cooler \\
\hline HX0405 & Compressor Feed Cooler \\
\hline HX0601 & Sulfator Heat Recovery Exchanger \\
\hline ME0540 & Heat Transfer Fluid System \\
\hline RX0201 & Transport Reactor \\
\hline SI0602 & Spent Solids Silo \\
\hline SU0601 & Sulfator (Atmoshperic Fluidized-Bed Combustor - AFBC) \\
\hline
\end{tabular}


Table 2.2-2 (Page 1 of 3)

Major Equipment in the Balance-of-Plant

\begin{tabular}{|l|l|}
\hline TAG NAME & \\
\hline B02920 & Auxiliary Boiler \\
\hline B02921 & Auxiliary Boiler - Superheater \\
\hline CL2100 & Cooling Tower \\
\hline C02201A-D & Service Air Compressor A-D \\
\hline C02202 & Air-Cooled Service Air Compressor \\
\hline C02203 & High-Pressure Air Compressor \\
\hline C02601A-C & Reciprocating N Compressor A-C \\
\hline CR0104 & Coal and Sorbent Crusher \\
\hline CV0100 & Crushed Feed Conveyor \\
\hline CV0101 & Crushed Material Conveyor \\
\hline DP2301 & Baghouse Bypass Damper \\
\hline DP2303 & Inlet Damper on Dilution Air Blower \\
\hline DP2304 & Outlet Damper on Dilution Air Blower \\
\hline DY2201A-D & Service Air Dryer A-D \\
\hline DY2202 & Air-Cooled Service Air Compressor Air Dryer \\
\hline DY2203 & High-Pressure Air Compressor Air Dryer \\
\hline FD0104 & MWK Coal Transport System \\
\hline FD0111 & MWK Coal Mill Feeder \\
\hline FD0113 & Sorbent Mill Feeder \\
\hline FD0140 & Coke Breeze and Bed Material Transport System \\
\hline FD0154 & MWK Limestone Transport System \\
\hline FD0810 & Ash Unloading System \\
\hline FD0820 & Baghouse Ash Transport System \\
\hline FL0700 & Baghouse \\
\hline FN0700 & Dilution Air Blower \\
\hline H00100 & Reclaim Hopper \\
\hline H00105 & Crushed Material Surge Hopper \\
\hline H00252 & Coal Surge Hopper \\
\hline H00253 & Sorbent Surge Hopper \\
\hline HT2101 & MWK Equipment Cooling Water Head Tank \\
\hline HT2103 & SCS Equipment Cooling Water Head Tank \\
\hline HT0399 & 60-Ton Bridge Crane \\
\hline HX2002 & MWK Steam Condenser \\
\hline HX2003 & MWK Feed Water Heater \\
\hline
\end{tabular}


Table 2.2-2 (Page 2 of 3)

Major Equipment in the Balance-of-Plant

\begin{tabular}{|l|l|}
\hline TAG NAME & \\
\hline HX2004 & MWK Subcooler \\
\hline HX2103A & SCS Cooling Water Heat Exchanger \\
\hline HX2103C & MWK Cooling Water Heat Exchanger \\
\hline LF0300 & Propane Vaporizer \\
\hline MC3001-3017 & MCCs for Various Equipment \\
\hline ME0700 & MWK Stack \\
\hline ME0701 & Flare \\
\hline ME0814 & Dry Ash Unloader for MWK Train \\
\hline ML0111 & Coal Mill for MWK Train \\
\hline ML0113 & Sorbent Mill for Both Trains \\
\hline PG0011 & Oxygen Supply Plant \\
\hline PG2600 & Nitrogen Plant \\
\hline PU2000A-B & MWK Feed Water Pump A-B \\
\hline PU2100A-B & Raw Water Pump A-B \\
\hline PU2101A-B & Service Water Pump A-B \\
\hline PU2102A-B & Cooling Tower Make-Up Pump A-B \\
\hline PU2103A-D & Circulating Water Pump A-D \\
\hline PU2107 & SCS Cooling Water Make-Up Pump \\
\hline PU2109A-B & SCS Cooling Water Pump A-B \\
\hline PU2111A-B & MWK Cooling Water Pump A-B \\
\hline PU2300 & Propane Pump \\
\hline PU2301 & Diesel Rolling Stock Pump \\
\hline PU2302 & Diesel Generator Transfer Pump \\
\hline PU2303 & Diesel Tank Sump Pump \\
\hline PU2400 & Fire Protection Jockey Pump \\
\hline PU2401 & Diesel Fire Water Pump \#1 \\
\hline PU2402 & Diesel Fire Water Pump \#2 \\
\hline PU2504A-B & Waste Water Sump Pump A-B \\
\hline PU2507 & Coal and Limestone Storage Sump Pump \\
\hline PU2700A-B & Demineralizer Forwarding Pump A-B \\
\hline
\end{tabular}


Table 2.2-2 (Page 3 of 3)

Major Equipment in the Balance-of-Plant

\begin{tabular}{|l|l|}
\hline TAG NAME & \\
\hline PU2920A-B & Auxiliary Boiler Feed Water Pump A-B \\
\hline SB3001 & 125-V DC Station Battery \\
\hline SB3002 & UPS \\
\hline SC0700 & Baghouse Screw Conveyor \\
\hline SG3000-3005 & 4160-V, 480-V Switchgear Buses \\
\hline SI0101 & MWK Crushed Coal Storage Silo \\
\hline SI0103 & Crushed Sorbent Storage Silo \\
\hline SI0111 & MWK Pulverized Coal Storage Silo \\
\hline SI0113 & MWK Limestone Silo \\
\hline SI0114 & FW Limestone Silo \\
\hline SI0810 & Ash Silo \\
\hline ST2601 & N Storage Tube Bank \\
\hline TK2000 & MWK Condensate Storage Tank \\
\hline TK2001 & FW Condensate Tank \\
\hline TK2100 & Raw Water Storage Tank \\
\hline TK2300A-D & Propane Storage Tank A-D \\
\hline TK2301 & Diesel Storage Tank \\
\hline TK2401 & Fire Water Tank \\
\hline XF3000A & 230/4.16-kV Main Power Transformer \\
\hline XF3001B-5B & $4160 / 480-V$ Station Service Transformer No. 1-5 \\
\hline XF3001G & $480 / 120-V$ Miscellaneous Transformer \\
\hline XF3010G & $120 / 208$ Distribution Transformer \\
\hline XF3012G & UPS Isolation Transformer \\
\hline VS2203 & High-Pressure Air Receiver \\
\hline & \\
\hline
\end{tabular}




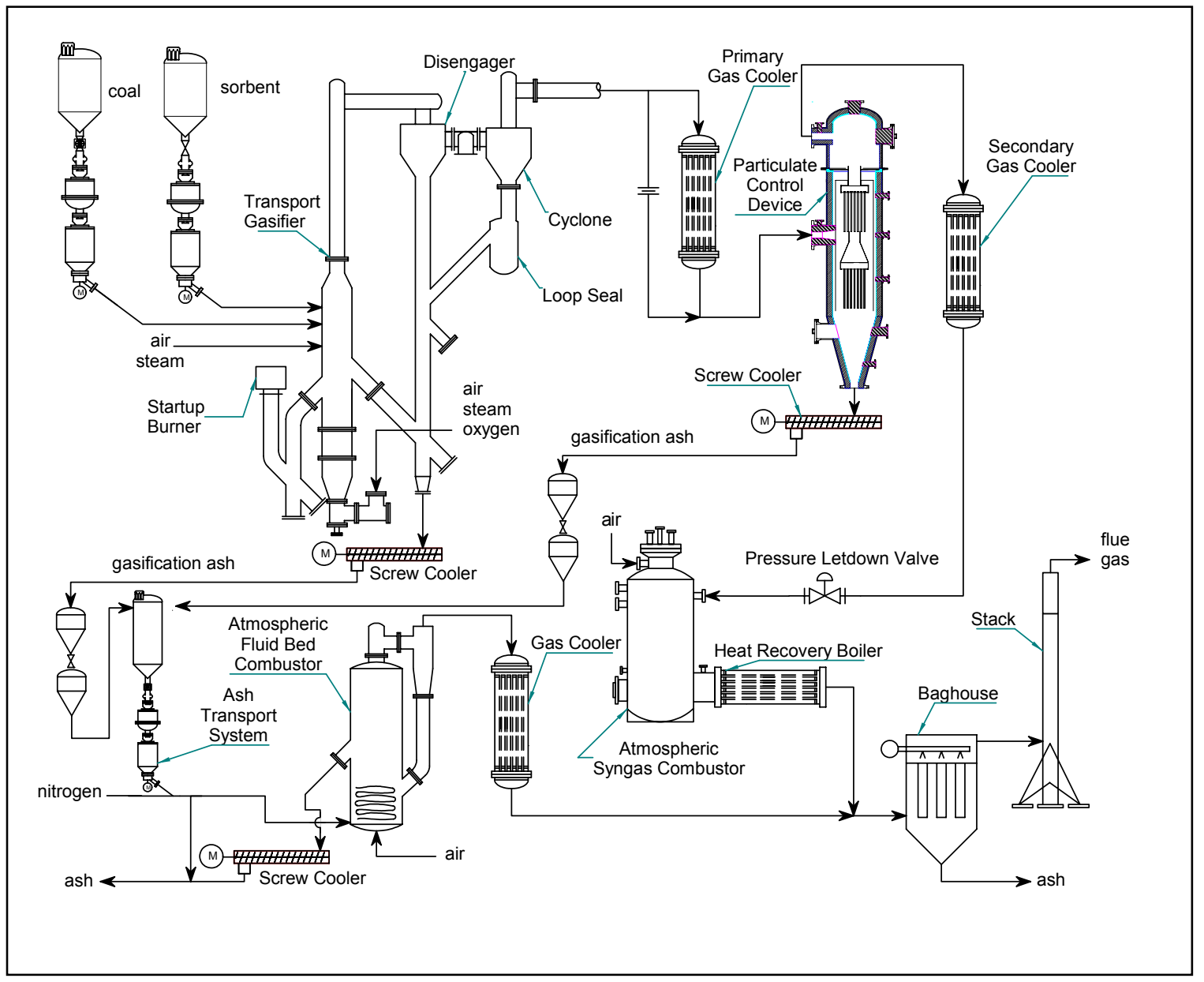

Figure 2.2-1 Flow Diagram of the Transport Reactor Train in Gasification Mode of Operation 
POWER SYSTEMS DEVELOPMENT FACILITY

\subsection{SIEMENS WESTINGHOUSE PARTICULATE CONTROL DEVICE}

The PCD (filter system designed by Siemens Westinghouse) was commissioned in 1996 and has been used in all of the testing to date. The dirty gas enters the PCD below the tubesheet, flows through the filter elements, and the ash collects on the outside of the filter. The clean gas passes from the plenum/filter element assembly through the plenum pipe to the outlet pipe. As the ash collects on the outside surface of the filter elements, the pressure drop across the filter system gradually increases. The filter cake is periodically dislodged by injecting a high-pressure gas pulse to the clean side of the filter elements. The cake then falls to the discharge hopper.

Until the first gasification run in late 1999, the Transport Reactor had been operated only in the combustion mode. Initially, high-pressure air was used as the pulse gas for the PCD, however, the pulse gas was changed to nitrogen early in 1997. The pulse gas was routed individually to the two-plenum/filter element assemblies via injection tubes mounted on the top head of the PCD vessel. The pulse duration was typically 0.1 to 0.5 seconds.

A sketch of the Siemens Westinghouse PCD is shown in Figure 2.3-1. 


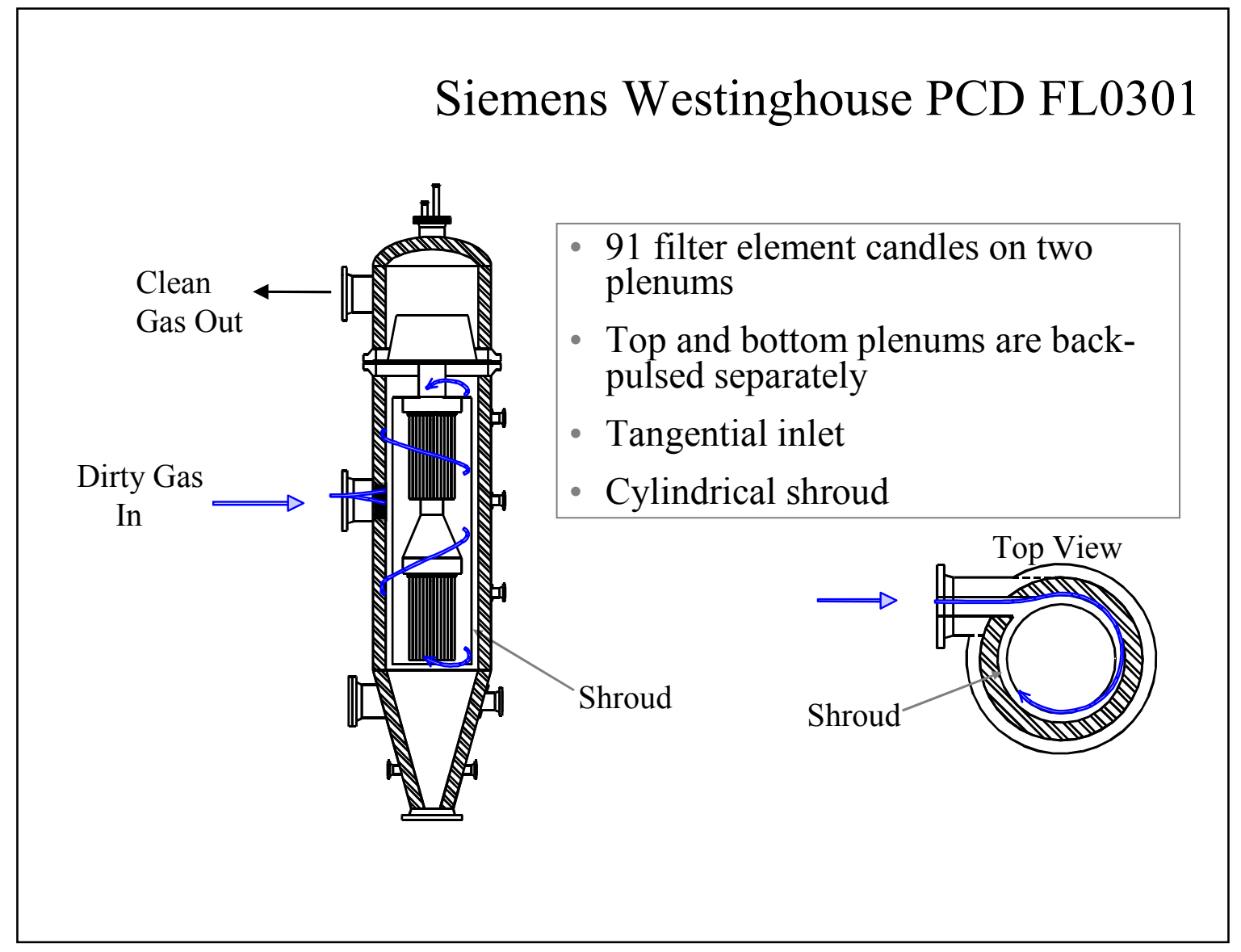

Figure 2.3-1 Siemens Westinghouse PCD FL0301 


\subsection{OPERATION STATUS}

Conversion of the Transport Reactor train to the gasification mode of operation was performed from May to September 1999. The first gasification test run, GCT1, was planned as a 250-hour test run to commission the Transport Reactor train in gasification mode of operation and to characterize the limits of operational parameter variations. GCT1 was started on September 9, 1999, with the first part completed on September 15, 1999 (GCT1A). The second part of GCT1 was started on December 7, 1999, and completed on December 15, 1999 (GCT1B-D). This test run provided the data necessary for preliminary analysis of reactor operations and for identification of necessary modifications to improve equipment and process performance. Five different feed combinations of coal and sorbent were tested to gain a better understanding of the reactor solids collection system efficiency.

GCT2, planned as a 250-hour characterization test run, was started on April 10, 2000, and completed on April 27, 2000. Additional data was taken to analyze the effect of different operating conditions on reactor performance and operability. A blend of several Powder River Basin (PRB) coals was used with Longview limestone from Alabama. In the outage following GCT2, the Transport Reactor underwent a major modification to improve the operation and performance of the reactor solids collection system. The most fundamental change was the addition of the loop seal underneath the primary cyclone.

GCT3 was planned as a 250-hour characterization with the primary objective to commission the loop seal. A hot solids circulation test (GCT3A) was started on December 1, 2000, and completed December 15, 2000. After a 1-month outage to address maintenance issues with the main air compressor, GCT3 was continued. The second part of GCT3 (GCT3B) was started on January 20, 2001, and completed on February 1, 2001. During GCT3B, a blend of several PRB coals was used with Bucyrus limestone from Ohio. The loop seal performed well needing little attention and promoting much higher solids-circulation rates and higher coal-feed rates that resulted in lower relative solids loading to the PCD and higher g-ash retention in the reactor.

GCT4, planned as a 250-hour characterization test run, was started on March 7, 2001, and completed on March 30, 2001. A blend of several PRB coals with Bucyrus limestone from Ohio was used. More experience was gained with the loop seal operations, and additional data was collected to better understand reactor performance.

TC06, planned as a 1,000-hour test campaign, was started on July 4, 2001, and completed on September 24, 2001. A blend of several PRB coals with Bucyrus limestone from Ohio was used. Both reactor and PCD operations were stable during the test run with a stable baseline pressure drop. Due to its length and stability, the TC06 test run provided valuable data necessary to analyze long-term reactor operations and to identify necessary modifications to improve equipment and process performance as well as progressing the goal of many thousands of hours of candle exposure.

TC07, planned as a 500-hour test campaign, was started on December 11, 2001, and completed on April 5, 2002. A blend of several PRB coals and a bituminous coal from the 
Calumet mine in Alabama along with Bucyrus limestone from Ohio were tested. Due to operational difficulties with the reactor as discussed in Section 4.1, the unit was taken offline several times. Reactor operations were problematic due to instrumentation problems in the lower mixing zone (LMZ) resulting in much higher than desired operating temperatures in the reactor. PCD operations were relatively stable considering the reactor upsets.

Figure 2.4-1 gives a summary of operating test hours achieved with the Transport Reactor at the PSDF. 


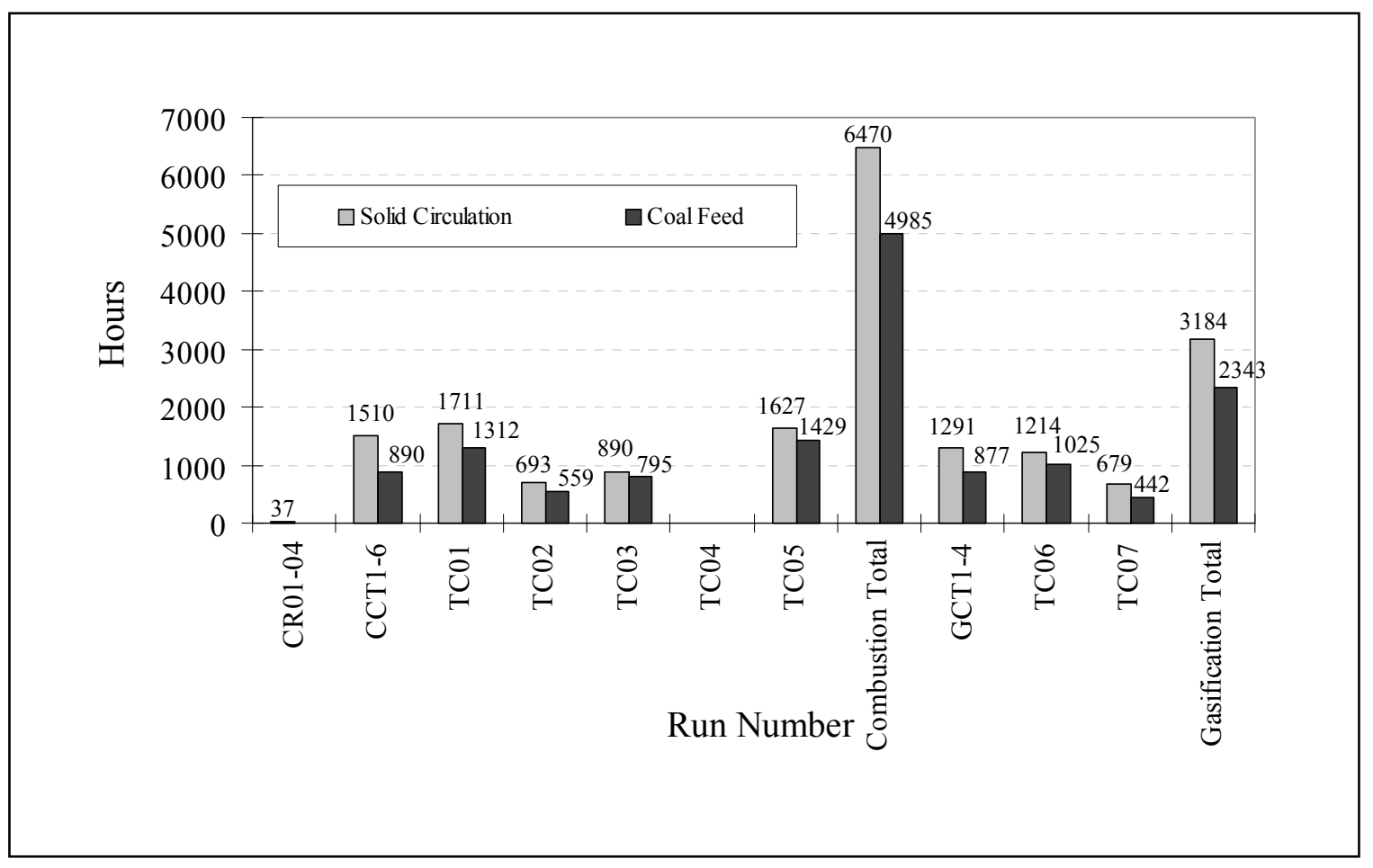

Figure 2.4-1 Operating Hours Summary for the Transport Reactor Train 


\subsection{PARTICLE FILTER SYSTEM}

\subsection{TCO7 RUN OVERVIEW}

TC07 tested a variety of operating conditions, including the commissioning of reactor hardware modifications, testing of different coals, and the implementation of several changes in Particulate Control Device (PCD) operation. An extension of the mixing zone, the lower mixing zone (LMZ), was added to the reactor, and during the run, both subbituminous and bituminous coals were tested. For PCD operation, the major operational concerns were to maintain a stable baseline pressure drop across the filter vessel and prevent gasification ash ( $g$-ash, formerly referred to as char) bridging. A stable baseline pressure drop was not observed in the previous test run using bituminous coal, although there were several factors that may have contributed to the rising pressure drop. Despite improved system operation in recent runs, g-ash bridging occurred in the previous four runs, so changes in PCD operation were made, such as adopting a more aggressive back-pulse strategy to prevent bridging and adding new instrumentation to track bridging growth.

TC07 consisted of four major periods of operation-TC07A, a sand circulation run, and three periods on coal, TC07B, TC07C, and TC07D. During TC07B, which consisted of 136 on-coal hours in January 2002, the LMZ was commissioned on coal feed. This run was also a test of operation on Alabama bituminous coal. TC07C, also a test using Alabama bituminous coal, occurred in February 2002. During this portion of the run, only 10 hours of on-coal operation was achieved due to unstable system conditions and particle leakage through the PCD. TC07D, consisting of 296 on-coal hours during March and April 2002, was a test of Powder River Basin (PRB) coal. This run was fairly stable, with no g-ash bridging and a relatively low pressure drop.

PCD operation was successful for much of TC07, although g-ash bridging and failure of two filter elements occurred during the short TC07C operation period. Unstable system conditions and the particle leakage resulting from the filter element failures precipitated system shutdown. In TC07B and D, no bridging or filter element failures occurred, and the pressure drop across the PCD tube sheet was controllable. Outlet loading samples, other than those taken after the instance of filter element failures, indicated good sealing of the filter vessel, with particle loading usually below 1 ppmw. Several new tests were conducted during TC07, such as failsafe testing of the Southern Research Institute (SRI) Safe Guard Device (SGD), backpulse intensity measurements, and new instrumentation including electrical resistance probes. Because thermal transients continued to be an operational concern, particularly those resulting from reactor upsets, new logic was utilized to address the concern of thermal transients, and this proved to be useful to PCD operation.

This report contains the following sections:

- Run Report, Section 3.2 - This section describes the main events and operating parameters affecting PCD operation during the three periods on coal of TC07. Operation of the fines removal system is also included in this section. 
- Inspection Report, Section 3.3 - The inspections performed following TC07B, C, and $\mathrm{D}$ are discussed in this section, including details of the post-run conditions of various PCD components and of the fines removal system.

- G-ash Characteristics and PCD Performance, Section 3.4 - This section includes a detailed discussion of g-ash physical and chemical properties, as well as the effects of these g-ash characteristics on PCD performance. The results of PCD inlet and outlet solids concentration sampling is presented in this section. 


\subsection{TCO7 RUN REPORT}

The TC07 test run was divided into four components designated as TC07A, TC07B, TC07C, and TC07D. TC07A started on December 11, 2001, and ended on December 14, 2001. TC07A was a sand circulation run to commission the new LMZ adapter that was added to the Transport Reactor. TC07B started on January 17 and ended on January 27, 2002. During TC07B, the PCD operated approximately 136 hours on both PRB and Alabama bituminous coal. TC07C started on February 7 and ended on February 8, 2002. During TC07C, the PCD operated approximately 10 hours on Alabama bituminous coal. Finally, TC07D started on March 22 and ended on April 5, 2002. During TC07D, the PCD operated approximately 296 hours on PRB coal. During the TC07 gasification test campaign the PCD operated on coal for a total of 442 hours.

\subsubsection{TCO7B and TCO7C}

\subsubsection{Introduction}

TC07B was the first run since GCT1 during which bituminous coal was used. During this run, the new addition to the Transport Reactor, the LMZ, was commissioned. Although system conditions were at times unstable, PCD operation was successful in TC07B with no filter element failures and no g-ash bridging. During this run, more stringent back-pulse parameters were employed consistently, which may have helped prevent bridging in TC07B. The pressure drop across the PCD tube sheet was fairly low and controllable, with the baseline pressure drop ranging from approximately 50 to $85 \mathrm{inH}_{2} \mathrm{O}$; however, due to changing system conditions, the baseline pressure drop was not steady for substantial lengths of time.

TC07C was a continuation of TC07B and was the short period of bituminous coal feed that did not produce steady operation. The solids loading to the PCD was quite high, exceeding the fines removal system capacity. High loading and unstable system conditions likely contributed to severe bridging. Throughout this period of operation, the baseline pressure drop continuously rose, ranging from 60 to $230 \mathrm{inH}_{2} \mathrm{O}$. Two filter element failures occurred, and the resulting particle leakage was one of the factors precipitating system shutdown of this portion of the run.

Run statistics for TC07B and $\mathrm{C}$ are shown in Table 3.2-1. The two filter element layouts implemented are shown in Figures 3.2-1 and 3.2-2. Filter Element Layout 22, used during TC07B and C, was modified to become Layout 23 after the filter element failures that required the removal and replacement of several filter elements and failsafes in TC07C.

\subsubsection{Test Objectives}

The primary test objectives for PCD operation were the following: 
- Maintain Stable Pressure Drop - A fairly stable baseline pressure drop was achieved in test runs GCT2 and TC06, both of these which used PRB subbituminous coal as fuel. In the previous instance of bituminous coal feed, GCT1, a stable baseline pressure drop was not observed, although there were several factors contributing to the rising baseline pressure drop, such as back-side blinding of the filter elements due to particle leakage. Maintaining a stable pressure drop while on bituminous coal feed was a major operational focus for TC07B and C.

- Evaluate Causes of G-ash Bridging — Since g-ash bridging had been a recurring problem, one goal of TC07 was to develop a better understanding of the origin and growth of bridging, which has primarily occurred on the bottom plenum of filter elements. Back-pulse intensity measurements were made to examine the possibility of lower back-pulse intensities (in certain areas of the bottom plenum) that could lead to insufficient cleaning and result in bridging. Using pressure taps inside two filter elements on the bottom plenum, the back-pulse intensities were monitored during the run to determine the uniformity of back-pulse pressure distribution. These two locations include an area where g-ash bridging has historically occurred and one area where bridging has not previously been observed. In addition, new thermocouples were added to the bottom plenum to monitor g-ash bridging presence and growth. A total of 26 filter element thermocouples were installed and placed at varying levels and locations.

- Filter Element Testing - Exposure of metallic filter elements, including $\mathrm{Pall}_{\mathrm{Fe}} \mathrm{Al}$ (Iron Aluminide), Pall Hastelloy-X, and USF/Fluid Dynamics HR-160 elements, was continued. Long-term exposure of these elements is expected to help assess material properties.

- Failsafe Testing - Several types of failsafe devices were installed for TC07. The SRI SGD was installed to be activated by nitrogen during the run. Eight metal fiberfilled Westinghouse failsafes were reinstalled, as were three PSDF-designed devices.

\subsubsection{Major Operating Events}

Refer to Figures 3.2-3 through -14 for operating trends corresponding to the following events.

A. System Startup: After a final pressure check, system pressure was held and backpulsing began at 01:00 on January 17, 2002. Reactor heat-up began with the start-up burner at 09:30. At 09:00 on February 18, 2002, coke-breeze feed was started.

B. Back-pulse Intensity Testing: At 10:45 on January 18, 2002, system pressure was increased and held at 150 psig with coke-breeze feed continuing so that back-pulse measurements could be taken. The testing involved varying the back-pulse valve open time and back-pulse pressure and taking local, high-speed measurements in the two bottom plenum filter elements equipped with pressure taps. (See Section 3.2.4.1 for details on this testing.) Before the measurements could be taken, a problem with the 
new PCD rate-of-change alarm logic caused continuous back-pulsing. The problem was temporarily corrected and several measurements were taken.

C. Reactor Upset with Carryover to PCD: At around 18:07 on January 18, 2002, a reactor upset caused the reactor inventory to suddenly carry over to the PCD. The PCD inlet temperature rose from 650 to $1,088^{\circ} \mathrm{F}$ and filter element temperatures rose from approximately 600 to $800^{\circ} \mathrm{F}$ in 3 minutes. At $18: 14$, FD0520 tripped due to the lock vessel spheri valve failure to close, and FD0502 tripped in turn. The fines removal system was back on-line at 19:05.

D. Coal Feed Started: Back-pulse pressure was increased to 400 psid on the top plenum and 600 psid on the bottom plenum, and the timer was kept at 5 minutes before coal feed was started at 09:16 on January 19, 2002. These back-pulse parameters were used throughout periods of coal feeding (except during TC07C as noted).

E. Reactor Trip: High conveying line pressure caused a reactor trip at 01:04 on January 20, 2002. Attempts to feed coke breeze were unsuccessful, and the start-up burner was started at 03.55 .

F. $\quad$ Reactor Upset: At 06:49 on January 20, 2002, a large amount of solids was carried over to the PCD due to a reactor upset. The large amount of hot solids caused the FD0502 screw cooler to trip on high outlet temperature, but operation of the screw cooler was restored within a few minutes.

G. System Shutdown: Because of a leaking flange (which required an off-line repair) the system was shut down at 10:45 on January 20, 2002.

H. System Startup: At 07:20 on January 20, 2002, system startup began. Back-pulse pressure was increased to $400 / 600$ psid with the timer at 5 minutes before coal feed began at 12:50 on January 21, 2002.

I. Coal Feeder Trip: After a coal feeder trip at 05:22 on January 24, 2002, coke breeze feed could not be established, and the start-up burner was lit at 09:00.

J. System Restart: After reheating the system, coal feed was reestablished at 17:40 on January 24, 2002.

K. Transition to Bituminous Coal: After the transition to bituminous coal on January 25, 2002, at around 14:45, solids loading to the PCD increased. Solids accumulation in the PCD cone was indicated by cone thermocouples. The solids removal system could not adequately clear the solids, so coal feed was reduced slightly.

L. System Shutdown: After a coal feeder trip occurred at 02:32 on January 27, 2002, oxygen breakthrough to the PCD caused a thermal excursion on the filter elements. Because of the loss of solids circulation in the reactor, the system was shut down. This marked the end of TC07B.

M. System Restart: On February 6, 2002, TC07C began as system heat-up began, and back-pulsing started at 15:05.

N. Reactor Upset: At 16:30 on February 07, 2002, while heating up on coke breeze, a reactor upset sent a large amount of solids to the PCD. Back-pulsing became continuous in response to many filter element temperature rate-of-change alarms. The 
fines removal system tripped immediately following the carryover. A second reactor upset occurred at 16:43.

O. Reactor Upset: Another reactor upset occurred at 21:30 on February 07, 2002. This upset was not as severe as the earlier events.

P. Coal Feed Started: At 22:00 on February 07, 2002, bituminous coal feed was started. Ten minutes later, the bottom plenum back-pulse pressure was lowered to 400 psid, because it was thought that the higher back-pulse pressure of 600 psid might have been contributing to unstable reactor conditions. Soon after coal feed began, PCD cone temperatures began to drop, which indicated solids buildup.

Q. G-ash Bridging Became Apparent: From approximately 00:30 to 01:00 on February 08, 2002, some bottom plenum filter element thermocouple readings were deviating from others, which indicated possible g-ash bridging. Also, the pressure drop reduction with the bottom plenum backpulse began to noticeably lessen, suggesting that flow through the bottom plenum had significantly decreased. At 01:30 on February 8, as steam flow through the reactor LMZ was established, PCD pressure drop increased dramatically. Back-pulse pressure was increased due to the high pressure drop.

R. Fines Removal System Trip: Due to the extremely high solids loading, the fines removal system tripped several times beginning at 07:45 on February 08, 2002. FD0530 tripped first due to high solids level, and this tripped FD0520 and FD0502. The system was back on-line by 07:58.

S. Coal Feeder Trip: At 08:04 on February 08, 2002, the coal feeder tripped. Cokebreeze feed could not be established, so reactor pressure was reduced so that the startup burner could be lit.

T. Continuous Backpulsing: Beginning at 08:24 on February 08, 2002, several filter element temperature rate-of-change alarms were triggered, and due to a control logic problem, back-pulsing became continuous for 28 minutes.

U. Start-up Burner Lit: At 08:52 on February 08, 2002, the start-up burner was lit. At that time oxygen breakthrough was detected by gas analyzers.

V. System Shutdown: At around 09:00 on February 08, 2002, the on-line particulate monitor showed some response, indicating a possible leak, and by 09:25, the monitor output was 100 percent. A PCD outlet sample performed at 10:10 that morning showed an outlet particle concentration of approximately $20 \mathrm{ppmw}$. A second outlet loading performed at 13:05 on February 08, 2002, confirmed particle leakage with a sample rate of $35 \mathrm{ppmw}$. The run was discontinued at this time due to the leak, which could damage the filter elements and downstream equipment, and because of inadequate circulation in the reactor. This concluded TC07C.

\subsubsection{Run Summary and Analysis}

PCD operation was fairly stable during TC07B despite changing system conditions. During the startup of this portion of the run, a reactor upset occurred and caused high solids 
carryover to the PCD. Rapid temperature increases were seen from the inlet and filter element thermocouples, although there was no evidence of filter element failure at that time. The large amount of material filled up the PCD cone and tripped the fines removal system. The system was quickly restored. During coal feed, the pressure drop in the PCD was very low, as the maximum peak pressure drop during steady-state operations was less than 150 in $\mathrm{H}_{2} \mathrm{O}$. During most of the coal run, the baseline pressure drop was approximately 50 to $60 \mathrm{inH}_{2} \mathrm{O}$ with a 10 to $20 \mathrm{inH}_{2} \mathrm{O}$ pressure drop rise during a back-pulse cycle. Even after the transition to bituminous coal, which greatly increased the solids carryover to the PCD, the pressure drop was low. The baseline pressure drop was fairly stable during steady system operations, and it did not show an overall increase throughout the run. The relatively low coal-feed rates, frequent back-pulsing, and possibly a change in g-ash characteristics contributed to the low pressure drop.

TC07B was the first run since GCT2 during which g-ash bridging apparently did not occur. Changing pulse cleaning parameters may have been one factor that helped lessen the bridging tendency. In earlier gasification runs, the back-pulse cycle time was dependent on the pressure drop across the tube sheet, keeping the pressure drop below approximately $250 \mathrm{inH}_{2} \mathrm{O}$ to protect the mechanical integrity of the filter vessel components. This method at times employed a relatively long-pulse frequency of 15 to 20 minutes when the pressure drop was low. Beginning with test campaign TC07, the strategy shifted to frequently pulse cleaning the filter elements, usually every 5 minutes, regardless of the pressure drop. Also, instead of using the same pulse pressure for both plenums, a higher pulse pressure was used on the bottom plenum than on the top plenum of filter elements in an effort to achieve similar back-pulse intensities on each plenum.

Prior to coal feed in $\mathrm{TC} 07 \mathrm{C}$, a series of reactor upsets occurred which caused high solids carryover to the PCD. It is likely that the cone did not completely empty of solids following the last reactor upset and remained partially full during the remainder of TC07C. The high solids level in the PCD may have contributed to the buildup of bridged material between the filter elements if the solids level reached as high as the bottom of the filter elements. Also, system operations were quite unstable, and could have negatively affected g-ash cake properties. The onset of bridging was rapid, and could be seen by filter element thermocouple response as well as by the disappearing response to bottom plenum backpulsing. During TC07C, the back-pulse frequency was kept at 5 minutes, although the bottom plenum back-pulse pressure was not kept as high throughout coal feed as it was during TC07B.

During the TC07C inspection, two cracked filter elements were found, although it is not clear exactly what caused the failures. At the time of the filter element failures, the on-line particulate monitor showed a clear response immediately following some unusual operating conditions. At this time, coal feed was stopped, and, due to a control logic problem, continuous back-pulsing occurred and lasted for 28 minutes. Then, as the start-up burner was being lit, oxygen breakthrough occurred, although combustion occurring on the filter element surfaces was not obvious by the thermocouple response. The constraint caused by the bridging may have contributed to the filter element failures. 
There were several instances of continuous back-pulsing, usually triggered by filter element temperature rate-of-change alarms. The rate-of-change alarms, set for $2 \mathrm{~F}^{\circ} / \mathrm{sec}$ temperature increase, were activated by reactor upsets and, at times, by temperature recovery following a back-pulse. The alarms were programmed to cause only one back-pulse; however, a flaw in the logic caused continuous back-pulsing from each alarm.

Back-pulse Pressure Measurements: During TC07B, pressure differential $(\Delta \mathrm{P})$ measurements were made in two filter elements in the bottom plenum of the PCD to determine the uniformity of the back-pulse pressure distribution. A 1/2-inch tube for pressure measurement and a 1/4-inch tube for a thermocouple feedthrough were installed through the bottom plates of two $1.5 \mathrm{~m} \mathrm{Pall} \mathrm{Fe}_{3} \mathrm{Al}$ filter elements. One of these filter elements was installed at location B45, which is in a bridging-prone area, while the other filter element was installed at location B2, which is in an area where bridging has not been seen. Pressure drop from the PCD dirty side volume to the inside of the filter element was measured using a fast-response Viatran Model $574 \Delta \mathrm{P}$ transducer. $\Delta \mathrm{P}$ data was recorded at $100 \mathrm{~Hz}$ using a PC-based data acquisition system so the peak $\Delta \mathrm{P}$ during back-pulsing could be determined. The thermocouples inside the filter elements were located just below the failsafes so the gas temperature during back-pulsing could be measured.

Filter element pressure measurements were made during warm up for TC07B on January 18, 2002, while coke breeze was being fed. Measurements were made at back-pulse tank pressures $250,400,600,700$, and 800 psi above reactor pressure with valve-open times of 0.2 and 0.4 seconds. The relationship between tank pressure and peak back-pulse $\Delta \mathrm{P}$ was almost linear, with a slight second order effect that is probably due to the failsafe and/or other plumbing where the relationship $\Delta \mathrm{P} \sim \mathrm{V}^{2}$ existed. It was found that increasing the valve-open time from 0.2 seconds to 0.4 seconds did not increase the peak $\Delta \mathrm{P}$ at any pressure. The longer valve-open time introduces more nitrogen into the system and upsets the reactor more; thus, it is probably not useful to have a valve-open time longer than 0.2 seconds. The difference between the back-pulse $\Delta \mathrm{P}$ at locations $\mathrm{B} 2$ and $\mathrm{B} 45$ was not significant for any condition. Additional filter element pressure measurements were made during normal operation on January 21, 2002. The back-pulse $\Delta \mathrm{P}$ was approximately 50 percent higher with dirty filter elements than it was with clean filter elements at the same tank pressure.

Filter element $\triangle \mathrm{P}$ measurements were also made at location B2 during TC07C and TC07D. During TC07D, there were a couple of occasions when the back-pulse was delayed due to problems with the control logic. This resulted in different filter element $\Delta \mathrm{P}$ levels prior to the back-pulse while all other conditions were essentially constant. Filter element $\Delta \mathrm{P}$ measurements were made during back-pulsing with initial $\Delta \mathrm{P}$ levels of approximately 95 , 115 , and $135 \mathrm{inH}_{2} \mathrm{O}$. The peak reverse $\Delta \mathrm{P}$ did not vary at all in these three cases, which seems to indicate that the peak $\Delta \mathrm{P}$ depends more on residual cake properties than on transient cake properties. 


\subsubsection{TCO7D}

\subsubsection{Introduction}

For PCD operation, TC07D was a stable run despite a major thermal excursion at startup and several minor thermal excursions following coal feeder trips. The pressure drop across the PCD tube sheet was relatively low and controllable, with the baseline pressure drop ranging from approximately 65 to $80 \mathrm{inH}_{2} \mathrm{O}$. There were no filter element failures and no indication of particle leakage, as outlet loading samples usually indicated particle loading of less than 0.1 ppmw. Run statistics for TC07D are shown in Table 3.2-2, and the filter element layout is shown in Figure 3.2-2.

\subsubsection{Test Objectives}

The primary test objectives for PCD operation were the following:

- Evaluate Causes of G-ash Bridging - In light of the occurrence of g-ash bridging in TC07C, g-ash bridging continued to be a major focus for PCD operation. Twenty-four filter element thermocouples were reinstalled to track g-ash bridging during operation and thereby further the understanding of $g$-ash bridging formation. In addition, two modified thermocouples were installed on adjacent filter elements, and these instruments were used to detect g-ash bridging between the filter elements. The instruments protruded approximately half an inch from the filter element surfaces, and, when covered by g-ash, measured a change in electrical resistances.

Because significant g-ash bridging has not been observed on the top plenum, which contains only two rows of filter elements, it has been reasoned that the support provided by a complete ring of filter elements is necessary for g-ash bridging to occur. Therefore, on the bottom plenum, six adjacent filter elements (half of one row) were removed and replaced with "blanks," leaving a break between the filter elements on one half of the bottom plenum. As a control, the other half of the bottom plenum was loaded with filter elements as usual.

- Filter Element Testing - Exposure of metallic filter elements continued in TC07D. Most of the filter elements installed were $\mathrm{Pall} \mathrm{Fe}_{3} \mathrm{Al}$ (Iron Aluminide), many of these new, and some having been exposed during previous runs. In addition, Hastelloy $\mathrm{X}$ and HR-160 filter elements were tested in TC07D. Long-term exposure of these elements is expected to help assess material properties of these materials.

- Failsafe Testing - Most of the failsafe devices from TC07C were reinstalled for TC07D. Because there was not an opportunity to activate the SRI Safe Guard Device (SGD) during TC07C, it was reinstalled so that it could be activated during this run. Six fiber-filled Westinghouse failsafes were reinstalled above the "blanks" to continue gas exposure, and several additional PSDF-designed devices were installed. 


\subsubsection{Major Operating Events}

Refer to Figures 3.2-15 through 3.2-20 for operating trends corresponding to the following events.

W. System Startup: System startup began on March 21, 2002, with back-pulsing started at 08:50. The start-up burner was lit at 01:30 on March 22. Startup was delayed slightly when FD0520 tripped due to a plugged line at 02:00 on March 22, and the system was restored within an hour. Coke breeze was started at 17:40.

X. Reactor Upset: A reactor upset occurred at 22:50 on March 22, 2002, followed by a more severe upset at 23:00. During the second upset, oxygen breakthrough occurred causing filter element temperatures to increase from approximately $740^{\circ} \mathrm{F}$ to as high as $1,440^{\circ} \mathrm{F}$ within 5 minutes. The temperature rate-of-change was as high as $28^{\circ} \mathrm{F} / \mathrm{sec}$. Filter element temperature rate-of-change alarms triggered emergency back-pulsing, which effectively stopped the temperature increases. The on-line particulate monitor showed some response to this event, and startup was delayed until it could be determined that there was not a leak through the PCD. The fines removal system tripped during this time due to the excessive solids loading.

Y. $\quad$ System Restart: Coke breeze feed was started at 07:20 on March 23, 2002.

Z. Reactor Upset: An upset occurred at 10:15 on March 23, 2002, causing filter element temperature rate-of-change alarms.

AA. Coal Feed Started: At 12:25 on March 23, 2002, coal feed was started at a low rate. At 13:00, a PCD outlet sample was taken, which indicated an outlet loading of 2.6 ppmw. Based on this relatively low outlet loading, the run was continued to see if the particulate loading would drop to an acceptable level. (Subsequent outlet loading samples were acceptable and did not indicate significant leakage.)

BB. Loss of Coal Feed: After the main air compressor tripped at 16:25 on March 23, 2002, which caused the coal feeder to trip, coal feed could not be reestablished. Also, coke breeze failed to feed, so system pressure was reduced to light the start-up burner.

CC. Coal Feed Started: Coke-breeze feed was started at 21:20 on March 23, 2002, and coal was started at 01:55 on March 24, 2002.

DD. Coal Feeder Trip: At 10:20 on March 28, 2002, the coal feeder tripped. Coal feed was resumed at 11:20.

EE. Coal Feeder Trip: Coal feed was lost at 03:40 on March 29, 2002. After several hours of difficulty with the feeder, coal feed was eventually restored at 11:00. 
FF. Coal Feeder Trips: Several coal feeder trips occurred, beginning at 09:30 on March 30,2002 , leading to several small thermal excursions in the PCD. Coal feed was steady by 11:45 on March 30, 2002.

GG. Coal Feeder Trip: At 07:35 on March 31, 2002, the coal feeder tripped, which caused a small thermal excursion in the PCD. Coal feed was resumed at 09:40.

HH. Attempt to Activate SRI SGD: At 18:00 on April 01, 2002, nitrogen was injected into the SGD to activate it. At that time, back-pulse cleaning was delayed so that the pressure drop across the failsafe was higher than during the previous attempt. However, this attempt was also unsuccessful.

II. Coal Feeder Trip: At 05:15 on April 05, 2002, the coal feeder tripped. Coal feed was resumed at 07:00.

JJ. Coal Feeder Trip and System Shutdown: At 11:55 on April 05, 2002, the coal feeder tripped again. At that time, there was some oxygen in the PCD, and therefore restart was not attempted, and the system was shut down.

\subsubsection{Run Summary and Analysis}

During the initial start-up of TC07D while heating up on coke breeze, a major thermal excursion occurred as a result of a reactor upset. The upset sent a large amount of material, and then oxygen, to the PCD. Filter element thermocouples reached as high as $1440^{\circ} \mathrm{F}$, although the rapid rise in temperature was stopped by emergency back-pulsing triggered by filter element temperature rate-of-change alarms. At the time, the on-line particulate monitor responded to the upset, and its baseline reading was elevated for several hours. An SRI outlet sample performed the following day showed approximately 2.6 ppmw loading, and the run was continued. Subsequent outlet sampling showed reduced loading, usually below the sampling system lower limit of detection of $0.1 \mathrm{ppmw}$.

The remainder of the run was stable for PCD operation, despite several minor thermal excursions resulting from coal feeder trips and oxygen breakthrough. The thermal excursions were usually not severe enough to trigger rate-of-change alarms. However, when the rate-of-change alarms were triggered, the response was appropriate, a single emergency back-pulse and the adding of diluting nitrogen. 
Table 3.2-1

TC07B/C Run Statistics and Steady-State PCD Operating Parameters

(January 17 Through February 9, 2002)

\begin{tabular}{|c|c|}
\hline Start Time: & 01/17/02 01:00 (for back-pulse system) \\
\hline End Time: & $02 / 08 / 02$ 20:45 \\
\hline Coal Type: & Powder River Basin and Alabama Bituminous \\
\hline Hours on Coal: & Approx. $146 \mathrm{hr}$ \\
\hline Sorbent Type: & Ohio limestone \\
\hline Number of Filter Elements: & 91 \\
\hline Filter Element Layout No.: & 22 (Figure 3.2-1) \\
\hline Filtration Area: & $258.4 \mathrm{ft}^{2}\left(24.0 \mathrm{~m}^{2}\right)$ \\
\hline Pulse-Valve-Open Time: & $0.2 \mathrm{sec}$ \\
\hline Pulse-Time Trigger: & $5 \mathrm{~min}$ \\
\hline Pulse Pressure, Top Plenum: & 400 psi (27.6 bar) above System Pressure \\
\hline Pulse Pressure, Bottom Plenum: & 400 to 600 psi (27.6 to 41.4 bar) above System Pressure \\
\hline Pulse-dP Trigger: & $275 \mathrm{inH}_{2} \mathrm{O}$ (685 mbar) \\
\hline Inlet Gas Temperature: & Approx. 715 to $800^{\circ} \mathrm{F}\left(380\right.$ to $\left.425^{\circ} \mathrm{C}\right)$ \\
\hline Face Velocity: & Approx. 2.3 to $3.5 \mathrm{ft} / \mathrm{min}(1.2$ to $1.8 \mathrm{~cm} / \mathrm{sec})$ \\
\hline Inlet Loading Concentration: & Approx. 13,600 to 18,000 ppmw \\
\hline Outlet Loading Concentration: & $<0.1$ ppmw to 1.4 ppmw $^{*}$ \\
\hline Baseline Pressure Drop: & Approx. 80 to $120 \mathrm{inH}_{2} \mathrm{O}$ (200 to 300 mbar) \\
\hline
\end{tabular}

* Except for outlet loading concentration of 34.8 ppmw detected on February 8, 2002, resulting from broken filter elements. 
Table 3.2-2

TCO7D Run Statistics and Steady-State PCD Operating Parameters

(March 21 Through April 5, 2002)

\begin{tabular}{|c|c|}
\hline Start Time: & 03/21/02 08:50 (for back-pulse system) \\
\hline End Time: & 04/05/02 15:15 \\
\hline Coal Type: & Powder River Basin \\
\hline Hours on Coal: & Approx. $296 \mathrm{hrs}$ \\
\hline Sorbent Type: & Ohio limestone \\
\hline Number of Filter Elements: & 85 \\
\hline Filter Element Layout No.: & 23 (Figure 3.2-2) \\
\hline Filtration Area: & $241.4 \mathrm{ft}^{2}\left(22.4 \mathrm{~m}^{2}\right)$ \\
\hline Pulse-Valve-Open Time: & $0.2 \mathrm{sec}$ \\
\hline Pulse-Time Trigger: & $5 \mathrm{~min}$ \\
\hline Pulse Pressure, Top Plenum & 400 psi (27.6 bar) above System Pressure \\
\hline Pulse Pressure, Bottom Plenum: & 600 psi (41.4 bar) above System Pressure \\
\hline Pulse-dP Trigger: & $275 \mathrm{inH}_{2} \mathrm{O}$ (685 bar) \\
\hline Inlet Gas Temperature: & Approx. $775^{\circ} \mathrm{F}\left(410^{\circ} \mathrm{C}\right)$ \\
\hline Face Velocity: & Approx. 3 to $4 \mathrm{ft} / \mathrm{min}(1.5$ to $2.0 \mathrm{~cm} / \mathrm{sec})$ \\
\hline Inlet Loading Concentration: & Approx. 14,200 to 21,400 ppmw \\
\hline Outlet Loading Concentration: & $<0.1$ to $2.6 \mathrm{ppmw}$ \\
\hline Baseline Pressure Drop: & Approx. 65 to $80 \mathrm{inH}_{2} \mathrm{O}$ (160 to 200 mbar) \\
\hline
\end{tabular}




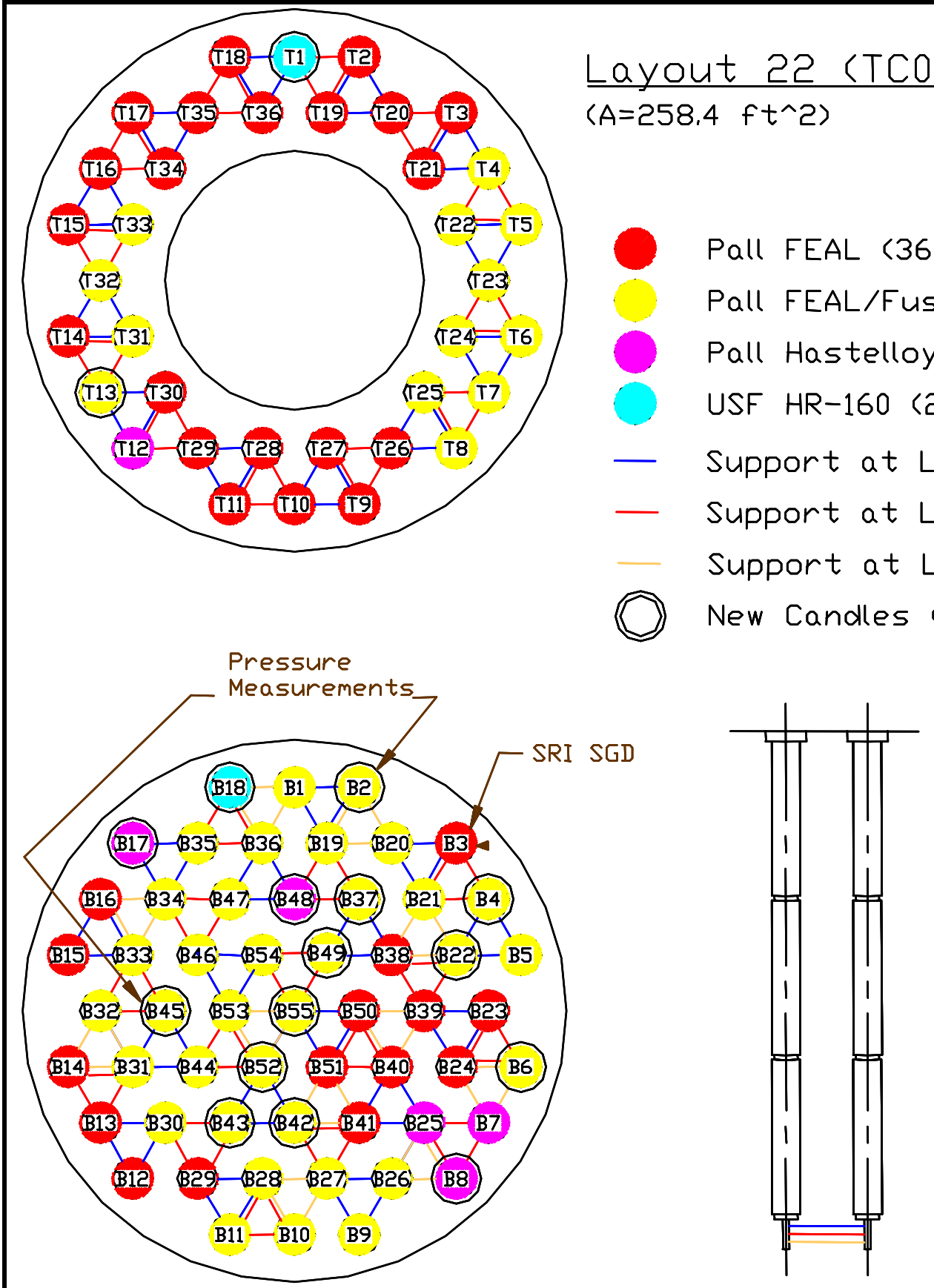

Figure 3.2-1 Filter Element Layout Implemented in TCO7B and TCO7C 


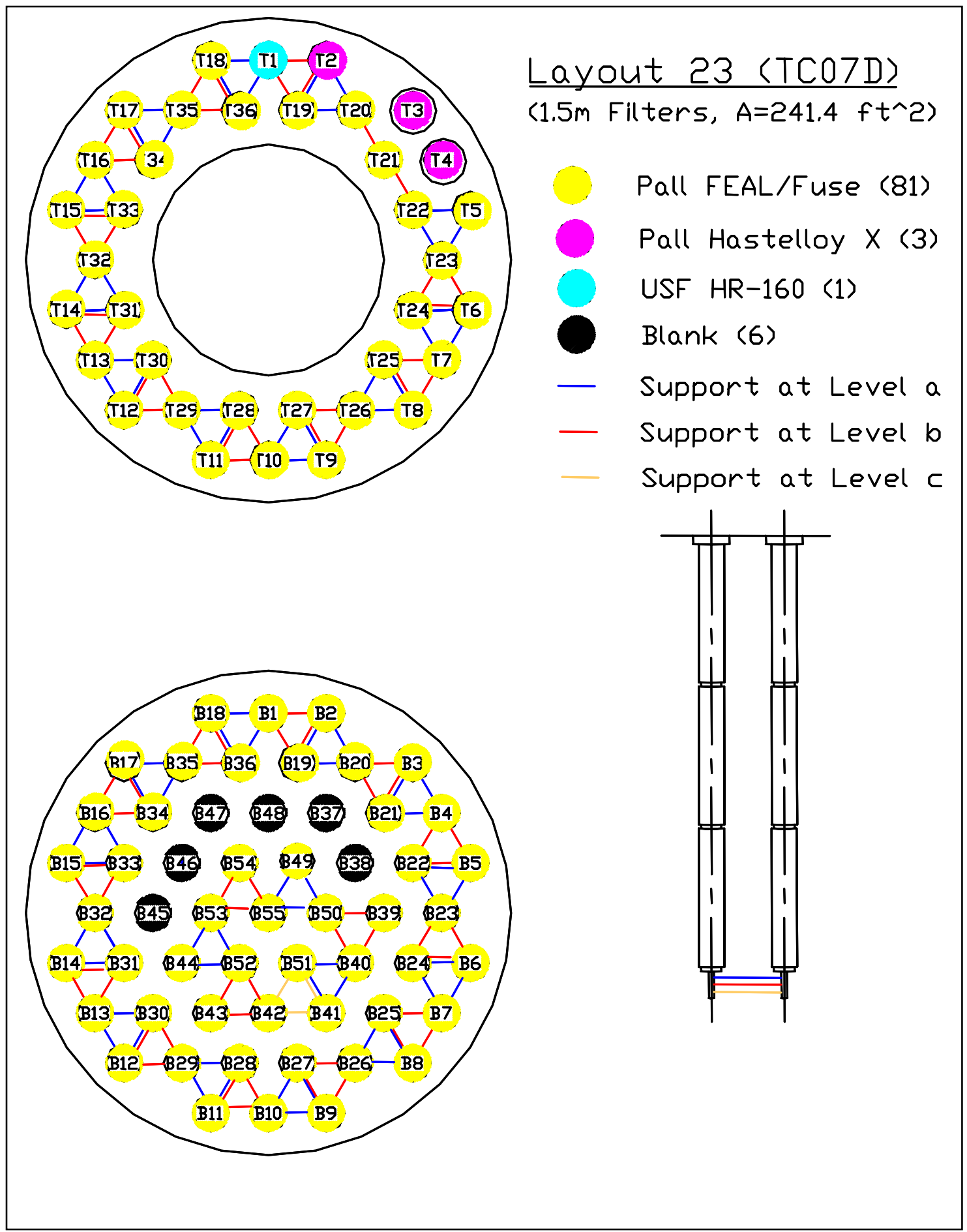

Figure 3.2-2 Filter Element Layout Implemented in TCO7D 


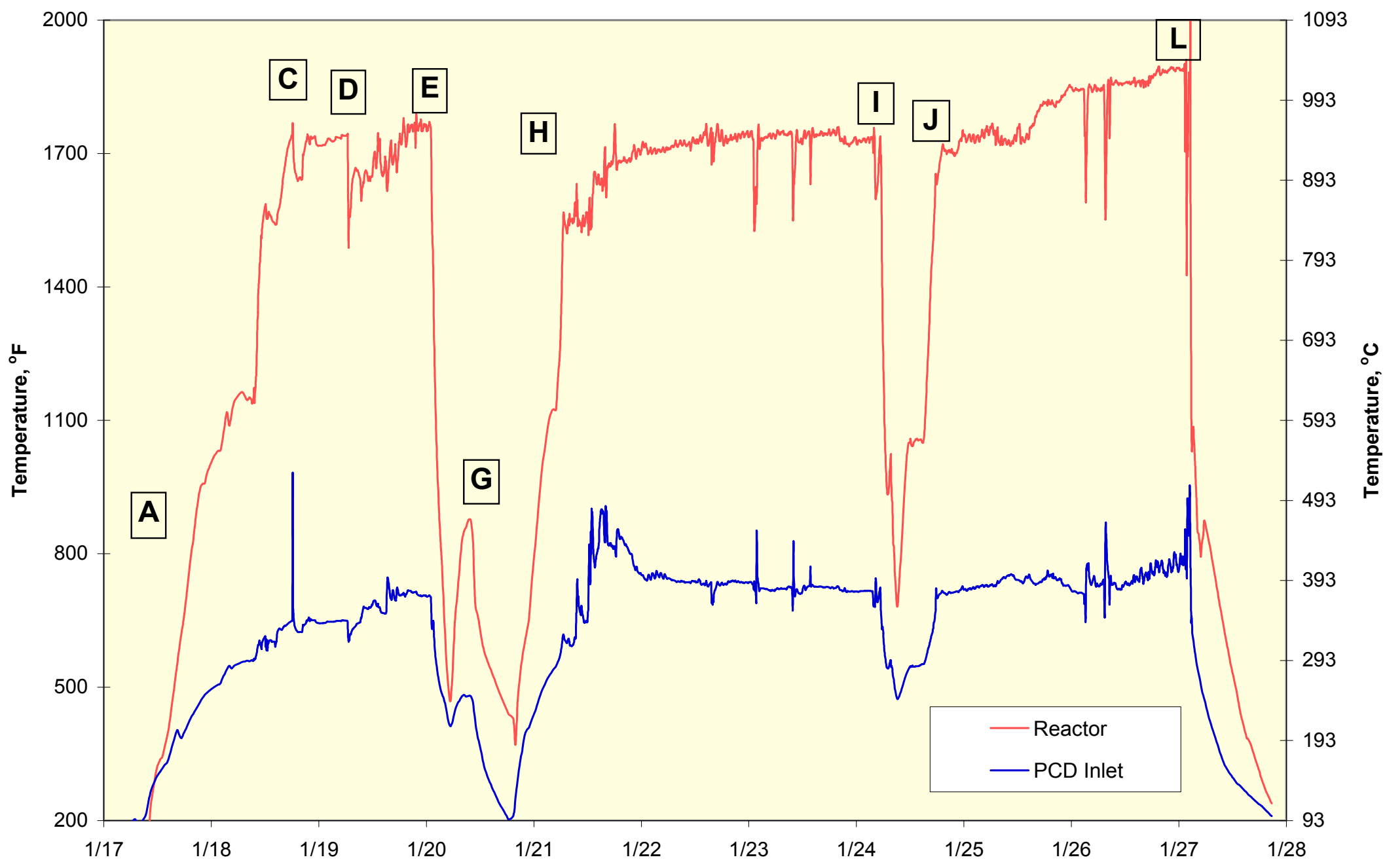

Figure 3.2-3 Reactor and PCD Temperatures, TCO7B 


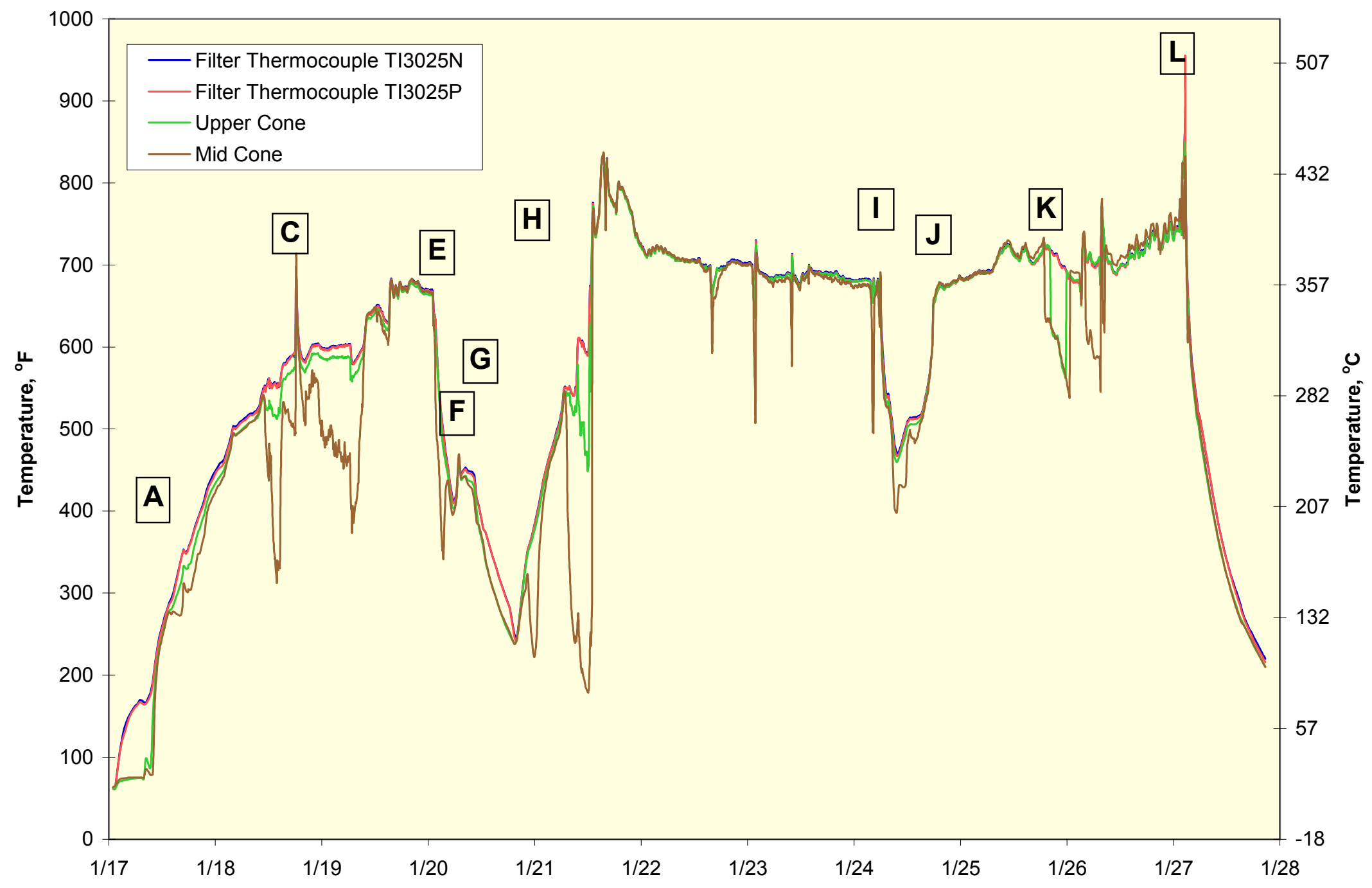

Figure 3.2-4 PCD Filter and Cone Temperatures, TC07B 


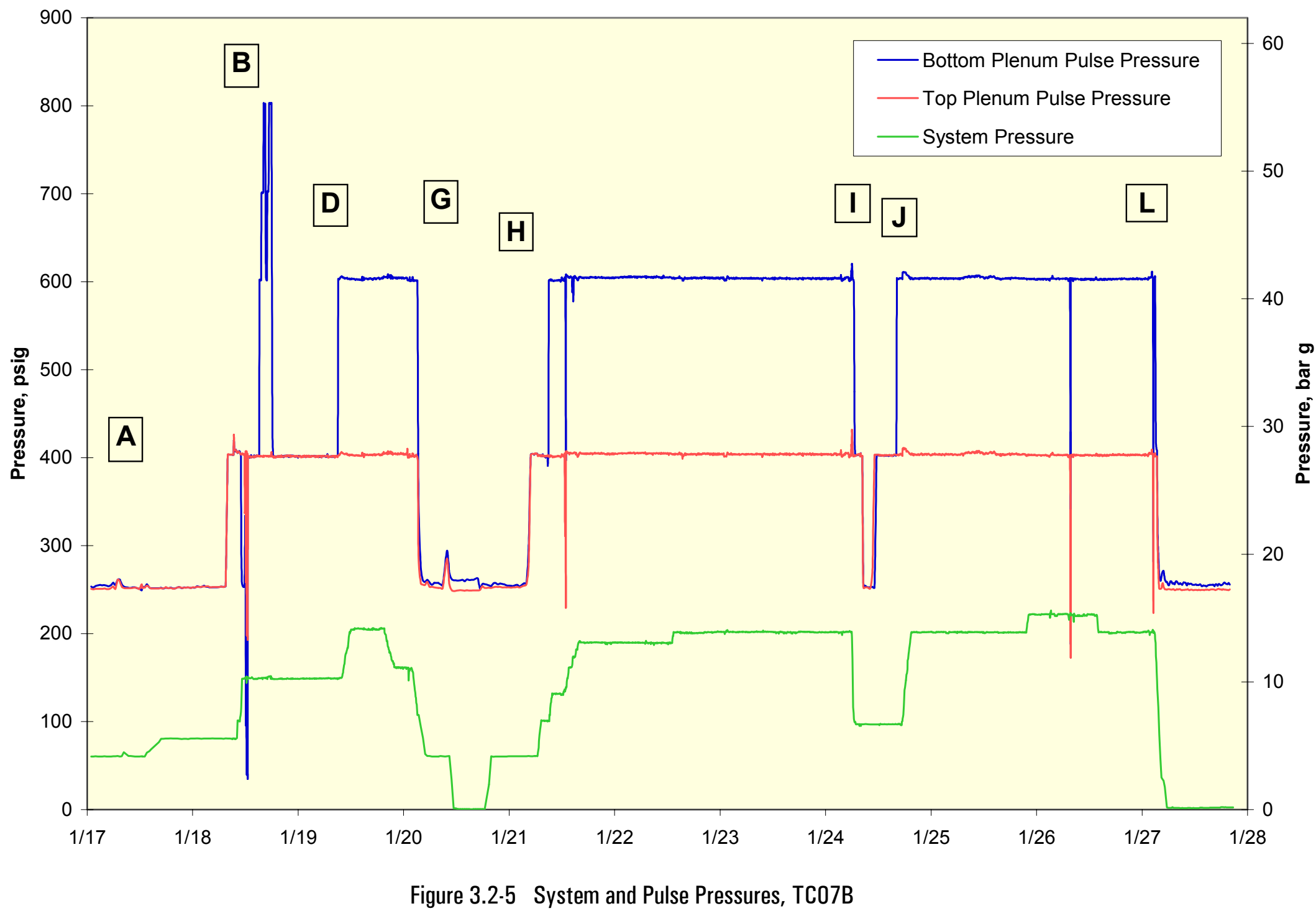




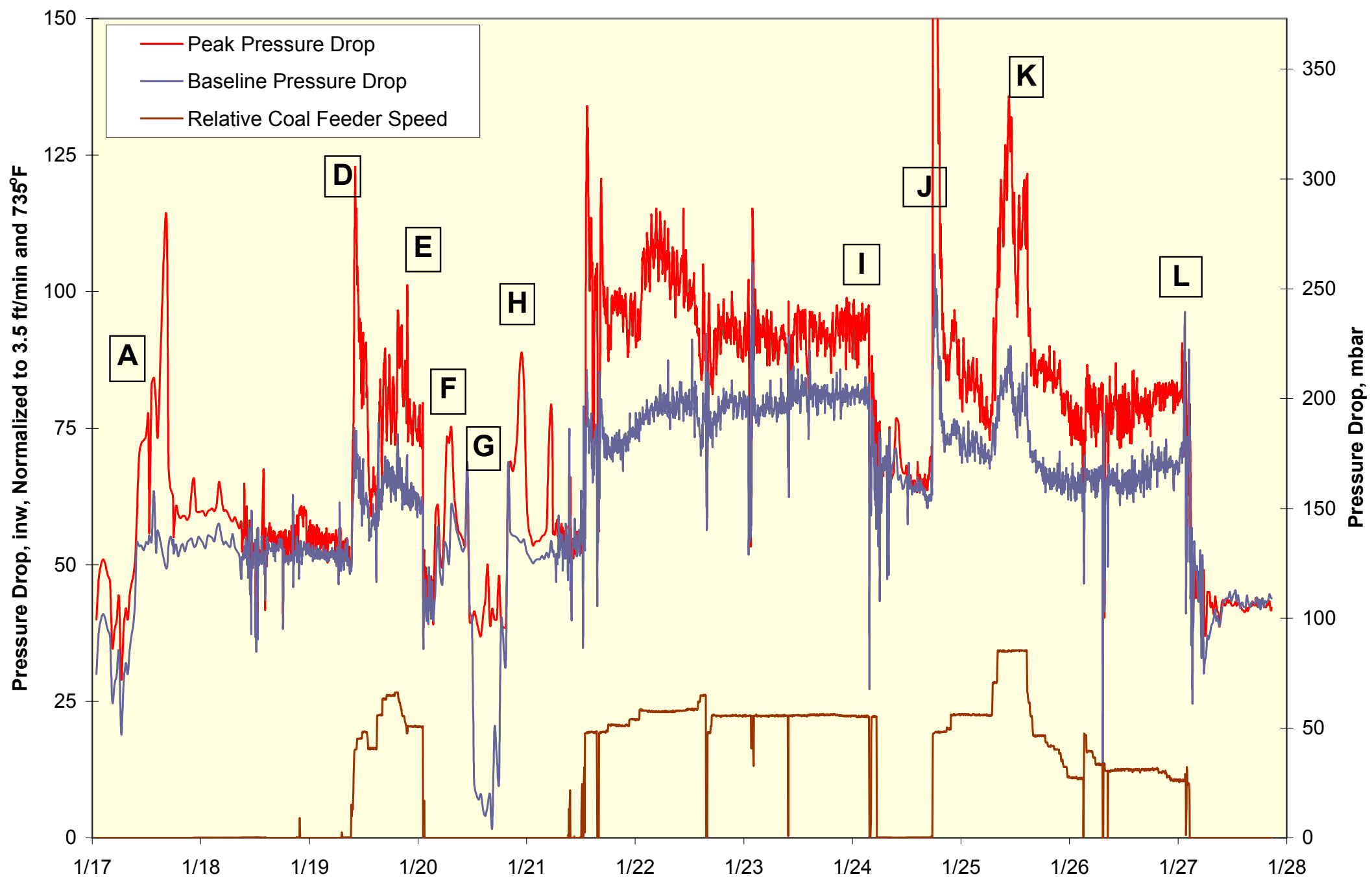

Figure 3.2-6 PCD Normalized Pressure Drop, TCO7B 


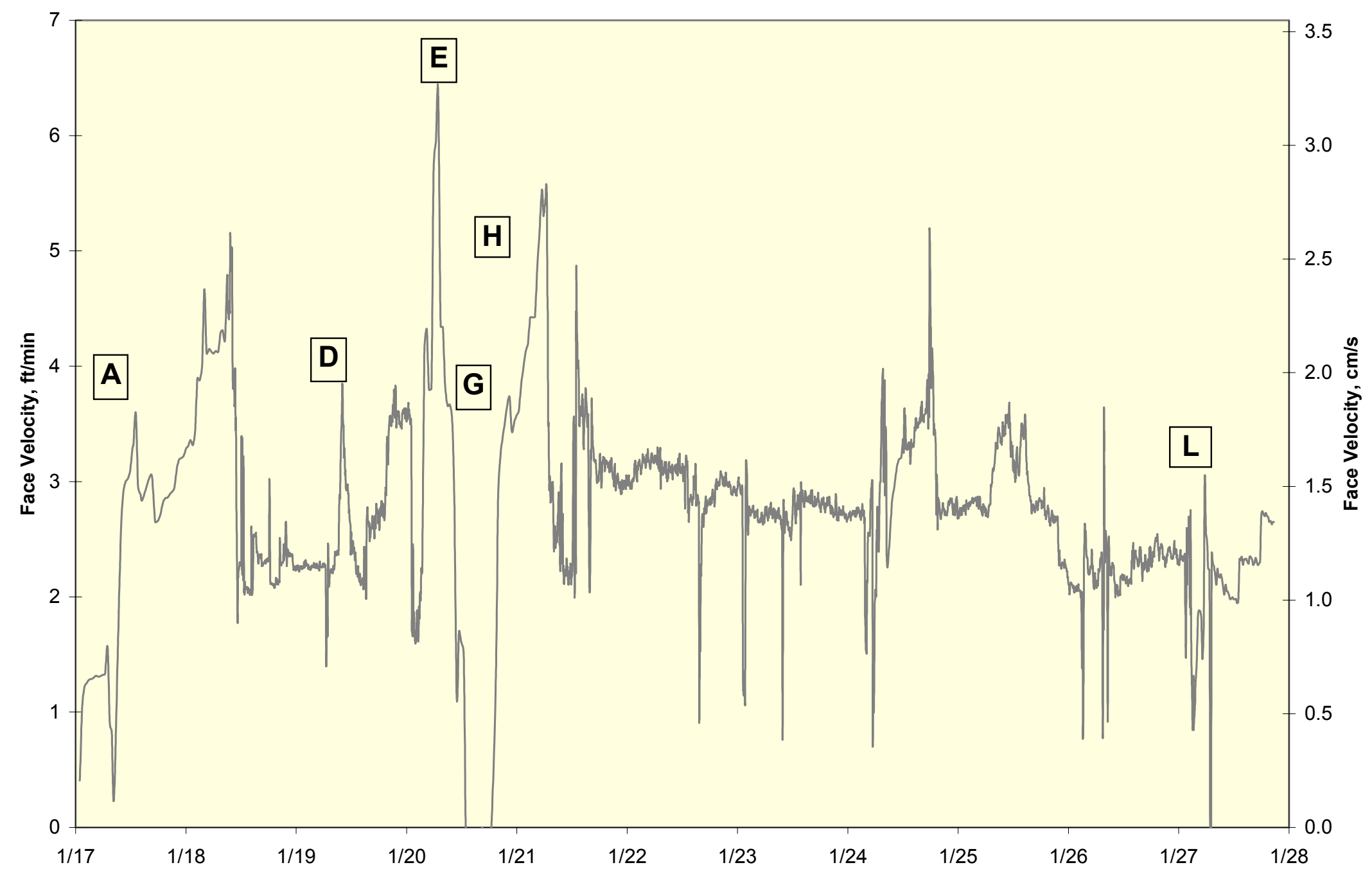

Figure 3.2-7 PCD Face Velocity, TCO7B 


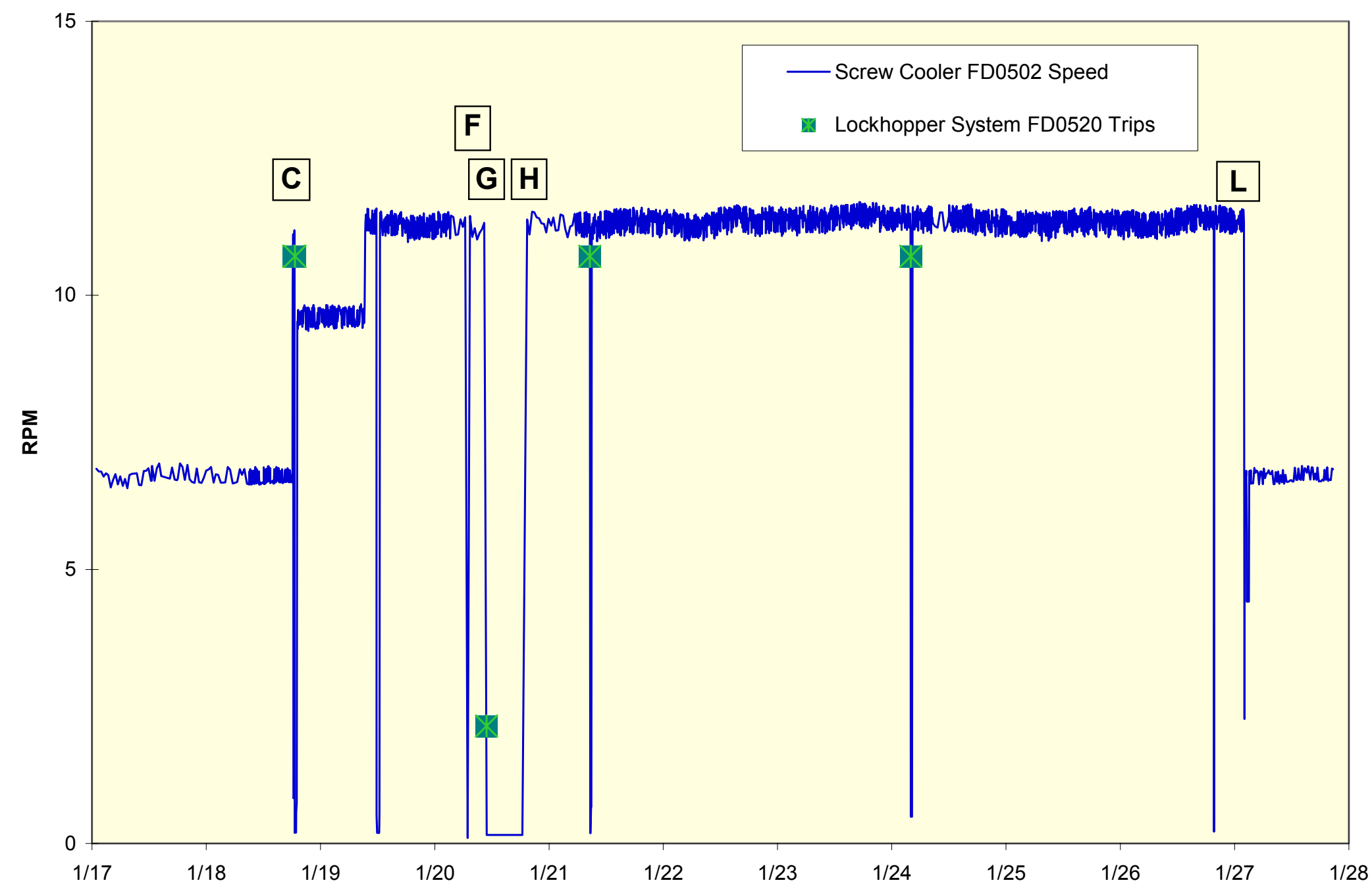

Figure 3.2-8 Fines Removal Operation, TC07B 


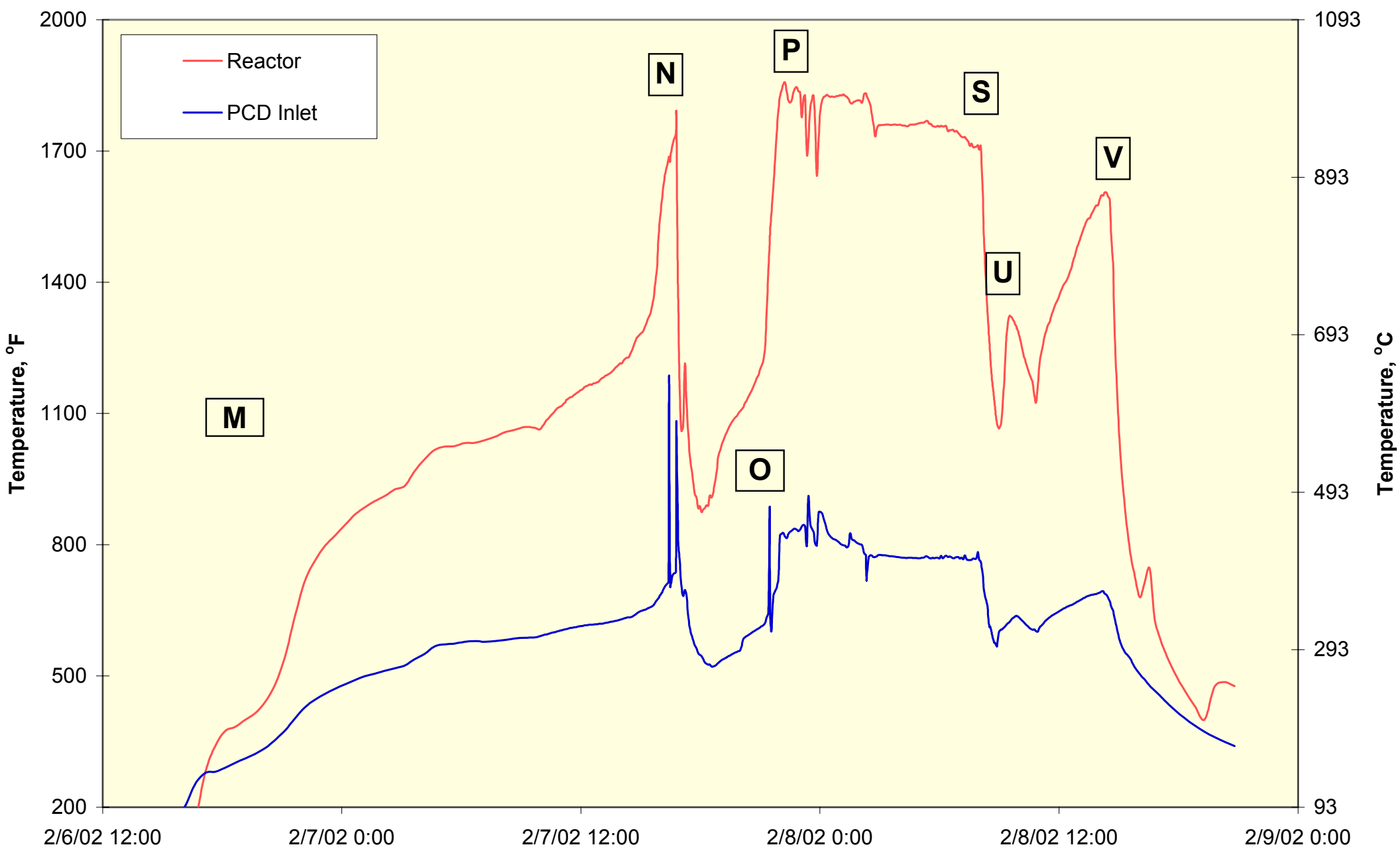

Figure 3.2-9 Reactor and PCD Temperatures, TCO7C 


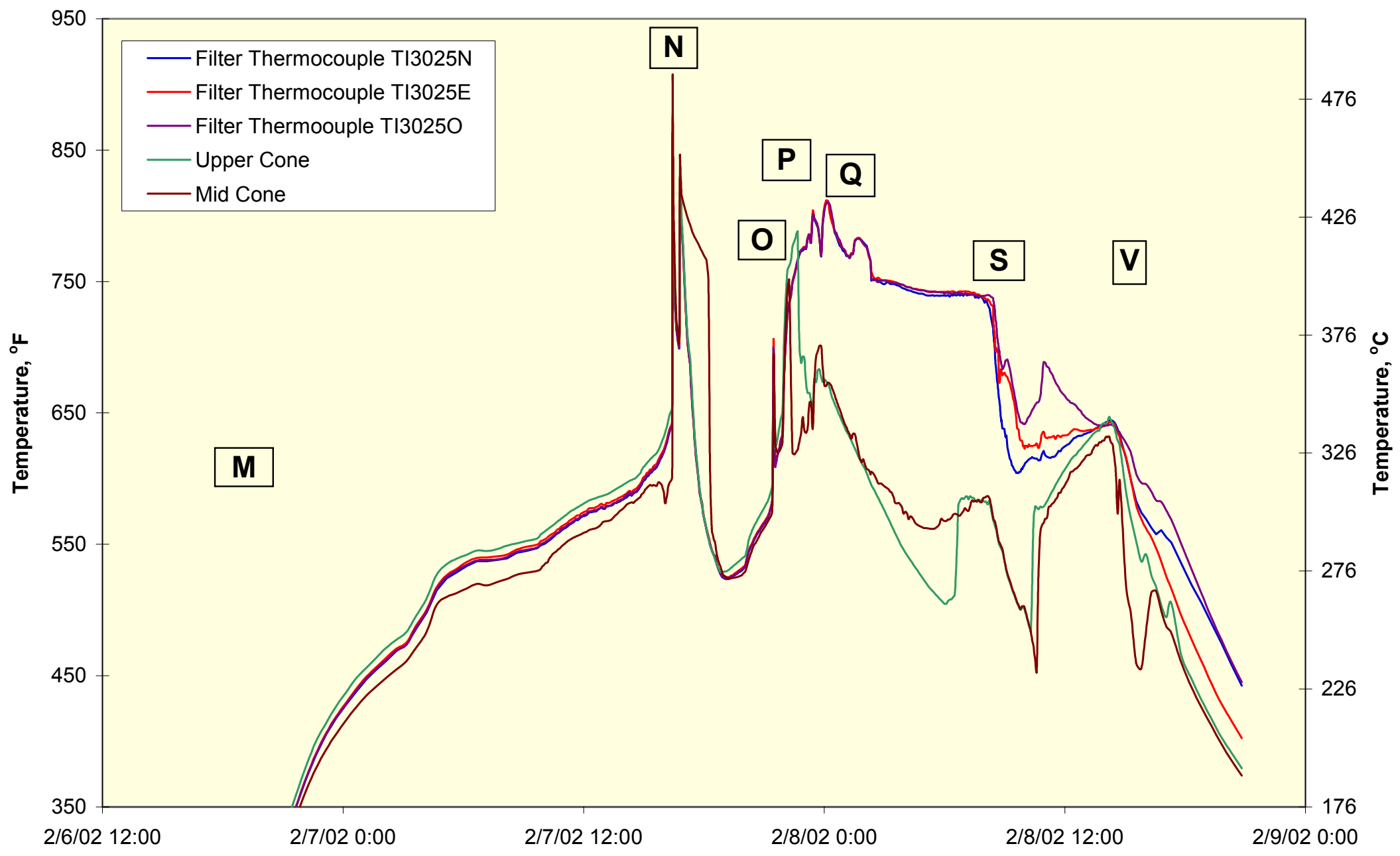

Figure 3.2-10 PCD Filter Element and Cone Temperatures, TCO7C 


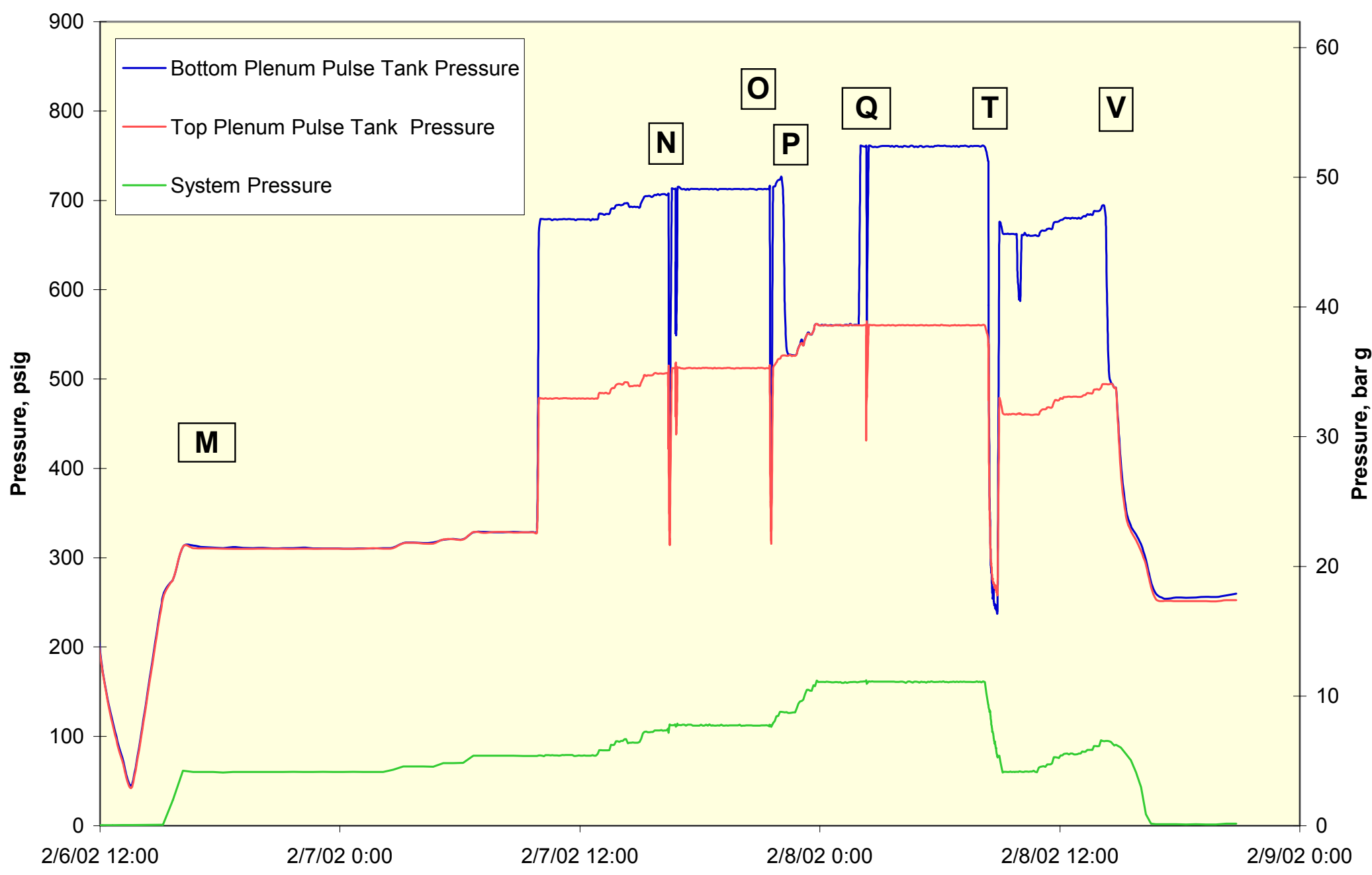

Figure 3.2-11 Pulse Pressures and System Pressure, TCO7C 


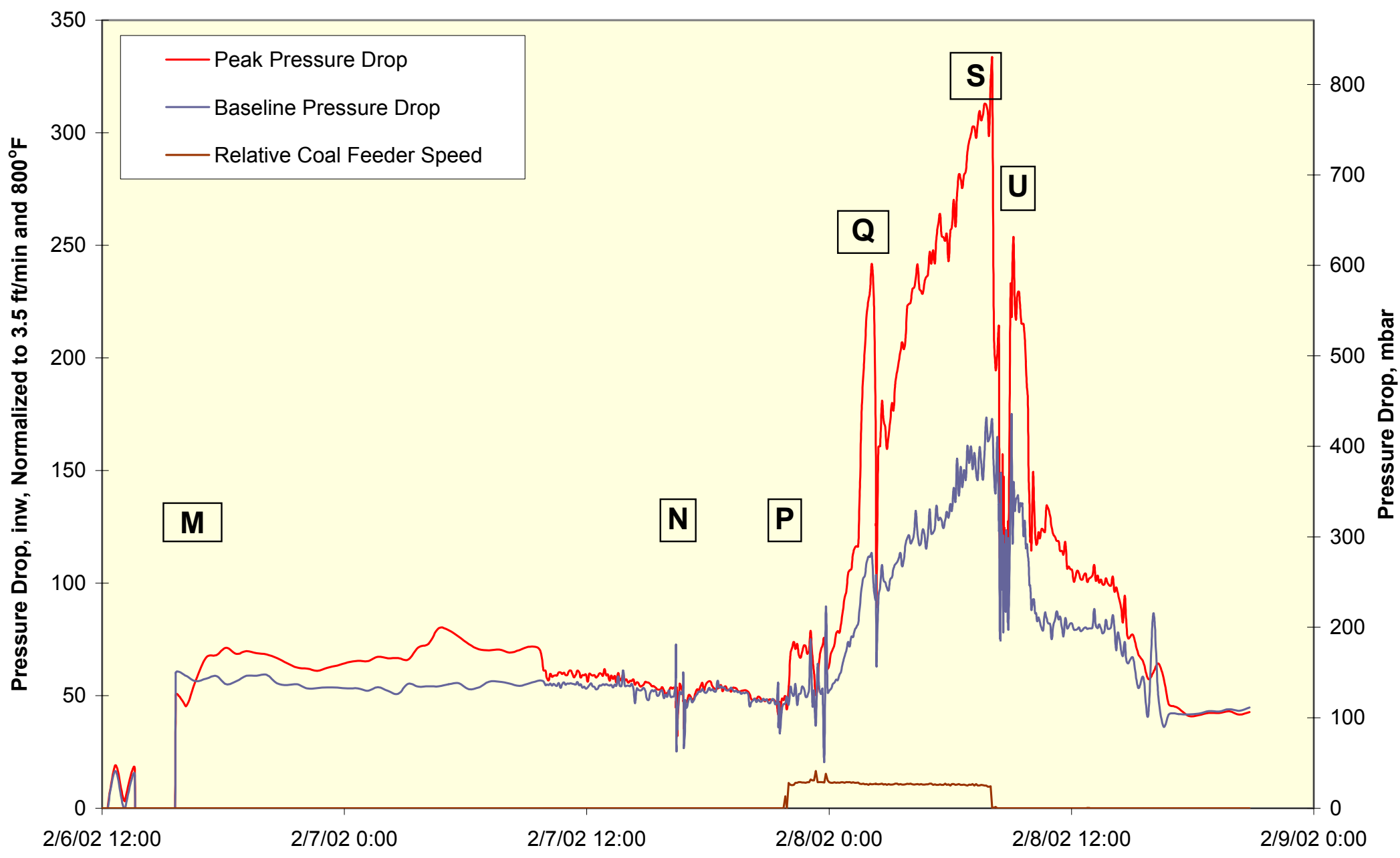

Figure 3.2-12 Normalized PCD Pressure Drop, TCO7C 


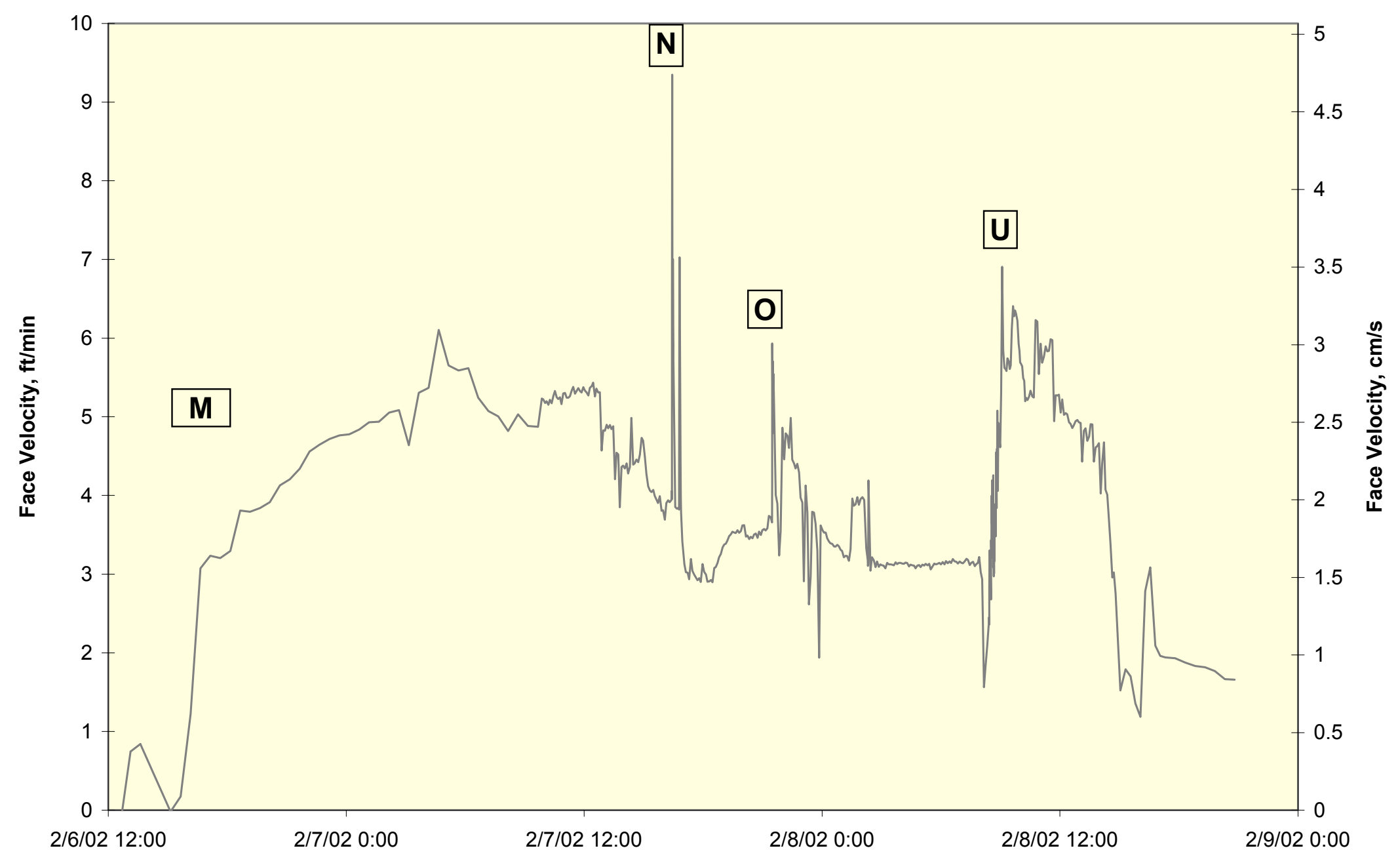

Figure 3.2-13 PCD Face Velocity, TC07C 


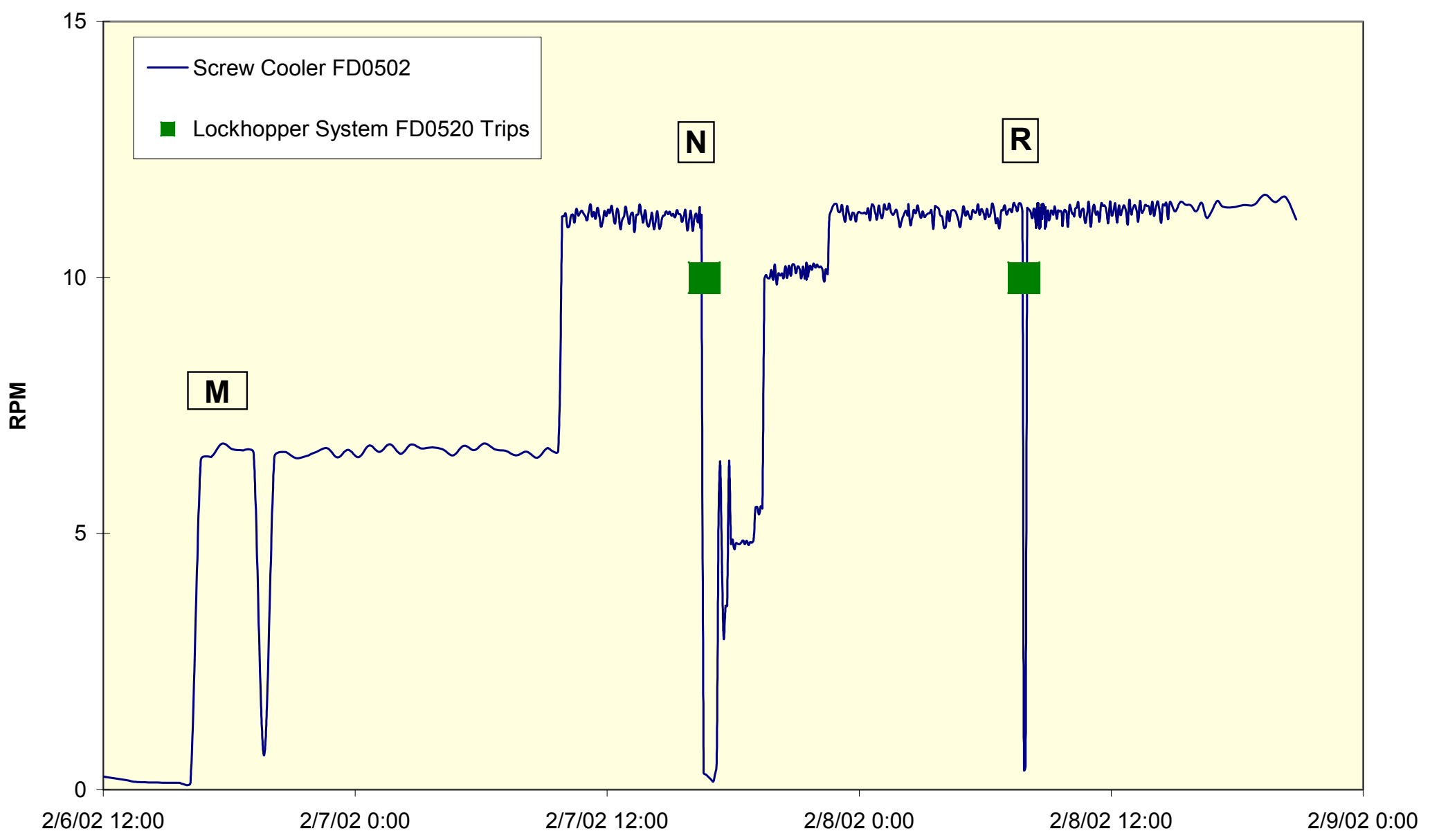

Figure 3.2-14 Fines Removal System Operation, TCO7C 


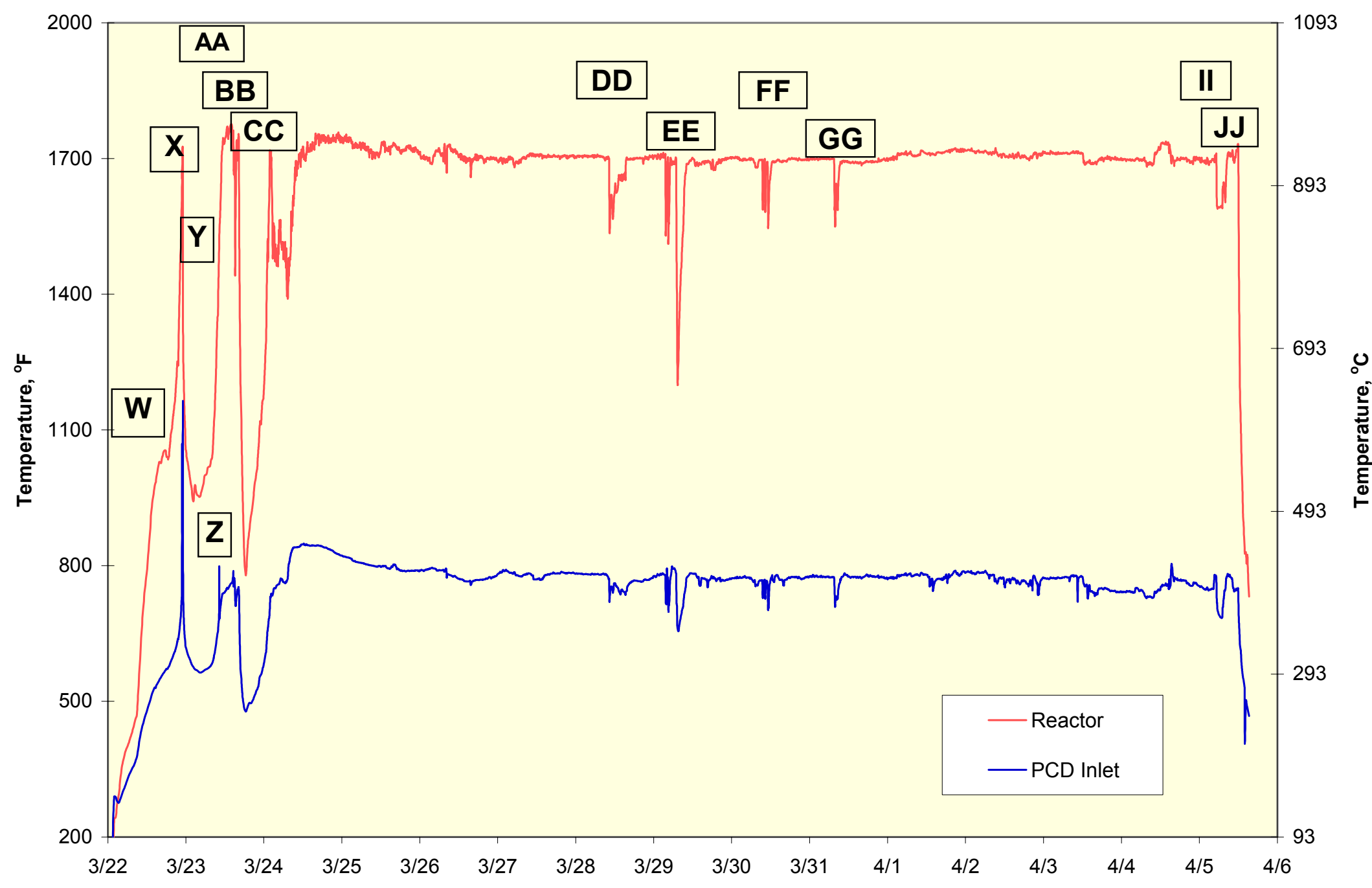

Figure 3.2-15 Reactor and PCD Temperatures, TCO7D 


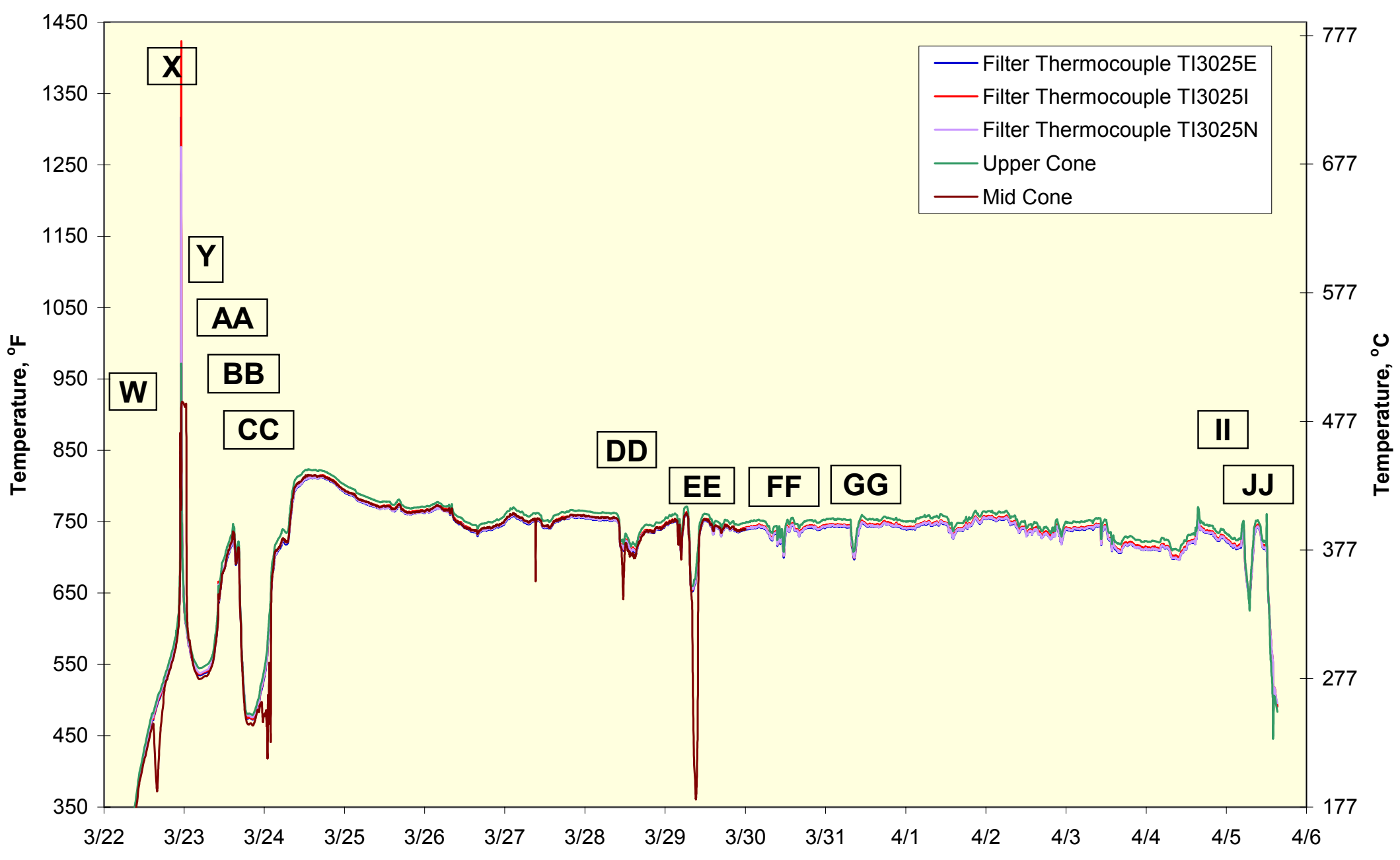

Figure 3.2-16 PCD Filter Element and Cone Temperatures, TCO7D 


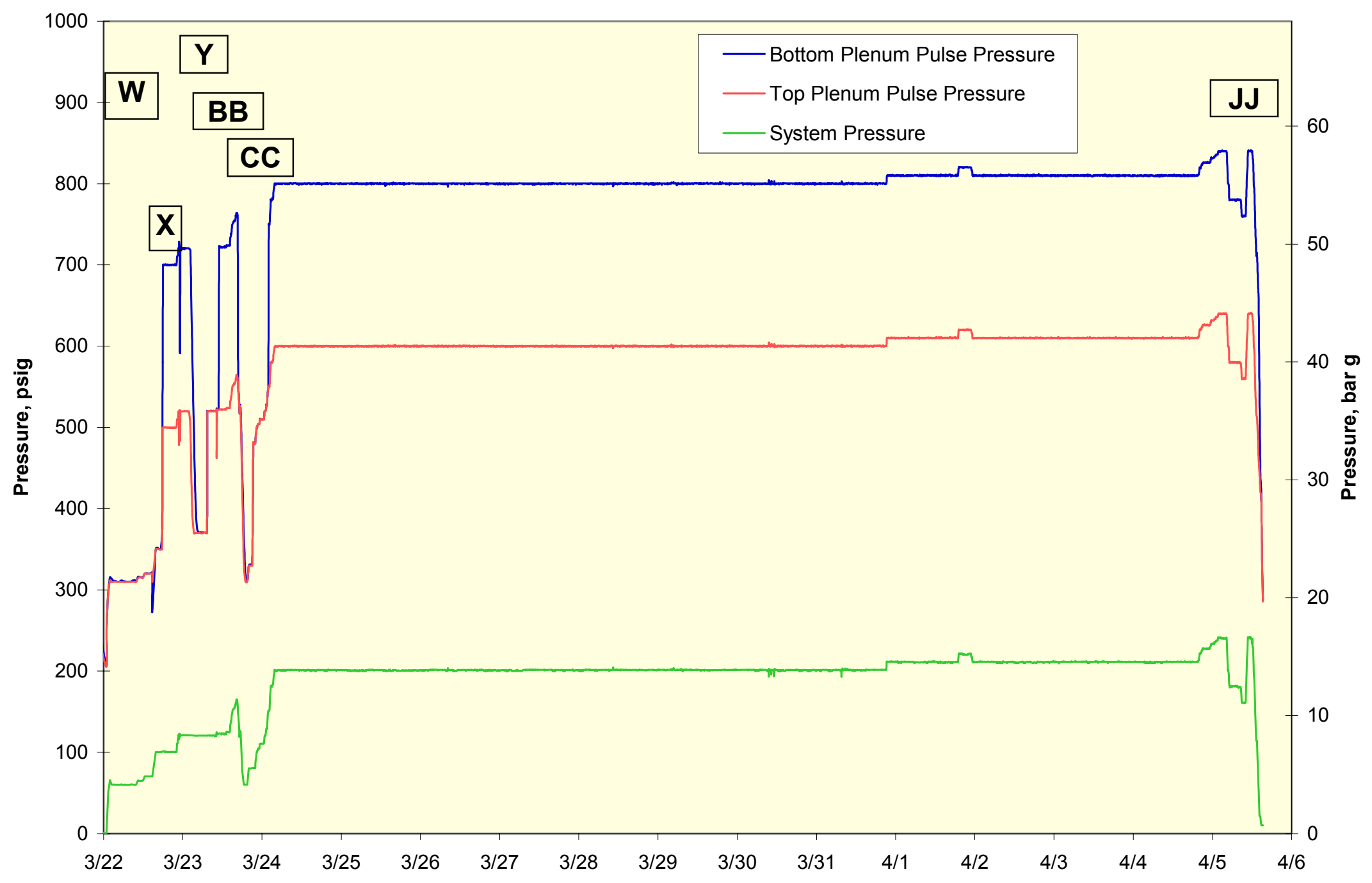

Figure 3.2-17 System and Pulse Pressures, TC07D 


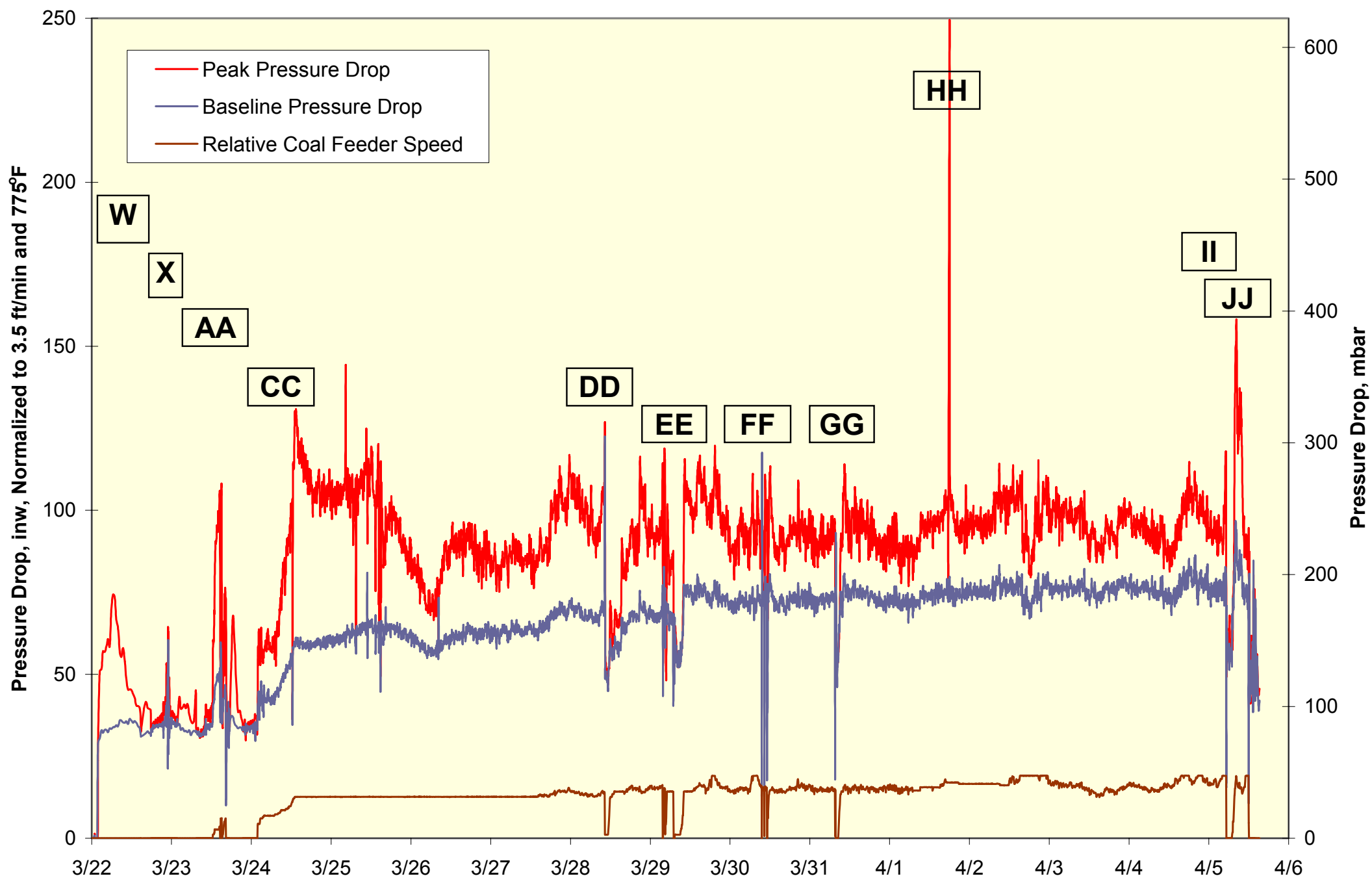

Figure 3.2-18 Normalized PCD Pressure Drop, TC07D 


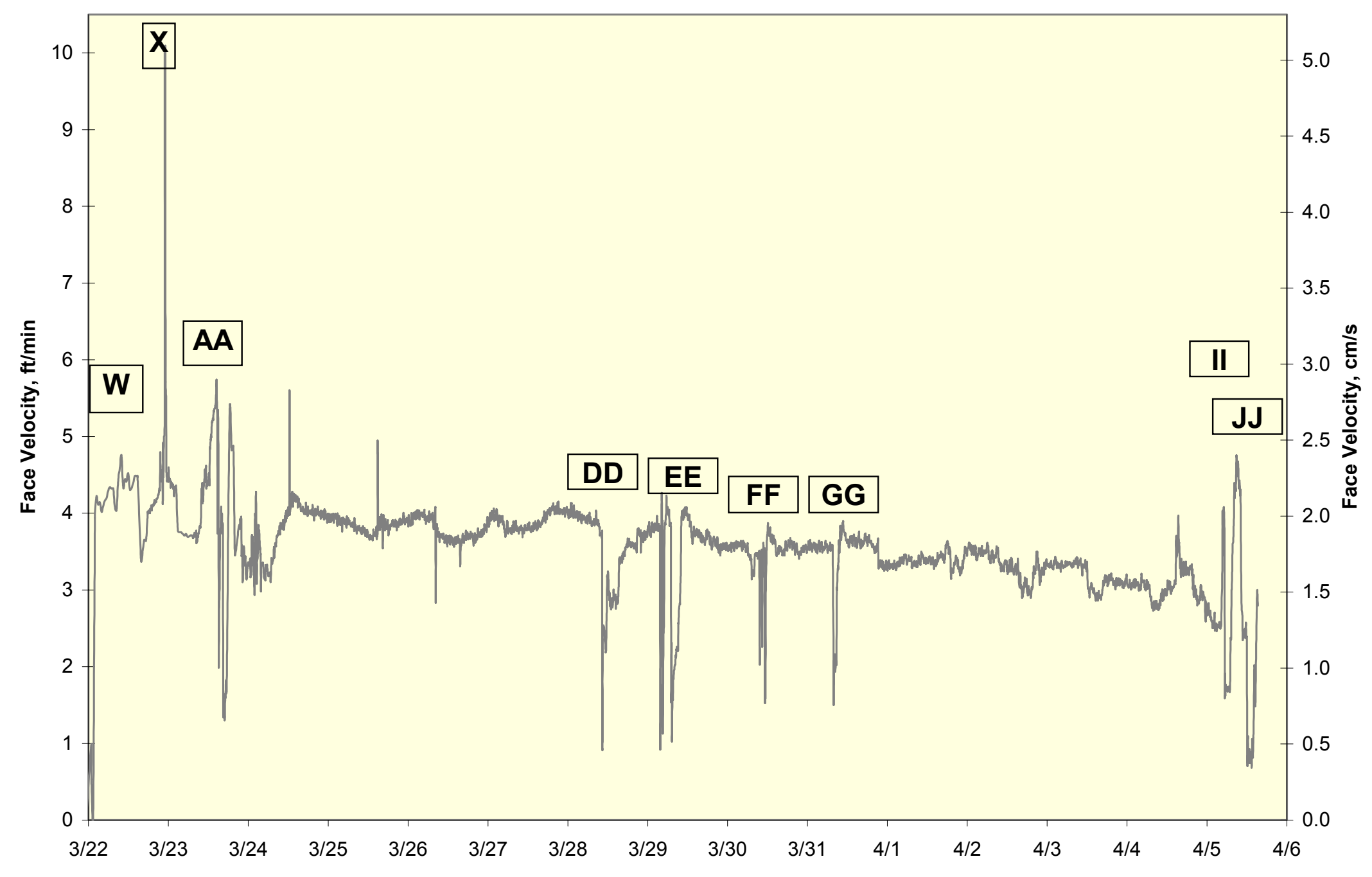

Figure 3.2-19 PCD Face Velocity, TC07D 


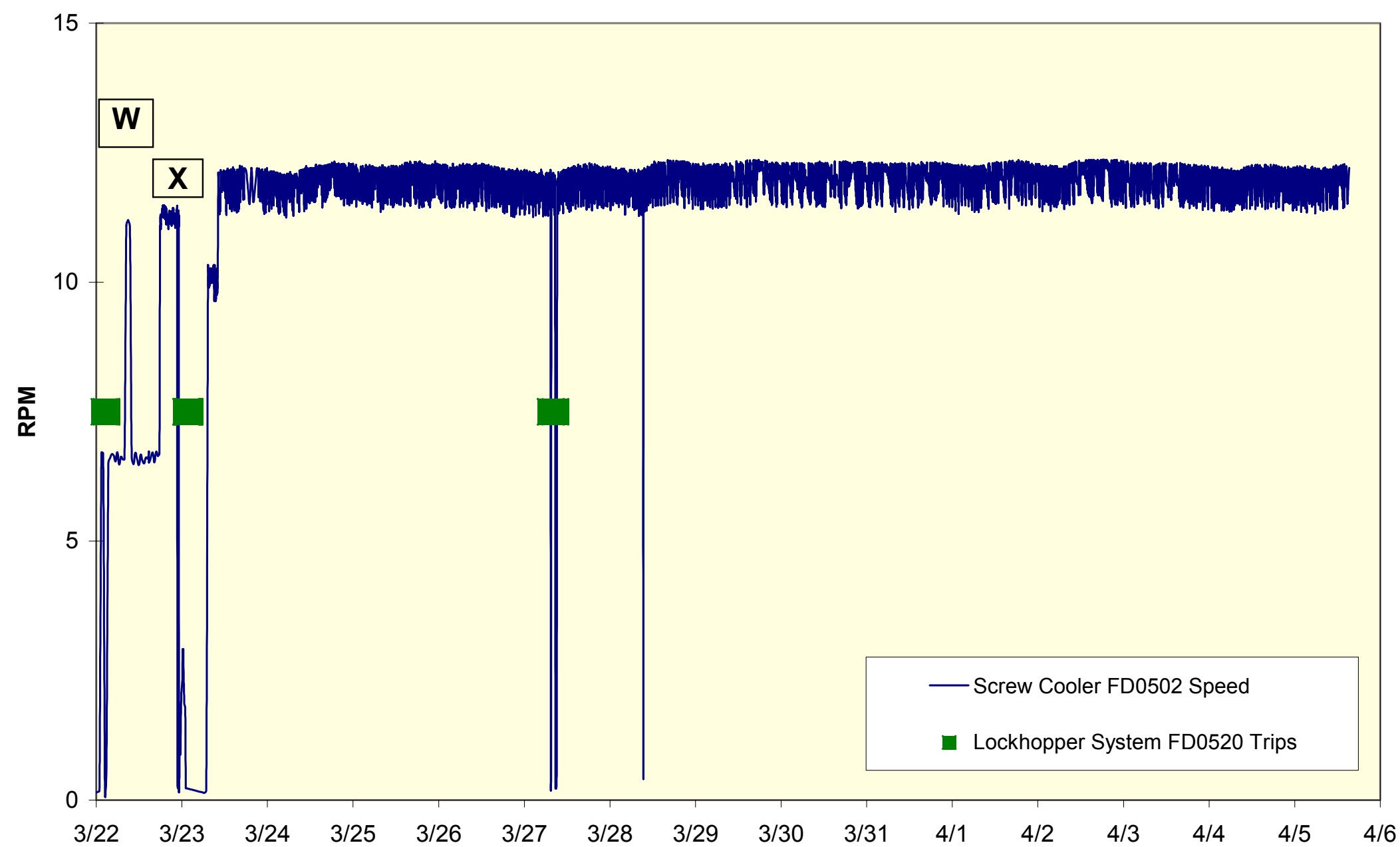

Figure 3.2-20 Fines Removal System Operation, TC07D 


\subsection{TCO7 INSPECTION REPORT}

\subsubsection{Introduction}

The TC07 test run was divided into four components designated TC07A, TC07B, TC07C, and TC07D. TC07A started on December 11 and ended on December 14, 2001. TC07A was a sand circulation run to commission the new LMZ adapter that was added to the Transport Reactor. TC07B started on January 17, 2002 and ended on January 27. During TC07B, the PCD operated approximately 136 hours on both PRB and Alabama bituminous coal. TC07C started on February 7, 2002, and ended on February 8. During TC07C, the PCD operated approximately 10 hours on Alabama bituminous coal. TC07D started on March 22, 2002, and ended on April 5, 2002. During TC07D, the PCD operated approximately 296 hours on PRB coal. During the TC07, the PCD operated on coal for a total of 442 hours.

The PCD internals were removed from the vessel and inspected after TC07C and TC07D. The outage inspection included examinations of the filter elements, their fixtures to the plenums, ash deposition, filter element gaskets, and auxiliary equipment. The subsequent sections will detail the findings of the inspection.

\subsubsection{TCO7A Inspection}

The purpose of TC07A was to commission the new LMZ addition to the reactor. The temperature and pressure in the PCD were approximately $500^{\circ} \mathrm{F}$ and $60 \mathrm{psig}$, respectively. It was not expected that the sand run would present any problems with the PCD; however, during startup the main gasket on the PCD head-to-vessel flanges blew out. It is believed that the recommended torque of 1,600 ft-lb was not enough compression; therefore, it was decided to increase the torqued to $2,400 \mathrm{ft}-\mathrm{lb}$. The blown gasket was replaced and the flange was torque to 2,400 ft-lb. During the sand commissioning run, the PCD performed well; thus, it was decided not to disassemble the PCD during the outage between TC07A and TC07B.

\subsubsection{TCO7B Inspection}

The PCD operated in gasification mode for approximately 136 on-coal hours during TC07B. During TC07B, the PCD operated on two different coals that included a bituminous and subbituminous. The Transport Reactor started up on PRB coal and transitioned to Alabama bituminous coal. The PCD operated for 101 hours on PRB and 34 hours on Alabama bituminous. The run was shut down due to the deposits that formed in the Transport Reactor; thereby, affecting performance.

The PCD parameters for TC07B were shown in the previous section (Table 3.2-1). The outlet loading from the PCD, as measured by SRI, was normally below 1 ppmw. After the system shutdown on January 27, 2002, the PCD lower manway was opened so that the lower part of the vessel internals could be inspected. This visual inspection revealed no problems in the PCD. All the filter element surfaces on the lower plenum were relatively clean. In 
other words, there was no significant g-ash buildup on the filter elements. Also, there was no significant $g$-ash buildup on the support bars. Finally, the inspection revealed no evidence of g-ash bridging on the lower plenum.

Since there was no indication of filter element failure, it was decided not to disassemble the PCD during this outage. The fines solids removal system performed well during the run. Without a full inspection being performed, the fines solids removal system continued to run for TC07C.

\subsubsection{TC07C Inspection}

The PCD operated in gasification mode for approximately 10 on-coal hours during TC07C. During TC07C, the PCD operated on Alabama bituminous coal. The PCD operating parameters for TC07C were shown in the previous section on Table 3.2-1. The run was shut down due to filter element failure. The outlet loading was measured twice by SRI to verify that there was a filter element failure. The first measurement revealed a 20 -ppmw outlet loading from the PCD. The second measurement revealed 35-ppmw outlet loading. In order to prevent backside blinding of adjacent filter elements, it was decided to shut the run down and replace the failed filter elements. The PCD was shut down clean, which means the back-pulse system continued to cycle after the coal feed was stopped. The PCD vessel was opened February 11, 2002. Upon inspection, the bottom plenum was found almost entirely covered with bridged material. Two failed filter elements were located during the inspection.

\subsubsection{TCO7C Filter Elements}

For TC07C the following filter elements were installed:

- 36 Pall 1.5-meter $\mathrm{Fe}_{3} \mathrm{Al}$.

- $\quad 47$ Pall 1.5 meter $\mathrm{Fe}_{3} \mathrm{Al}$ with fuse.

- 6 Pall Hastelloy X.

- 2 U.S. Filter HR-160 sintered metal fiber filters (Figure 3.2-1).

The Pall fuse is an SGD inserted into the clean side of the filter element. In the event of a filter failure, the fuse acts as a back-up filter to protect downstream equipment.

As mentioned above, TC07C ended due to failed filter elements. During the outage, the filter elements were inspected to locate the failed filters. Upon inspection, a crack was found on filter elements B-12 and B-14 (Figures 3.3-1 and 3.3-2). B-12 and B-14 denote where in the plenum the filter elements were located (Figure 3.2-1). Both of these filter elements were Pall $\mathrm{Fe}_{3} \mathrm{Al}$, and both elements failed in the same location. Each filter element failed near the top flange; however, B-12 failed at the weld, while B-14 failed at the media in the weld affected zone. Figure 3.3-3 shows the flange from B-12. Figure 3.3-3 shows that there is no weld material left on the flange indicating that the failure was at the weld. However, Figure 3.3-2 shows that the failure was in the porous material near the weld. This area is referred to as the weld affected zone. It has been noted in the past that when the Pall $\mathrm{Fe}_{3} \mathrm{Al}$ 
filter elements fail, it is usually at the weld or in this weld-affected zone. The $\mathrm{Pall} \mathrm{Fe}_{3} \mathrm{Al}$ filter elements have a very thin weld connecting the porous material to the solid joint. This is one of the issues that needs to be addressed by Pall for the $\mathrm{Fe}_{3} \mathrm{Al}$ filter material to become a commercially viable option in hot gas filtration.

Small metal pieces were noticed in 10 of the 1.5-meter Pall $\mathrm{Fe}_{3} \mathrm{Al}$ filter elements during the inspection. During an earlier gasification run, the top of one of the SWPC failsafe devices came off and allowed the internals to be blown into the plenum. It is believed that these metal pieces found in the filter elements were from that failsafe. During the outage, the plenum was borescoped and a large amount of material that looked like rust, small pieces of refractory, and metal were found. The metal pieces that were found in the Pall $\mathrm{Fe}_{3} \mathrm{Al}$ filter elements did not appear to have caused any damage.

Once the filter elements were removed, it was noticed that some of the Pall 1.5-meter $\mathrm{Fe}_{3} \mathrm{Al}$ filter elements with fuses had significantly higher resistance to flow than when they were installed. The flow results revealed that many of the filters had a significantly higher resistance to flow. It is believed that the higher resistance to flow was due to the solids that leaked from the failed filter elements; thereby, blinding the fuse (See Section 3.3.4.4 for Pall fuse flow performance). Based on these results, it was decided to remove all the filter elements with a flow resistance greater than $20 \mathrm{inH}_{2} \mathrm{O}$ at $3 \mathrm{ft} / \mathrm{min}$.

In TC06, the PSDF started working with Pall/Fluid Dynamics (formerly U.S. Filter/Fluid Dynamics) to test new sintered metal fiber filter element material. One advantage of the sintered metal fiber elements is that they have lower pressure drops than sintered metal powder elements. Based on their experience with filtration media, Pall/Fluid Dynamics suggested that the following materials be tested:

- Fecralloy-M (FeCrAlY).

- Haynes Alloy 214.

- Haynes Alloy 160.

- Haynes Alloy 230.

After TC06, the filter elements were sent back to Pall Corporation to be evaluated. Based on their recommendation, it was decided to do further testing on the Haynes HR-160 material. Pall Corporation believes that these filter elements are ideal for gasification environment due to their resistance to corrosion by sulfur. During TC07A/B/C, two Haynes HR-160 were installed and tested. Both filters were visually inspected and no obvious damage was found. Due to the unstable reactor operation during TC07C, it was decided to remove one of the HR-160 filter elements for preservation.

During TC07A/B/C, six 1.5-meter Pall Hastelloy X filter elements were tested. The filter elements were visually inspected and no obvious damage was found. These filter elements have collected up to 1,100 on-coal hours in gasification. They have been tested since TC06 and have experienced many process upsets without any filter failures. This appears to be a very robust and durable filter element. The Pall Hastelloy X filter has greater strength and is 
more ductile than the Pall $\mathrm{Fe}_{3} \mathrm{Al}$ filter element. By comparison the Pall Hastelloy X filter is an order of magnitude more ductile than the $\mathrm{Pall} \mathrm{Fe}_{3} \mathrm{Al}$ at $750^{\circ} \mathrm{F}$. One of the earlier concerns for the Pall Hastelloy X filter was pore blinding over time due to reaction with sulfur. The literature reports that at temperatures greater than $932^{\circ} \mathrm{F}$ the nickel in the filter element reacts with the sulfur in the gas to form a nickel-sulfide product that blinds the filter. The temperature in the PCD has consistently been below $900^{\circ} \mathrm{F}$ (normally $750^{\circ} \mathrm{F}$ ) for most of the hours collected on these filter elements. To date there is no evidence that these filters are reacting with the sulfur in the gas stream and blinding. Therefore, based on these findings, the Pall Hastelloy X filter elements will continue to be tested at the PSDF.

\subsubsection{TCO7C Gasification Ash Deposition}

The initial inspection of the PCD plenum revealed a large amount of $g$-ash bridging. Figure 3.3-4 shows the severity of the g-ash bridging after the plenum was lifted out of the PCD vessel. Once the plenum was set in the maintenance bay, inspection of the PCD internals continued. The g-ash bridging was isolated to the lower plenum.

Figure 3.3-5 is a filter layout that shows where the g-ash bridging was noticed on the lower plenum. The numbers around the layout designate how far down the length of the filter the g-ash penetrated. It was estimated that approximately 70 percent of the lower plenum was covered with this bridge material.

The bridged g-ash material was very adherent with a consistency very similar to modeling clay. In other words, PCD process engineers were able to push on the bridged material and shake the entire plenum without destroying it; however, the bridged g-ash was not hard and rigid like combustion ash bridging seen during earlier fluid-bed combustion testing. Once the bridged material was removed from in between the filters, it behaved just like a powder. In other words, it was no longer adherent. Therefore, it was not believed that the bridged material was the result of a chemical reaction such as seen with combustion at higher temperatures. (Refer to Section 3.4 for detailed information on the physical properties of the g-ash material.)

Finding g-ash bridge material during this outage was disturbing since the following changes were made before TC07 to prevent bridging:

- Removed all 2-meter filter elements: It was believed that the 2-meter filter elements promoted an uneven distribution of back-pulse flow throughout the lower plenum; thereby, reducing the back-pulse intensity. It was decided that all 2-meter filter elements be removed before TC07.

- $\quad$ Removed tie wire: During TC06, all the filter elements were secured with a tie wire. The purpose of the tie wire was to prevent the filter element from falling into the fine solids removal system in the event of a filter failure. It was believed that the tie wire was a possible origination point for the g-ash bridging; therefore, they were removed. 
- Maintained constant back-pulse timer and higher back-pulse pressure: In past gasification runs, the back-pulse timer was increased as the peak pressure drop across the PCD vessel would allow in order to see the effect of longer back-pulse time intervals. It was decided to maintain the back-pulse timer constant at 5 minutes. The thought was that the back-pulse intensity was ineffective with thicker dustcakes. It should be noted that the higher back-pulse pressure was not consistently applied in TC07C as in TC07B due to unstable reactor operation.

These changes did not seem to prevent the filter vessel from plugging; however, it is hard to determine what caused the bridging at this point due to the unstable reactor performance during TC07C.

Based on the findings during this outage, the following actions were taken before TC07D:

- $\quad$ Removed a half row of filters: During the outage between TC07C and TC07D, a half row of filter elements was removed to determine if filter spacing had any effect on g-ash bridging. Figure 3.3-6 shows which row of filter elements was removed before TC07D. The idea was that if g-ash bridging occurs where the filter elements were removed, then filter spacing is not the issue and there is something more process related that is causing the bridging. However, if the g-ash bridging occurs on the side of the plenum where the row was not removed, then filter spacing becomes very important with respect to a commercial filter vessel.

- Maintained constant back-pulse timer and high back-pulse pressure: As mentioned above, it is believed that the unstable reactor performance was the cause of the bridging during TC07C. Therefore, it is believed that maintaining a constant and short back-pulse interval will prevent the dustcake from building up to the point of bridging. Also, higher back-pulse pressures were used to maintain a higher backpulse intensity across the filters. The back-pulse pressure was 400 and 600 psid across the upper and lower plenum, respectively.

- Continued monitoring the temperature profile on the lower plenum: For TC07D, 23 thermocouples were installed on the lower plenum to determine where the gash bridging originates. It has been noticed in the past that when g-ash covers the thermocouples the response was altered, thereby deviating from the other uncovered thermocouples.

The mechanism for the g-ash bridging is not fully understood at this time. Hopefully, the changes made during this outage plus stable operation will prevent the $g$-ash bridging.

Upon inspection of the filter elements, the g-ash dustcake was not as sticky or adherent as seen in previous gasification test campaigns. Before TC06, a coke breeze feeder system was installed to reduce tar formation during reactor startups. This feeder was used during the TC07 test run and it appears that it reduced tars, which resulted in a less adherent dustcake. See section 3.4 for more details concerning dustcake properties. 


\subsubsection{TCO7C Filter Element Gaskets}

The redesigned filter gasket arrangement used in GCT2 through TC06 (the gasket types have been outlined in past run reports) has proved to be very reliable. This means that none of the outlet loadings from the PCD greater than $1 \mathrm{ppmw}$ were attributed to leaking gaskets. Therefore, these gaskets were used during TC07. Based on the inspection of these gaskets, the following observations were made:

- There were no flow paths in the area of the failsafe holder flanges that would indicate a leak past the sealing gaskets.

- Some of the gaskets were cut to inspect the extent of the g-ash penetration. The inside of the sealing gaskets was relatively clean.

- The gaskets between the failsafe and plenum were clean.

Since the outlet loading started off below 1 ppmw during TC07 and the inspection didn't reveal any obvious leak paths, it is believed that the gaskets performed well throughout TC07A/B/C.

\subsubsection{TCO7C Failsafe Inspection}

During TC07A/B/C, four different types of failsafe devices were tested. These failsafe devices included:

- Standard SWPC Failsafe Device.

- New Prototype SWPC Failsafe Device.

- Pall Fuse.

- PSDF Designed Failsafe Device.

The PSDF has started to investigate failsafe performance. In a commercial process a hot-gas filter unit must have a reliable failsafe device in the event of a filter failure. Gas Turbine manufacturers have set strict inlet loading requirements on their turbines. Therefore, verification of failsafe performance has become one of the main test objectives at the PSDF. Currently, the PSDF is testing different failsafe devices in the hot-gas environment in order to determine their resistance to corrosion and ability to withstand the harsh environment of the PCD. In the future, test runs will include solids injection to these different failsafe devices to test collection efficiency.

During TC07A/B/C, eight SWPC prototype failsafe devices were installed. Only one of the eight was removed during the outage and inspected. Also, during this test campaign thirtyfour Siemens Westinghouse standard failsafe devices were installed. As mentioned above, the run was ended due to filter failure. Upon inspection, two 1.5-meter $\mathrm{Pall} \mathrm{Fe}_{3} \mathrm{Al}$ filter elements were found cracked at the weld. One filter element (B-12) had a standard Siemens- 
Westinghouse failsafe device above it, while the other failed filter element (B-14) had one of the new prototype failsafe devices above it.

Each failsafe device above the failed filter elements was flow tested during this outage. The following table shows how the flow coefficient changed before and after TC07C.

\begin{tabular}{|l|l|l|}
\hline Failsafe Type & $\begin{array}{l}\text { Flow Coefficient* } \\
\text { Before TC07C }\end{array}$ & $\begin{array}{l}\text { Flow Coefficient* } \\
\text { After TC07C }\end{array}$ \\
\hline Prototype SWPC Failsafe & 153 & 148 \\
\hline Standard SWPC Failsafe & 134 & 130 \\
\hline
\end{tabular}

$\overline{* \text { Flow coefficient }}=(\mathrm{lb} / \mathrm{hr}) /\left(\left(\mathrm{lb} / \mathrm{ft}^{3}\right)\left(\text { in. } \mathrm{H}_{2} \mathrm{O}\right)\right)^{1 / 2}$

The results in the above table shows that the flow resistance increased slightly; however, neither of the failsafe devices plugged. The outlet loading as measured by SRI was 34.8 ppmw at the end of TC07C. Due to the performance of these failsafe devices, it was decided that the Siemens Westinghouse failsafe devices (standard and the new prototype) needed to be pulled out of operation for the next run. To continue exposure to process gas, six of the SWPC prototype failsafe devices will be installed for TC07D over blanks.

During TC07A/B/C, forty-six Pall fuses were tested. These failsafe devices were welded in the Pall $\mathrm{Fe}_{3} \mathrm{Al}$ filter elements. They were flow tested and it was noticed that some of the filter elements had a significantly higher flow resistance than when they were installed. It was believed that this was due to backside blinding of the fuse in the filter element. One filter element was taken to the maintenance shop in order to have the fuse cut out of the filter. While the filter element was in the maintenance shop, maintenance personnel noticed that the fuse had fallen down into the filter element which had been observed one other time in the past. On both occasions there was a break at the weld where the fuse is joined to the filter flange. Once again this is an area of concern because the welds on these filter elements are very thin and appear to be prone to failure.

Eventually, a fuse was removed from one of the filter elements (B-54) and flow tested. The results are shown on Figure 3.3-7. Figure 3.3-7 is a flow curve that shows the pressure drop across the failsafe at different flow rates. Figure 3.3-7 shows that after TC07C the flow resistance increased significantly. This finding supported the belief that the increase of flow resistance on some of these filter elements was due to backside blinding of the fuse. Therefore, it was decided to remove all the filter elements with elevated flow resistance. Figure 3.3-7 also shows the flow response of the Pall fuse after cleaning. The fuse was soaked in an ultrasonic bath using a mild detergent for 3 hours and dried in an oven. The fuse was flow tested and the results showed that some of the original flow response can be recovered. Therefore, it was decided to clean all of the Pall filter elements that were removed. This proved to be more challenging than expected. Cleaning the fuses at the PSDF by soaking them in the ultrasonic bath required that the fuses be cut out of the filter element. This was not an attractive option due to problems associated with welding porous material to solid metal. The other option was to send 10 filter elements to Southern Metal 
Processing Company, Inc., in Oxford, Alabama. Southern Metal Processing Company has been working with the PSDF to devise filter cleaning methods for the different types of filter elements tested at the PSDF. They were not able to reduce the flow resistance for these 10 filter elements with the first few methods tested. First, Southern Metal Processing Company soaked the filter elements in an ultrasonic bath using water and surfactant. Cleaning by this method was not successful. Next, they tried to clean one of the filter elements by soaking it in a caustic solution. This method was also unsuccessful in reducing the flow resistance. The final cleaning method Southern Metal Processing tried was placing one of the filter elements in a furnace at temperatures around $900^{\circ} \mathrm{F}$ to combust the high-carbon content gash to ash. After the filter was removed from the furnace, it was soaked in the ultrasonic bath again with water and surfactant. This method did reduce the flow resistance by approximately 72 percent. Although the resistance to flow decreased, the filter element was returned with spots that appeared to be rust on the surface of the element.

At this point a method to clean the $\mathrm{Pall} \mathrm{Fe}_{3} \mathrm{Al}$ filters that have fuses welded in them is still being investigated. It is believed that mounting any failsafe device external to the filter element is preferred over mounting the fuse internally. It has been found that when there is backside blinding it is difficult to clean the failsafe without cutting on the filter element. Also, when the fuse is mounted internally to the filter element it does not protect equipment downstream of the PCD in the event of a seal leak past the filter element and tubesheet.

During TC07C, three PSDF-designed failsafe devices were installed for syngas exposure. The following table lists the corresponding exposure hours with each failsafe device:

\begin{tabular}{|c|c|}
\hline PSDF Designed Failsafe & Exposure Hours (On-Coal) \\
\hline PSDF \#1 & 148 \\
\hline PSDF \#2 & 1161 \\
\hline PSDF \#3 & 1161 \\
\hline
\end{tabular}

Each failsafe was removed and visually inspected. The PSDF-designed failsafe devices appeared to be in good condition with no evidence of failsafe damage. One of the objectives of testing the new failsafe was to determine whether or not the different alloys used would corrode and blind over time. Therefore, each failsafe device was flow tested before and after TC07A/B/C. Figures 3.3-8, 3.3-9, 3.3-10 show the flow curves of the different failsafe devices before and after TC07A/B/C. All three graphs show that each failsafe device increased in flow resistance after TC07A/B/C. To determine whether the increase in flow resistance was due to corrosion or backside blinding, each failsafe was soaked in an ultrasonic bath. The flow resistance for all three failsafe devices decreased significantly after cleaning; therefore, the increase in flow resistance was attributed to backside blinding and not corrosion.

\subsubsection{TCO7D Inspection}

The PCD operated in gasification mode for approximately 296 on-coal hours during TC07D. The PCD parameters for TC07D are shown in Table 3.2-2. With the exception of one isolated incident, the outlet loading as measured by SRI was below 1 ppmw. SRI did 
measure an outlet loading of approximately $2.6 \mathrm{ppmw}$ after a process upset. At the time it was believed that there was a filter failure as a result of the upset. The inspection did not reveal any failed filter elements or g-ash bridging. The PCD was shut down clean, which means the back-pulse system continued to cycle after the coal feed was stopped.

The fines solids removal system operated well during TC07D. During the outage FD0502 (screw cooler) and FD0520 (lock-vessel) were thoroughly inspected. The inspection included disassembling the FD0502 and FD0520 system.

\subsubsection{TCO7D Filter Elements}

For TC07D, the following filter elements were installed: 81 Pall 1.5-meter $\mathrm{Fe}_{3} \mathrm{Al}$ filters with fuse, 3 Pall 1.5-meter Hastelloy X, and 1 Pall/Fluid Dynamics 1.5-meter HR-160 sinter metal fiber filter (see Figure 3.2-2). During this run 63 new Pall 1.5-meter $\mathrm{Fe}_{3} \mathrm{Al}$ filter elements were installed. The reason for replacing so many filter elements was to preserve filter elements that had accumulated long-term exposure hours. During the last two gasification test runs (TC07B and TC07C) there were several process upsets that resulted in thermal transients in the PCD. Also, during the TC07C inspection, the bottom plenum was significantly covered with g-ash bridging. Until stable process operation is established and the mechanism for g-ash bridging is understood, part of the filter elements with long-term exposure will be preserved in storage. Figure 3.3-11 shows the layout for TC07D with the corresponding exposure hours.

Early in the test run the Transport Reactor had an upset that sent a large amount of solids over to the PCD. Shortly after the upset, oxygen broke through to the PCD, resulting in a temperature excursion. After the event, the PCME (See Section 3.4 for details on the PCME) detected a leak from the PCD. SRI took an outlet sample and measured $2.6 \mathrm{ppmw}$ leak; therefore, it was believed that there was a filter(s) failure. SRI took another outlet sample 2 days later and measured an outlet loading of 0.3 ppmw. At that time it was believed that one of the failsafe devices had successfully plugged. During the outage, all activity revolved around trying to locate the failed filter element(s).

Initial inspection of the filter elements (while still installed on the plenum) did not reveal any failed filter elements. It was decided that each filter element would be removed for closer visual inspection. The inspection included looking for cracks in the weld, weld-affected zone, and the porous material. The visual inspection did not expose the failed filter element; therefore, each of the $\mathrm{Pall} \mathrm{Fe}_{3} \mathrm{Al}$ filters was flow tested. The reason for flow testing all the Pall $\mathrm{Fe}_{3} \mathrm{Al}$ filter elements was because they each had a fuse welded inside. It was believed that the failed filter element should have a higher resistance to flow since the fuse should have been blinded. The flow resistance of all the $\mathrm{Pall} \mathrm{Fe}_{3} \mathrm{Al}$ filter elements was found to be in an acceptable range. In other words, no one filter or filters had a flow resistance significantly higher than the others, which would have indicated a plugged fuse.

The Pall Hastelloy X filters and Pall/Fluid Dynamics HR-160 filter were looked at as possible candidates as the source of the filter leak. Each filter was visually inspected and appeared to be in good condition. Next, the failsafe devices above each of the filter 
elements were flow tested. Once again, the thought was that if any of the elements leaked, the failsafe device installed above the filter element would be plugged. None of the failsafe devices had a significant increase in flow resistance; therefore, it was decided that none of the Pall Hastelloy X or HR-160 filter elements were the source of the leak.

To say the least, these findings were puzzling. SRI went back and looked closer at the outlet sample they collected that revealed the $2.6 \mathrm{ppmw}$ leak. Closer inspection revealed that large particles $(>500 \mu)$ were present on the filter mat used to collect the outlet sample. It was decided that it was highly improbable that $500 \mu$ particles made it through the filter vessel without there being a significant leak. Therefore, the particles were coming from another location. Several locations that were considered are:

- Plenum - One source of these particles could be the plenum since there have been filter failures in the past. It is possible that during the upset condition, particles in the plenum were disturbed and entrained over time into the outlet duct.

- Back-Pulse Pipes - Another potential source of these large particles that was suggested was the back-pulse pipes. It has been noticed in the past that a large amount of tar and scale material forms on back-pulse pipes during the runs, especially near the nozzle flange where the temperature is lower than process temperature. The lower temperature pipe condenses tars. It is possible that this scale material, over time, flakes off and entrains in the duct work. Although this is a possible scenario, a mechanism to describe how and when this material flakes off is not understood at this time.

- Refractory - Another possible source of these large particles is the refractory-lined outlet pipe and refractory-lined PCD head. It was noticed during the outage that the insertion point for the back-pulse pipe into the PCD had a large amount of material that appeared to be condensed tar, rust, and pieces of refractory. So, it is possible that these solids are entrained into the outlet gas flow.

- Gas Analyzer Probe - Downstream of the PCD there is a gas analyzer probe that is inserted into the gas stream. This analyzer sits directly above SRI's outlet sampling monitor. The gas analyzer contains a refrigerated condenser to prevent tars from plugging the analyzer. The tars that are condensed drop into the duct; therefore, it is possible that this could be the source of the particles found on SRI's outlet probe.

Due to time constraints during this outage and uncertainties surrounding where these particles originated, the attempt will be made by SRI to detect any particles during TC08.

Based on the inspection, no failed filter elements were located. The Pall $\mathrm{Fe}_{3} \mathrm{Al}$ filter elements performed well during TC07D. There was no apparent damage or corrosion noticed on these filter elements. However, small metal pieces were found in 19 of the Pall $\mathrm{Fe}_{3} \mathrm{Al}$ filter elements. The small metal pieces were found only in filters on the top plenum. It is believed that the source of these pieces is a Siemens Westinghouse failsafe that lost its internals during an earlier gasification run. By the end of TC07D, 11 out of the $81 \mathrm{Pall} \mathrm{Fe}_{3} \mathrm{Al}$ had accumulated 1,710 on-coal hours of exposure. 
As mentioned above, three Pall Hastelloy X filter elements were tested during TC07D. These filters were removed and inspected, but no obvious damage was noted. By the end of TC07D, one Pall Hastelloy X filter had accumulated 1,468 on-coal hours of exposure. Based on past successes, such as no filter failures or pore blinding, future testing will continue with the Pall Hastelloy X filter.

During TC07D, one Pall/Fluid Dynamics HR-160 filter element was tested. This filter was installed new during TC07A/B/C. No obvious damage was noted at inspection. By the end of TC07D, this filter element had accumulated 443 on-coal hours of exposure. To date, we have tested three HR-160 filter elements. During TC06, one HR-160 filter element was tested for 1,025 hours. This material is reported to resist sulfur corrosion in a reducing environment. Based on the results of TC06 and TC07, more filter elements will be included in the filter test plan at the PSDF.

\subsubsection{TCO7D Gasification Ash Deposition}

The plenum was pulled out of the PCD vessel on April 10, 2002. Figure 3.3-12 shows the bottom plenum after TC07D. No g-ash bridging was noticed during this outage. This inspection was encouraging since many changes were made before TC07D to prevent g-ash bridging on the lower plenum. The changes that were made before TC07D, such as removing a half row of filter elements and maintaining constant back-pulse pressure and timer, will also be implemented for TC08.

Upon inspection, it was noticed that the g-ash on the filter elements was very thin. The residual dustcake was too thin to obtain a reliable measurement for thickness. Figure 3.3-13 shows the g-ash buildup on the filter element holders on the lower plenum. By comparison, the buildup on the filter element holders was less than what has been seen in past gasification runs. Figure 3.3-14 shows the g-ash buildup on the upper ash shed. The solids accumulation on the both the upper and lower ash shed was light compared to past gasification runs. Figure 3.3-15 shows the g-ash accumulation on the filter support brackets. There was very little g-ash buildup noticed on the support brackets during the inspection. The thin residual dustcake on the filter elements and the small amount of buildup on the different PCD internals appears to indicate that tar condensation was not an issue during TC07D.

\subsubsection{TCO7D Filter Element Gasket}

During this outage all the filter elements and failsafe devices were removed so that all the gaskets could be inspected. The gaskets were thought to be a possible leak path. Based on the inspection of these gaskets, the following observations were made:

- There were no apparent leak paths in the area of the failsafe holder flanges that would indicate a leak past the primary gasket. 
- Some of the gaskets were cut to inspect the extent of the g-ash penetration. The inside of the sealing gaskets were relatively clean.

- The gaskets between the failsafe and plenum were clean.

Based on these findings, the gasket material performed well throughout the 296-hour test run.

\subsubsection{TCO7D Failsafe Devices}

During TC07D, the following failsafe devices were tested: four PSDF-designed failsafe devices, 81 Pall fuses and 1 SRI-designed safeguard device. In past gasification runs, the majority of failsafe testing was done with the Siemens Westinghouse failsafe devices. The Siemens Westinghouse design has proven to be unreliable during filter failures. Figure 3.316 shows the outlet loading as measured by SRI during each gasification run. The PSDF has set an objective to maintain the outlet loading from the PCD below 1 ppmw. Each data point on Figure 3.3-16 greater than 1 ppmw represents a filter failure or gasket leak. In each case of an outlet loading greater than 1 ppmw before TC07C, the SWPC standard failsafe was installed. During TC07C, when the outlet loading was greater than $30 \mathrm{ppmw}$, there were two failed filter elements. One filter element had a standard SWPC failsafe device installed above it, while the other failed filter element had one of the new prototype SWPC failsafe devices. It was determined that neither of these failsafe devices would be adequate to protect a downstream turbine; therefore, it was decided to remove all of the SWPC failsafe devices and replace them with Pall $\mathrm{Fe}_{3} \mathrm{Al}$ filter elements that contained the Pall fuse. Also, four PSDF-designed failsafe devices were installed for TC07D.

As mentioned above, all the filter elements with fuses were removed and flow tested. Once again, nothing appeared to be unusual about the flow results. The flow test results did not indicate that any of the fuses were plugged due to a filter failure. This does reveal one of the setbacks of welding the fuse into the filter element. It is impossible to flow test the fuse without cutting it out of the filter element. This makes it difficult to determine if the fuse is plugging over time due to normal operations. Another problem with welding the fuse into the filter element is that the fuse does not protect the downstream turbine in the event of a gasket leak. Failsafe devices that are installed into the tubesheet offer the advantage of catching particles that might flow by a failed gasket between the filter element and the tubesheet. Based on these findings, all future filter elements will be ordered without a failsafe device welded in the filter.

Before TC07D, four PSDF-designed failsafe devices were installed. The PSDF-designed failsafe devices appeared to be in good condition with no evidence of failsafe damage. One of the test objectives for the new failsafe design is to determine whether or not the porous media blinds over time. Each failsafe device was flow tested during the outage. Figures 3.3-17, 3.3-18, 3.3-19, and 3.3-20 are flow curves for each of the failsafe devices tested after TC07D. Each failsafe material increased in flow resistance to some extent during the test run. The following table shows the percent change in flow coefficient from the original (Pre-TC07D) value and total exposure hours. 


\begin{tabular}{|c|c|c|}
\hline PSDF Failsafe Device & Percent of Original Flow Coefficient & Exposure Hours \\
\hline PSDF \#4 & $93 \%$ & 296 \\
\hline PSDF \#1 & $85 \%$ & 443 \\
\hline PSDF \#3 & $98 \%$ & 1468 \\
\hline PSDF \#5 & $82 \%$ & 296 \\
\hline
\end{tabular}

Several possible reasons have been given why the flow resistance increased for each of the failsafe devices. One reason offered is that the increase in flow resistance was due to backside blinding. Past inspections have revealed particles in the plenum of FL0301 from past filter failures. It is reasonable to suspect that these particles are disturbed during a back-pulse and forced into the porous media. Another reason given for the increase in flow resistance is that fine particles pass through the filter elements and blind the failsafe devices. The final reason given for the material blinding is corrosion of the alloys. All three reasons are possible explanations for the increase in flow resistance; however, it is possible that the sintered metal fiber initially loses a fraction of its flow coefficient due to exposure to process conditions and eventually levels off. At this point it is not possible to say what caused the increase in flow resistance. Future testing will be required to understand more about the performance of these different alloys.

During TC07D, a new safeguard device, designed by SRI, was installed into the PCD. Experiments were conducted during TC07D to evaluate the ability of the SRI Safeguard Device to close under actual process conditions. The device, shown in Figure 3.3-21, is essentially a check valve that closes when the flow rate that runs through it (actually the velocity head due to the flow) exceeds a specified value. The flow rate at which the device activates is chosen to be well above the normal flow rate for an intact filter element, but below the expected flow rate for a broken filter element.

For the activation test, the SRI safeguard device was installed at Location B3 in the PCD. A simplified P\&I diagram for the test setup is shown in Figure 3.3-22. The SRI device was installed above a Pall Fe3Al filter element. A backup PSDF-designed failsafe was installed above the SRI safeguard device. Two $1 / 2$-inch stainless steel tubes were routed through the bottom plate of the filter element. One of these tubes was used for injecting nitrogen to activate the SGD, while the other tube was used for a pressure measurement. A differential pressure measurement was made between the dirty side volume of the PCD and the inside of the filter element. A second differential pressure measurement was made between the inside of the filter element and the lower clean side plenum of the PCD. Nitrogen for activating the device was supplied from a $1.5 \mathrm{ft}^{3}$ receiver (a size " $\mathrm{K}$ " compressed gas bottle). A calibrated needle valve was used to set the nitrogen flow rate. The $\mathrm{N}_{2}$ supply system was sized to supply nitrogen at flow rates up to about $1.4 \mathrm{lb} / \mathrm{sec}$ and maintain the flow for 2 seconds. Gas pressure and temperature in the receiver were measured and the $\mathrm{N}_{2}$ flow rate was determined from the rate of pressure loss in the receiver. The filter element differential pressure, SRI safeguard device differential pressure, receiver pressure, and receiver temperature were recorded at $1 \mathrm{~Hz}$ throughout TC07C using a dedicated PC-based data acquisition system. During activation experiments, data was recorded at $100 \mathrm{~Hz}$. 
The SRI safeguard device was installed during test runs TC07A/B/C/D. The original intention was to perform the activation tests during TC07B, but for various reasons an appropriate time was never found to perform the tests during TC07B or C. The first series of activation experiments were performed during TC07D on March 28, 2002. Nitrogen was injected at increasing rates of approximately $0.2,0.4,0.6,0.8,1.0$, and $1.3 \mathrm{lb} / \mathrm{sec}$. During each test, the flow was maintained for about 2 seconds. The SRI safeguard device did not close at $1.3 \mathrm{lb} / \mathrm{sec} \mathrm{N}_{2}$ flow, which was near the maximum rate the system could supply, so it was decided to try another test with a higher differential pressure across the filter.

During the tests on March 28, 2002, the PCD was being back-pulsed at 5 minute intervals, and the peak pressure drop between back-pulses was less than $100 \mathrm{inH}_{2} \mathrm{O}$. It was thought that the nitrogen injection would be more effective in closing the SRI safeguard device if the filter element pressure drop was higher, (i.e., with a higher $\Delta \mathrm{P}$ across the filter element more of the injected flow would go through the SGD rather than flowing in the reverse direction through the filter). A second activation test was performed on April 1, 2002. For this test, the PCD back-pulse was delayed until the filter pressure drop reached about $250 \mathrm{inH}_{2} \mathrm{O}$ and nitrogen was injected at that condition.

Data from the test on April 1, 2002, is plotted in Figure 3.3-23. The blue line on the graph is the pressure drop across the SRI safeguard device plus the backup PSDF designed failsafe. The red line is the pressure drop across the filter element. The yellow line is the pressure in the nitrogen receiver. When $\mathrm{N}_{2}$ injection started the filter element pressure drop rapidly changed from about +245 in $_{2} \mathrm{O}$ to about -35 in $_{2} \mathrm{O}$, indicating that some of the injected gas was flowing in the reverse direction through the filter rather than through the SRI safeguard device. At the same time, the failsafe pressure drop increased from about 8 in $_{2} \mathrm{O}$ to over $250 \mathrm{inH}_{2} \mathrm{O}$. It should be noted that the filter element pressure drop measurement was made using a special fast-response pressure transducer, while the failsafe pressure drop measurement was made using one of the standard plant transducers. The standard transducer has built-in damping, which explains why the failsafe pressure drop measurement appears to lag the filter element pressure drop measurement, and also why the rate of rise and decrease of the failsafe pressure drop is slower than the rate for the filter element pressure drop. It should also be noted that after nitrogen injection stopped, the failsafe pressure drop was much higher than before injection started $\left(59 \mathrm{inH}_{2} \mathrm{O}\right.$ vs. 8 inH $\left._{2} \mathrm{O}\right)$. This is because the reverse flow through the filter element removed the transient dust cake, causing the syngas flow rate through this filter element to be higher than through the other filter elements that still had the transient cake. After the next PCD cleaning cycle, the failsafe pressure drop returned to its normal value, confirming that the SRI safeguard device did not close. Based on the filter element pressure drop measurement, the duration of $\mathrm{N}_{2}$ injection was about 1.8 seconds. Receiver pressure measured during the test is plotted in Figure 3.3-24. The average rate of pressure decrease was $198 \mathrm{psi} / \mathrm{sec}$, which corresponds to a nitrogen flow rate of $1.43 \mathrm{lb} / \mathrm{sec}$.

After the conclusion of TC07D, the SRI safeguard device and the backup PSDF designed failsafe were removed and flow tested. The flow test was conducted using compressed air at ambient temperature and pressure. Flow test results for the combined SRI SGD plus PSDF-designed failsafe are plotted in Figure 3.3-25. During the flow test, the SRI SGD 
closed at a pressure drop of about $120 \mathrm{inH}_{2} \mathrm{O}$. (This was the total pressure drop across both the SGD and the backup failsafe. During a separate flow test of the SGD without the backup failsafe, it closed at a pressure drop of about $70 \mathrm{inH}_{2} \mathrm{O}$.)

Since the pressure drop achieved during the PCD activation test was more than twice the level required to close the SRI SGD during the cold-flow test $\left(250 \mathrm{inH}_{2} \mathrm{O}\right.$ vs. $\left.120 \mathrm{inH}_{2} \mathrm{O}\right)$, it appears that the nitrogen flow rate used during the April 1, 2002, PCD test should have been adequate to close the SGD. The two most likely causes for the failure of the SRI SGD to close appear to be either that injection was not maintained long enough, or that something about the process conditions may have caused the mechanism to stick in its open position. The first possible cause could be tested during a future run by increasing the size of the nitrogen receiver to allow injection to be maintained for a longer period.

\subsubsection{Auxiliary Equipment}

Two g-ash resistance probes were tested during TC07D. The probes were installed to determine when g-ash bridging forms in the PCD. Before TC07D, the only method to determine if $g$-ash bridging was present during operation was to watch the thermocouple readings. It has been noticed in past runs that the thermocouple readings changed when bridging was present. It is hoped that the g-ash resistance probes will aid in the understanding of the mechanism that forms the bridged material.

The probes were installed halfway down the length of adjacent filter elements at locations B30 and B43 (see Figure 3.3-26). The minimum distance between adjacent filter elements is approximately 2.6 in. The probe tips were located approximately one-fourth $(\sim 0.65$ inches from the surfaces of B30 and B43) the minimum distance between the two filter elements. The resistance from the probe tip to ground is monitored. If the area between the probe tip and the element surface becomes bridged, the resistance should decrease (on the order of 100 to $1,000 \mathrm{ohms})$.

The probes were made by stripping the ends off of $1 / 16$ in. mineral-insulated thermocouples. The exposed thermocouple wires were used as a conductor, as shown in Figure 3.3-27. One of the two probes installed during TC07D shorted approximately 100 hours into the test. During the outage, the inspection revealed a short at the point of the Inconel sheath. It is believed that the thermocouple was damaged when the sheath was stripped; therefore, a better tool for stripping off the sheath has been obtained to prevent future damage. The reliability of the gasification ash probe to detect gasification ash bridging has not been demonstrated since there was no evidence of $\mathrm{g}$-ash bridging during TC07D. The g-ash probe will be installed for TC08 to continue testing whether or not it has promise to detect bridge material in the PCD.

The back-pulse pipes were removed and inspected during this outage. The inspection revealed a thin layer of what appeared to be tar on the back-pulse pipe. The inner liner appeared to be in good condition as well. There was no significant damage on the pulse pipes; however, there was some pitting noticed (see Figure 3.3-28). The pitting was localized toward the top of the pulse pipe. At this point it is hard to tell if the pitting on the pulse 
pipes is occurring during operation or while they are exposed to atmospheric conditions. Material selection for back-pulse pipes will be important for a commercial plant because of the temperature profile along the length of the pipe. In other words, the temperature of the pipe at the insertion flange is significantly lower than where the pipe is exposed to the process temperature; therefore, the potential for condensate on the back-pulse pipe near the flange is always a concern.

During the outage, Nozzle 13 on FL0301 was inspected. Nozzle 13 sits on top of the PCD where the back-pulse pipes are inserted into FL0301. Figure 3.3-29 shows the carbon steel flange from Nozzle 13. Figure 3.3-29 also shows a significant amount of rust that was easily scraped off on the refractory. Rust had come from the carbon steel blind flange. It is possible that these particles could be entrained into the outlet duct. Further inspection revealed that the refractory in Nozzle 13 was soft and had some minor erosion. (See Figure 3.3-30, which shows the refractory eroding away). Erosion probably happens when the back-pulse pipes are inserted into the PCD head. As the refractory wears away hot spots on the carbon steel nozzle become a concern. Since the PCD has been operating significantly below design (design temperature is $1,800^{\circ} \mathrm{F}$ ), the current plans are to monitor the progression of the erosion by taking skin temperatures of the nozzle and inspection after each run.

\subsubsection{Fine Solids Removal System Inspection}

The fine solids removal system performed well during TC07D. During the outage, the fine solids removal system was thoroughly inspected to include disassembling the screw cooler and the lock vessel system.

The screw cooler performed well during TC07A/B/C/D. This was based on the fact that after 440 on-coal hours, it did not fail. Other than minor packing adjustments, the screw cooler did not require any maintenance during operation. Before TC07, several modifications were made to the stuffing box in an attempt to increase reliability. The lantern ring was increased to $3 / 4$ in. from $1 / 2$ in. to allow for more adjustment room. The previous stuffing box had the lantern ring positioned with five packing rings on each side. The new modification moved the lantern ring toward the process so that there were two packing rings between the lantern ring and the process; thereby, allowing eight packing rings to be installed between the lantern ring and atmosphere. The purpose of the new modification was to add flow resistance between the lantern rings and atmosphere which will promote the purged gas to flow towards the process. Finally, the packing follower and guide studs were extended to allow more room to adjust the follower. The new modification on the drive end appears to be an improvement over the original design. The initial packing follower gap before TC07 was $1 \frac{3}{4}$ in. The gap after TC07D was $1 \frac{1}{4}$ in. Based on the performance of the new modification, it was decided to make the same modifications to the nondrive end of the screw cooler before TC08.

The fine solids depressurization system (FD0520) performed well during TC07D. This was based on the fact that FD0520 did not interrupt operation. However, the fine solids depressurization system did require a large amount of attention by process engineers and 
operations. During TC07D, the solids loading increased due to reactor upsets and solids injection test upstream of the PCD. As a result of the increased solids loading, the cycle timer was constantly being changed to accommodate the changes in solids flow. To date a reliable level probe has not been located. Also, FD0520 had trouble conveying reactor bed material (mostly sand) after reactor upsets. Once the bed material was removed and stable operation resumed, the fine solids depressurization system was able to convey material without any difficulty.

During the inspection of FD0520, it was noticed that the seal material on the top sphere valve was cracked. (See Figure 3.3-31 for the location of the crack.) Although this did not result in a failure during operation, it appears that this seal was near failure. Based on this finding, sphere valve seals from past runs were inspected and found to have cracks as well. Clyde Pneumatics was contacted for advice on this problem. According to the vendor the seal material was made from Nomex-filled Viton. This material is relatively brittle at temperatures below $200^{\circ} \mathrm{F}$. However, once the Nomex-filled Viton material approaches $200^{\circ} \mathrm{F}$, it begins to soften and become more ductile. It appears that either during operation startups or shutdowns, when the solids temperature was low, the seal material was cycling while brittle. Therefore, the vendor has suggested a material that is more pliable at lower temperatures. Clyde Pneumatics has suggested a seal material made from Nomex-filled silicone as an alternative to the current material.

During the outage, FD0520 vent lines were inspected. The vent valves appeared to be in good condition. However, some erosion (see Figure 3.3-32) was noticed on the B-vent line. Figure 3.3-33 shows the opposite flange face that the flange in Figure 3.3-32 connects. When comparing Figure 3.3-32 with Figure 3.3-33, a significant difference in internal diameter is noticed. It is believed that the discontinuity between the internal diameters of the two flanges contributed to the erosion. Current eddies in the vent line during depressurization were given as a possible reason for the erosion. The flange in Figure 3.3-32 will be replaced so that its internal diameter matches the flange in Figure 3.3-33. 


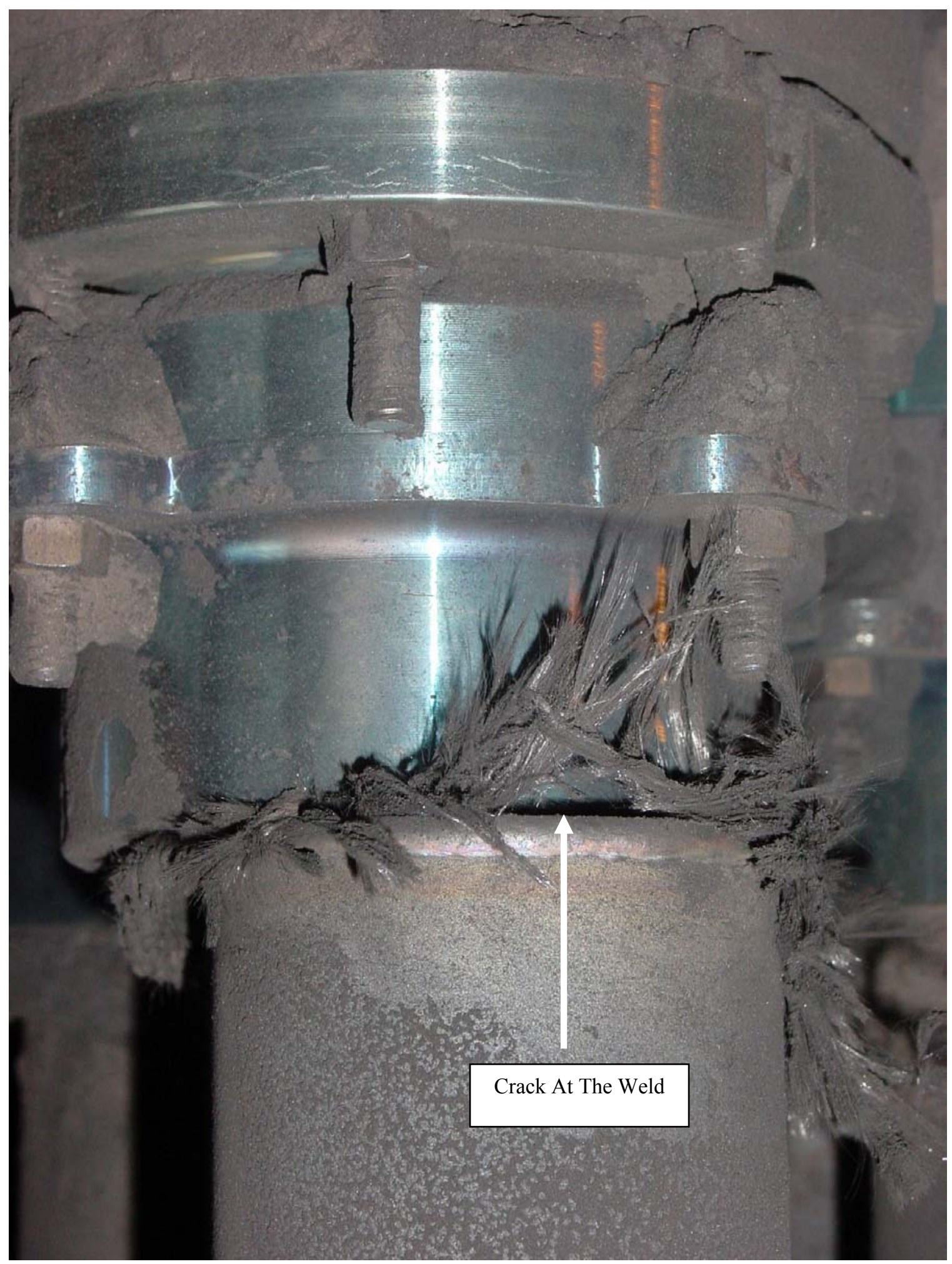

Figure 3.3-1 Failed Filter Element After TC07C (B-12) 


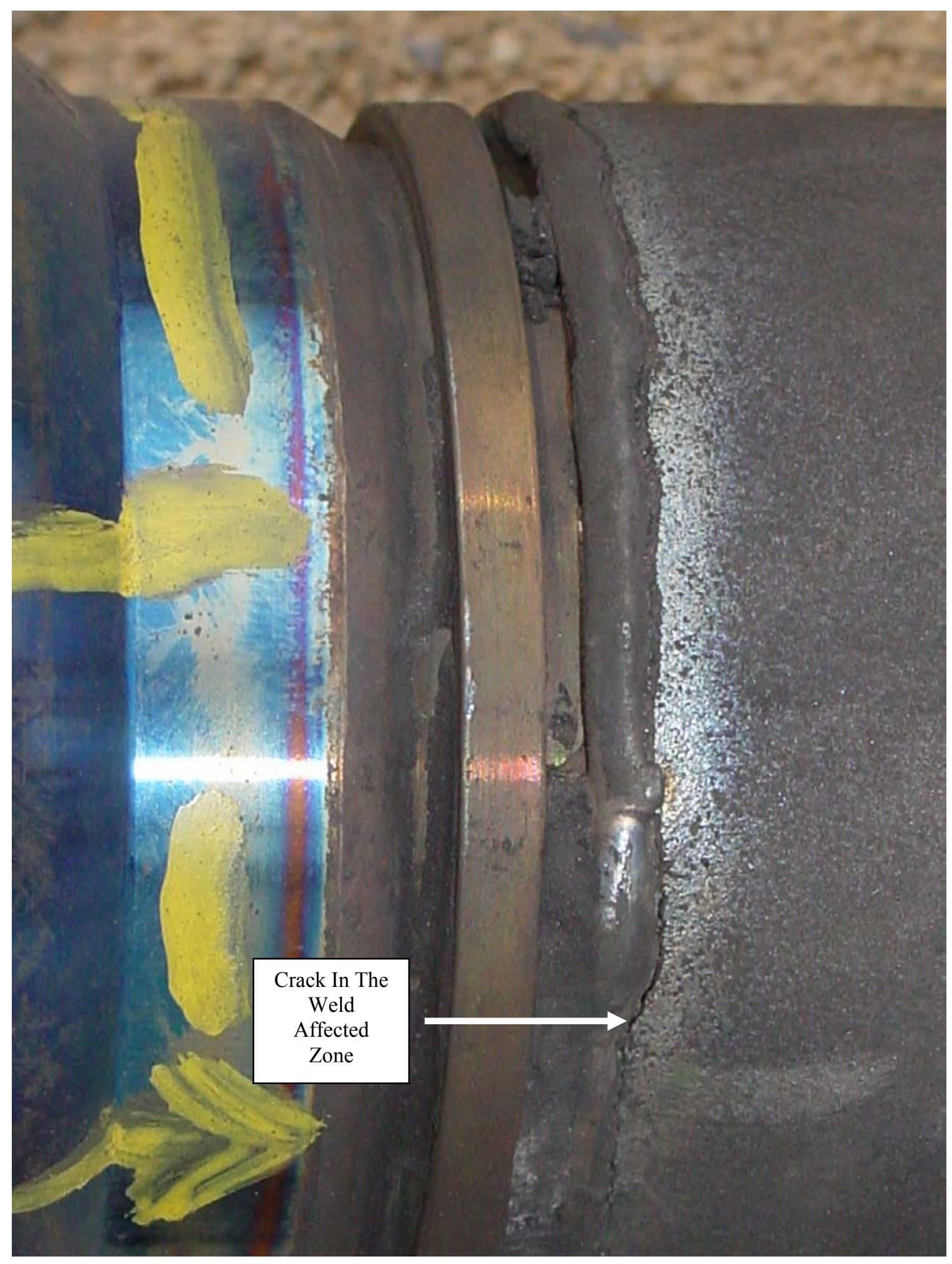

Figure 3.3-2 Failed Filter Element After TCO7C (B-14) 


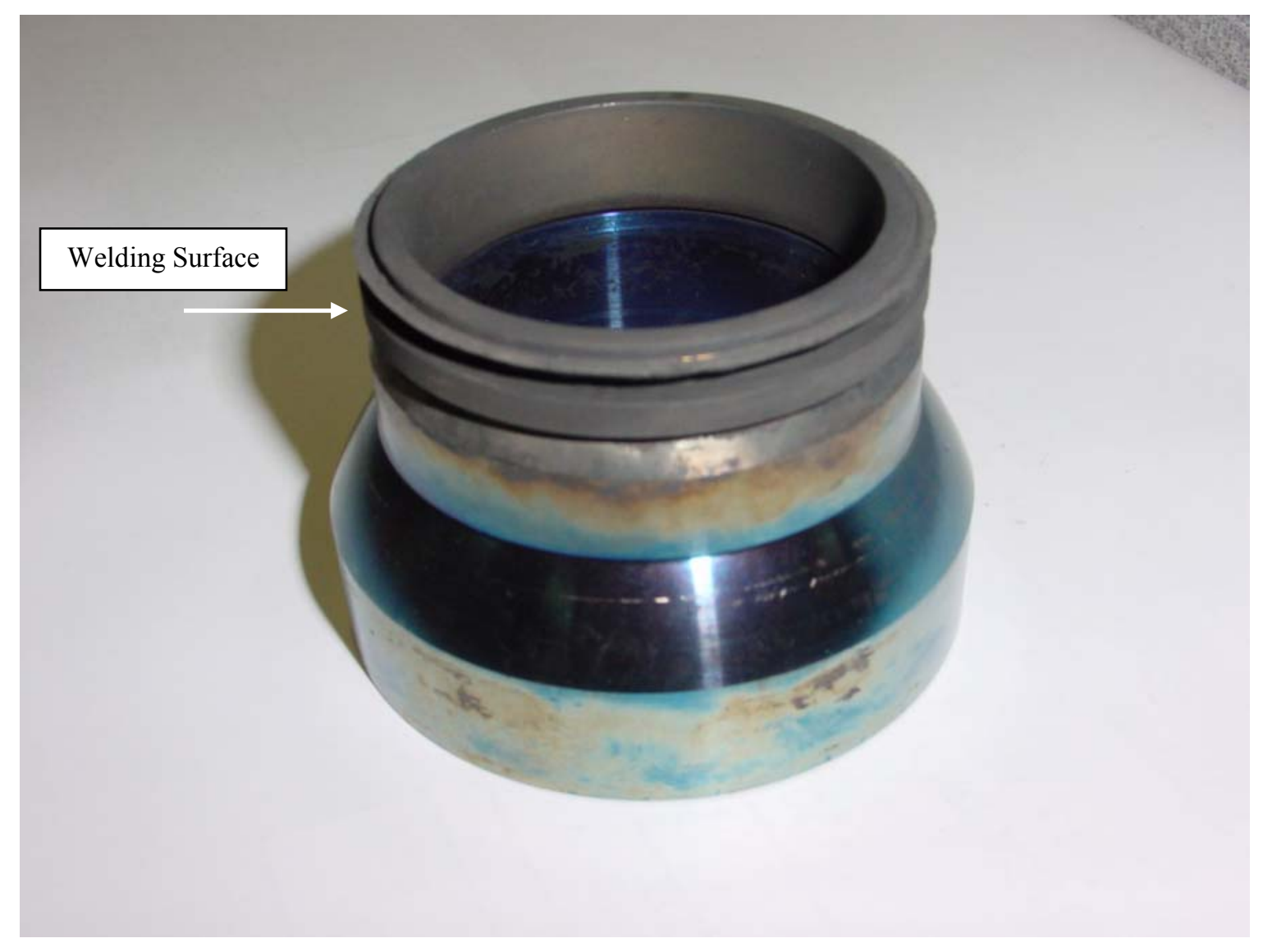

Figure 3.3-3 B-12 Filter Flange After TCO7C 


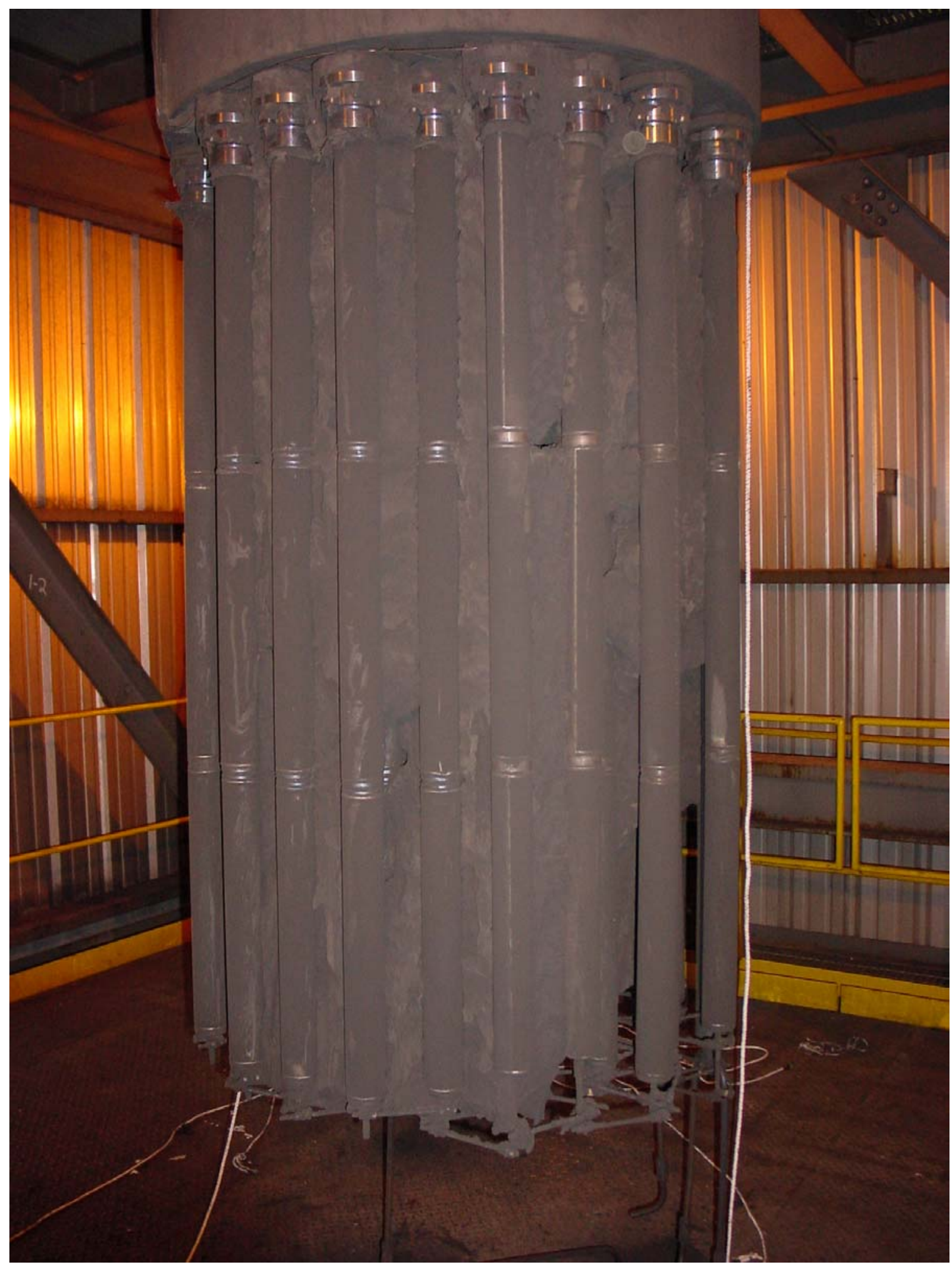

Figure 3-3-4 G-ash Bridging After TCO7C 


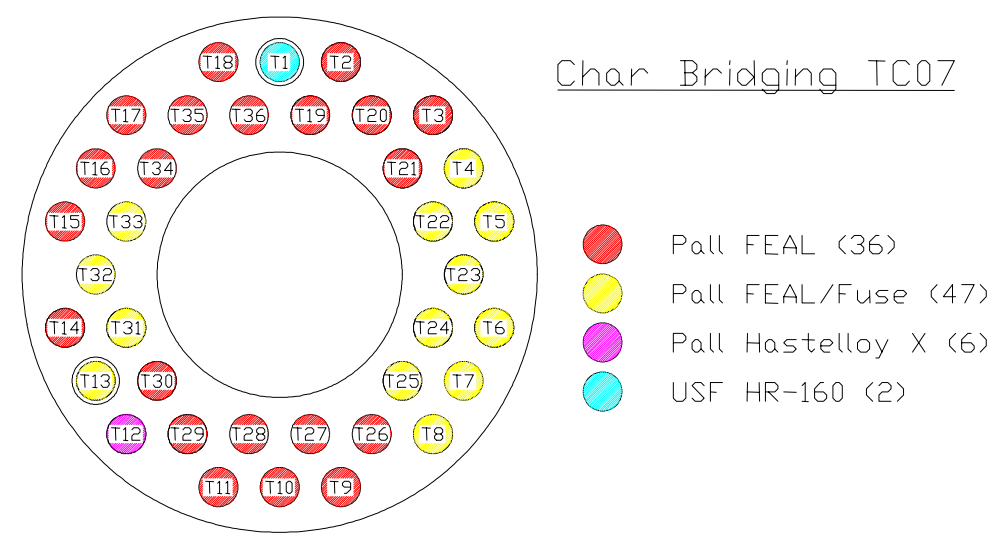

Coverage $\sim 70 \%$ of Bottom Plenum

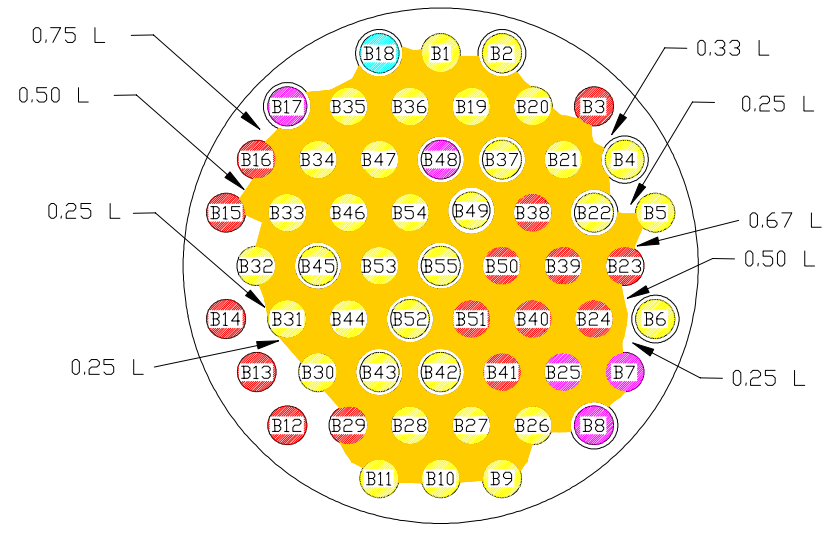

Figure 3.3-5 Location of G-ash Bridging After TCO7C 


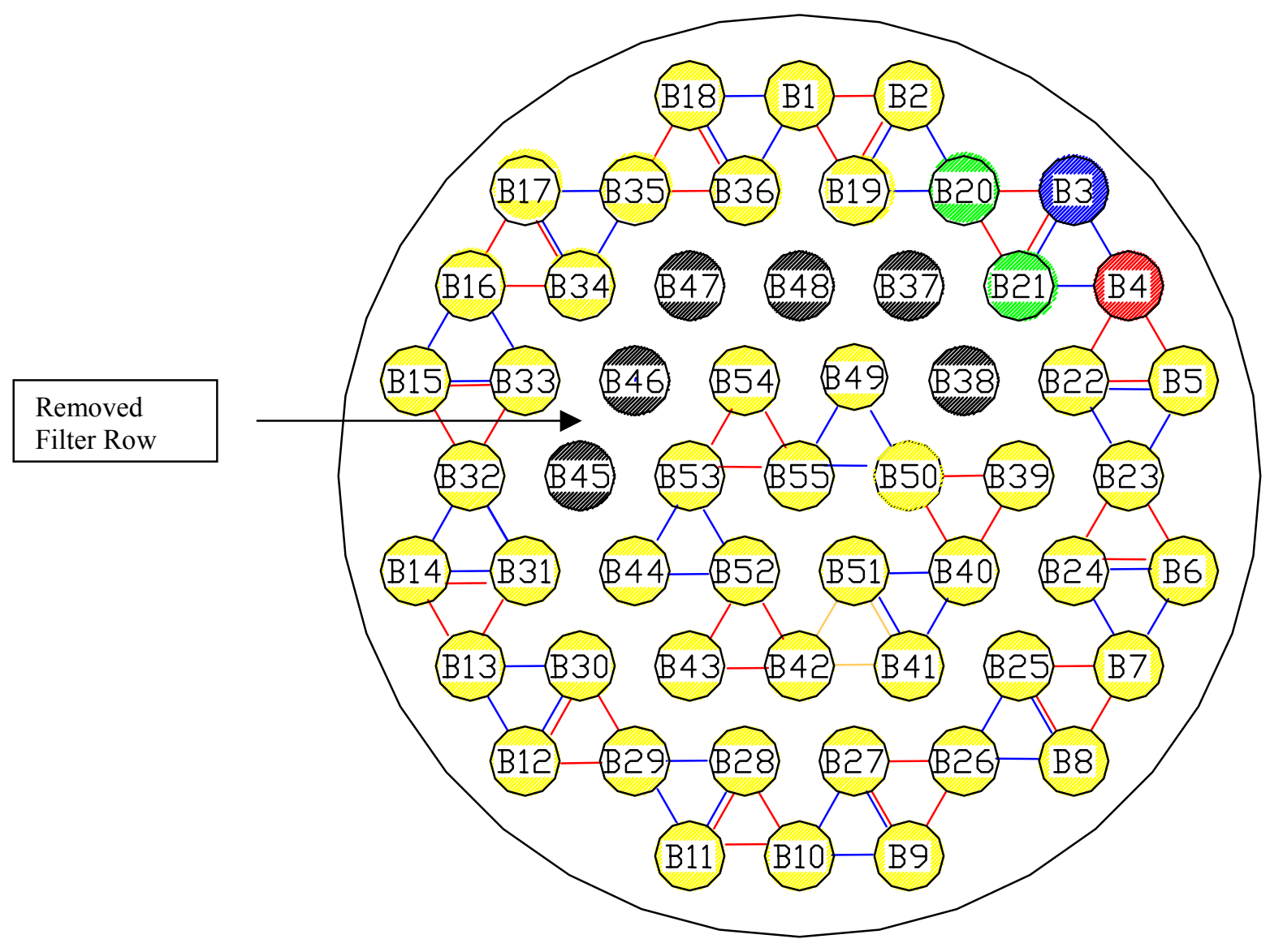

Figure 3.3-6 Location of Removed Filter Row Before TCO7D 


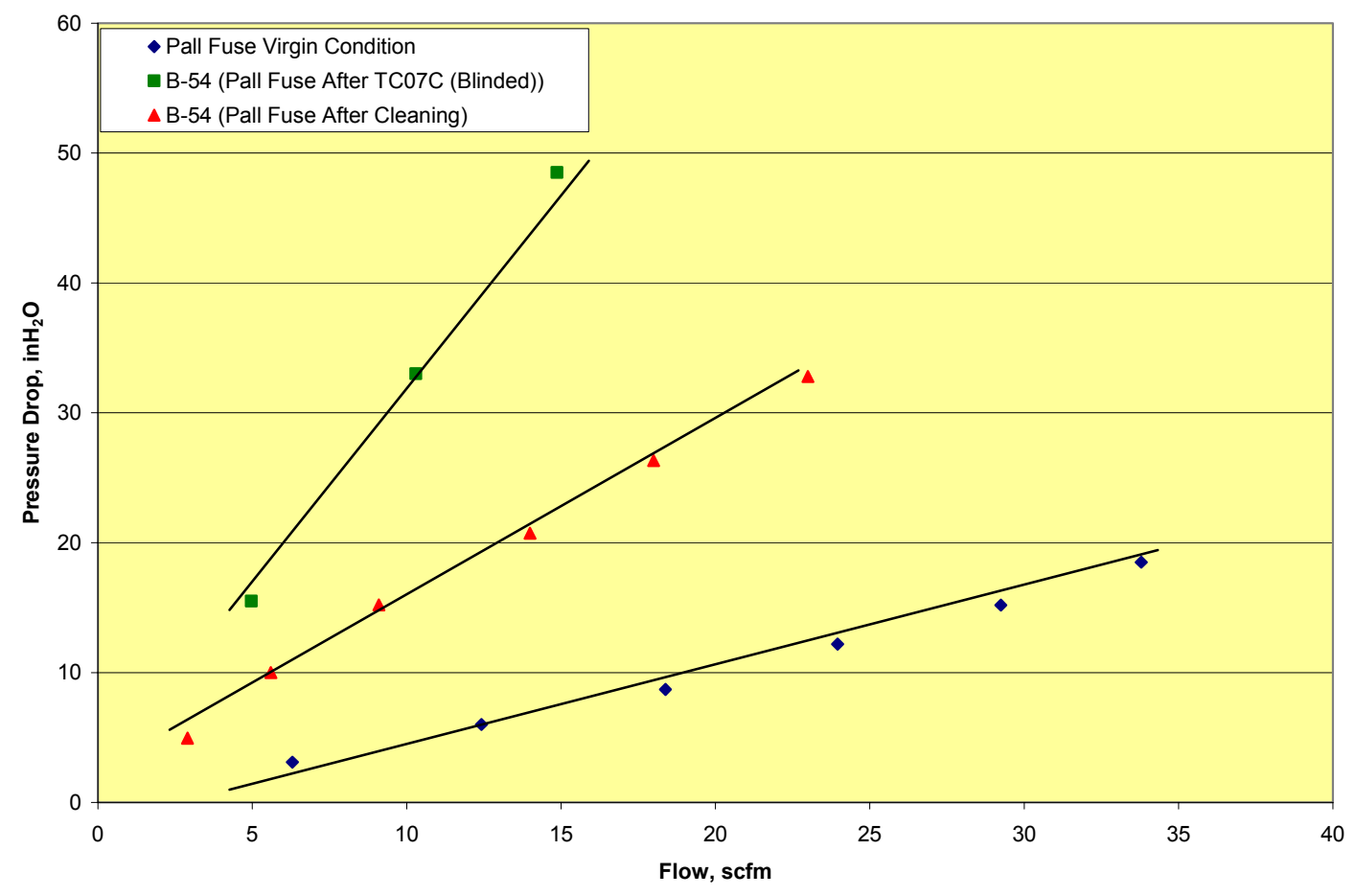

Figure 3.3-7 Flow Curve for Blinded Pall Fuse After TCO7C 


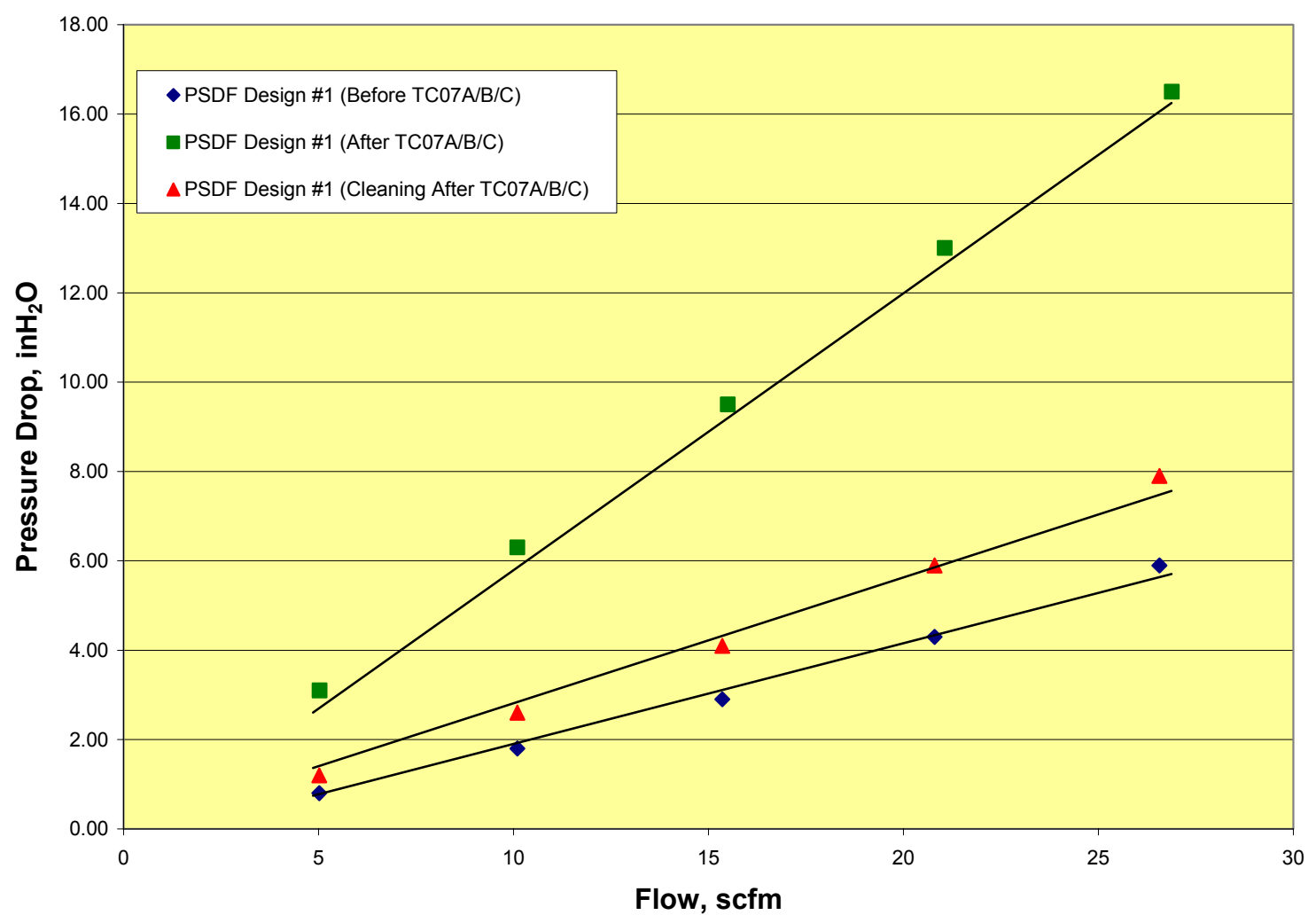

Figure 3.3-8 PSDF Designed \#1 Flow Curve After TC07C 


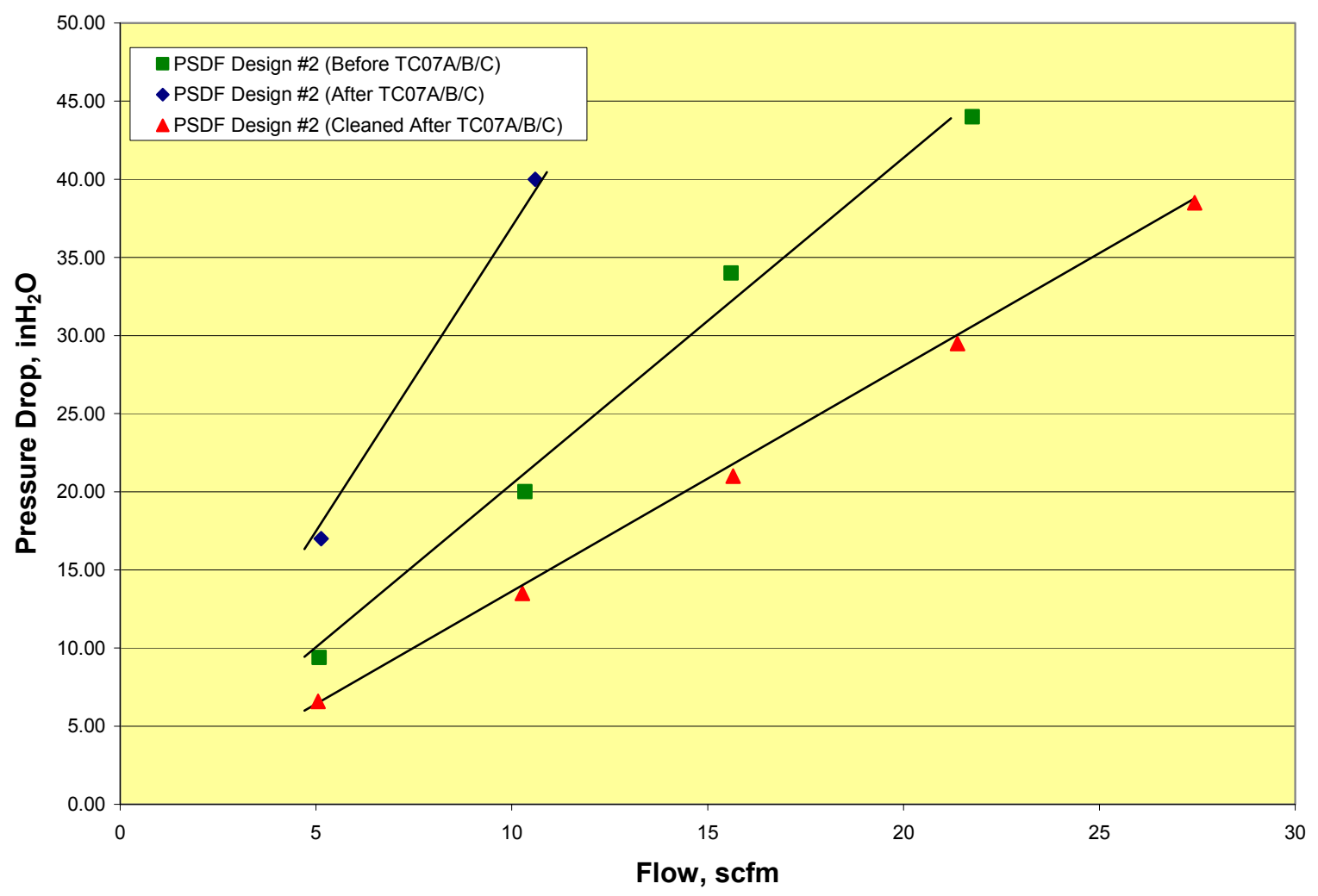

Figure 3.3-9 PSDF Designed \#2 Flow Curve After TC07C 


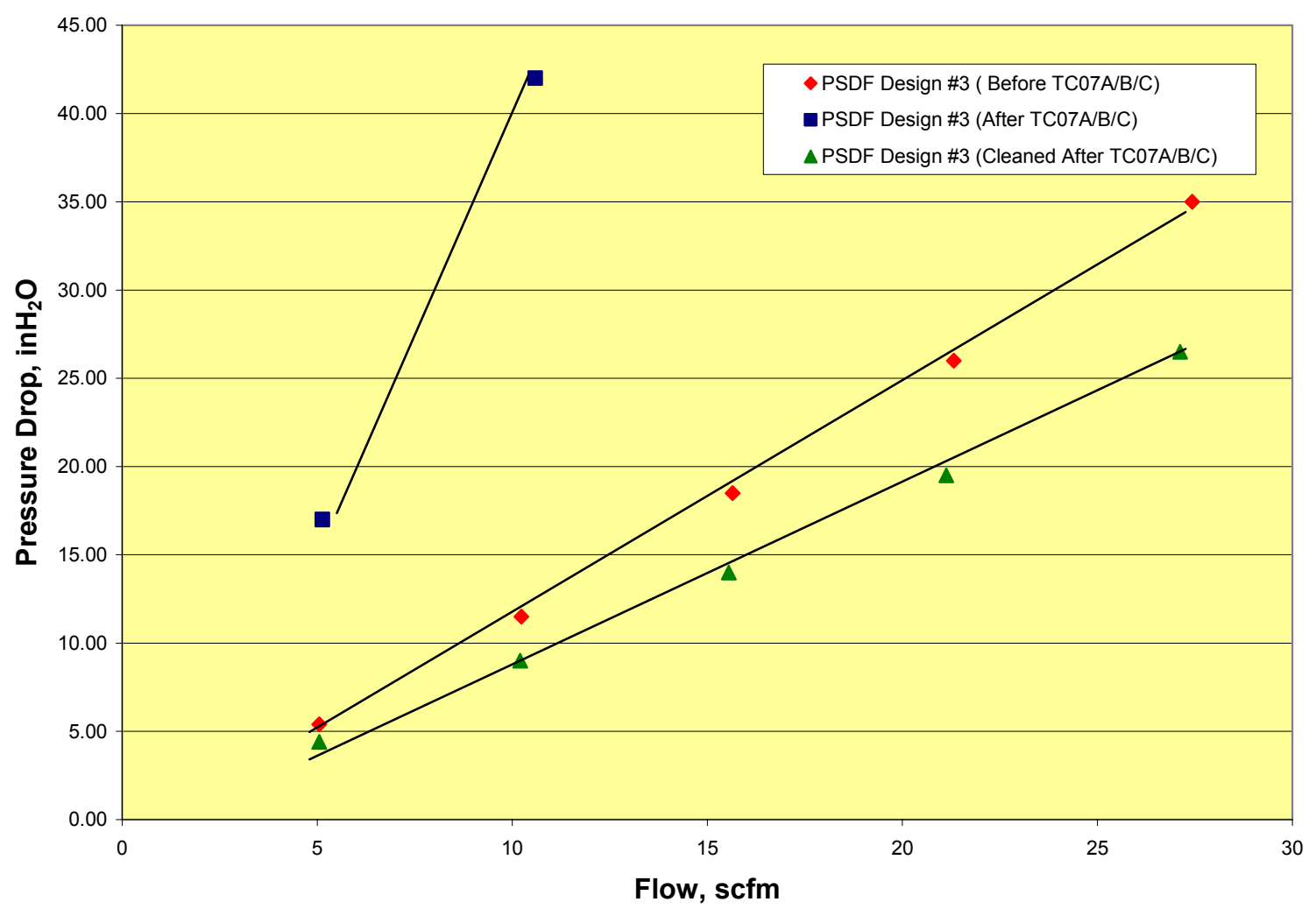

Figure 3.3-10 PSDF Designed \#3 Flow Curve After TCO7C 


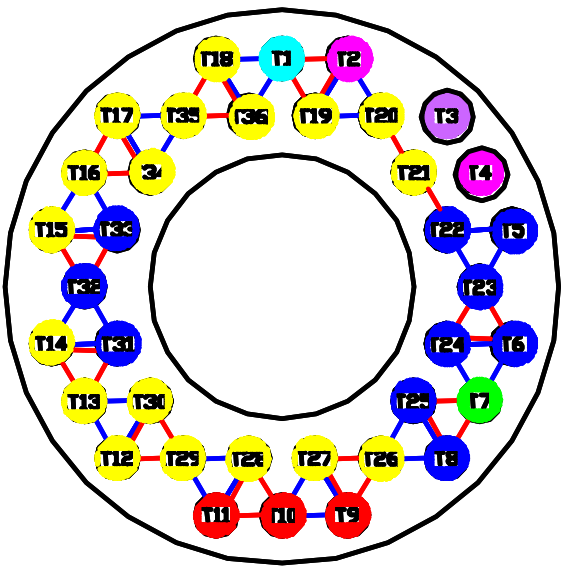

Layout 23 (TCO7D)

(1.5m Filters, $A=241.4$ ft^2)

Pall FEAL/Fuse, New (63)

Pall FEAL/Fuse, 148 Hrs (4)

Pall FEAL/Fuse, 945 Hrs (3)

Pall FEAL/Fuse, 1415 Hrs (11)

Pall Hastelloy $X, 148$ Hrs (2)

Pall Hastelloy $X, 1173$ Hrs (1)

USF HR-160, 148 Hrs (1)

Blank (6)

- Support at Level a

- Support at Level b

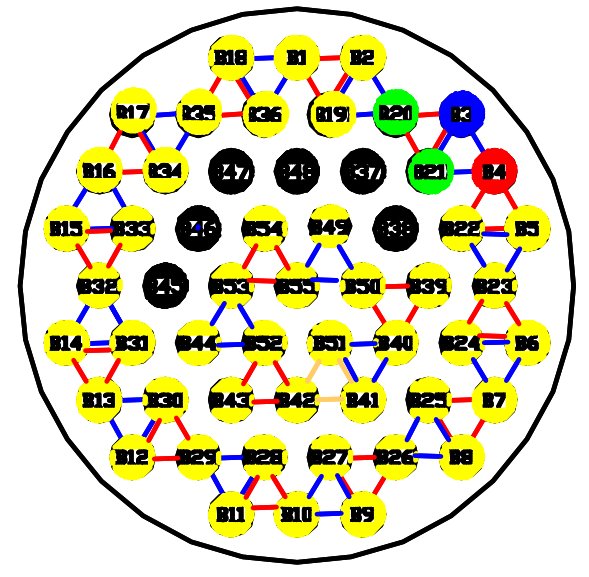

Support at Level $c$

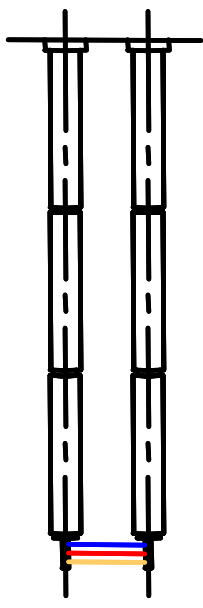

Figure 3.3-11 Filter Layout With Corresponding Exposure Hours 


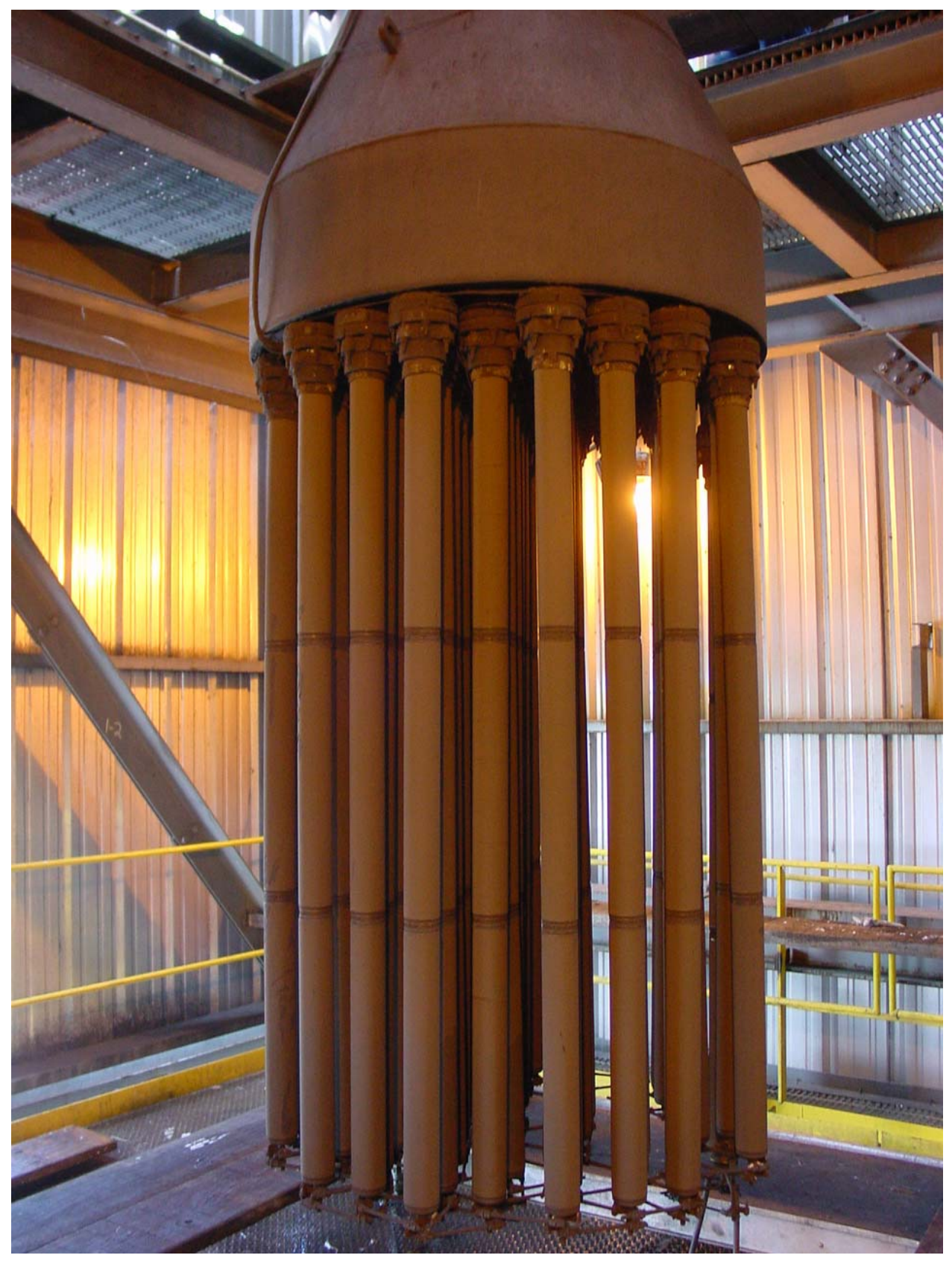

Figure 3.3-12 PCD Lower Plenum After TC07D 


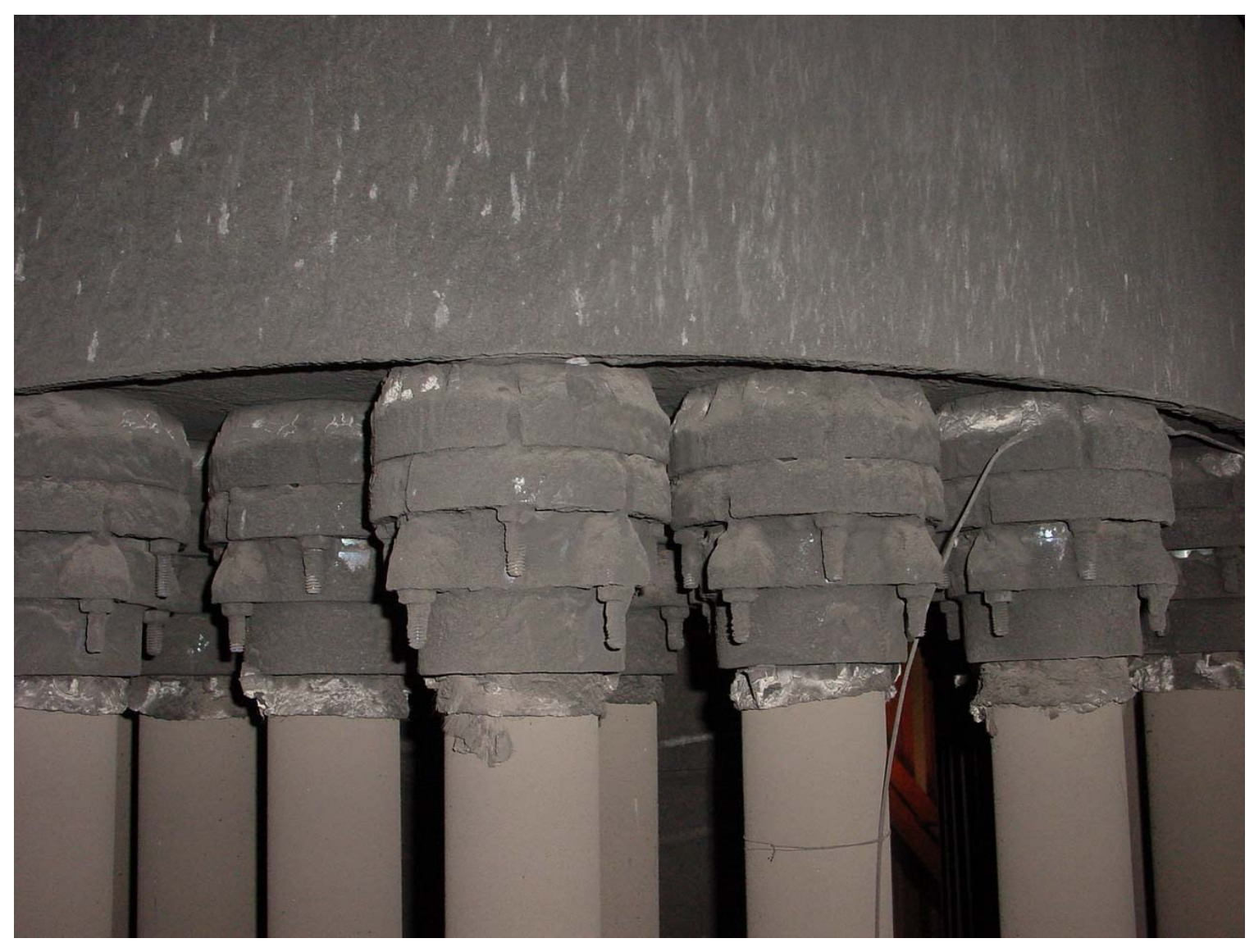

Figure 3.3-13 G-ash Build-Up on Filter Holders After TC07D 


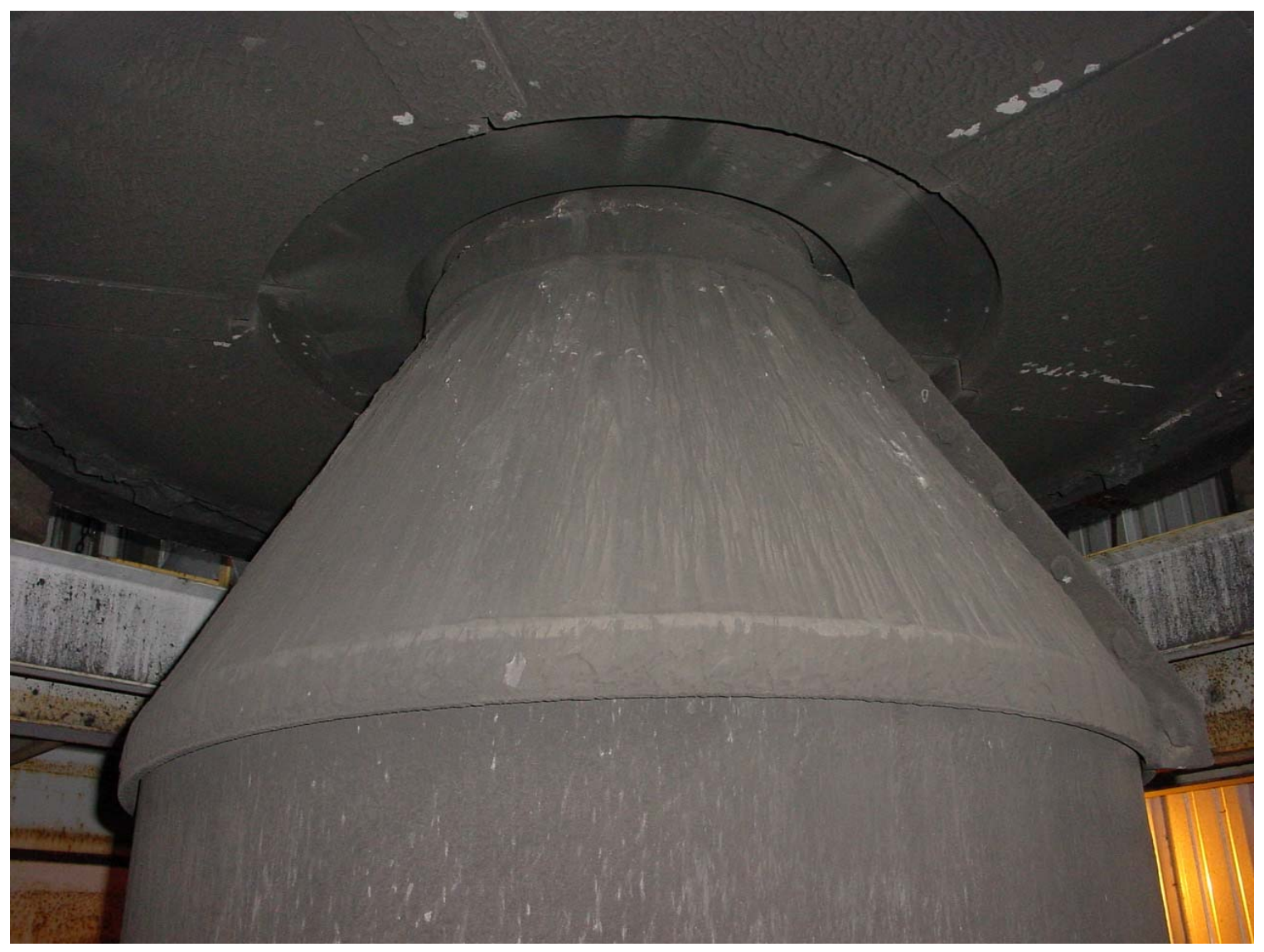

Figure 3.3-14 G-ash Build-Up on Upper Ash Shed After TC07D 


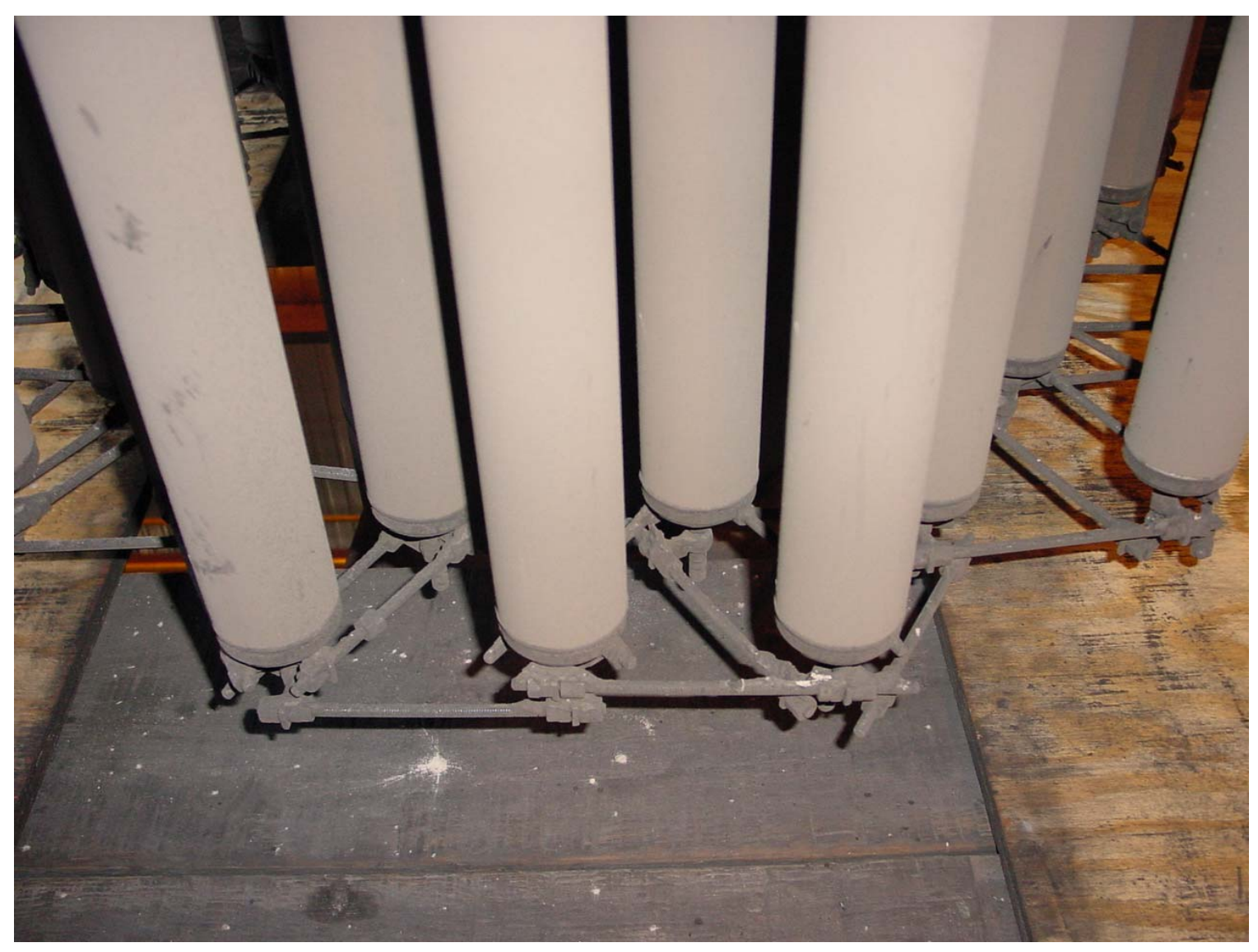

Figure 3.3-15 G-ash Build-Up on Support Brackets After TCO7D 


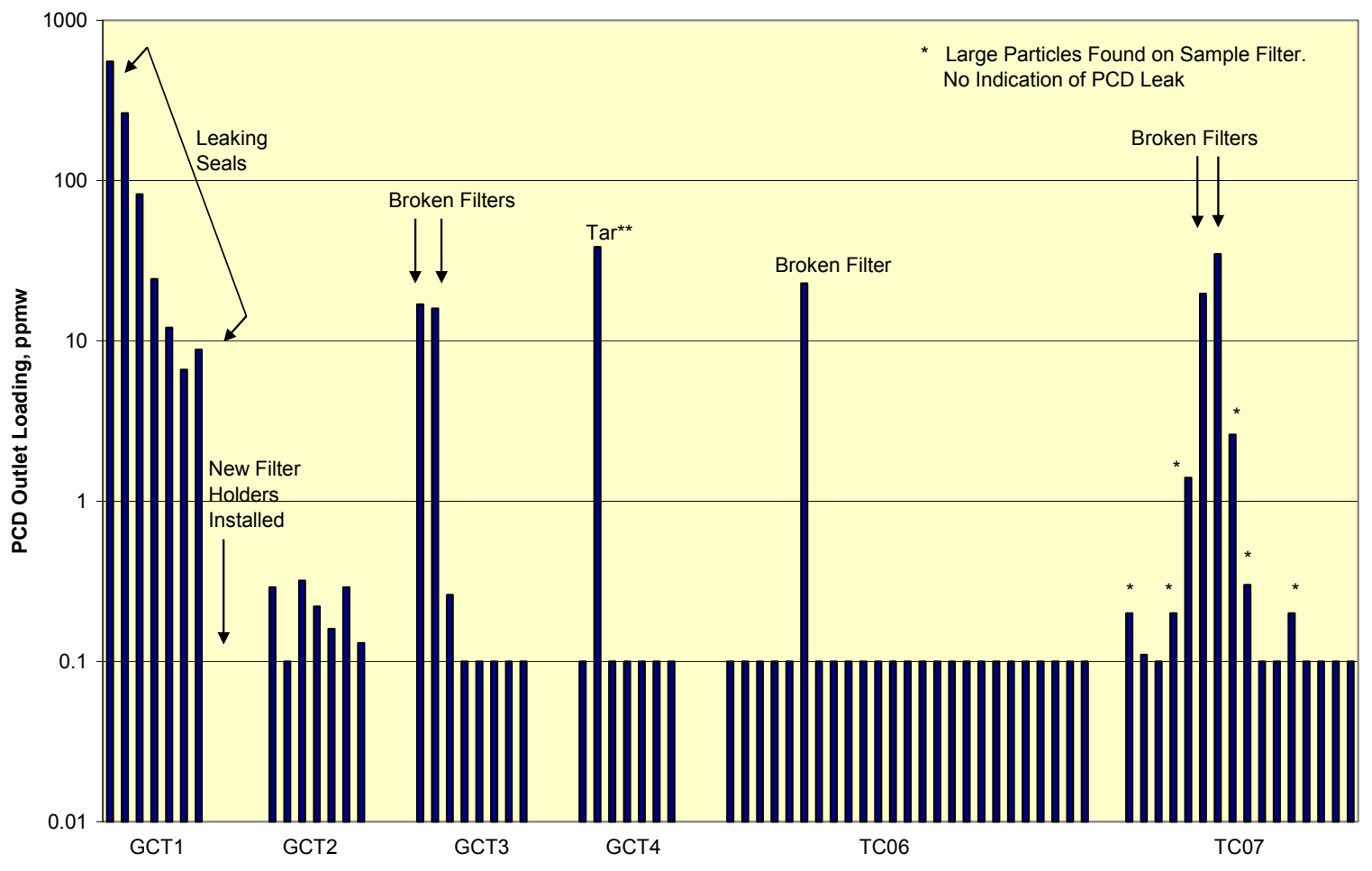

Figure 3.3-16 Outlet Loading From PCD for All Gasification Runs 


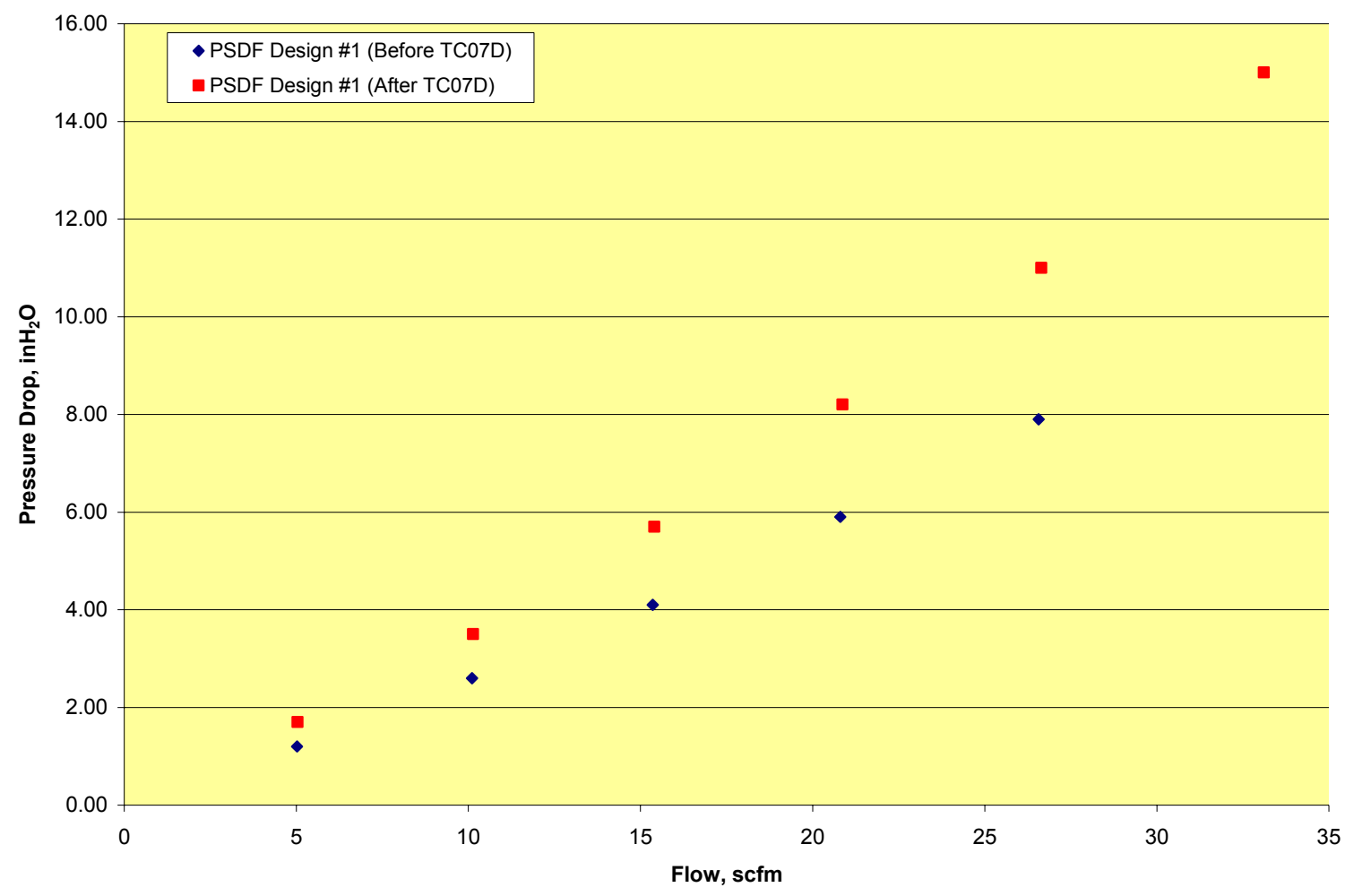

Figure 3.3-17 PSDF Design \#1 Flow Curve After TC07D 
POWER SYSTEMS DEVELOPMENT FACILITY

PARTICLE FILTER SYSTEM

TEST CAMPAIGN TCO7

TCO7 INSPECTION REPORT

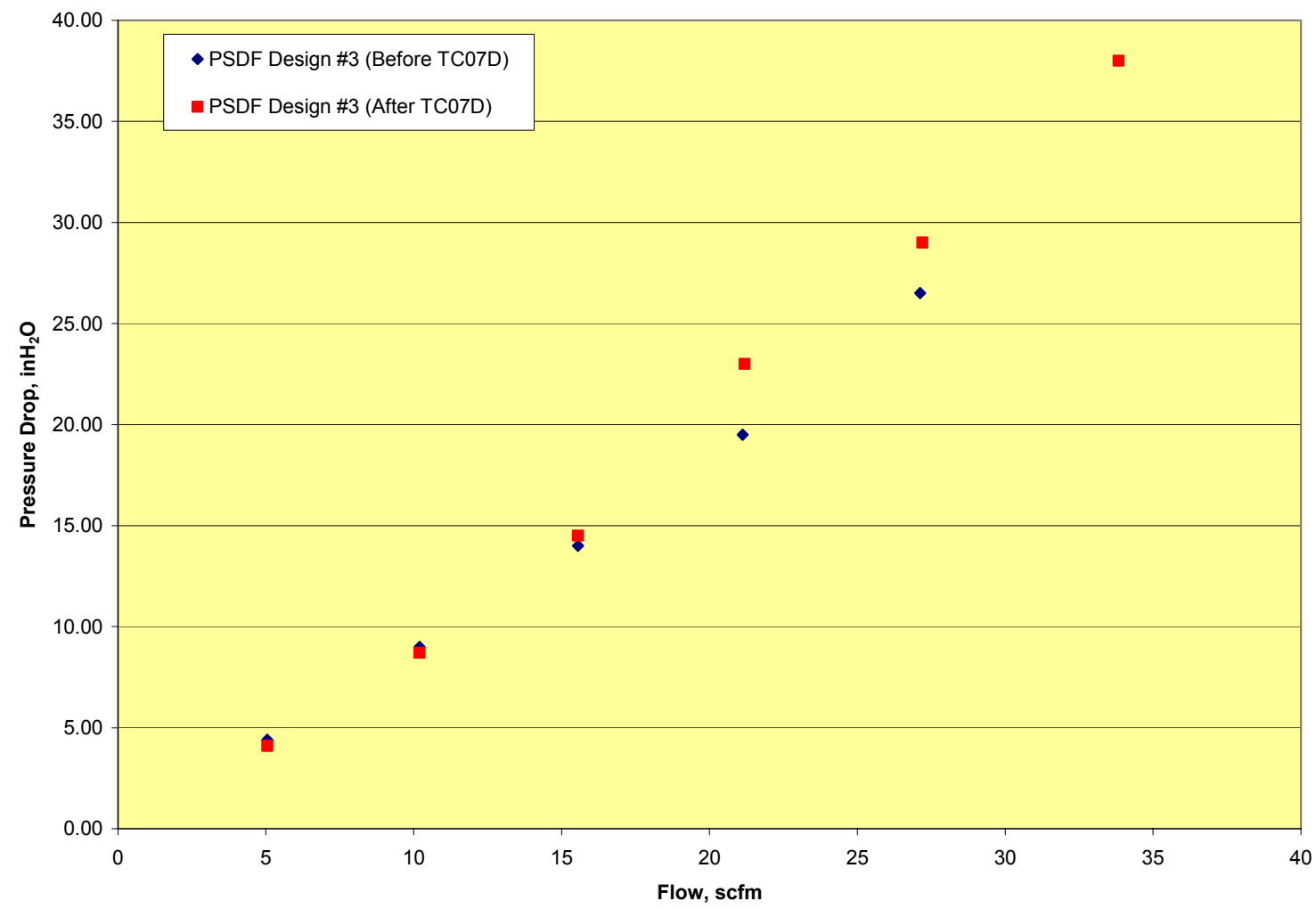

Figure 3.3-18 PSDF Designed \#3 Flow Curve After TCO7D 


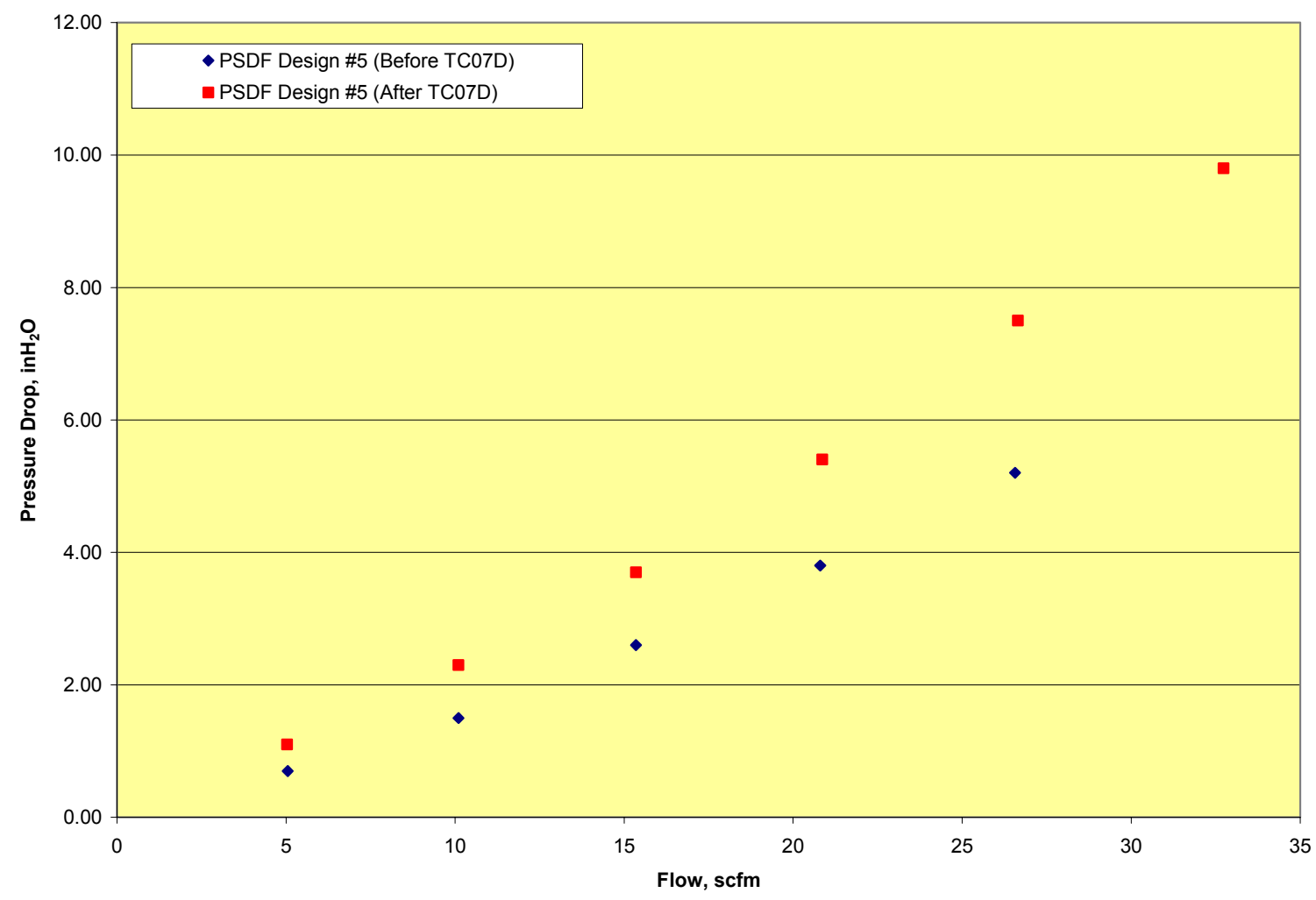

Figure 3.3-19 PSDF Designed \#5 Flow Curve After TC07D 
POWER SYSTEMS DEVELOPMENT FACILITY

PARTICLE FILTER SYSTEM

TEST CAMPAIGN TCO7

TCO7 INSPECTION REPORT

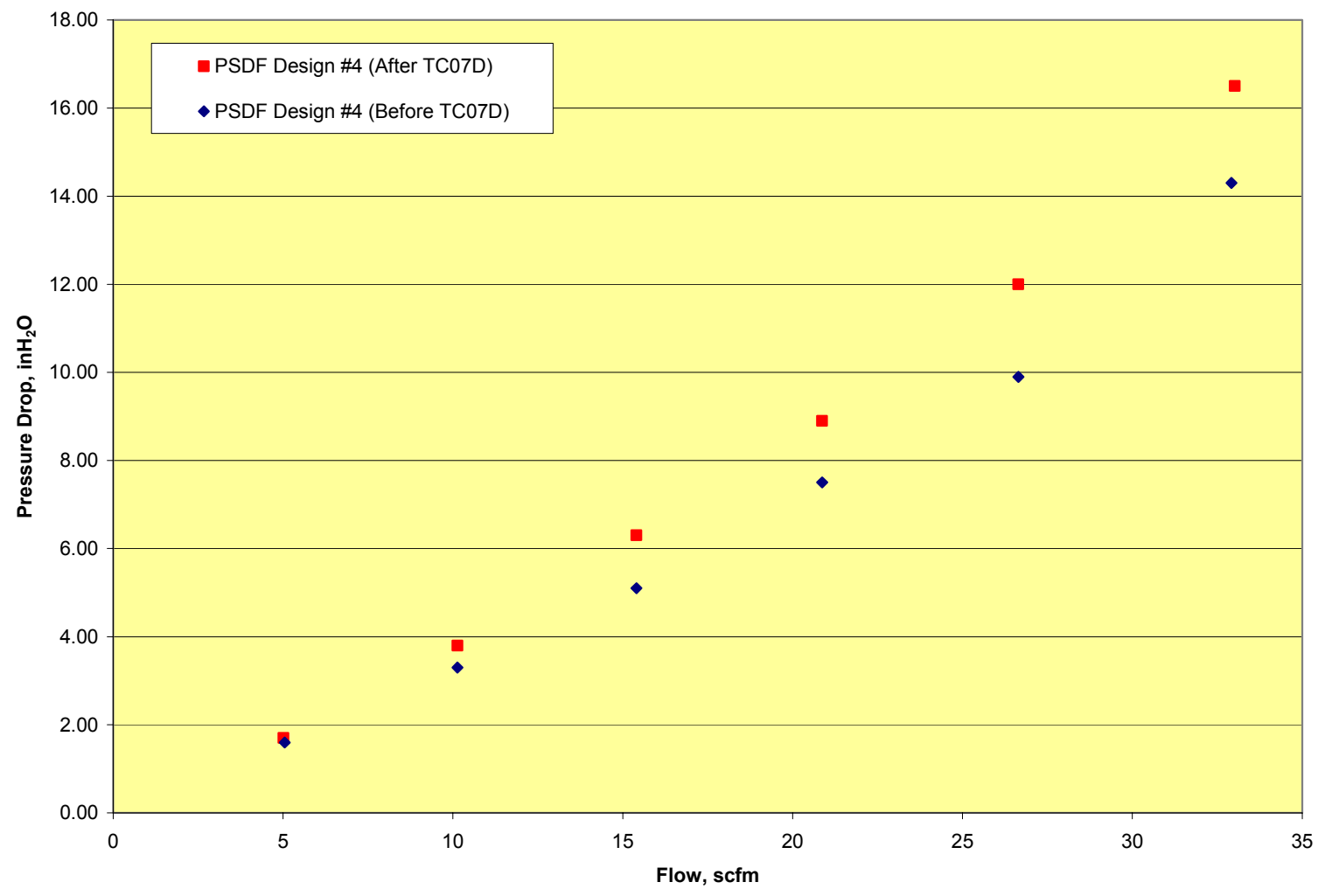

Figure 3.3-20 PSDF Designed \#4 Flow Curve After TCO7D 


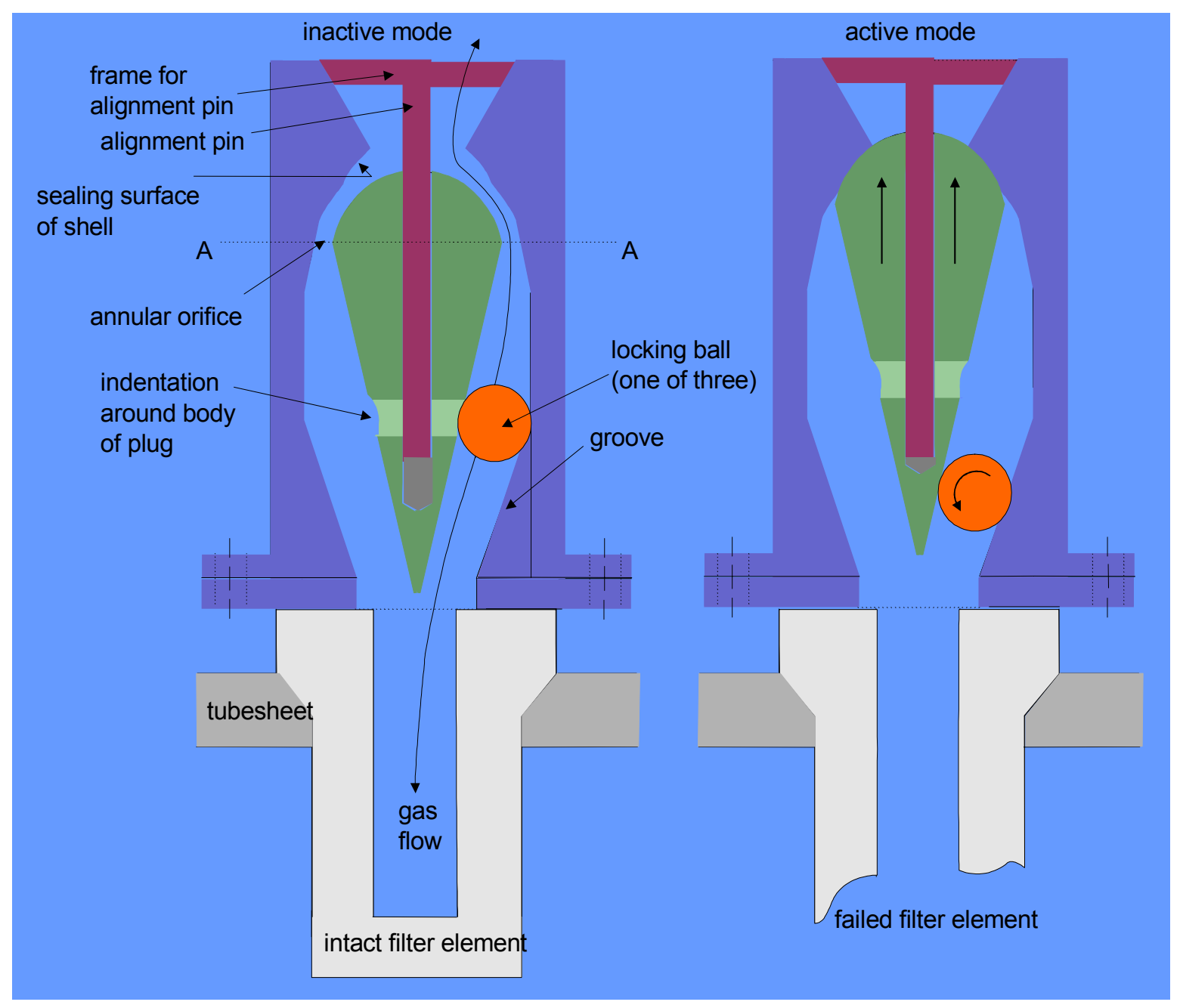

Figure 3.3-21 Simplified Schematic of the SRI Safeguard Device 


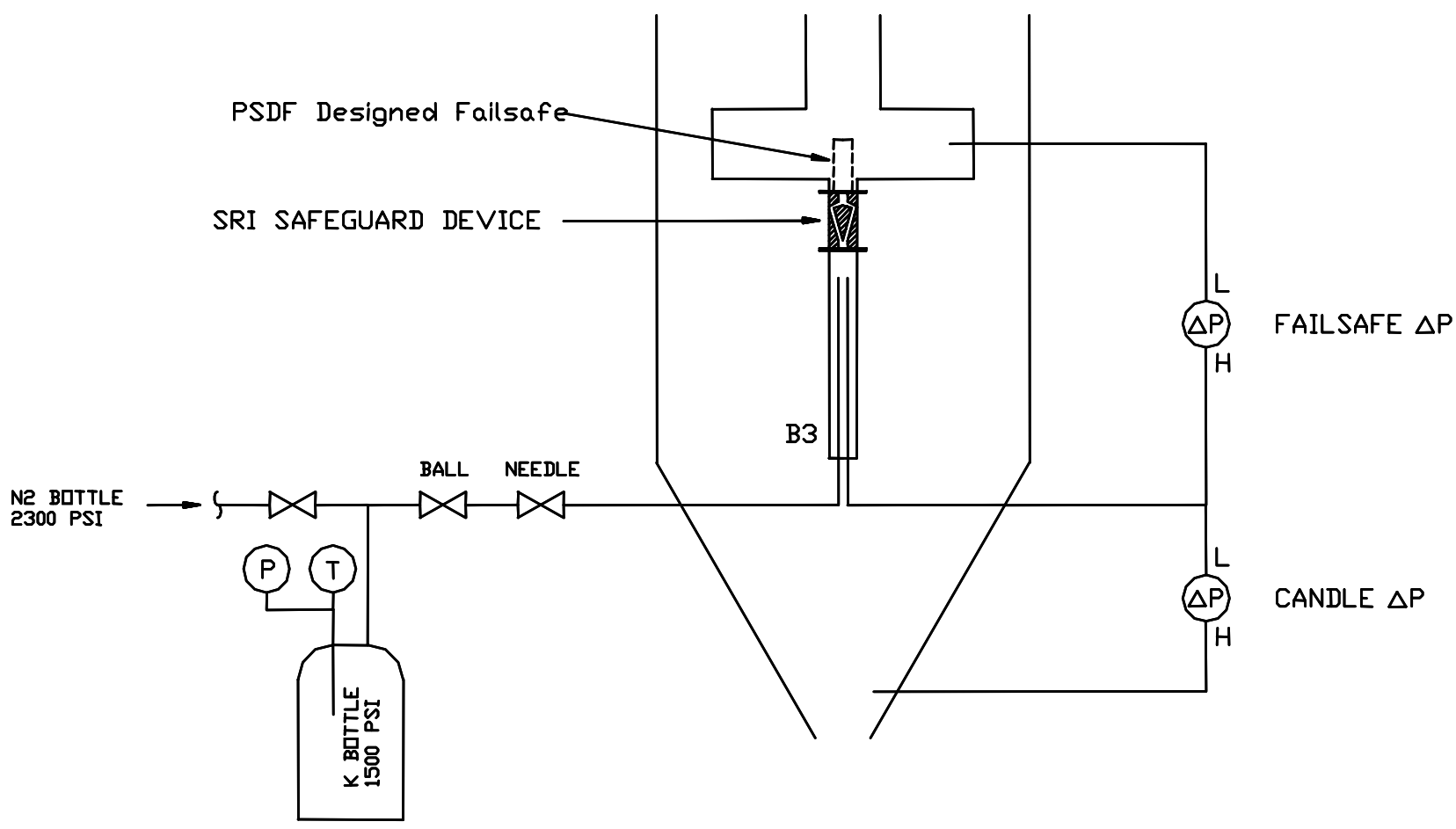

Figure 3.3-22 Simplified Schematic of Test Setup 
PARTICLE FILTER SYSTEM

TCOT INSPECTION REPORT
POWER SYSTEMS DEVELOPMENT FACILITY

TEST CAMPAIGN TCO7

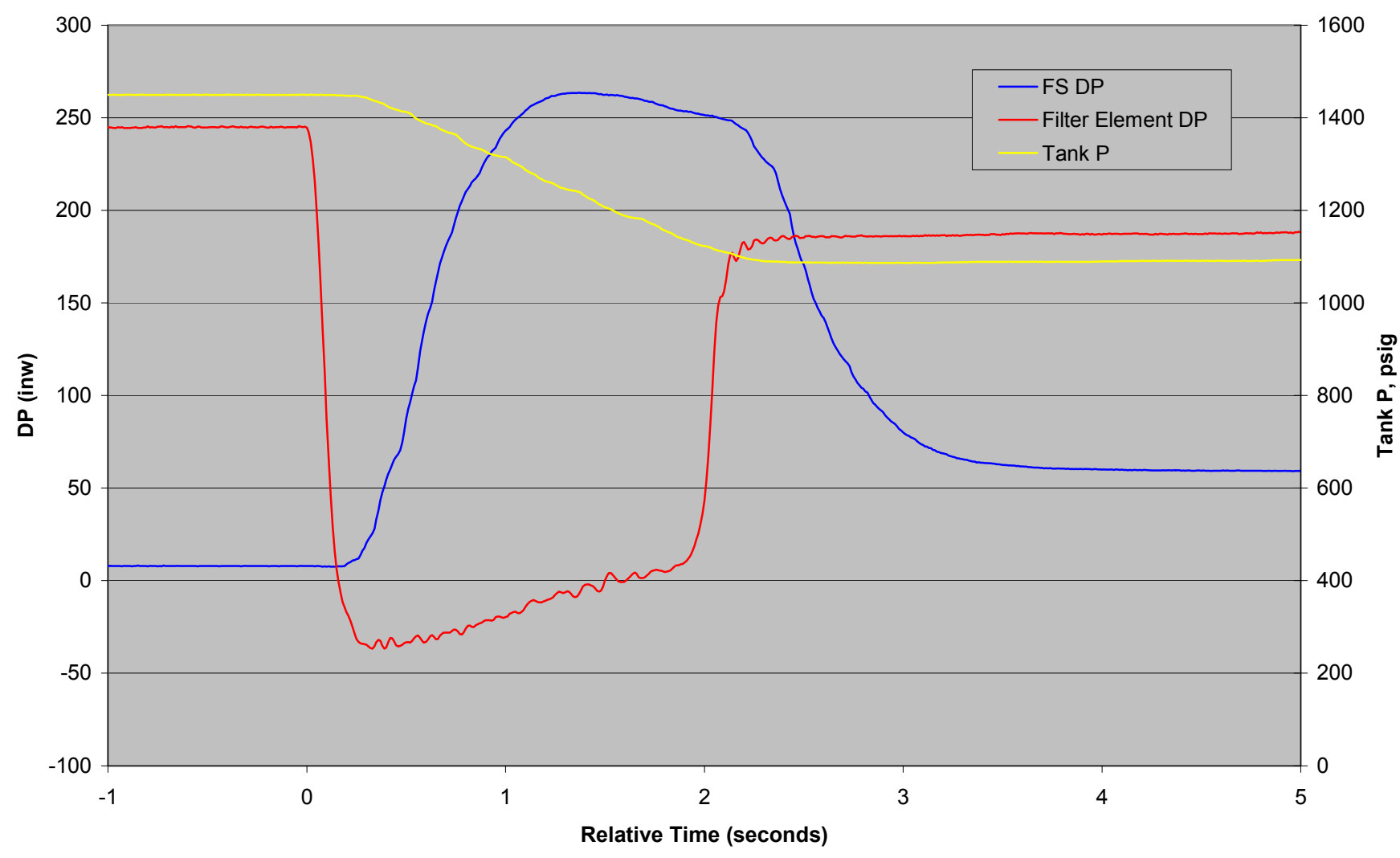

Figure 3.3-23 Data From April 1, 2002, SGD Activation Test 
POWER SYSTEMS DEVELOPMENT FACILITY

PARTICLE FILTER SYSTEM

TEST CAMPAIGN TCO7

TCO7 INSPECTION REPORT

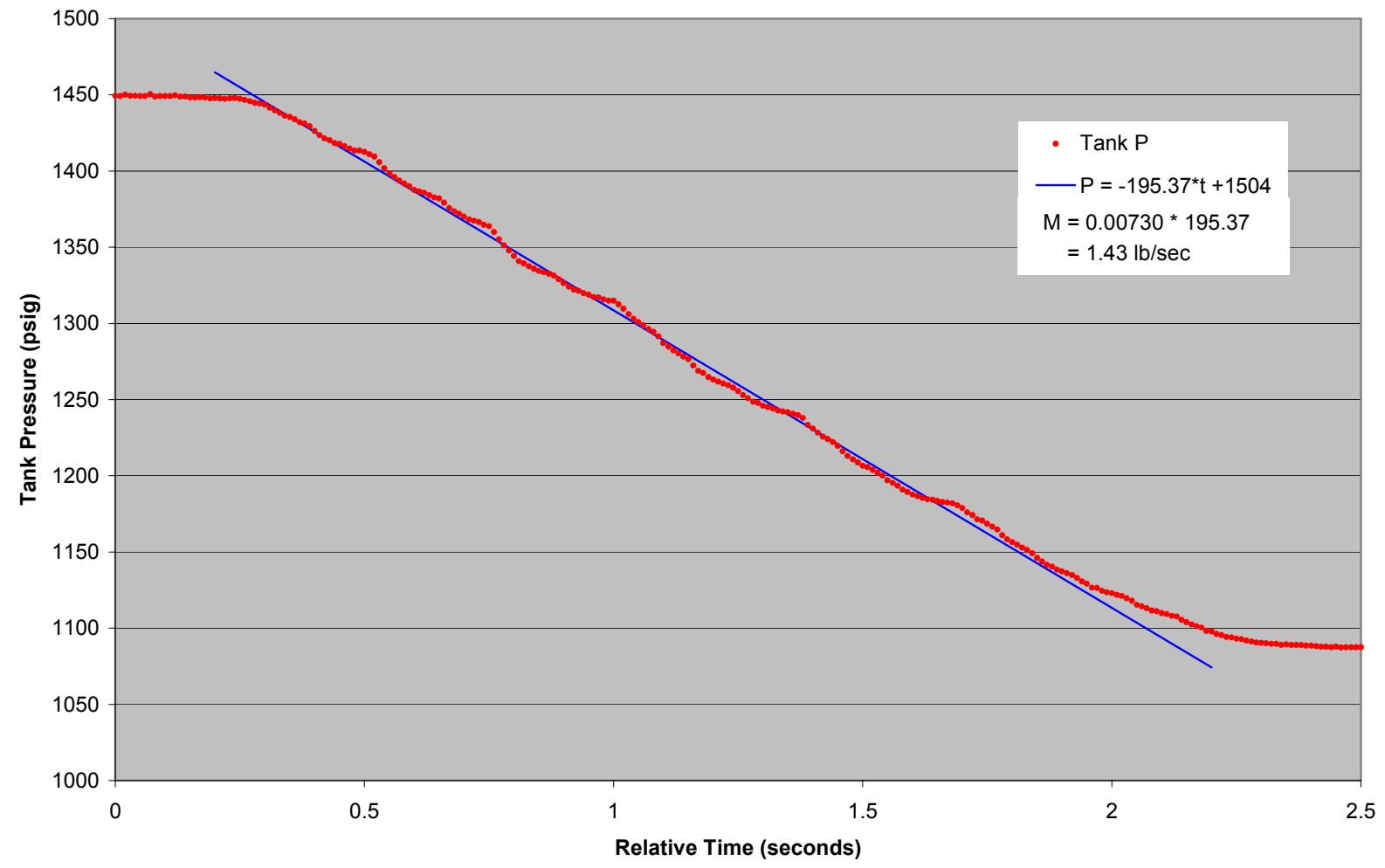

Figure 3.3-24 Receiver Pressure During April 1, 2002, SGD Activation Test 


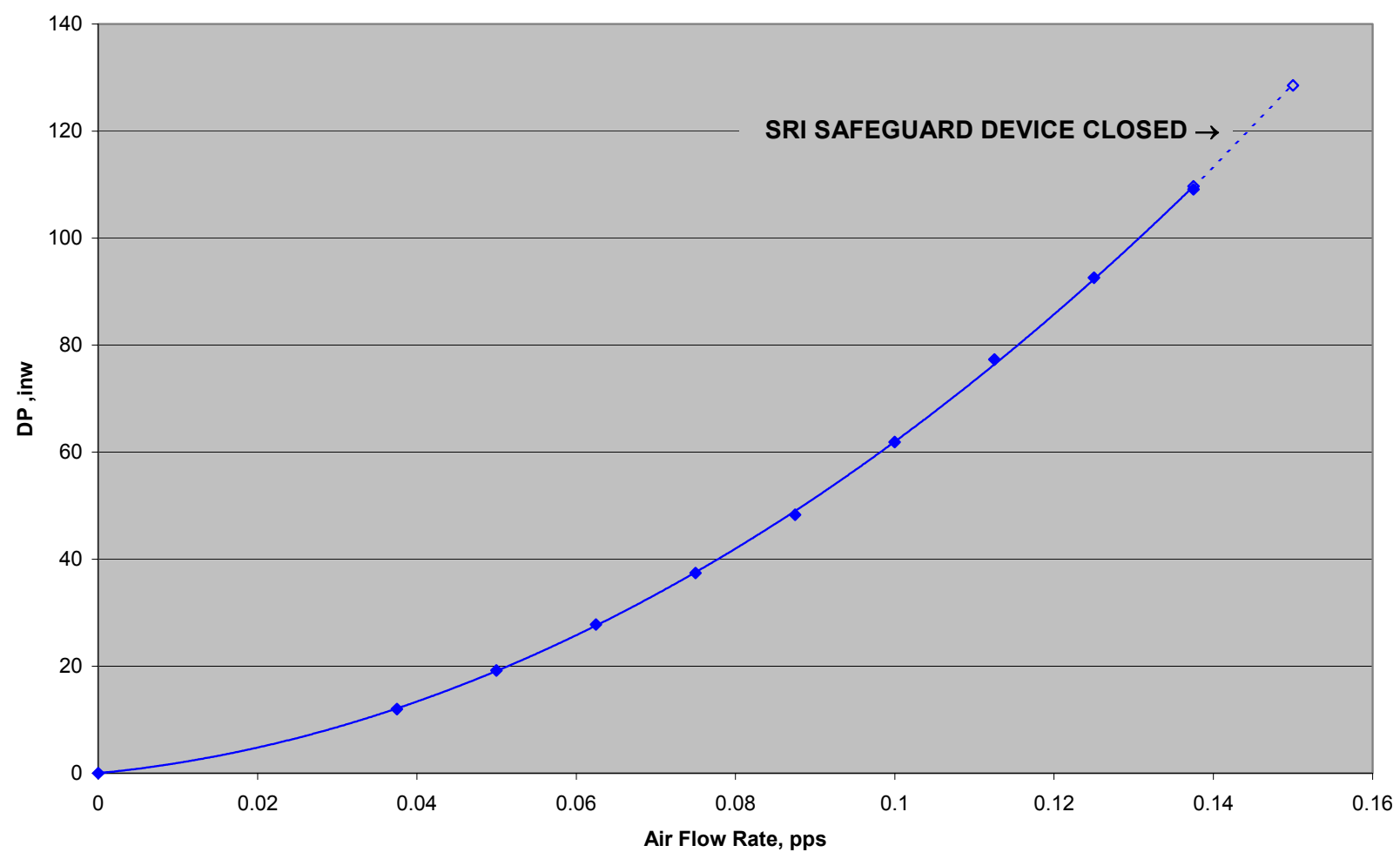

Figure 3.3-25 Flow Test Results for Combined SRI SGD Plus Backup PSDF Designed Failsafe 


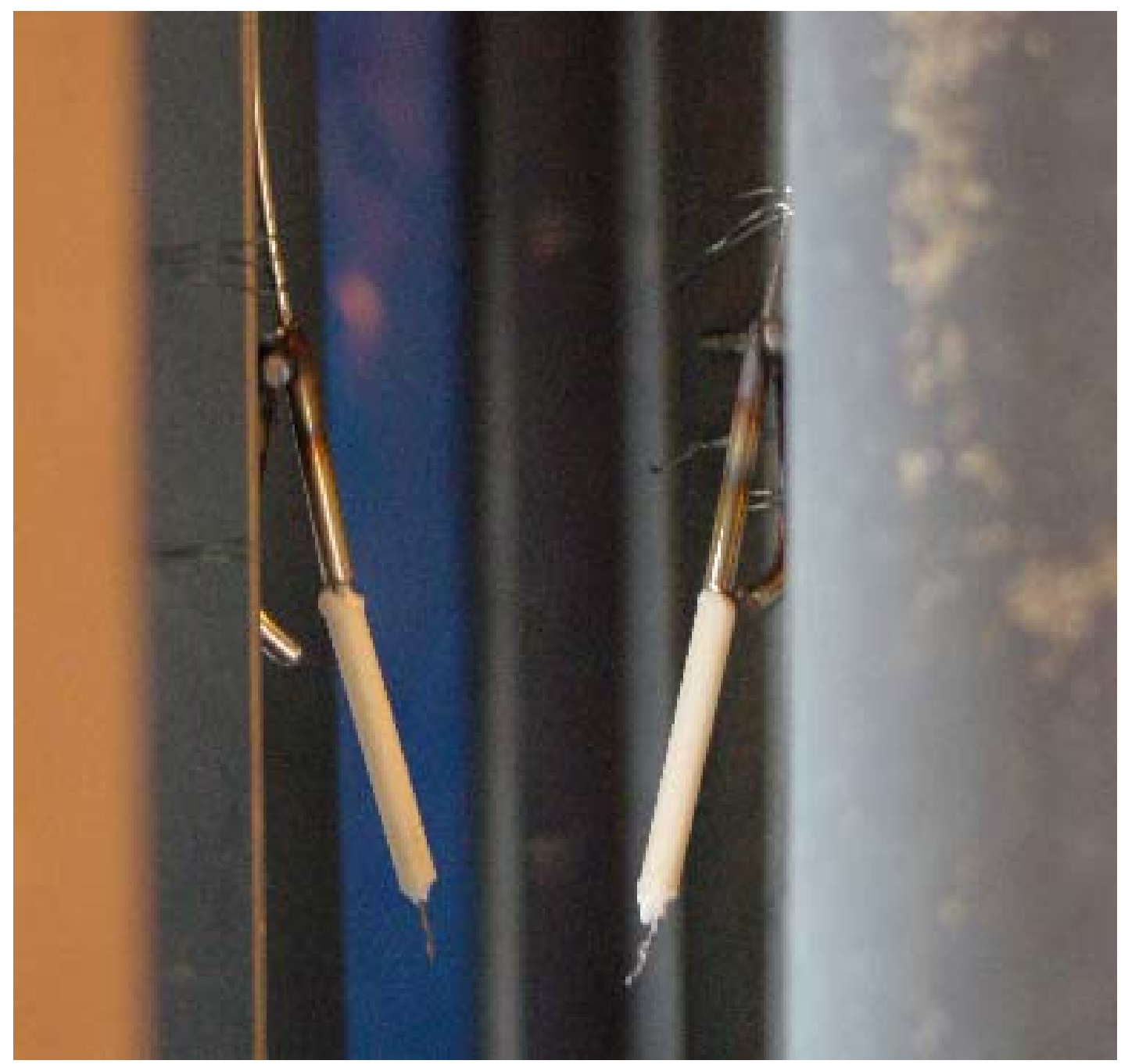

Figure 3.3-26 G-ash Resistance Probes Used During TCO7D 


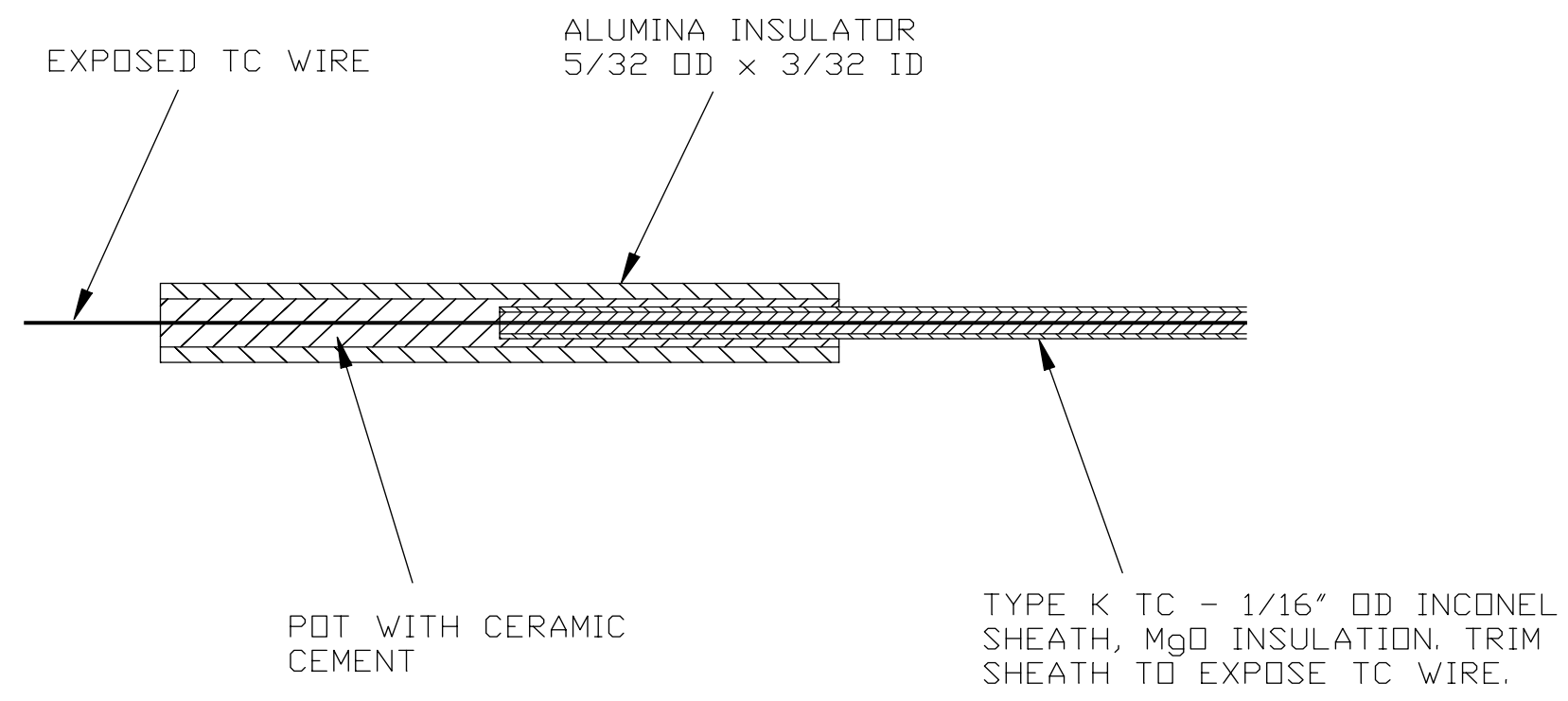

Figure 3.3-27 Resistance Probe Construction 


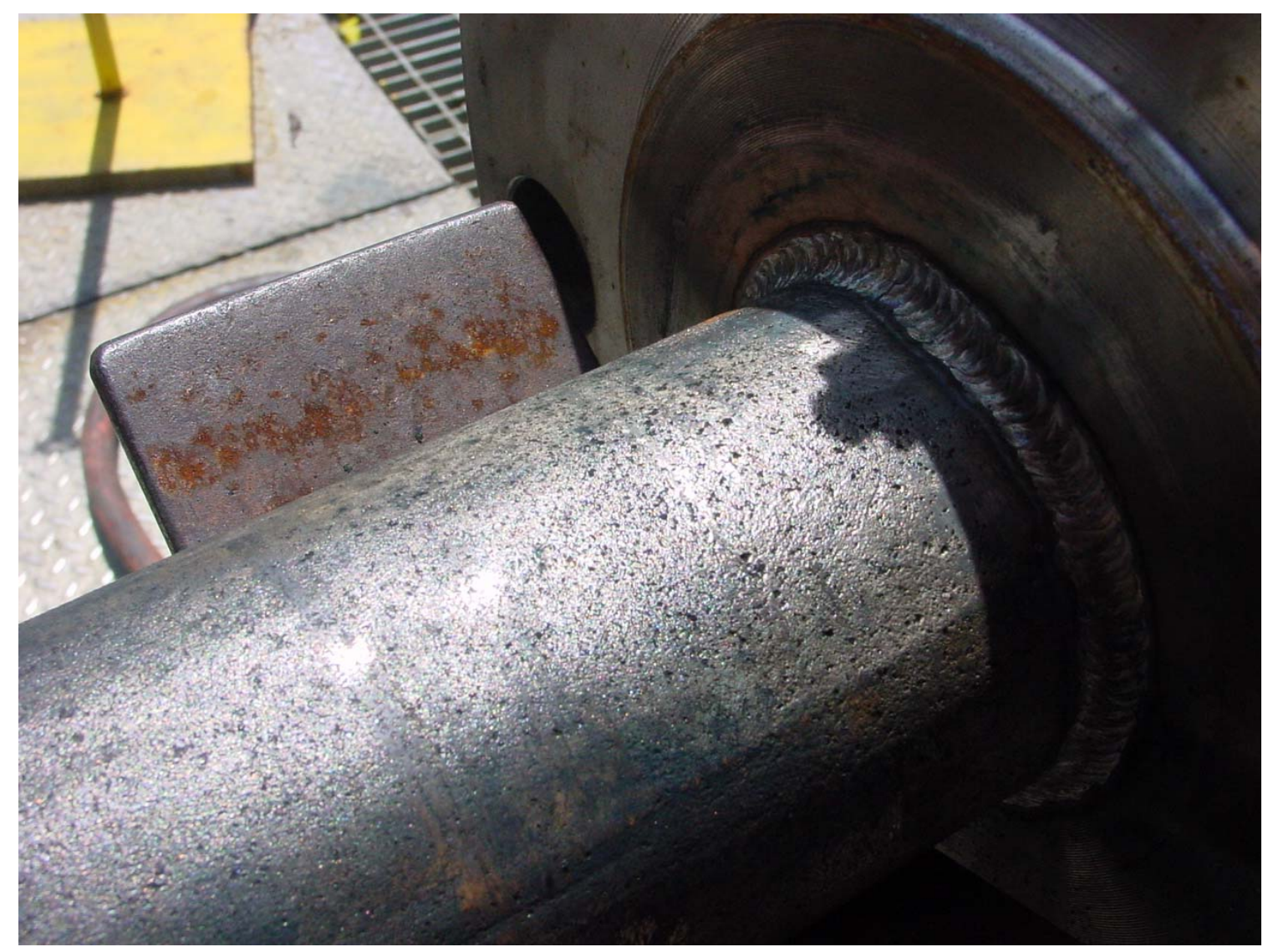

Figure 3.3-28 Pitting on Back-Pulse Pipe After TCO7D 


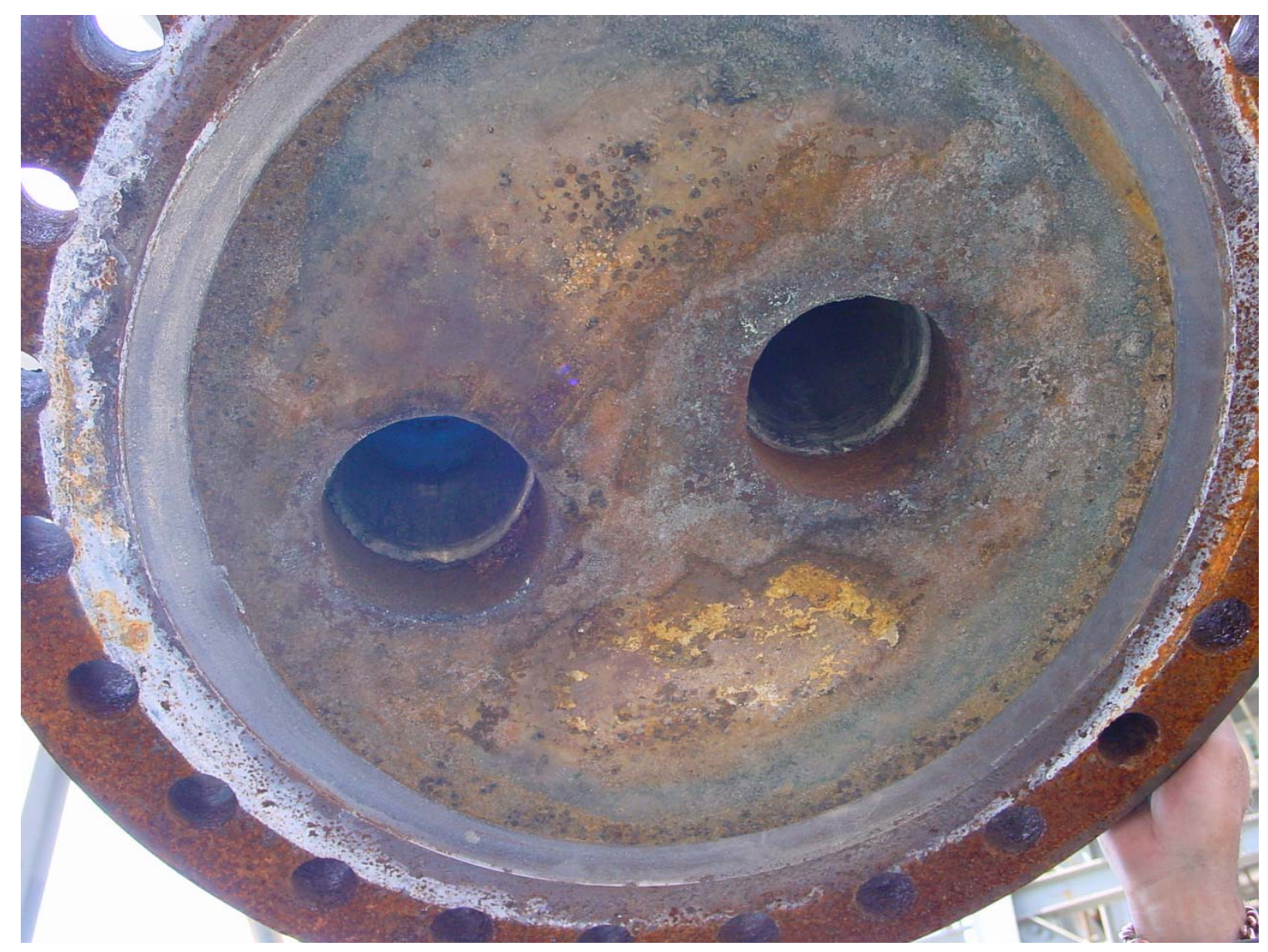

Figure 3.3-29 Nozzle 13 Flange After TCO7D 


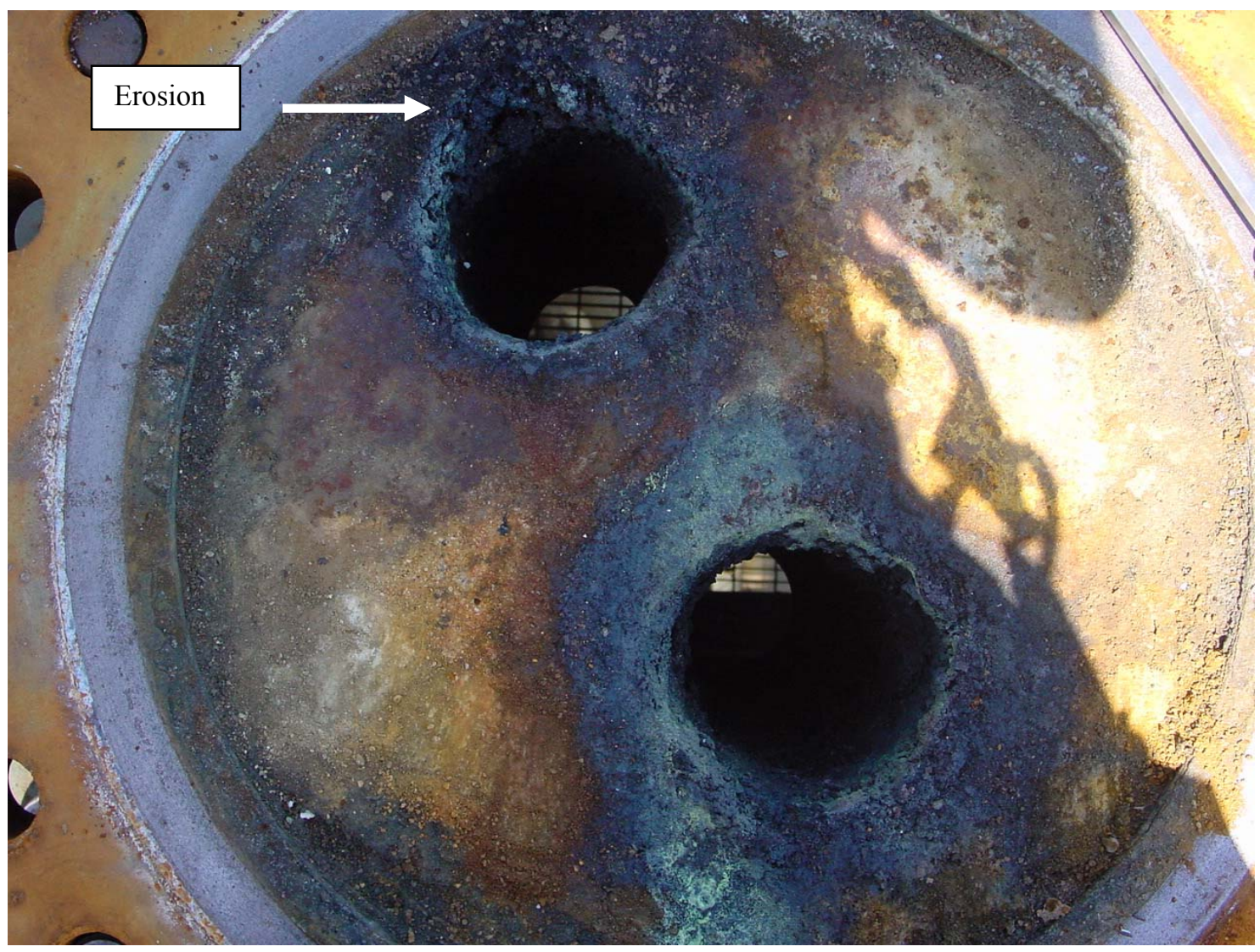

Figure 3.3-30 Nozzle 13 Refractory Erosion 


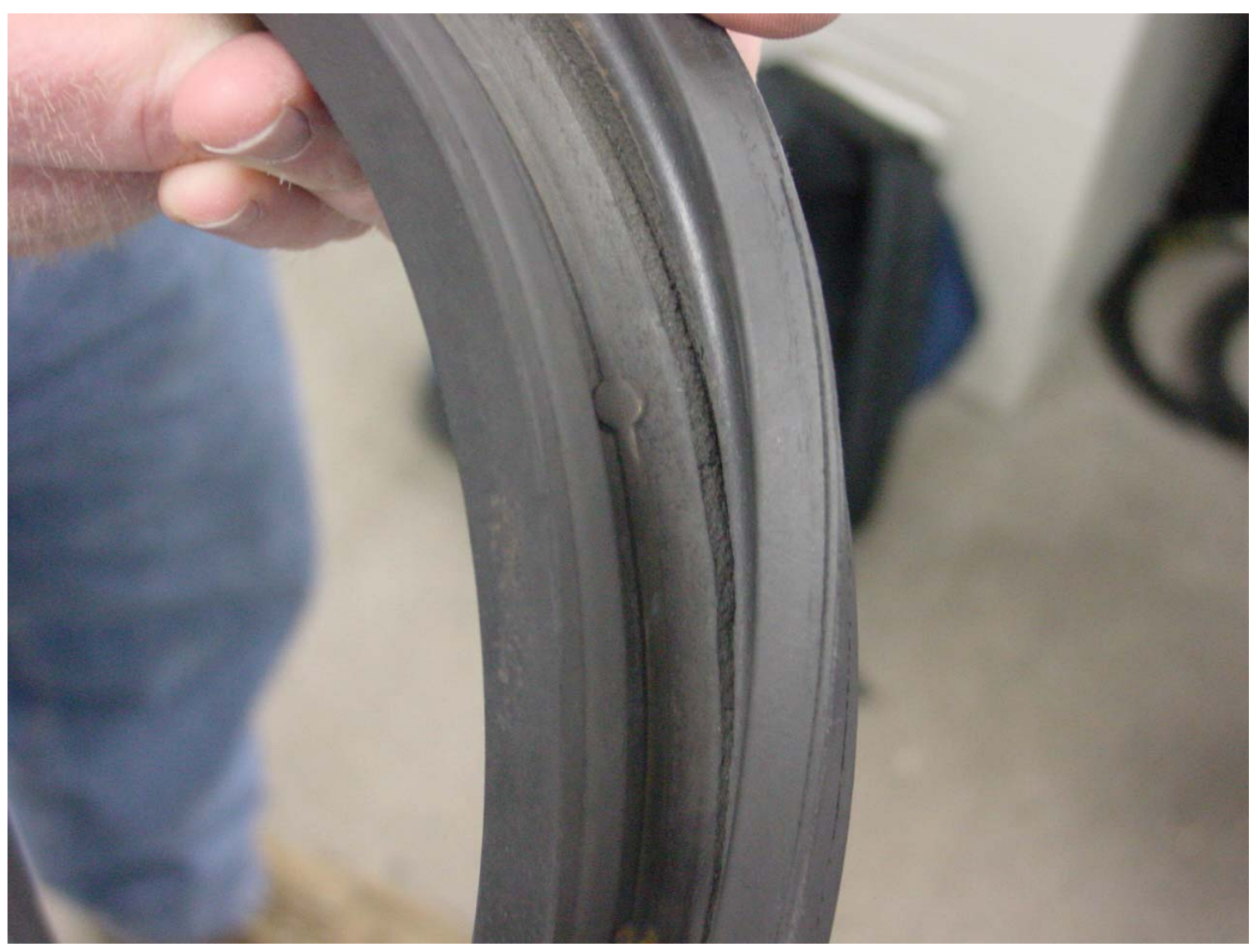

Figure 3.3-31 Cracked Spheri Valve Seal After TC07D 


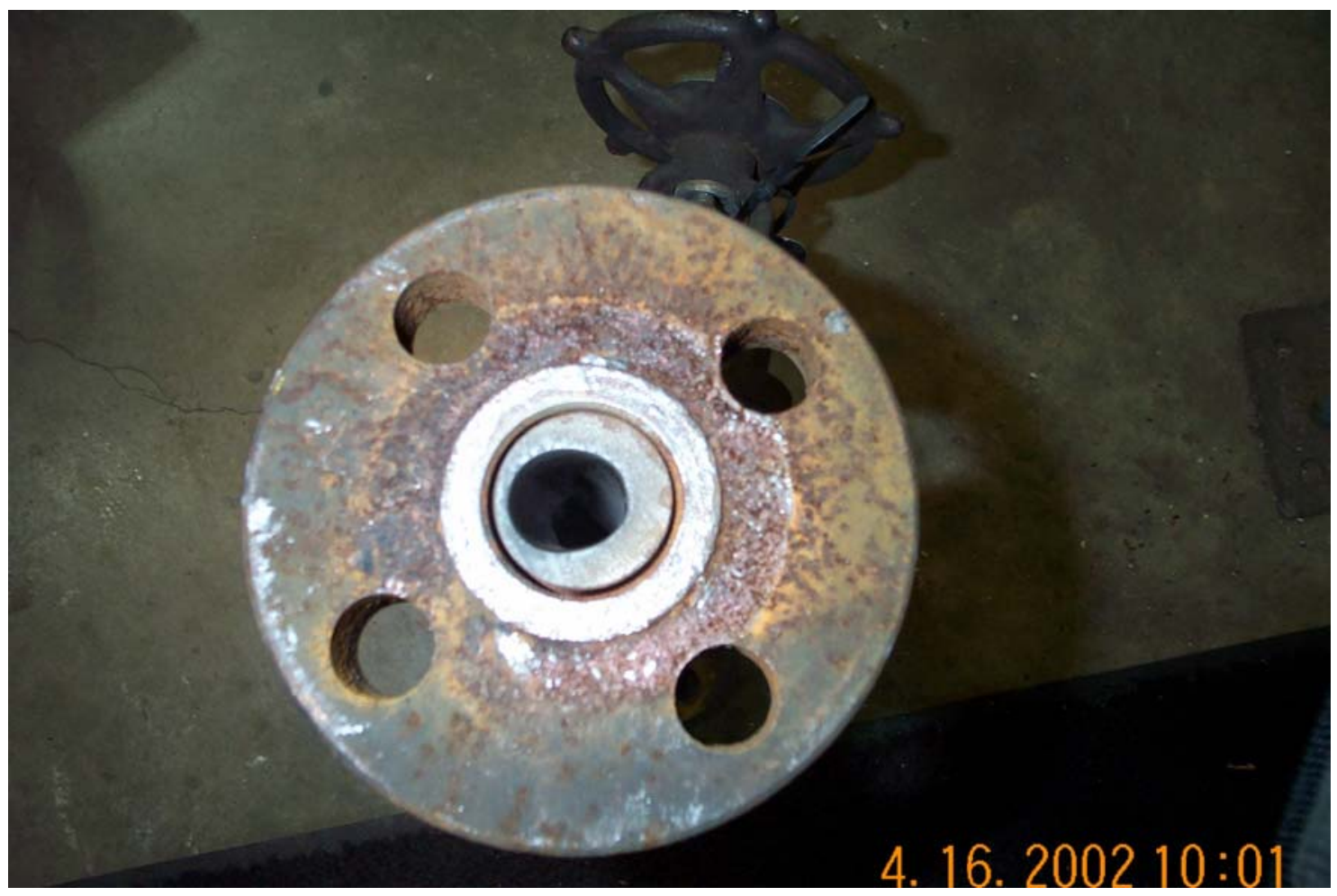

Figure 3.3-32 Erosion of FD0520 Vent Line After TCO7D 


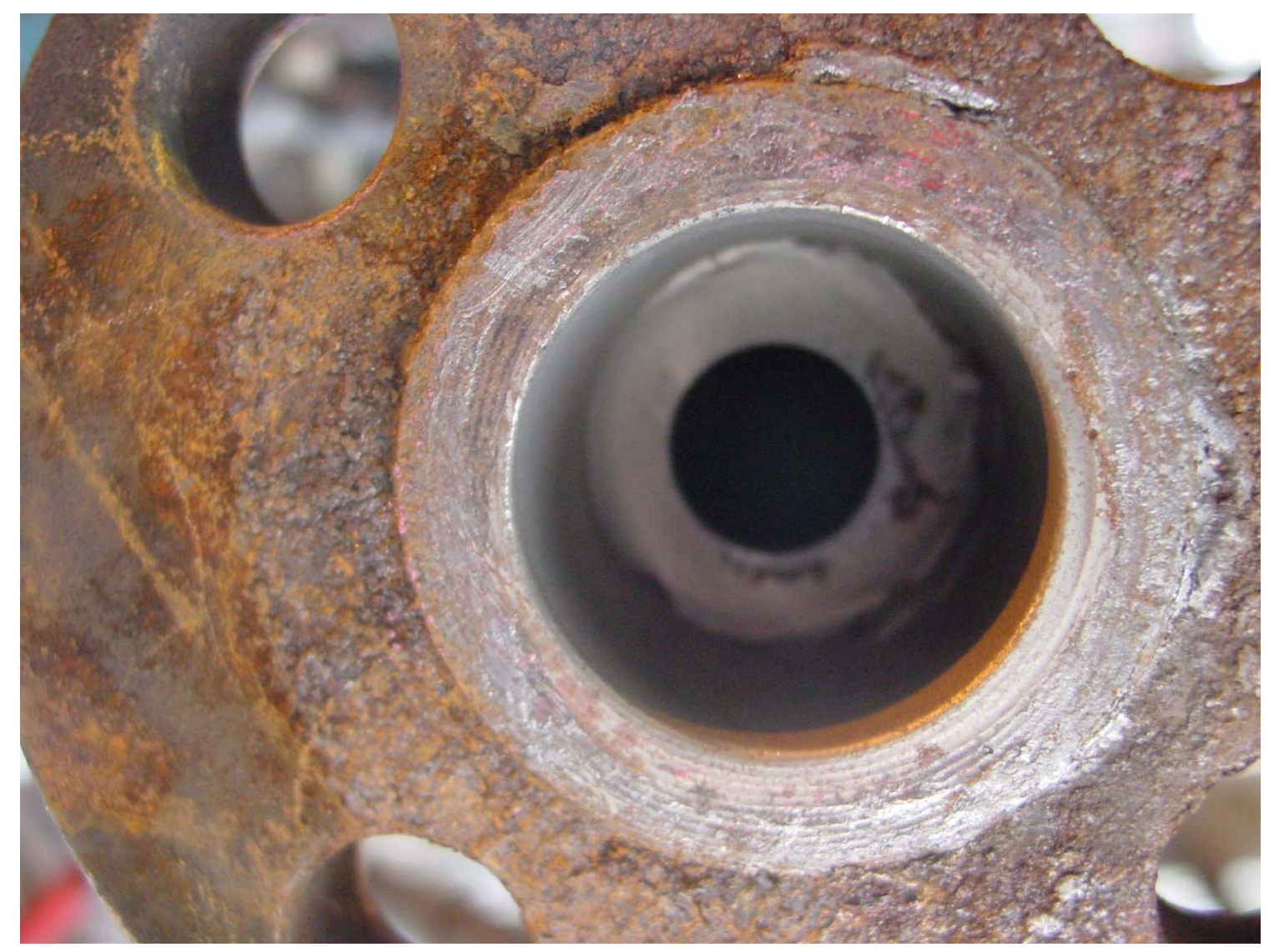

Figure 3.3-33 FD0520 Vent-Line Flange 
POWER SYSTEMS DEVELOPMENT FACILITY

PARTICLE FILTER SYSTEM

TEST CAMPAIGN TCO7

TCO7 G-ASH CHARACTERISTICS AND PCD PERFORMANCE

\subsection{TCO7 GASIFICATION ASH CHARACTERISTICS AND PCD PERFORMANCE}

This section deals with the characteristics of the g-ash produced during TC07 and the relationship between the g-ash characteristics and PCD performance. As in previous tests, in situ g-ash samples and dustcake samples from TC07 were thoroughly characterized in an effort to better understand the effects of the $g$-ash characteristics on filter pressure drop $(\Delta \mathrm{P})$ and the formation of bridged deposits. Characterization of the in situ g-ash samples, dustcake samples, and bridged deposits included measurements of the true particle density, bulk density, uncompacted bulk porosity, and specific-surface area; chemical analyses; particle-size analyses; and laboratory drag measurements. As in the previous gasification tests, drag measurements were made using the resuspended ash permeability tester (RAPTOR) as modified to allow measurements as a function of particle size. As in previous tests, the RAPTOR drag measurements were compared to transient drag values determined from PCD performance data. The results were used to better understand the contribution of the dustcake to PCD $\triangle \mathrm{P}$ and to gain insight into the effect of particle size and morphology on drag.

The TC07 test campaign was split into four test segments designated TC07A, B, C, and D. TC07A was a sand-circulation test to evaluate the solids flow in the Transport Reactor system with the new LMZ in place. TC07B primarily involved commissioning of the new LMZ with PRB coal feed with no steam addition. At the end of TC07B, we transitioned from PRB coal feed to Alabama bituminous coal feed in preparation for the next test segment, TC07C.

In TC07C, Alabama bituminous coal was fed to the Transport Reactor with steam addition. Gasifier operation during TC07C was largely unstable, and the bottom plenum of the PCD became completely plugged with bridged g-ash deposits. Particulate leakage through the PCD was also detected during TC07C, and two broken filter elements were found during the subsequent PCD inspection. As discussed in the section on PCD operations, the filter elements apparently failed after the bridging incident and after a series of high-frequency back-pulses that resulted from a thermal event coupled with an error in the back-pulse control logic.

The final test segment, TC07D, was characterized by much more stable operation of the gasifier on PRB coal with steam addition. There was no particulate leakage through the PCD during TC07D, and no bridged deposits were found in the PCD after TC07D.

\subsubsection{In situ Sampling}

The system and procedures used for the in situ particulate sampling have been described in previous reports. No in situ samples were collected at either the PCD inlet or outlet during TC07A, since this run was just a sand-circulation test. Four inlet samples and four outlet samples were collected during TC07B. During TC07C, three outlet samples were collected. No inlet sampling was done, because of the unstable gasifier operation, and because much of the run was done with coke feed. (After detecting significant particulate leakage through the 
PCD, coke feed was used in lieu of coal feed for the remainder of TC07C to minimize the amount of dust reaching the clean side. These leaks were repaired between TC07C and TC07D.) During TC07D, which provided the most stable operating conditions, the sampling included seven inlet runs and nine outlet runs.

\subsubsection{PCD Inlet Particle Mass Concentrations}

Table 3.4-1 gives a summary of the particulate loadings measured at the PCD inlet and outlet during TC07. Excluding one run that was high due to iron injection, the inlet loadings varied from about 14,000 to $21,000 \mathrm{ppmw}$, with an overall average of about 16,000 ppmw and a standard deviation of about $2,500 \mathrm{ppmw}$ (coefficient of variation of 0.16 ). This average value was very close to the average mass loading measured during TC06. After excluding the runs done with low coal feed and with coke feed, the average inlet mass loading for TC06 was 15,700 ppmw with a standard deviation of 1,700 ppmw (coefficient of variation of 0.11). Therefore, the inlet particulate loadings measured during TC07 are essentially in the same range as those measured during TC06. The only exception (Run No. 12) was a loading of 33,100 ppmw, which was measured during the injection of iron for additional capture of $\mathrm{H}_{2} \mathrm{~S}$. As discussed later, chemical analysis of this sample confirmed that the higher mass loading was attributable to the presence of the iron. As noted in the table, iron injection was also attempted during Run No. 11, but it was not successful, and the chemical analysis confirmed that there was no additional iron in the sample. Therefore, Run No. 11 was included with the other runs in calculating the average inlet g-ash loading. It should also be noted that Run No. 6 was included in the calculation of the average loading. The limestone feed was discontinued during this run, but the measured loading still appeared to be consistent with the other runs.

\subsubsection{PCD Outlet Particle Mass Concentrations}

Table 3.4-1 also shows the particle concentrations measured at the outlet of the PCD along with the PCD collection efficiency calculated from the corresponding inlet and outlet measurements. Figure 3.4-1 compares the TC07 outlet loadings with those measured in GCT4 and TC06. The lower dashed line on the graph indicates the lower limit of detection, which is currently about $0.1 \mathrm{ppmw}$. The lower limit is a function of the sampling time interval, and the current limit is based on a nominal sampling time of 4 hours. The upper dashed line at $1 \mathrm{ppmw}$ is included to guide the eye and does not necessarily indicate an acceptable emissions limit. The acceptable emissions limit is a function of the specifications on downstream equipment (e.g., gas turbine, fuel cell, gas separation membrane, etc.). These specifications vary from one supplier to another.

As shown in Figure 3.4-1, there were only two instances of elevated outlet loadings during the two runs that preceded TC07. As indicated on the graph, the high loading that occurred during GCT4 was caused by tar contamination, and the single elevated loading that was detected during TC06 was caused by a PCD thermal transient that resulted in a cracked filter element. With these two exceptions, the outlet particulate loading remained below the current detection limit $(<0.1 \mathrm{ppmw})$ throughout GCT4 and TC06. 
During TC07, on the other hand, the measured outlet particulate loading exceeded the detection limit eight times. As indicated on the graph, two of the high outlet loadings were caused by the filter elements that cracked in TC07C. Inspection of the sampling filters from these two runs confirmed the presence of fine g-ash particles that had leaked through the PCD. Some of these fine g-ash particles were also present in the sample collected the day before the elements cracked and in the first sample collected after the cracked elements were replaced. The latter sample was apparently affected by reentrainment of fine g-ash particles that had leaked through the PCD previously. No satisfactory explanation has been found for the elevated particulate loading that was measured the day before the filter elements failed. We do not believe that the cracks in the elements were starting to develop at that time, because the real-time particulate monitor showed that the loading returned to the lower detection limit after this sampling run and before the bridging incident occurred.

The sampling filters from the other runs that exceeded the particulate detection limit (runs 2, 4 , and 13) contained mostly large $(>100-\mu \mathrm{m})$ particles with very few particles smaller than $10 \mu \mathrm{m}$. This result suggests that these particles did not come from a PCD leak. Microscopic examination showed that these particles were not refractory or metallic scale; their appearance was similar to that of coal or $g$-ash particles. In an effort to determine where these large particles came from, some of the particles were removed from the sampling filter and burned in a muffle furnace in air. The ash residue that remained after this treatment was very similar to the residues produced by burning coal or g-ash particles in the same manner, suggesting that the large particles contain some inorganic components (mineral matter) in addition to carbonaceous material. The residue from the large particles was distinctly different from the residue that was produced by burning solidified tar that was scraped from the PCD back-pulse pipes. This suggests that the large particles are not solidified tar. In addition to this evidence, the irregular, angular shape of the large particles suggests that they are not solidified or condensed tar droplets, since such droplets would be more or less spherical.

As shown in the graph of the outlet loadings, the problem with the large particles seemed to clear up at the end of TC07, with the last four runs giving loadings below the detection limit. This result suggests that the large particles may have come from reentrainment of material that was deposited somewhere on the clean side of the PCD or in the process piping between the PCD and the outlet sampling system. Since there was no evidence of reentrainment during the last 4 days of the run, it was hoped that the problem would not reoccur in the future. Nevertheless, some effort was made to remove potential sources of material that could be reentrained. Loose dust and deposits that were present on the clean side of the PCD head were removed by vacuuming, and the tar deposits were cleaned off the PCD back-pulse pipes. We thought that these procedures would be sufficient to eliminate the source of the large-particle contamination, so no further effort was made to remove any deposits that may have been present in the process piping downstream from the PCD.

\subsubsection{Syngas Moisture Content}

As in previous tests, measurements of the syngas moisture content were made in conjunction with the outlet particulate sampling runs. The water vapor content of the 
syngas was determined by collecting the condensate from the syngas in an ice-bath condenser and calculating the vapor concentration from the volume of gas sampled and the volume of condensate collected. The values determined for individual runs are included in Table 3.4-1. The data obtained in TC07B with PRB coal and no steam addition showed an average syngas moisture value of 6.8 percent by volume, with a standard deviation of 0.6 percent (coefficient of variation of 0.09 ). Moisture values measured with the same coal with steam addition in TC07D varied with the rate of steam addition as expected. The average syngas moisture content during TC07D was 9.2 percent by volume, with a standard deviation of 3.2 percent (coefficient of variation of 0.35 ). Thus, it is clear that the steam injection increased the syngas moisture content substantially. In the section on Transport Reactor operations, the manual moisture measurements are compared to moisture data obtained from on-line instrumentation.

\subsubsection{Real-Time Particle Monitoring}

Evaluation of the PCME Dustalert 90 as a real-time particulate monitor for measuring PCD outlet emissions was continued during TC07. No calibration tests of the PCME were conducted with injected dust as during TC06, but four episodes of elevated outlet dust concentrations occurred where in situ measurements were obtained for comparison with the output of the PCME.

Figure 3.4-2 shows the response of the PCME during startup at the beginning of TC07C. The narrow, red trace shows the real-time response of the instrument while the solid blue trace is a 5-minute rolling average of the PCME output. The spikes on the real-time trace are associated with back-pulsing of the PCD. Also marked on the graph is a solid horizontal arrow indicating the time period of the in situ particle measurement (outlet run 5) along with the actual measured concentration. The average PCME output was 2.3 percent during the period that the in situ measurement indicated a value of $1.4 \mathrm{ppmw}$. The PCME response also showed that the elevated outlet loading was transient in nature, with the response returning to the lower detection limit prior to the candle failures that occurred the next day. In this particular case, the initial response corresponded to the start of coke feed and an increase in the gas flow rate. It is not known whether these process changes played a role in the PCME response. In any case, the transient nature of the response suggests that the element was not starting to crack at this time, or, if it was, that the failsafe plugged temporarily (which seems unlikely).

As shown in Figure 3.4-3, the PCME responded strongly when the filter elements failed on February 8, 2002. The response of the PCME suggests that initially the outlet particle loading may have been even higher than the concentrations that were measured in the subsequent particulate sampling runs (about 20 ppmw and then about 35 ppmw 3 hours later). During the in situ measurements the average PCME response ranged from 35 to 40 percent. Coal was not being fed at the time of the filter failure or emissions would likely have been higher.

After the broken filter elements were replaced, and as the system was being restarted in TC07D, another transient PCME response was recorded as shown in Figure 3.4-4. This 
transient response looks somewhat different from Figure 3.4-2, because the PCME response on March 23, 2002, appears to be related to fluctuations in gas flow rate. We suspect that this particular transient was caused by reentrainment of particles that had leaked through the PCD in TC07C when the filter elements were broken. The following day, the PCME reading was still slightly elevated (average of 1.1 percent) with a measured concentration of 0.3 ppmw. By the third day the measured concentration was below the resolution limit.

When the measured particulate loading was below the lower detection limit $(<0.1 \mathrm{ppmw})$, the output signal from the PCME monitor generally averaged less than 0.3 percent of full scale with small back-pulse spikes as shown in Figure 3.4-5. During the periods of time that large particles were found contaminating the in situ filter samples (outlet runs 2, 4, and 13), the PCME monitor did not respond with an elevated output. This is presumably because the number concentration of these large particles was too low or because the large particles dropped out before they reached the PCME.

The responses of the PCME monitor during the four episodes of elevated emissions are plotted along with the TC06 data in Figure 3.4-6. The plot compares the measured particle mass concentration to the average value of the PCME monitor output. Since the PCME signal is a function of the particulate mass flow rate (as opposed to the particulate mass concentration), all of the measured particulate concentrations have been normalized to a syngas flow rate of $25,000 \mathrm{lb} / \mathrm{hr}$. Because the average value includes the back-pulse spikes, all of the data were also normalized to a 5-minute back-pulse time. The resulting plot shows a very good correlation between measured mass concentration and PCME response $\left(\mathrm{r}^{2}=\right.$ 0.93), suggesting that the PCME monitor has good potential as a particulate mass monitor for concentrations above about 0.5 ppmw.

The PCME percent output values shown in this report are somewhat different than the values previously shown in Figure 3.4-9 of the TC06 report. In the analysis of the TC06 data, the back-pulse spikes were excluded from the PCME output and only the average of the values between the back-pulses was used. However, we have since come to believe that the elevation of the back-pulse spikes is the most sensitive indication of particles in the outlet duct and should not be ignored. The correlation between the PCME output and the actual particle concentration is also improved (at least thus far) by using an average that includes the back-pulse spikes. We will continue to study this issue in the analysis of future data.

\subsubsection{Sampling of PCD Dustcakes and Consolidated Deposits}

Since the PCD was not opened after TC07A or B, there were no dustcake measurements or samples from those runs. During TC07C, the bottom plenum became completely plugged with bridged g-ash deposits, so most of the gas flow was going through the top plenum. Because of this situation, it was decided that measurements of the dustcake thickness and areal loading would not be meaningful, and none of those measurements were made. Nevertheless, dustcake samples and samples of bridged deposits were collected after TC07C. Over $600 \mathrm{lb}$ of g-ash was recovered from the bridged deposit in the lower plenum. 
There was no bridging during TC07D, and extremely thin residual dustcakes were observed on both the top and bottom plenums during the PCD inspection. The dustcake appeared to consist of a light-gray outer layer and a darker inner layer. The lighter-colored outer layer appeared to be partially oxidized g-ash that resulted from an oxygen excursion during the TC07D shutdown. In view of the oxygen excursion and the apparent oxidation of the dustcake, it was again decided that measurements of the dustcake thickness and areal loading would not be meaningful, but samples of the residual dustcake were collected. As discussed later, chemical analysis of the TC07-D residual dustcake confirmed that it had been partially oxidized.

\subsubsection{Physical Properties of In situ Samples and Dustcakes}

The TC07 in situ particulate samples and dustcake samples were subjected to the standard suite of physical measurements, including: true (skeletal) particle density, bulk density, uncompacted bulk porosity, specific-surface area, and particle-size analysis. The instruments and procedures used for making these measurements have been described in previous reports.

\subsubsection{In situ Particulate Samples}

Physical properties of the in situ particulate samples from TC07B and D are presented in detail in Table 3.4-2, and the following table compares the average in situ physical properties for these test segments with the properties of the TC06 g-ash. (Again, no in situ samples were collected during TC07A and TC07C.) The averages for TC07B and D exclude the runs that were done during unusual limestone feed conditions and during iron injection, as noted in Table 3.4-2.

\begin{tabular}{|l|c|c|c|}
\cline { 2 - 4 } \multicolumn{1}{c|}{} & TC07B & TC07D & TC06 \\
\hline Bulk density, g/cc & 0.32 & 0.32 & 0.29 \\
\hline Skeletal particle density, g/cc & 2.57 & 2.47 & 2.45 \\
\hline Uncompacted bulk porosity, \% & 87.7 & 86.9 & 88.2 \\
\hline Specific-surface area, $\mathrm{m}^{2} / \mathrm{g}$ & 179 & 170 & 222 \\
\hline Mass-median diameter, $\mu \mathrm{m}$ & 16 & 17 & 15 \\
\hline
\end{tabular}

Based on the above comparison, the g-ash produced in TC07B and D appears to have slightly less surface area and slightly lower bulk porosity than does the TC06 g-ash. These differences are relatively minor and would not be expected to produce a significant difference in flow resistance (drag). Despite the similar physical properties of the TC06 and TC07 g-ashes, there is a significant difference in the flow resistance (drag) as shown in both laboratory drag measurements and transient drag values calculated from the PCD $\triangle \mathrm{P}$ rise. 
This difference in drag and the effects of physical properties on drag are discussed in more detail in Sections 3.4.6 and 3.4.7.

\subsubsection{Dustcake Samples}

The physical properties of the residual dustcake samples and bridged deposits from TC07C and $\mathrm{D}$ are compiled in Table 3.4-3, and the average properties of the various TC07C and D samples are compared to those from TC06B in the table below. (Again, the PCD was not opened after TC07A and B, so no dustcake samples were available from those runs.) The TC07C residual dustcake may have been affected by the coke breeze feed that was used after the outlet particulate measurements showed that the PCD was leaking. Also, as mentioned earlier, the TC07D dustcake was apparently altered by partial oxidation due to an oxygen transient that occurred during shutdown. The TC06A dustcake is not included in the comparison, because it too was altered by partial oxidation as discussed in the TC06 report.

\begin{tabular}{|l|c|c|c|c|c|}
\cline { 2 - 6 } \multicolumn{1}{c|}{} & \multicolumn{3}{c|}{ Residual Dustcake } & \multicolumn{2}{c|}{ Bridged G-ash } \\
\cline { 2 - 6 } \multicolumn{1}{c|}{} & TC07C & TC07D & TC06B & TC07C & TC06B \\
\hline Sample notes & Coke Feed & $\begin{array}{c}\text { Partially } \\
\text { Oxidized }\end{array}$ & \multicolumn{3}{c|}{ Representative Samples } \\
\hline Bulk density, g/cc & 0.33 & 0.40 & 0.25 & 0.29 & 0.27 \\
\hline Skeletal particle density, g/cc & 2.28 & 3.00 & 2.28 & 2.14 & 2.41 \\
\hline Uncompacted bulk porosity, \% & 85.5 & 86.9 & 89.0 & 86.6 & 88.8 \\
\hline Specific-surface area, $\mathrm{m}^{2} / \mathrm{g}$ & 40 & 57 & 257 & 83 & 260 \\
\hline Mass-median diameter, $\mu \mathrm{m}$ & 12 & 7 & 9 & 22 & 11 \\
\hline
\end{tabular}

Again, the TC07C residual dustcake may not be representative of bituminous coal, since the latter portion of the TC07C run (after the bridging and candle failures) was done with coke breeze feed. Since the bridged deposits were apparently formed before the coke feed was initiated, the bridged deposits should be representative of bituminous-coal operation. This may explain some of the observed differences between the TC07C residual dustcake and bridged deposits. The differences between the TC07C and TC06 samples reflect various differences between bituminous and PRB g-ashes and cannot be used to infer anything about the effect of the new LMZ on properties. The most appropriate comparison of dustcake properties is between TC07D and TC06B. However, the TC07D dustcake was altered by partial oxidation. This explains why the TC07D dustcake has much less surface area and lower bulk porosity than does the TC06B dustcake. 


\subsubsection{Chemical Composition of In situ Samples and Dustcakes}

The TC07 in situ particulate samples and dustcake samples were analyzed for carbon, hydrogen, sulfur, nitrogen, ash, and $\mathrm{CO}_{2}$ content. For all of the samples, hydrogen and nitrogen were below about $0.5 \mathrm{wt}$ percent and were ignored in the calculation of the bulk chemical composition. The $\mathrm{CaCO}_{3}$ content was calculated assuming that all of the $\mathrm{CO}_{2}$ originated from $\mathrm{CaCO}_{3}$. CaS content was calculated assuming that all of the sulfur was present as $\mathrm{CaS}$. Any remaining calcium was assumed to be free lime $(\mathrm{CaO})$. All carbon not accounted for in $\mathrm{CaCO}_{3}$ was assumed to be present as elemental (noncarbonate) carbon. The balance was assumed to be inerts (ash and sand). The justification for the assumptions used in these calculations are discussed in detail in previous reports and will not be duplicated here.

\subsubsection{In situ Particulate Samples}

As discussed previously, no in situ samples were collected at the PCD inlet during the TC07A sand circulation run or during the TC07C run on bituminous coal. The in situ samples from the TC07B run on PRB coal were not obtained under steady-state conditions. Therefore, only the in situ samples from TC07D were analyzed. The chemical composition of the TC07D in situ samples is presented in detail in Table 3.4-4, and the table below compares the composition with that of the TC06 g-ash. Again, both of these g-ashes were produced from air-blown gasification of PRB coal with Ohio (Bucyrus) limestone. The average values given below exclude the runs with unusual limestone feed and with iron injection, as noted in Table 3.4-4.

\begin{tabular}{|l|c|c|}
\cline { 2 - 3 } \multicolumn{1}{c|}{} & TCO7D & TCO6 \\
\hline CaCO $_{3}$, Wt \% & 9.1 & 8.8 \\
\hline CaS, Wt \% & 0.1 & 1.3 \\
\hline Free Lime (CaO), Wt \% & 20.3 & 19.6 \\
\hline Noncarbonate Carbon, Wt \% & 24.2 & 32.0 \\
\hline Inerts (Ash/Sand), Wt \% & 46.3 & 38.3 \\
\hline
\end{tabular}

In terms of bulk composition, the g-ash produced in TC07D contains significantly less g-ash carbon, possibly reflecting an improvement in carbon conversion in the gasifier or an increased carryover of bed material. Chemical analysis of the ignited g-ashes did not reveal any significant difference in silica content, suggesting that the difference is not attributable to sand carryover. This result suggests that the difference in noncarbonate (elemental) carbon content is indeed related to improved carbon conversion. 
The TC07D g-ash also contains an unusually low amount of CaS (average of only 0.1-wt percent, excluding the runs with unusual limestone feed conditions and with iron injection). This CaS concentration seems unreasonably low, and significantly higher CaS concentrations were obtained for some of the excluded runs. If all of the TC07D runs are included, the average $\mathrm{CaS}$ content is increased to 0.6 -wt percent. If only the runs with high limestone feed are considered, the average is further increased to 1.4-wt percent, which is close to the average for TC06 (1.3-wt percent). These trends suggest that perhaps the low values of CaS are related to low limestone feed rate, but the concentrations of the other sorbent components $\left(\mathrm{CaCO}_{3}\right.$ and $\left.\mathrm{CaO}\right)$ are similar to the average values for the TC06 g-ash.

Although the reason for the unusually low CaS during some of the TC07D runs is unknown, results from previous tests suggest that these low values are not representative for PRB gash. In any case, the highest CaS content of any of the TC07 and TC06 g-ash samples was only 1.9 percent, so it seems unlikely that the $\mathrm{CaS}$ content had any significant affect on the flow resistance of the g-ash.

It is conceivable, however, that the drag of the g-ash could be affected by the observed difference in noncarbonate carbon content (24-wt percent in TC07 versus 32 -wt percent in TC06). As mentioned previously, this difference apparently reflects an improvement in carbon conversion, possibly related to the installation of the new LMZ. With the installation of the new LMZ, the locations for air and steam injection were changed. These changes apparently resulted in improved carbon conversion and changed the characteristics of the gash in such a way that drag was reduced, although the change in g-ash characteristics is not evident in any of the measured physical properties (surface area, particle-size distribution, porosity, etc.). Again, this comment applies to the comparison of the PRB g-ashes from TC06 and TC07D as no in situ samples were obtained with the bituminous coal. The difference in the drag of the PRB g-ash between TC06 and TC07 and the relationship between drag and g-ash characteristics are discussed in more detail in Sections 3.4.6 and 3.4.7.

\subsubsection{Dustcake Samples}

The chemical compositions of the residual dustcake samples and bridged deposits from TC07C and D are compiled in Table 3.4-5, and the average properties of the various TC07C and D samples are compared to those from TC06B in the table below. Data on the TC06A dustcake is not included, because it was altered by partial oxidation as discussed in the TC06 report. Also, the TC07D dustcake was affected by the oxygen transient and partial oxidation that occurred during the TC07 shutdown, as mentioned earlier. Despite these problems, it is interesting to compare the chemical compositions to better understand the biases introduced by the coke feed and by the partial oxidation of the residual cake.

Since the TC07C samples were produced from a different coal, the most appropriate comparison of dustcake properties would be between TC07D and TC06B. This comparison shows that the TC07D dustcake contains much less noncarbonate carbon than does the TC06B dustcake, but, again, this is probably the result of the partial oxidation that took place during the TC07D shutdown. 


\begin{tabular}{|l|c|c|c|c|c|}
\cline { 2 - 6 } \multicolumn{1}{c|}{} & \multicolumn{3}{c|}{ Residual Dustcake } & \multicolumn{2}{c|}{ Bridged G-ash } \\
\cline { 2 - 6 } \multicolumn{1}{c|}{} & TC07C & TC07D & TC06B & TC07C & TC06B \\
\hline Sample notes & Coke Feed & $\begin{array}{c}\text { Partially } \\
\text { Oxidized }\end{array}$ & \multicolumn{2}{c|}{ Representative Samples } \\
\hline CaCO 3 , Wt \% & 1.1 & 5.6 & 13.4 & 0.7 & 13.8 \\
\hline CaS, Wt \% & 1.9 & 1.0 & 1.8 & 2.2 & 1.8 \\
\hline Free Lime (CaO), Wt \% & 1.1 & 17.0 & 10.5 & 0 & 15.4 \\
\hline Noncarbonate Carbon, Wt \% & 49.7 & 14.9 & 40.1 & 60.4 & 32.5 \\
\hline Inerts (Ash/Sand), Wt \% & 46.1 & 61.5 & 34.2 & 36.7 & 36.5 \\
\hline
\end{tabular}

The compositions of the $\mathrm{TC} 07 \mathrm{C}$ dustcakes and deposits produced from the Alabama bituminous coal show interesting differences between the residual dustcake and the bridged deposits. The bridged deposit contains more g-ash carbon than does the residual dustcake (60- versus 50-wt percent). Part of this difference may be related to the difference between bituminous and PRB g-ash, and part of the difference may be attributable to the use of coke breeze during the latter part of TC07C. In situ samples collected during coke breeze feed in TC06 showed that the carbon content was in the range of 60- to 70-wt percent. One other possible explanation is that the bridging occurred during a period when the carbon conversion was relatively low. During such a period of low carbon conversion, the additional carryover of carbon would result in an increase in the total amount of solids reaching the filter, which could be a contributing factor in the bridging.

It is also interesting that the TC07C dustcake and bridged deposit from the bituminous coal contain more noncarbonate carbon than does the TC06 dustcake from the PRB coal (50- to 60 -wt percent versus 32- to 40 -wt percent). This suggests better carbon conversion with the PRB coal than with the bituminous coal. This result is consistent with the relative reactivities of these coal types. As suggested above, the lower carbon conversion may also imply increased solids carryover and less efficient cracking of tars with the bituminous coal. Both the increased solids carryover and the less efficient tar cracking could be factors in the tendency of the bituminous g-ash to form bridged deposits.

\subsubsection{Particle-Size Analysis of In situ Samples}

Figure 3.4-7 shows the particle-size distributions of the TC07 in situ g-ash samples as measured using a Microtrac X-100 Particle-Size Analyzer. All of the measured size distributions were reasonably consistent, with the exception of Run No. 12, which showed a substantial increase in the concentration of particles smaller than about $50 \mu \mathrm{m}$. Run No. 12 
was done during iron injection for capture of $\mathrm{H}_{2} \mathrm{~S}$, and the chemical analysis of this sample showed that the increased particle concentration was attributable to the added iron.

Figure 3.4-8 compares the average particle-size distribution of the TC07 in situ g-ash samples with those from TC06, GCT4, GCT3, and GCT2. All of these samples were generated from air-blown gasification of PRB coal with Ohio (Bucyrus) limestone added for sulfur capture. This comparison reveals considerable similarity in the particle-size distributions from all of the runs, except for GCT2. Between GCT2 and 3, the recycle loop was modified to improve the solids retention and carbon conversion in the Transport Reactor system. As discussed in previous reports, this modification reduced the particle concentrations across almost the entire range of particle sizes, with the biggest reduction occurring in the large particles $(>10 \mu \mathrm{m})$. Between TC06 and TC07, the new LMZ was installed in the Transport Reactor in preparation for oxygen-blown operation, but this modification apparently did not have any appreciable effect on the particle-size distribution of the g-ash. As mentioned previously, there were no significant differences in any of the other physical properties of the PRB g-ashes from TC06 and TC07. Nevertheless, there was a significant difference in flow resistance (drag) as discussed below.

\subsubsection{Laboratory Measurements of Gasification Ash Drag}

As in previous tests, the drag of the TC07 g-ash was measured as a function of particle size using the RAPTOR system with various combinations of cyclones to adjust the particle-size distribution reaching the filter. Measurements were made on a sample of the PCD hopper g-ash from TC07D and a sample of the bridged bituminous g-ash from TC07C. The measured drag as a function of particle size is shown in Figure 3.4-9. As shown in this graph, the data for the PRB g-ash from TC07D and for the bituminous g-ash from TC07C fall on distinctly different trend lines. It is interesting that the trend line for the bituminous $\mathrm{g}$-ash data has a steeper slope than the trend line for the PRB g-ash data, suggesting that the drag of the bituminous $g$-ash is more sensitive to particle size than is the drag of the PRB gash. It is interesting that the difference in slope is apparently not related to differences in surface area, since all of the bituminous g-ash size fractions have lower surface areas than do the PRB g-ash size fractions. This result implies that the effect of an upstream cyclone or other precollector on the performance of a hot-gas filter may depend on the type of g-ash being collected.

It is also interesting to compare the TC07D g-ash to the other PRB g-ashes generated in prior gasification tests. As shown in Figure 3.4-9, this comparison shows that the TC07D gash has a lower drag than do the PRB g-ashes from TC06, GCT3, and GCT4. All of these runs were done with PRB coal and Ohio (Bucyrus) limestone after the Transport Reactor recycle loop was modified to improve solids retention and carbon conversion. The drag of the TC07D g-ash is still higher than that of the GCT2 g-ash, which was generated before the recycle loop modifications. Again, all of these runs were performed with the same PRB coal and the same Ohio limestone, and the Transport Reactor was operated in air-blown gasification mode during all tests. The only significant changes in the Transport Reactor system were the modification of the recycle loop between GCT2 and GCT3 and the 
installation of the new LMZ between TC06 and TC07. Both of these changes had a significant effect on drag as illustrated in Figure 3.4-9.

The increase in drag after GCT2 has been explained in previous reports in terms of a change in the g-ash surface area and morphology that was apparently caused by the improved recycle. This change was evident in the specific-surface areas measured by the BET technique. For the GCT2 g-ash, the specific-surface area was in the range of 50 to $60 \mathrm{~m}^{2} / \mathrm{g}$; while the g-ashes from GCT3, GCT4, and TC06 had specific-surface areas in the range of 150 to $250 \mathrm{~m}^{2} / \mathrm{g}$. This clearly indicates a substantial change in morphology and/or pore structure that could explain the observed change in drag.

Unfortunately, the decrease in drag that was observed between TC06 and TC07 cannot be explained by a change in specific-surface area. Both the TC06 and TC07D g-ashes had specific-surface areas in the same range, about 150 to $250 \mathrm{~m}^{2} / \mathrm{g}$. Again, the dustcake samples show differences, but this may be related to the partial oxidation of the TC07 dustcake. The particle-size distributions of the RAPTOR filter catches were also similar, and SEM examination of the $\mathrm{g}$-ashes failed to provide a definitive distinction between the TC06 and TC07D samples.

In comparing the PRB g-ashes from TC06 and TC07, the only significant difference that has been identified to date is in the chemical composition. As mentioned earlier, the TC07D gash contained about 24-wt percent noncarbonate carbon on average; while the TC06 g-ash contained about 32-wt percent noncarbonate carbon. This difference apparently reflects a change in the carbon conversion associated with the installation of the new LMZ. With the new LMZ installation, there was a change in the locations where air and steam were introduced into the Transport Reactor loop. This change could have altered the dynamics of the carbonization/gasification reactions occurring in the reactor, which could explain the apparent increase in carbon conversion suggested by the lower noncarbonate carbon content of the TC07D samples. With these changes, there apparently was also a change in particle characteristics that produced a reduction in drag. This explanation of the lower TC07 drag seems reasonable, but additional work would be required to confirm or refute it.

\subsubsection{Analysis of PCD Pressure Drop}

In this section, the contribution of the transient dustcake to PCD $\triangle \mathrm{P}$ is examined by comparing dustcake drag values calculated from the PCD $\triangle \mathrm{P}$ to dustcake drag values measured by RAPTOR. This is a valuable comparison, because mismatches between these two methods of determining drag can indicate that other factors (e.g., tar deposition, failsafe plugging, element blinding, etc.) may be influencing the filter $\Delta \mathrm{P}$.

This analysis was performed using the same procedure described in previous reports. For each in situ particulate sampling run, the transient PCD drag during the run was determined from the rate of $\Delta \mathrm{P}$ rise $(\Delta \mathrm{P} / \Delta \mathrm{t})$ during the run and the rate of $\mathrm{g}$-ash accumulation in the transient cake. The latter was determined from the measured particulate loading and the syngas mass flow rate during the run. To allow direct comparison of this PCD drag value with the RAPTOR drag measurements, the PCD drag was adjusted to the RAPTOR 
conditions using the ratio of the syngas viscosity at process temperature to the viscosity of air at laboratory room temperature. The RAPTOR drag value for each particulate sampling run was taken from the plot of drag versus MMD shown previously in Figure 3.4-9 using the MMD values determined by Microtrac analysis of each in situ g-ash sample.

Table 3.4-6 summarizes the PCD transient drag calculations discussed above and compares the PCD transient drag values to the corresponding drag values measured by RAPTOR. Average values of PCD transient drag and RAPTOR drag are given below for TC07B, D, and TC06.

\begin{tabular}{|l|c|c|c|}
\cline { 2 - 4 } \multicolumn{1}{c|}{} & \multicolumn{3}{c|}{ Drag, inWc/(lb/ft' $\left.{ }^{2}\right) /(\mathrm{ft} / \mathrm{min})$} \\
\cline { 2 - 4 } & TC07B & TC07D & TC06 \\
\hline Average from PCD $\Delta \mathrm{P} / \Delta \mathrm{t}$ & 42 & 42 & 83 \\
\hline Average from RAPTOR Data & 51 & 48 & 94 \\
\hline Percent difference & 19 & 13 & 12 \\
\hline
\end{tabular}

The drag values given above are on the viscosity basis of air at $77^{\circ} \mathrm{F}$. This comparison shows that the PCD performance calculations and the RAPTOR measurements agree within 12 to 19 percent difference. As shown in Figure 3.4-10, plotting the individual values of PCD drag and RAPTOR drag determined for each sampling run also shows the good agreement between these two methods of determining drag. This plot, which includes all of the drag measurements made on PRB g-ash, shows that the RAPTOR drag values track the PCD transient drag values reasonably well. This result suggests that the flow resistance of the g-ash is high enough to fully account for the transient PCD $\Delta \mathrm{P}$. There is no evidence that tar deposition or any other anomalies affected the PCD $\triangle \mathrm{P}$.

Based on both the RAPTOR data and the PCD $\triangle \mathrm{P}$, there was no difference in the flow resistance of the TC07B and TC07D g-ashes. However, both the lab drag measurements and the PCD $\triangle \mathrm{P}$ show that the drag of the PRB g-ash from TC07 is substantially lower than the drag of the PRB g-ash from TC06. Again, this difference in drag cannot be explained by a difference in specific-surface area, particle-size distribution, or particle morphology. Chemical composition is the only factor that has been identified thus far that shows a significant difference and might be related to the observed reduction in drag. Perhaps the reduced drag of the TC07 $\mathrm{g}$-ash is related to the changes in process conditions that brought about the improved carbon conversion. Regardless of whether the differences in carbon conversion and drag are related, both factors suggest that there should be an observable difference in particle morphology. Despite these indications, SEM examinations failed to provide any clear distinction between the PRB g-ash from TC06 and the PRB g-ash from TC07. Clearly, additional work will be required to fully understand the cause of the lower drag in TC07. 


\subsubsection{Conclusions}

TC07 confirmed the ability of the PCD to achieve excellent particulate collection in the absence of filter element failures. When two of the filter elements failed after the bridging incident in TC07C, the outlet particulate loading increased to $35 \mathrm{ppmw}$. In a commercial PCD, this particle penetration would have been prevented by a reliable system of failsafe devices. Unfortunately, the elements that failed were equipped with an old type of failsafe that does not plug reliably.

With the PRB coal that has been used extensively in the past, the PCD operated smoothly with no bridging. Pressure drop across the PCD remained acceptable throughout the PRB portion of the run with minimal increase in the baseline $\Delta \mathrm{P}$. Bridging occurred only with the Alabama bituminous coal, which seems to have a propensity to form deposits in the PCD and gasifier. Because of this tendency, the Alabama bituminous coal will be replaced with other types of coal for future bituminous coal tests.

Inlet particulate loadings and particle-size distributions were reasonably consistent throughout TC07, with the exception of one run performed during iron injection for $\mathrm{H}_{2} \mathrm{~S}$ capture. In the absence of iron injection, the average inlet particulate loading was about $16,000 \mathrm{ppmw}$ with a standard deviation of 2,400 ppmw (coefficient of variance of 0.15). The average MMD of the inlet $g$-ash was about $16 \mu \mathrm{m}$ with a standard deviation of $1.2 \mu \mathrm{m}$ (coefficient of variance of 0.07). With iron injection, the inlet loading (based on a single measurement) was about 33,000 ppmw, and the MMD was about $19 \mu \mathrm{m}$. Comparison of the particle-size distributions showed that the iron injection increased the concentrations of all particles smaller than $50 \mu \mathrm{m}$. The size distributions for all of the other inlet samples were reasonably consistent and were very similar to those measured in GCT3, GCT4, and TC06.

Laboratory drag measurements and calculations of PCD transient drag were in good agreement for TC07, suggesting that all of the PCD $\triangle \mathrm{P}$ rise could be explained by the buildup of the transient $\mathrm{g}$-ash cake. There was no indication that tar deposition or any other anomalies affected the PCD $\Delta$ P. Both lab-measured drag and PCD transient drag values showed that the TC07D g-ash had less flow resistance than did the g-ashes from GCT3, GCT4, and TC06. The lower drag of the TC07D g-ash cannot be explained by any corresponding differences in particle-size distribution, specific-surface area, or bulk porosity. Chemical composition is the only factor identified thus far that distinguishes the TC07D gash from the other PRB g-ashes generated after the recycle loop was modified. The main difference appears to be that the TC07D g-ash contains less noncarbonate carbon (or more inerts) than do the g-ashes from GCT3, GCT4, and TC06. Coal analyses from these test programs are reasonably consistent, suggesting that the difference is not related to variations in the coal feed. The most likely explanation for the lower carbon content of the TC07D gash appears to be an increase in carbon conversion.

With the addition of the new LMZ between TC06 and TC07, the locations used for air and steam addition into the gasifier were changed. It is possible that this change produced a higher degree of carbon conversion and altered the morphology of the g-ash particles. (Since most of the particle surface area is in internal pores, particle morphology could be 
POWER SYSTEMS DEVELOPMENT FACILITY

altered without a substantial change in specific-surface area.) This is one possible explanation for the lower drag of the TC07 g-ash. Additional work will be required to confirm or refute this assertion, but it seems to be a reasonable explanation based on all of the available information.

As in previous tests, the PCME particulate monitor continued to show good response to four episodes of elevated particulate concentrations. The PCME appeared to respond to concentrations as low as 0.3 ppmw, although that response was very small. Results from TC07 are in good agreement with the data collected during TC06 using both injected g-ash and actual PCD leaks. 
Table 3.4-1

PCD Inlet and Outlet Particulate Measurements From TCO7

\begin{tabular}{|c|c|c|c|c|c|c|c|c|c|c|}
\hline \multirow[b]{2}{*}{$\begin{array}{l}\text { Test } \\
\text { Date } \\
\end{array}$} & \multicolumn{4}{|c|}{ PCD Inlet } & \multicolumn{5}{|c|}{ PCD Outlet } & \multirow{2}{*}{$\begin{array}{c}\text { PCD } \\
\text { Collection } \\
\text { Efficiency, } \\
\%\end{array}$} \\
\hline & $\begin{array}{l}\text { SRI } \\
\text { Run } \\
\text { No. } \\
\end{array}$ & $\begin{array}{l}\text { Start } \\
\text { Time }\end{array}$ & $\begin{array}{l}\text { End } \\
\text { Time } \\
\end{array}$ & $\begin{array}{c}\text { Particle } \\
\text { Loading, } \\
\text { ppmw }\end{array}$ & $\begin{array}{l}\text { SRI } \\
\text { Run } \\
\text { No. } \\
\end{array}$ & $\begin{array}{l}\text { Start } \\
\text { Time } \\
\end{array}$ & $\begin{array}{l}\text { End } \\
\text { Time } \\
\end{array}$ & $\begin{array}{c}\mathrm{H}_{2} \mathrm{O} \\
\text { Vapor, } \\
\text { Vol. \% } \\
\end{array}$ & $\begin{array}{c}\text { Particle } \\
\text { Loading, } \\
\text { ppmw } \\
\end{array}$ & \\
\hline \multicolumn{11}{|c|}{ TCO7-B (LMZ Commissioning With PRB Coal, No Steam Addition) } \\
\hline $1 / 19 / 02$ & 1 & 14:05 & 14:20 & 14,800 & 1 & $12: 45$ & $14: 45$ & 6.5 & $<0.2$ & $>99.999$ \\
\hline $1 / 22 / 02$ & 2 & 09:10 & 09:25 & 14,200 & 2 & 09:00 & $13: 15$ & 6.3 & $0.11^{(8)}$ & $>99.999$ \\
\hline $1 / 23 / 02$ & 3 & 09:00 & 09:20 & 13,600 & $3^{(1)}$ & 08:30 & $14: 20$ & 6.7 & $<0.1$ & $>99.999$ \\
\hline $1 / 25 / 02$ & 4 & 10:00 & $10: 15$ & 18,000 & 4 & 09:00 & 13:00 & 7.7 & $0.2^{(8)}$ & 99.999 \\
\hline \multicolumn{4}{|c|}{ TCO7B Average } & 15,200 & \multicolumn{3}{|c|}{ TCO7B Average } & 6.8 & $<0.15$ & $>99.999$ \\
\hline \multicolumn{4}{|c|}{ Standard Deviation } & 2,000 & \multicolumn{3}{|c|}{ Standard Deviation } & 0.6 & $<0.06$ &. \\
\hline \multicolumn{11}{|c|}{ TCO7-C (AL Bituminous Coal, With New LMZ and Steam Addition) } \\
\hline $2 / 07 / 02$ & .. & .. & .. & .. & $5^{(2)}$ & $13: 20$ & $14: 20$ & 5.1 & 1.4 & .. \\
\hline $2 / 08 / 02$ & ... & ... & ... & .. & $6^{(2)}$ & $10: 10$ & $10: 20$ & 5.9 & 19.7 & ... \\
\hline $2 / 08 / 02$ &.. &.. &.. &.. & $7^{(2)}$ & 13:05 & $13: 25$ & 4.9 & 34.8 &.. \\
\hline \multicolumn{4}{|c|}{ TCOTC Average } &.. & \multicolumn{3}{|c|}{ TCOTC Average } & 5.3 & 18.6 &.. \\
\hline \multicolumn{4}{|c|}{ Standard Deviation } & $\ldots$ & \multicolumn{3}{|c|}{ Standard Deviation } & 0.5 & 16.7 &. \\
\hline \multicolumn{11}{|c|}{ TCO7-D (PRB Coal, With New LMZ and Steam Addition) } \\
\hline $3 / 23 / 02$ &.. &.$\cdot$ &.$\cdot$ &.$\cdot$ & 8 & 13:05 & 14:05 & 3.9 & 2.6 &.- \\
\hline $3 / 25 / 02$ & 5 & $12: 50$ & 13:04 & 21,400 & 9 & $08: 45$ & $12: 45$ & 6.1 & 0.3 & 99.999 \\
\hline $3 / 26 / 02$ & $6^{(3)}$ & 10:15 & $10: 25$ & 16,900 & 10 & 09:30 & $12: 55$ & 11.3 & $<0.1$ & $>99.999$ \\
\hline $3 / 27 / 02$ & 7 & 09:10 & $09: 25$ & 14,500 & 11 & 09:00 & 13:00 & 12.0 & $<0.1$ & $>99.999$ \\
\hline $3 / 29 / 02$ & $9^{(4)}$ & 13:15 & 13:30 & 16,000 & $13^{(4)}$ & $12: 00$ & $15: 00$ & 14.5 & $0.2^{(8)}$ & 99.999 \\
\hline $3 / 30 / 02$ & ... & .. & .. & .. & $14^{(5)}$ & 09:00 & $11: 15$ & 8.2 & $<0.1$ & ... \\
\hline $4 / 01 / 02$ & 10 & 08:50 & 09:05 & 16,200 & 15 & $08: 30$ & $12: 30$ & 9.2 & $<0.1$ & $>99.999$ \\
\hline $4 / 01 / 02$ & $11^{(6)}$ & $13: 27$ & 13:35 & 14,200 & .. & .. & .. & .. & ... & .. \\
\hline $4 / 02 / 02$ & .. & .. & .- & .. & 16 & $08: 30$ & $11: 30$ & 8.6 & $<0.1$ & .. \\
\hline 4/03/02 & .. & .. & .. & .. & 17 & $10: 45$ & $14: 45$ & 8.6 & $<0.1$ & .. \\
\hline $4 / 04 / 02$ & $12^{(7)}$ & $08: 30$ & $08: 45$ & 33,100 & .. & .. & .. &.. & ... & ... \\
\hline \multicolumn{4}{|c|}{ TCO7D Average } & 16,500 & \multicolumn{3}{|c|}{ TCO7D Average } & 9.2 & $<0.4$ & $>99.999$ \\
\hline \multicolumn{4}{|c|}{ Standard Deviation } & 2,600 & \multicolumn{3}{|c|}{ Standard Deviation } & 3.2 & $<0.8$ &.. \\
\hline \multicolumn{11}{|c|}{$\begin{array}{l}\text { 1. Outlet Run No. } 3 \text { paused from } 09: 46 \text { to 10:36; total run time was } 295 \text { min. } \\
\text { 2. Outlet Run Nos. 5, } 6 \text { and } 7 \text { done with coke breeze only; no coal feed. } \\
\text { 3. Inlet Run No. } 6 \text { done with no limestone feed. } \\
\text { 4. Inlet Run No. } 8 \text { and Outlet Run No. } 12 \text { were discarded because of process upset. } \\
\text { 5. Several coal feeder upsets during Outlet Run No. 14; water value may be questionable. } \\
\text { 6. Iron and sand injected during Inlet Run No. 11; no apparent effect on loading. } \\
\text { 7. Iron injected through FDO220 during Inlet Run No. 12; loading not included in average. } \\
\text { 8. Run Nos. 2, 4, and } 13 \text { contaminated with large particles. }\end{array}$} \\
\hline
\end{tabular}


POWER SYSTEMS DEVELOPMENT FACILITY

PARTICLE FILTER SYSTEM

TEST CAMPAIGN TCO7

TCO7 G-ASH CHARACTERISTICS AND PCD PERFORMANCE

Table 3.4-2

Physical Properties of TCO7 In situ Samples

\begin{tabular}{|c|c|c|c|c|c|c|c|}
\hline Date & $\begin{array}{l}\text { SRI } \\
\text { Run } \\
\text { No. }\end{array}$ & $\begin{array}{c}\text { Bulk } \\
\text { Density, } \\
\mathrm{g} / \mathrm{cm}^{3}\end{array}$ & $\begin{array}{c}\text { True } \\
\text { Density, } \\
\mathrm{g} / \mathrm{cm}^{3}\end{array}$ & $\begin{array}{l}\text { Uncom- } \\
\text { pacted } \\
\text { Bulk } \\
\text { Porosity, } \\
\% \\
\end{array}$ & $\begin{array}{c}\text { Specific- } \\
\text { Surface } \\
\text { Area, } \\
\mathrm{m}^{2} / \mathrm{g}\end{array}$ & $\begin{array}{c}\text { Mass- } \\
\text { Median } \\
\text { Diameter, } \\
\mu \mathrm{m}\end{array}$ & Comments \\
\hline \multicolumn{8}{|c|}{ TCO7B (LMZ Commissioning With PRB Coal, No Steam Addition) } \\
\hline $01 / 23 / 02$ & TCO7-I-3 & 0.33 & 2.69 & 87.7 & 172 & 15.9 & Not steady-state \\
\hline $01 / 25 / 02$ & TC07-I-4 & 0.30 & 2.46 & 87.8 & 185 & 15.0 & Not steady-state \\
\hline \multicolumn{2}{|c|}{ ТСОТВ Average } & 0.32 & 2.57 & 87.7 & 179 & 15.5 & \multirow{2}{*}{$\begin{array}{c}\text { Standard deviation not } \\
\text { applicable with only two runs }\end{array}$} \\
\hline \multicolumn{2}{|c|}{ Standard Deviation } & .. & .. & .- & .- & .. & \\
\hline \multicolumn{8}{|c|}{ TCO7D (PRB Coal, With New LMZ and Steam Addition) } \\
\hline $03 / 25 / 02$ & TCO7-I-5 & 0.31 & 2.29 & 86.5 & 203 & 15.9 & Very high limestone feed \\
\hline $03 / 26 / 02$ & TCO7-I-6 & 0.26 & 2.27 & 88.6 & 237 & 15.7 & No limestone feed \\
\hline $03 / 27 / 02$ & TCO7-I.7 & 0.34 & 2.50 & 86.4 & 164 & 15.0 & \\
\hline $03 / 28 / 02$ & TCO7-I-8 & -. & -. &.- & -. & -. & $\begin{array}{c}\text { Run discarded due to process } \\
\text { upset }\end{array}$ \\
\hline $03 / 29 / 02$ & TCO7-I-9 & 0.32 & 2.38 & 86.6 & 178 & 18.4 & \\
\hline $04 / 01 / 02$ & TC07-I-10 & 0.31 & 2.54 & 87.8 & 167 & 17.3 & \\
\hline $04 / 01 / 02$ & TC07-I-11 & 0.26 & 2.46 & 89.4 & 233 & 16.1 & $\begin{array}{c}\text { Iron oxide and sand injected, } \\
\text { no limestone feed }\end{array}$ \\
\hline $04 / 04 / 02$ & TC07-I-12 & 0.37 & 2.75 & 86.6 & 131 & 19.2 & $\begin{array}{c}\text { Iron oxide and high limestone } \\
\text { feed via FD0220 }\end{array}$ \\
\hline \multicolumn{2}{|c|}{ TCO7D Average } & 0.32 & 2.47 & 86.9 & 170 & 16.9 & \multirow{2}{*}{$\begin{array}{c}\text { Excludes Run Nos. TCO7-I-5, } \\
6, \cdot 11, \text { and }-12\end{array}$} \\
\hline \multicolumn{2}{|c|}{ Standard Deviation } & 0.015 & 0.08 & 0.8 & 7 & 1.7 & \\
\hline
\end{tabular}


Table 3.4-3

Physical Properties of TCO7 Dustcake Samples

\begin{tabular}{|c|c|c|c|c|c|c|c|}
\hline Date & $\begin{array}{l}\text { Type } \\
\text { of } \\
\text { Sample }\end{array}$ & $\begin{array}{c}\text { Bulk } \\
\text { Density, } \\
\text { g/cm }\end{array}$ & $\begin{array}{c}\text { True } \\
\text { Density, } \\
\mathrm{g} / \mathrm{cm}^{3}\end{array}$ & $\begin{array}{c}\text { Uncom- } \\
\text { pacted } \\
\text { Bulk } \\
\text { Porosity, } \\
\%\end{array}$ & $\begin{array}{c}\text { Specific- } \\
\text { Surface } \\
\text { Area, } \\
\mathrm{m}^{2} / \mathrm{g}\end{array}$ & $\begin{array}{c}\text { Mass- } \\
\text { Median } \\
\text { Diameter, } \\
\mu \mathrm{m}\end{array}$ & Comments \\
\hline \multicolumn{8}{|c|}{ TCO7C (AL Bituminous, Extensive Bridging in Bottom Plenum) ${ }^{(1)}$} \\
\hline $02 / 13 / 02$ & Bridging & 0.30 & 2.12 & 85.8 & 140 & 21.1 & Sample 1 (see candle layout) \\
\hline $02 / 13 / 02$ & Bridging & 0.28 & 2.13 & 86.8 & 105 & 22.2 & Sample 2 (see candle layout) \\
\hline $02 / 13 / 02$ & Bridging & 0.29 & 2.20 & 86.8 & 56.7 & 23.2 & Sample 3 (see candle layout) \\
\hline $02 / 13 / 02$ & Bridging & 0.27 & 2.11 & 87.2 & 35.9 & 22.9 & Sample 4 (see candle layout) \\
\hline $02 / 13 / 02$ & Bridging & 0.29 & 2.16 & 86.6 & 75.1 & 22.5 & Bulk sample of bridged deposit \\
\hline \multicolumn{2}{|c|}{ TCO7C Bridging Avg } & 0.29 & 2.14 & 86.6 & 82.5 & 22.4 & \\
\hline \multicolumn{2}{|c|}{ Standard Deviation } & 0.11 & 0.36 & 0.5 & 40.9 & 0.8 & \\
\hline $02 / 13 / 02$ & Residual & 0.34 & 2.35 & 85.5 & 37.2 & 7.6 & $\begin{array}{c}\text { Residual dustcake from top } \\
\text { plenum }\end{array}$ \\
\hline $02 / 13 / 02$ & Residual & 0.32 & 2.21 & 85.5 & 42.9 & 15.9 & $\begin{array}{c}\text { Residual dustcake from bottom } \\
\text { plenum }\end{array}$ \\
\hline \multicolumn{2}{|c|}{ TC07C Residual Avg } & 0.33 & 2.28 & 85.5 & 40.1 & 11.8 & \\
\hline \multicolumn{8}{|c|}{ TCO7D (PRB Coal, No Bridging) ${ }^{(2)}$} \\
\hline $04 / 10 / 02$ & Top Plenum & 0.45 & 3.10 & 85.5 & 36.1 & 5.8 & Bulk dustcake from top plenum \\
\hline $04 / 10 / 02$ & $\begin{array}{l}\text { Bottom } \\
\text { Plenum }\end{array}$ & 0.34 & 2.90 & 88.3 & 78.1 & 8.4 & $\begin{array}{l}\text { Bulk dustcake from bottom } \\
\text { plenum }\end{array}$ \\
\hline \multicolumn{2}{|c|}{ TCO7D Average } & 0.40 & 3.00 & 86.9 & 57.1 & 7.1 & \\
\hline \multicolumn{8}{|c|}{$\begin{array}{l}\text { 1. Entire bottom plenum was plugged with bridged g-ash deposits. } \\
\text { 2. Extremely thin residual dustcakes on both top and bottom plenums. Top layer of dustcake appears to be lighter in color, } \\
\text { possibly indicating that it was partially ashed during an oxygen transient that occurred during shutdown. }\end{array}$} \\
\hline
\end{tabular}


POWER SYSTEMS DEVELOPMENT FACILITY

PARTICLE FILTER SYSTEM

TEST CAMPAIGN TCO7

TCO7 G-ASH CHARACTERISTICS AND PCD PERFORMANCE

Table 3.4-4

Chemical Composition of TCO7D In situ Samples ${ }^{(1)}$

\begin{tabular}{|c|c|c|c|c|c|c|c|}
\hline Date & $\begin{array}{l}\text { SRI } \\
\text { Run } \\
\text { No. }\end{array}$ & $\begin{array}{l}\mathrm{CaCO}_{3}, \\
\mathrm{Wt} \%\end{array}$ & $\begin{array}{l}\text { CaS, } \\
\text { Wt \% }\end{array}$ & $\begin{array}{l}\text { Free } \\
\text { Lime } \\
(\mathrm{CaO}) \text {, } \\
\mathrm{Wt} \%\end{array}$ & $\begin{array}{c}\text { Non- } \\
\text { Carbonate } \\
\text { Carbon, } \\
\text { Wt \% }\end{array}$ & $\begin{array}{l}\text { Inerts } \\
\text { (Ash/ } \\
\text { Sand), } \\
\text { Wt \% }\end{array}$ & Comments \\
\hline \multicolumn{8}{|c|}{ TCO7D (PRB Coal, With New LMZ and Steam Addition) } \\
\hline $03 / 25 / 02$ & TC07-I-5 & 14.61 & 1.52 & 12.09 & 37.06 & 34.72 & Very high limestone feed \\
\hline $03 / 26 / 02$ & TC07-I-6 & 6.32 & 0.47 & 14.62 & 36.24 & 42.35 & No limestone feed \\
\hline $03 / 27 / 02$ & TC07-I-7 & 9.50 & 0.07 & 20.88 & 23.23 & 46.32 & \\
\hline $03 / 28 / 02$ & TCO7-I-8 & -. & -. & -. & $\cdot-$ & -. & $\begin{array}{c}\text { Run discarded due to process } \\
\text { upset }\end{array}$ \\
\hline $03 / 29 / 02$ & TCO7-I-9 & 8.89 & 0.09 & 18.00 & 28.36 & 44.66 & \\
\hline $04 / 01 / 02$ & TC07-I-10 & 8.75 & 0.13 & 22.12 & 20.99 & 48.01 & \\
\hline $04 / 01 / 02$ & TC07-I-11 & 4.80 & 0.87 & 13.60 & 32.33 & 48.40 & \begin{tabular}{|c|}
$\begin{array}{c}\text { Iron oxide and sand injected, no } \\
\text { limestone feed }\end{array}$ \\
\end{tabular} \\
\hline $04 / 04 / 02$ & TC07-I-12 & 18.27 & 1.23 & 5.34 & 20.74 & 54.42 & $\begin{array}{c}\text { Iron oxide and high limestone feed } \\
\text { via FDO220 } \\
\end{array}$ \\
\hline \multicolumn{2}{|c|}{ TCO7D Average } & 9.1 & 0.1 & 20.3 & 24.2 & 46.3 & \multirow{2}{*}{$\begin{array}{l}\text { Excludes Run Nos. TCO7. } \\
\quad 1-5,-6,-11 \text {, and }-12\end{array}$} \\
\hline \multicolumn{2}{|c|}{ Standard Deviation } & 0.40 & 0.03 & 2.1 & 3.8 & 1.7 & \\
\hline \multicolumn{2}{|c|}{$\begin{array}{l}\text { Average with High } \\
\text { Limestone Feed }\end{array}$} & 16.4 & 1.4 & 8.7 & 28.9 & 44.6 & Run Nos. TC07-I.5 and -12 \\
\hline \multicolumn{2}{|c|}{$\begin{array}{l}\text { Average with No } \\
\text { Limestone Feed }\end{array}$} & 5.6 & 0.7 & 14.1 & 34.3 & 45.4 & Run Nos. TCO7-I-6 and -11 \\
\hline
\end{tabular}

1. None of the TCO7B samples were selected for chemical analysis, since steady-state conditions were never achieved during TCO7B. 
Table 3.4-5

Chemical Composition of TCO7 Dustcake Samples

\begin{tabular}{|c|c|c|c|c|c|c|c|}
\hline Date & $\begin{array}{l}\text { Type of } \\
\text { Sample }\end{array}$ & $\begin{array}{l}\mathrm{CaCO}_{3}, \\
\mathrm{Wt} \%\end{array}$ & $\begin{array}{l}\text { CaS, } \\
\mathrm{Wt} \%\end{array}$ & $\begin{array}{l}\text { Free } \\
\text { Lime } \\
(\mathrm{CaO}) \\
\mathrm{Wt} \%\end{array}$ & $\begin{array}{l}\text { Non- } \\
\text { Carbonate } \\
\text { Carbon, } \\
\text { Wt \% }\end{array}$ & $\begin{array}{l}\text { Inerts } \\
\text { (Ash/ } \\
\text { Sand), } \\
\text { Wt \% }\end{array}$ & Comments \\
\hline \multicolumn{8}{|c|}{ TCOTC (AL Bituminous, Extensive Bridging in Bottom Plenum) ${ }^{(1)}$} \\
\hline $02 / 13 / 02$ & Bridging & 1.18 & 1.91 & 0 & 56.32 & 40.59 & Sample 1 (see candle layout) \\
\hline $02 / 13 / 02$ & Bridging & 0.34 & 1.91 & 0 & 59.24 & 38.51 & Sample 2 (see candle layout) \\
\hline $02 / 13 / 02$ & Bridging & 0.48 & 2.21 & 0 & 60.49 & 36.82 & Sample 3 (see candle layout) \\
\hline $02 / 13 / 02$ & Bridging & 1.16 & 2.97 & 0 & 63.95 & 31.92 & Sample 4 (see candle layout) \\
\hline $02 / 13 / 02$ & Bridging & 0.34 & 2.08 & 0 & 61.78 & 35.80 & Bulk sample of bridged deposit \\
\hline \multicolumn{2}{|c|}{ TCO7C Bridging Avg } & 0.70 & 2.22 & 0 & 60.36 & 36.72 & \\
\hline \multicolumn{2}{|c|}{ Standard Deviation } & 0.43 & 0.44 & 0 & 2.85 & 3.24 & \\
\hline $02 / 13 / 02$ & Residual & 1.61 & 1.81 & 1.83 & 43.54 & 51.21 & $\begin{array}{l}\text { Residual dustcake from top } \\
\text { plenum }\end{array}$ \\
\hline $02 / 13 / 02$ & Residual & 0.66 & 1.90 & 0.43 & 55.94 & 41.07 & $\begin{array}{c}\text { Residual dustcake from bottom } \\
\text { plenum }\end{array}$ \\
\hline \multicolumn{2}{|c|}{ TCO7C Residual Avg } & 1.14 & 1.85 & 1.13 & 49.74 & 46.14 & \\
\hline \multicolumn{8}{|c|}{ TCO7D (PRB Coal, No Bridging) ${ }^{(2)}$} \\
\hline $04 / 10 / 02$ & Top Plenum & 4.23 & 0.72 & 19.98 & 7.67 & 67.40 & Bulk dustcake from top plenum \\
\hline $04 / 10 / 02$ & $\begin{array}{l}\text { Bottom } \\
\text { Plenum }\end{array}$ & 7.07 & 1.31 & 14.02 & 22.07 & 55.53 & $\begin{array}{c}\text { Bulk dustcake from bottom } \\
\text { plenum }\end{array}$ \\
\hline \multicolumn{2}{|c|}{ TCO7D Average } & 5.65 & 1.02 & 17.00 & 14.87 & 61.46 & \\
\hline \multicolumn{8}{|c|}{$\begin{array}{l}\text { 1. Entire bottom plenum was plugged with bridged g-ash deposits. } \\
\text { 2. Extremely thin residual dustcakes on both top and bottom plenums. Top layer of dustcake appears to be lighter } \\
\text { in color, possibly indicating that it was partially ashed during an oxygen transient that occurred during } \\
\text { shutdown. }\end{array}$} \\
\hline
\end{tabular}


POWER SYSTEMS DEVELOPMENT FACILITY

Table 3.4-6

TC07 Transient Drag Determined From PCD $\triangle \mathrm{P}$ and from RAPTOR

\begin{tabular}{|c|c|c|c|c|c|c|c|c|}
\hline \multirow{2}{*}{$\begin{array}{l}\text { Run } \\
\text { No. }\end{array}$} & \multirow{2}{*}{$\begin{array}{l}\Delta \mathrm{P} / \Delta \mathrm{t} \\
\text { inwc/min }\end{array}$} & \multirow{2}{*}{$\begin{array}{l}\Delta(\mathrm{AL}) / \Delta \mathrm{t}, \\
\mathrm{lb} / \mathrm{min} / \mathrm{ft}^{2}\end{array}$} & \multirow{2}{*}{$\begin{array}{l}\mathrm{FV}, \\
\mathrm{ft} / \mathrm{min}\end{array}$} & \multirow{2}{*}{$\begin{array}{c}\mathrm{MMD}, \\
\mu \mathrm{m}\end{array}$} & \multicolumn{3}{|c|}{ Drag, inWc/(lb/ft² $) /(\mathrm{ft} / \mathrm{min})$} & \multirow{2}{*}{ Comments } \\
\hline & & & & & PCD & PCD@RT & RAPTOR & \\
\hline \multicolumn{9}{|c|}{ TCOTB (LMZ Commissioning with PRB Coal, No Steam Addition) } \\
\hline 3 & 2.55 & 0.0185 & 3.14 & 15.9 & 44 & 27 & 50 & Not steady state \\
\hline 4 & 9.58 & 0.0302 & 3.45 & 15.0 & 92 & 56 & 53 & Not steady state \\
\hline $\operatorname{Avg}$ & 6.07 & 0.0244 & 3.30 & 15.5 & 68 & 42 & 51 & \multirow{2}{*}{$\begin{array}{c}\text { Standard deviation not } \\
\text { applicable with only two } \\
\text { runs }\end{array}$} \\
\hline S.D. & $N / A$ & $N / A$ & $N / A$ & $N / A$ & $N / A$ & $N / A$ & $N / A$ & \\
\hline \multicolumn{9}{|c|}{ TCO7D (PRB Coal, with New LMZ and Steam Addition) } \\
\hline 5 & 11.28 & 0.0344 & 3.71 & 15.9 & 88 & 52 & 50 & Very high limestone feed \\
\hline 6 & 9.63 & 0.0277 & 3.70 & 15.7 & 94 & 56 & 51 & No limestone feed \\
\hline 7 & 6.76 & 0.0244 & 3.81 & 15.0 & 73 & 44 & 53 & \\
\hline 8 & \multicolumn{8}{|c|}{ Run discarded due to process upset } \\
\hline 9 & 7.47 & 0.0261 & 3.68 & 18.4 & 78 & 47 & 44 & \\
\hline 10 & 4.99 & 0.0251 & 3.34 & 17.3 & 59 & 35 & 47 & \\
\hline 11 & 8.43 & 0.0226 & 3.41 & 16.1 & 109 & 65 & 50 & $\begin{array}{c}\text { Iron oxide and sand } \\
\text { injected, no limestone feed }\end{array}$ \\
\hline 12 & 3.19 & 0.0450 & 2.80 & 19.2 & 25 & 15 & N.M. & $\begin{array}{c}\text { Iron oxide and high } \\
\text { limestone feed via FD0220 }\end{array}$ \\
\hline Avg & 6.41 & 0.0252 & 3.61 & 16.9 & 70 & 42 & 48 & \multirow{2}{*}{$\begin{array}{c}\text { Includes Run Nos. TCO7-I } \\
7,-9, \text { and }-10 \text { Only }\end{array}$} \\
\hline S.D. & 1.28 & 0.00085 & 0.24 & 1.7 & 10 & 6 & 5 & \\
\hline
\end{tabular}

Nomenclature:

1. $\Delta \mathrm{P} \mid \Delta \mathrm{t}=$ rate of pressure drop rise during particulate sampling run, inwc/min

2. $\Delta(\mathrm{AL}) / \Delta \mathrm{t}=$ rate of increase in areal loading during sampling run, $\mathrm{lb} / \mathrm{min} / \mathrm{ft}^{2}$

3. $\mathrm{FV}=$ average $\mathrm{PCD}$ face velocity during particulate sampling run, $\mathrm{ft} / \mathrm{min}$

4. $\mathrm{MMD}=$ mass-median diameter of in situ particulate sample, $\mu \mathrm{m}$

5. $\mathrm{RT}=$ room temperature, $77^{\circ} \mathrm{F}\left(25^{\circ} \mathrm{C}\right)$

6. $\quad$ RAPTOR $=$ resuspended ash permeability tester 


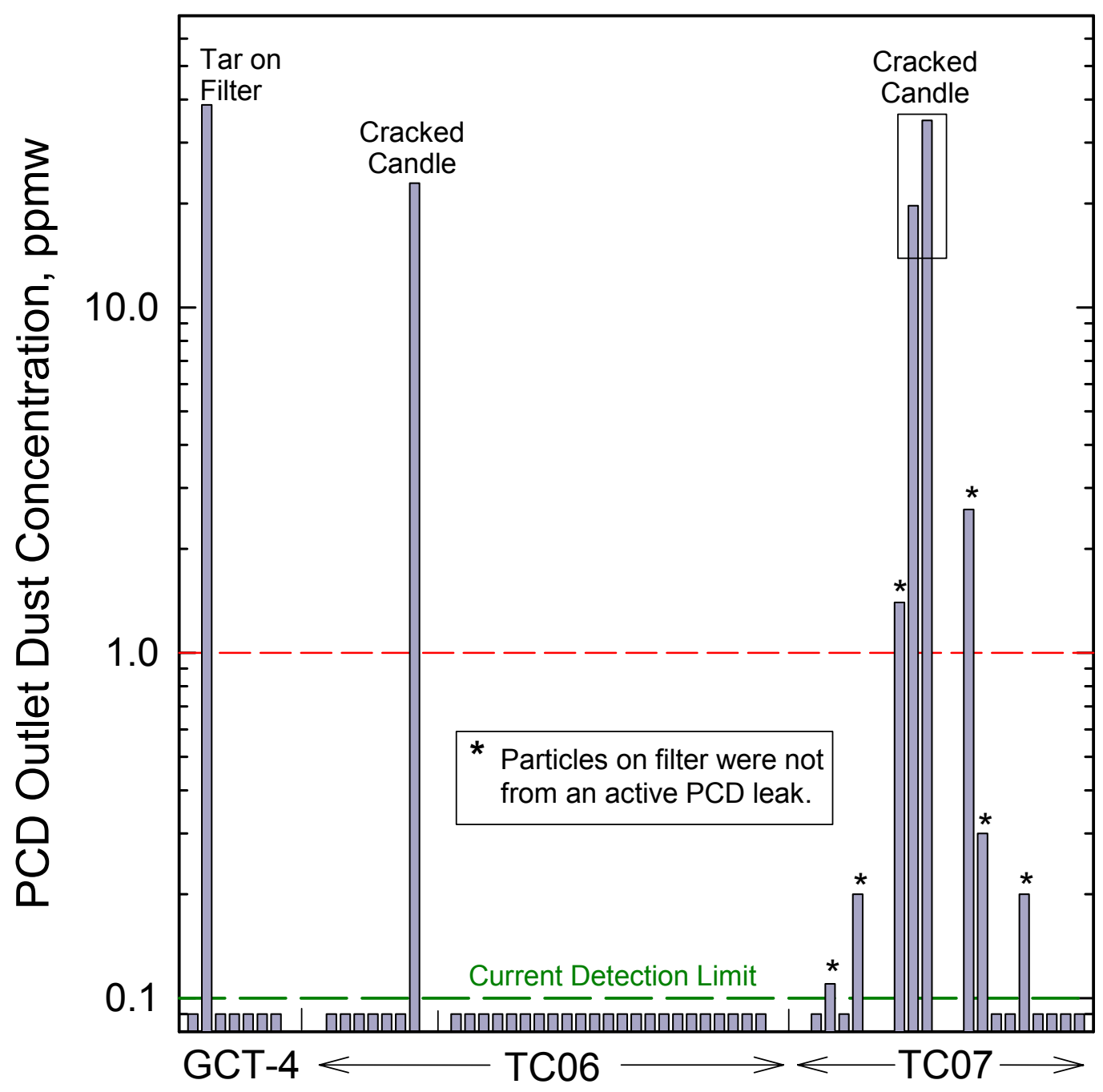

Figure 3.4-1 PCD Outlet Loadings Measured During GCT4, TC06, and TC07 
POWER SYSTEMS DEVELOPMENT FACILITY

PARTICLE FILTER SYSTEM

TEST CAMPAIGN TCO7

TCO7 G-ASH CHARACTERISTICS AND PCD PERFORMANCE

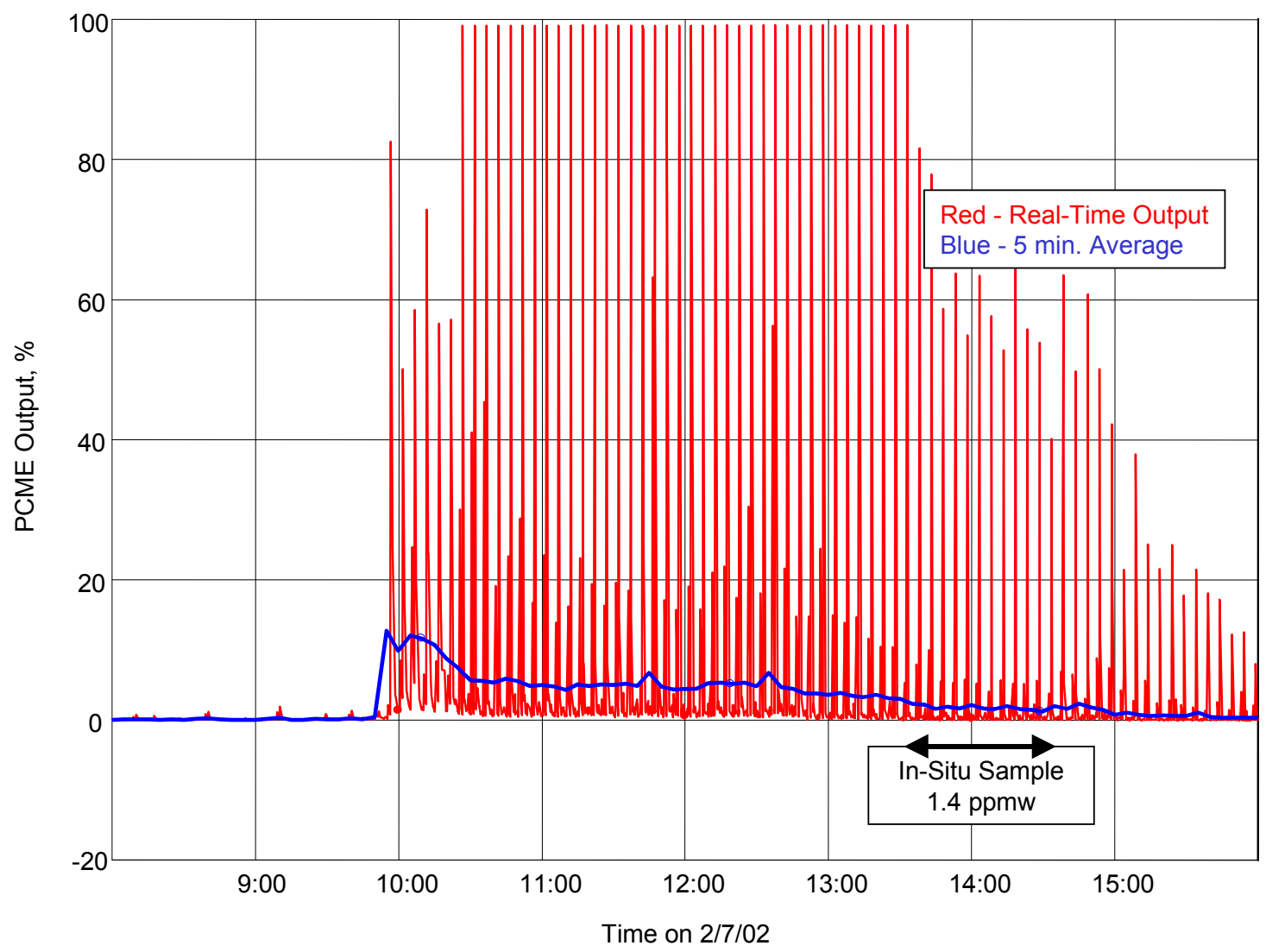

Figure 3.4-2 PCME Dustalert 90 Response During Startup Transient on February 7, 2002 


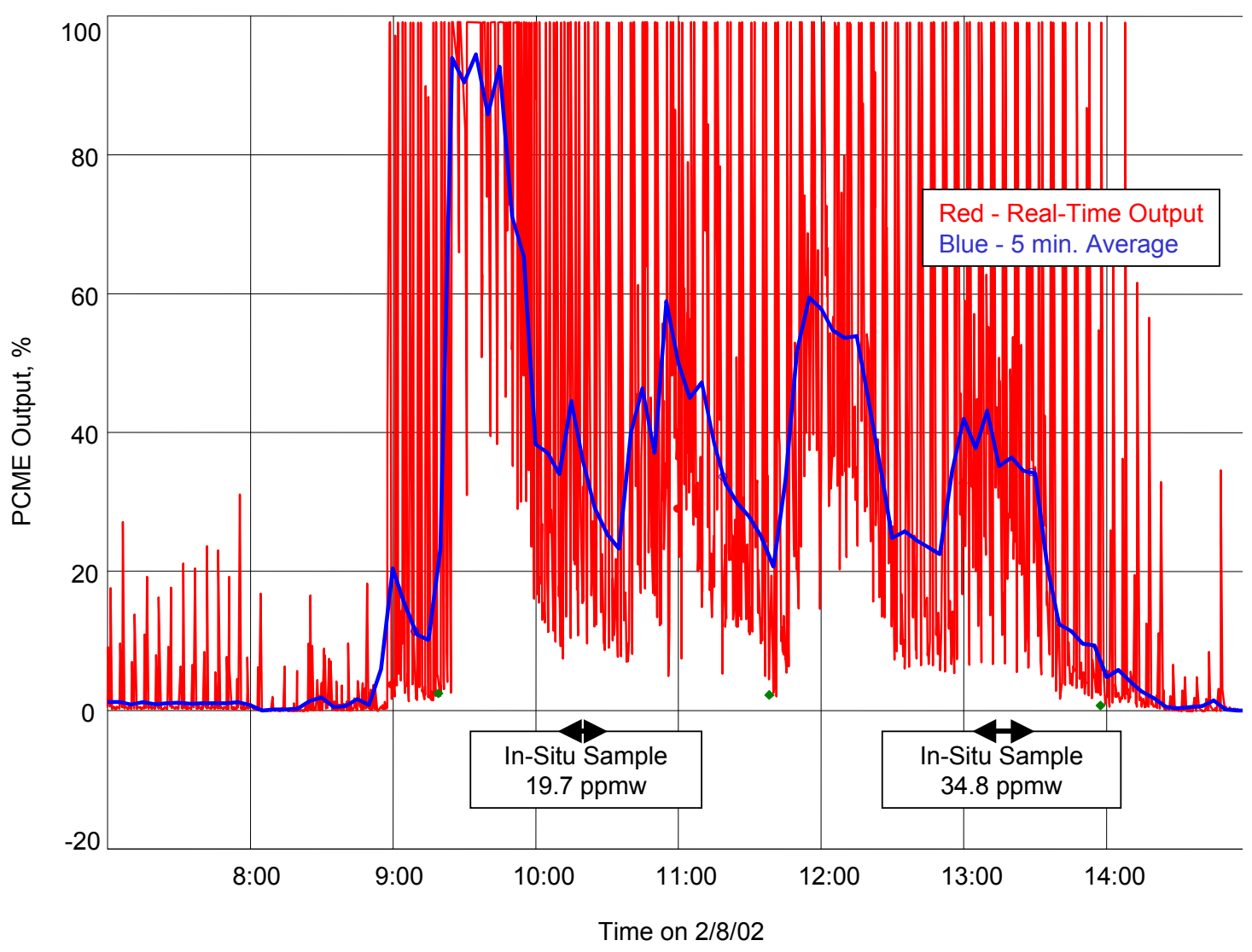

Figure 3.4-3 PCME Dustalert 90 Response During Filter Element Breakage on February 8, 2002 


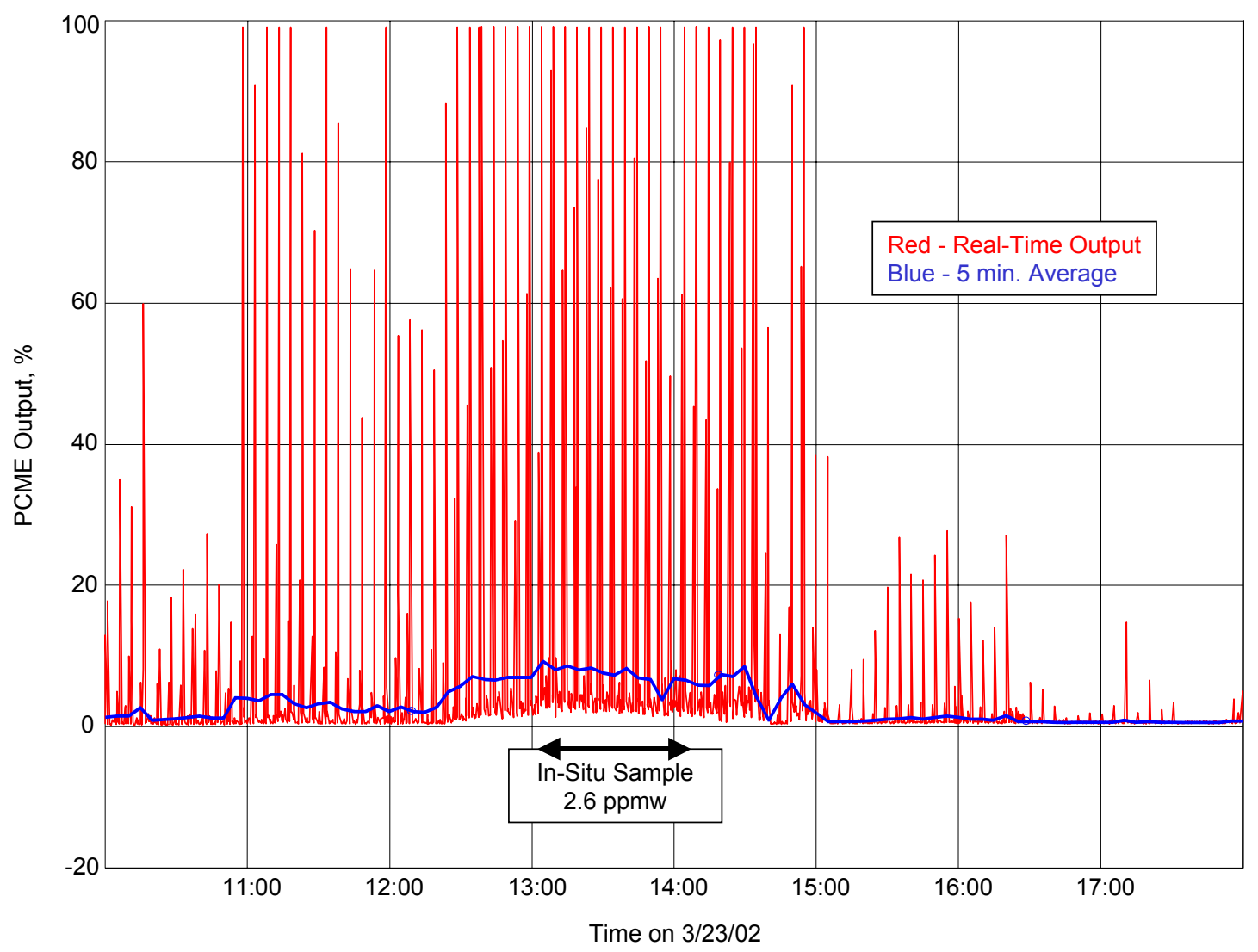

Figure 3.4-4 PCME Dustalert 90 Response During Startup Transient on March 23, 2002 


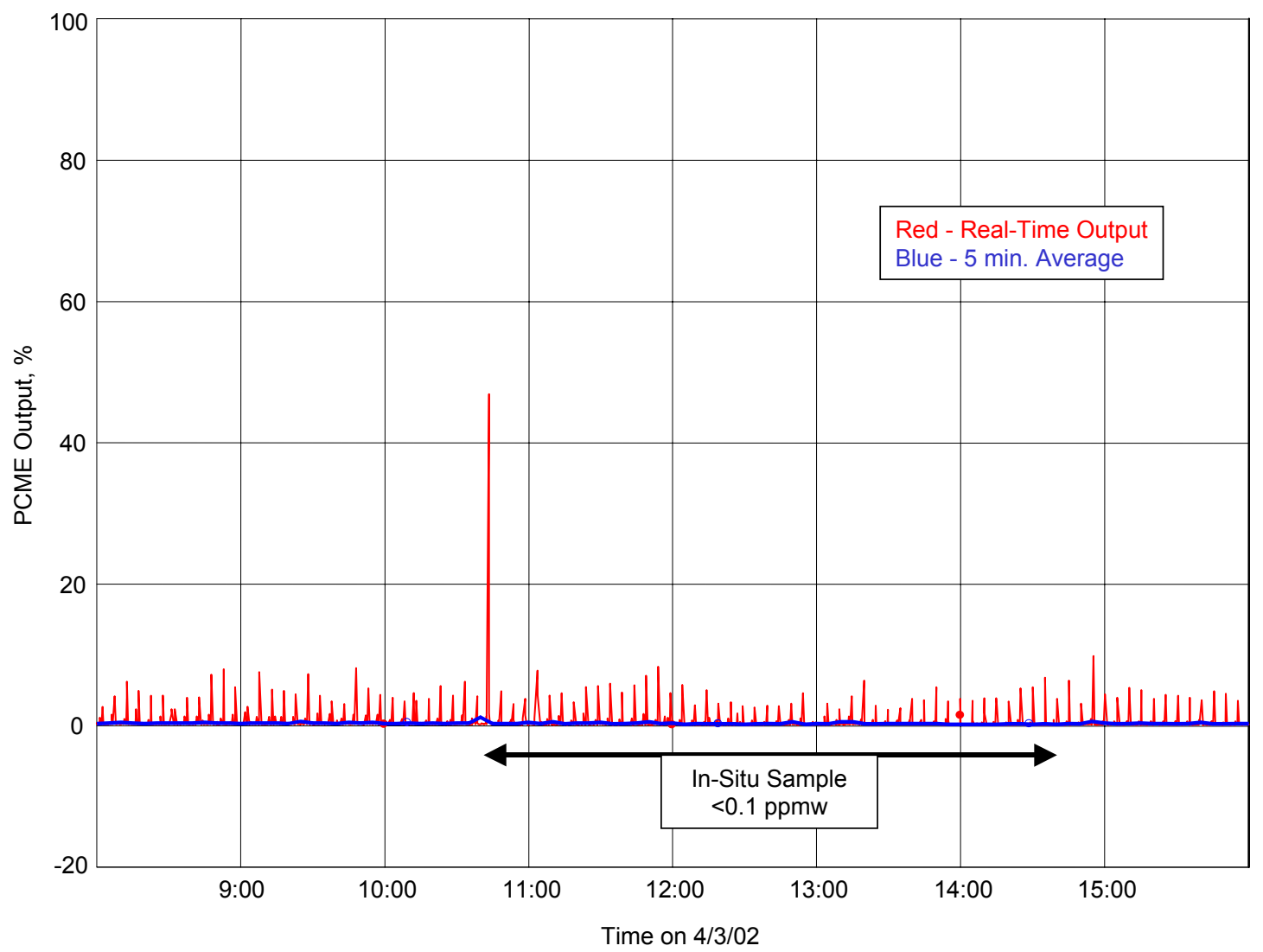

Figure 3.4-5 PCME Dustalert 90 Response With Low Particle Concentration 
POWER SYSTEMS DEVELOPMENT FACILITY

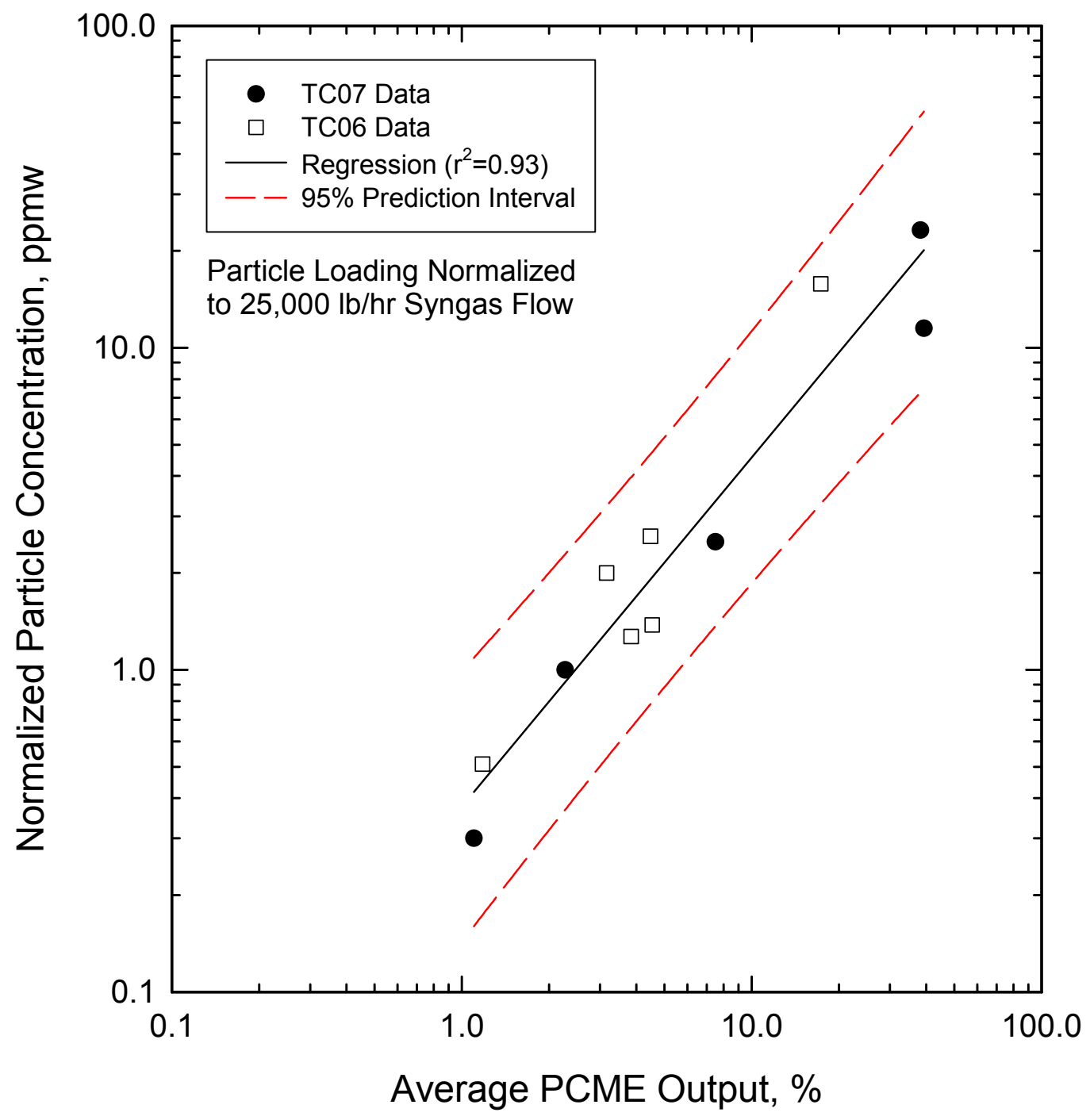

Figure 3.4-6 Comparison of PCME Response and Actual Particle Concentration 


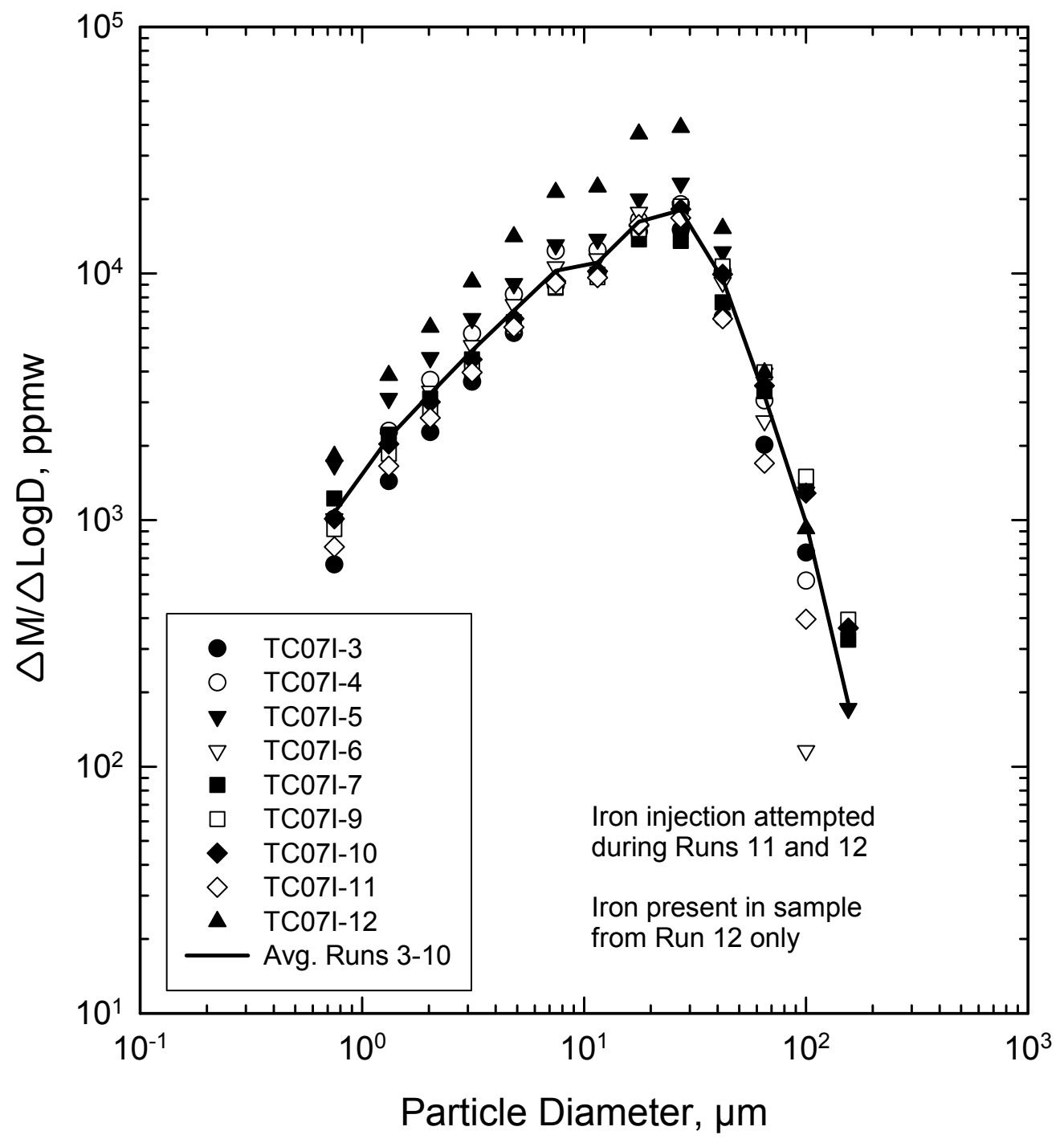

Figure 3.4-7 TCO7 Inlet Particle-Size Distributions 
POWER SYSTEMS DEVELOPMENT FACILITY

PARTICLE FILTER SYSTEM

TEST CAMPAIGN TCO7

TCO7 G-ASH CHARACTERISTICS AND PCD PERFORMANCE

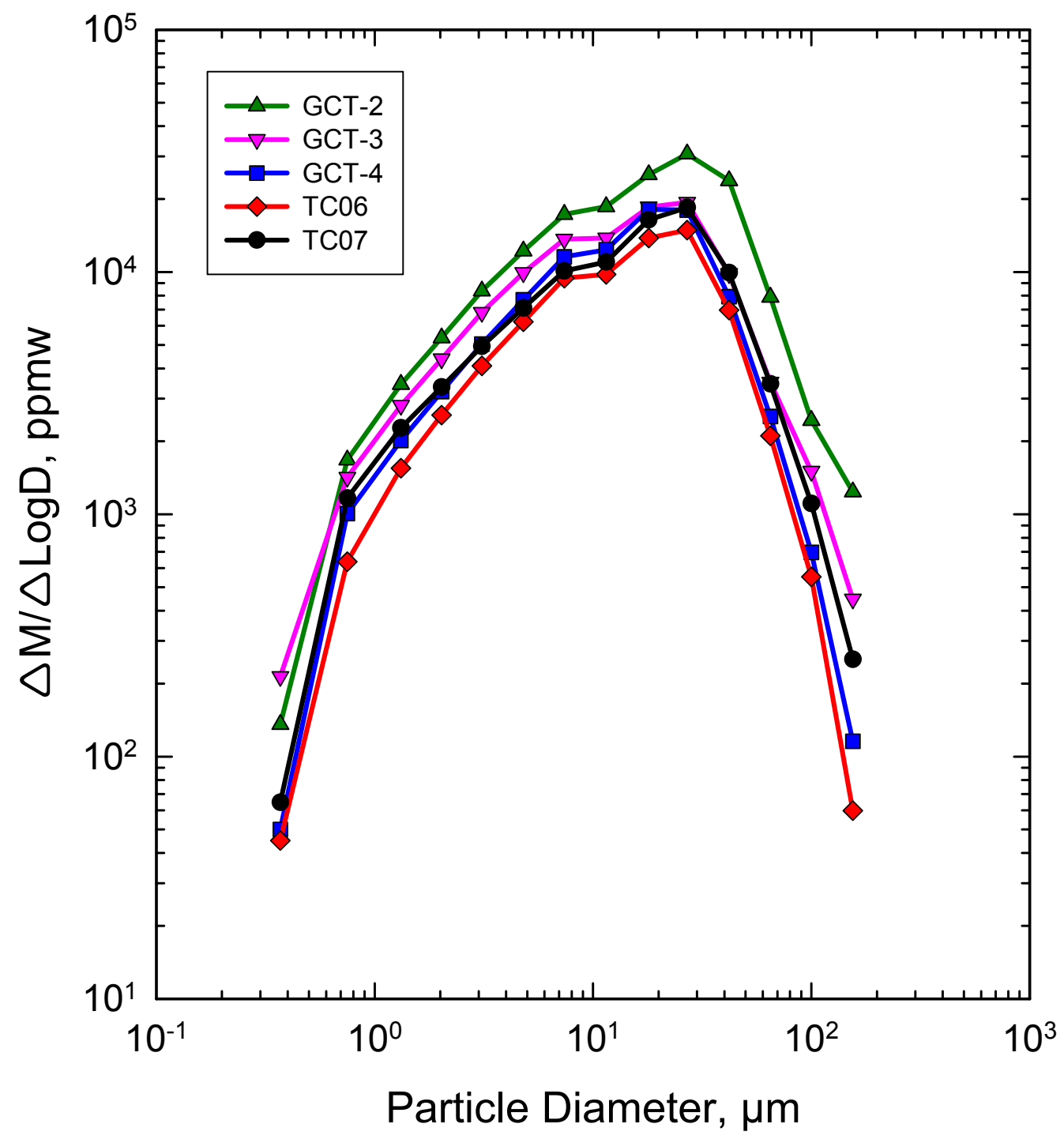

Figure 3.4-8 Comparison of Average Inlet Particle-Size Distributions From TCO7 and Other Gasification Runs 


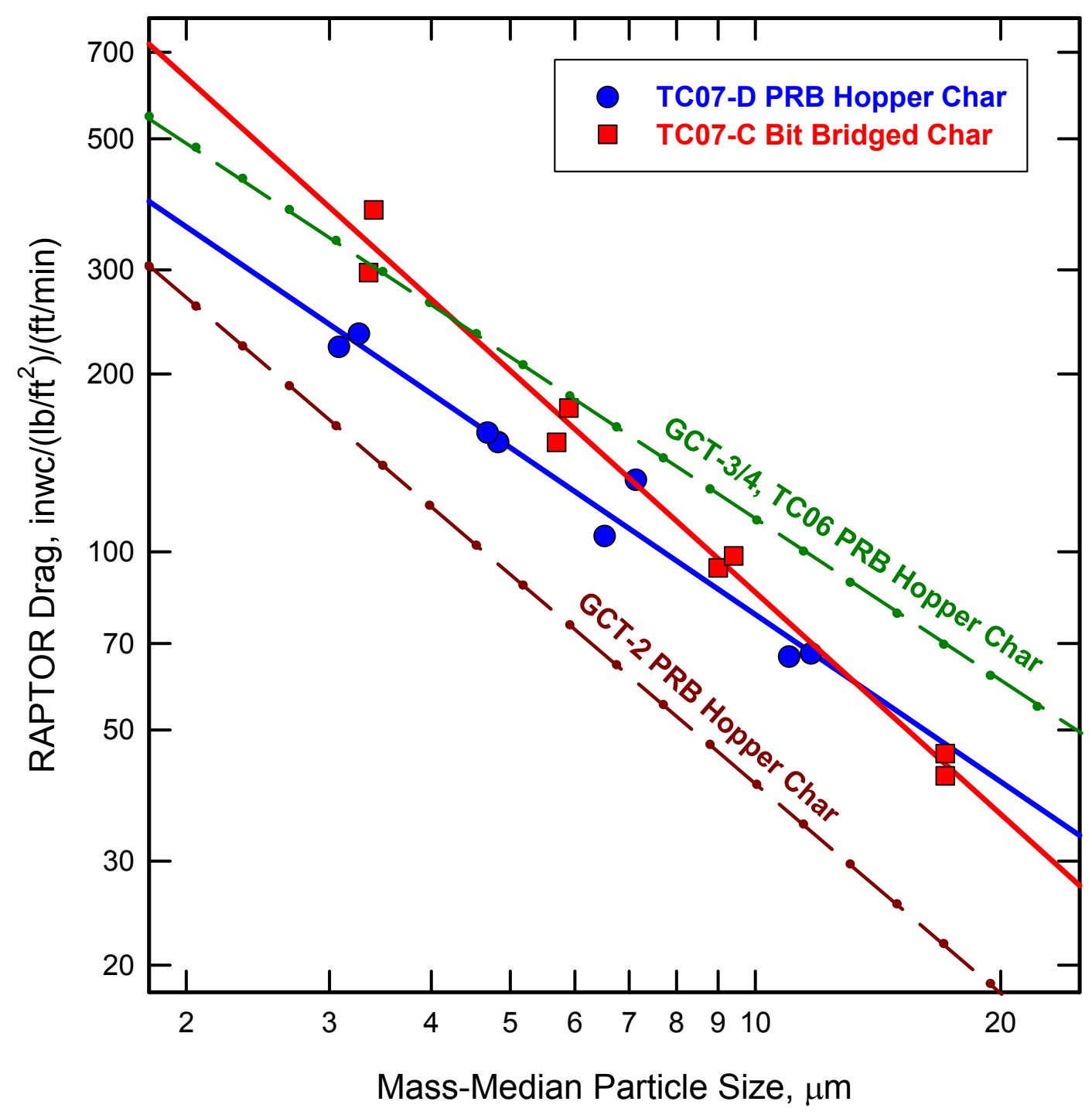

Figure 3.4-9 Effect of Particle Size on Drag of G-ash From TCO7 and Other Gasification Runs 


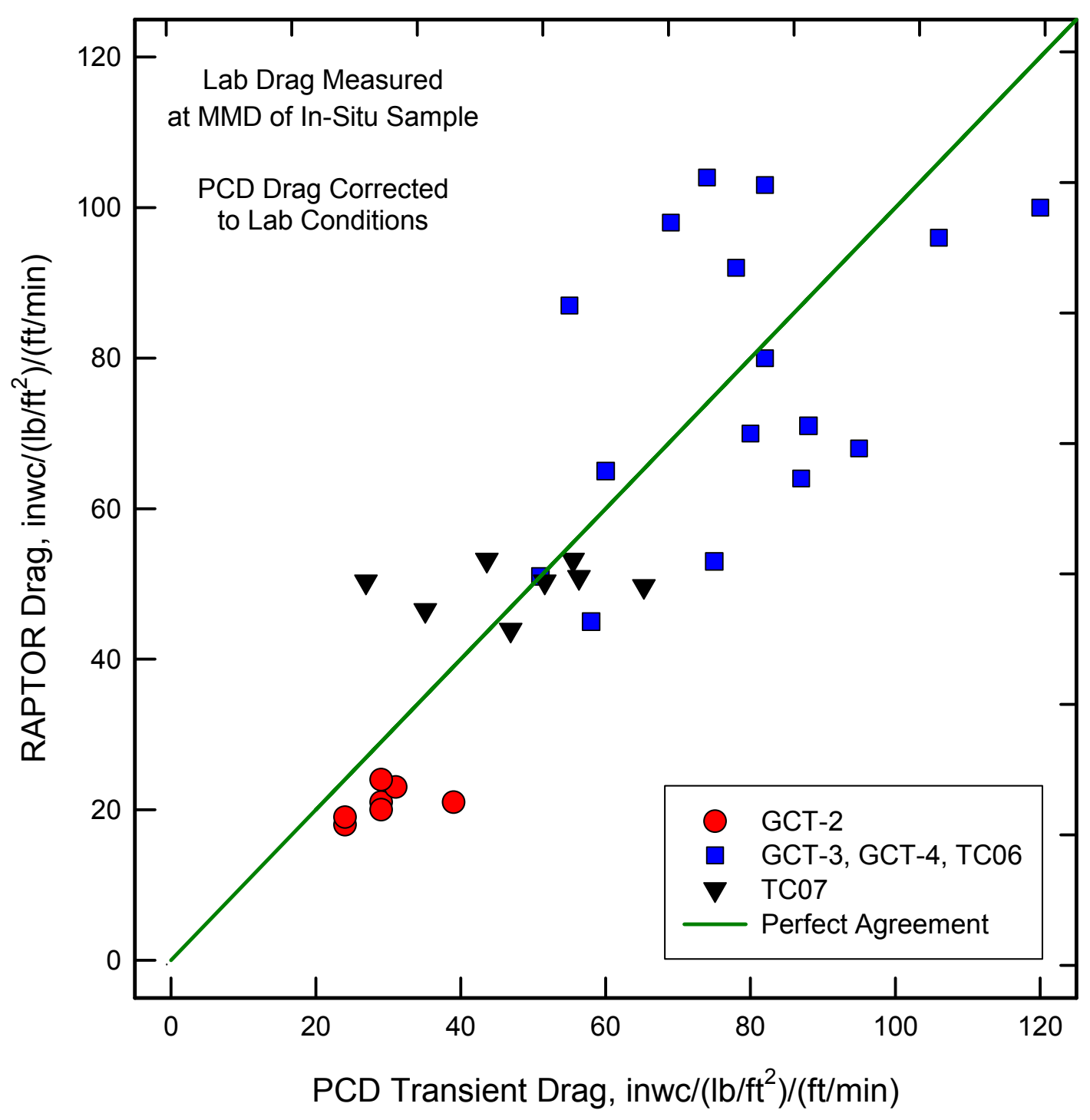

Figure 3.4-10 Comparison of PCD Drag With RAPTOR Measurements 


\subsection{TRANSPORT REACTOR}

\subsection{REACTOR OPERATIONS}

Prior to TC07, a major modification was made to the Transport Gasifier to allow operations with enriched air and pure oxygen. The modification involved removing the combustor heat exchanger J-leg and replacing it with a spool piece to allow oxygen, air, steam, and nitrogen to be fed and distributed. The new spool piece is designated as the lower mixing zone (LMZ). The spool piece allows the Transport Gasifier to operate in enriched air and oxygen-blown modes. The spool piece was necessary because the existing air feed lines were not suitable for oxygen service. The spool piece was designed to test the effectiveness of distribution from a central jet without internals. A drawing of the spool piece can be found in Figure 4.1-1.

The primary objective for TC07 was as follows:

- Reactor Operations - The Transport Reactor was modified to operate with enriched air or pure oxygen for future test runs by adding a LMZ. Evaluate effect of the LMZ on temperature profiles, circulation rates, operational stability, and process performance in air-blown operation and evaluate the effects on the LMZ of changes in circulation rate, velocity in the LMZ, and air/steam ratios in the LMZ.

The secondary objectives included the following:

- Minimize Tar Formation - Effects of using coke breeze to eliminate tar formation during transition from start-up burner to coal and hot restarts.

- Reactor Operations - Devolatilization and tar cracking effects, effect of process operations on heat release, heat transfer and accelerated fuel particle heatup rates, and effect of changes in reactor conditions on transient temperature profiles and pressure balance.

- Effects of Reactor Conditions on Process Performance - Continue to study effects of different reactor parameters such as steam/coal ratio and reactor temperature on $\mathrm{CO} / \mathrm{CO}_{2}$ ratio, carbon conversion, product gas composition, and cold- and hot-gas efficiencies.

- Use of Refuse Iron Oxide as Polishing Sorbent for Sulfur - Inject refuse iron oxide downstream of the primary gas cooler to evaluate its effectiveness in removing sulfur from the syngas stream.

During TC07, the unit operated for a total of 442 hours on coal and 33 hours of coke breeze feed. Table 4.1-1 gives the general operating conditions. The coal feed consisted of 398 
hours of PRB and 44 hours of Alabama bituminous. Table 4.1-2 lists both coal analyses. The sorbent for TC07 was Ohio Bucyrus limestone, see Table 4.1-3.

The December part of TC07 was concerned with curing the refractory in the new spool piece and testing the effects of the LMZ on the hydrodynamics of the gasifier by circulating sand. Because the new tube bundle for the primary gas cooler had not yet been delivered, the particulate control device (PCD) was preheated using the start-up burner (SU0601) for the atmospheric fluidized-bed combustor (AFBC). On December 11, the start-up burner was fired to begin the cure. Over the next few days most of the instrumentation and valves associated with the new LMZ were tested. The sand tests did not reveal any circulation problems from the spool piece. TC07A was concluded on December 14, 2001, when the unit was shutdown.

After the TC07A test run, the hydrodynamics of the circulating bed during TC07 were compared to data from before the addition of the LMZ. Two areas that were investigated were the effect of standpipe level on circulation rate and the effect of J-leg aeration on circulation rate. Figure 4.1-2 compares the standpipe solids level with the differential pressure across the riser which is used to calculate the circulation rate in TC06. In both tests runs, there was strong, linear correlation between the two measurements. The slopes are parallel to one another and the slight difference in values is likely due to either differences in the density of the circulating bed or errors from improperly zeroed differential pressure measurements. Figure 4.1-3 shows a slight increase in circulation rate with increasing dipleg aeration flows in TC06 and TC07. Hourly averages from PRB coal operation were used in Figures $4.1-2$ and -3 .

The new tube bundle arrived and was installed in early January 2002. The TC07 test run resumed in January with TC07B and the start-up burner was lit on January 17. During startup, many of the pressure taps in the gasifier were found to be plugged and required cleanout to operate properly. Coal feed was delayed when several small agglomerates were found plugging the feeder. Coal feed with Powder River Basin (PRB) was established on January 19, 2002. Coal feed was discontinued after a short time because of problems with the nitrogen plant air compressor and a leaking flange on the reactor. The coke breeze system was started but plugged allowing the temperatures to drop low enough to force the burner to be fired.

Coal feed started again on January 21, 2002. After resolving a couple of initial problems with the coal feed motor inverter, the unit ran well until January 23, with only one 20-minute coal stoppage. During this time, it was observed that the temperatures in the LMZ were more than $1,000^{\circ} \mathrm{F}$ lower than expected. The thermocouples in the LMZ indicated between 100 and $300^{\circ} \mathrm{F}$. In the early morning of January 23,2002 , the coal feeder ran out of coal when the conveying line from the pulverized coal silo to the coal feeder plugged resulting in a 30-minute coal stoppage.

Starting at about 09:00 on January 23, 2002, a pressure tap on the mixing zone used to in the operation of the coal feed system started to become plugged intermittently. When the line 
plugged, the coal feeder would trip. The coal feed logic was changed to stop the problem. On January 24, the coal feed was interrupted for 14 hours when both the coal feed and coke breeze feed lines plugged.

During the afternoon of January 25, 2002, the unit was transitioned from PRB to Alabama bituminous coal. With the transition to bituminous coal, the amount of gasification ash (gash, formerly referred to as char) going to the PCD increased, which resulted in making it difficult to remove the g-ash from the PCD and to feed g-ash to the AFBC at rates sufficient to prevent $g$-ash from accumulating in the g-ash feeder surge bin. This necessitated a decrease in the coal-feed rate.

Within about 12 hours of starting bituminous coal feed, temperatures in the mixing zone started to indicate that deposits were forming. About the same time, pressure taps in the mixing zone were becoming difficult to maintain clear. The reactor lost circulation early January 27, 2002, and was shut down to clear the deposits from the mixing zone, thus concluding TC07B. An inspection revealed that the gasifier had heavy deposits from the LMZ up to just below the reactor J-leg and then from just above the reactor J-leg to near the coal feed nozzle. The deposits were removed and the unit prepared to restart the run.

On February 7, 2002, TC07 continued (TC07C) as bituminous coal feed was restarted to the reactor. Within an hour, the mixing zone thermocouples again indicated the formation of deposits. After 10 hours of coal feed, the gasifier lost circulation and was shutdown. An inspection revealed that the deposits were in much the same place as before. The deposits were removed. The inspection also revealed that the thermocouples in the LMZ were only partially inserted and that the actual temperature in the LMZ had been sufficient to partially melt one of the thermowells. It was decided that the rest of the run should be dedicated to commissioning the LMZ on PRB.

TC07 continued (TC07D) with PRB feed starting on March 22, 2002, with a few hours of problematic coal feed apparently due to control logic issues. On March 23, consistent coal feed was achieved. The LMZ temperatures were, as expected, closer to temperatures in the upper mixing zone (UMZ). With steady operation achieved, commissioning of the LMZ was able to proceed in earnest. Correcting the thermocouple installations allowed the correct temperature profile in the LMZ to be seen. During the remainder of the run, the air and steam flows to the LMZ were controlled over their entire operating range to find the practical minimum and maximum feedrates and their effect on temperature and pressure profiles. Various control valves associated with flows in the LMZ were tuned. With the PRB coal, it was found that the limiting factor on the air feed to the LMZ was the maximum flow possible through the lines. After testing at different parts of the operational envelope, the operation finally settled on feeding 4,500 to $5,000 \mathrm{pph}$ of air through the LMZ and 0 to $1,000 \mathrm{pph}$ of steam.

On March 28, 29, 30, and 31, brief coal feeder trips were encountered with coal feed usually being reestablished within 15 minutes. On March 29, a new feed system (FD0230), installed to feed sorbents and other materials to the PCD inlet, was tested using sand for the first 
time. After successful operation with sand, refuse iron oxide was loaded into the feeder and fed to the PCD. A slight decrease in the sulfur in the gas stream was then measured. See section 4.6 for more details. From March 30 to April 3, 2002, additional iron oxide tests were carried out using different iron oxides, feed sizes, and feed rates. Most of these tests were brief, typically lasting 15 to 30 minutes. On April 3 and 4, 2002, iron oxide was fed to the PCD inlet using the gasifier sorbent feeder. On April 5, a test was carried out in which iron oxide was injected directly into the mixing zone from the sorbent feeder. Due to the high moisture content of the syngas from the high inherent moisture in PRB coal, the effects of the iron oxide injection on sulfur capture were marginal.

TC07D ended on April 5, 2002, when a high conveying line pressure forced the coal feeder to trip. The defined steady-state operating periods for TC07 are listed in Table 4.1-4.

\section{$\underline{\text { Reactor Inspections }}$}

Inspections on the reactor loop after the two loss of circulation events and a full inspection on the reactor loop and the PCD at the completion of the test run were performed.

On January 27, 2002, the gasifier was shutdown due to loss of circulation and suspected deposits in the mixing zone. The reactor was inspected and a variety of problems were encountered. Most seriously, the mixing zone had deposits stretching from the bottom of the LMZ to just below the coal-feed nozzle. In the LMZ, up to about the J-legs, the deposits were light in color, brittle, and looked like agglomerations of the start-up sand material and ash. Above the J-legs up to about 2 feet below the coal-feed nozzle, the deposits were harder, dark in color, and looked like melted ash had fused bed material. Around the immediate area of the J-legs, the mixing zone was clear. The mixing zone deposits blocked almost the entire cross sectional area of the mixing zone. Cleanup of the deposits required the removal of the LMZ. The downcomer to the loop seal had a small deposit blocking the entry to the loop seal. The burner had some deposits and loose fused material in the J-leg and a large coke deposit (caused by the propane fuel) near the burner tip.

On February 8, 2002, the gasifier was shutdown after only about 10 hours on coal due to the possibility of a PCD leak and suspected mixing zone deposit. Upon inspection, the mixing zone was again found to be nearly completely blocked from the LMZ to about 5 feet below the coal-feed nozzle. Again, the area around the J-legs was found to be relatively clean. Above the J-legs the deposits were of widely varying properties. There were soft agglomerations of different colors some with visible layers and there were also deposits that showed evidence of melting. In the LMZ the deposits were dark gray and showed signs of melting. The LMZ inspection also revealed that the thermocouples in the LMZ had been improperly installed leaving the thermocouples about 6 inches short of the proper length. This led to operation of the LMZ at much higher temperatures than indicated and as a result one stainless steel thermowell in the LMZ was found to be partially melted. Clean-up of these deposits also required removal of the mixing zone. 
After completion of the test run a full inspection was conducted. The mixing zone, LMZ, riser, and standpipe were found to be in good condition. Only the normal wear and tear and very small deposits were found in these areas. The downcomer to the loop seal was inspected with a boroscope. The upper part of the downcomer was very clean and in good condition. However, the condition deteriorated near the bottom of the downcomer. About 15 feet from the bottom, there was a large, deep piece of missing refractory. Below this, the walls were covered with small, bumpy deposits. About 5 feet from the bottom, the refractory began to look very rough as if many small pieces of refractory had fallen from the wall.

In the primary gas cooler, the new ceramic ferrules were found to have performed well but there were deposits on the tubesheet and some of the tubes were plugged or partially plugged. The syngas combustor and waste heat boiler were inspected and found to be in excellent condition. 
Table 4.1-1

TCO7 Operating Conditions

\begin{tabular}{|c|c|}
\hline Start-up Bed Material & Sand, $\sim 120 \mu \mathrm{m}$ \\
\hline Start-up Fuel & Coke Breeze \\
\hline Fuel Type & Powder River Basin / Alabama Bituminous \\
\hline Fuel Particle Size (mmd) & $275 \mu \mathrm{m}$ \\
\hline Average Fuel-Feed Rate, pph & 5,000 \\
\hline Sorbent Type & Ohio Bucyrus limestone \\
\hline Sorbent Particle Size (mmd) & $40 \mu \mathrm{m}$ \\
\hline Sorbent Feed Rate & $\begin{array}{l}125-250 \mathrm{pph}(\mathrm{Ca} / \mathrm{S} \text { molar ratio }=2.0-4.0) \\
\text { for sulfur capture and cracking tar }\end{array}$ \\
\hline Reactor Temperature, ${ }^{\circ} \mathrm{F}$ & $1,750-1,800$ \\
\hline Reactor Pressure, psig & $180-250$ \\
\hline Riser Gas Velocity, fps & $45-70$ \\
\hline Riser Mass Flux, lb/ $\mathrm{ft}^{2}$ & $150-450$ (average slip ratio $=2$ ) \\
\hline Primary Gas Cooler Bypass & $0 \%$ \\
\hline PCD Temperature, ${ }^{\circ} \mathrm{F}$ & $700-900$ \\
\hline Total Gas Flowrate, pph & $20,000-30,000$ \\
\hline Air/coal ratio & as needed to control reactor temperature \\
\hline Primary Air Split ( $1^{\text {st }} / 2^{\text {nd }}$ levels $)$ & $50 / 50$ \\
\hline Steam/coal molar ratio & 0.0 to 0.4 \\
\hline Sulfator Operating Temperature, ${ }^{\circ} \mathrm{F}$ & $1,600-1,650$ \\
\hline
\end{tabular}


Table 4.1-2

Coal Analyses

\begin{tabular}{|c|c|c|c|}
\hline & Powde & iver Basin & AL Bit. \\
\hline & Value & $\begin{array}{l}\text { Standard } \\
\text { Deviation }\end{array}$ & Value \\
\hline Moisture, $\mathrm{Wt} \%$ & 22.11 & 0.75 & 4.64 \\
\hline Carbon, $\mathrm{Wt} \%$ & 54.67 & 0.53 & 67.42 \\
\hline Hydrogen ${ }^{1}, \mathrm{Wt} \%$ & 3.39 & 0.17 & 4.14 \\
\hline Nitrogen, $\mathrm{Wt} \%$ & 0.72 & 0.01 & 1.50 \\
\hline Oxygen, $\mathrm{Wt} \%$ & 13.47 & 0.34 & 6.45 \\
\hline Sulfur, $\mathrm{Wt} \%$ & 0.24 & 0.02 & 0.77 \\
\hline Ash, $\mathrm{Wt} \%$ & 5.40 & 0.32 & 15.08 \\
\hline Volatiles, $\mathrm{Wt} \%$ & 32.92 & 0.66 & 28.62 \\
\hline Fixed Carbon, $\mathrm{Wt} \%$ & 39.57 & 0.47 & 51.66 \\
\hline Higher Heating Value, Btu/lb & 9,249 & 102 & 11,644 \\
\hline Lower Heating Value, Btu/lb & 8,707 & 104 & 11,212 \\
\hline $\mathrm{CaO}, \mathrm{Wt} \%$ & 1.11 & 0.03 & 0.64 \\
\hline $\mathrm{SiO}_{2}, \mathrm{Wt} \%$ & 1.94 & 0.17 & 8.32 \\
\hline $\mathrm{Al}_{2} \mathrm{O}_{3}, \mathrm{Wt} \%$ & 0.91 & 0.07 & 3.89 \\
\hline $\mathrm{MgO}, \mathrm{Wt} \%$ & 0.25 & 0.01 & 0.21 \\
\hline $\mathrm{Fe}_{2} \mathrm{O}_{3}, \mathrm{Wt} \%$ & 0.31 & 0.03 & 0.78 \\
\hline $\mathrm{Ca} / \mathrm{S}$, mole/mole & 2.63 & 0.20 & 0.48 \\
\hline $\mathrm{Fe} / \mathrm{S}$, mole/mole & 0.51 & 0.05 & 0.41 \\
\hline
\end{tabular}

Notes:

1. All analyses are as sampled at FD0210.

2. Hydrogen in coal is reported separately from hydrogen in moisture.

3. Samples AB09801 and AB10150 excluded.

4. Only two Alabama Bituminous coal samples analyzed. 
Table 4.1-3

Limestone Analysis

\begin{tabular}{|c|c|c|}
\hline Compound & $\begin{array}{c}\text { Weight } \\
\%\end{array}$ & $\begin{array}{l}\text { Standard } \\
\text { Deviation }\end{array}$ \\
\hline $\mathrm{CaCO}_{3}$ & 74.71 & 1.24 \\
\hline $\mathrm{MgCO}_{3}$ & 17.66 & 0.40 \\
\hline $\mathrm{CaSO}_{4}$ & 0.19 & 0.22 \\
\hline $\mathrm{SiO}_{2}$ & 3.94 & 1.32 \\
\hline $\mathrm{Al}_{2} \mathrm{O}_{3}$ & 0.83 & 0.10 \\
\hline $\mathrm{Fe}_{2} \mathrm{O}_{3}$ & 0.42 & 0.06 \\
\hline Other Inerts $^{2}$ & 0.17 & 0.04 \\
\hline $\mathrm{H}_{2} \mathrm{O}$ & 0.22 & 0.05 \\
\hline Total & 98.15 & \\
\hline
\end{tabular}

Notes:

1. All analyses are as sampled at FD0220.

2. Other inerts consist of $\mathrm{P}_{2} \mathrm{O}_{5}, \mathrm{Na}_{2} \mathrm{O}, \mathrm{K}_{2} \mathrm{O}, \& \mathrm{TiO}_{2}$. 
Table 4.1-4

Operating Periods

\begin{tabular}{|c|c|c|c|c|c|c|c|c|}
\hline $\begin{array}{c}\text { Test } \\
\text { Period }\end{array}$ & Duration & $\begin{array}{c}\text { MZ temp } \\
\text { deg } F\end{array}$ & $\begin{array}{c}\text { Rsr Temp } \\
\text { deg F }\end{array}$ & $\begin{array}{c}\text { Pressure } \\
\text { Psig }\end{array}$ & $\begin{array}{c}\text { Coal Fd } \\
\text { Rate }^{1} \\
\text { lb/hr }\end{array}$ & $\begin{array}{c}\text { Air Flow } \\
\mathrm{lb} / \mathrm{hr}\end{array}$ & Air/Coal & Air/C \\
\hline TC07-1 & $8: 00$ & 1,708 & 1,743 & 200 & 3,930 & 13,874 & 3.53 & 6.42 \\
\hline TC07-2 & $2: 00$ & 1,712 & 1,743 & 200 & 3,956 & 13,821 & 3.49 & 6.35 \\
\hline TC07-3 & $8: 30$ & 1,696 & 1,720 & 200 & 4,006 & 13,483 & 3.37 & 6.12 \\
\hline TC07-4 & $8: 30$ & 1,711 & 1,721 & 200 & 3,695 & 13,900 & 3.76 & 6.84 \\
\hline TC07-5 & $2: 30$ & 1,693 & 1,696 & 200 & 3,782 & 14,490 & 3.83 & 6.97 \\
\hline TC07-6 & $3: 30$ & 1,732 & 1,701 & 200 & 3,719 & 13,457 & 3.62 & 6.58 \\
\hline TC07-7 & $5: 45$ & 1,732 & 1,700 & 200 & 3,768 & 13,610 & 3.61 & 6.57 \\
\hline TC07-8 & $2: 30$ & 1,744 & 1,697 & 200 & 3,917 & 14,388 & 3.67 & 6.68 \\
\hline TC07-9 & $25: 15$ & 1,745 & 1,705 & 200 & 4,309 & 14,120 & 3.28 & 5.96 \\
\hline TC07-10 & $4: 00$ & 1,740 & 1,700 & 200 & 4,421 & 12,963 & 2.93 & 5.33 \\
\hline TC07-11 & $6: 30$ & 1,748 & 1,703 & 200 & 4,296 & 13,728 & 3.20 & 5.81 \\
\hline TC07-12 & $3: 15$ & 1,740 & 1,689 & 200 & 4,315 & 13,497 & 3.13 & 5.69 \\
\hline TC07-13 & 9:00 & 1,745 & 1,699 & 200 & 4,503 & 13,384 & 2.97 & 5.40 \\
\hline TC07-14 & $6: 30$ & 1,744 & 1,697 & 200 & 4,501 & 13,388 & 2.97 & 5.41 \\
\hline TC07-15 & 6:00 & 1,746 & 1,699 & 200 & 4,558 & 13,407 & 2.94 & 5.35 \\
\hline TC07-16 & $7: 00$ & 1,742 & 1,692 & 200 & 4,682 & 13,559 & 2.90 & 5.27 \\
\hline TC07-17 & 3:00 & 1,745 & 1,700 & 210 & 4,719 & 13,285 & 2.82 & 5.12 \\
\hline TC07-18 & $5: 45$ & 1,754 & 1,709 & 210 & 4,786 & 13,505 & 2.82 & 5.13 \\
\hline TC07-19 & $9: 15$ & 1,756 & 1,712 & 210 & 5,042 & 13,719 & 2.72 & 4.95 \\
\hline TC07-20 & $4: 15$ & 1,761 & 1,717 & 210 & 5,037 & 14,193 & 2.82 & 5.12 \\
\hline TC07-21 & $3: 00$ & 1,749 & 1,705 & 210 & 4,577 & 13,345 & 2.92 & 5.30 \\
\hline TC07-22 & $11: 00$ & 1,758 & 1,712 & 210 & 4,502 & 13,561 & 3.01 & 5.48 \\
\hline TC07-23 & $3: 00$ & 1,741 & 1,691 & 210 & 4,203 & 12,083 & 2.88 & 5.23 \\
\hline TC07-24 & $11: 00$ & 1,745 & 1,699 & 210 & 4,399 & 12,583 & 2.86 & 5.20 \\
\hline TC07-25 & 3:00 & 1,744 & 1,689 & 210 & 4,404 & 11,687 & 2.65 & 4.82 \\
\hline TC07-26 & $1: 30$ & 1,747 & 1,700 & 210 & 4,620 & 13,006 & 2.82 & 5.12 \\
\hline TC07-27 & $2: 00$ & 1,749 & 1,695 & 226 & 4,578 & 12,641 & 2.76 & 5.02 \\
\hline TC07-28 & $2: 15$ & 1,751 & 1,693 & 240 & 4,576 & 11,927 & 2.61 & 4.74 \\
\hline TC07-29 & $1: 00$ & 1,751 & 1,708 & 160 & 4,820 & 13,766 & 2.86 & 5.19 \\
\hline
\end{tabular}

${ }^{1}$ Based on the nuclear density gauges. 


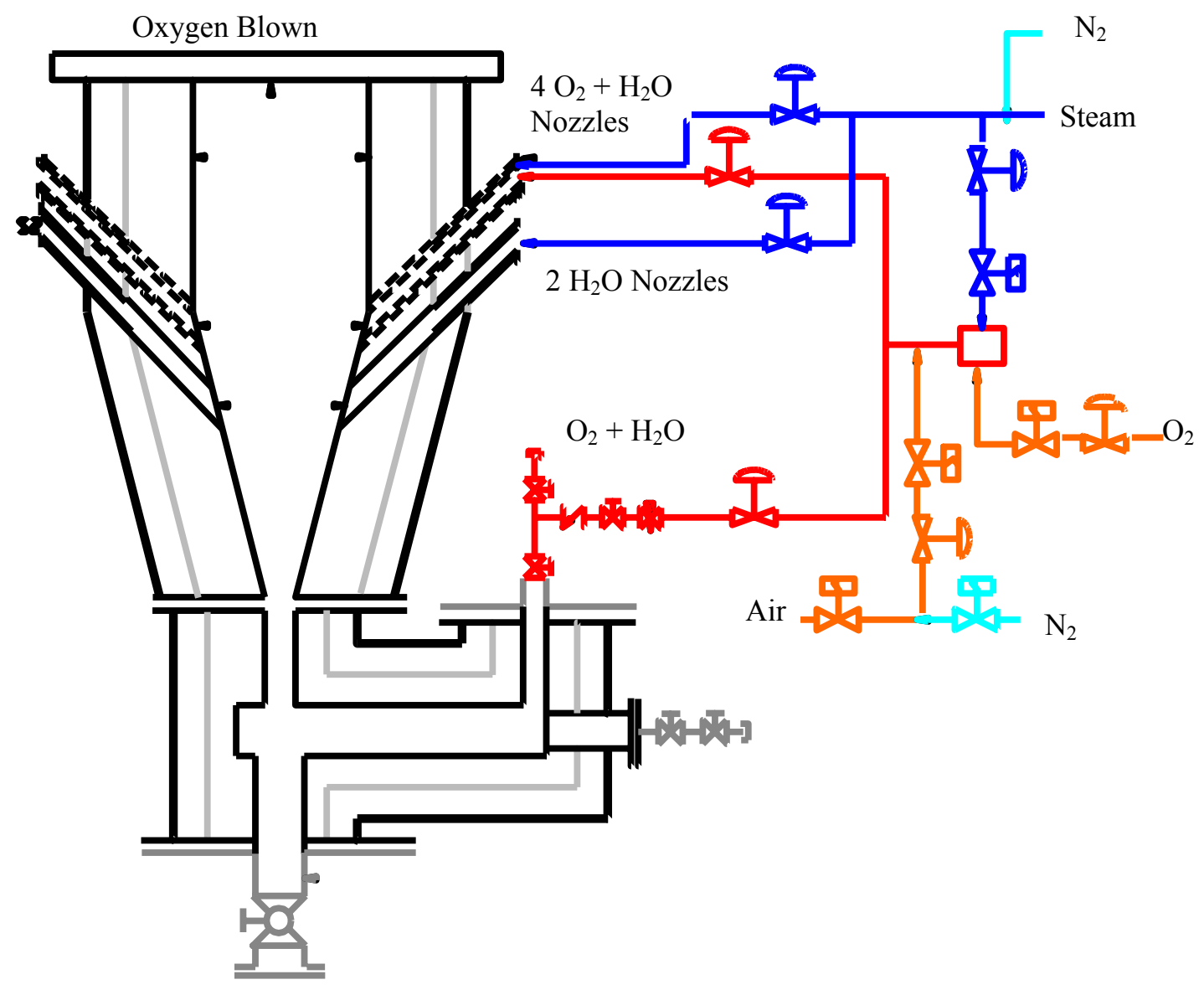

Figure 4.1-1 Lower Mixing Zone Spool Piece for Enriched Air and Oxygen-Blown Operations 


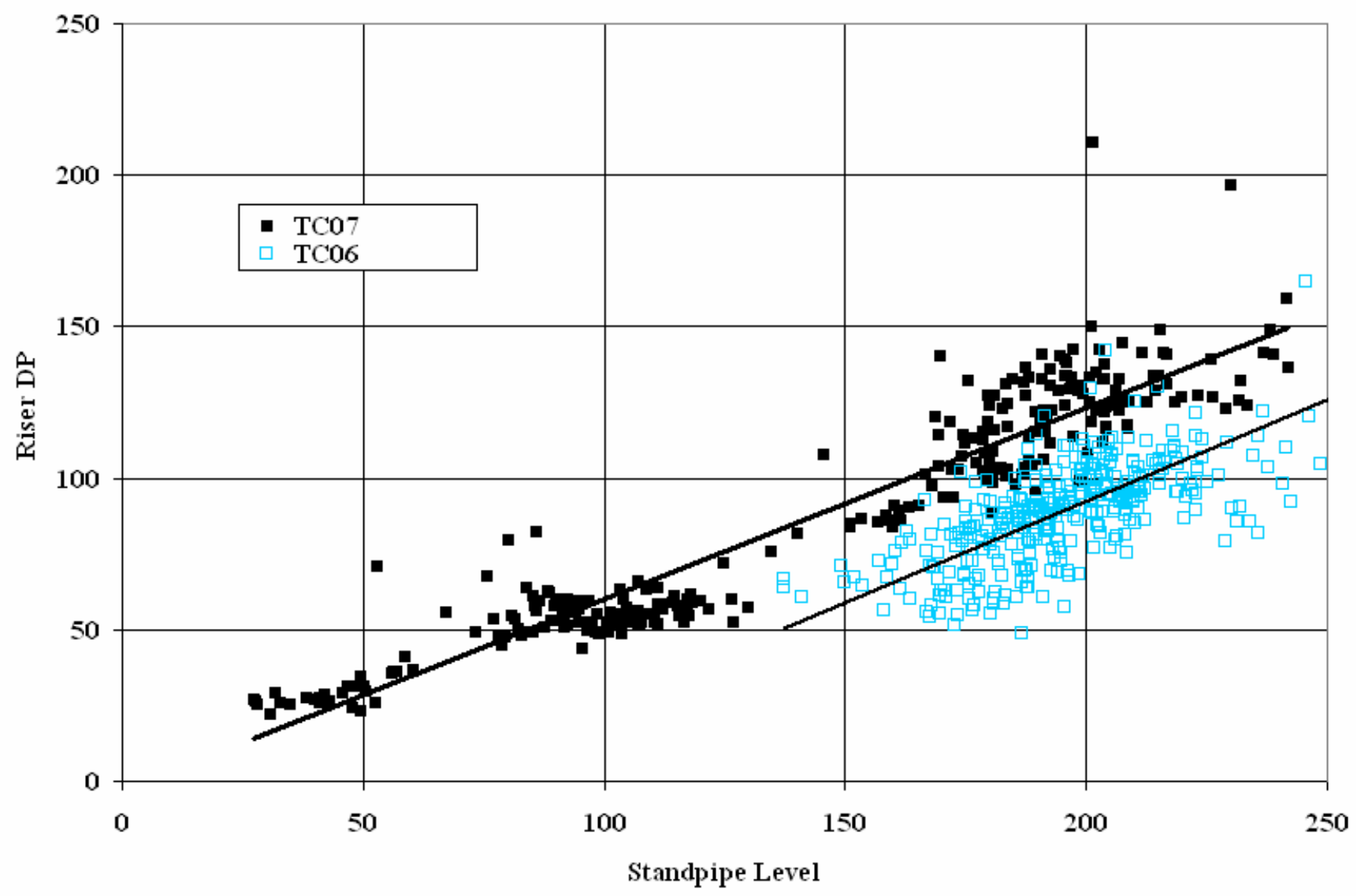

Figure 4.1-2 Compare the Effect of Standpipe Level on Circulation Rate in TCO7 and TCO6 


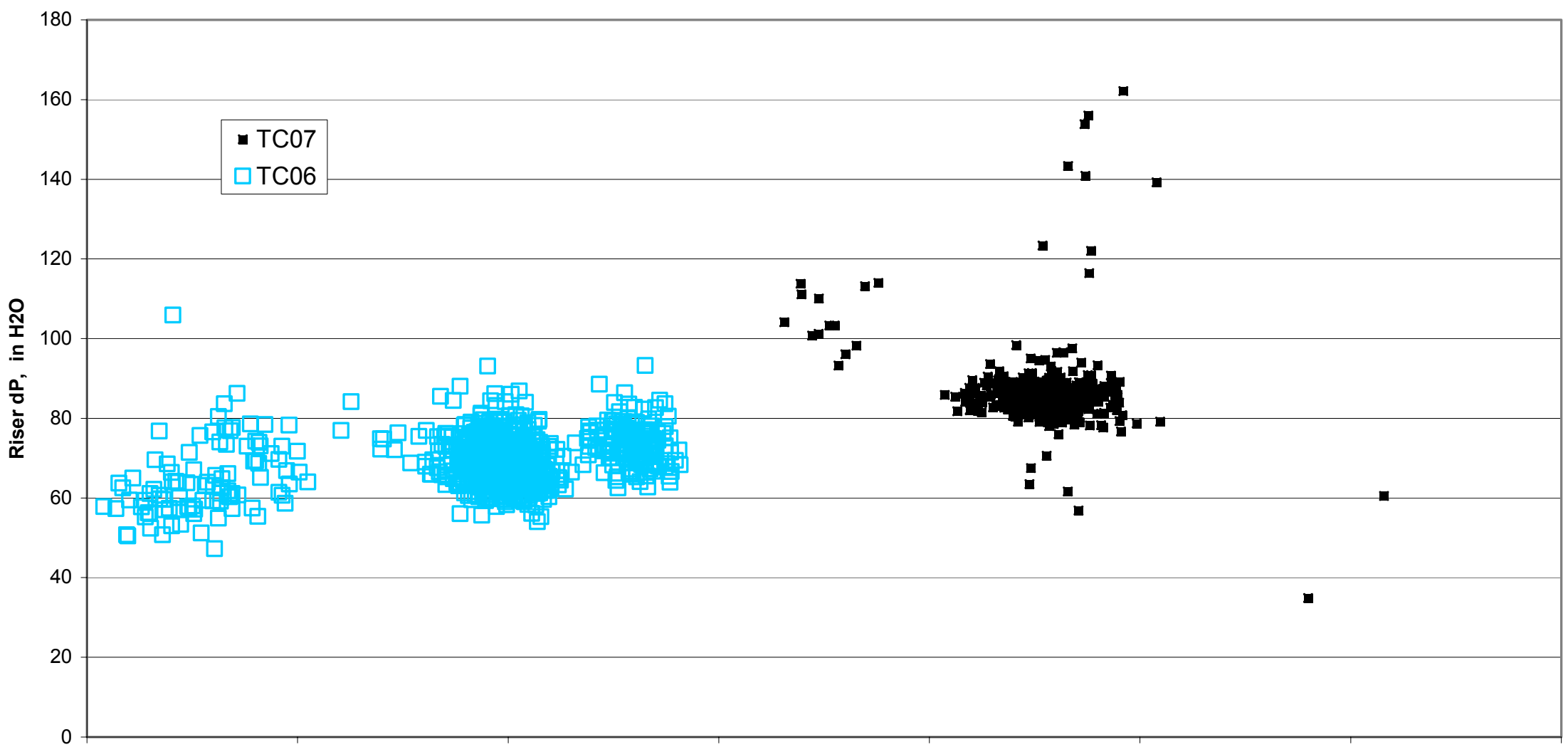

J-Leg Aeration Flow, pph

Figure 4.1-3 Compare the Effect of Dipleg Aeration on Circulation Rate in TCO7 and TCO6 


\subsection{REACTOR TEMPERATURE PROFILES}

Section 4.2 describes the temperature profiles in TC07. A schematic of the reactor with relative thermocouple locations is given in Figure 4.2-1. The temperature profile for steadystate period TC07D-13 is shown in Figure 4.2-2. The temperature in the LMZ, T1-T3, increases quickly as the heat released from g-ash combustion heats the air, steam, and solids in the LMZ. The temperature then decreases as cooler solids from the J-leg, T11, enter the upper mixing zone (UMZ), T4. Air and steam added in the UMZ decrease the temperature, T5, slightly further. The temperature, T6-T7, begins to increase as g-ash combustions occur. Coal and sorbent are added as the UMZ transitions into the riser, see Figure 4.2-1. Coal, sorbent, and conveying gas heat-up, coal devolatilization and endothermic gasification reactions combined with heat losses decrease the temperature, T8, as the gas and solids flow up through the riser. The solids removed by the disengager and cyclone cool as they flow down the standpipe (T9-T11).

Several operating parameters influence the temperature profile: coal-feed rate, amount of carbon in circulating solids, solids circulation rate, and air and steam flow distribution. The effect of solids circulation rate on the temperature profile is shown in Figures 4.2-3 and -4. The temperature profiles at a medium circulation rate (TC07D-9) and a high solids circulation rate (TC07D-13) are given in Figure 4.2-3. The high solids circulation rate is about 1.7 times greater than the medium solids circulation rate. The medium and high solids circulation rate temperature profiles are similar with a few notable differences. First, the temperature decrease in the riser is higher for the medium solids circulation rate. Also, the temperature decrease in the standpipe is slightly higher. Thus the solids entering the UMZ are much cooler and have to be heated more in the UMZ to maintain the same reactor exit temperature. Figure 4.2-4 gives the temperature profile in the standpipe at three solids circulation rates: low (TC07D-2), medium (TC07D-9), and high (TC07D-13). The overall temperature drop for the high, medium, and low solids circulation rate is about 25, 30, and $45^{\circ} \mathrm{F}$, respectively. In summary the overall temperature drop in the standpipe decreases as the solids circulation rate increases consistent with observations in GCT3 and GCT4.

To evaluate the effect of the addition of the LMZ on the temperature profile, the profile for TC07 (TC07D-13) was compared to GCT4, see Figure 4.2-5. The TC07 temperature profile is much more uniform than in GCT4 especially in the UMZ (T4-T7). In TC07, much of the air, steam, and solids are heated in the LMZ before entering the UMZ whereas in GCT4 all of the gas and solids heating occurs in the UMZ itself. With the LMZ the temperature distribution throughout the reactor is much more uniform allowing the combustion zone temperatures to be relatively lower to maintain the same reactor exit temperature. This reduces the chances of agglomeration and clinker formation in the reactor. The uniform temperature distribution also allows operation at higher riser temperatures therefore increasing the carbon conversion and syngas quality as well as reducing tar formation to near zero. 


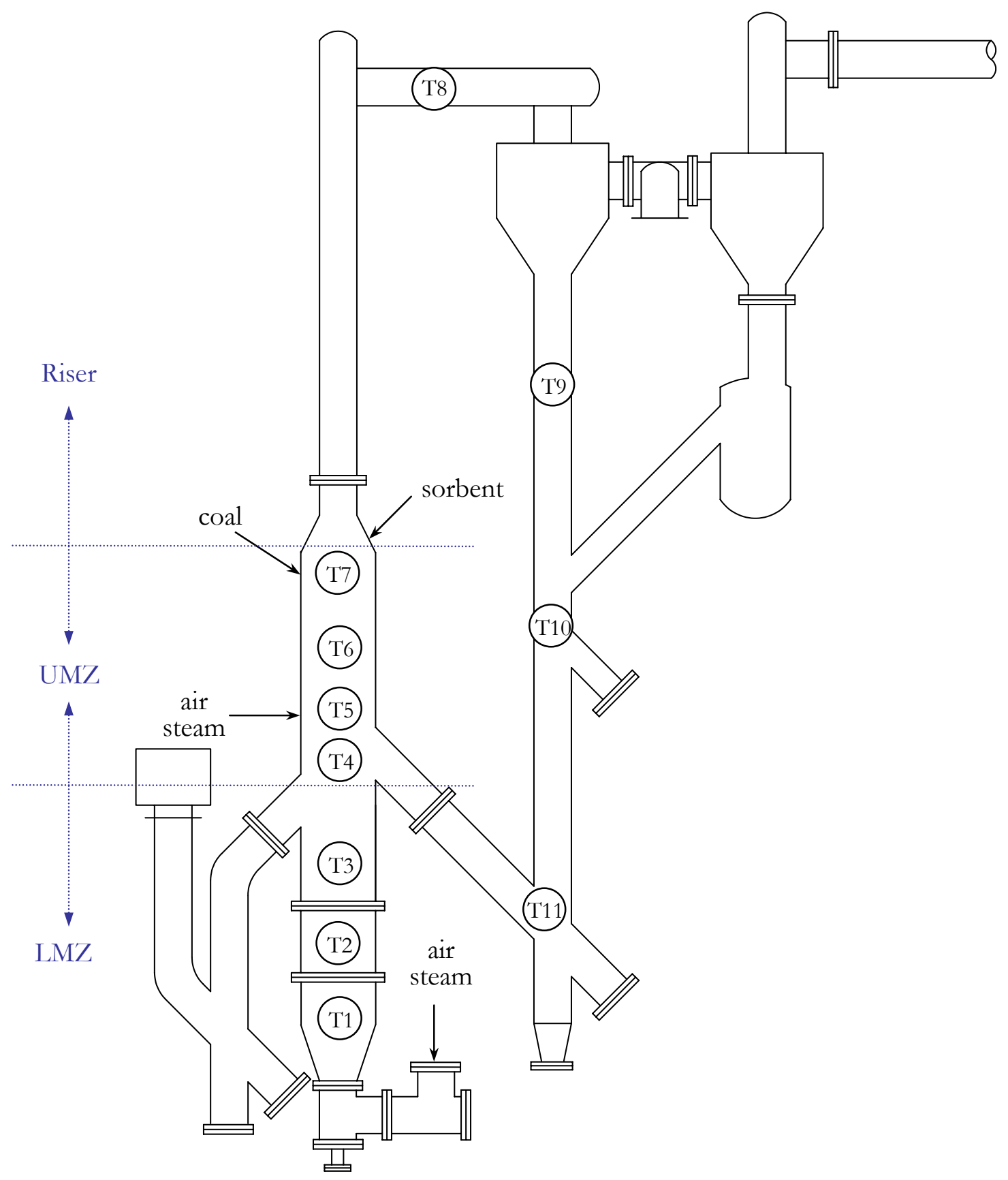

Figure 4.2-1 Transport Reactor Schematic 


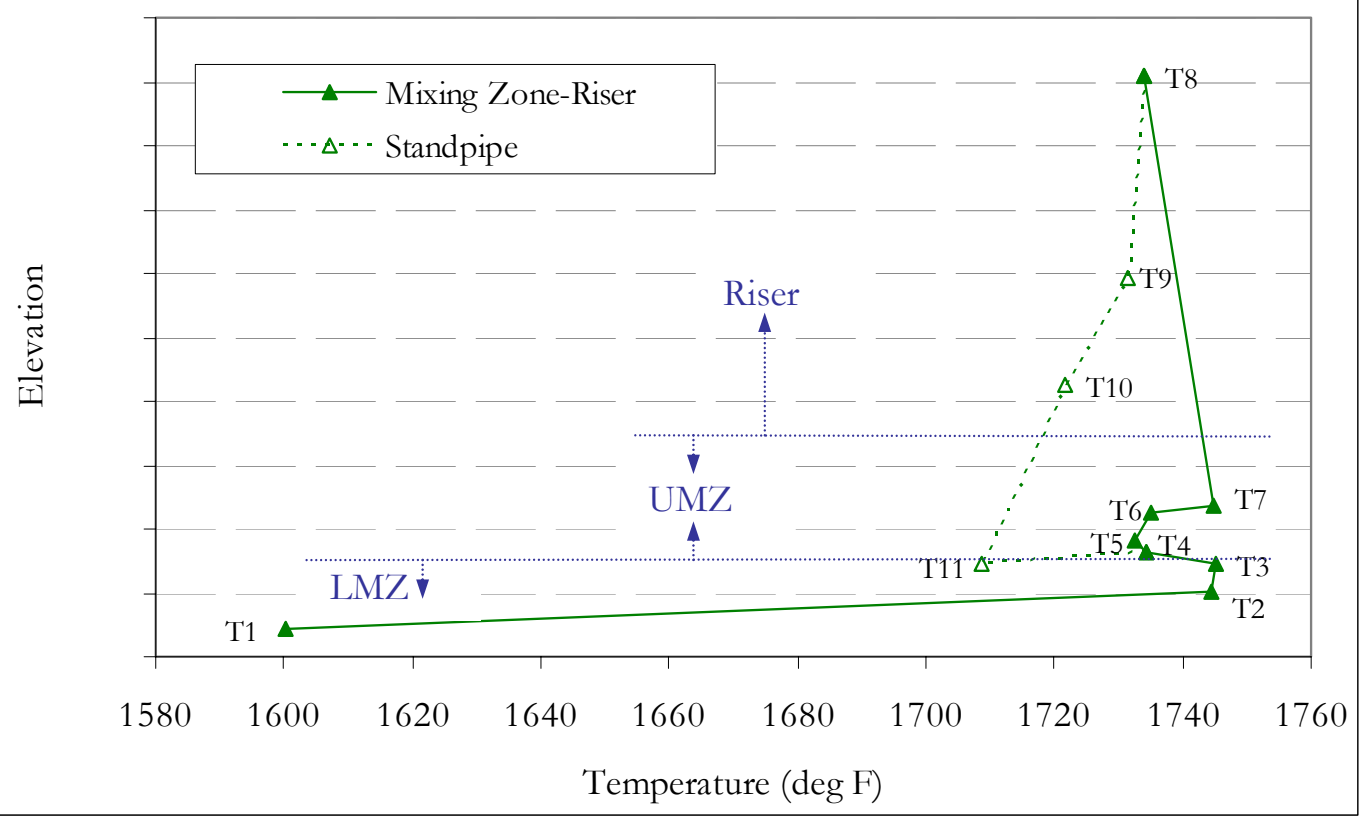

Figure 4.2-2 TCO7 Reactor Temperature Profile

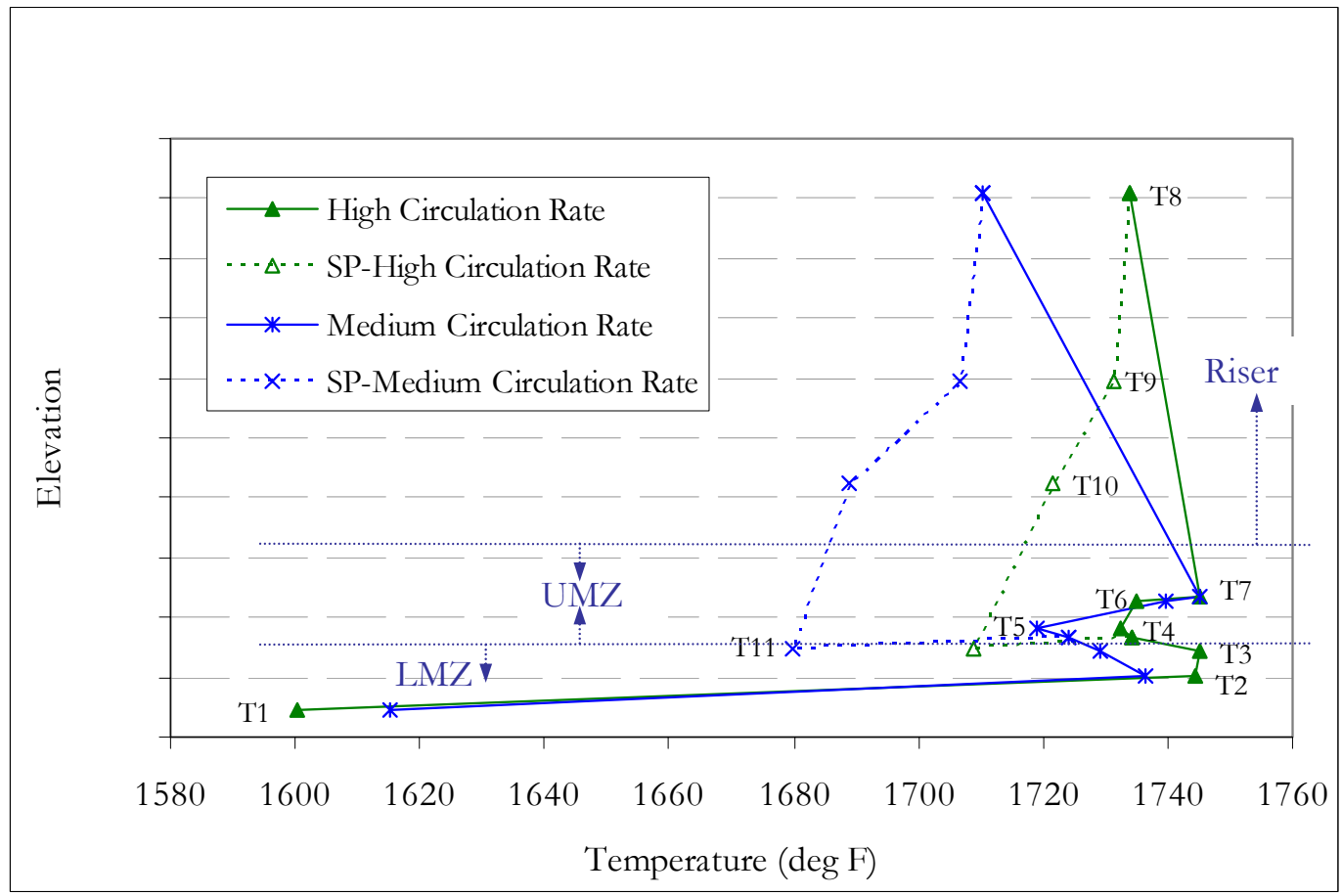

Figure 4.2-3 Reactor Temperature Profile for Medium and High Solids Circulation Rates 


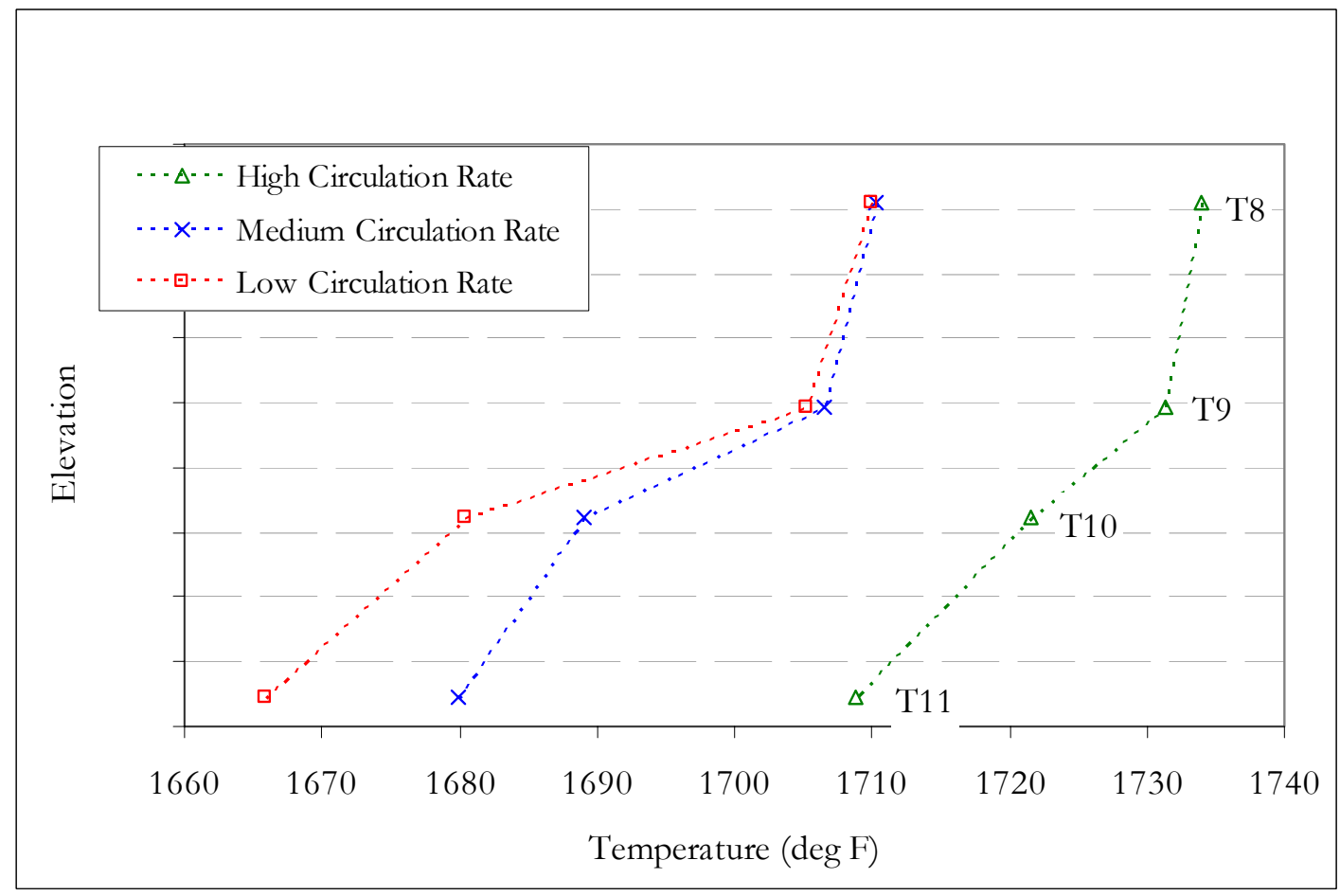

Figure 4.2-4. Standpipe Temperature Profiles for Low, Medium, and High Solids Circulation Rates

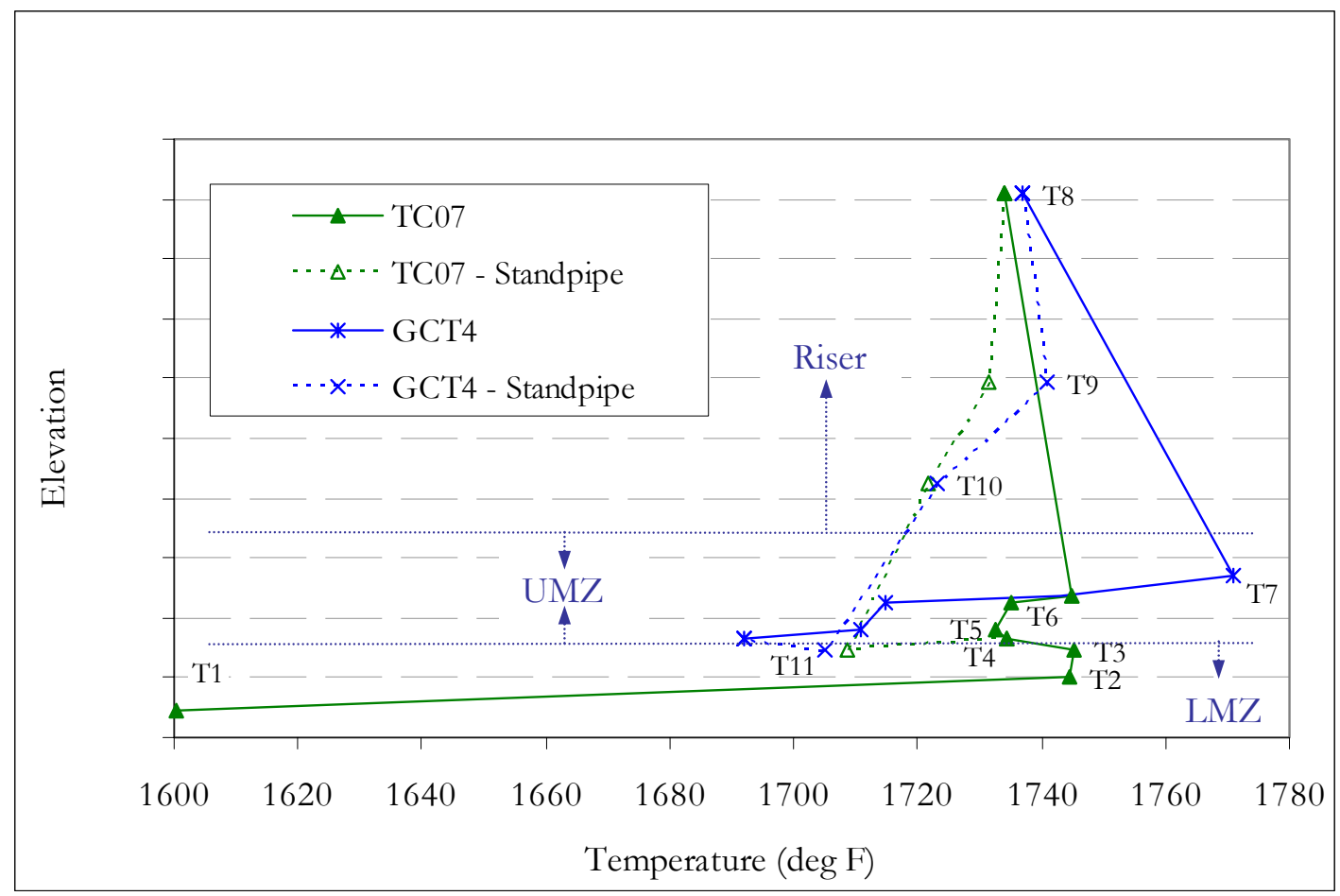

Figure 4.2-5 Temperature Profiles for TCO7 and GCT4 


\subsection{GAS ANALYSIS}

\subsubsection{Summary and Conclusions}

- The raw synthesis gas lower heating values (LHV) were between 52 and 64 Btu/SCF.

- The nitrogen corrected, adiabatic synthesis gas LHV were between 85 and $117 \mathrm{Btu} / \mathrm{SCF}$.

- Total reduced sulfur (TRS, mostly $\mathrm{H}_{2} \mathrm{~S}$ ) emissions were between 111 and 280 ppm. The concentrations were consistent with equilibrium thermodynamic calculations and were a strong function of the synthesis gas-moisture content and steam-injection rate.

- The nitrogen corrected, adiabatic synthesis gas TRS emissions were estimated at between 199 and 466 ppm.

- Synthesis gas ammonia emissions were between 1,511 and 1,907 $\mathrm{ppm} \mathrm{NH}_{3}$.

- The nitrogen corrected, adiabatic synthesis gas ammonia emissions were estimated at between 2,222 to $2,886 \mathrm{ppm}$.

- Synthesis Gas analyzer data for CO was excellent, with five of six analyzers in agreement with each other at the end of the run.

- Synthesis Gas analyzer data for $\mathrm{H}_{2}$ was excellent, with both gas chromatographs agreeing at the end of the run.

- Synthesis Gas analyzer data for $\mathrm{CH}_{4}$ was poor in that the old GC (AI464) was consistently 0.4 percent higher than the new GC (AI419). AI464 data was used for analysis.

- Synthesis Gas analyzer data for $\mathrm{C}_{2}^{+}$was poor in that the AI419 read about 0.275 percent higher than AI464. AI464 data was used for analysis.

- Synthesis Gas analyzer data for $\mathrm{N}_{2}$ was acceptable in that AI464 was 2 to 3 percent higher than AI419. AI464 data was used for analysis.

- Synthesis gas analyzer data for $\mathrm{H}_{2} \mathrm{O}$ only agreed with 3 out of the 10 in situ $\mathrm{H}_{2} \mathrm{O}$ measurements. The synthesis gas moisture was calculated using the thermodynamic equilibrium of the water-gas shift reaction at the mixing zone temperature.

- $\quad$ The $\mathrm{CO} / \mathrm{CO}_{2}$ ratio was between 0.7 and 1.4.

- The water gas shift constants using the in situ $\mathrm{H}_{2} \mathrm{O}$ measurements were between 0.6 and 0.8 .

- The synthesis gas molecular weight was between 26.1 and $27.3 \mathrm{lb} / \mathrm{mole}$.

- The synthesis gas combustor oxygen balance was excellent.

- The synthesis gas combustor hydrogen balance was excellent. 
- The synthesis gas combustor carbon balance was poor, in that the synthesis gas combustor $\mathrm{CO}_{2}$ analyzer measured more $\mathrm{CO}_{2}$ from the synthesis gas combustor than was calculated from the synthesis gas rate and synthesis gas analyzers. This indicated that there could be more carbon in the synthesis gas than measured by the synthesis gas analyzers.

\subsubsection{Introduction}

The major goal for TC07 was the commissioning of the LMZ on air with both PRB and an Alabama bituminous coal to prepare for oxygen-blown operation. PRB coal feed was established on January 19, 2002. After 102 hours on PRB, the Transport Reactor was transitioned to bituminous coal on January 25. The bituminous coal was fed for 34 hours before a loss of circulation in the Transport Reactor led to a reactor shutdown. An inspection revealed deposits in the mixing zone and LMZ. An analysis of the data found no steady operating periods between January 19 and 25, 2002.

After a short outage, coal feed using Alabama bituminous coal was started on February 7. Almost immediately, there were indications of deposits forming in the mixing zone. After 10 hours, coal feed was discontinued because of a loss of circulation in the Transport Reactor and particulate leakage through PCD filter elements.

Rather than return to bituminous coal operation, TC07 coal feed was restarted on March 23, 2002, as an air blown PRB test run to complete the LMZ commissioning. The Transport Reactor was then operated for 296 hours on PRB. The LMZ temperature and pressure profiles were acceptable over a wide range of air and steam flows.

There were 29 steady-periods of operation between March 23 and April 5, 2002. The steady periods of operation are given on Table 4.3-1. The only fuel used during the 29 steady periods of TC07 was PRB coal, which is a mixture of four different coals. Period TC07-9 was over 24 hours long and was split into three smaller operating periods. The sorbent used was Ohio Bucyrus limestone.

During seven periods, TC07-6, TC07-19, and TC07-25 to 29, limestone was not added to the reactor. There were periods (TC07-24 and 25) when iron oxide was added to the PCD. During TC07-29 iron oxide was added to the Transport Reactor. Iron oxide was also added to the reactor in between some of the operating periods on April 5, 2002.

\subsubsection{Raw Gas Analyzer Data}

During TC07, Transport and synthesis gas combustor outlet gas analyzers were continuously monitored and recorded by the Plant Information System (PI). Several in situ grab samples of synthesis gas moisture content were measured during PCD outlet loading sampling.

The gas analyzer system analyzed synthesis gas for the following gases during TC07, using the associated analyzers: 
- $\mathrm{CO}$ AI425, AI434B, AI453G, AI464C, AI419C, AI475C.

- $\mathrm{CO}_{2}$ AI434C, AI464D, AI419D, AI475D

- $\mathrm{CH}_{4} \quad$ AI464E, AI419E, AI475E

- $\mathrm{C}_{2}{ }^{+}$AI464F, AI419F

- $\mathrm{H}_{2}$ AI464G, AI419G

- $\mathrm{H}_{2} \mathrm{O}$ AI419H, AI475H

- $\mathrm{N}_{2}$ AI464B, AI419B

- $\mathrm{NH}_{3} \quad \mathrm{AI} 475 \mathrm{Q}$

- $\mathrm{H}_{2} \mathrm{~S} \quad \mathrm{AI} 419 \mathrm{~J}$

The AI464 and AI419 analyzers use a gas chromatograph and typically have about a 6minute delay. The other four CO analyzers (AI425, AI434B, AI453B, and AI475C) and two $\mathrm{CO}_{2}$ analyzers (AI434C and AI475C) are IR based and give more real-time measurements. All analyzers except for AI475 require that the gas sample be conditioned to remove water vapor, therefore all the analyzers except for AI475 report gas compositions on a dry basis. The AI464 bank of analyzers was used in previous testing. The AI419 bank of analyzers is new to TC07. The new GC provides backup for the entire AI464 syngas components and provides the first on-line $\mathrm{H}_{2} \mathrm{~S}$ analyzer data for the PSDF Transport Reactor.

New analyzer AI475 is an in situ gas analyzer, and hence all readings include moisture (wet). The analyzer bank provides backup $\mathrm{CO}, \mathrm{CO}_{2}$, and $\mathrm{CH}_{4}$ and is the only gas analyzer for $\mathrm{NH}_{3}$.

The locations of the synthesis gas analyzers are shown on Figure 4.3-1. The gas analyzers obtain synthesis gas samples from three different locations:

- Between the PCD and the secondary gas cooler (HX0402).

- Between the secondary gas cooler and the pressure letdown valve (PCV-287).

- Between the pressure letdown valve and the syngas combustor (BR0401).

With six CO analyzers, there is a measure of self-consistency when all or several of the six analyzers read the same value. There is also the choice of which analyzer to use. The TC07 hourly averages for the six $\mathrm{CO}$ analyzers are given in Figure 4.3-2. There were usually periods when several of the $\mathrm{CO}$ analyzers were in good agreement. The dry equivalent reading of AI475C is plotted in Figure 4.3-2 to be consistent with the other analyzers. Analyzer AI474C (dry) was consistently lower than the other analyzers and was sent back to the manufacturer for calibration at the completion of TC07. From hour 164 to hour 253, AI425 was used for further analysis since it seemed to be the average of the other four reliable CO analyzers. From hour 260 until the end of TC07, AI434B was used for further 
analysis. The analyzer selection for each operating period is given in Table 4.3-2. The good agreement between the $\mathrm{CO}$ analyzers gives good confidence to the accuracy of the data. The low CO measurements are either periods when the gas analyzers were being calibrated or measurements during coal feeder trips. The CO compositions used in calculations were interpolated for times when the gas analyzers were being calibrated.

TC07 hourly averages data for the $\mathrm{H}_{2}$ analyzers is shown on Figure 4.3-3. Analyzer AI464G was giving reasonable results for nearly the entire test run, while AI419G gave reasonable results for between hours 81 to 150 and between hours 259 and the end of the run. The two analyzers were in good agreement from hour 280 until the end of the run. Gas analyzer AI464G was used for all of the operating periods except for TC07-14, when AI419G was used.

The TC07 hourly average gas analyzer data for $\mathrm{CH}_{4}$ is given in Figure 4.3-4. Both AI475E and AI464E gave reasonable results for the entire run, with AI475E about 1 percent higher than AI464E. Analyzer AI419E worked from hour 80 to 150 and between hours 263 and the end of the run. While AI419E was working it seemed to read the average of AI475E and AI464E. With no agreement from the multiple $\mathrm{CH}_{4}$ readings, the value from AI464E was used for further analysis to be consistent with previous test runs and the thermal oxidizer oxygen and hydrogen balances.

The TC07 hourly average gas analyzer data for $\mathrm{C}_{2}{ }^{+}$is given in Figure 4.3-5. The $\mathrm{C}_{2}{ }^{+}$analyzer AI464F read 0.02 percent for the entire PRB operation and read up to .05 percent during Alabama bituminous operation. Analyzer AI419F read between 0.26 and 0.3 percent during the Alabama bituminous operation and about 0.275 percent for the last 150 hours of the PRB testing. It would appear that the $\mathrm{C}_{2}{ }^{+}$was either 0.02 percent or .275 percent for TC07 PRB operation. The choice is difficult based on just the gas analyzer data. As for the $\mathrm{CH}_{4}$ analyzer data, it was decided to use the lower AI464F values to be consistent with previous testing and the synthesis gas combustor oxygen and hydrogen balances.

The $\mathrm{CO}_{2}$ analyzer data is given on Figure 4.3-6. Analyzers AI434C and AI464D followed the same trends during TC07 with AI434C about 1 percent higher than AI464D for the entire run. When AI419D was operating (hours 80 to 150 and hours 259 to the end) it was very close to AI434C. Analyzer 475D was not consistent with the other three $\mathrm{CO}_{2}$ analyzers. Since AI434C was close to AI419D (when it was working) AI434C was used for further data analysis.

The nitrogen analyzer data is given is in Figure 4.3-7. Analyzer AI464B was consistently higher than analyzer AI419B when AI419B was giving reasonable results. Analyzer AI464B was selected for further analysis because of consistency with past testing.

Since both GC analyzers AI419 and AI464 analyze for nearly the entire spectrum of expected gas components, a useful test of the each analyzer is to plot the sum of the gases measured. This is a consistency check on each GC to see how close the sum of compositions is to 100 percent. The sum of both of the GC analyzer banks is given on Figure 4.3-8. AI464 was fairly consistent during TC07 with a small low bias since the 
component sums were between 98 to 100 percent. This could imply that 1 percent of the synthesis gas is not being measured, or that some of the measured compounds are being measured low. During the periods between hours 80 to 150, AI419 was consistent with AI464. From hour 275 to the end of the run, the AI419 sum was from 97 to 98 percent, which is about 1 to 2 percent lower than AI464. The better consistency of AI464 would give it preference in choosing which gas analyzer to use for a particular component.

The synthesis gas $\mathrm{H}_{2} \mathrm{O}$ analyzer $\mathrm{AI} 475 \mathrm{H}$ and in situ $\mathrm{H}_{2} \mathrm{O}$ (Table 3.4-1) data are plotted on Figure 4.3-9. Sixteen in situ $\mathrm{H}_{2} \mathrm{O}$ measurements were taken during TC07. Most of the in situ $\mathrm{H}_{2} \mathrm{O}$ did not agree well with $\mathrm{AI} 475 \mathrm{H}$ data. Twelve of the in situ $\mathrm{H}_{2} \mathrm{O}$ measurements are plotted on Figure 4.3-9. Three in situ $\mathrm{H}_{2} \mathrm{O}$ measurements taken on February 7 - 8, 2002, are excluded because they were not taken during coal feed. The March 23, 2002, in situ $\mathrm{H}_{2} \mathrm{O}$ measurement was excluded because it was taken during a brief period of coal feed that did not produce a representative syngas. Most of the in situ $\mathrm{H}_{2} \mathrm{O}$ did not agree well with AI475H data. TC07 was the first test run that AI475H was used and the in situ technique has given reliable results in the past. As a result, the in situ results will be used for further analysis. Note the low levels of $\mathrm{H}_{2} \mathrm{O}$ during the Alabama bituminous testing, indicating that inadequate steam was probably fed to the reactor.

The $\mathrm{H}_{2} \mathrm{O}$ analyzer AI419J is part of the AI419 GC. Since both GCs operate dry and the synthesis gas $\mathrm{H}_{2} \mathrm{O}$ is removed prior to analysis, AI419J always read 0.0 percent and will not be discussed further.

The raw $\mathrm{NH}_{3}$ analyzer $\mathrm{AI}^{475 \mathrm{Q}}$ data is shown on Figure 4.3-10. TC07 is the first test run that $\mathrm{NH}_{3}$ compositions have been measured continuously. Analyzer AI475Q is an in situ analyzer and measured the $\mathrm{NH}_{3}$ composition without any sample conditioning, hence the compositions are "wet." The $\mathrm{NH}_{3}$ compositions were between 1,400 and 1,900 ppm. During the last 150 hours of TC07, the $\mathrm{NH}_{3}$ seemed to stabilize at about 1,800 ppm. Ammonia extractive sampling data was taken during TC06 using PRB and found to be in the same range as the TC07 $\mathrm{PRB} \mathrm{NH}_{3}$ analyzer data.

The raw $\mathrm{H}_{2} \mathrm{~S}$ analyzer AI419K data is shown on Figure 4.3-11. This is the first test run to have a continuous $\mathrm{H}_{2} \mathrm{~S}$ analyzer. The analyzer is part of the AI419 bank of analyzers and took a while to produce reasonable results. The AI419K data will be compared with the synthesis gas combustor $\mathrm{SO}_{2}$ analyzer data in Section 4.3.8.

\subsubsection{Gas Analysis Results}

The dry, raw synthesis gas analyzer data was adjusted to produce the best estimate of the actual gas composition in three steps:

- Choice of $\mathrm{CO}, \mathrm{H}_{2}, \mathrm{CH}_{4}, \mathrm{~N}_{2}$, and $\mathrm{CO}_{2}$ analyzer data to use.

- Normalization of dry gas compositions (force to 100 percent total).

- Conversion of dry compositions to wet compositions. 
For the rest of this section, the data analysis will be based on only the TC07 operating periods. This means that the first 100 hours of PRB testing and all of the Alabama bituminous testing are excluded. The hourly plots of data and results will now all start at hour 150. The last 300 hours of TC07 are called TC07D in other sections of this report.

The operating period averages of the sum of the dry gas analyses selected are shown on Figure 4.3-12. The majority of the operating periods have the sum of dry gas compositions between 99 and 101 percent indicating that the data is consistent. There is a slight high bias in that there are more sums that are over 100 percent than sums that are under 100 percent. Operating periods TC07-4 to TC07-5 have the worse deviation (2.2 percent). It is possible that these operating periods will not be consistent with the other operating periods.

In previous gasification runs, the water-gas shift reaction was used to interpolate $\mathrm{H}_{2} \mathrm{O}$ measurements between in situ $\mathrm{H}_{2} \mathrm{O}$ measurements and to check the consistency of the $\mathrm{H}_{2} \mathrm{O}$ analyzer. Since the $\mathrm{H}_{2} \mathrm{O}$ analyzer AI475H did not agree well with the in situ $\mathrm{H}_{2} \mathrm{O}$ measurements, the water-gas shift equilibrium will be used to interpolate $\mathrm{H}_{2} \mathrm{O}$ data between in situ $\mathrm{H}_{2} \mathrm{O}$ measurements. The water-gas shift equilibrium constant should be a function of a Transport Reactor mixing zone or riser temperature. Plotted on Figure 4.3-13 are the $\mathrm{H}_{2} \mathrm{O}$ concentrations calculated from the water-gas shift equilibrium constant based on the mixing zone temperature TI350 and using the measured $\mathrm{H}_{2}, \mathrm{CO}$, and $\mathrm{CO}_{2}$ concentrations. These interpolated $\mathrm{H}_{2} \mathrm{O}$ measurements analyzer readings will be used for further data analyses.

The water-gas shift reaction and equilibrium constant:

$$
\begin{gathered}
\mathrm{CO}+\mathrm{H}_{2} \mathrm{O} \leftrightarrow \mathrm{H}_{2}+\mathrm{CO}_{2} \\
\mathrm{Kp}=\frac{\left(\mathrm{H}_{2}\right)\left(\mathrm{CO}_{2}\right)}{\left(\mathrm{H}_{2} \mathrm{O}\right)(\mathrm{CO})}
\end{gathered}
$$

Eight of the 16 in situ $\mathrm{H}_{2} \mathrm{O}$ measurements were in the last 300 hours of operation which included the operating periods. Analyzer AI475H only agreed with two of the last eight in situ $\mathrm{H}_{2} \mathrm{O}$ measurements, while the WGS calculation was closer to the in situ measurements than AI475H. For the last 300 hours the WGS calculation was about 2 percent lower than the AI475H. The WGS $\mathrm{H}_{2} \mathrm{O}$ agreed with AI475H from hour 192 to 282.

The synthesis gas $\mathrm{H}_{2} \mathrm{O}$ concentration should be a strong function of the amount of steam added to the Transport Reactor. This is shown clearly on Figure 4.3-14 where the synthesis gas $\mathrm{H}_{2} \mathrm{O}$ content is plotted against the amount of steam added to the reactor. If the water-gas shift equilibrium is controlling the gas compositions, as $\mathrm{H}_{2} \mathrm{O}$ increases, $\mathrm{CO}$ should decrease. This is shown to be the case in Figure 4.3-14, where the CO decreases while steam rate and syngas $\mathrm{H}_{2} \mathrm{O}$ increase.

The best estimates of the wet-gas compositions for the TC07 operating periods are given on Table 4.3-3 and shown on Figure 4.3-15. Also shown on Table 4.3-3 are the synthesis gas 
molecular weights for each operating period. The $\mathrm{CO}$ concentration was steady at 9 percent for the first three operating periods. The $\mathrm{CO}$ then decreased from 9 percent to between 7 and 8 percent from hour 180 to hour 230. The CO then slowly increased from 7 percent to 11 percent by the end of the TC07. The $\mathrm{CO}$ concentration decreased when the steam rate increased, as shown on Figure 4.3-14.

The $\mathrm{H}_{2}$ concentration was at 5 percent for the first three operating periods and then was steady at about 7 percent until hour 400 . After hour 400, the $\mathrm{H}_{2}$ concentration slowly decreased to 6 percent at the end of TC07.

The $\mathrm{CO}_{2}$ concentration was at 8 percent for the first three operating periods, then increased to 9 to 10 percent during the periods (hours 180 to 280) of higher steam rates. After the steam rate was decreased at hour 280, the $\mathrm{CO}_{2}$ decreased from 9.5 percent down to 8.5 percent at the end of the run.

The TC07 $\mathrm{CH}_{4}$ concentration was steady at about 1.3 percent.

The $\mathrm{CO} / \mathrm{CO}_{2}$ ratios were calculated from the gas data for each operating period and are listed on Table 4.3-3. The TC07 $\mathrm{CO} / \mathrm{CO}_{2}$ ratio varied from 0.7 to 1.4.

The Lower Heating Value (LHV) for each gas composition was calculated and is given on Table 4.3-3 and plotted on Figure 4.3-16.

The LHV value was calculated using the formula:

$$
\operatorname{LHV}(\mathrm{Btu} / \mathrm{SCF})=\left\{\begin{array}{l}
275 \times\left(\mathrm{H}_{2} \%\right)+322 \times(\mathrm{CO} \%)+ \\
913 \times\left(\mathrm{CH}_{4} \%\right)+1641 \times\left(\mathrm{C}_{2}^{+} \%\right)
\end{array}\right\} / 100
$$

The raw LHV was from 50 to $65 \mathrm{Btu} / \mathrm{SCF}$. The raw LHV was generally constant at about $55 \mathrm{Btu} / \mathrm{SCF}$ from hour 168 to hour 282. The LHV then slowly increased from 55 to 65 Btu/SCF from hour 282 to hour 365. After hour 365 until the end of TC07, the LHV was constant between 60 and $65 \mathrm{Btu} / \mathrm{SCF}$. The increase in LHV was due to a decreased steam rate.

One way to compare the results of different test runs is to determine the percent of oxygen of all the gas that is fed to the Transport Reactor. This compensates for the different amount of pure nitrogen and steam that are added to the reactor. The overall percent $\mathrm{O}_{2}$ is calculated by the following formula:

$$
\text { Overall } \% \mathrm{O}_{2}=\frac{.21 * \text { air }}{\text { air }+(\text { pure nitrogen })+\text { steam }}
$$

The air, nitrogen, and steam flows are in moles per hour. At the PSDF, a large amount of pure nitrogen is fed to the reactor for instrument purges, coal, and sorbent transport, and equipment purges. In PSDF air-blown operation, about 50 percent of the synthesis gas 
nitrogen comes from air and 50 percent comes from the pure nitrogen system. The TC07 raw LHV data is plotted against overall percent $\mathrm{O}_{2}$ on Figure 4.3-17. Also plotted on Figure 4.3-17, is the straight-line correlation of TC06 data. The TC07 data is from $53 \mathrm{Btu} / \mathrm{scf}$ at 12.25 percent $\mathrm{O}_{2}$ to $65 \mathrm{Btu} / \mathrm{scf}$ at 14.3 percent $\mathrm{O}_{2}$ and follows a clear trend of increasing $\mathrm{Btu} / \mathrm{scf}$ with percent $\mathrm{O}_{2}$. The TC07 results are consistently $5 \mathrm{Btu} / \mathrm{scf}$ lower than the TC06 $\mathrm{LHV}$ at equivalent percent $\mathrm{O}_{2}$. This difference is about the error band of $\pm 5 \mathrm{Btu} / \mathrm{scf}$.

\subsubsection{Nitrogen and Adiabatic Corrected Synthesis Gas Lower Heating Values}

The PSDF Transport Reactor adds more $\mathrm{N}_{2}$ per pound synthesis gas than a commercial reactor because of the additional PSDF sampling purges, additional PSDF instrument purges, and the need to aerate the lower portion of the reactor. Instrument purges would be proportionally smaller in a commercial design due to the scale factor (number of instruments stay the same size as plant size increases). The pure nitrogen will be replaced by recycle gas in a commercial-sized reactor. A commercial plant would use proportionally less recycle gas than the pure nitrogen requirement of the PSDF Transport Reactor. Pure $\mathrm{N}_{2}$ added to the riser requires additional fuel to bring the additional $\mathrm{N}_{2}$ up to operating temperatures. This additional fuel then requires additional air, which then adds additional $\mathrm{N}_{2}$ to the reactor and further dilutes the synthesis gas. Any recycle gas replacing the pure nitrogen used at the PSDF will also have to be heated. The PSDF Transport Reactor heat loss per pound of coal fed is much greater that the heat loss from a commercial-sized reactor. To correct for the lower heat loss per pound of coal fed, the additional coal required to compensate for the heat loss is subtracted from the coal-feed rate. To estimate the commercial synthesis LHV, the following components are deleted from the raw synthesis gas:

- All pure nitrogen ("nonair" nitrogen).

- Air nitrogen that is required for burning additional coal that is used for heating pure nitrogen to the reactor process temperature.

- Carbon dioxide from burning the additional coal required for heating pure nitrogen.

- Water vapor from burning the additional coal required for heating pure nitrogen.

- Air nitrogen that is required for burning additional coal that is required to compensate for the estimated reactor heat loss of $1.5 \times 10^{6} \mathrm{Btu} / \mathrm{hr}$.

- Carbon dioxide from burning the additional coal required for the reactor heat loss.

- Water vapor from burning the additional coal required for the reactor heat loss.

The sum of all these corrections is the adiabatic nitrogen-corrected LHV. The pure nitrogen was determined by subtracting the air nitrogen from the synthesis gas nitrogen. Note that these corrections change the water-gas shift equilibrium constant, the $\mathrm{CO} / \mathrm{CO}_{2}$ ratio, the airto-coal ratio, the $\mathrm{H}_{2} \mathrm{~S}$ concentration, and the $\mathrm{NH}_{3}$ concentration. These calculations are an oversimplification of the gasification process. A more sophisticated model is required to correctly predict the effect of decreasing pure nitrogen and reactor heat loss. The adiabatic $\mathrm{N}_{2}$ corrected LHVs for each operating period are given in Table 4.3-4 and plotted on 
Figure 4.3-16. All the $\mathrm{N}_{2}$ corrected LHVs were between 85 and $117 \mathrm{Btu} / \mathrm{SCF}$. The lower $\mathrm{N}_{2}$-corrected LHVs were during the periods of high steam rates.

For comparing the raw $\mathrm{LHV}$ with the adiabatic $\mathrm{N}_{2}$-corrected $\mathrm{LHV}$, an equivalent to the overall percent $\mathrm{O}_{2}$ is defined as:

$$
\text { Adiabatic Overall } \% \mathrm{O}_{2}=\frac{.21 *(\text { adiabatic air })}{(\text { adiabatic air })+\text { steam }}
$$

The adiabatic air is defined as the air used when no pure nitrogen is fed to the system. This is less than the actual air by the amount of air used by the extra coal required to heat-up the pure nitrogen. The adiabatic $\mathrm{N}_{2}$-corrected LHV are plotted against the adiabatic overall percent $\mathrm{O}_{2}$ in Figure 4.3-18. Also plotted in Figure 4.3-18 is the corrected TC06 results, which are slightly higher than the corrected TC07 results. Due to a larger range in coal and steam rates, TC07 had a much higher range of overall percent $\mathrm{O}_{2}$ than TC06.

\subsubsection{Synthesis Gas-Water Gas-Shift Equilibrium}

The water gas-shift equilibrium constants were calculated for 10 of the 16 in situ moisture measurements and are given on Table 4.3-5. The equilibrium constant varied from 0.56 to 0.79. The $\mathrm{H}_{2} \mathrm{O}$ analyzer, $\mathrm{AI} 475 \mathrm{H}$, data for the sampling period is also given. Analyzer AI475H only agreed well with the March 29 in situ data. The thermodynamic equilibrium temperature for each equilibrium constant was calculated from thermodynamic data and is shown on Table 4.3-5. The thermodynamic equilibrium temperature varied from 1,619 to $1,860^{\circ} \mathrm{F}$. These temperatures are approximately the mixing zone temperatures, which are listed in Table 4.3-5 for the sampling periods. The WGS constants calculated from the mixing zone temperatures are compared with the measured WGS constants in Figure 4.3-19. The WGS constants determined from the mixing zone temperature has much less variation than the measured WGS constants. The two measured WGS constants below 0.63 were taken during periods of nonsteady operation. Three measured WGS constants agreed with the WGS constants determined from the mixing zone temperature.

\subsubsection{Synthesis Gas Combustor Oxygen, Carbon, and Hydrogen Balance Calculations}

The synthesis gas compositions and synthesis gas-flow rate can be checked by oxygen balances, hydrogen balances, and carbon balances around the synthesis gas combustor (SGC) since the synthesis gas combustor flue gas composition is measured by the following gas analyzers:

- $\quad$ AIT8775 $-\mathrm{O}_{2}$.

- $\mathrm{AI} 476 \mathrm{H}-\mathrm{H}_{2} \mathrm{O}$.

- $\mathrm{AI} 476 \mathrm{D}-\mathrm{CO}_{2}$. 
The synthesis gas combustor gas composition was calculated for each operating period by using synthesis gas composition synthesis gas flow rate, FI463, and the following process tags:

- Primary air flow, FI8773.

- Secondary air flow, FIC8772.

- Quench air flow, FI8771.

- Propane flow, FI8753.

The measured and mass balance calculated $\mathrm{O}_{2}$ values are shown in Figure 4.3-20 and Table 4.3-6. The measured and calculated synthesis gas combustor $\mathrm{O}_{2}$ concentrations agreed well for nearly all the operating periods, with a maximum difference of about 0.6 percent $\mathrm{O}_{2}$. The oxygen concentrations were 3- to 6 -percent $\mathrm{O}_{2}$ during TC07. The measured percent $\mathrm{O}_{2}$ was lower than the calculated percent $\mathrm{O}_{2}$ up to hour 215, which indicates that the assumed synthesis gas composition had fewer combustibles (lower LHV) than the actual synthesis gas. From hour 230 to 378, the agreement between the measured and calculated percent $\mathrm{O}_{2}$ was very good. From hour 378 to the end of the run, the calculated percent $\mathrm{O}_{2}$ was less than the measured $\mathrm{O}_{2}$, indicating that there were more combustibles in the synthesis gas (higher LHV) than determined from the synthesis gas analyzers.

The measured and mass balance calculated $\mathrm{CO}_{2}$ values are shown in Figure 4.3-21 and Table 4.3-6. The calculated $\mathrm{CO}_{2}$ concentrations are consistently lower than the measured $\mathrm{CO}_{2}$, which implies that there is more carbon in the synthesis gas than indicated by the synthesis gas analyzers. This means that the carbon conversion and LHV may be higher than indicated by the synthesis gas analyzers. This is inconsistent with the $\mathrm{SGC} \mathrm{O}_{2}$ analyzer data which indicated good balance on combustible synthesis gas components between hours 230 and 341. This is the first test that AI476D has been in operation, so the results of AIT8775 should be considered more reliable.

The AI475H measured and mass balance calculated $\mathrm{H}_{2} \mathrm{O}$ values are shown in Figure 4.3-22 and Table 4.3-6. The measured and calculated $\mathrm{H}_{2} \mathrm{O}$ concentrations were consistent with each other, but not too close for the first 210 hours. From hour 215 to 268, the analyzer $\mathrm{H}_{2} \mathrm{O}$ concentrations were lower than the calculated $\mathrm{H}_{2} \mathrm{O}$ concentrations, indicating less hydrogen (from $\mathrm{H}_{2} \mathrm{O}, \mathrm{H}_{2}$, or $\mathrm{CH}_{4}$ ) in the synthesis gas than measured by the synthesis gas analyzers. This was during the run hours that the $\mathrm{SGC}_{2}$ analyzer gave good agreement with the synthesis gas compositions. From hour 282 to the end of the run the $\mathrm{H}_{2} \mathrm{O}$ analyzer gave excellent agreement with the calculated SGC $\mathrm{H}_{2} \mathrm{O}$ concentration (except for hour 310). In this time period, the $\mathrm{CO}_{2}$ and $\mathrm{O}_{2}$ analyzer concentrations were not in agreement. This was also the first test that AI476H has been in operation.

The results of the SGC analyzers do not seem to indicate any consistent error in the synthesis gas composition except for the consistent low carbon content indicated by the SGC $\mathrm{CO}_{2}$ measurement. 
The synthesis gas LHV can be estimated by doing an energy balance around the synthesis gas combustor. The synthesis gas combustor energy balance is done by estimating the synthesis gas combustor heat loss to make the synthesis gas LHV calculated by the synthesis gas combustor energy balance agree with LHV calculated from the synthesis gas analyzer data. In some of the commissioning tests (GTC test series), the gas analyzers were not operational during the entire run, but the SGC energy balance determined that LHV could be used to estimate synthesis gas LHV during periods when there was no gas analyzer data. Table 4.3-7 lists the estimated SGC combustor heat loss for the previous four test runs, from GCT2 to TC06. A comparison between the measured TC07 LHV and the synthesis gas combustor energy balance LHV, using a synthesis gas combustor heat loss of $1.00 \times 10^{6} \mathrm{Btu} / \mathrm{hr}$, is given on Figure 4.3-23. This value of 1.0 was consistent with previous test runs, especially GCT3. The SGC combustor energy balance LHV was slightly higher than the gas analyzers LHV from hour 168 to 268 by about 1 to 3 Btu/scf. From hour 341 to the end of the run, the energy balance was lower than the gas analyzer LHV by from 1 to $4 \mathrm{Btu} /$ scf. Generally the agreement was very good.

\section{$\underline{4.3 .8 \quad \text { Sulfur Emissions }}$}

The $\mathrm{H}_{2} \mathrm{~S}$ concentration measured by AI419J is plotted on Figure 4.3-24. It is compared with the synthesis gas combustor $\mathrm{SO}_{2}$ analyzer AI474N, and the synthesis gas total reduced sulfur (TRS). The synthesis gas combustor $\mathrm{SO}_{2}$ analyzer, AI534A, measures the total sulfur emissions from the Transport Reactor. The total sulfur emissions consist of $\mathrm{H}_{2} \mathrm{~S}, \mathrm{COS}$, and $\mathrm{CS}_{2}$. The main sulfur species in coal gasification are considered to be $\mathrm{H}_{2} \mathrm{~S}$ and carbon oxysulfide (COS). There should be only a minor amount of carbon disulfide $\left(\mathrm{CS}_{2}\right)$. The sulfur emissions for the operating periods of TC07 are listed on Table 4.3-6. Since the synthesis gas combustor exit gas flow rate is about twice that of the synthesis gas rate, the synthesis gas total reduced sulfur concentration is about twice that of the measured synthesis gas combustor $\mathrm{SO}_{2}$ concentration. The $\mathrm{H}_{2} \mathrm{~S}$ analyzer was not working from hour 150 to hour 263. From hour 334 to the end of the run, the $\mathrm{H}_{2} \mathrm{~S}$ analyzer data was higher than the total reduced sulfur, which is not realistic since there should be a higher TRS concentration than $\mathrm{H}_{2} \mathrm{~S}$ concentration in the synthesis gas. Since TC07 was the first test used to determine that AI419J was operational, and AI419J readings are not consistent with AI474N, $\mathrm{H}_{2} \mathrm{~S}$ analyzer AI419J data will not be used for the remainder of this report.

The TRS sulfur emissions generally followed the synthesis gas moisture content and the steam rate, as predicted by equilibrium. The sulfur emissions were low (128 to $143 \mathrm{ppm}$ ) between hours 168 and 180, when the $\mathrm{H}_{2} \mathrm{O}$ content was about 6 percent. At hour 192, the sulfur emissions increased to $242 \mathrm{ppm}$ when the $\mathrm{H}_{2} \mathrm{O}$ content increased to about 12 percent. The TRS increased to $286 \mathrm{ppm}$ at hour 263, and then slowly decreased to $232 \mathrm{ppm}$ at hour 310. The TRS was constant at $240 \mathrm{ppm}$ from hour 310 to 354. During this period, the $\mathrm{H}_{2} \mathrm{O}$ content was constant at about 10 percent. The last four operating periods had a decreasing TRS and decreasing $\mathrm{H}_{2} \mathrm{O}$ concentration. It is expected that the $\mathrm{H}_{2} \mathrm{~S}$ should be slightly (about $100 \mathrm{ppm}$ ) less than the TRS due to COS and $\mathrm{CS}_{2}$. The operating periods when limestone was not added to the Transport Reactor are noted on Figure 3.4-24. The absence of limestone did not seem to increase the sulfur emissions. 
The calculation of the equilibrium synthesis $\mathrm{H}_{2} \mathrm{~S}$ concentration has been described in previous PSDF reports. In summary, the equilibrium $\mathrm{H}_{2} \mathrm{~S}$ concentration is a function of the partial pressures of $\mathrm{H}_{2} \mathrm{O}$ and $\mathrm{CO}_{2}$ as long as there is calcium sulfide present in the solids. As the partial pressures of $\mathrm{H}_{2} \mathrm{O}$ and $\mathrm{CO}_{2}$ increase, the $\mathrm{H}_{2} \mathrm{~S}$ concentration should increase. Using Aspen simulations, the equilibrium $\mathrm{H}_{2} \mathrm{~S}$ concentrations were determined for all of the operating periods and listed in Table 4.3-6.

The measured total reduced sulfur and minimum $\mathrm{H}_{2} \mathrm{~S}$ concentrations are compared on Figure 4.3-25. The first three operating periods had a very close agreement between the TRS and equilibrium $\mathrm{H}_{2} \mathrm{~S}$. From hour 192 to 282, the equilibrium $\mathrm{H}_{2} \mathrm{~S}$ was higher than the measured TRS by 10 to $60 \mathrm{ppm}$. This would indicate better than thermodynamic equilibrium removal. For the remainder of TC07, the TRS emissions were higher than the equilibrium $\mathrm{H}_{2} \mathrm{~S}$ (except for TC07-25), which indicated that the equilibrium removal was not being obtained. Plotted on Figure 4.3-25 are the maximum TRS emissions which are calculated from the coal-sulfur and coal-feed rate, assuming that there is no sulfur capture in the Transport Reactor. The measured Transport Reactor TRS emissions should not exceed the levels indicated. For all of TC07, there was some TRS removal, with significant TRS removal for the first three operating periods and the final 150 hours of testing. Between hours 192 and 288, which was during higher steam rates, there was less TRS removal. For about 60 hours (from hour 222 to 282) the maximum TRS was about equal to the equilibrium $\mathrm{H}_{2} \mathrm{~S}$, indicating that no $\mathrm{H}_{2} \mathrm{~S}$ removal was thermodynamically possible.

Figure 4.3-26 plots the TRS and equilibrium $\mathrm{H}_{2} \mathrm{~S}$ directly against each other for TC06 and TC07. Both data sets bracket the 45-degree line, indicating that when allowing for experimental data scatter, the TRS is about the same as the minimum $\mathrm{H}_{2} \mathrm{~S}$ equilibrium. This indicates that the COS and $\mathrm{CS}_{2}$ are within the scatter of the experimental data. Data above the 45-degree line would indicate lower than equilibrium $\mathrm{H}_{2} \mathrm{~S}$ emissions. There appears to be slightly more points above the line than below. The TC07 TRS concentrations were generally higher than the TC06 concentrations due to higher synthesis gas $\mathrm{H}_{2} \mathrm{O}$ contents resulting from higher steam rates. Again the use of limestone sorbent with PRB coal does not seem to effect the sulfur emissions.

When the nitrogen and adiabatic corrections are made, the minimum equilibrium $\mathrm{H}_{2} \mathrm{~S}$ concentration also changes, since the $\mathrm{H}_{2} \mathrm{O}$ and $\mathrm{CO}_{2}$ partial pressures change. The corrected equilibrium $\mathrm{H}_{2} \mathrm{~S}$ concentration are listed on Table 4.3-4 and plotted on Figure 4.3-27. The maximum TRS emissions also increase when the nitrogen correction is made since the synthesis gas rate decreases and the coal sulfur feed rate decreases slightly. To estimate what the TRS emissions would be for the corrected gas composition, use either the $\mathrm{H}_{2} \mathrm{~S}$ equilibrium concentration or the maximum TRS coal sulfur emissions, whichever is less. If the maximum TRS emissions are less than the equilibrium $\mathrm{H}_{2} \mathrm{~S}$ emissions, then the coal does not contain enough sulfur to form $\mathrm{CaS}$ at the operating conditions of the Transport Reactor. The maximum coal TRS emissions are plotted in Figure 4.3-27. For the first three operation conditions, the equilibrium $\mathrm{H}_{2} \mathrm{~S}$ controlled $\mathrm{H}_{2} \mathrm{~S}$ emissions, as well as the last 155 hours of TC07. Between hour 222 and 282, the maximum TRS controlled $\mathrm{H}_{2} \mathrm{~S}$ emissions. 


\subsubsection{Ammonia Emissions}

Synthesis gas ammonia concentration data was taken continuously by gas analyzer AI475Q. This data is plotted on Figure 4.3-28. Analyzer AI475Q was used for the first time in TC07. The operating period $\mathrm{NH}_{3}$ concentration is listed on Table 4.3-3. The $\mathrm{NH}_{3}$ concentrations were around 1,600 ppm for the first three operating periods and then rose from 1,800 to $1,900 \mathrm{ppm}$ for the rest of TC07, except for the last operating period when the $\mathrm{NH}_{3}$ dropped to $1,700 \mathrm{ppm}$.

The $\mathrm{NH}_{3}$ emissions were estimated for the corrected synthesis gas concentration by assuming the same amount of conversion of fuel nitrogen to ammonia as measured during TC07 and using the corrected synthesis-gas and coal-flow rates. The conversion of fuel nitrogen to $\mathrm{NH}_{3}$ is discussed in Section 4.5. The corrected $\mathrm{NH}_{3}$ emissions were higher than the measured $\mathrm{NH}_{3}$ emissions and were between 2,500 and 3,000 ppm except for hour 222 at 2,256 ppm. 
Table 4.3-1

Operating Periods

\begin{tabular}{|c|c|c|c|c|c|c|}
\hline \multirow[b]{2}{*}{$\begin{array}{l}\text { Operating } \\
\text { Period }\end{array}$} & \multirow[b]{2}{*}{ Start Time } & \multirow[b]{2}{*}{ End Time } & \multirow[b]{2}{*}{$\begin{array}{c}\text { Duration } \\
\text { Hours }\end{array}$} & \multicolumn{2}{|c|}{ Operating Period } & \multirow[b]{2}{*}{ Notes } \\
\hline & & & & Average Time & $\begin{array}{c}\text { Relative } \\
\text { Hours }\end{array}$ & \\
\hline TC07-1 & $3 / 24 / 2002 \quad 16: 00$ & $3 / 25 / 2002 \quad 00: 00$ & $8: 00$ & $3 / 24 / 2002 \quad 20: 00$ & 168 & \\
\hline TC07-2 & $3 / 25 / 2002 \quad 00: 15$ & $3 / 25 / 2002 \quad 02: 15$ & $2: 00$ & $3 / 25 / 2002$ & 173 & \\
\hline TC07-3 & $3 / 25 / 2002 \quad 03: 30$ & $3 / 25 / 2002 \quad 12: 00$ & $8: 30$ & $3 / 25 / 2002 \quad 7: 45$ & 180 & \\
\hline TC07-4 & $3 / 25 / 2002 \quad 15: 30$ & $3 / 26 / 200200: 00$ & $8: 30$ & $3 / 25 / 2002 \quad 19: 45$ & 192 & \\
\hline TC07-5 & $3 / 26 / 2002 \quad 01: 30$ & $3 / 26 / 200204: 00$ & $2: 30$ & $3 / 26 / 2002 \quad 2: 45$ & 199 & \\
\hline TC07-6 & $3 / 26 / 2002 \quad 12: 00$ & $3 / 26 / 2002 \quad 15: 30$ & $3: 30$ & $3 / 26 / 2002 \quad 13: 45$ & 210 & (1) \\
\hline TC07-7 & $3 / 26 / 2002 \quad 16: 30$ & $3 / 26 / 2002 \quad 22: 15$ & $5: 45$ & $3 / 26 / 2002 \quad 19: 22$ & 215 & \\
\hline TC07-8 & $3 / 27 / 2002 \quad 01: 00$ & $3 / 27 / 2002 \quad 03: 30$ & $2: 30$ & $3 / 27 / 2002 \quad 2: 15$ & 222 & \\
\hline TC07-9a & $3 / 27 / 2002 \quad 07: 45$ & $3 / 27 / 200216: 15$ & $8: 30$ & $3 / 27 / 2002 \quad 12: 00$ & 232 & \\
\hline TC07-9b & $3 / 27 / 2002 \quad 16: 15$ & $3 / 28 / 2002 \quad 00: 30$ & $8: 15$ & $3 / 27 / 2002 \quad 20: 22$ & 240 & \\
\hline TC07-9c & $3 / 28 / 2002 \quad 00: 30$ & $3 / 28 / 2002 \quad 09: 00$ & $8: 30$ & $3 / 28 / 2002 \quad 4: 45$ & 249 & \\
\hline TC07-10 & $\begin{array}{ll}3 / 28 / 2002 & 16: 30\end{array}$ & $3 / 28 / 2002 \quad 20: 30$ & $4: 00$ & $3 / 28 / 2002 \quad 18: 30$ & 263 & \\
\hline TC07-11 & $3 / 28 / 2002 \quad 21: 00$ & $3 / 29 / 2002 \quad 03: 30$ & $6: 30$ & $3 / 29 / 2002 \quad 00: 15$ & 268 & \\
\hline TC07-12 & $3 / 29 / 2002 \quad 12: 45$ & $3 / 29 / 200216: 00$ & $3: 15$ & $3 / 29 / 2002 \quad 14: 22$ & 282 & \\
\hline TC07-13 & $3 / 29 / 2002 \quad 21: 00$ & $3 / 30 / 200206: 00$ & 9:00 & $3 / 30 / 2002 \quad 1: 30$ & 294 & \\
\hline TC07-14 & $3 / 30 / 2002 \quad 14: 30$ & $3 / 30 / 2002 \quad 21: 00$ & $6: 30$ & $3 / 30 / 2002 \quad 17: 45$ & 310 & \\
\hline TC07-15 & $3 / 31 / 2002 \quad 01: 30$ & $3 / 31 / 2002 \quad 07: 30$ & $6: 00$ & $3 / 31 / 2002 \quad 4: 30$ & 321 & \\
\hline TC07-16 & $3 / 31 / 2002 \quad 14: 00$ & $3 / 31 / 2002 \quad 21: 00$ & $7: 00$ & $3 / 31 / 2002 \quad 17: 30$ & 334 & \\
\hline TC07-17 & $3 / 31 / 2002 \quad 23: 45$ & $4 / 1 / 2002 \quad 02: 45$ & $3: 00$ & $4 / 1 / 2002$ & 341 & \\
\hline TC07-18 & $4 / 1 / 2002 \quad 03: 15$ & 4/1/2002 09:00 & $5: 45$ & $4 / 1 / 2002$ & 346 & \\
\hline TC07-19 & 4/1/2002 09:30 & $4 / 1 / 2002 \quad 18: 45$ & $9: 15$ & $\begin{array}{ll}4 / 1 / 2002 & 14: 07\end{array}$ & 354 & (1) \\
\hline TC07-20 & $4 / 1 / 2002 \quad 23: 15$ & 4/2/2002 03:30 & $4: 15$ & $4 / 2 / 2002$ & 365 & \\
\hline TC07-21 & $4 / 2 / 2002$ & $4 / 2 / 2002$ & $3: 00$ & $4 / 2 / 2002 \quad 13: 30$ & 378 & \\
\hline TC07-22 & $4 / 3 / 2002 \quad 00: 00$ & $4 / 3 / 2002$ & $11: 45$ & $4 / 3 / 2002$ & 394 & \\
\hline TC07-23 & $4 / 3 / 2002$ & $4 / 3 / 2002$ & $3: 00$ & $4 / 3 / 2002 \quad 14: 30$ & 403 & \\
\hline TC07-24 & $4 / 3 / 2002 \quad 17: 00$ & $4 / 4 / 2002$ & $11: 00$ & $4 / 3 / 2002 \quad 22: 30$ & 411 & (2) \\
\hline TC07-25 & $4 / 4 / 2002 \quad 07: 00$ & $4 / 4 / 2002$ & $3: 00$ & $4 / 4 / 2002$ & 421 & $(1),(2)$ \\
\hline TC07-26 & $4 / 4 / 2002 \quad 18: 00$ & $4 / 4 / 2002 \quad 19: 30$ & $1: 30$ & $4 / 4 / 2002$ & 431 & (1) \\
\hline TC07-27 & $4 / 4 / 2002$ & $4 / 4 / 2002$ & $2: 00$ & $4 / 4 / 2002$ & 434 & (1) \\
\hline TC07-28 & $4 / 5 / 2002$ & $4 / 5 / 2002$ & $2: 15$ & $4 / 5 / 2002$ & 439 & (1) \\
\hline TC07-29 & 4/5/2002 09:00 & $4 / 5 / 2002$ & $1: 00$ & $4 / 5 / 2002$ & 446 & (1), (3) \\
\hline
\end{tabular}

Notes:

1. Limestone not fed to reactor during this period.

2. Iron oxide fed to PCD during this period.

3. Iron oxide fed to reactor during this period. 
Table 4.3-2

Gas Analyzer Choices

\begin{tabular}{|c|c|c|c|c|c|c|c|c|}
\hline \multirow{2}{*}{$\begin{array}{l}\text { Operating } \\
\text { Period }\end{array}$} & \multirow{2}{*}{$\begin{array}{c}\text { Average } \\
\text { Relative } \\
\text { Hours }\end{array}$} & \multicolumn{7}{|c|}{ Gas Component } \\
\hline & & $\mathrm{CO}$ & $\mathrm{H}_{2}$ & $\mathrm{CO}_{2}$ & $\mathrm{CH}_{4}$ & $\mathrm{~N}_{2}$ & $\mathrm{C}_{2}^{+}$ & $\mathrm{H}_{2} \mathrm{O}$ \\
\hline TC07-1 & 168 & 425 & 464 & 434 & 464 & 464 & 464 & Note \\
\hline TC07-2 & 173 & 425 & 464 & 434 & 464 & 464 & 464 & Note \\
\hline TC07-3 & 180 & 425 & 464 & 434 & 464 & 464 & 464 & Note \\
\hline TC07-4 & 192 & 425 & 464 & 434 & 464 & 464 & 464 & Note \\
\hline TC07-5 & 199 & 425 & 464 & 434 & 464 & 464 & 464 & Note \\
\hline TC07-6 & 210 & 425 & 464 & 434 & 464 & 464 & 464 & Note \\
\hline TC07-7 & 215 & 425 & 464 & 434 & 464 & 464 & 464 & Note \\
\hline TC07-8 & 222 & 425 & 464 & 434 & 464 & 464 & 464 & Note \\
\hline TC07-9a & 232 & 425 & 464 & 434 & 464 & 464 & 464 & Note \\
\hline TC07-9b & 240 & 425 & 464 & 434 & 464 & 464 & 464 & Note \\
\hline TC07-9c & 249 & 425 & 464 & 434 & 464 & 464 & 464 & Note \\
\hline TC07-10 & 263 & 434 & 464 & 434 & 464 & 464 & 464 & Note \\
\hline TC07-11 & 268 & 434 & 464 & 434 & 464 & 464 & 464 & Note \\
\hline TC07-12 & 282 & 434 & 464 & 434 & 464 & 464 & 464 & Note \\
\hline TC07-13 & 294 & 434 & 464 & 434 & 464 & 464 & 464 & Note \\
\hline TC07-14 & 310 & 434 & 419 & 419 & 464 & 464 & 464 & Note \\
\hline TC07-15 & 321 & 434 & 464 & 434 & 464 & 464 & 464 & Note \\
\hline TC07-16 & 334 & 434 & 464 & 434 & 464 & 464 & 464 & Note \\
\hline TC07-17 & 341 & 434 & 464 & 434 & 464 & 464 & 464 & Note \\
\hline TC07-18 & 346 & 434 & 464 & 434 & 464 & 464 & 464 & Note \\
\hline TC07-19 & 354 & 434 & 464 & 434 & 464 & 464 & 464 & Note \\
\hline TC07-20 & 365 & 434 & 464 & 434 & 464 & 464 & 464 & Note \\
\hline TC07-21 & 378 & 434 & 464 & 434 & 464 & 464 & 464 & Note \\
\hline TC07-22 & 394 & 434 & 464 & 434 & 464 & 464 & 464 & Note \\
\hline TC07-23 & 403 & 434 & 464 & 434 & 464 & 464 & 464 & Note \\
\hline TC07-24 & 411 & 434 & 464 & 434 & 464 & 464 & 464 & Note \\
\hline TC07-25 & 421 & 434 & 464 & 434 & 464 & 464 & 464 & Note \\
\hline TC07-26 & 431 & 434 & 464 & 434 & 464 & 464 & 464 & Note \\
\hline TC07-27 & 434 & 434 & 464 & 434 & 464 & 464 & 464 & Note \\
\hline TC07-28 & 439 & 434 & 464 & 434 & 464 & 464 & 464 & Note \\
\hline TC07-29 & 446 & 434 & 464 & 434 & 464 & 464 & 464 & Note \\
\hline
\end{tabular}

Note: $\mathrm{H}_{2} \mathrm{O}$ determined from water-gas shift equilibrim at mixing zone temperature TI350. 
Table 4.3-3 Gas Compositions, Molecular Weight, and Heating Value

\begin{tabular}{|c|c|c|c|c|c|c|c|c|c|c|c|c|c|c|c|}
\hline $\begin{array}{c}\text { Operating } \\
\text { Period }\end{array}$ & $\begin{array}{c}\text { Average } \\
\text { Relative } \\
\text { Hour }\end{array}$ & $\begin{array}{c}\mathrm{H}_{2} \mathrm{O} \\
\text { Mole } \\
\%\end{array}$ & $\begin{array}{c}\mathrm{CO} \\
\text { Mole } \\
\%\end{array}$ & $\begin{array}{c}\mathrm{H}_{2} \\
\text { Mole } \\
\%\end{array}$ & $\begin{array}{c}\mathrm{CO}_{2} \\
\text { Mole } \\
\%\end{array}$ & $\begin{array}{c}\mathrm{CH}_{4} \\
\text { Mole } \\
\%\end{array}$ & $\begin{array}{c}\mathrm{C}_{2} \mathrm{H}_{6} \\
\text { Mole } \\
\%\end{array}$ & $\begin{array}{c}\mathrm{N}_{2} \\
\text { Mole } \\
\%\end{array}$ & $\begin{array}{c}\text { Total } \\
\text { Mole } \\
\%\end{array}$ & $\begin{array}{c}\text { Syngas } \\
\text { LHV } \\
\text { Btu/SCF }\end{array}$ & $\begin{array}{c}\text { Syngas } \\
\mathrm{NH}_{3} \\
\mathrm{ppm}\end{array}$ & $\begin{array}{c}\text { Syngas } \\
\text { TRS }^{1} \\
\text { ppm }\end{array}$ & $\begin{array}{c}\text { Syngas } \\
\text { MW } \\
\text { lb./Mole }\end{array}$ & $\begin{array}{c}\mathrm{O}_{2} \text { in } \\
\text { Feed } \\
\%\end{array}$ & $\begin{array}{c}\text { Syngas } \\
\mathrm{CO} / \mathrm{CO}_{2} \\
\text { Ratio }\end{array}$ \\
\hline TC07-1 & 168 & 6.8 & 9.0 & 5.2 & 8.0 & 1.2 & 0.0 & 69.8 & 100.0 & 54 & 1,576 & 133 & 27.1 & 12.6 & 1.1 \\
\hline TC07-2 & 173 & 6.7 & 9.0 & 5.2 & 7.9 & 1.1 & 0.0 & 70.1 & 100.0 & 53 & 1,561 & 143 & 27.1 & 12.5 & 1.1 \\
\hline TC07-3 & 180 & 6.0 & 9.0 & 4.7 & 7.9 & 1.2 & 0.0 & 71.2 & 100.0 & 53 & 1,622 & 128 & 27.3 & 12.5 & 1.1 \\
\hline TC07-4 & 192 & 12.4 & 7.4 & 6.4 & 9.8 & 1.1 & 0.0 & 62.9 & 100.0 & 52 & 1,752 & 240 & 26.5 & 12.4 & 0.8 \\
\hline TC07-5 & 199 & 13.3 & 7.3 & 7.0 & 9.7 & 1.1 & 0.0 & 61.7 & 100.0 & 52 & 1,747 & 223 & 26.3 & 12.8 & 0.7 \\
\hline TC07-6 & 210 & 11.5 & 8.0 & 6.8 & 9.0 & 1.3 & 0.0 & 63.4 & 100.0 & 56 & 1,845 & 237 & 26.4 & 12.6 & 0.9 \\
\hline TC07-7 & 215 & 11.6 & 7.8 & 6.6 & 9.2 & 1.1 & 0.0 & 63.6 & 100.0 & 54 & 1,726 & 213 & 26.4 & 12.5 & 0.9 \\
\hline TC07-8 & 222 & 12.9 & 7.4 & 6.8 & 9.4 & 0.8 & 0.0 & 62.6 & 100.0 & 50 & 1,511 & 231 & 26.3 & 12.3 & 0.8 \\
\hline TC07-9a & 232 & 13.6 & 7.4 & 6.9 & 9.5 & 1.1 & 0.0 & 61.5 & 100.0 & 53 & 1,757 & 237 & 26.2 & 12.3 & 0.8 \\
\hline TC07-9b & 240 & 13.5 & 7.4 & 6.9 & 9.4 & 1.1 & 0.0 & 61.6 & 100.0 & 53 & 1,814 & 243 & 26.2 & 12.2 & 0.8 \\
\hline TC07-9c & 249 & 13.7 & 7.3 & 6.9 & 9.4 & 1.1 & 0.0 & 61.5 & 100.0 & 53 & 1,799 & 248 & 26.2 & 12.2 & 0.8 \\
\hline TC07-10 & 263 & 15.0 & 7.0 & 7.0 & 9.9 & 1.2 & 0.0 & 59.8 & 100.0 & 53 & 1,869 & 282 & 26.1 & 12.2 & 0.7 \\
\hline TC07-11 & 268 & 14.5 & 7.3 & 7.1 & 9.7 & 1.2 & 0.0 & 60.2 & 100.0 & 54 & 1,836 & 269 & 26.1 & 12.6 & 0.7 \\
\hline TC07-12 & 282 & 14.3 & 7.3 & 7.1 & 9.7 & 1.1 & 0.0 & 60.6 & 100.0 & 53 & 1,860 & 265 & 26.2 & 12.3 & 0.7 \\
\hline TC07-13 & 294 & 10.8 & 8.8 & 6.8 & 9.3 & 1.1 & 0.0 & 63.1 & 100.0 & 58 & 1,811 & 244 & 26.5 & 13.1 & 0.9 \\
\hline TC07-14 & 310 & 9.4 & 9.5 & 6.7 & 8.9 & 0.9 & 0.0 & 64.8 & 100.0 & 57 & 1,821 & 229 & 26.6 & 13.2 & 1.1 \\
\hline TC07-15 & 321 & 10.3 & 9.2 & 6.9 & 9.2 & 1.2 & 0.0 & 63.2 & 100.0 & 59 & 1,819 & 238 & 26.5 & 13.3 & 1.0 \\
\hline TC07-16 & 334 & 10.2 & 9.0 & 6.7 & 9.1 & 1.2 & 0.0 & 63.7 & 100.0 & 58 & 1,856 & 246 & 26.5 & 13.2 & 1.0 \\
\hline TC07-17 & 341 & 8.8 & 9.8 & 6.6 & 8.7 & 1.1 & 0.0 & 64.9 & 100.0 & 60 & 1,772 & 233 & 26.7 & 13.9 & 1.1 \\
\hline TC07-18 & 346 & 8.8 & 9.9 & 6.5 & 8.7 & 1.1 & 0.0 & 64.9 & 100.0 & 60 & 1,721 & 235 & 26.7 & 14.0 & 1.1 \\
\hline TC07-19 & 354 & 8.5 & 10.3 & 6.7 & 8.6 & 1.2 & 0.0 & 64.6 & 100.0 & 63 & 1,850 & 234 & 26.6 & 13.9 & 1.2 \\
\hline TC07-20 & 365 & 8.2 & 10.8 & 6.7 & 8.6 & 1.2 & 0.0 & 64.5 & 100.0 & 64 & 1,845 & 211 & 26.7 & 14.2 & 1.3 \\
\hline TC07-21 & 378 & 8.8 & 10.4 & 6.9 & 8.7 & 1.2 & 0.0 & 64.0 & 100.0 & 64 & 1,879 & 224 & 26.6 & 13.8 & 1.2 \\
\hline TC07-22 & 394 & 8.6 & 10.8 & 6.8 & 8.7 & 1.2 & 0.0 & 64.0 & 100.0 & 65 & 1,907 & 224 & 26.6 & 14.3 & 1.2 \\
\hline TC07-23 & 403 & 8.1 & 10.1 & 6.4 & 8.5 & 1.3 & 0.0 & 65.6 & 100.0 & 62 & 1,832 & 177 & 26.7 & 13.8 & 1.2 \\
\hline TC07-24 & 411 & 8.5 & 10.1 & 6.6 & 8.6 & 1.2 & 0.0 & 64.9 & 100.0 & 62 & 1,811 & 209 & 26.7 & 13.9 & 1.2 \\
\hline TC07-25 & 421 & 6.4 & 11.0 & 5.8 & 8.0 & 1.3 & 0.0 & 67.5 & 100.0 & 63 & 1,734 & 110 & 27.0 & 13.6 & 1.4 \\
\hline TC07-26 & 431 & 8.8 & 9.9 & 6.5 & 8.7 & 1.2 & 0.0 & 64.9 & 100.0 & 61 & 1,853 & 207 & 26.7 & 14.0 & 1.1 \\
\hline TC07-27 & 434 & 8.1 & 10.2 & 6.3 & 8.6 & 1.2 & 0.0 & 65.6 & 100.0 & 61 & 1,831 & 189 & 26.8 & 13.8 & 1.2 \\
\hline TC07-28 & 439 & 7.9 & 10.5 & 6.3 & 8.5 & 1.3 & 0.0 & 65.6 & 100.0 & 63 & 1,840 & 196 & 26.8 & 13.9 & 1.2 \\
\hline TC07-29 & 446 & 7.1 & 11.1 & 6.2 & 8.4 & 1.2 & 0.0 & 66.0 & 100.0 & 64 & 1,698 & 170 & 26.9 & 14.3 & 1.3 \\
\hline
\end{tabular}

Note 1. Synthesis gas total reduced sulfur (TRS) estimated from Synthesis gas combustor $\mathrm{SO}_{2}$ analyzer data. 
Table 4.3-4 Corrected ${ }^{1}$ Gas Compositions, Molecular Weight, and Heating Value

\begin{tabular}{|c|c|c|c|c|c|c|c|c|c|c|c|c|c|c|c|c|}
\hline $\begin{array}{c}\text { Operating } \\
\text { Period }\end{array}$ & $\begin{array}{c}\text { Average } \\
\text { Relative } \\
\text { Hour }\end{array}$ & $\begin{array}{c}\mathrm{H}_{2} \mathrm{O} \\
\text { Mole } \\
\%\end{array}$ & $\begin{array}{c}\mathrm{CO} \\
\text { Mole } \\
\%\end{array}$ & $\begin{array}{c}\mathrm{H}_{2} \\
\text { Mole } \\
\%\end{array}$ & $\begin{array}{c}\mathrm{CO}_{2} \\
\text { Mole } \\
\%\end{array}$ & $\begin{array}{c}\mathrm{CH}_{4} \\
\text { Mole } \\
\%\end{array}$ & $\begin{array}{c}\mathrm{C}_{2} \mathrm{H}_{6} \\
\text { Mole } \\
\%\end{array}$ & $\begin{array}{c}\mathrm{N}_{2} \\
\text { Mole } \\
\%\end{array}$ & $\begin{array}{c}\text { Total } \\
\text { Mole } \\
\%\end{array}$ & $\begin{array}{c}\text { Syngas } \\
\text { LHV } \\
\text { Btu/SCF }\end{array}$ & $\begin{array}{c}\text { Syngas } \\
\mathrm{NH}_{3}{ }^{2} \\
\mathrm{ppm}\end{array}$ & \begin{tabular}{|c|} 
Equilibrium \\
$\mathrm{H}_{2} \mathrm{~S}^{3}$ \\
ppm
\end{tabular} & $\begin{array}{c}\text { Maximum } \\
\text { TRS }^{4} \\
\text { ppm }\end{array}$ & $\begin{array}{c}\text { Syngas } \\
\text { MW } \\
\text { lb./Mole }\end{array}$ & $\begin{array}{c}\mathrm{O}_{2} \text { in } \\
\text { Feed } \\
\%\end{array}$ & $\begin{array}{c}\text { Syngas } \\
\mathrm{CO} / \mathrm{CO}_{2} \\
\text { Ratio }\end{array}$ \\
\hline TC07-1 & 168 & 10.1 & 18.2 & 10.5 & 10.5 & 2.3 & 0.0 & 48.4 & 100.0 & 109 & 2,721 & 233 & 557 & 25.6 & 20.8 & 1.7 \\
\hline TC07-2 & 173 & 10.0 & 18.3 & 10.5 & 10.4 & 2.3 & 0.0 & 48.6 & 100.0 & 109 & 2,723 & 229 & 562 & 25.6 & 20.9 & 1.8 \\
\hline TC07-3 & 180 & 8.6 & 18.9 & 9.9 & 10.6 & 2.4 & 0.0 & 49.6 & 100.0 & 110 & 2,897 & 200 & 578 & 25.9 & 20.9 & 1.8 \\
\hline TC07-4 & 192 & 18.8 & 12.8 & 11.1 & 12.7 & 1.9 & 0.0 & 42.7 & 100.0 & 89 & 2,644 & 468 & 473 & 25.0 & 17.1 & 1.0 \\
\hline TC07-5 & 199 & 19.7 & 12.1 & 11.6 & 12.4 & 1.8 & 0.0 & 42.4 & 100.0 & 87 & 2,551 & 487 & 443 & 24.8 & 17.7 & 1.0 \\
\hline TC07-6 & 210 & 17.6 & 14.1 & 12.0 & 11.5 & 2.2 & 0.0 & 42.6 & 100.0 & 99 & 2,839 & 421 & 493 & 24.7 & 17.7 & 1.2 \\
\hline TC07-7 & 215 & 17.8 & 13.8 & 11.7 & 11.8 & 2.0 & 0.0 & 42.9 & 100.0 & 95 & 2,656 & 430 & 488 & 24.8 & 17.5 & 1.2 \\
\hline TC07-8 & 222 & 19.6 & 12.8 & 11.7 & 12.0 & 1.4 & 0.0 & 42.5 & 100.0 & 86 & 2,258 & 477 & 453 & 24.7 & 16.5 & 1.1 \\
\hline \begin{tabular}{|l|} 
TC07-9a \\
\end{tabular} & 232 & 20.5 & 12.5 & 11.7 & 12.2 & 1.9 & 0.0 & 41.3 & 100.0 & 89 & 2,601 & 501 & 455 & 24.6 & 16.4 & 1.0 \\
\hline \begin{tabular}{|l|} 
TC07-9b \\
\end{tabular} & 240 & 20.6 & 12.6 & 11.9 & 12.1 & 2.0 & 0.0 & 40.9 & 100.0 & 91 & 2,707 & 502 & 458 & 24.5 & 16.3 & 1.0 \\
\hline \begin{tabular}{|l|} 
TC07-9c \\
\end{tabular} & 249 & 20.8 & 12.5 & 11.9 & 12.1 & 2.0 & 0.0 & 40.8 & 100.0 & 91 & 2,685 & 507 & 457 & 24.5 & 16.4 & 1.0 \\
\hline \begin{tabular}{|l|} 
TC07-10 \\
\end{tabular} & 263 & 22.6 & 11.7 & 11.7 & 12.6 & 2.1 & 0.0 & 39.3 & 100.0 & 89 & 2,733 & 560 & 454 & 24.4 & 16.0 & 0.9 \\
\hline \begin{tabular}{|l|} 
TC07-11 \\
\end{tabular} & 268 & 21.6 & 12.0 & 11.8 & 12.2 & 2.0 & 0.0 & 40.4 & 100.0 & 89 & 2,668 & 530 & 450 & 24.5 & 16.3 & 1.0 \\
\hline \begin{tabular}{|l|} 
TC07-12 \\
\end{tabular} & 282 & 21.4 & 12.2 & 11.9 & 12.4 & 1.8 & 0.0 & 40.2 & 100.0 & 89 & 2,736 & 528 & 454 & 24.5 & 16.2 & 1.0 \\
\hline \begin{tabular}{|l|} 
TC07-13 \\
\end{tabular} & 294 & 15.9 & 15.1 & 11.7 & 11.7 & 2.0 & 0.0 & 43.5 & 100.0 & 99 & 2,728 & 385 & 494 & 25.0 & 17.9 & 1.3 \\
\hline \begin{tabular}{|l|} 
TC07-14 \\
\end{tabular} & 310 & 13.7 & 16.7 & 11.8 & 11.2 & 1.5 & 0.0 & 45.1 & 100.0 & 100 & 2,803 & 324 & 502 & 25.2 & 18.4 & 1.5 \\
\hline \begin{tabular}{|l|} 
TC07-15 \\
\end{tabular} & 321 & 14.9 & 15.8 & 11.7 & 11.6 & 2.0 & 0.0 & 43.9 & 100.0 & 102 & 2,734 & 359 & 503 & 25.0 & 18.5 & 1.4 \\
\hline \begin{tabular}{|l|} 
TC07-16 \\
\end{tabular} & 334 & 15.0 & 15.6 & 11.6 & 11.6 & 2.1 & 0.0 & 44.2 & 100.0 & 101 & 2,812 & 359 & 492 & 25.1 & 18.3 & 1.4 \\
\hline \begin{tabular}{|l|} 
TC07-17 \\
\end{tabular} & 341 & 12.6 & 17.2 & 11.5 & 10.9 & 2.0 & 0.0 & 45.7 & 100.0 & 105 & 2,725 & 302 & 512 & 25.2 & 20.4 & 1.6 \\
\hline \begin{tabular}{|l|} 
TC07-18 \\
\end{tabular} & 346 & 12.6 & 17.2 & 11.4 & 10.9 & 1.9 & 0.0 & 46.0 & 100.0 & 104 & 2,631 & 301 & 510 & 25.3 & 20.5 & 1.6 \\
\hline \begin{tabular}{|l|} 
TC07-19 \\
\end{tabular} & 354 & 12.1 & 18.0 & 11.7 & 10.6 & 2.1 & 0.0 & 45.7 & 100.0 & 109 & 2,827 & 285 & 520 & 25.2 & 20.4 & 1.7 \\
\hline \begin{tabular}{|l|} 
TC07-20 \\
\end{tabular} & 365 & 11.3 & 18.4 & 11.3 & 10.5 & 2.0 & 0.0 & 46.6 & 100.0 & 108 & 2,764 & 267 & 513 & 25.4 & 20.4 & 1.7 \\
\hline \begin{tabular}{|l|} 
TC07-21 \\
\end{tabular} & 378 & 12.4 & 17.9 & 11.9 & 10.6 & 2.1 & 0.0 & 45.2 & 100.0 & 109 & 2,848 & 292 & 532 & 25.1 & 20.4 & 1.7 \\
\hline \begin{tabular}{|l|} 
TC07-22 \\
\end{tabular} & 394 & 11.8 & 18.2 & 11.6 & 10.6 & 2.1 & 0.0 & 45.7 & 100.0 & 110 & 2,865 & 279 & 533 & 25.2 & 20.9 & 1.7 \\
\hline \begin{tabular}{|l|} 
TC07-23 \\
\end{tabular} & 403 & 11.6 & 18.4 & 11.6 & 10.7 & 2.4 & 0.0 & 45.4 & 100.0 & 113 & 2,905 & 274 & 543 & 25.2 & 20.9 & 1.7 \\
\hline \begin{tabular}{|l|}
$\mathrm{TC} 07-24$ \\
\end{tabular} & 411 & 12.2 & 18.0 & 11.7 & 10.8 & 2.2 & 0.0 & 45.1 & 100.0 & 110 & 2,834 & 290 & 547 & 25.2 & 20.9 & 1.7 \\
\hline \begin{tabular}{|l|} 
TC07-25 \\
\end{tabular} & 421 & 8.7 & 20.7 & 10.9 & 9.8 & 2.4 & 0.0 & 47.6 & 100.0 & 118 & 2,832 & 199 & 583 & 25.5 & 20.9 & 2.1 \\
\hline \begin{tabular}{|l|} 
TC07-26 \\
\end{tabular} & 431 & 12.6 & 17.5 & 11.6 & 10.9 & 2.1 & 0.0 & 45.3 & 100.0 & 107 & 2,892 & 301 & 550 & 25.2 & 20.9 & 1.6 \\
\hline \begin{tabular}{|l|} 
TC07-27 \\
\end{tabular} & 434 & 11.5 & 18.3 & 11.3 & 10.8 & 2.2 & 0.0 & 45.8 & 100.0 & 110 & 2,905 & 281 & 572 & 25.3 & 20.9 & 1.7 \\
\hline \begin{tabular}{|l|} 
TC07-28 \\
\end{tabular} & 439 & 11.1 & 18.9 & 11.4 & 10.5 & 2.3 & 0.0 & 45.9 & 100.0 & 113 & 2,918 & 238 & 589 & 25.3 & 20.9 & 1.8 \\
\hline \begin{tabular}{|l|} 
TC07-29 \\
\end{tabular} & 446 & 9.6 & 19.3 & 10.7 & 10.2 & 2.1 & 0.0 & 48.0 & 100.0 & 111 & 2,624 & 205 & 571 & 25.6 & 20.9 & 1.9 \\
\hline
\end{tabular}

\section{Notes:}

1. Correction is to assume that only air nitrogen is in the synthesis gas and that the reactor is adiabatic.

2. The corrected synthesis gas $\mathrm{NH}_{3}$ is calculated by assuming that the same percent coal nitrogen is converted to $\mathrm{NH}_{3}$ as in the raw synthesis gas.

3. The corrected equilibrium $\mathrm{H}_{2} \mathrm{~S}$ is calculated from the corrected $\mathrm{H}_{2} \mathrm{O}$ and $\mathrm{CO}_{2}$ partial pressures and the corrected synthesis gas rate.

4. The corrected maximum TRS is calculated from the corrected coal-feed and synthesis-gas rates.

5. The expected corrected TRS emissions will be the lesser of the corrected $\mathrm{H}_{2} \mathrm{~S}$ equilibrium and the corrected TRS. 
Table 4.3-5

Water-Gas Shift Equilibrium Constant

\begin{tabular}{|c|c|c|c|c|c|c|c|c|c|}
\hline $\begin{array}{c}\text { In situ } \\
\text { Start }\end{array}$ & $\begin{array}{l}\text { In situ } \\
\text { End }\end{array}$ & $\begin{array}{c}\text { Average } \\
\text { Run Time } \\
\text { Hours }\end{array}$ & $\begin{array}{c}\text { Operating } \\
\text { Period }\end{array}$ & $\begin{array}{c}\text { In-situ } \\
\mathrm{H}_{2} \mathrm{O} \\
\%\end{array}$ & $\begin{array}{c}\mathrm{Al} 475 \mathrm{H} \\
\mathrm{H}_{2} \mathrm{O} \\
\%\end{array}$ & $\mathrm{Kp}$ & $\begin{array}{c}\text { WGS } \\
\text { Eqm. } \\
\text { Temp. } \\
\text { F॰ }^{\circ}\end{array}$ & $\begin{array}{c}\text { Mixing } \\
\text { Zone } \\
\text { Temp. } \\
\mathrm{F}^{\circ}\end{array}$ & $\begin{array}{c}\text { Mixing } \\
\text { Zone } \\
\text { Kp }\end{array}$ \\
\hline $1 / 19 / 2002$ 12:45 & $1 / 19 / 200214: 45$ & 4 & (1) & 6.5 & 0.38 & (3) & & & \\
\hline 1/22/2002 09:00 & $1 / 22 / 200213: 15$ & 39 & (1) & 6.3 & 7.30 & (3) & & & \\
\hline $1 / 23 / 2002$ 08:00 & $1 / 23 / 200214: 20$ & 63 & $(1),(4)$ & 6.7 & 6.45 & 0.60 & 1,801 & 1,727 & 0.67 \\
\hline $1 / 25 / 2002$ 09:00 & $1 / 25 / 200213: 00$ & 99 & (1) & 7.7 & 5.87 & 0.56 & 1,860 & 1,731 & 0.67 \\
\hline $3 / 25 / 200208: 45$ & $3 / 25 / 200212: 45$ & 183 & TC07-3 & 6.1 & 7.92 & 0.78 & 1,626 & 1,697 & 0.70 \\
\hline $3 / 26 / 2002$ 09:39 & $3 / 26 / 200212: 55$ & 207 & TC07-6 & 11.3 & 11.96 & 0.73 & 1,673 & 1,739 & 0.66 \\
\hline 3/27/2002 09:00 & $3 / 27 / 2002$ 13:00 & 231 & TC07-9a & 12.0 & 13.31 & 0.75 & 1,654 & 1,745 & 0.65 \\
\hline $3 / 29 / 2002$ 12:00 & $3 / 29 / 200215: 00$ & 281 & TC07-12 & 14.5 & 14.55 & 0.65 & 1,748 & 1,737 & 0.66 \\
\hline 3/30/2002 09:00 & $3 / 30 / 200211: 15$ & 302 & (2) & 8.2 & 10.95 & 0.79 & 1,624 & 1,706 & 0.69 \\
\hline $4 / 1 / 2002$ 08:30 & $4 / 1 / 200212: 30$ & 350 & TC07-19 & 9.2 & 10.50 & 0.79 & 1,619 & 1,746 & 0.65 \\
\hline 4/2/2002 08:30 & $4 / 2 / 200211: 30$ & 374 & (5) & 8.6 & 10.49 & 0.65 & 1,745 & 1,747 & 0.65 \\
\hline 4/3/2002 10:45 & $4 / 3 / 200214: 45$ & 401 & TC07-22 & 8.6 & 10.18 & 0.65 & 1,751 & 1,742 & 0.66 \\
\hline
\end{tabular}

Notes:

1. Data not taken during operating period.

2. Data taken between TC07-13 and TC07-14

3. Neither $\mathrm{H}_{2}$ analyzer operating during this period.

4. Two coal trips during this moisture measurement.

5. Data taken between TC07-20 and TC07-21. 
Table 4.3-6 Synthesis Gas Combustor Calculations

\begin{tabular}{|c|c|c|c|c|c|c|c|c|c|c|c|c|}
\hline $\begin{array}{c}\text { Operating } \\
\text { Period }\end{array}$ & $\begin{array}{c}\text { Average } \\
\text { Relative } \\
\text { Hour }\end{array}$ & $\begin{array}{c}\text { AIT8775 } \\
\text { SGC Exit } \\
\mathrm{O}_{2} \\
\mathrm{M} \%\end{array}$ & $\begin{array}{c}\text { Calculated } \\
\text { SGC Exit } \\
\mathrm{O}_{2} \\
\mathrm{M} \%\end{array}$ & $\begin{array}{c}\text { AI476D } \\
\text { SGC Exit } \\
\mathrm{CO}_{2} \\
\mathrm{M} \%\end{array}$ & $\begin{array}{c}\text { Calculated } \\
\text { SGC Exit } \\
\mathrm{CO}_{2} \\
\mathrm{M} \%\end{array}$ & $\begin{array}{c}\text { AI476H } \\
\text { SGC Exit } \\
\mathrm{H}_{2} \mathrm{O} \\
\mathrm{M} \%\end{array}$ & $\begin{array}{c}\text { Calculated } \\
\text { SGC Exit } \\
\mathrm{H} 2 \mathrm{O} \\
\mathrm{M} \%\end{array}$ & $\begin{array}{c}\text { Gas } \\
\text { Analyzer } \\
\text { LHV } \\
\text { Btu/SCF }\end{array}$ & $\begin{array}{c}\text { Energy } \\
\text { Balance } \\
\text { LHV }^{1} \\
\text { Btu/SCF }\end{array}$ & $\begin{array}{c}\text { Combustor } \\
\mathrm{SO}_{2} \\
\mathrm{AI} 534 \mathrm{~A} \\
\mathrm{ppm}\end{array}$ & $\begin{array}{c}\text { Syngas } \\
\text { Total Reduced } \\
\text { Sulfur }^{2} \\
\text { ppm }\end{array}$ & $\begin{array}{c}\text { Thermo. } \\
\text { Equlibrium } \\
\mathrm{H}_{2} \mathrm{~S} \\
\mathrm{ppm}\end{array}$ \\
\hline TC07-1 & 168 & 4.0 & 4.3 & 11.6 & 10.3 & 9.2 & 9.2 & 54 & 56 & 74 & 134 & 142 \\
\hline TC07-2 & 173 & 3.9 & 4.3 & 11.5 & 10.3 & 9.4 & 9.1 & 53 & 55 & 80 & 143 & 139 \\
\hline TC07-3 & 180 & 3.9 & 4.5 & 11.5 & 10.2 & 9.7 & 8.5 & 53 & 56 & 71 & 128 & 124 \\
\hline TC07-4 & 192 & 3.6 & 4.2 & 11.8 & 10.6 & 12.9 & 13.2 & 52 & 55 & 137 & 242 & 280 \\
\hline TC07-5 & 199 & 3.4 & 3.8 & 12.2 & 10.7 & 13.0 & 14.2 & 52 & 54 & 130 & 226 & 300 \\
\hline ТC07-6 & 210 & 4.9 & 5.5 & 10.7 & 9.5 & 12.0 & 12.0 & 56 & 59 & 122 & 240 & 252 \\
\hline TC07-7 & 215 & 6.0 & 6.1 & 9.9 & 9.1 & 10.9 & 11.5 & 54 & 56 & 105 & 216 & 256 \\
\hline TC07-8 & 222 & 5.4 & 5.4 & 10.3 & 9.6 & 12.0 & 12.7 & 50 & 52 & 123 & 233 & 287 \\
\hline TC07-9a & 232 & 6.2 & 6.4 & 9.8 & 9.0 & 11.6 & 12.4 & 53 & 56 & 117 & 240 & 304 \\
\hline TC07-9b & 240 & 5.1 & 5.3 & 10.5 & 9.6 & 12.2 & 13.2 & 53 & 57 & 128 & 246 & 302 \\
\hline TC07-9c & 249 & 4.0 & 4.2 & 11.3 & 10.2 & 12.8 & 14.1 & 53 & 55 & 141 & 251 & 305 \\
\hline TC07-10 & 263 & 3.6 & 3.9 & 11.7 & 10.5 & 13.7 & 15.2 & 53 & 57 & 162 & 286 & 341 \\
\hline TC07-11 & 268 & 4.2 & 4.4 & 11.3 & 10.2 & 13.2 & 14.5 & 54 & 57 & 150 & 273 & 326 \\
\hline TC07-12 & 282 & 3.9 & 4.2 & 11.5 & 10.4 & 14.2 & 14.5 & 53 & 55 & 151 & 269 & 321 \\
\hline TC07-13 & 294 & 4.3 & 4.4 & 11.4 & 10.6 & 12.3 & 12.1 & 58 & 58 & 133 & 246 & 240 \\
\hline TC07-14 & 310 & 4.5 & 4.8 & 11.7 & 10.5 & 11.9 & 10.9 & 57 & 58 & 124 & 232 & 204 \\
\hline TC07-15 & 321 & 4.5 & 4.4 & 11.3 & 10.8 & 11.6 & 11.8 & 59 & 58 & 129 & 241 & 227 \\
\hline TC07-16 & 334 & 3.1 & 3.0 & 12.4 & 11.6 & 12.7 & 12.6 & 58 & 57 & 145 & 248 & 225 \\
\hline TC07-17 & 341 & 3.3 & 3.2 & 12.3 & 11.6 & 11.6 & 11.5 & 60 & 58 & 136 & 235 & 194 \\
\hline TC07-18 & 346 & 3.2 & 2.9 & 12.5 & 11.8 & 11.6 & 11.6 & 60 & 57 & 139 & 237 & 194 \\
\hline TC07-19 & 354 & 4.4 & 4.2 & 11.8 & 11.0 & 11.0 & 10.8 & 63 & 62 & 126 & 236 & 186 \\
\hline TC07-20 & 365 & 4.5 & 4.2 & 11.6 & 11.2 & 10.7 & 10.5 & 64 & 61 & 114 & 213 & 180 \\
\hline TC07-21 & 378 & 4.7 & 4.7 & 11.6 & 10.7 & 10.9 & 10.7 & 64 & 64 & 117 & 226 & 193 \\
\hline TC07-22 & 394 & 4.3 & 3.9 & 11.8 & 11.4 & 11.2 & 11.0 & 65 & 61 & 123 & 226 & 187 \\
\hline TC07-23 & 403 & 5.5 & 5.1 & 10.8 & 10.3 & 10.1 & 10.1 & 62 & 61 & 90 & 179 & 176 \\
\hline TC07-24 & 411 & 5.2 & 4.9 & 11.0 & 10.5 & 10.4 & 10.4 & 62 & 60 & 108 & 211 & 186 \\
\hline TC07-25 & 421 & 5.8 & 5.5 & 10.7 & 10.2 & 8.9 & 8.7 & 63 & 61 & 54 & 111 & 136 \\
\hline TC07-26 & 431 & 5.1 & 4.8 & 11.1 & 10.6 & 10.5 & 10.6 & 61 & 59 & 109 & 208 & 192 \\
\hline TC07-27 & 434 & 5.2 & 4.9 & 11.1 & 10.5 & 10.0 & 10.1 & 61 & 60 & 98 & 190 & 181 \\
\hline TC07-28 & 439 & 5.4 & 5.1 & 10.9 & 10.5 & 9.8 & 9.9 & 63 & 61 & 100 & 198 & 157 \\
\hline TC07-29 & 446 & 5.2 & 5.1 & 11.5 & 10.7 & 9.5 & 9.4 & 64 & 61 & 87 & 171 & 142 \\
\hline
\end{tabular}

1. Energy LHV calcualted assuming the sythesis gas combustor heat loss was $1.0 \times 10^{6} \mathrm{Btu} / \mathrm{hr}$.

2. Synthesis gas total reduced sulfur (TRS) estimated from Synthesis gas combustor $\mathrm{SO}_{2}$ analyzer data. 
Table 4.3-7

SGC Heat Loss

\begin{tabular}{|l|c|}
\hline Test & Synthesis Gas Combustor \\
\hline Run & Heat Loss in $10^{6} \mathrm{Btu} / \mathrm{hr}$ \\
\hline GCT2 & 1.5 to 4.0 \\
\hline GCT3 & 1.00 \\
\hline GCT4 & 2.25 \\
\hline TC06 & 2.25 \\
\hline TC07 & 1.00 \\
\hline
\end{tabular}




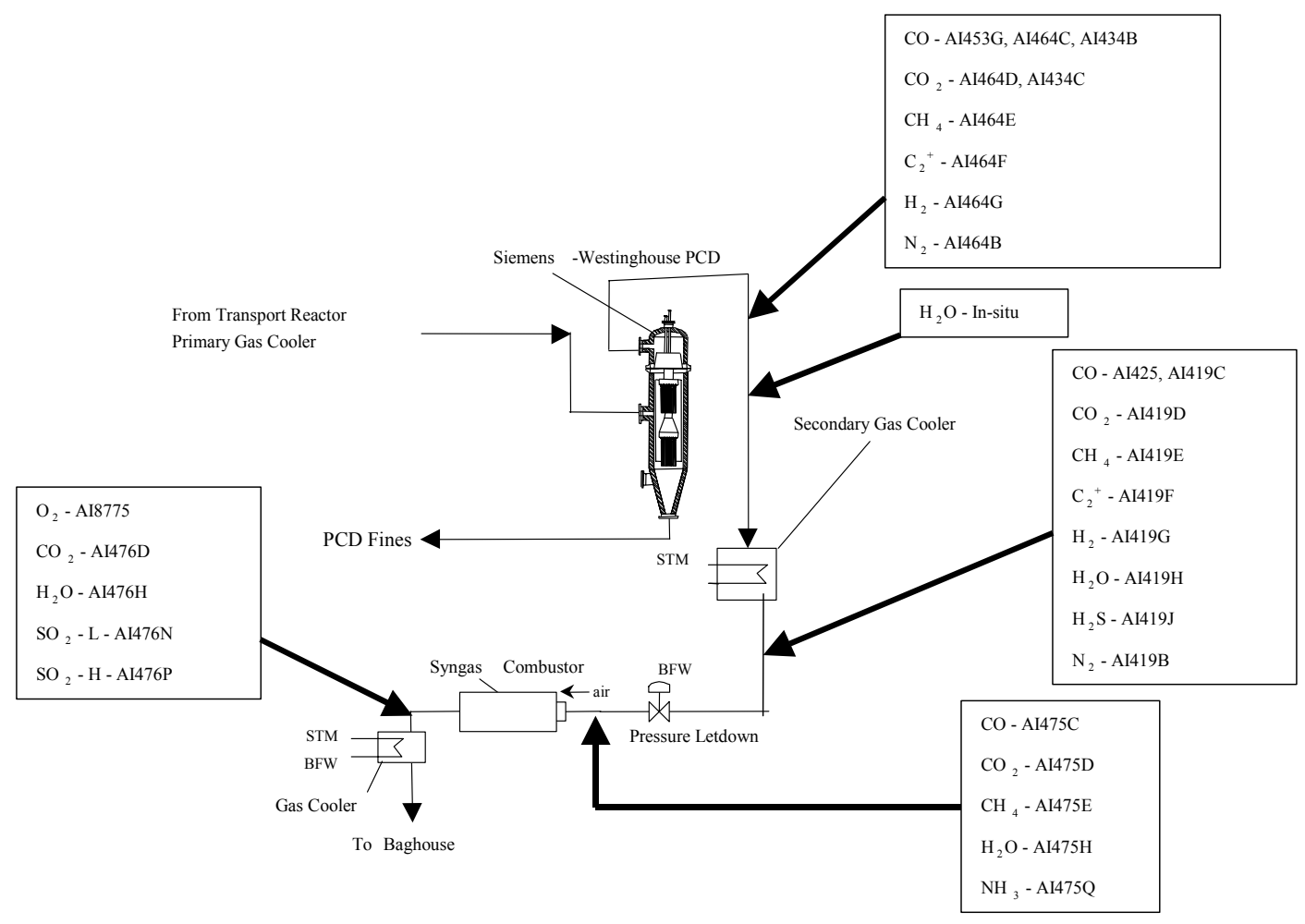

Figure 4.3-1 Gas Sampling Locations 


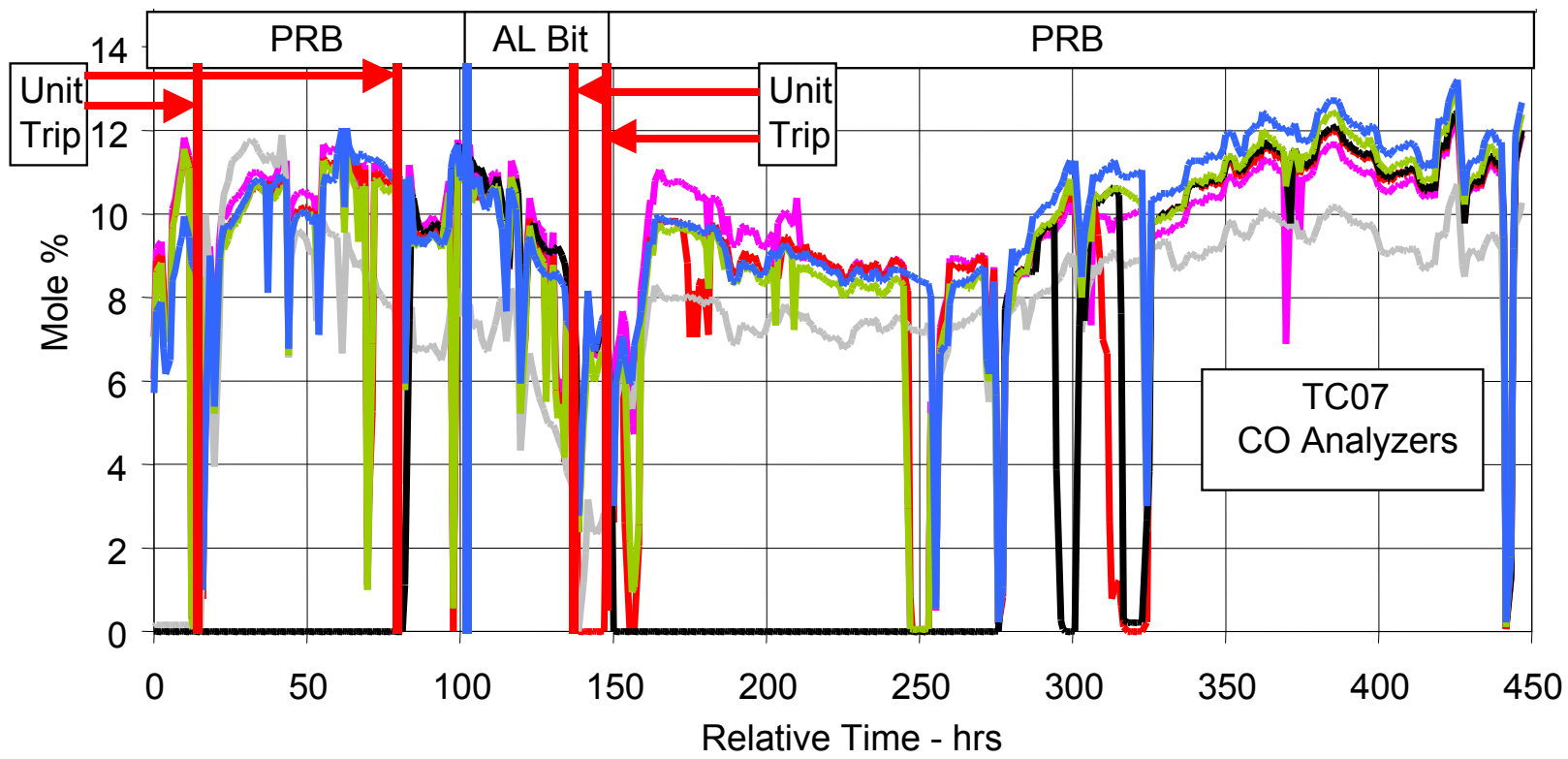

Figure 4.3-2 CO Analyzer Data

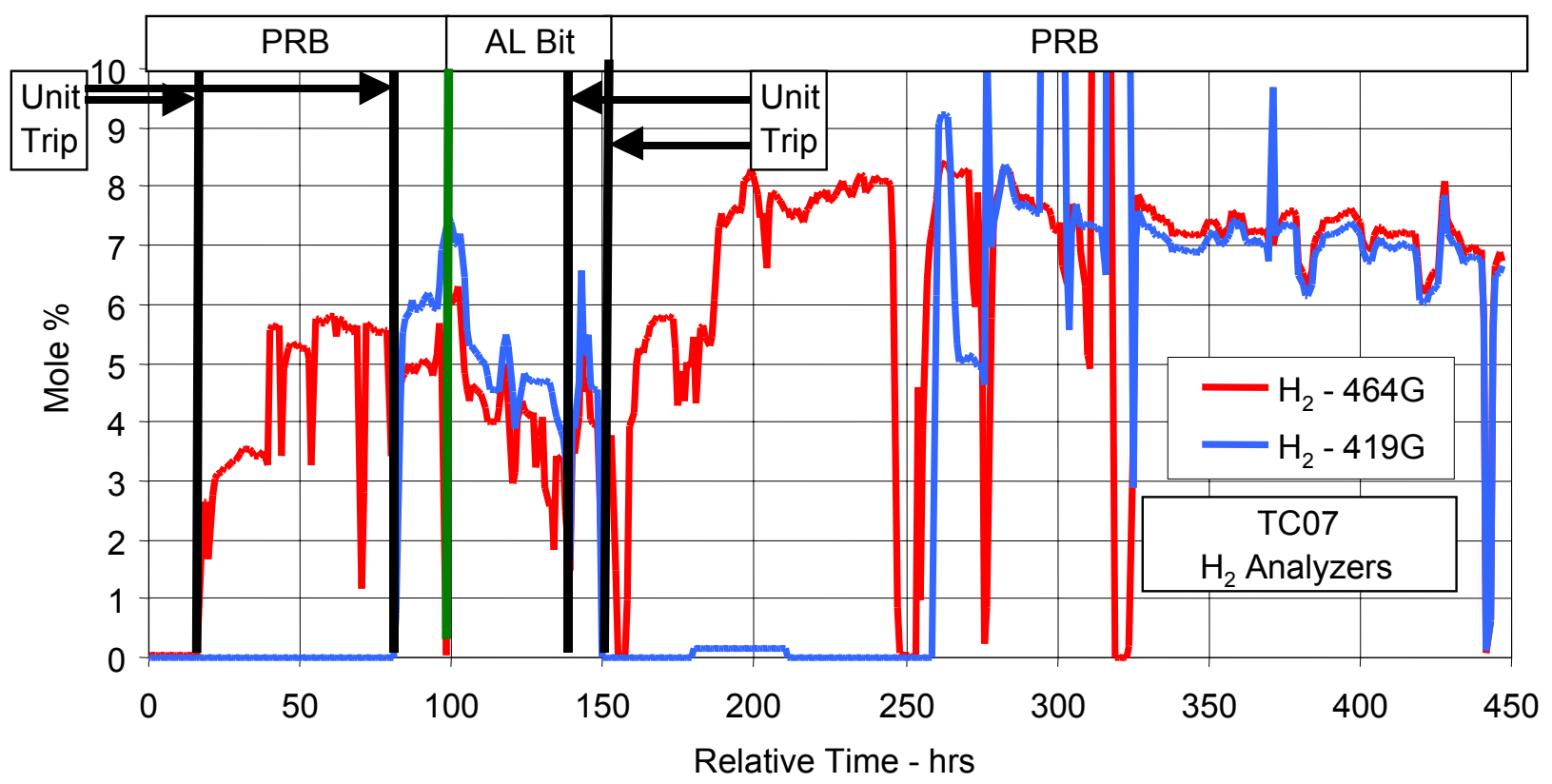

Figure 4.3-3 Analyzer $\mathrm{H}_{2}$ Data 


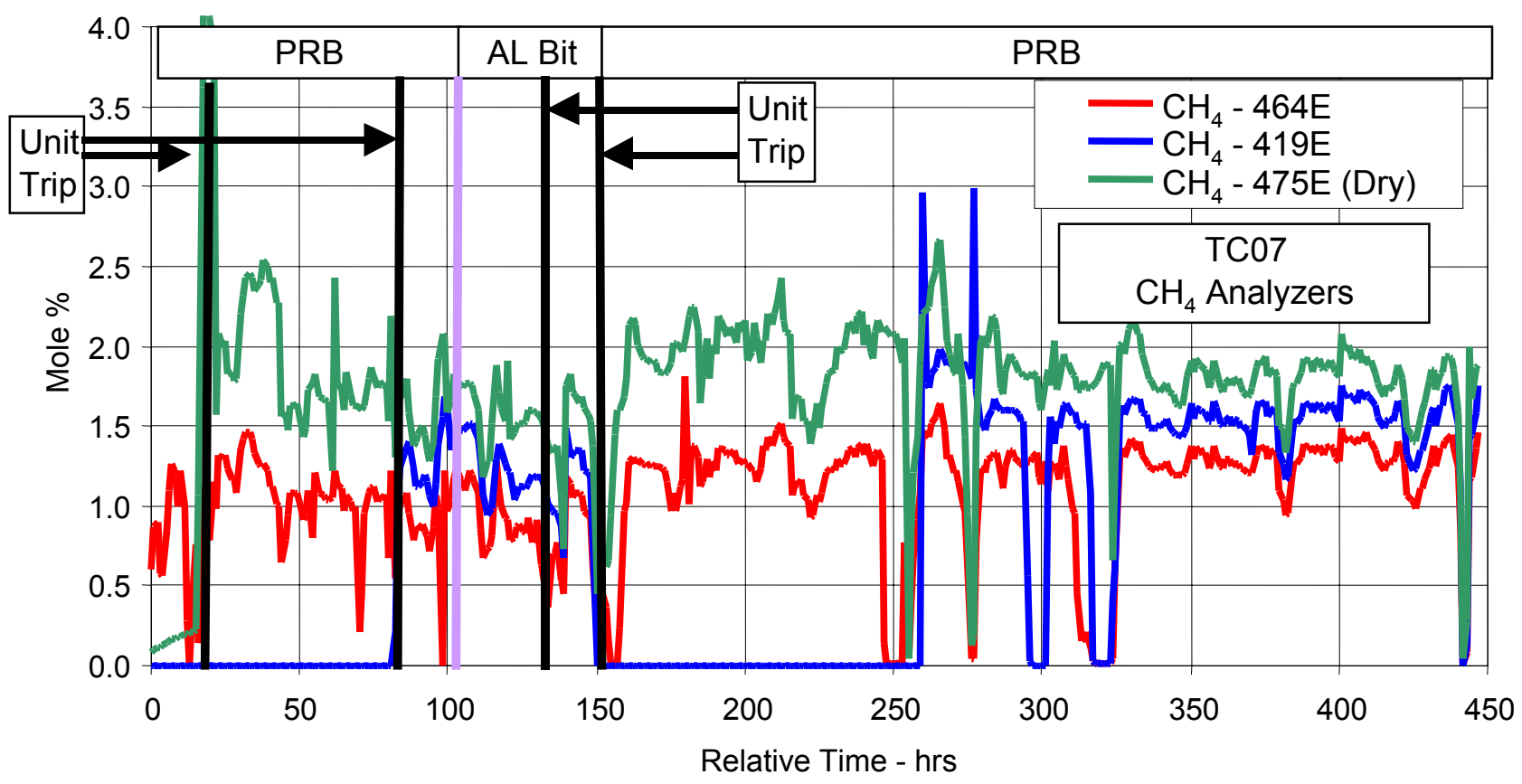

Figure 4.3-4 Analyzer $\mathrm{CH}_{4}$ Data

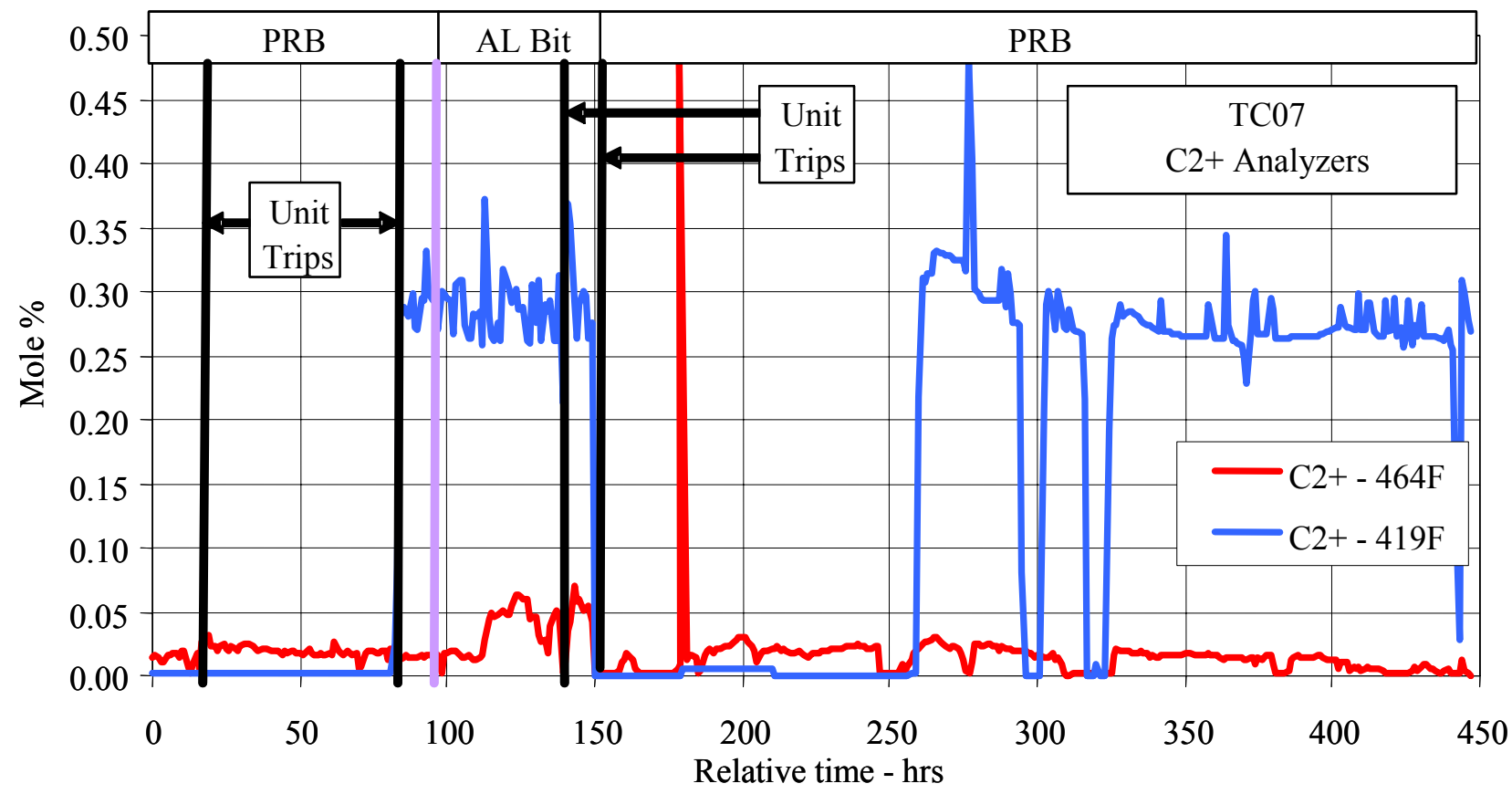

Figure 4.3-5 Analyzer $\mathrm{C}_{2}{ }^{+}$Data 


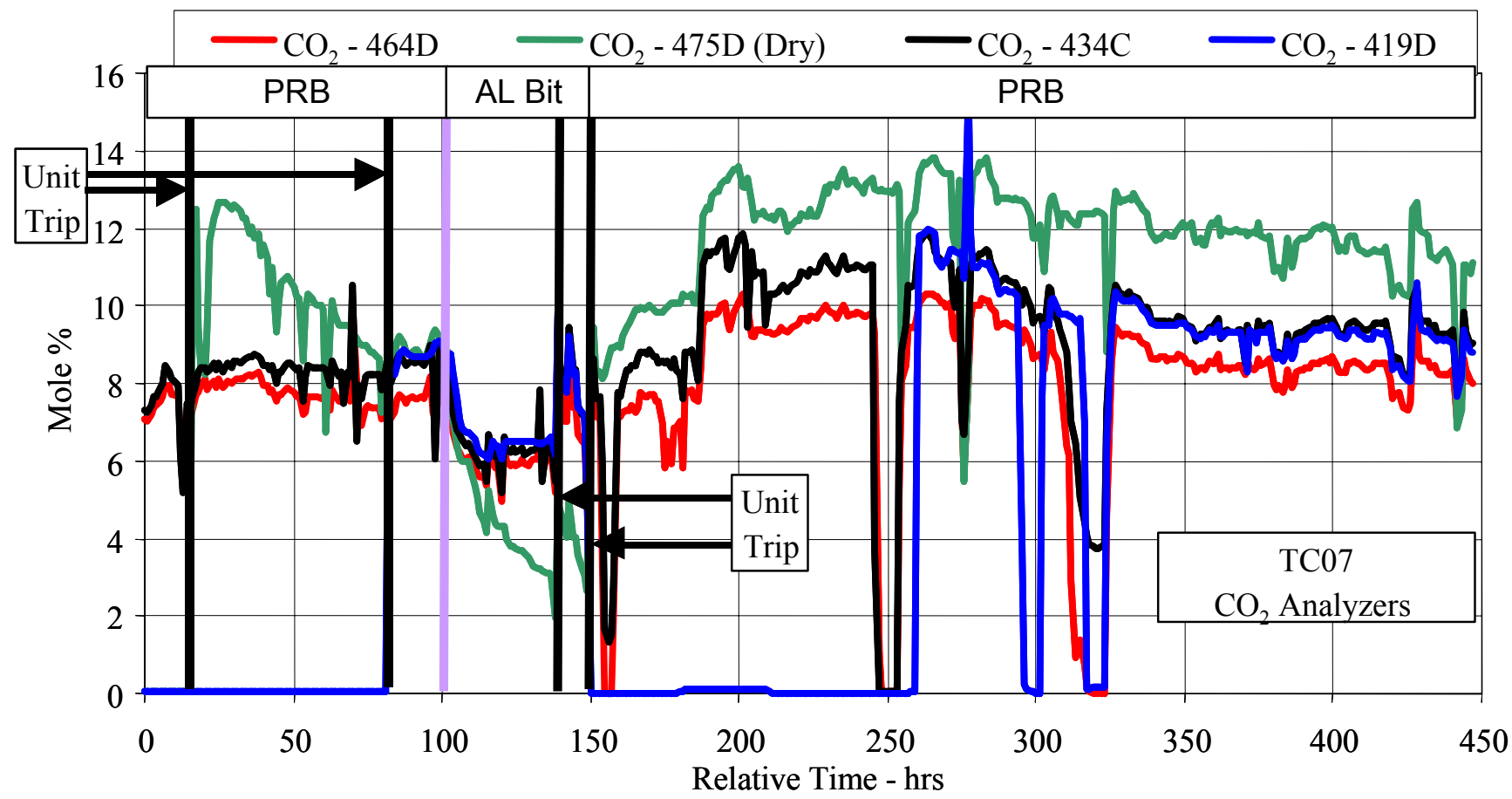

Figure 4.3-6 $\mathrm{CO}_{2}$ Analyzer Data

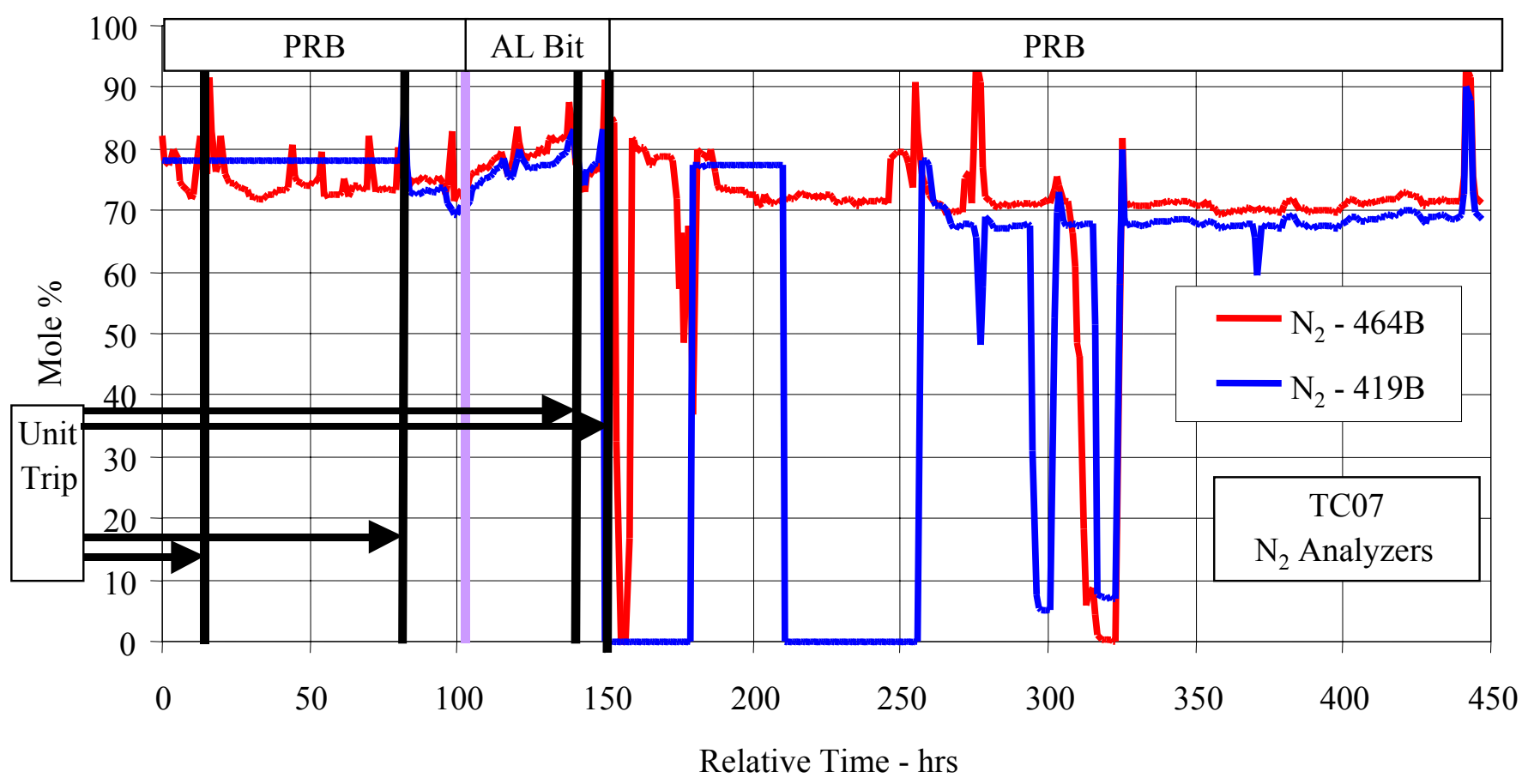

Figure 4.3-7 Analyzer $\mathrm{N}_{2}$ Data 


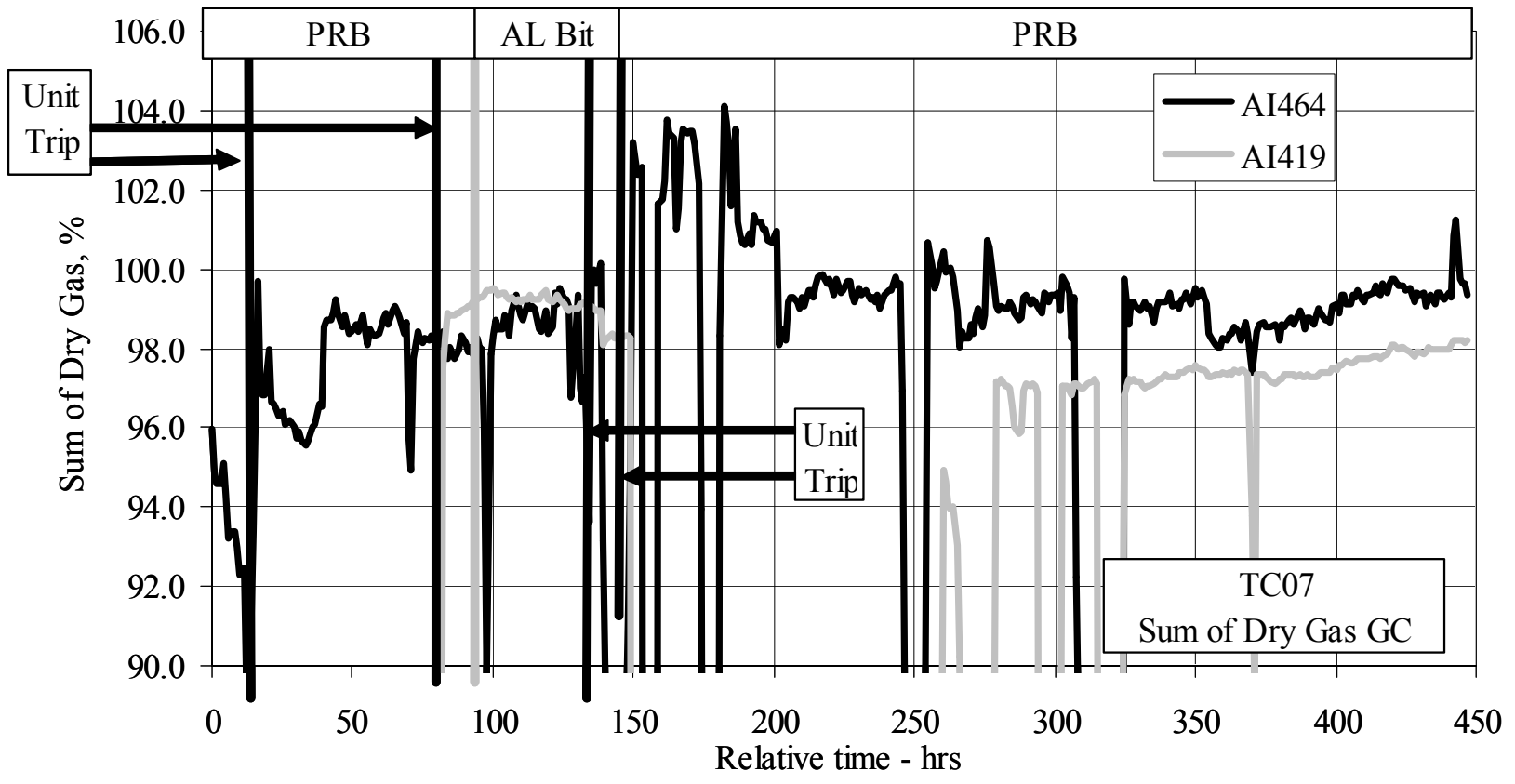

Figure 4.3-8 Sum of GC Gas Compositions (Dry)

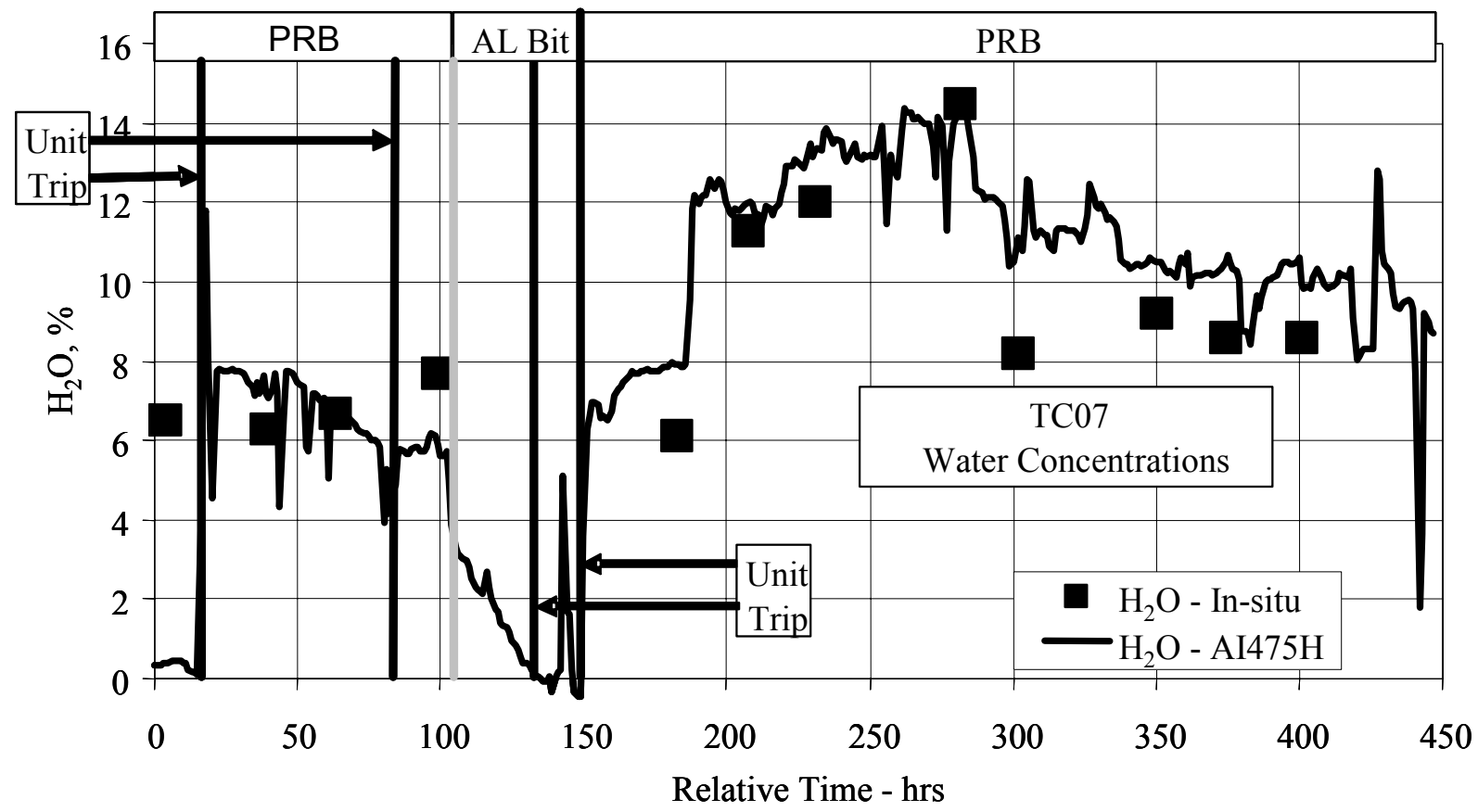

Figure 4.3-9 Synthesis Gas $\mathrm{H}_{2} \mathrm{O}$ Data 


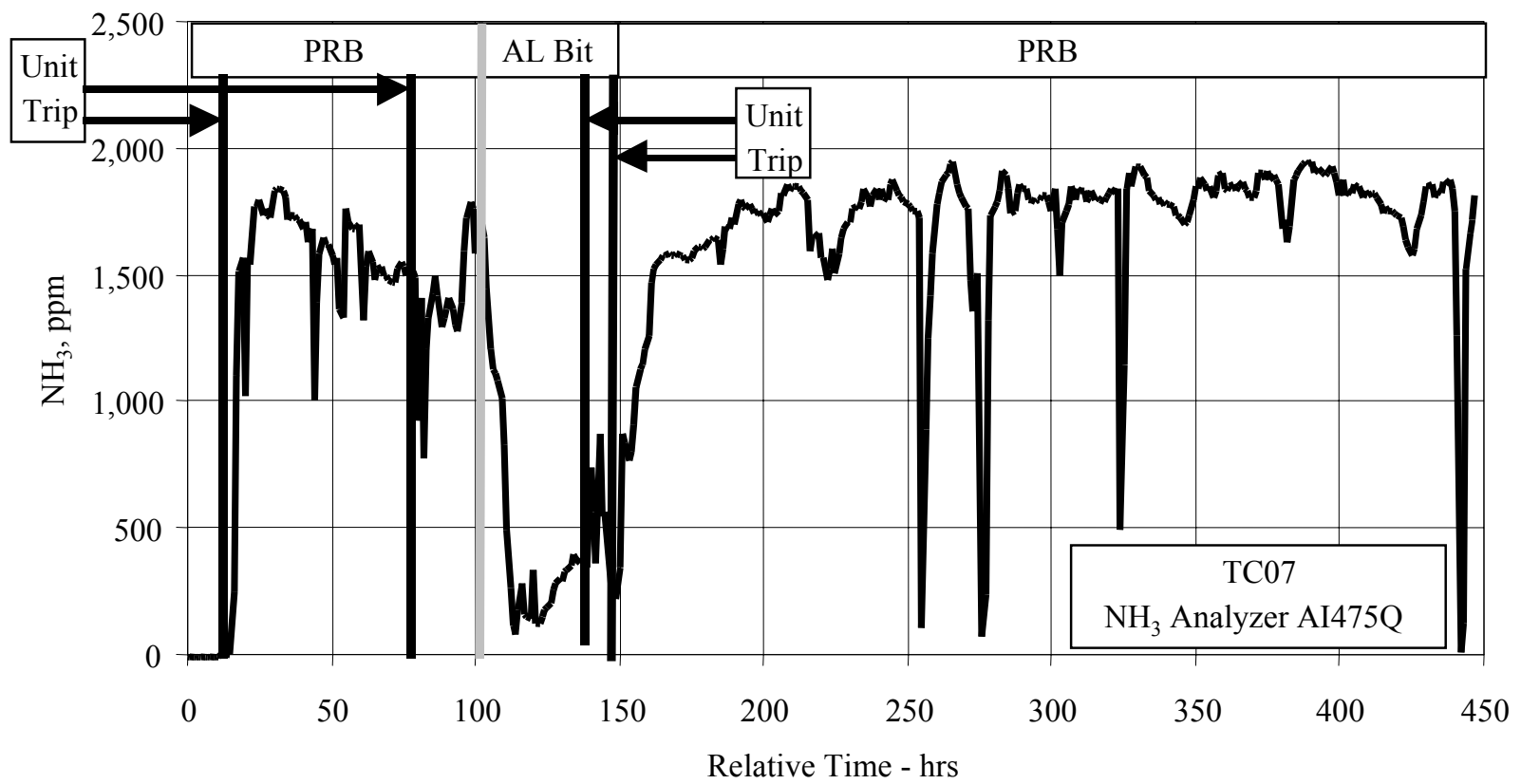

Figure 4.3-10 $\mathrm{NH}_{3}$ Analyzer Data

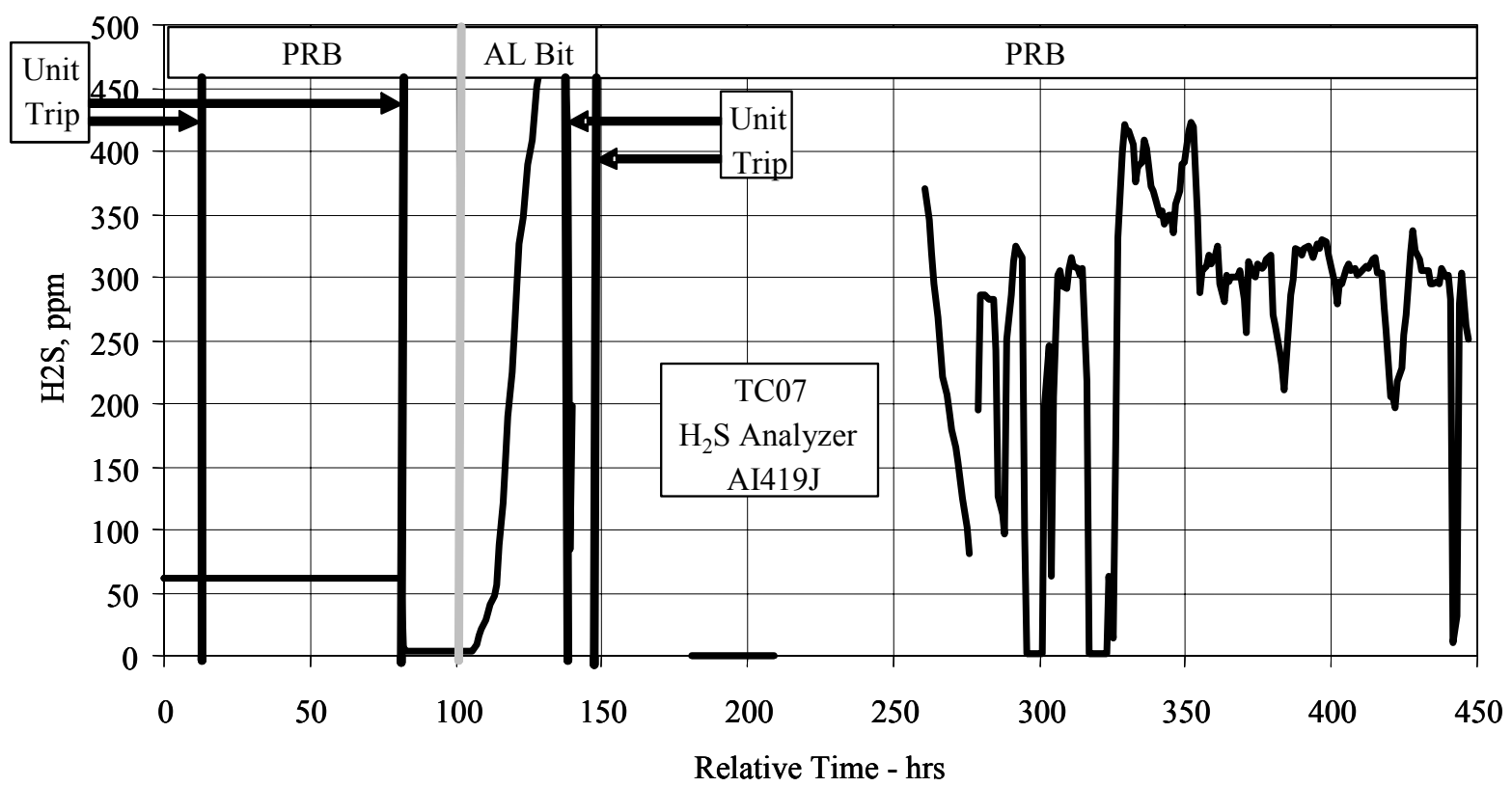

Figure 4.3-11 $\mathrm{H}_{2} \mathrm{~S}$ Analyzer Data 


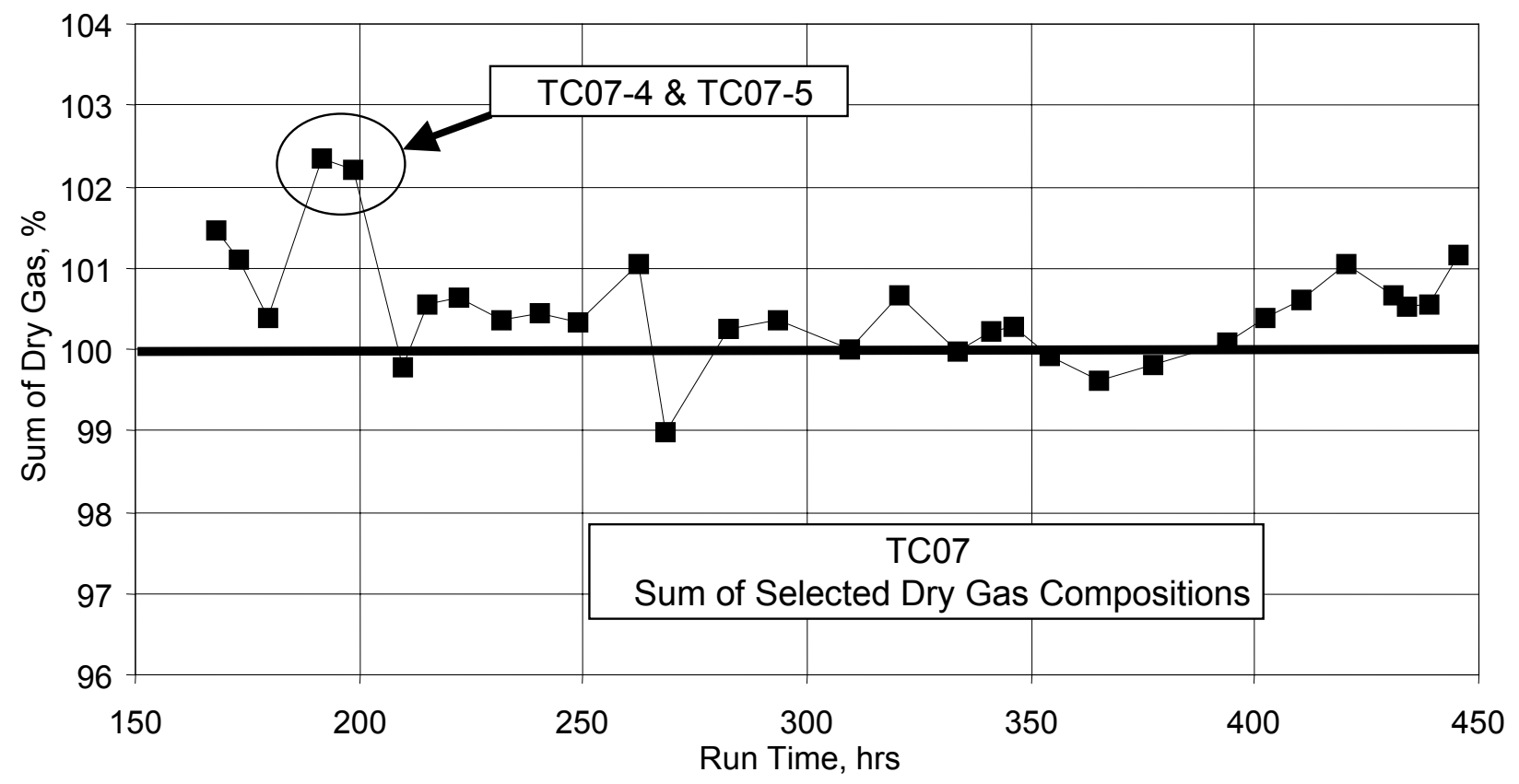

Figure 4.3-12 Sum of Dry Gas Compositions

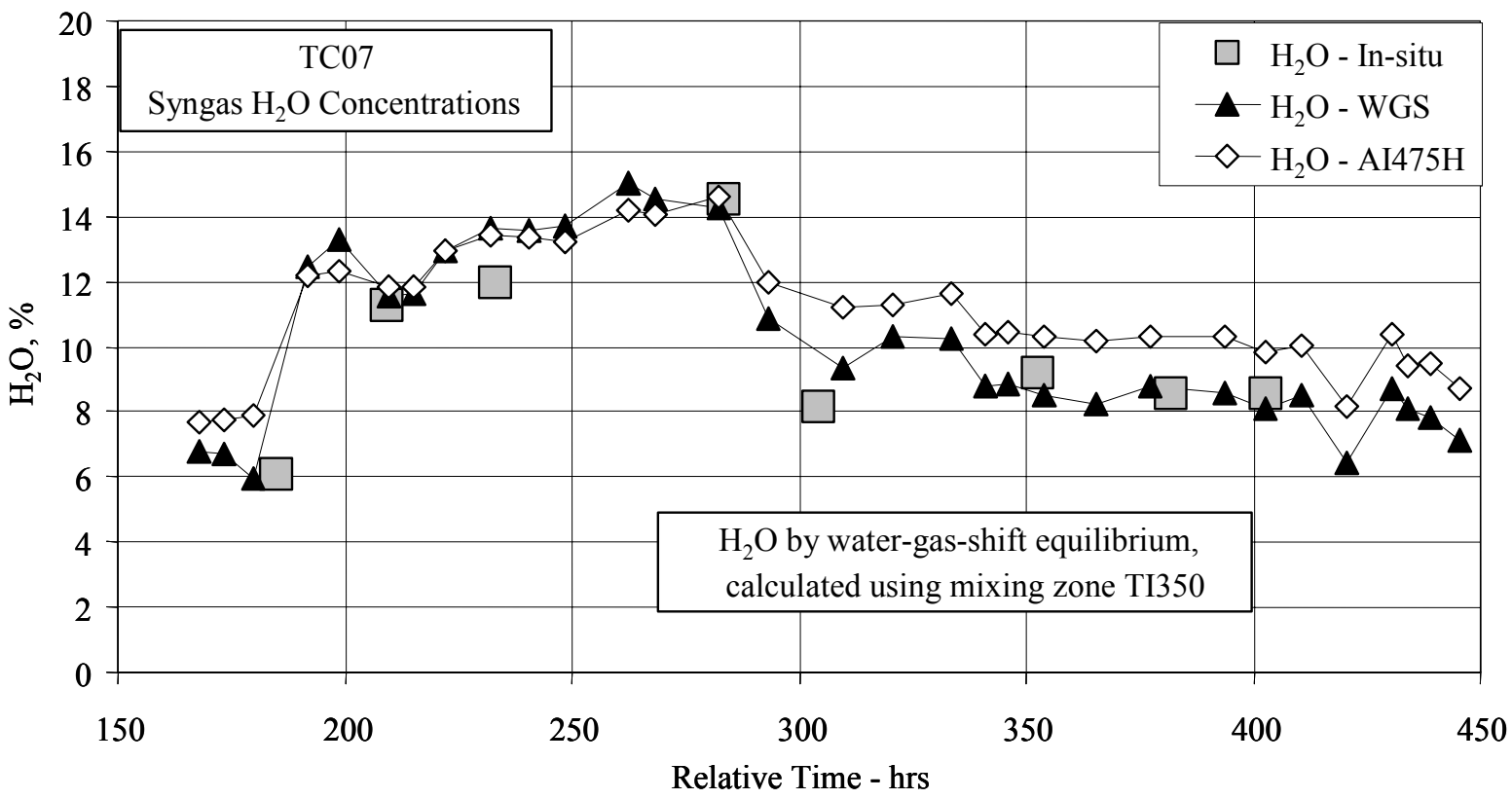

Figure 4.3-13 $\mathrm{H}_{2} \mathrm{O}$ Data 


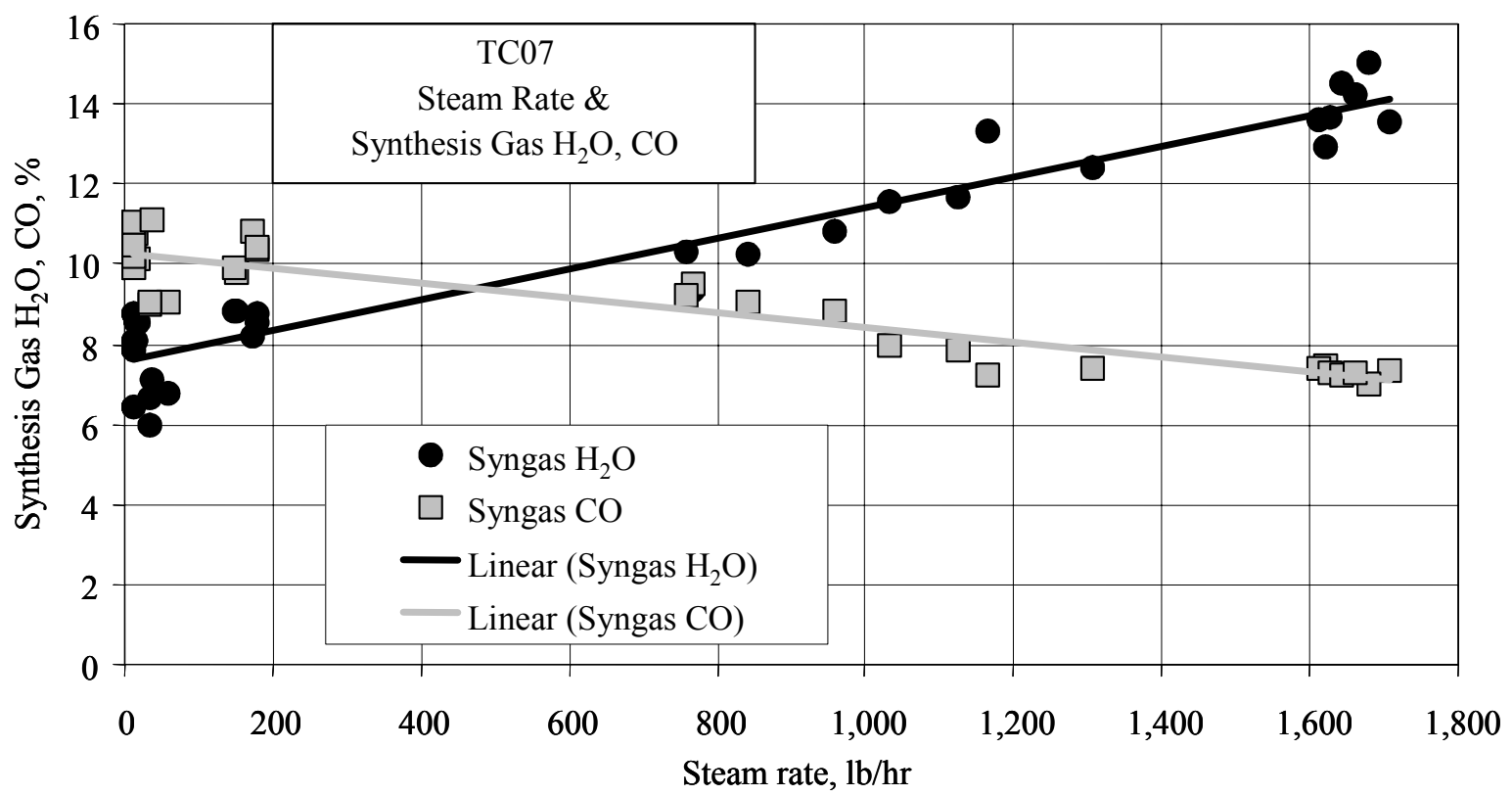

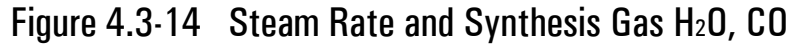

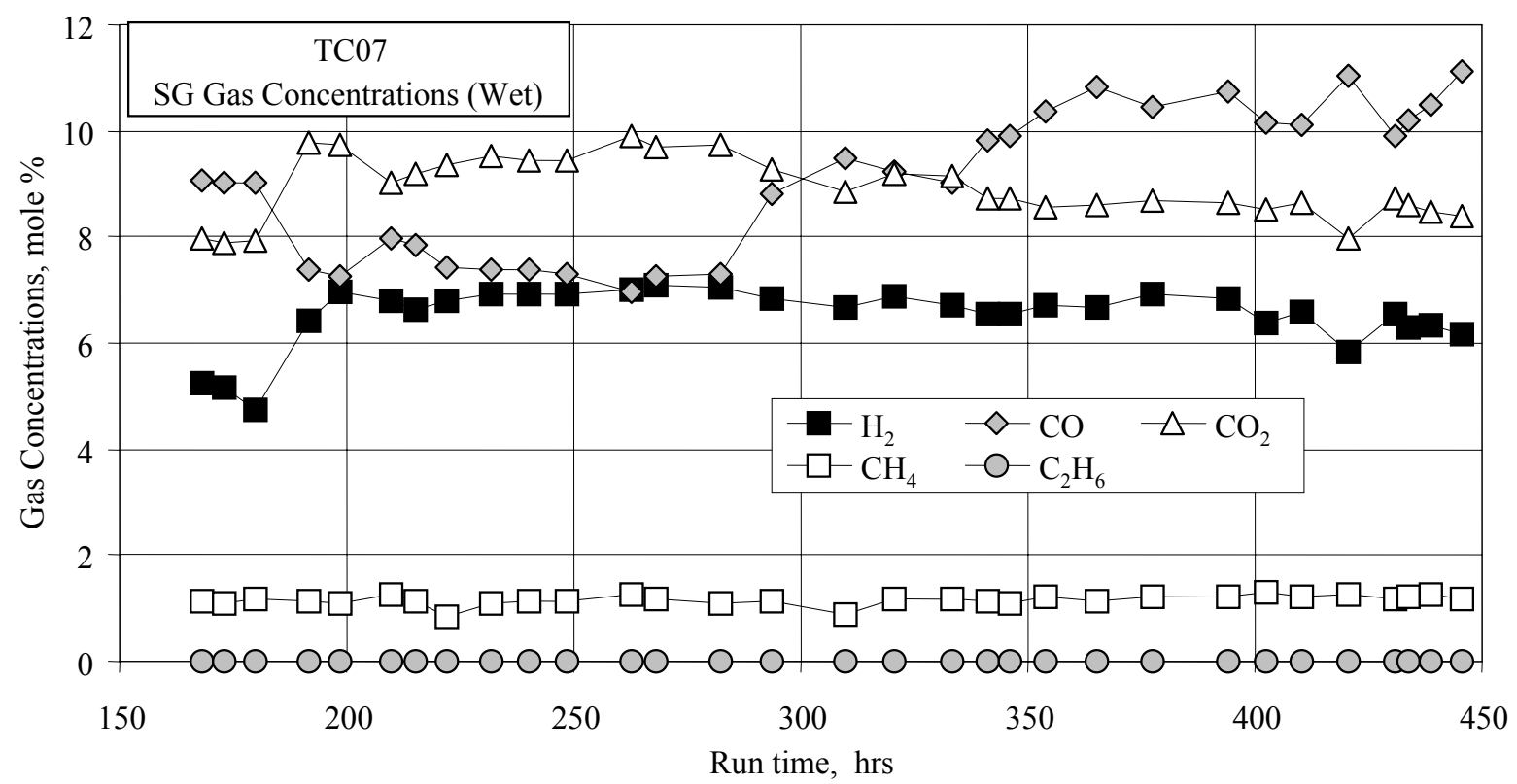

Figure 4.3-15 Wet Synthesis Gas Compositions 


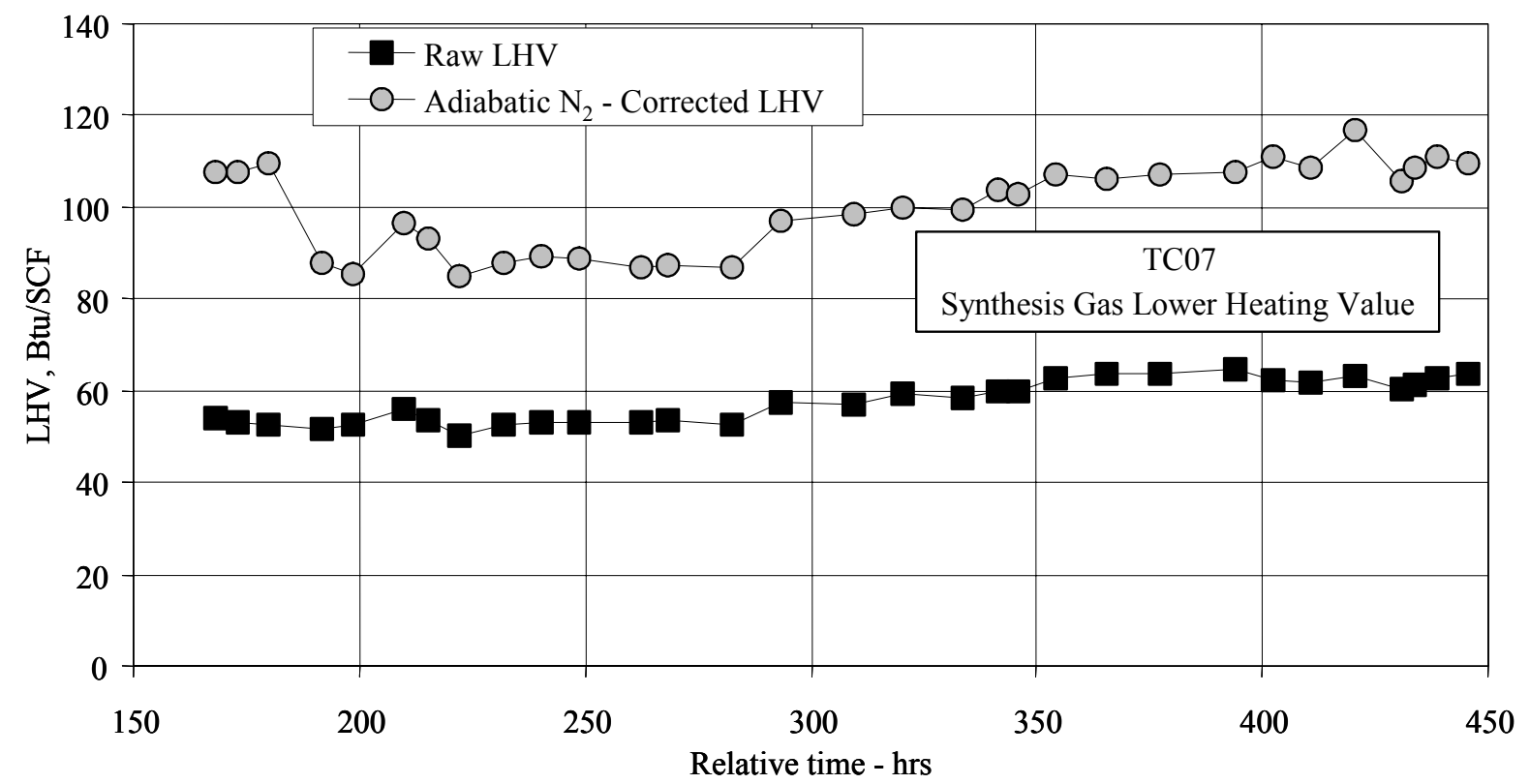

Figure 4.3-16 Synthesis Gas Lower Heating Values

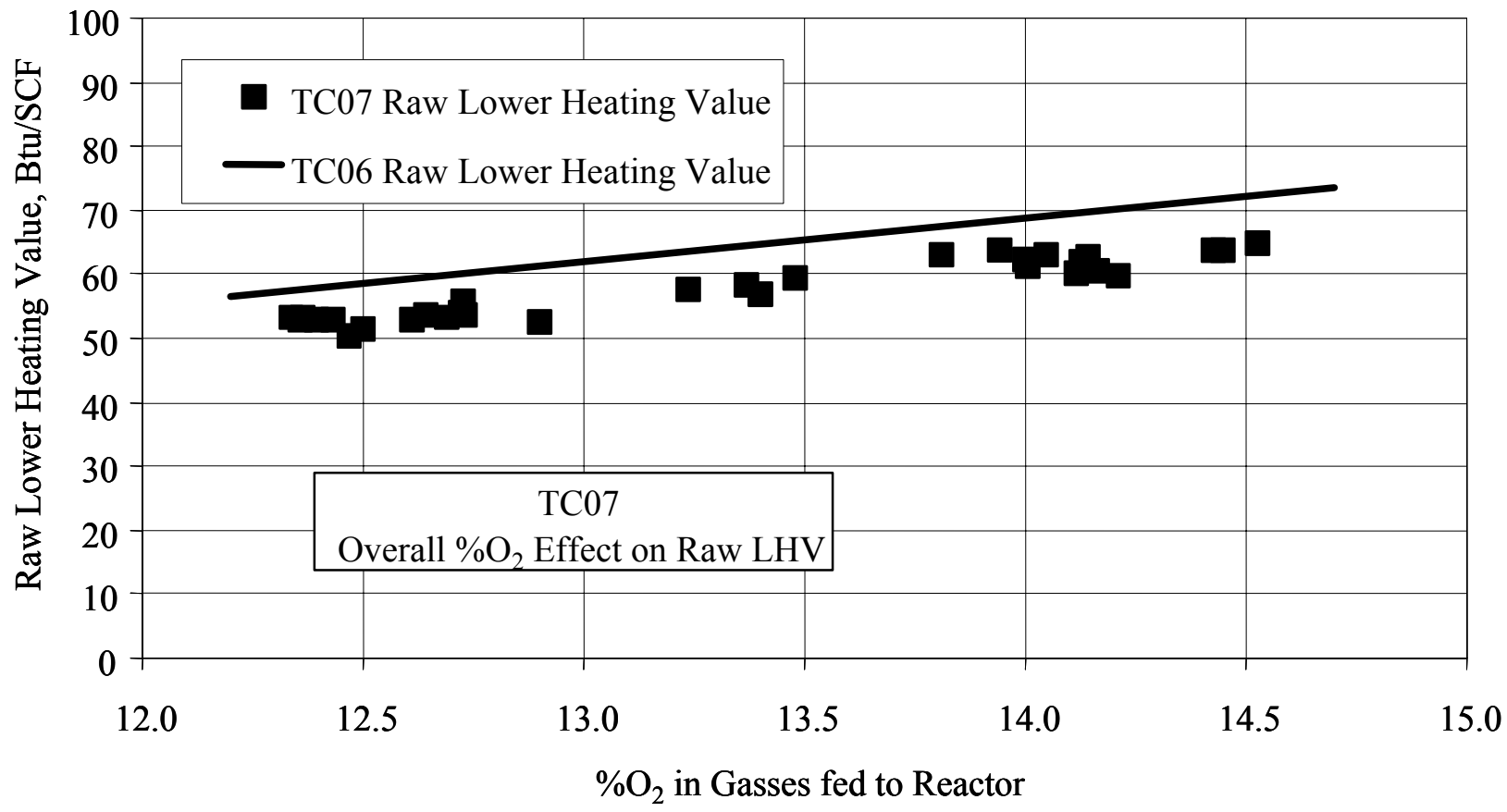

Figure 4.3-17 Raw Lower Heating Value and Overall Percent $\mathrm{O}_{2}$ 


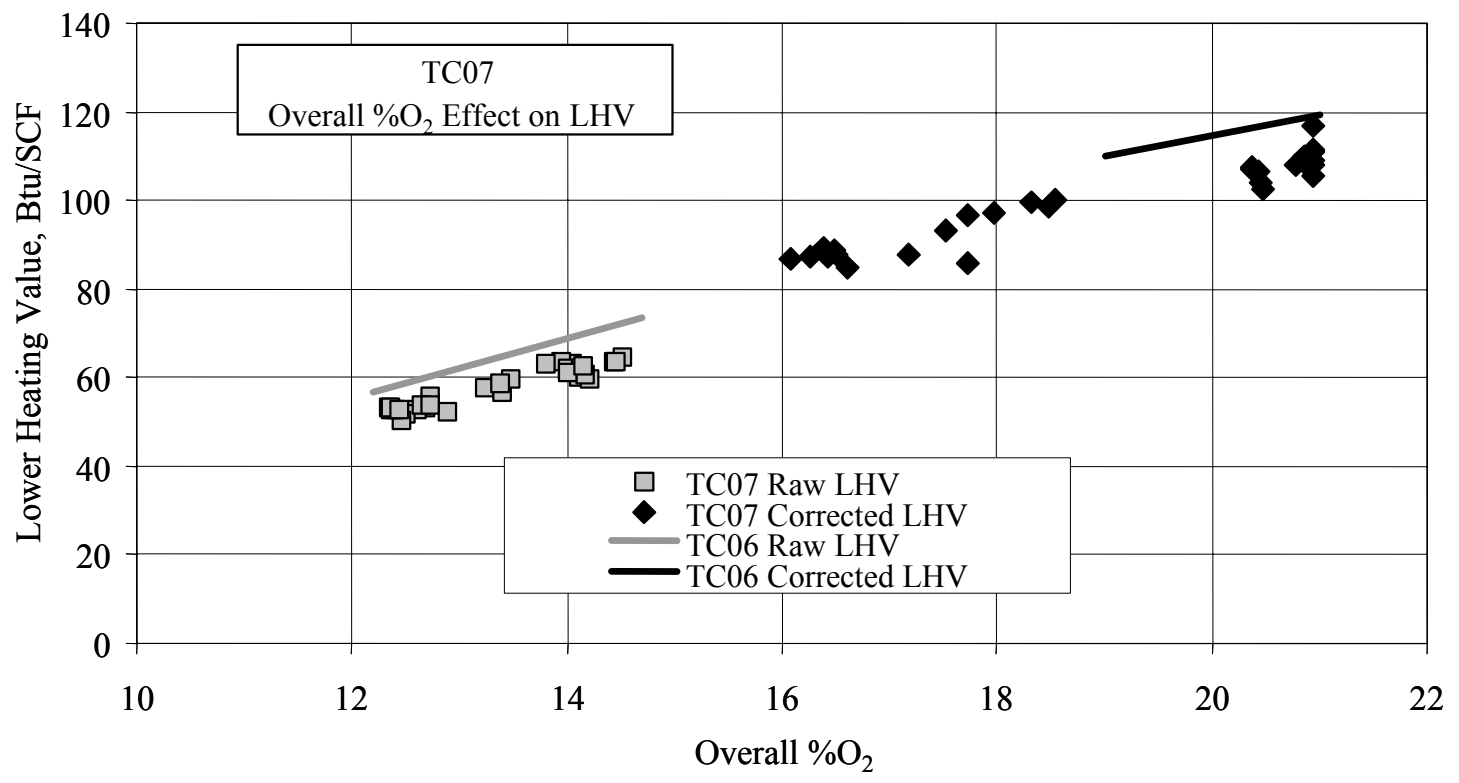

Figure 4.3-18 Lower Heating Value and Overall $0_{2} \%$

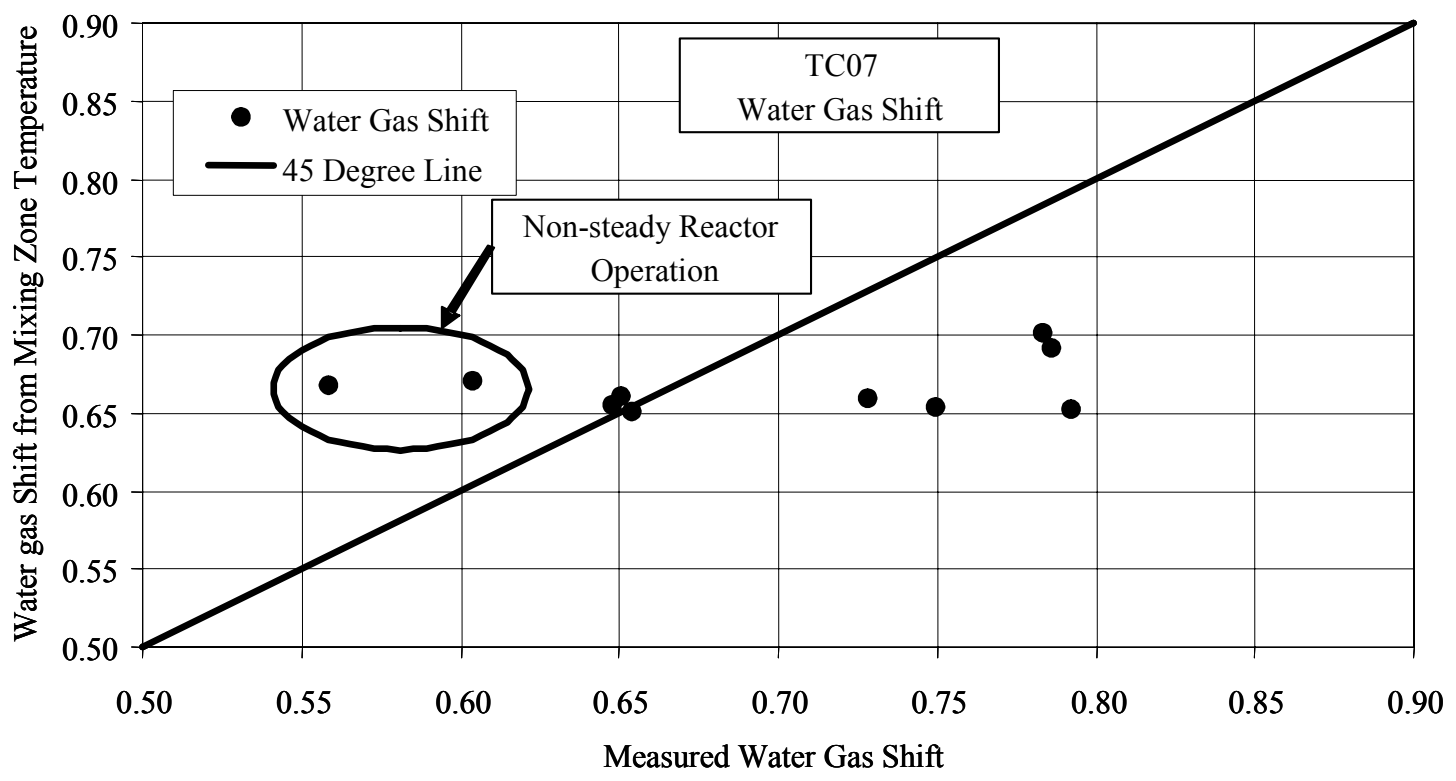

Figure 4.3-19 Water-Gas Shift Constant 


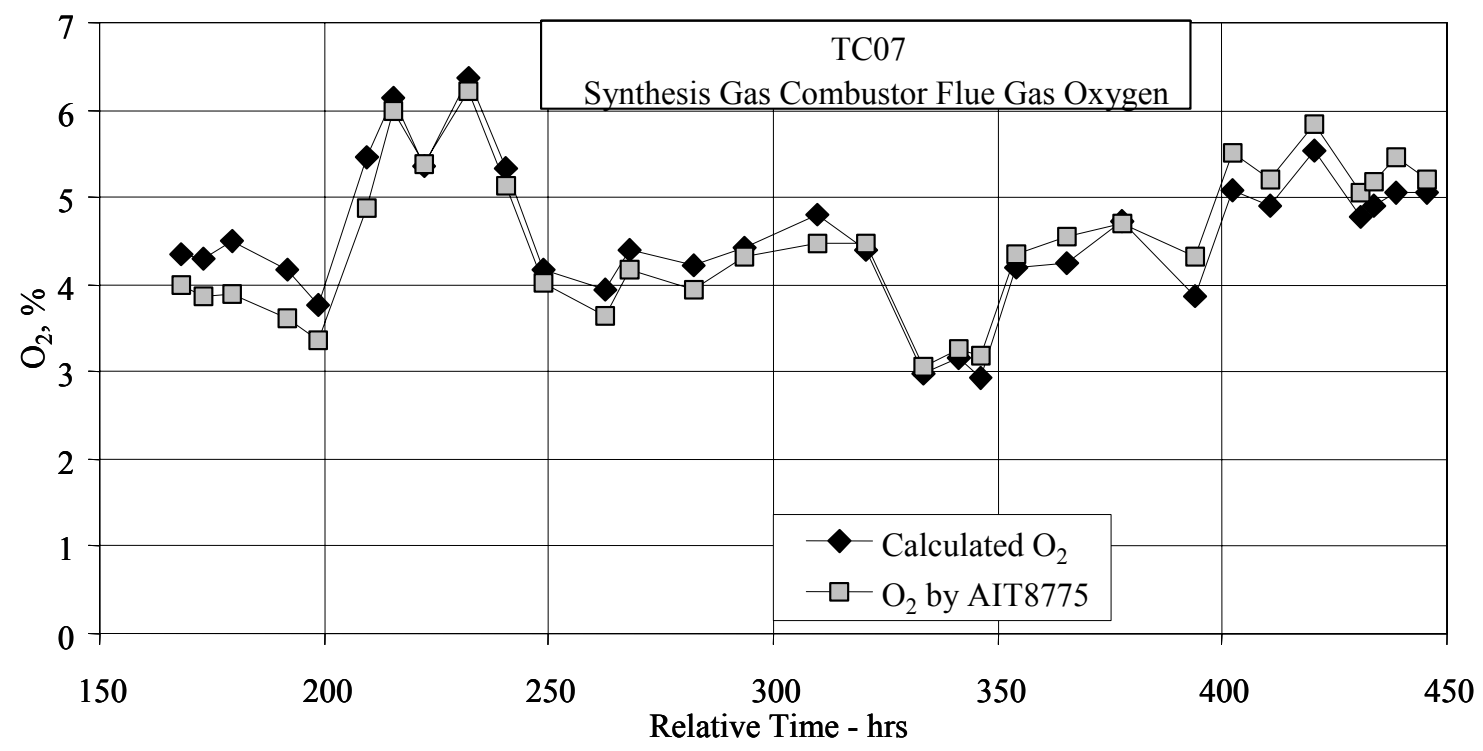

Figure 4.3-20 Synthesis Gas Combustor Outlet Oxygen

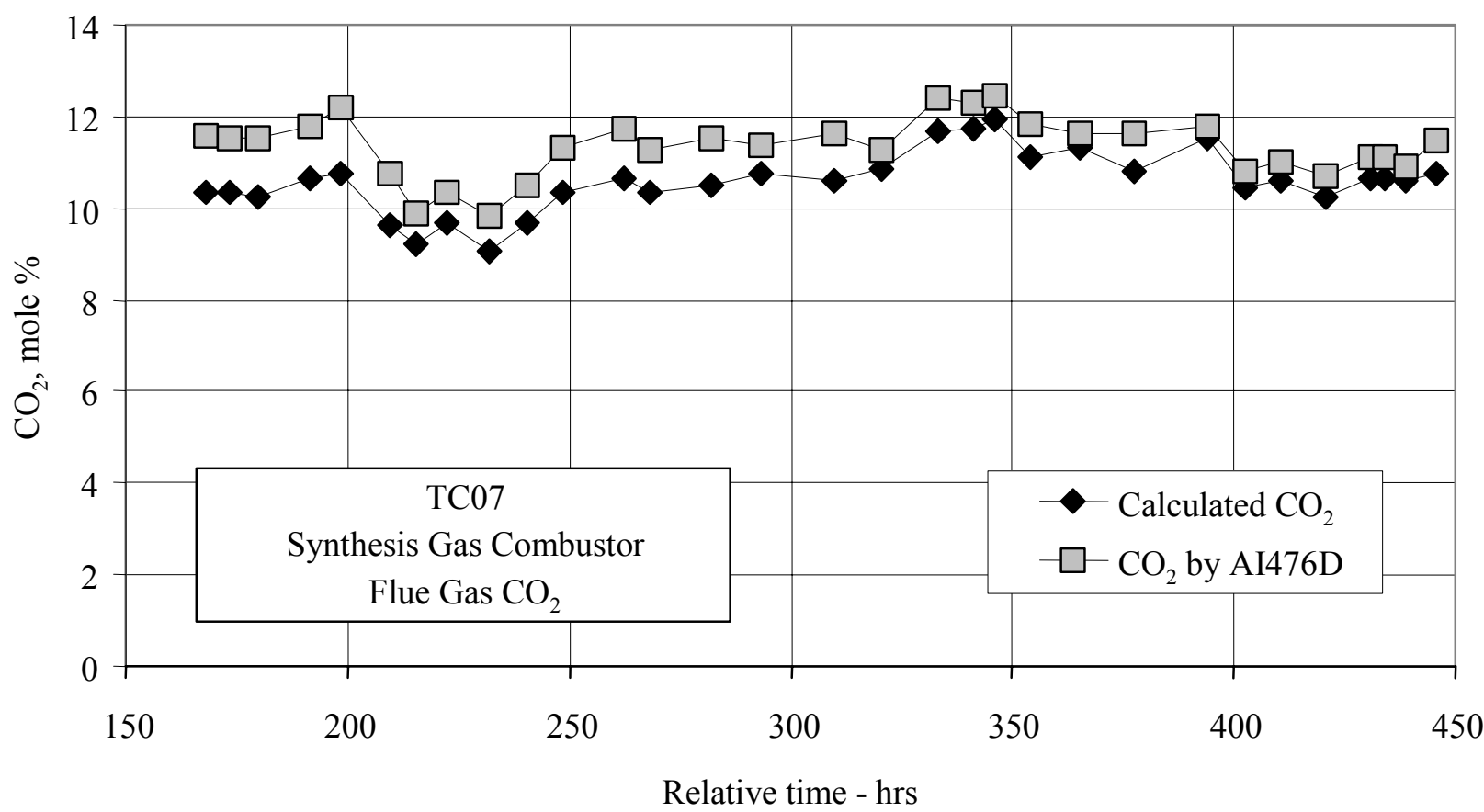

Figure 4.3-21 Synthesis Gas Combustor Outlet Carbon Dioxide 


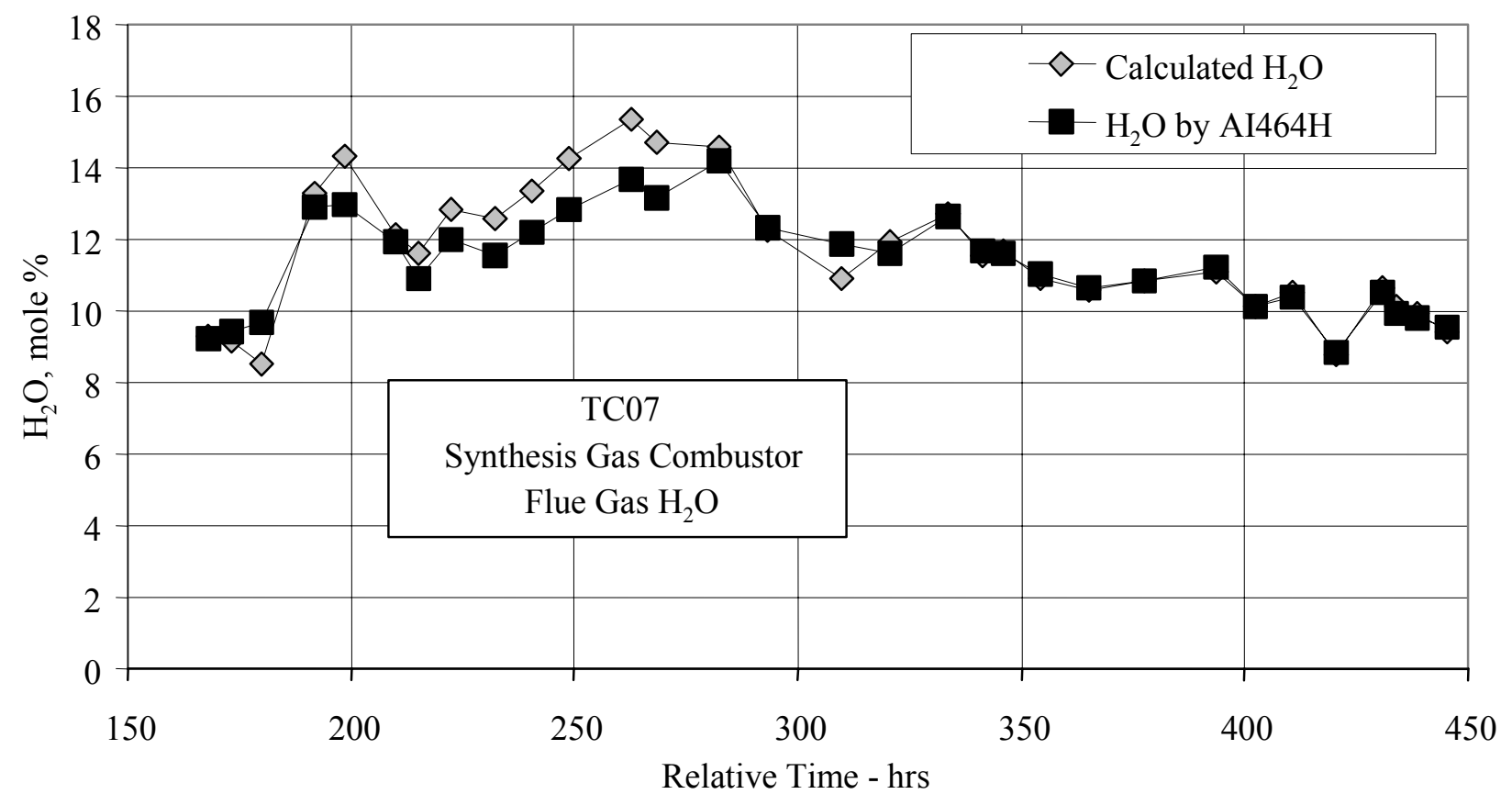

Figure 4.3-22 Synthesis Gas Combustor Outlet Moisture

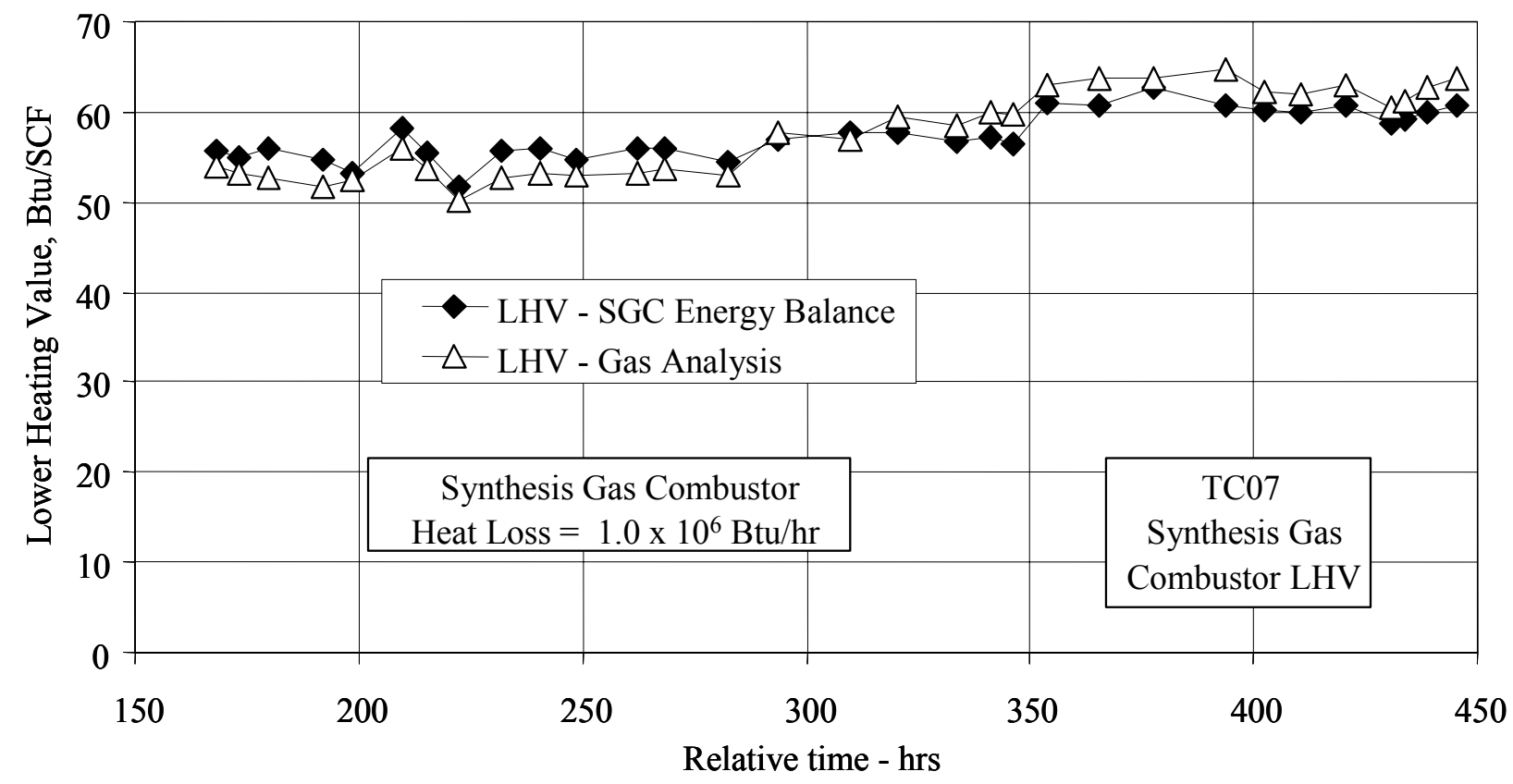

Figure 4.3-23 Synthesis Gas Combustor LHV 


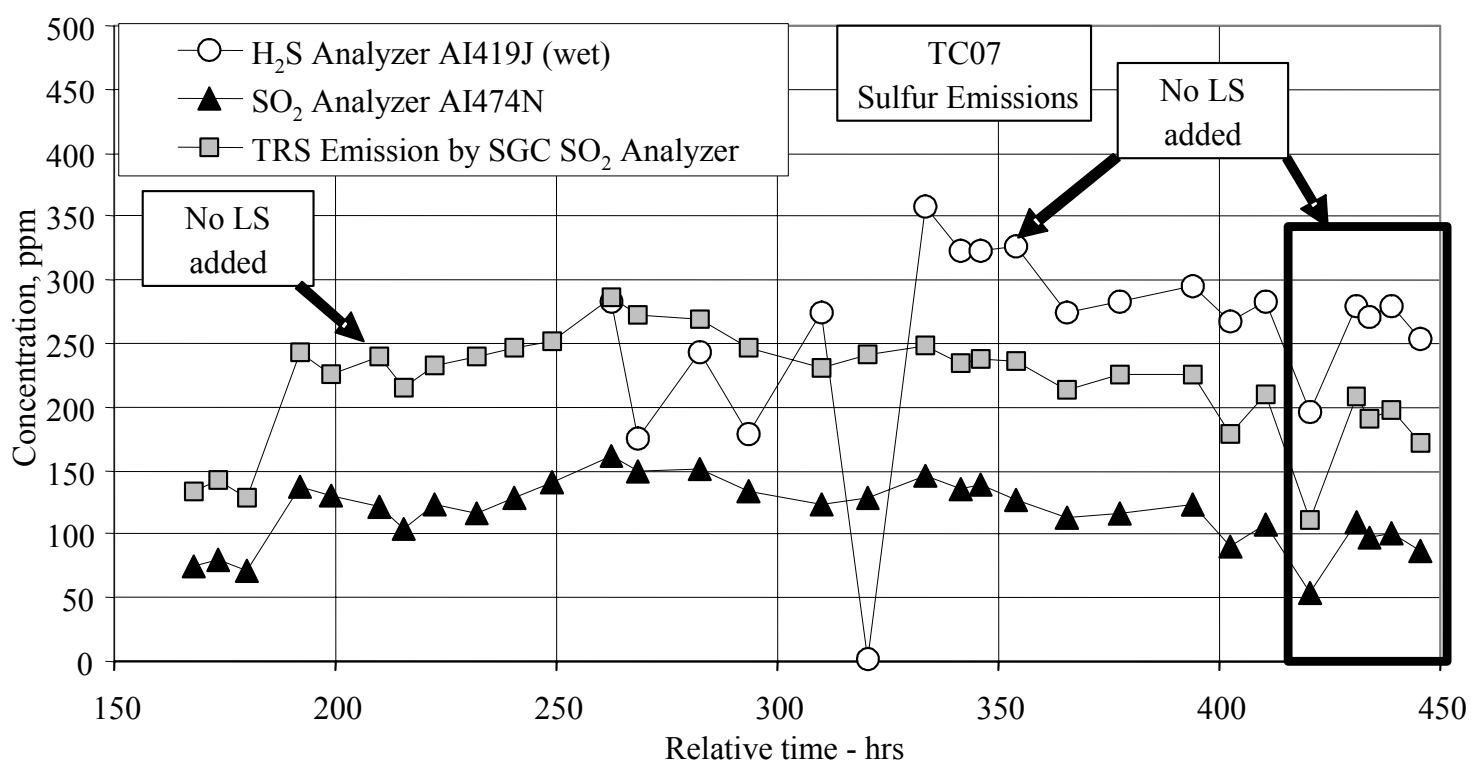

Figure 4.3-24 Sulfur Emissions

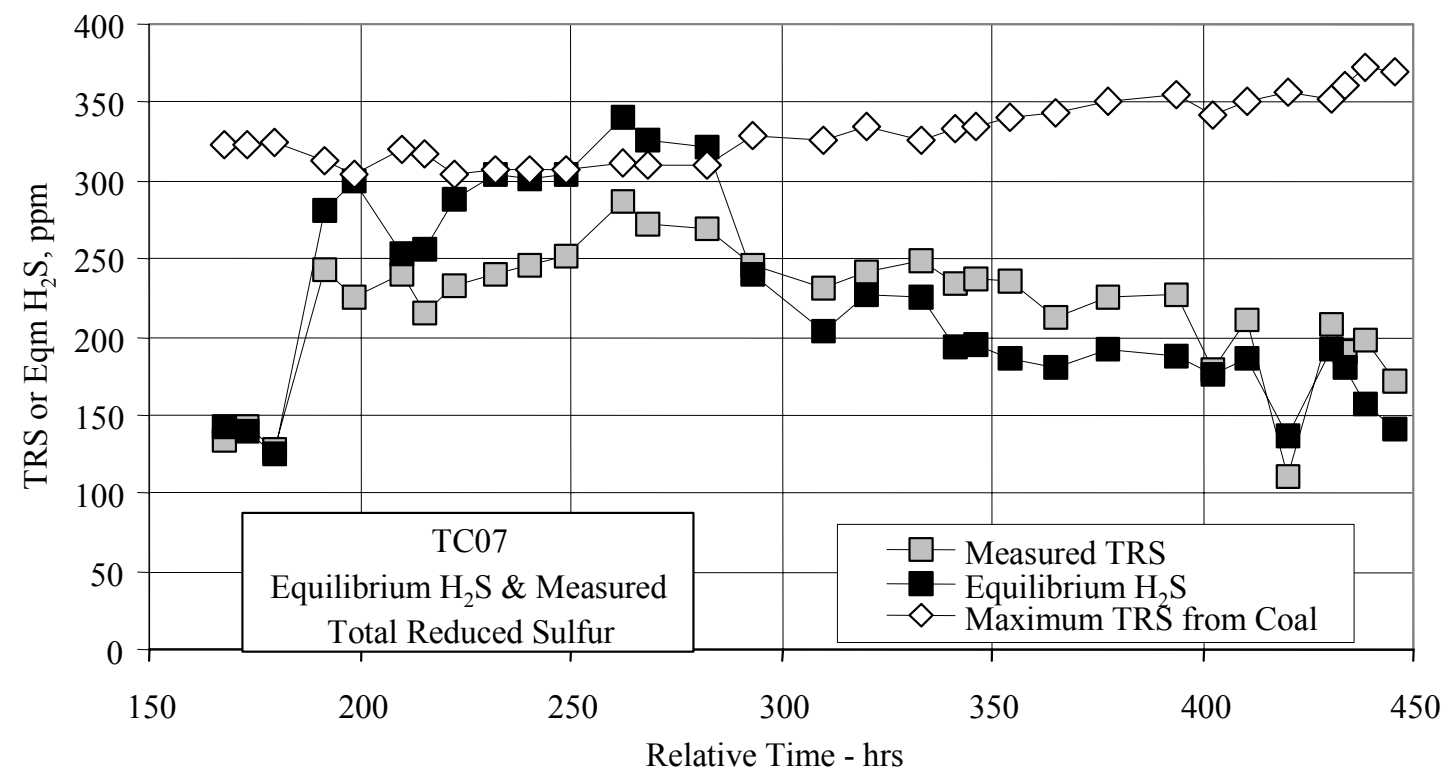

Figure 4.3-25 Equilibrium Sulfur Emissions 


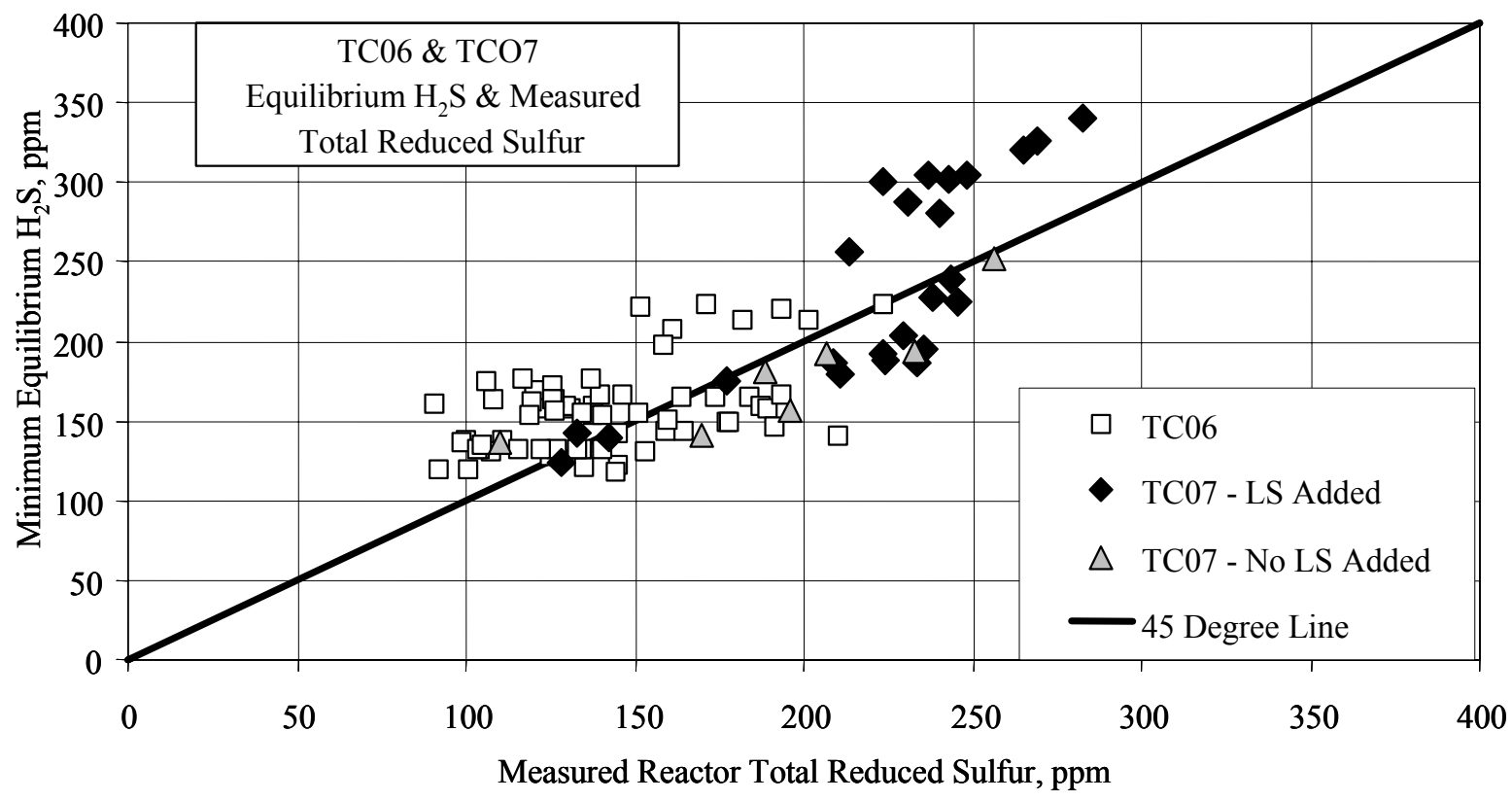

Figure 4.3-26 Equilibrium $\mathrm{H}_{2} \mathrm{~S}$ and Measured TRS

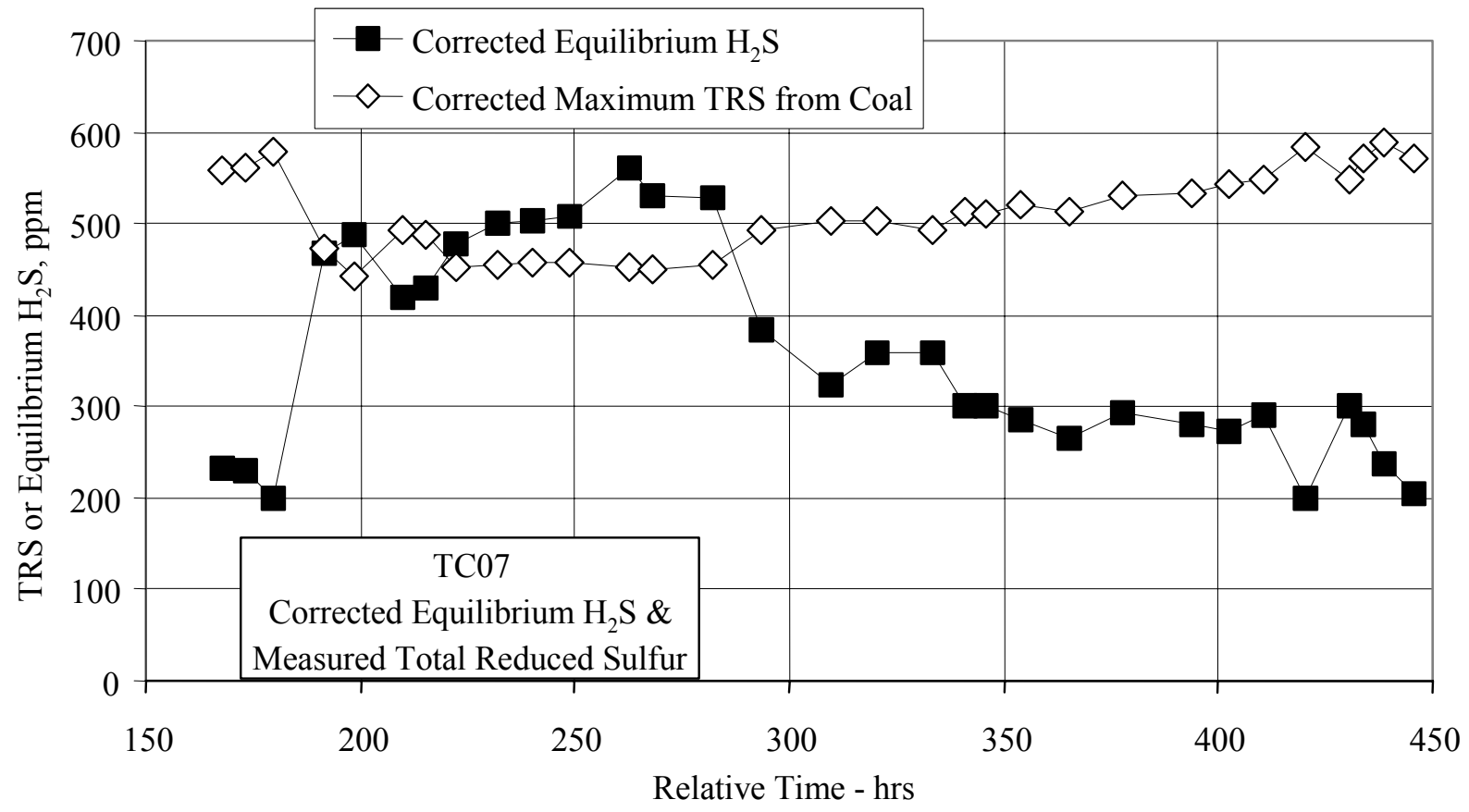

Figure 4.3-27 Corrected Equilibrium $\mathrm{H}_{2} \mathrm{~S}$ and Maximum TRS 
POWER SYSTEMS DEVELOPMENT FACILITY

TRANSPORT REACTOR

TEST CAMPAIGN TCO7

GAS ANALYSIS

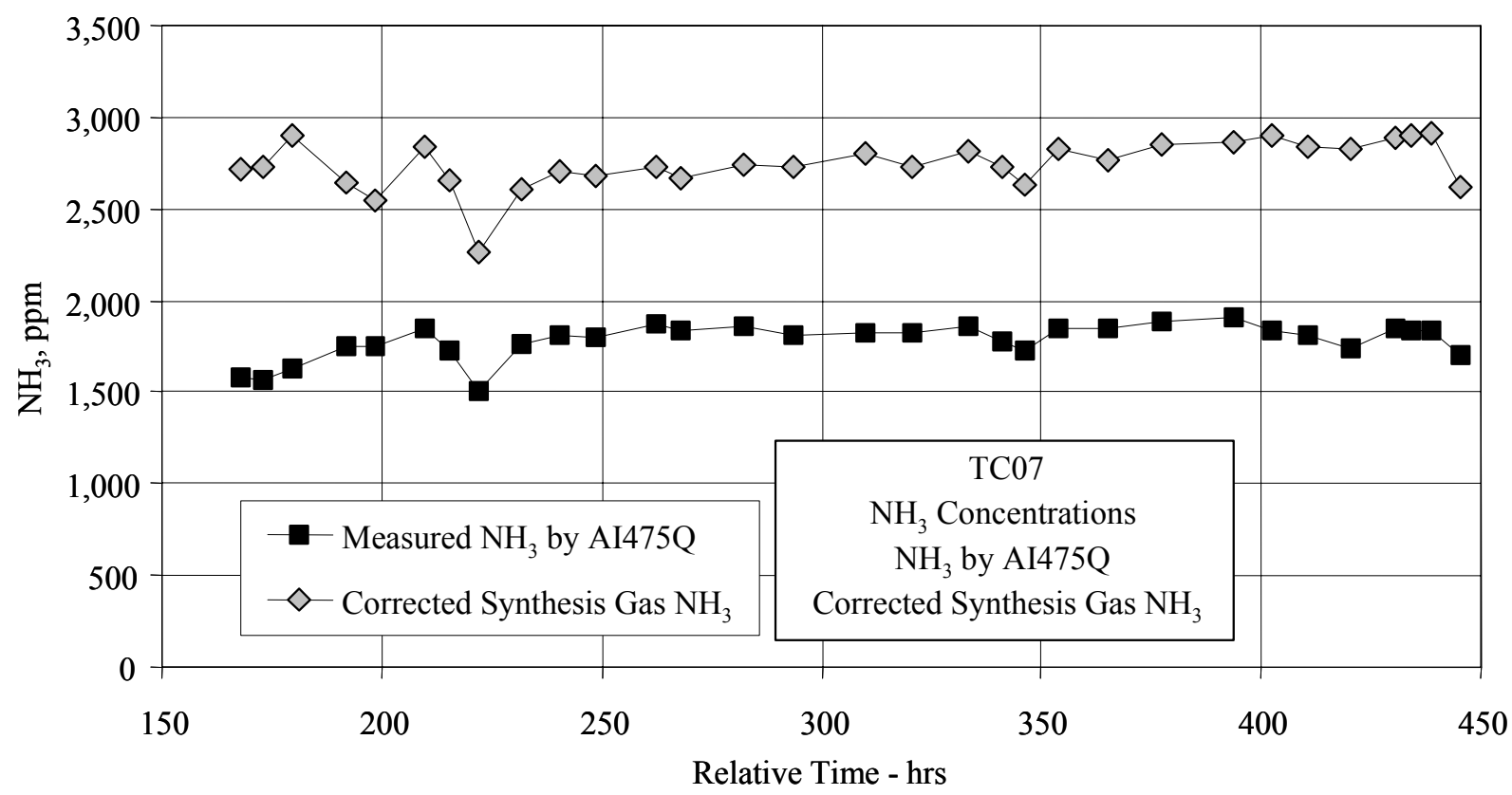

Figure 4.3-28 $\mathrm{NH}_{3}$ Emissions 


\subsection{SOLIDS ANALYSES}

\subsubsection{Summary and Conclusions}

- PRB coal composition was constant during TC07 testing.

- Ohio Bucyrus limestone composition was constant during TC07 testing.

- Standpipe carbon was between 0.1 and 0.3 weight percent for the steady operating periods.

- Standpipe solids did not reach steady compositions with respect to $\mathrm{SiO}_{2}, \mathrm{CaO}$, $\mathrm{Al}_{2} \mathrm{O}_{3}$, and $\mathrm{MgO}$.

- Standpipe solids contained small amounts of $\mathrm{CaS}$ and $\mathrm{CaCO}_{3}$; standpipe calcium was nearly completely calcined.

- In situ PCD inlet solids samples generally had the same chemical composition as the solids sampled from FD0520.

- The carbon content of PCD solids during PRB operation indicated that there were several periods of good carbon conversion.

- The PCD fines sulfur and standpipe solids sulfur content indicate very little overall Transport Reactor sulfur capture.

- The PCD fines calcium was typically 80 to 90 percent calcined.

- Coal feed particle size was constant during TC07 testing at about $200 \mu$ SMD.

- The coal feed did not have large amounts of fines during TC07 testing.

- Standpipe solids particle size increased and solids bulk density decreased during testing.

- $\quad$ PCD solids particle size was constant during PRB operation at $10 \mu$ SMD.

- PCD solids bulk density was constant at $25 \mathrm{lb} /$ cubic feet.

- The particle sizes of the TC07 solids were similar to the particle sizes of TC06.

\section{$\underline{4.4 .2 \quad \text { Introduction }}$}

During TC07, solid samples were collected from the fuel feed system (FD0210), the sorbent feed system (FD0220), the Transport Reactor standpipe, and the PCD fine solids transport system (FD0520). In situ solids samples were also collected from the PCD inlet. The sample locations are shown in Figure 4.4-1. These solids were analyzed for chemical composition and particle size. 


\subsubsection{Feeds Analysis}

Table 4.4-1 gives the average coal composition for the samples analyzed during TC07. The first samples taken after both startups were excluded from the averages on Table 4.4-1 because the coal moisture level was low, probably due to air drying between testing. The coal carbon and moisture contents (as sampled from FD0210) are shown in Figure 4.4-2. The average PRB coal carbon was 54.7-wt percent and the average PRB moisture was 22.1wt percent, while the average Alabama bituminous moisture was 4.6-wt percent and carbon content was 67.4-wt percent.

Figure 4.4-3 shows the fuel sulfur and ash as sampled from the fuel feed system during TC07. The average values are given on Table 4.4-1. The Powder River Basin (PRB) average coal sulfur was 0.24 percent and the average ash was 5.4 percent. The Alabama bituminous coal sulfur was 0.77 -wt percent and the ash was 15.1 -wt percent.

The coal HHV and LHV are given on Figure 4.4-4 with the TC07 average values given on Table 4.4-1. The LHV was determined from HHV by reducing the heating value to account for the coal moisture and hydrogen. The low moisture in the coal during the first samples after the initial startup caused the LHV and HHV to be higher than the averages. The average $\mathrm{HHV}$ for PRB was 9,249 $\mathrm{Btu} / \mathrm{lb}$ and the average LHV was 8,707 Btu/lb. The average HHV for Alabama bituminous was 11,644 Btu/lb and the average LHV was 11,212 $\mathrm{Btu} / \mathrm{lb}$.

Average values for TC07 coal moisture, carbon, hydrogen, nitrogen, sulfur, ash, oxygen, volatiles, fixed carbon, $\mathrm{HHV}, \mathrm{LHV}, \mathrm{CaO}, \mathrm{SiO}_{2}, \mathrm{Al}_{2} \mathrm{O}_{3}, \mathrm{Fe}_{2} \mathrm{O}_{3}$, and $\mathrm{MgO}$ are given in Table 4.4-1. Also given on Table 4.4-1 are the molar ratios for coal calcium to sulfur $(\mathrm{Ca} / \mathrm{S})$ and coal iron to sulfur (Fe/S). PRB has sufficient alkalinity in the ash to remove all of the coal sulfur, while Alabama bituminous does not have sufficient alkalinity to remove all of the coal sulfur.

FD0220 was used during TC07 to feed Ohio Bucyrus limestone into the Transport Reactor. The average composition of the samples taken during TC07 are given in Table 4.4-2 (two samples are excluded from the averages). The $\mathrm{CaCO}_{3}$ and $\mathrm{MgCO}_{3}$ contents are plotted on Figure 4.4-5. The $\mathrm{CaCO}_{3}$ average concentration was 74.7 percent, and the $\mathrm{MgCO}_{3}$ average concentration was 17.7 percent. Both were constant during TC07 until the iron oxide injection tests started at hour 400. During the iron oxide tests, FD0220 was used to feed iron oxide either upstream of the PCD or into the Transport Reactor mixing zone.

\subsubsection{Reactor Solids Analysis}

The chemical compositions of the solid compounds produced by the Transport Reactor were determined using the solids chemical analysis and the following assumptions:

1. All carbon dioxide measured came from $\mathrm{CaCO}_{3}$, hence moles $\mathrm{CO}_{2}=$ moles $\mathrm{CaCO}_{3}$. 
2. All sulfide sulfur measured came from $\mathrm{CaS}$.

3. All calcium not taken by $\mathrm{CaS}$ and $\mathrm{CaCO}_{3}$ came from $\mathrm{CaO}$.

4. All magnesium came from $\mathrm{MgO}$.

5. Total carbon is measured, which is the sum of organic and inorganic $\left(\mathrm{CO}_{2}\right)$ carbon. The organic carbon is the total carbon minus the inorganic carbon $\left(\mathrm{CO}_{2}\right)$.

6. All iron reported as $\mathrm{Fe}_{2} \mathrm{O}_{3}$ is assumed to be present in the solids as $\mathrm{FeO}$.

7. Inerts are the sum of the $\mathrm{P}_{2} \mathrm{O}_{5}, \mathrm{~K}_{2} \mathrm{O}, \mathrm{Na}_{2} \mathrm{O}$, and $\mathrm{TiO}_{2}$ concentrations.

The TC07 solids sulfur content was taken from the coal ash minerals $\mathrm{SO}_{3}$ data rather than the coal elemental sulfur data because the elemental coal sulfur data was extremely low and did not appear to be consistent with other test campaign solid sulfur contents.

It will be assumed that all iron in both the standpipe and PCD solids is in the form of FeO and not in the form of $\mathrm{Fe}_{3} \mathrm{O}_{4}$ or $\mathrm{Fe}_{2} \mathrm{O}_{3}$. Thermodynamically, the mild reducing conditions in the Transport Reactor should reduce all $\mathrm{Fe}_{2} \mathrm{O}_{3}$ to $\mathrm{FeO}$. The assumption of iron as $\mathrm{FeO}$ seemed to give solids compositions totals that add up to around 100 percent.

It will also be assumed that no FeS is formed in the Transport Reactor and that all the sulfur in the standpipe and PCD fines solids is present as CaS. It is thermodynamically possible that some FeS is formed. Most of the captured sulfur should be in the form of CaS due to the larger amount of calcium than iron in the system up until the iron oxide injection tests. Once iron oxide is injected, FeS should form in the reactor. There is no analytical method to determine the relative amount of $\mathrm{CaS}$ and $\mathrm{FeS}$ in reactor solids.

Table 4.4-3 and Figure 4.4-6 show the results from the standpipe solids analyses. Hours 116 and 132 were taken during Alabama bituminous operation, while all the other samples were taken during PRB operation. The standpipe solids are solids that recirculate through the mixing zone, riser, and standpipe and change slowly with time, since a small amount of solids are taken out of the standpipe via FD0510. FD0510 was operated intermittently during TC07 to control the standpipe level. The flow rates for FD0510 and FD0520 solids during the stable operating periods will be given in Section 4.5.

On startup, the standpipe solids mainly contained $\mathrm{SiO}_{2}$, with 72-percent $\mathrm{SiO}_{2}$ at the start of TC07 and 85.1-percent $\mathrm{SiO}_{2}$ after the 8-week break. This is because the starting bed material was sand with 96.7-percent $\mathrm{SiO}_{2}$ and 1.45-percent $\mathrm{Al}_{2} \mathrm{O}_{3}$. The standpipe did not contain sand at zero hours and the restart since there were several periods of coal and coke breeze operation prior to the starting of the clock for the test, which diluted the standpipe sand.

As the run progressed, the start-up sand was slowly replaced by $\mathrm{CaO}, \mathrm{Al}_{2} \mathrm{O}_{3}, \mathrm{Fe}_{2} \mathrm{O}_{3}$, and other inerts. This is shown in Figure 4.4-6. The $\mathrm{SiO}_{2}$ content slowly decreased and both the $\mathrm{Al}_{2} \mathrm{O}_{3}$ and the $\mathrm{CaO}$ increased to replace the $\mathrm{SiO}_{2}$. The two test periods (after fresh sand 
was added to the gasifier) were not sufficiently long enough to produce steady-state standpipe solids concentration, as in TC06, since the $\mathrm{SiO}_{2}$ concentration was still decreasing just before both the 8 -week break and the end of TC07.

The standpipe solids data in Table 4.4-3 shows that none of the volatile elements (sulfur and carbon) are present in very high concentrations after the unit was in operation for a few days. The organic carbon quickly decreases after startup to less than 0.5 percent. The high start-up carbon is probably due to the coke breeze used during startup. The high level of organic carbon at hour 116 and hour 132 were during the unsteady operation on Alabama bituminous coal. The heating value of the standpipe solids sampled was measured and was less than $100 \mathrm{Btu} / \mathrm{lb}$ for all samples with organic carbon content less than 0.5 percent.

The standpipe $\mathrm{CaCO}_{3}$ was at very low levels, less than 1.0 percent, which indicated that there was very little inorganic carbon in the reactor. Since there were much higher levels of $\mathrm{CaO}$ than $\mathrm{CaCO}_{3}$, all calcium that circulated in the standpipe was nearly completely calcined. Since the standpipe calcium could come from either sorbent or fuel calcium, it is unknown whether the standpipe solids calcium came from sorbent or fuel calcium. Whatever the source, it was completely calcined. Long-term operation on a lower calcium fuel will be required to determine whether the standpipe accumulates fuel ash or sorbent calcium (or both).

The sulfur level in the solids was very low, less than 0.1 percent as $\mathrm{CaS}$, for all of the samples except two. This indicates that all of the sulfur removed from the synthesis gas is removed via the PCD solids and is not accumulating in the reactor or leaving with the reactor solids. The $\mathrm{MgO}, \mathrm{Fe}_{2} \mathrm{O}_{3}$, and other inerts contents are not plotted on Figure 4.4-6, but they follow the same trends as the $\mathrm{CaO}$ and $\mathrm{Al}_{2} \mathrm{O}_{3}$, that is, they are accumulating in the reactor as the start-up sand is replaced by feed solids.

\subsubsection{Reactor Products Solids Analysis}

Figure 4.4-7 plots the organic carbon (total carbon minus $\mathrm{CO}_{2}$ carbon) for the PCD solids sampled from FD0520. The organic carbon content for every PCD fines sample analyzed is also given on Table 4.4-4. Since FD0520 ran continuously during TC07, solid samples were taken often, with a goal of one sample every 4 hours. About half of the TC07 PCD solids that were sampled were analyzed. Solids recovered in situ during the PCD inlet particulate sampling were also analyzed. The in situ carbon contents are compared with the FD0520 solids on Figure 4.4-7. The in situ solids organic carbon analyses compared well with the FD0520 solids for five of the seven in situ solid samples. The two exceptions were the two in situ analyses at hours 284 and 354 . The 284 hour sample was taken during sand addition upstream of the PCD and hour 354 was taken during iron oxide addition upstream of the PCD. The iron oxide addition at hour 354 should not have caused the poor comparison because the in situ sample taken at hour 421 (also taken during iron oxide addition) had excellent agreement with the FD0520 solids carbon.

The organic carbon started the run at 38 percent, and then decreased to between 20 and 30 percent for the first 100 hours. The 50 hours of Alabama bituminous coal operation had 
high FD0520 solids carbon contents from 35 to 65 percent, which indicated poor carbon conversion. After the 8-week break, the organic carbon decreased from 40 percent to 20 percent at hour 352. The iron injections tests gave more scatter to the PCD fines carbon contents. Periods of low organic carbon content from hour 228 to the end of TC07 indicate excellent carbon conversion.

Figure 4.4-8 and Table 4.4-3 give the amounts of $\mathrm{SiO}_{2}$ and $\mathrm{CaO}$ in the PCD solids as sampled from FD0520. Also plotted on Figure 4.4-8 are the in situ solids concentrations for $\mathrm{SiO}_{2}$ and $\mathrm{CaO}$. The seven in situ $\mathrm{SiO}_{2}$ and $\mathrm{CaO}$ concentrations showed good agreement with the FD0520 solids $\mathrm{SiO}_{2}$ and $\mathrm{CaO}$ concentrations with a couple exceptions at hour 185 for $\mathrm{CaO}$ and hour 284 for $\mathrm{SiO}_{2}$. The $\mathrm{SiO}_{2}$ and $\mathrm{CaO}$ concentrations were between 19 and 26 percent for the first 100 hours of operation if the first analysis is ignored. The Alabama bituminous operation had higher $\mathrm{SiO}_{2}$ concentrations (up to 35 percent), while the $\mathrm{CaO}$ decreased from 20 percent down to nearly 0 percent. The decrease in $\mathrm{CaO}$ PCD solids during Alabama bituminous operation was due to the lower level of $\mathrm{CaO}$ in the Alabama bituminous coal ash concentration and no limestone feed during Alabama bituminous operation. The $\mathrm{SiO}_{2}$ increased after the 8-week break during PRB coal operation from 20 percent up to 70 percent. Some of this increase was due to sand and sand-iron oxide injections. After hour 350 there were periods when limestone was not fed to the Transport Reactor which caused high $\mathrm{SiO}_{2}$ and low $\mathrm{CaO}$ concentrations. The $\mathrm{CaO}$ FD0520 solids concentrations from hour 150 to hour 350 were similar to the $\mathrm{CaO}$ concentrations prior to hour 100 (10 to 25 percent). After hour 350, the $\mathrm{CaO}$ concentrations were lower than 16 percent (with one outlier) to the end of TC07.

Figure 4.4-9 and Table 4.4-4 give the amounts of $\mathrm{CaCO}_{3}$ and $\mathrm{CaS}$ in the PCD solids as sampled from FD0520. Also plotted on Figure 4.4-9 are the in situ solids concentrations for $\mathrm{CaCO}_{3}$ and $\mathrm{CaS}$. The first two and last two in situ samples $\mathrm{CaCO}_{3}$ concentration agreed well with FD0520 solids $\mathrm{CaCO}_{3}$, while the middle three (hours 229, 284, and 349) were consistently about 0.5 to 2.0 percent higher than the $\mathrm{CaCO}_{3}$ concentration from FD0520 solids. The middle three in-situ $\mathrm{CaCO}_{3}$ concentrations had the same difference with the FD0520 $\mathrm{CaCO}_{3}$ concentrations as in TC06. The lower $\mathrm{CaCO}_{3}$ concentration was a result of a lower measured $\mathrm{CO}_{2}$ in the FD0520 solids. This may be due to the FD0520 solids being slightly degassed in the PCD or FD0520 by aeration or back-pulse nitrogen. The in situ CaS and FD0520 CaS solids analyses agreed well with each other during TC07.

The FD0520 solids $\mathrm{CaCO}_{3}$ concentration decreased from the start of the run from 10 percent to 6 percent at 100 hours, when the Alabama bituminous coal testing began. During the Alabama coal testing, the $\mathrm{CaCO}_{3}$ decreased due to no limestone being fed to the reactor. No limestone was fed to the reactor during the Alabama bituminous testing to decrease the PCD solids loading. (The higher ash content of Alabama bituminous coal and higher limestone rate produced higher PCD solids rates than the PCD ash removal system could handle.) The high $\mathrm{CaCO}_{3}$ of the FD0520 solids at 200 hours were due to a high rate $(1,000$ $\mathrm{lb} / \mathrm{hr}$ ) of limestone fed to the reactor. From hours 212 to 348, the $\mathrm{CaCO}_{3}$ FD0520 solids concentrations were constant from 4 to 8 percent with one outlier. Limestone was intermittently fed to the Transport Reactor from hours 348 to 376 during iron oxide testing. Limestone was fed to the PCD at hour 409 which increased the FD0520 solids $\mathrm{CaCO}_{3}$ 
concentration up to 43.9 percent. At the end of TC07, the limestone was turned off and the $\mathrm{CaCO}_{3}$ concentration decreased.

In the first 100 hours the FD0520 solids had some sulfur capture, with 1.4- to 2.7-percent $\mathrm{CaS}$ in the solids. During the Alabama bituminous coal testing, the CaS concentration decreased to nearly 0.0 percent, which indicated there was no reactor sulfur capture. There was some CaS in the FD0520 solids from hours 168 to 180, and then the FD0520 solids CaS decreased to nearly zero for the rest of TC07.

The PCD fines calcination is defined as:

$$
\% \text { Calcination }=\frac{\mathrm{M} \% \mathrm{CaO}}{\mathrm{M} \% \mathrm{CaO}+\mathrm{M} \% \mathrm{CaCO}_{3}}
$$

The PCD fines calcination is plotted on Figure 4.4-10. For the first 100 hours the PCD fines calcination was between about 83 to 87 percent. For the Alabama bituminous testing the calcination was from 69 to 92 percent. From hour 225 to hour 400 in PRB coal operation, the calcination was from 80 to 90 percent with two outliers above 95 percent. During the iron oxide testing (after hour 400), limestone was fed directly into the PCD. Limestone fed to the PCD could not obtain a high enough temperature to calcine, so it would be present in the PCD fines as $\mathrm{CaCO}_{3}$. The small amount of limestone calcination was therefore from the PRB coal calcium. The data does not indicate 85 percent feed limestone calcination for TC07 up to hour 400 since the calcium in the PCD fines comes from both the PRB ash and the sorbent limestone. The percent feed limestone calcination will be determined and compared with the $\mathrm{CO}_{2}$ partial pressure in Section 4.5.

The calcium sulfation is defined as:

$$
\% \text { Sulfation }=\frac{\mathrm{M} \% \mathrm{CaS}}{\mathrm{M} \% \mathrm{CaO}+\mathrm{M} \% \mathrm{CaCO}_{3}+\mathrm{M} \% \mathrm{CaS}}
$$

The PCD fines sulfation is plotted on Figure 4.4-10 with the limestone calcination. The PCD fines sulfation was between 5 and 11 percent for all of the PBR coal testing up to 180 hours, which indicated some sulfur capture. The Alabama bituminous sulfation was from 10 to 30 percent, but this did not indicate significant sulfur capture since there was no limestone fed to the reactor and Alabama bituminous ash does not contain much calcium. The sulfation from hours 192 to 360 was very low indicating low sulfur capture. Hours 368 to 372 indicated some sulfur capture as the sulfation went up to nearly 5 percent. The samples taken during hours 374 and 375 were taken during iron oxide injection. Sulfur removals will be determined in Section 4.5 for all of the operating periods and compared with the equilibrium removals.

Table 4.4-4 gives the PCD fines compositions for the samples collected in FD0520. The consistency is excellent in that the totals usually add up to between 97.0 and 100.0 percent. Most of the outliers were during Alabama bituminous coal testing or iron oxide injection. Additional components on Table 4.4-4, other than those plotted on Figures 4.4-7, 4.4-8, 
and 4.4-9, are $\mathrm{MgO}, \mathrm{FeO}$, and $\mathrm{Al}_{2} \mathrm{O}_{3}$. The $\mathrm{MgO}$ concentration was between 3 and 7 percent during PRB coal testing and between 0.5 and 6 percent for Alabama bituminous testing. The $\mathrm{Al}_{2} \mathrm{O}_{3}$ concentration was between 4 and 11 percent during PRB coal testing and between 9 and 12 percent for Alabama bituminous testing. Also given on Table 4.4-4 are the HHV, LHV, and volatiles for the PCD fines. As expected, the trend of heating values follows the carbon content of the PCD fines.

The FeO concentration was between 1.6 and 4.7 percent prior to iron oxide injection for both the PRB and Alabama bituminous testing. From hours 300 to 400, the iron oxide was intermittently fed to the PCD through a small feeder. A large amount of iron oxide could not be fed for long periods of time through this small feeder. At 400 hours, iron oxide was fed through FD220 directly to the PCD and the PCD solids FeO contents increased up to 46.1 percent.

No FD0510 solid samples were taken during TC07 because the standpipe samples should give a more accurate view of the circulating solids composition.

\subsubsection{Feeds Particle Size}

The TC07 Sauter mean diameter (SMD) and mass mean diameter $\left(\mathrm{D}_{50}\right)$ particle sizes of the coal feed sampled from FD0210 are plotted on Figure 4.4-11. The PRB coal SMD particle size was fairly constant during TC07, with values between 169 and 289. The Alabama bituminous coal had a narrower range of SMD (183 to $214 \mu)$.

The PRB mass mean diameter $\left(\mathrm{D}_{50}\right)$ was also fairly constant during TC07 at between 255 and $338 \mu$. The $\mathrm{D}_{50}$ was always greater than the $\mathrm{SMD}$, usually by about $100 \mu$. At the beginning and end of TC07 the $\mathrm{D}_{50}$ was $50 \mu$ higher than the SMD. The last 300 hours of PRB operation had a slow decrease in $\mathrm{D}_{50}$ from 353 to $275 \mu$. The TC06 feed coal particle sizes had a much larger variation than the TC07 feed coal particle sizes.

In past testing, high fines content resulted in increased number of coal feeder outages due to coal feeder plugging caused by the packing of coal fines. A measure of the amount of fines in the coal is the percent of the smallest size fraction. To show the level of fines in the coal feed, the percent of ground coal less than $45 \mu$ is plotted in Figure 4.4-12. The fines percent less than $45 \mu$ was 2 to 12 percent during TC07. Keeping the percent fines under 15 percent for TC07 greatly helped the coal feeder performance. Previous testing has indicated that when the percent fines are above 20 percent, there are numerous coal feeder trips. TC06 had several periods with the amount of $45 \mu$ fines greater than 15 percent, and experienced several coal feeder trips during those periods.

The SMD and mass mean diameter $\left(\mathrm{D}_{50}\right)$ of the solids sampled from the sorbent feeder FD0220 are plotted on Figure 4.4-13. The SMD was between 2 to $20 \mu$ for TC07 when limestone was in FD0220. Several times when $150 \mu$ sand was in FD0220 during TC07 are clearly noted by SMD spikes up to $130 \mu$. The spike at hour 162 was the start-up sand 
added to the reactor after the 8-week outage and the second two spikes at hours 266 and 290 were when sand was in FD0220 for testing the small PCD inlet feeder.

The sorbent solids $\mathrm{D}_{50}$ was consistently higher than the SMD. There were high spikes of $\mathrm{D}_{50}$ up to 150,100 , and $80 \mu$ simultaneously with the SMD spikes. During the periods when FD0220 contained limestone, the $\mathrm{D}_{50}$ was 2 to $10 \mu$ higher than the SMD.

\subsubsection{Reactor Solids Particle Size}

The TC07 standpipe solids particle sizes are given in Figure 4.4-14. The particle size of the solids increased as the start-up sand is replaced by sorbent and coal ash. The SMD of the reactor solids increased from 150 to $190 \mu$ during the first 64 hours of operation. After the reactor solids were replaced by fresh sand during the 8-week break, the reactor solids SMD fell to $140 \mu$. The high SMD of the second standpipe solids sampled during the Alabama bituminous operation (hour 116) might indicate some solids agglomeration in the standpipe. After the Alabama bituminous operation, the SMD slowly increased as start-up sand was replaced by PRB coal ash, limestone inerts, and reaction products. The SMD increased from 140 to $180 \mu$ from hours 178 to 402 . The $\mathrm{D}_{50}$ was about the same value as the SMD for the first 64 hours of operation and about 15 to $20 \mu$ less than the SMD for the remainder of TC07. The standpipe particle size seemed to level off after 350 hours at $170 \mu$ SMD and $150 \mu$ D50, which were the TC06 steady-state standpipe solids particle sizes after hour 700 .

Figure 4.4-15 plots the SMD and $\mathrm{D}_{50}$ for the PCD solids sampled from FD0520 and the in situ solids collected at the PCD inlet. Eleven of the 12 in situ particle sizes (both SMD and $\mathrm{D}_{50}$ ) agree with the FD0520 solid samples particle sizes, with the exception of the hour 286 sample. The FD0520 PCD fines SMD was fairly constant at about $10 \mu$ for nearly all of the PRB TC07 operation, except for the first two samples analyzed. The PCD fines SMD increased for the first 20 hours of Alabama bituminous coal operation to $20 \mu$ at hour 120 , then decreased to $16 \mu$. The FD0520 $\mathrm{D}_{50}$ showed the same trends as the SMD, starting the run at $22 \mu$, then decreasing to $15 \mu$ and remained at about $15 \mu$ for the rest of the PRB coal testing. For the Alabama bituminous coal testing, the $\mathrm{D}_{50}$ peaked at $25 \mu$ at hour 120 . The $\mathrm{D}_{50}$ was about $5 \mu$ larger than the SMD. TC07 PRB PCD fines particle sizes were similar to TC06 PCD fines particle sizes.

\subsubsection{Particle Size Comparison}

Figure 4.4-16 plots all the solids SMD particle size. The Transport Reactor is fed approximately $200 \mu$ SMD coal and $10 \mu$ SMD limestone and produces $160 \mu$ SMD reactor solids and $10 \mu$ SMD PCD fines. The coal, limestone, reactor solids, and PCD fines particle sizes were essentially constant during PRB operations.

The $\mathrm{D}_{50}$ diameters were larger than the SMD for the FD2010 (coal), FD0220 (limestone), and FD0520 (PCD fines), while the TC07 SMD particle sizes are larger than the $\mathrm{D}_{50}$ particle sizes for the standpipe solids. This trend was also seen in TC06. The standpipe solids have 
a non-Gaussian distribution (bimodal), which probably caused the standpipe SMD to be larger than the standpipe $\mathrm{D}_{50}$.

\subsubsection{Standpipe and PCD Fines Bulk Densities}

The TC07 standpipe bulk and PCD fines densities are given in Figure 4.4-17. The standpipe bulk density of the solids decreased slightly as the start-up sand is replaced by $\mathrm{CaO}$ and $\mathrm{Al}_{2} \mathrm{O}_{3}$ after both the original startup and the 8-week break. The standpipe solids bulk density decreased from 97 to 91 during the first 100 hours of PRB operation if the first data point is neglected. From 150 hours to the end of TC07, the standpipe bulk density decreased from 91 to $80 \mathrm{lb} / \mathrm{ft}^{3}$.

The bulk densities for the FD0520 PCD and in situ PCD inlet solids are also plotted on Figure 4.4-17. Most of the in situ bulk densities agree well with the FD0520 bulk densities. There is less scatter in the in situ bulk densities and the average in situ bulk density is slightly less than the average FD0520 bulk density. The bulk densities of the PCD fines were about $25 \mathrm{lb} / \mathrm{ft}^{3}$ for most of the PRB operation, with several periods of higher bulk density at the end of the run during iron oxide injection.

TC07 standpipe and PCD fines bulk densities were similar to the bulk densities measured in TC06. 
Table 4.4-1 Coal Analyses

\begin{tabular}{|c|c|c|c|}
\hline & \multicolumn{2}{|c|}{ Powder River Basin } & \multirow[b]{2}{*}{$\begin{array}{l}\text { AL Bit. } \\
\text { Value }\end{array}$} \\
\hline & Value & $\begin{array}{l}\text { Standard } \\
\text { Deviation }\end{array}$ & \\
\hline Moisture, $\mathrm{Wt} \%$ & 22.11 & 0.75 & 4.64 \\
\hline Carbon, Wt\% & 54.67 & 0.53 & 67.42 \\
\hline Hydrogen, Wt\% & 3.39 & 0.17 & 4.14 \\
\hline Nitrogen, Wt\% & 0.72 & 0.01 & 1.50 \\
\hline Oxygen, Wt\% & 13.47 & 0.34 & 6.45 \\
\hline Sulfur, Wt\% & 0.24 & 0.02 & 0.77 \\
\hline Ash, Wt\% & 5.40 & 0.32 & 15.08 \\
\hline Volatiles, Wt\% & 32.92 & 0.66 & 28.62 \\
\hline Fixed Carbon, Wt\% & 39.57 & 0.47 & 51.66 \\
\hline Higher Heating Value, Btu/lb & 9,249 & 102 & 11,644 \\
\hline Lower Heating Value, Btu/lb & 8,707 & 104 & 11,212 \\
\hline $\mathrm{CaO}, \mathrm{Wt} \%$ & 1.11 & 0.03 & 0.64 \\
\hline $\mathrm{SiO}_{2}, \mathrm{Wt} \%$ & 1.94 & 0.17 & 8.32 \\
\hline $\mathrm{Al}_{2} \mathrm{O}_{3}, \mathrm{Wt} \%$ & 0.91 & 0.07 & 3.89 \\
\hline $\mathrm{MgO}, \mathrm{Wt} \%$ & 0.25 & 0.01 & 0.21 \\
\hline $\mathrm{Fe}_{2} \mathrm{O}_{3}, \mathrm{Wt} \%$ & 0.31 & 0.03 & 0.78 \\
\hline $\mathrm{Ca} / \mathrm{S}, \mathrm{mole} / \mathrm{mole}$ & 2.63 & 0.20 & 0.48 \\
\hline $\mathrm{Fe} / \mathrm{S}, \mathrm{mole} / \mathrm{mole}$ & 0.51 & 0.05 & 0.41 \\
\hline
\end{tabular}

Notes:

1. All analyses are as sampled at FD0210.

2. Hydrogen in coal is reported separately from hydrogen in moisture.

3. Samples AB09801 and AB10150 excluded.

4. Only two Alabama Bituminous coal samples analyzed.

Table 4.4-2 Limestone Analysis

\begin{tabular}{|l|c|c|}
\hline Compound & $\begin{array}{c}\text { Weight } \\
\%\end{array}$ & $\begin{array}{c}\text { Standard } \\
\text { Deviation }\end{array}$ \\
\hline $\mathrm{CaCO}_{3}$ & 74.71 & 1.24 \\
\hline $\mathrm{MgCO}_{3}$ & 17.66 & 0.40 \\
\hline $\mathrm{CaSQ}$ & 0.19 & 0.22 \\
\hline $\mathrm{SiO}_{2}$ & 3.94 & 1.32 \\
\hline $\mathrm{Al}_{2} \mathrm{O}_{3}$ & 0.83 & 0.10 \\
\hline $\mathrm{Fe}_{2} \mathrm{O}_{3}$ & 0.42 & 0.06 \\
\hline Other Inerts & 0.17 & 0.04 \\
\hline $\mathrm{H}_{2} \mathrm{O}$ & 0.22 & 0.05 \\
\hline Total & 98.15 & \\
\hline
\end{tabular}

Notes:

1. All analyses are as sampled at FD0220.

2. Other inerts consist of $\mathrm{P}_{2} \mathrm{O}_{5}, \mathrm{Na}_{2} \mathrm{O}, \mathrm{K}_{2} \mathrm{O}$, and $\mathrm{TiO}_{2}$. 
Table 4.4-3

\section{Standpipe Analysis}

\begin{tabular}{|c|c|c|c|c|c|c|c|c|c|c|c|c|}
\hline $\begin{array}{l}\text { Sample } \\
\text { Number }\end{array}$ & $\begin{array}{c}\text { Sample } \\
\text { Date \& Time }\end{array}$ & \begin{tabular}{|c|} 
Sample \\
Run Time \\
Hours \\
\end{tabular} & $\begin{array}{r}\mathrm{SiO}_{2} \\
\text { Wt. \% }\end{array}$ & $\begin{array}{l}\mathrm{Al}_{2} \mathrm{O}_{3} \\
\text { Wt. \% }\end{array}$ & $\begin{array}{c}\text { FeO } \\
\text { Wt. \% }\end{array}$ & $\begin{array}{l}\text { Other } \\
\text { Inerts }^{1} \\
\text { Wt. } \%\end{array}$ & $\begin{array}{l}\mathrm{CaCO}_{3} \\
\text { Wt. \% }\end{array}$ & $\begin{array}{r}\text { CaS } \\
\text { Wt. \% } \\
\end{array}$ & $\begin{array}{r}\mathrm{CaO} \\
\text { Wt. \% }\end{array}$ & $\begin{array}{l}\mathrm{MgO} \\
\text { Wt. \% }\end{array}$ & $\begin{array}{c}\text { Organic } \\
\text { Carbon } \\
\text { Wt. \% }\end{array}$ & $\begin{array}{r}\text { Total } \\
\text { Wt. \% } \\
\end{array}$ \\
\hline AB09798 & 1/19/2002 12:00 & 2 & 72.2 & 6.5 & 3.9 & 1.7 & 0.6 & 0.2 & 7.5 & 1.4 & 7.4 & 101.4 \\
\hline AB09799 & 1/19/2002 20:00 & 10 & 86.2 & 3.8 & 1.7 & 1.0 & 0.2 & 0.0 & 5.8 & 1.0 & 0.1 & 99.8 \\
\hline AB09800 & 1/22/2002 08:00 & 36 & 81.1 & 4.9 & 1.7 & 1.2 & 0.2 & 0.0 & 8.8 & 1.5 & 0.2 & 99.7 \\
\hline AB09823 & $1 / 22 / 200220: 00$ & 48 & 88.9 & 2.9 & 1.1 & 0.6 & 0.1 & 0.0 & 5.2 & 0.9 & 0.4 & 100.2 \\
\hline AB09824 & $1 / 23 / 200204: 00$ & 56 & 78.1 & 5.5 & 1.9 & 1.5 & 0.2 & 0.0 & 10.3 & 1.8 & 0.1 & 99.4 \\
\hline AB09844 & 1/23/2002 20:00 & 72 & 76.9 & 5.5 & 1.9 & 1.3 & 0.2 & 0.0 & 12.0 & 2.0 & 0.0 & 99.7 \\
\hline AB09880 & $1 / 25 / 200212: 00$ & 100 & 70.2 & 7.2 & 2.3 & 1.7 & 0.3 & 0.0 & 15.2 & 2.5 & 0.1 & 99.5 \\
\hline AB09882 & "1/26/2002 04:00 & 116 & 64.0 & 111.2 & 2.8 & 2.2 & 0.8 & 0.7 & 10.6 & 2.1 & 6.4 & 100.7 \\
\hline AB09891 & 1/26/2002 20:00 & 132 & 61.5 & 14.6 & 4.1 & 2.9 & 0.5 & 0.7 & 7.0 & 1.6 & 3.7 & 96.5 \\
\hline AB10148 & 3/24/2002 20:00 & 168 & 85.1 & 4.5 & 0.9 & 1.8 & 0.3 & 0.0 & 4.7 & 0.8 & 1.0 & 99.2 \\
\hline AB10149 & $3 / 25 / 2002$ 04:00 & 176 & 82.0 & 5.8 & 1.1 & 1.8 & 0.2 & 0.1 & 5.2 & 0.9 & 0.5 & 97.7 \\
\hline AB10179 & $3 / 26 / 2002$ 04:00 & 200 & 78.5 & 5.4 & 1.1 & 2.0 & 0.3 & 0.0 & 9.8 & 1.4 & 0.1 & 98.7 \\
\hline AB10208 & $3 / 26 / 2002$ 12:00 & 208 & 70.5 & 6.1 & 1.2 & 1.8 & 0.8 & 0.0 & 16.7 & 2.5 & 0.1 & 99.7 \\
\hline AB10223 & $3 / 27 / 200212: 00$ & 232 & 65.8 & 7.7 & 1.5 & 2.4 & 0.4 & 0.0 & 19.2 & 2.7 & 0.3 & 99.9 \\
\hline AB10224 & $3 / 27 / 2002$ 20:00 & 240 & 66.8 & 6.7 & 1.5 & 2.2 & 0.4 & 0.0 & 19.7 & 2.6 & 0.1 & 99.9 \\
\hline AB10225 & $3 / 28 / 200204: 00$ & 248 & 63.3 & 7.5 & 1.6 & 2.3 & 0.3 & 0.0 & 21.8 & 2.9 & 0.1 & 99.8 \\
\hline $\mathrm{AB} 10256$ & 3/29/2002 20:00 & 288 & 64.5 & 7.9 & 1.9 & 2.5 & 0.3 & 0.0 & 19.7 & 2.8 & 0.2 & 99.7 \\
\hline AB10257 & $3 / 30 / 2002$ 04:00 & 296 & 64.1 & 8.4 & 1.9 & 2.6 & 0.2 & 0.0 & 19.7 & 2.8 & 0.2 & 99.8 \\
\hline AB10260 & 3/31/2002 04:00 & 320 & 62.9 & 8.0 & 1.9 & 2.6 & 0.3 & 0.0 & 20.4 & 2.9 & 0.3 & 99.4 \\
\hline AB10305 & 4/1/2002 12:00 & 352 & 64.5 & 8.6 & 2.0 & 2.9 & 0.0 & 0.0 & 18.6 & 2.7 & 0.2 & 99.5 \\
\hline AB10306 & 4/1/2002 20:00 & 360 & 63.8 & 8.5 & 2.2 & 3.8 & 0.0 & 0.0 & 18.6 & 2.8 & 0.1 & 99.8 \\
\hline AB10307 & 4/2/2002 04:00 & 368 & 62.2 & 9.0 & 2.3 & 3.0 & 0.1 & 0.0 & 19.9 & 3.0 & 0.1 & 99.6 \\
\hline AB10353 & 4/2/2002 12:00 & 376 & 60.8 & 9.7 & 2.5 & 3.2 & 0.1 & 0.0 & 20.4 & 3.1 & 0.1 & 99.8 \\
\hline AB10354 & 4/2/2002 20:00 & 384 & 57.6 & 9.7 & 2.6 & 3.1 & 0.3 & 0.0 & 22.8 & 3.4 & 0.0 & 99.6 \\
\hline AB10397 & 4/3/2002 12:00 & 400 & 58.8 & 10.3 & 3.3 & 3.4 & 0.0 & 0.0 & 20.2 & 3.3 & 0.1 & 99.4 \\
\hline AB10398 & 4/3/2002 20:00 & 408 & 56.7 & 10.7 & 3.4 & 3.4 & 0.0 & 0.0 & 21.8 & 3.6 & 0.3 & 99.9 \\
\hline AB10399 & 4/4/2002 04:00 & 416 & 57.2 & 11.9 & 3.5 & 3.6 & 0.0 & 0.0 & 19.8 & 3.3 & 0.2 & 99.4 \\
\hline AB10442 & 4/4/2002 12:00 & 424 & 56.1 & 11.6 & 3.8 & 3.6 & 0.1 & 0.1 & 20.9 & 3.5 & 0.0 & 99.9 \\
\hline AB10443 & 4/4/2002 20:00 & 432 & 52.8 & 11.1 & 5.0 & 3.5 & 0.2 & 0.0 & 23.5 & 3.6 & 0.1 & 99.8 \\
\hline
\end{tabular}


Table 4.4-4 PCD Fines From FD0520

\begin{tabular}{|c|c|c|c|c|c|c|c|c|c|c|c|c|c|c|}
\hline $\begin{array}{l}\text { Sample } \\
\text { Number }\end{array}$ & $\begin{array}{c}\text { Sample } \\
\text { Date \& Time }\end{array}$ & \begin{tabular}{|c|} 
Sample \\
Run Time \\
Hours \\
\end{tabular} & $\begin{array}{c}\mathrm{SiO}_{2} \\
\text { Wt. \% }\end{array}$ & $\begin{array}{l}\mathrm{Al}_{2} \mathrm{O}_{3} \\
\text { Wt. \% }\end{array}$ & $\begin{array}{c}\mathrm{FeO} \\
\text { Wt. \% }\end{array}$ & $\begin{array}{l}\text { Other } \\
\text { Inerts } \\
\text { Wt. \% } \\
\end{array}$ & $\begin{array}{l}\mathrm{CaCO}_{3} \\
\text { Wt. } \% \\
\end{array}$ & $\begin{array}{c}\mathrm{CaS} \\
\text { Wt. } \%\end{array}$ & $\begin{array}{r}\mathrm{CaO} \\
\text { Wt. \% } \\
\end{array}$ & $\begin{array}{r}\mathrm{MgO} \\
\text { Wt. \% } \\
\end{array}$ & $\begin{array}{c}\text { Organic C } \\
\left(\mathrm{C}^{-} \mathrm{CO}_{2}\right) \\
\text { Wt. } \% \\
\end{array}$ & $\begin{array}{r}\text { Total } \\
\text { Wt. \% }\end{array}$ & $\begin{array}{c}\mathrm{HHV} \\
\mathrm{Btu} / \mathrm{lb} .\end{array}$ & $\begin{array}{l}\text { LHV } \\
\text { Btu/lb. }\end{array}$ \\
\hline AB09805 & $1 / 19 / 200212: 00$ & 2 & 24.1 & 6.6 & 2.3 & 1.4 & 10.0 & 1.4 & 7.0 & 3.3 & 37.7 & 93.9 & \begin{tabular}{|l|}
5,585 \\
\end{tabular} & 5,522 \\
\hline AB09808 & 1/22/2002 08:00 & 36 & 18.0 & 8.5 & 2.6 & 2.2 & 7.4 & 1.6 & 19.7 & 5.7 & 32.8 & 98.5 & \begin{tabular}{|l|}
5,330 \\
\end{tabular} & 5,279 \\
\hline $\mathrm{AB} 09828$ & 1/23/2002 00:00 & 52 & 21.1 & 9.5 & 2.9 & 2.3 & 6.8 & 2.5 & 22.5 & 6.3 & 24.2 & 98.0 & \begin{tabular}{|l|}
3,903 \\
\end{tabular} & 3,863 \\
\hline AB09830 & $1 / 23 / 200208: 00$ & 60 & 21.9 & 9.9 & 2.9 & 2.3 & 7.0 & 1.7 & 26.0 & 6.7 & 21.9 & 100.3 & \begin{tabular}{|l|}
3,557 \\
\end{tabular} & 3,521 \\
\hline AB09846 & 1/23/2002 16:00 & 68 & 19.4 & 9.3 & 2.7 & 2.3 & 7.0 & 2.7 & 22.3 & 6.1 & 26.5 & 98.3 & \begin{tabular}{|l|}
4,287 \\
\end{tabular} & 4,245 \\
\hline $\mathrm{AB} 09848$ & \begin{tabular}{|l|l|}
$1 / 24 / 200200: 00$ \\
\end{tabular} & 76 & 20.6 & 9.8 & 2.7 & 2.4 & 6.2 & 2.3 & 18.5 & 5.2 & 30.5 & 98.2 & \begin{tabular}{|l|}
4,820 \\
\end{tabular} & 4,771 \\
\hline AB09883 & $1 / 25 / 200208: 00$ & 96 & 24.0 & 11.5 & 2.9 & 2.5 & 6.0 & 2.0 & 22.4 & 5.9 & 19.9 & 97.1 & \begin{tabular}{|l|}
2,845 \\
\end{tabular} & 2,794 \\
\hline AB09884 & 1/25/2002 12:00 & 100 & 20.7 & 9.8 & 2.6 & 2.4 & "7.9 & (1.5 & 20.8 & "5.7 & 28.5 & (99.9 & \begin{tabular}{|l|l|}
4,409 \\
\end{tabular} & $\begin{array}{ll}4,367 \\
\end{array}$ \\
\hline AB09885 & $1 / 25 / 200215: 00$ & 103 & 20.6 & 9.3 & 2.3 & 2.4 & 6.7 & 2.9 & 15.0 & 4.7 & 35.2 & 99.1 & 5,440 & 5,394 \\
\hline AB09886 & \begin{tabular}{|l|}
$1 / 25 / 200220: 00$ \\
\end{tabular} & 108 & 27.4 & 9.1 & 2.0 & 2.0 & 3.4 & 2.7 & 8.2 & 2.4 & 45.2 & 102.5 & \begin{tabular}{|l|}
5,749 \\
\end{tabular} & 5,716 \\
\hline AB09892 & \begin{tabular}{|l|}
$1 / 26 / 200200: 05$ \\
\end{tabular} & 112 & 22.5 & 10.5 & 1.9 & 2.2 & 3.1 & 3.2 & 3.8 & 1.7 & 52.7 & \begin{tabular}{l|l|}
101.6 \\
\end{tabular} & \begin{tabular}{|l|}
7,703 \\
\end{tabular} & 7,672 \\
\hline AB09893 & $1 / 26 / 200204: 00$ & 116 & 34.8 & 11.3 & 2.3 & 2.3 & 1.4 & 1.6 & 6.0 & 1.6 & 45.1 & 106.4 & \begin{tabular}{|l|}
5,506 \\
\end{tabular} & 5,476 \\
\hline AB09895 & 1/26/2002 12:00 & 124 & 34.6 & 10.8 & 2.3 & 2.2 & 0.7 & 0.7 & 4.5 & 1.1 & 33.7 & 90.6 & \begin{tabular}{|l|}
5,310 \\
\end{tabular} & 5,294 \\
\hline AB09897 & $1 / 26 / 200220: 00$ & 132 & 32.1 & 12.2 & 2.4 & 2.5 & 0.5 & 0.7 & 2.8 & 0.9 & 57.9 & 112.0 & \begin{tabular}{|l|}
6,574 \\
\end{tabular} & 6,543 \\
\hline $\mathrm{AB} 09898$ & $1 / 27 / 200200: 05$ & 136 & 22.7 & 10.2 & 1.6 & 2.2 & 0.4 & 0.5 & 1.0 & 0.5 & 63.4 & \begin{tabular}{l|l|}
102.6 \\
\end{tabular} & \begin{tabular}{|l|}
8,653 \\
\end{tabular} & 8,614 \\
\hline AB10144 & $3 / 24 / 200220: 00$ & 168 & 19.4 & 6.9 & 2.4 & 1.9 & 10.8 & 2.7 & 15.3 & 4.8 & 34.0 & 98.3 & \begin{tabular}{|l|}
5,274 \\
\end{tabular} & 5,225 \\
\hline $\mathrm{AB} 10145$ & \begin{tabular}{|l|}
$3 / 25 / 200204: 00$ \\
\end{tabular} & 176 & 21.0 & 7.5 & 2.4 & 2.1 & 9.0 & 2.7 & 13.8 & 4.2 & 36.3 & 98.7 & 5,654 & 5,601 \\
\hline $\mathrm{AB} 10146$ & $3 / 25 / 200208: 00$ & 180 & 19.3 & 7.4 & 2.3 & 2.0 & 4.1 & 2.7 & 15.9 & 4.1 & 38.9 & 96.8 & \begin{tabular}{|l|}
5,923 \\
\end{tabular} & 5,865 \\
\hline $\mathrm{AB} 10183$ & \begin{tabular}{|l|}
$3 / 25 / 200220: 00$ \\
\end{tabular} & 192 & 21.9 & 6.8 & 1.9 & 1.8 & 15.8 & 0.8 & 21.9 & 6.7 & 20.7 & 98.4 & \begin{tabular}{|l|}
3,143 \\
\end{tabular} & 3,104 \\
\hline $\mathrm{AB} 10185$ & \begin{tabular}{|l|}
$3 / 26 / 200204: 00$ \\
\end{tabular} & 200 & 17.4 & 4.2 & 1.3 & 1.2 & 28.3 & 0.6 & 26.8 & 9.2 & 9.9 & 99.0 & \begin{tabular}{|l|}
1,429 \\
\end{tabular} & 1,411 \\
\hline AB10205 & 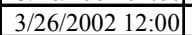 & 208 & 21.1 & 7.9 & 2.2 & 2.3 & 12.8 & 0.6 & 18.8 & 5.4 & 27.5 & 98.6 & \begin{tabular}{|l|}
4,132 \\
\end{tabular} & 4,085 \\
\hline AB10206 & \begin{tabular}{|l|l|}
$3 / 26 / 2002$ & $16: 00$ \\
\end{tabular} & 212 & 22.3 & 8.8 & 2.6 & 2.6 & 5.9 & 0.8 & 12.3 & 3.4 & 39.3 & 98.0 & \begin{tabular}{|l|}
6,060 \\
\end{tabular} & 5,996 \\
\hline AB10207 & \begin{tabular}{|l|}
$3 / 27 / 2002$ 08:00 \\
\end{tabular} & 228 & 26.1 & 9.6 & 2.6 & 2.7 & 7.5 & 0.2 & 22.9 & 5.7 & 21.2 & 98.5 & \begin{tabular}{|l|}
3,228 \\
\end{tabular} & 3,188 \\
\hline $\mathrm{AB} 10226$ & 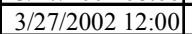 & 232 & 25.8 & 9.4 & 2.6 & 2.6 & 7.6 & 0.3 & 22.6 & 5.8 & 22.7 & 99.4 & \begin{tabular}{|l|}
3,301 \\
\end{tabular} & 3,260 \\
\hline $\mathrm{AB} 10220$ & \begin{tabular}{|l|}
$3 / 27 / 2002 \quad 16: 00$ \\
\end{tabular} & 236 & 23.9 & 8.9 & 2.5 & 2.6 & 2.0 & 0.3 & 25.3 & 5.7 & 26.0 & 97.2 & \begin{tabular}{|l|}
3,796 \\
\end{tabular} & 3,751 \\
\hline $\mathrm{AB} 10227$ & \begin{tabular}{|l|}
$3 / 27 / 200220: 00$ \\
\end{tabular} & 240 & 27.0 & 8.8 & 2.5 & 2.5 & 7.2 & 0.3 & 20.8 & 5.0 & 25.1 & 99.2 & \begin{tabular}{|l|}
3,845 \\
\end{tabular} & 3,799 \\
\hline AB10229 & \begin{tabular}{|l|}
$3 / 28 / 2002$ 04:00 \\
\end{tabular} & 248 & 24.8 & 8.9 & 2.4 & 2.4 & 7.1 & 0.5 & 20.0 & 4.8 & 27.5 & 98.5 & \begin{tabular}{|l|}
4,191 \\
\end{tabular} & 4,144 \\
\hline AB10247 & \begin{tabular}{|l|}
$3 / 29 / 200200: 00$ \\
\end{tabular} & 268 & 29.1 & 9.0 & 2.5 & 2.4 & 6.9 & 0.2 & 21.8 & 5.2 & 22.3 & 99.4 & \begin{tabular}{|l|}
3,251 \\
\end{tabular} & 3,210 \\
\hline $\mathrm{AB} 10264$ & \begin{tabular}{|l|}
$3 / 29 / 200220: 00$ \\
\end{tabular} & 288 & 36.4 & 7.6 & 4.7 & 2.3 & 5.8 & 0.4 & 15.6 & 4.1 & 22.4 & 99.2 & \begin{tabular}{|l|}
3,245 \\
\end{tabular} & 3,204 \\
\hline AB10266 & \begin{tabular}{|l|}
$3 / 30 / 200204: 00$ \\
\end{tabular} & 296 & 27.0 & 8.9 & 2.5 & 2.5 & 6.9 & 0.5 & 22.0 & 5.4 & 21.8 & 97.5 & \begin{tabular}{|l|}
3,358 \\
\end{tabular} & 3,317 \\
\hline $\mathrm{AB} 10270$ & \begin{tabular}{|l|}
$3 / 30 / 200220: 00$ \\
\end{tabular} & 312 & 46.5 & 6.6 & 7.8 & 2.2 & 4.0 & 0.3 & 14.4 & 3.5 & 13.8 & 99.1 & \begin{tabular}{|l|}
2,138 \\
\end{tabular} & 2,114 \\
\hline $\mathrm{AB} 10272$ & 3/31/2002 04:00 & 320 & 29.8 & 9.9 & 2.9 & 2.7 & 5.6 & 0.6 & 24.4 & 5.5 & 17.7 & 99.1 & 2,534 & 2,501 \\
\hline $\mathrm{AB} 10276$ & \begin{tabular}{|l|}
$3 / 31 / 200220: 00$ \\
\end{tabular} & 336 & 28.6 & 9.3 & 2.6 & 2.6 & 6.3 & 0.8 & 25.1 & 5.6 & 17.9 & 98.7 & \begin{tabular}{|l|}
2,514 \\
\end{tabular} & 2,483 \\
\hline $\mathrm{AB} 10277$ & 4/1/2002 08:00 & 348 & 28.6 & 10.2 & 2.8 & 2.8 & 5.9 & 0.8 & 23.6 & 5.5 & 18.7 & 98.9 & \begin{tabular}{|l|}
2,843 \\
\end{tabular} & 2,812 \\
\hline $\mathrm{AB} 10316$ & 4/1/2002 12:00 & 352 & 34.7 & 10.6 & 2.9 & 3.0 & 1.3 & 0.7 & 21.6 & 4.5 & 19.3 & 98.5 & \begin{tabular}{|l|}
2,766 \\
\end{tabular} & 2,735 \\
\hline $\mathrm{AB} 10335$ & $4 / 1 / 200220: 00$ & 360 & 53.3 & 8.0 & 4.1 & 2.6 & 2.9 & 0.6 & 10.8 & 2.7 & 14.0 & 99.0 & \begin{tabular}{|l|}
1,974 \\
\end{tabular} & 1,951 \\
\hline AB10336 & 4/2/2002 04:00 & 368 & 54.2 & 7.4 & 3.0 & 2.5 & 3.2 & 1.8 & 12.4 & 3.3 & 9.6 & 97.3 & 964 & 949 \\
\hline $\mathrm{AB} 10362$ & 4/2/2002 09:43 & 374 & 69.4 & 4.4 & 7.3 & 2.1 & 1.5 & 0.6 & 4.0 & 1.1 & 8.2 & 98.6 & \begin{tabular}{|l|}
1,008 \\
\end{tabular} & 995 \\
\hline $\mathrm{AB} 10366$ & 4/2/2002 12:02 & 376 & 65.9 & 5.1 & 7.3 & 2.3 & 1.9 & 0.6 & 4.4 & 1.3 & 24.5 & 113.2 & \begin{tabular}{|l|}
1,447 \\
\end{tabular} & 1,411 \\
\hline AB10373 & 4/2/2002 16:00 & 380 & 34.8 & 6.9 & 6.3 & 2.1 & 5.0 & 0.4 & 11.9 & 3.5 & 33.9 & 104.9 & \begin{tabular}{|l|}
4,044 \\
\end{tabular} & 3,995 \\
\hline AB10374 & 4/2/2002 20:00 & 384 & 25.0 & 7.4 & 3.1 & 2.0 & 8.9 & 0.7 & 24.5 & 6.7 & 20.8 & 99.1 & \begin{tabular}{|l|}
3,209 \\
\end{tabular} & 3,175 \\
\hline AB10385 & 4/3/2002 04:00 & 392 & 34.5 & 10.7 & 3.4 & 2.9 & 4.3 & 0.6 & 13.1 & 3.3 & 26.4 & 99.1 & \begin{tabular}{|l|}
3,944 \\
\end{tabular} & 3,906 \\
\hline AB10405 & $4 / 3 / 2002 \quad 12: 00$ & 400 & 39.8 & 8.8 & 6.2 & 2.6 & 3.6 & 0.7 & 11.4 & 3.1 & 22.3 & 98.5 & \begin{tabular}{|l|}
3,278 \\
\end{tabular} & 3,244 \\
\hline $\mathrm{AB} 10406$ & 4/3/2002 16:00 & 404 & 26.9 & 4.2 & 25.2 & 1.3 & 15.1 & 0.4 & 3.4 & 2.7 & 13.6 & 92.7 & \begin{tabular}{|l|}
1,780 \\
\end{tabular} & 1,757 \\
\hline AB10408 & 4/3/2002 18:00 & 406 & 15.1 & 4.8 & 32.1 & 1.2 & 18.9 & 0.5 & 4.9 & 3.6 & 13.2 & 94.3 & \begin{tabular}{|l|}
1,734 \\
\end{tabular} & 1,708 \\
\hline $\mathrm{AB} 10410$ & 4/3/2002 20:00 & 408 & 13.1 & 4.4 & 28.9 & 1.1 & 29.3 & 0.3 & 3.2 & 4.4 & 11.9 & 96.7 & \begin{tabular}{|l|}
1,640 \\
\end{tabular} & 1,617 \\
\hline $\mathrm{AB} 10412$ & $4 / 3 / 200222: 00$ & 410 & 13.1 & 4.6 & 15.8 & 1.1 & 43.9 & 0.5 & 0.3 & 5.4 & 13.9 & 98.5 & \begin{tabular}{|l|}
1,811 \\
\end{tabular} & 1,788 \\
\hline $\mathrm{AB} 10414$ & 4/4/2002 00:00 & 412 & 13.6 & 4.5 & 14.7 & 1.2 & 40.2 & 0.3 & 0.4 & 5.3 & 18.2 & 98.6 & \begin{tabular}{|l|}
2,592 \\
\end{tabular} & 2,563 \\
\hline $\mathrm{AB} 10415$ & 4/4/2002 01:00 & 413 & 12.7 & 4.3 & 14.9 & 1.1 & 44.1 & 0.4 & 0.6 & 5.4 & 13.6 & 97.2 & \begin{tabular}{|l|}
1,828 \\
\end{tabular} & 1,805 \\
\hline $\mathrm{AB} 10416$ & 4/4/2002 06:00 & 418 & 13.9 & 5.4 & 26.1 & 1.3 & 14.5 & 0.7 & 8.2 & 3.7 & 19.2 & 92.8 & \begin{tabular}{|l|}
2,695 \\
\end{tabular} & 2,662 \\
\hline AB10417 & 4/4/2002 07:00 & 419 & 11.8 & 3.7 & 39.9 & 1.1 & 19.9 & 0.6 & 1.1 & 2.8 & 15.8 & 96.9 & \begin{tabular}{|l|}
2,280 \\
\end{tabular} & 2,250 \\
\hline $\mathrm{AB} 10418$ & 4/4/2002 08:00 & 420 & 11.3 & 3.5 & 39.5 & 1.0 & 17.4 & 1.0 & 3.0 & 3.0 & 18.9 & 98.5 & \begin{tabular}{|l|}
2,892 \\
\end{tabular} & 2,860 \\
\hline AB10419 & 4/4/2002 09:00 & 421 & 9.7 & 3.0 & 46.1 & 0.8 & 19.7 & 0.9 & 1.1 & 2.8 & 16.4 & 100.5 & \begin{tabular}{|l|}
2,345 \\
\end{tabular} & 2,317 \\
\hline $\mathrm{AB} 10451$ & 4/4/2002 10:00 & 422 & 10.4 & 4.1 & 40.7 & 0.8 & 19.0 & 1.2 & 3.4 & 3.3 & 15.6 & 98.5 & \begin{tabular}{|l|}
2,495 \\
\end{tabular} & 2,468 \\
\hline $\mathrm{AB} 10453$ & 4/4/2002 12:00 & 424 & 12.3 & 4.8 & 36.8 & 1.1 & 20.6 & 1.1 & 4.3 & 3.7 & 14.2 & 99.0 & \begin{tabular}{|l|}
2,016 \\
\end{tabular} & 1,990 \\
\hline AB10456 & 4/4/2002 20:00 & 432 & 29.9 & 8.5 & 11.1 & 2.3 & 4.4 & 0.8 & 9.4 & 2.8 & 28.5 & 97.7 & \begin{tabular}{|l|}
4,452 \\
\end{tabular} & 4,409 \\
\hline $\mathrm{AB} 10458$ & 4/5/2002 04:00 & 440 & 26.8 & 9.6 & 8.2 & 2.7 & 4.2 & 1.0 & 10.3 & 3.0 & 33.4 & 99.1 & 4,971 & 4,921 \\
\hline
\end{tabular}




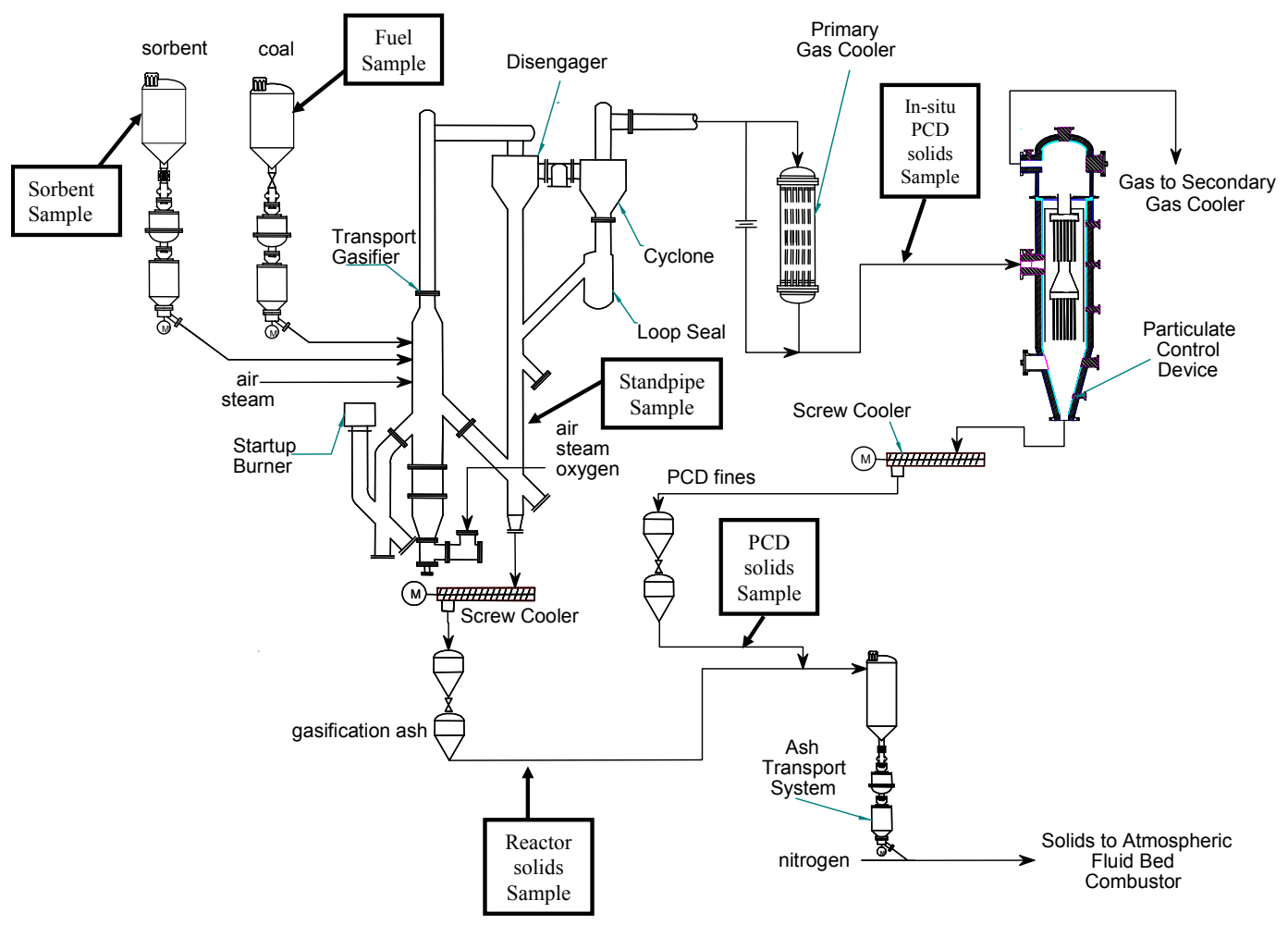

Figure 4.4-1 Solid Sample Locations

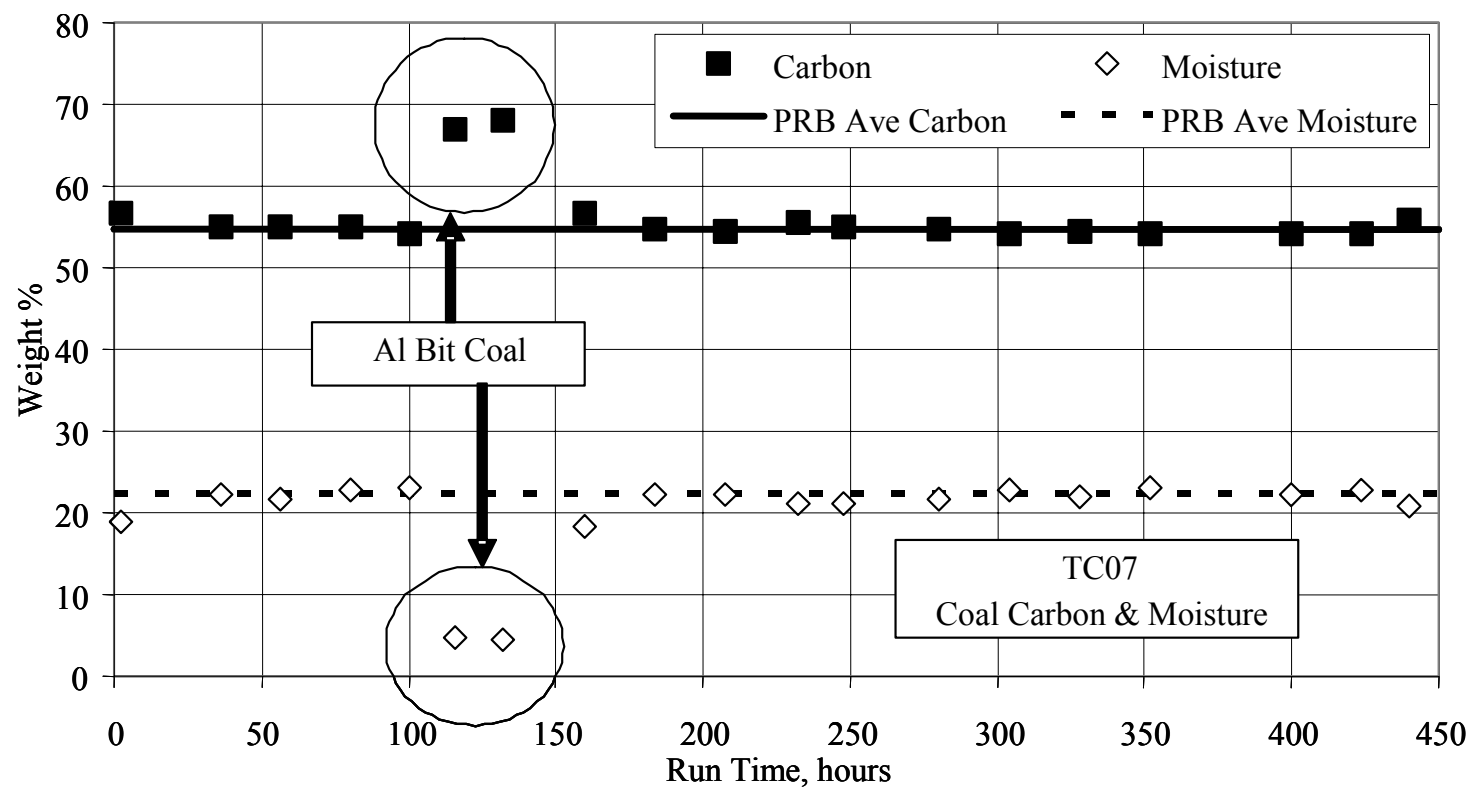

Figure 4.4-2 Coal Carbon \& Moisture 


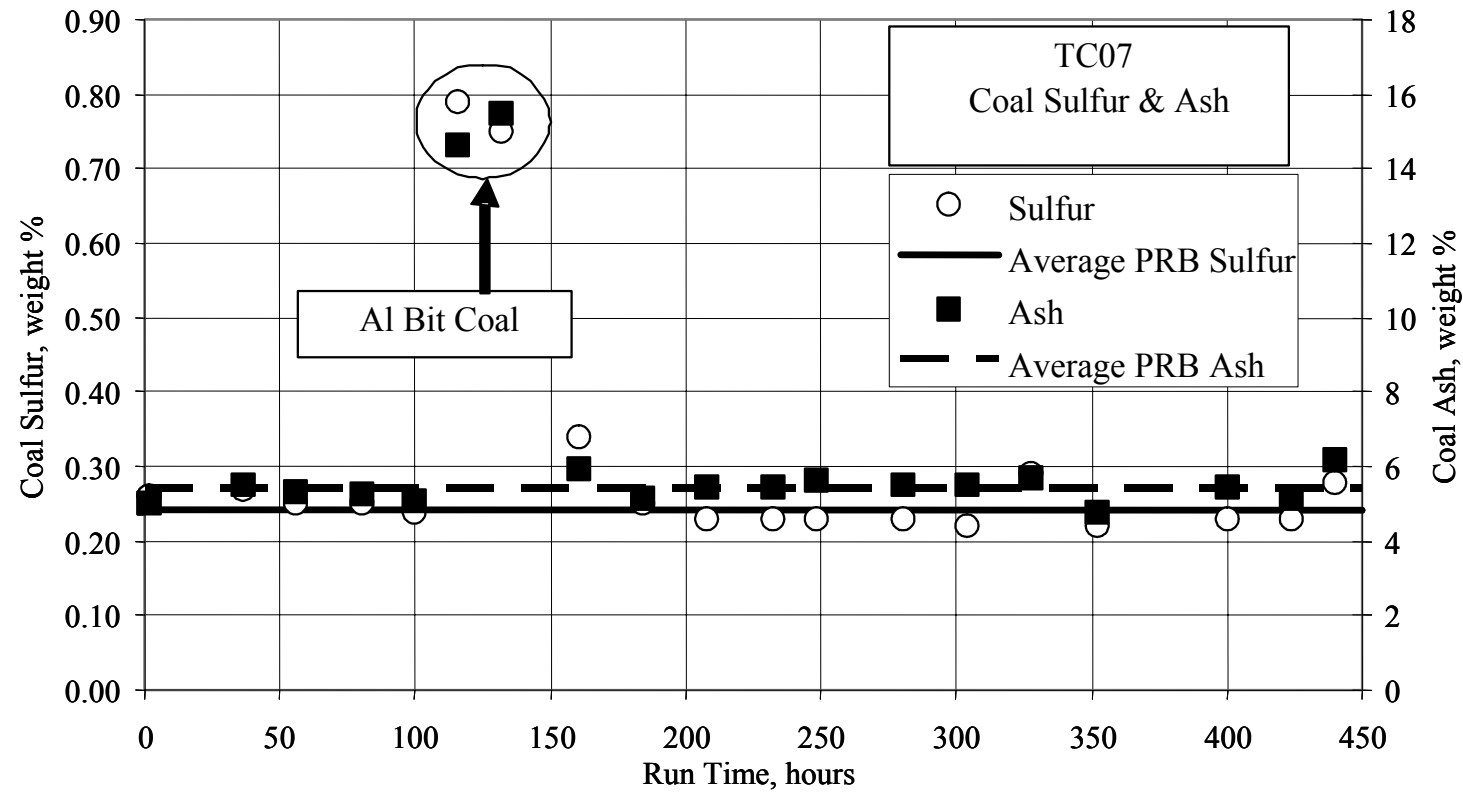

Figure 4.4-3 Coal Sulfur and Ash

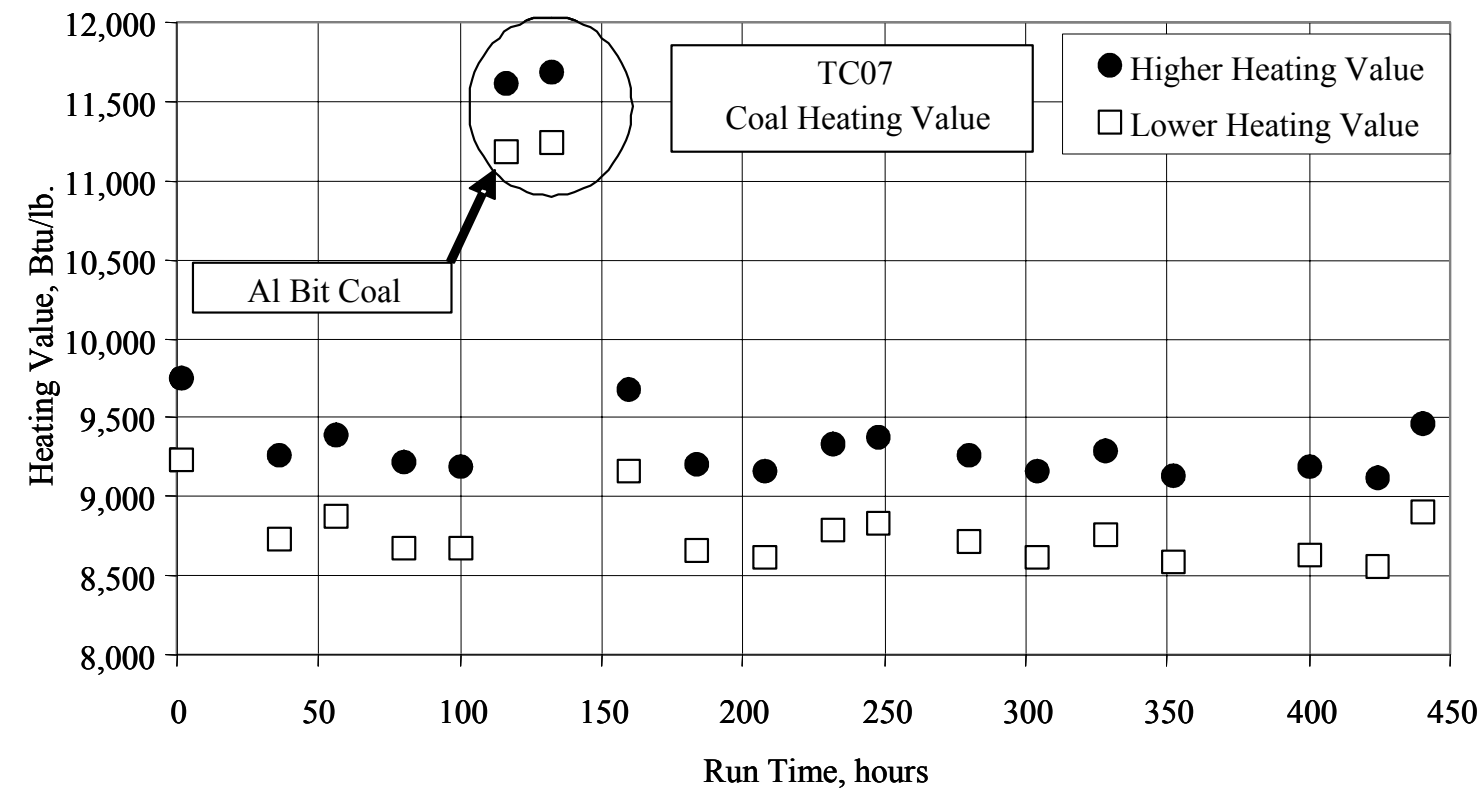

Figure 4.4-4 Coal Heating Value 


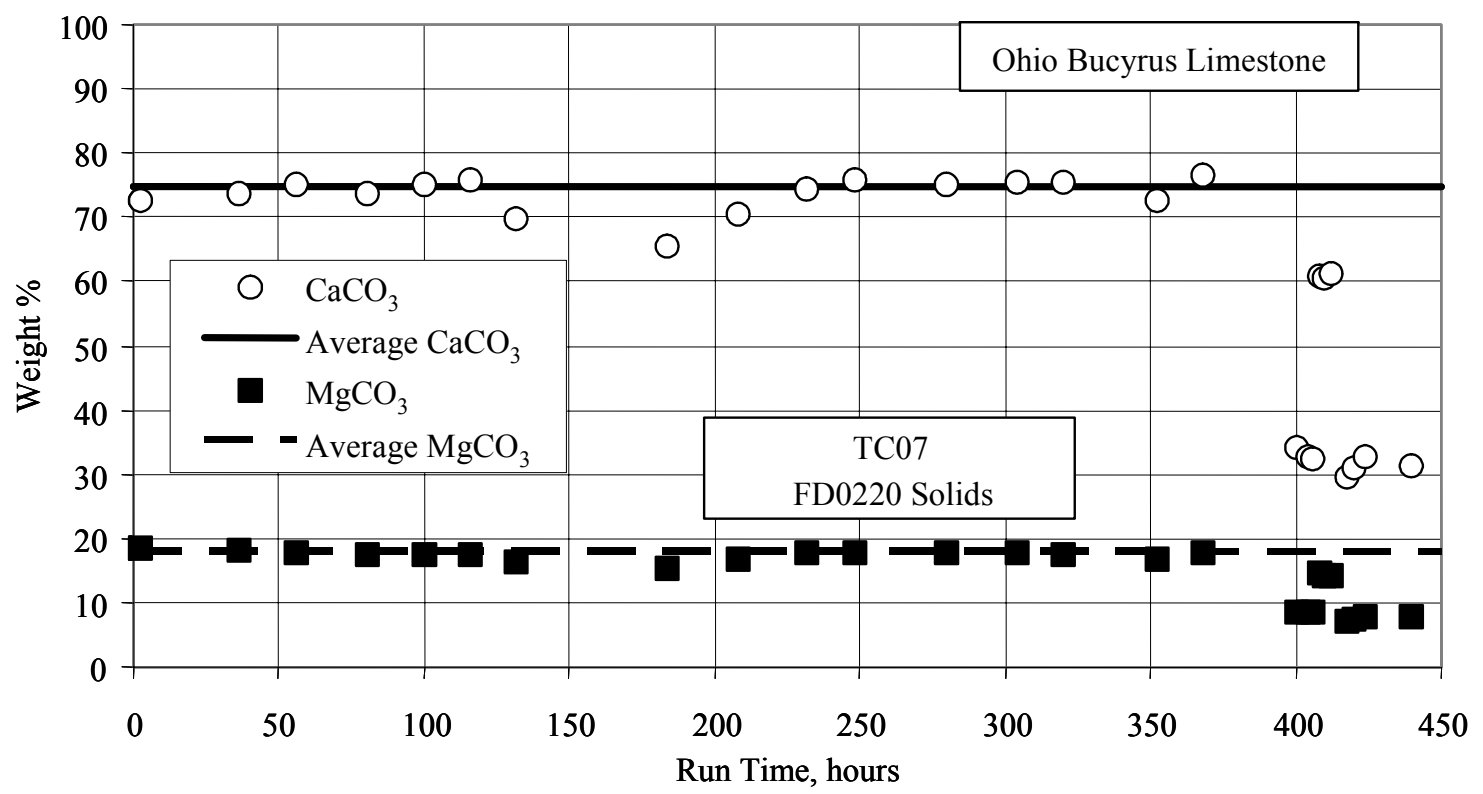

Figure 4.4-5 Limestone $\mathrm{CaCO}_{3}$ and $\mathrm{MgCO}_{3}$

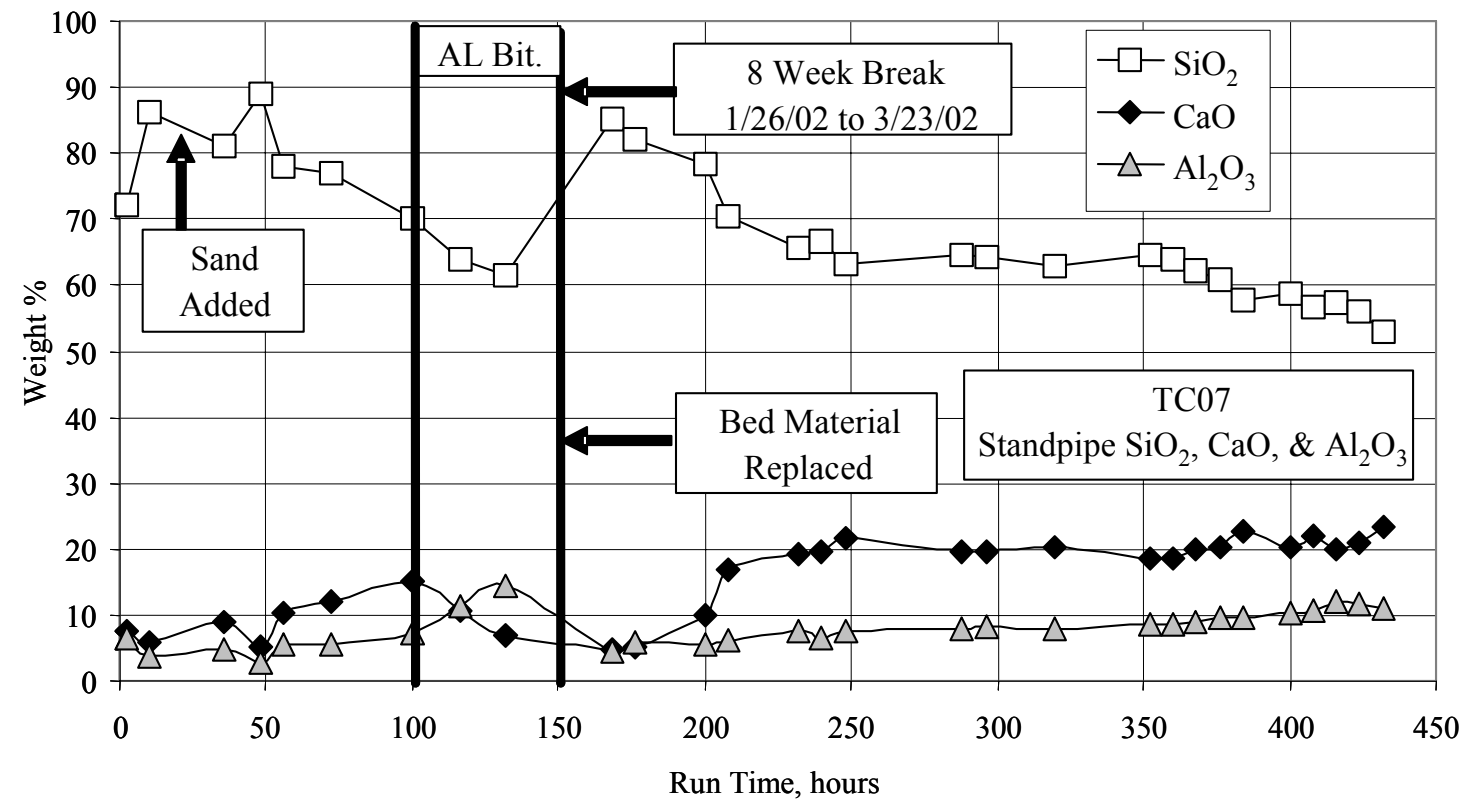

Figure 4.4-6 Standpipe $\mathrm{SiO}_{2}, \mathrm{CaO}$, and $\mathrm{Al}_{2} \mathrm{O}_{3}$ 


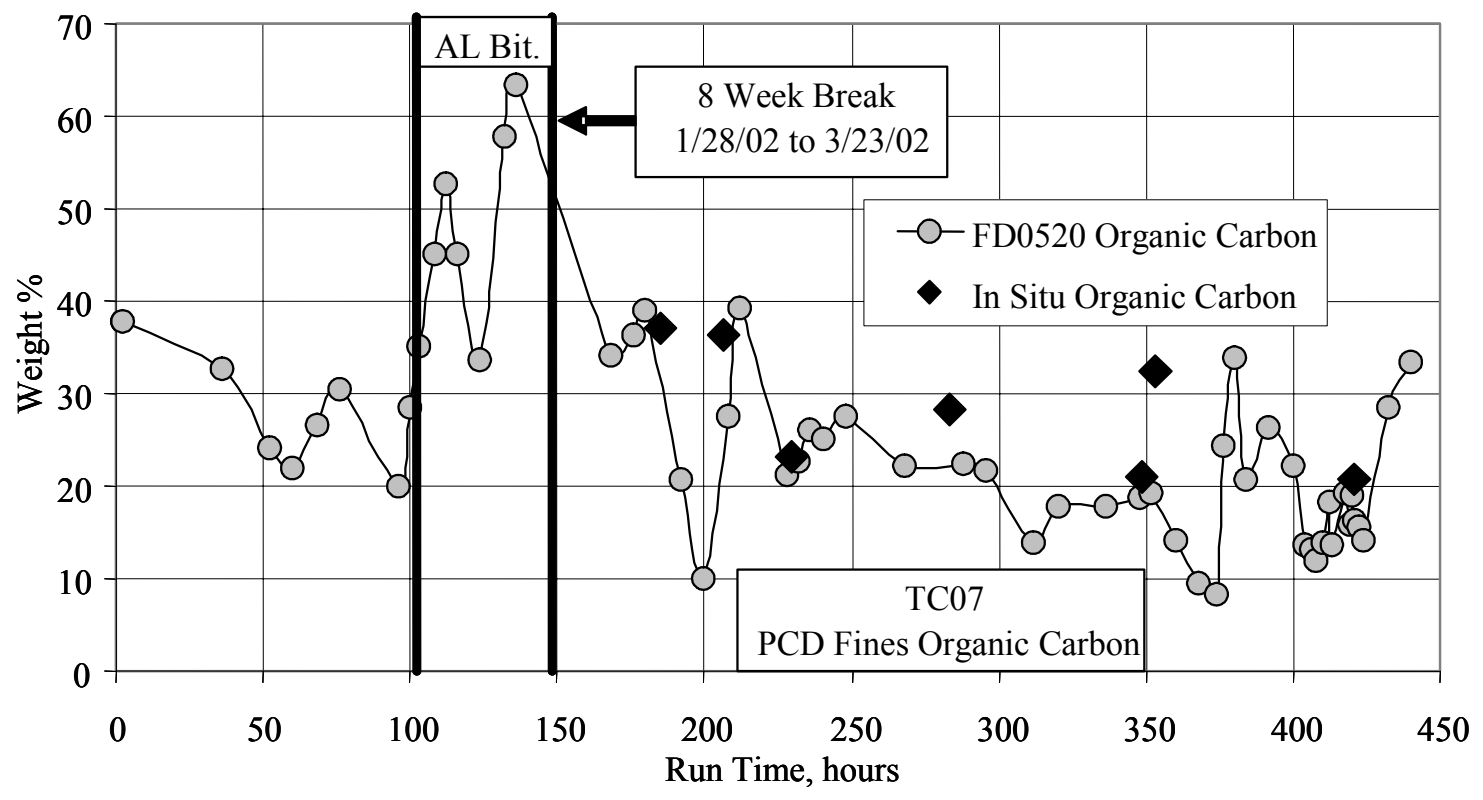

Figure 4.4-7 PCD Fines Organic Carbon

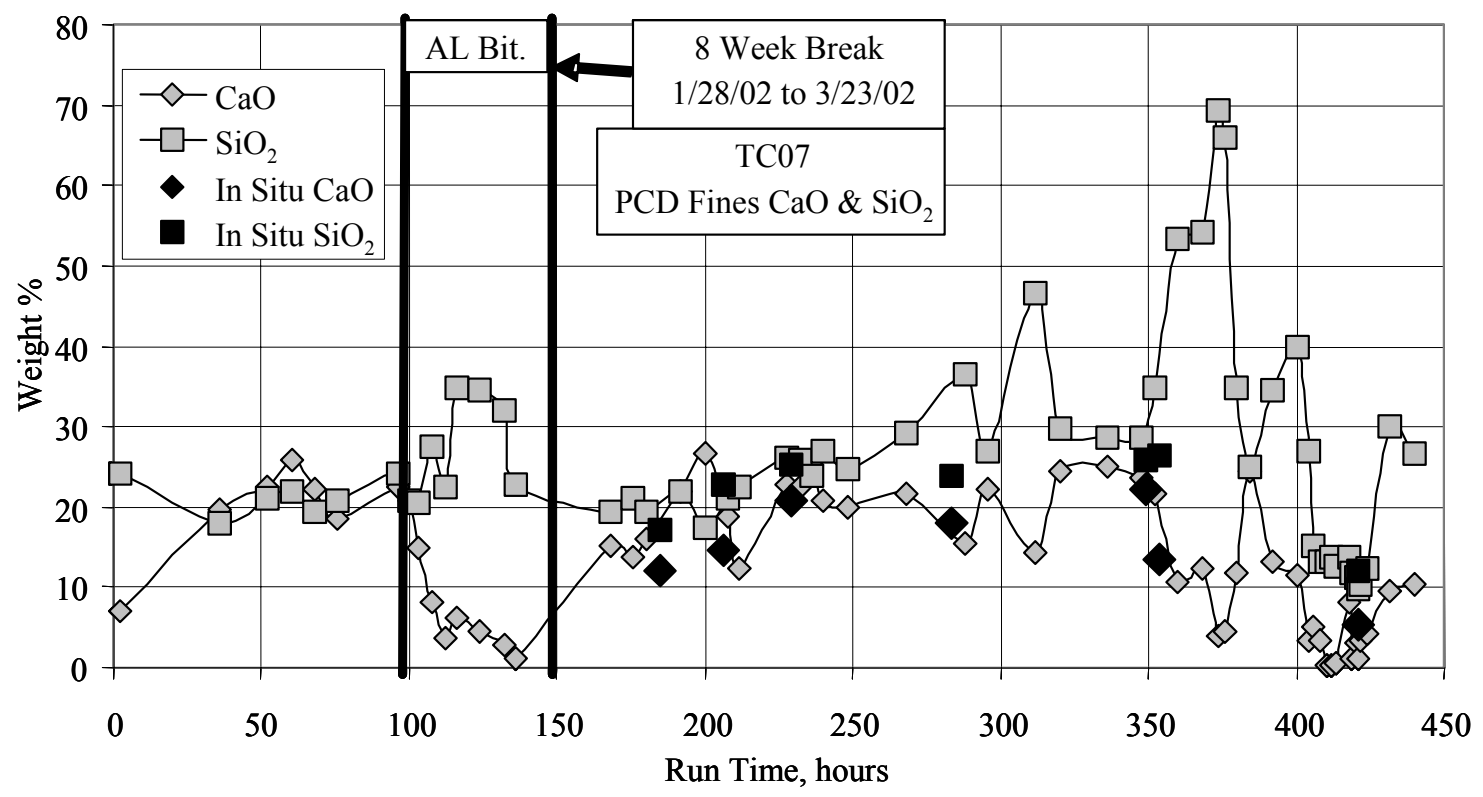

Figure 4.4-8 PCD Fines $\mathrm{SiO}_{2}$ and $\mathrm{CaO}$ 


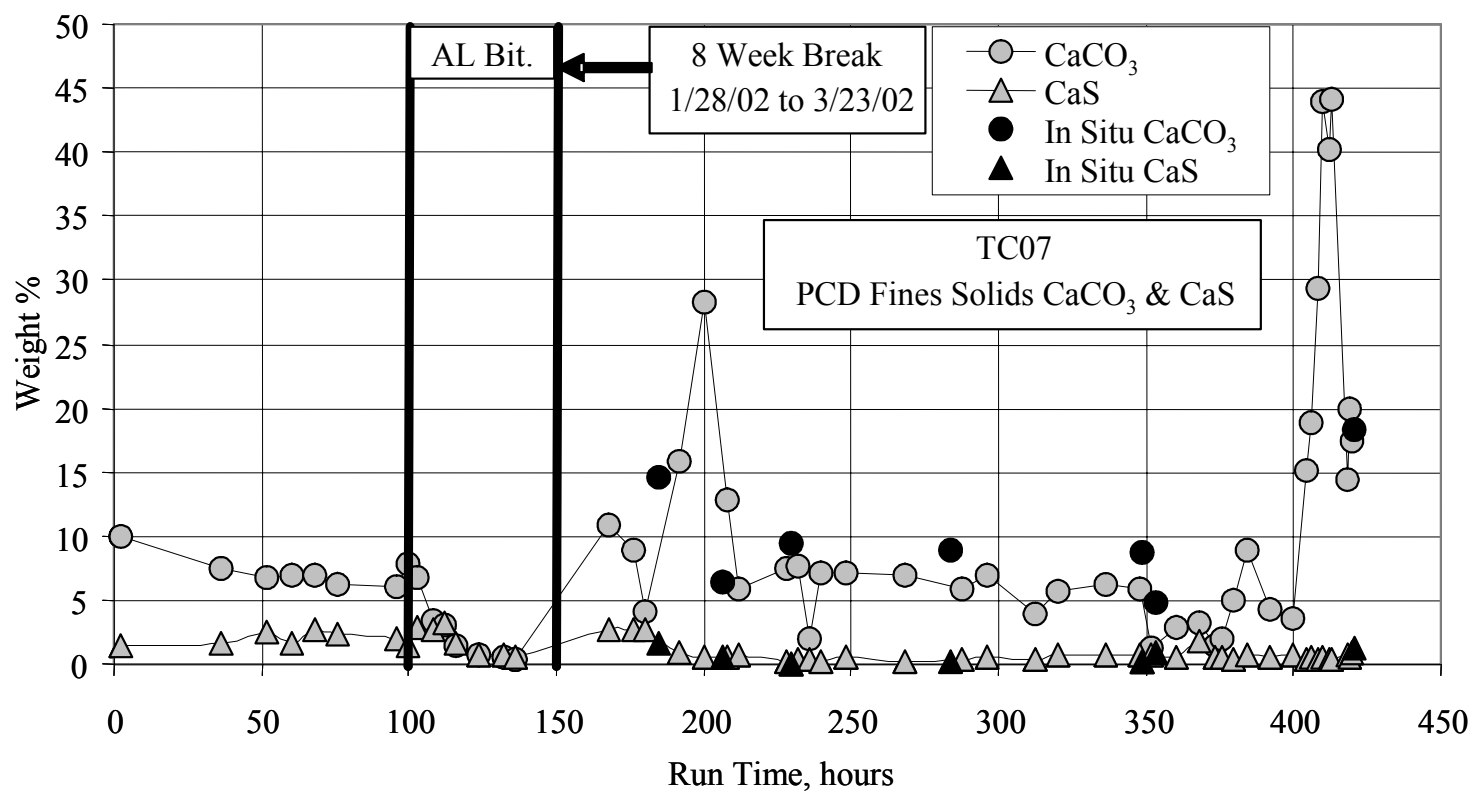

Figure 4.4-9 PCD Fines $\mathrm{CaCO}_{3}$ and $\mathrm{CaS}$

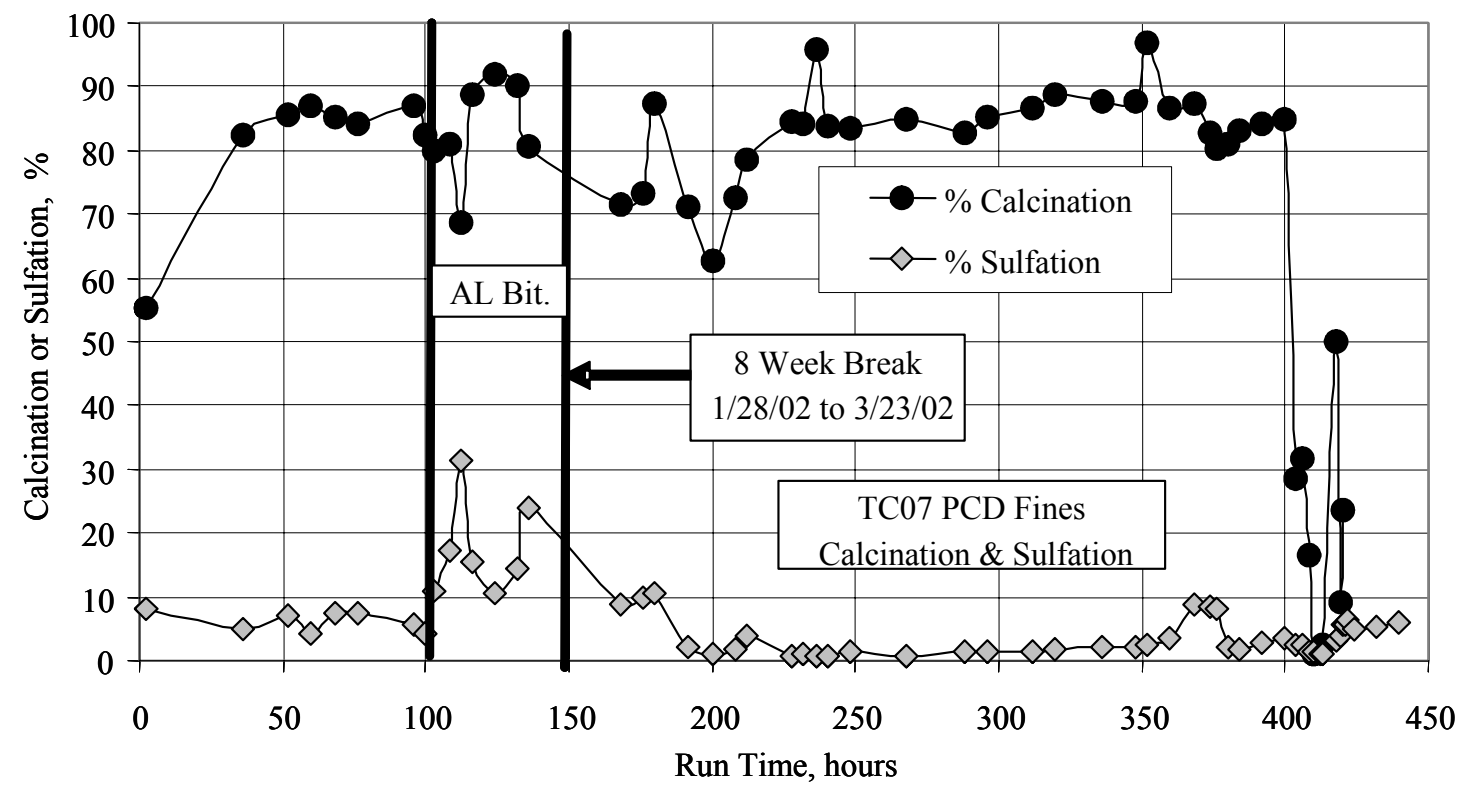

Figure 4.4-10 PCD Fines Calcination and Sulfation 


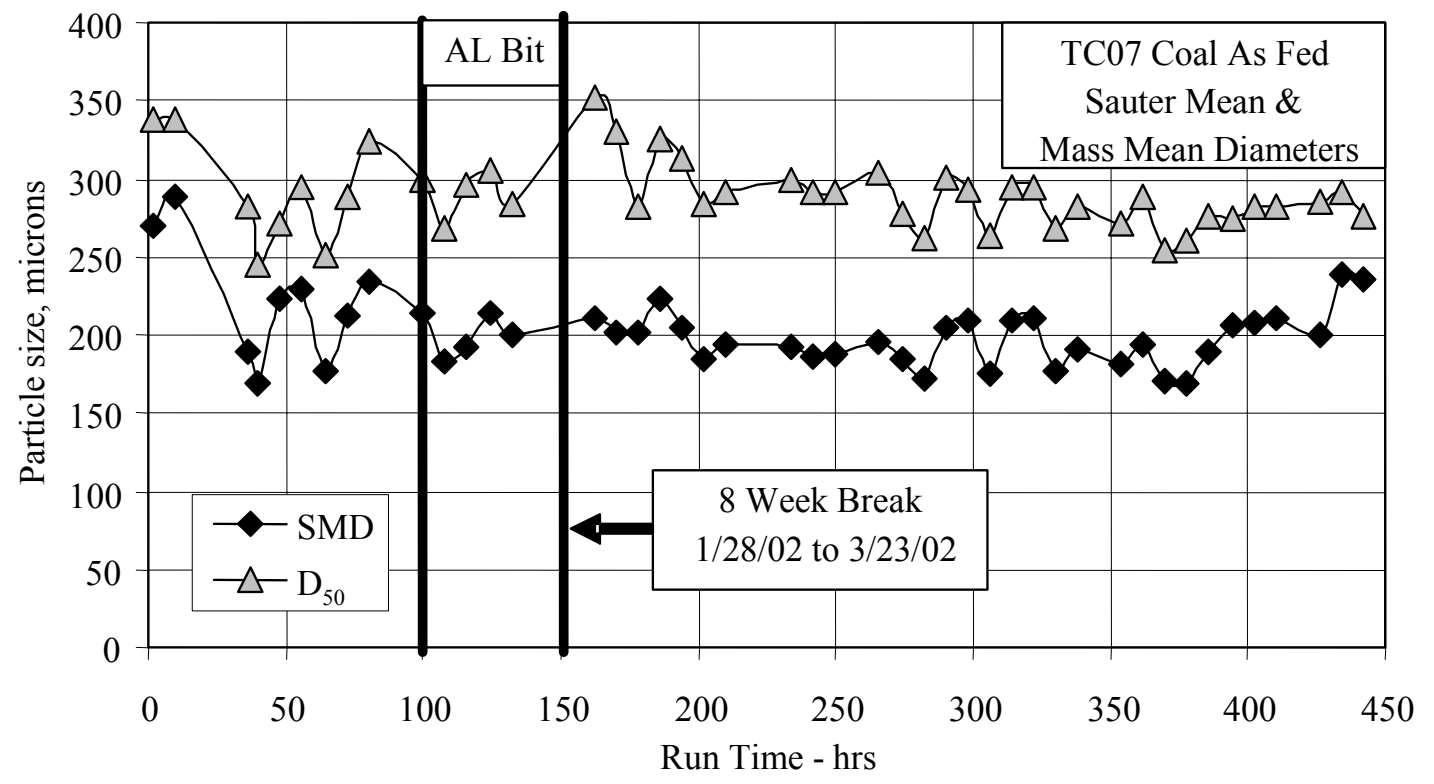

Figure 4.4-11 Coal Particle Size

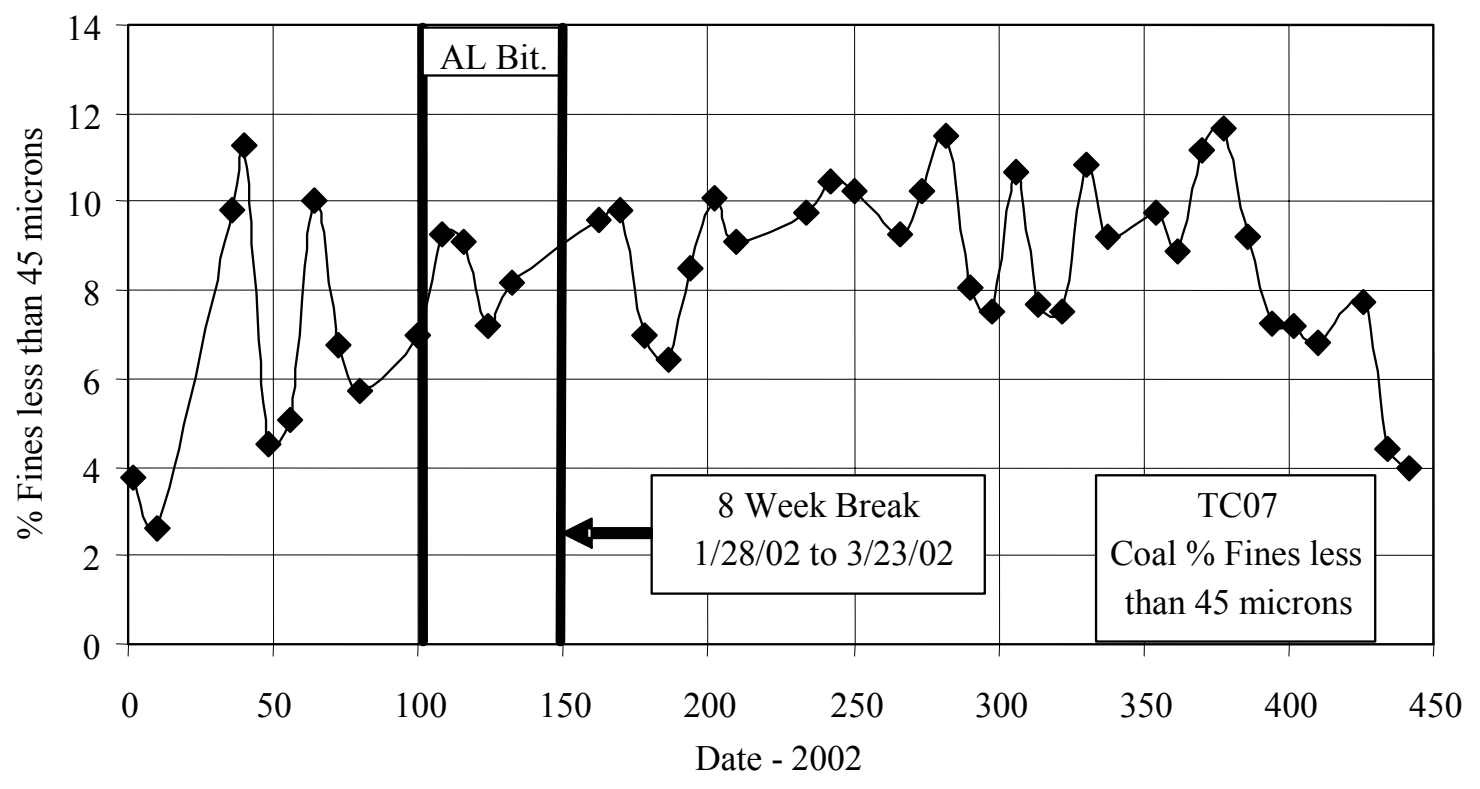

Figure 4.4-12 Percent Coal Fines 


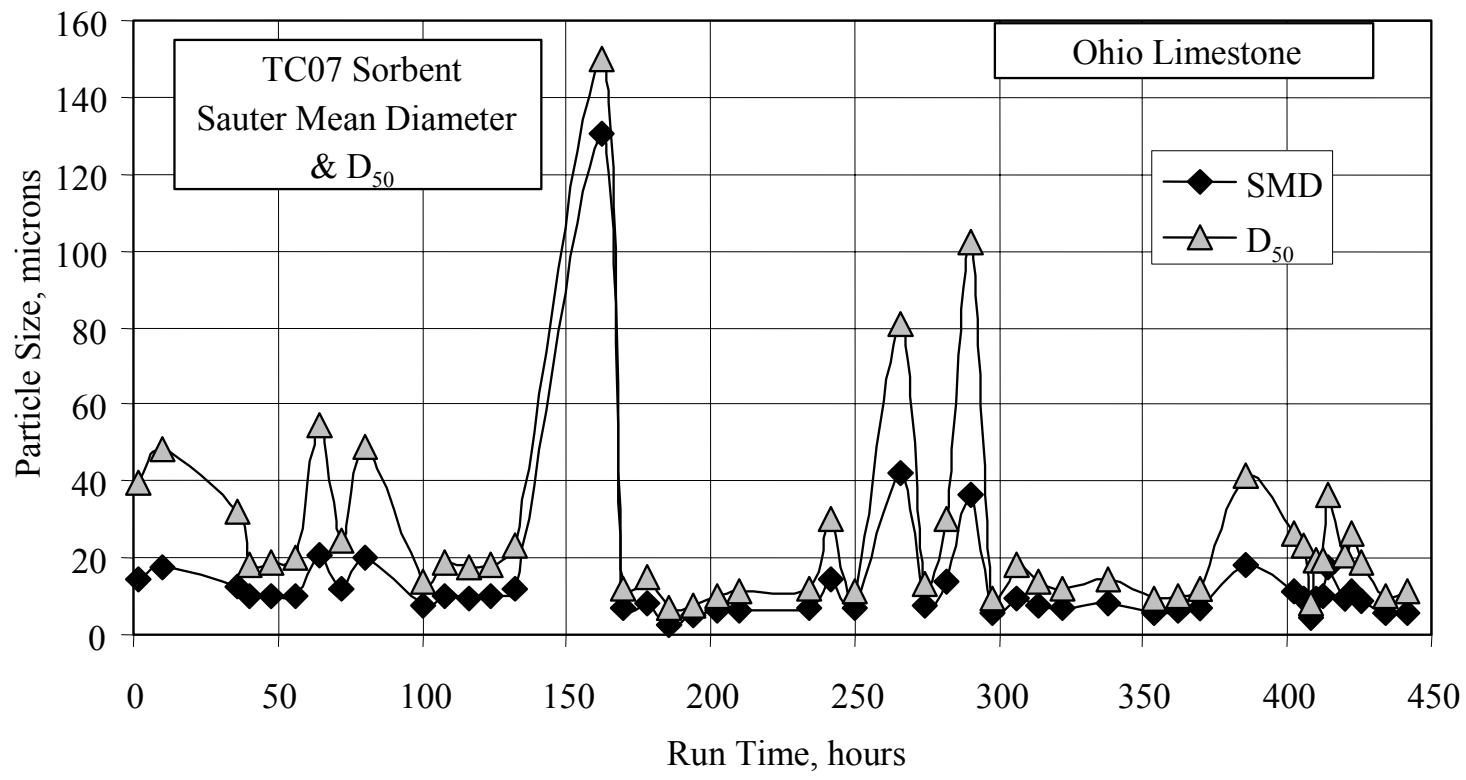

Figure 4.4-13 Sorbent Particle Size

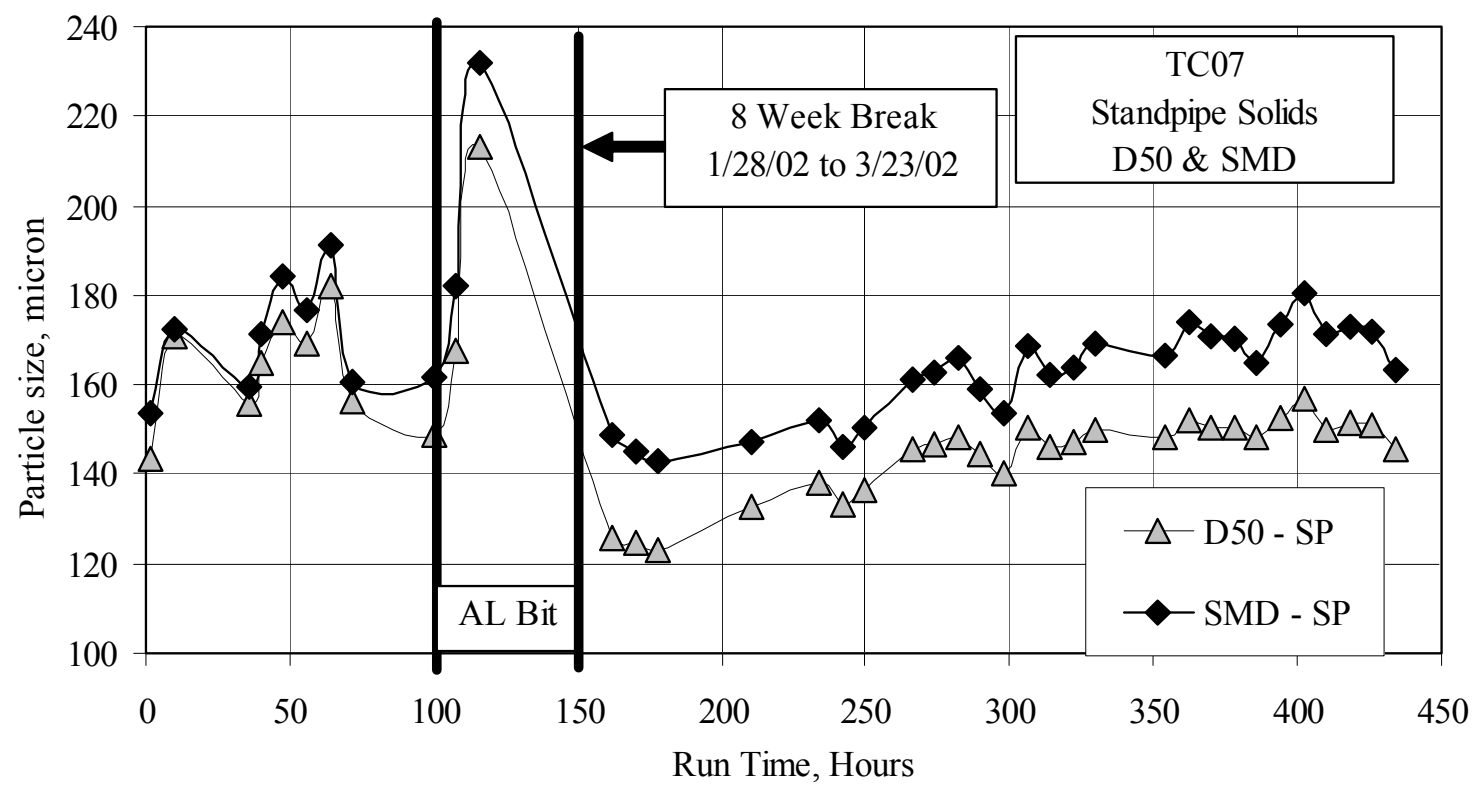

Figure 4.4-14 Standpipe Solids Particle Size 


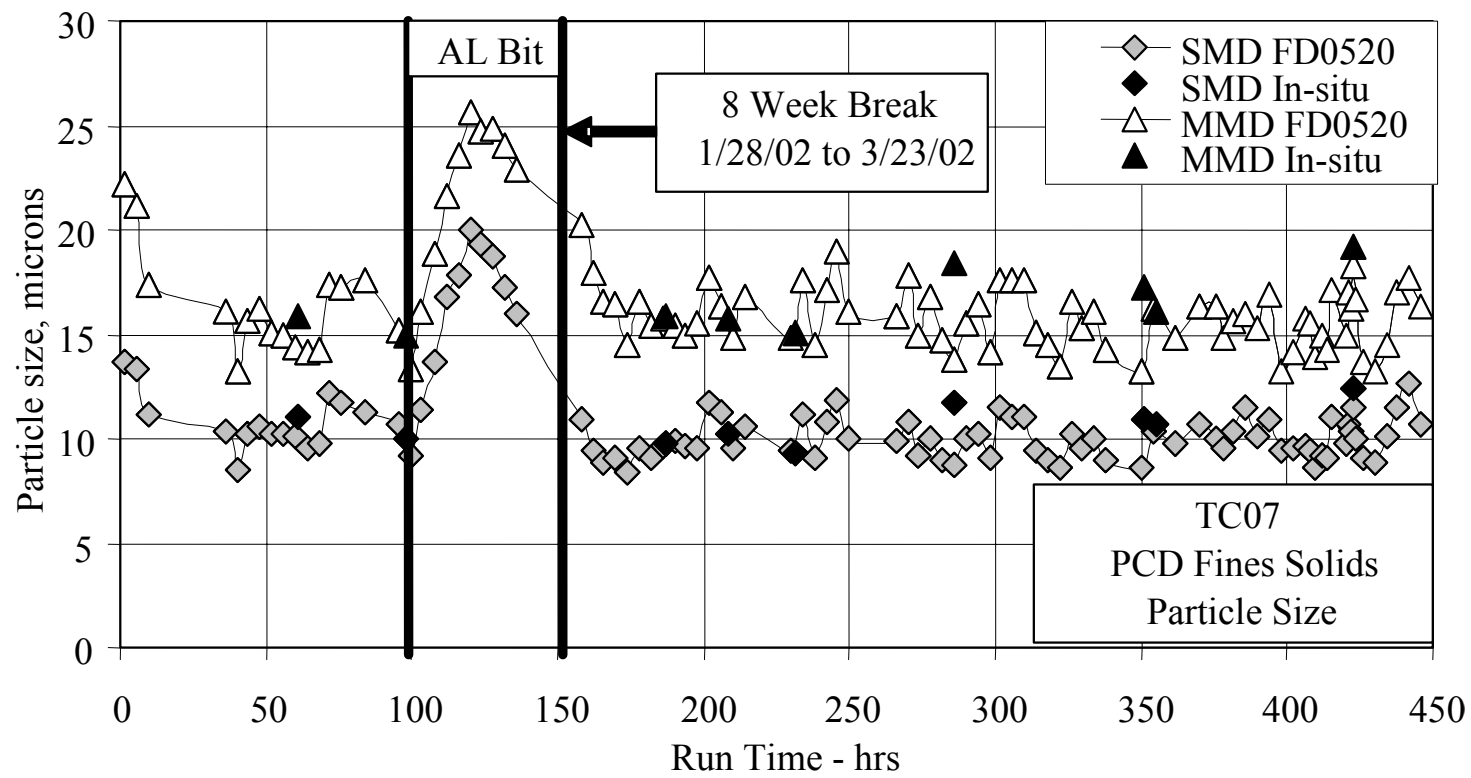

Figure 4.4-15 PCD Fines Particle Size

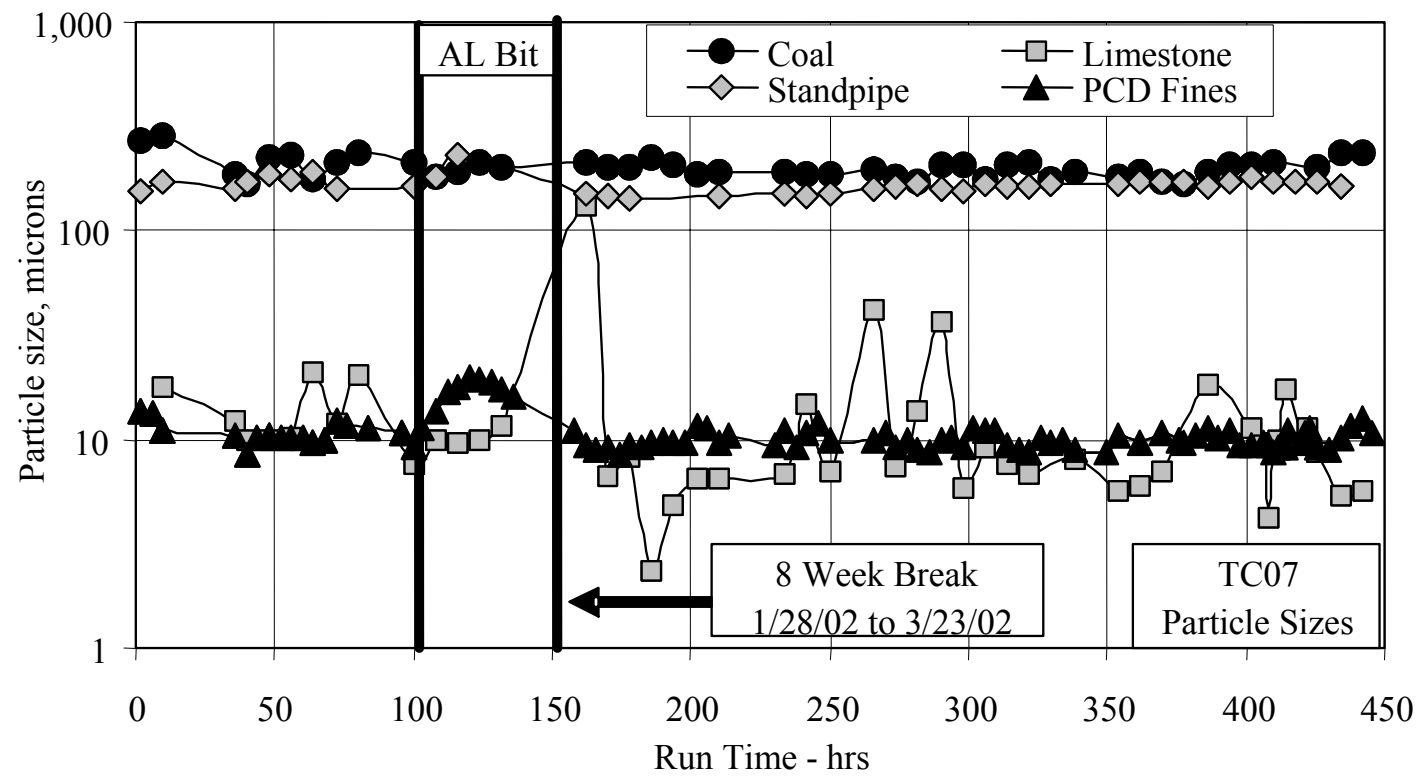

Figure 4.4-16 Particle Size Distribution 


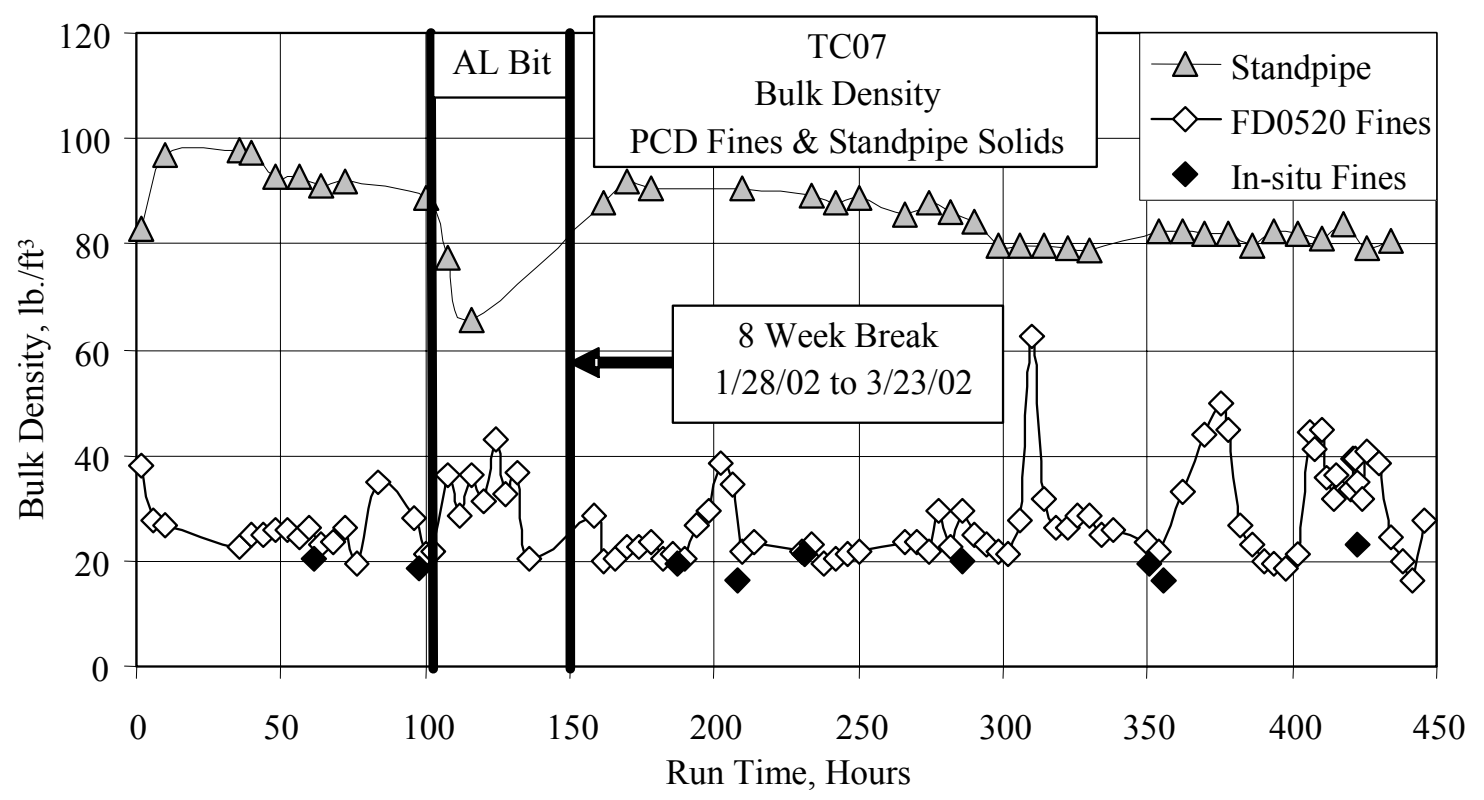

Figure 4.4-17 Standpipe and PCD Fines Solids Bulk Density 


\subsection{MASS AND ENERGY BALANCES}

\subsubsection{Summary and Conclusions}

- Carbon conversions were between 90 and 98 percent, with most around 95 percent. The carbon conversion increased slightly with increasing riser temperature.

- Coal rate was from 3,800 to $4,500 \mathrm{lb} / \mathrm{hr}$.

- Air-to-coal ratio was from 3.0 to 3.5 .

- Overall mass balance was good, between +1.0 and -4.6 percent $(+271$ to $-1,046$ $\mathrm{lb} / \mathrm{hr}$ nitrogen), with a negative bias.

- Nitrogen balance was excellent, between \pm 2 percent $( \pm 500 \mathrm{lb} / \mathrm{hr})$, assuming $500 \mathrm{lb} / \mathrm{hr}$ FI609 nitrogen did not enter the reactor.

- Coal nitrogen conversion to ammonia was 70 to 88 percent.

- Sulfur balance was acceptable for the most of TC07 between -10 percent and +20 percent $(-2$ to $+4 \mathrm{lb} / \mathrm{hr}$ sulfur), with a positive bias.

- Sulfur removal was from 5 to 50 percent and strongly dependant on steam rate.

- Sulfur emissions were from 0.16 to $0.48 \mathrm{lb} \mathrm{SO}_{2}$ per million Btu coal.

- Hydrogen balance was poor, from -30 to 0 percent $(-120$ to $0 \mathrm{lb} / \mathrm{hr}$ ), with a negative bias. Steam rate by hydrogen balance was about $500 \mathrm{lb} / \mathrm{hr}$ more than measured steam rate.

- Oxygen balance was poor, between -3 and -20 percent (-250 to $-850 \mathrm{lb}$ oxygen $/ \mathrm{hr}$ ), with a negative bias.

- Calcium balance was good for about half of the operating periods at \pm 20 percent $( \pm 20 \mathrm{lb} / \mathrm{hr}$ calcium). The other half of the operating periods had poor calcium balances between +40 to -124 percent, with a negative bias.

- Sulfur capture did not show any dependence on feed calcium to sulfur ratio.

- Silicon dioxide balance was poor, between \pm 50 percent ( $\pm 80 \mathrm{lb} / \mathrm{hr}$ silicon dioxide), with a positive bias.

- Energy balance was acceptable at +3 to +10 percent (1.4 to $3.7 \times 10^{6}$ Btu/hour), with a positive bias, assuming $1.5 \times 10^{6} \mathrm{Btu} / \mathrm{hr}$ heat loss.

- The raw cold gasification efficiency was 54 to 62 percent.

- The raw hot gasification efficiency was 85 to 94 percent.

- The corrected cold gas efficiency was between 65 and 73 percent. 


\section{$\underline{4.5 .2 \quad \text { Introduction }}$}

The process flows into the KBR Transport Reactor process were:

- Coal flow through FD0210.

- Sorbent flow through FD0220.

- $\quad$ Air flow measured by FI205.

- Pure nitrogen flow measured by FI609.

- Steam flow measured by the sum of FI204, FI727, FI734, and FI733.

The process flows from the KBR Transport Reactor process were:

- $\quad$ Synthesis gas-flow rate from the PCD measured by FI465.

- $\quad$ PCD solids flow through FD0520.

- Reactor solids flow through FD0510.

The coal flow through FD0210 is usually determined by a correlation between feeder speed and coal dumps from the FD0210 surge bin between fills. In previous gasification testing, this method resulted in both carbon and energy balance being 10 to 20 percent high. It appeared that the coal rates determined from the FD0210 weigh cell data were consistently higher than actual coal rate. For TC07, the Transport Reactor carbon balance was used to determine the coal rate. This was also done in TC06. This was one of the methods used to determine the coal rate in combustion when the coal rate was determined by the flue gas rate, flue gas $\mathrm{CO}_{2}$, and the fuel carbon.

\subsubsection{Feed Rates}

The sorbent flow through FD0220 was determined from a correlation between feeder speed and sorbent dumps from the FD0220 storage bin between fills. The correlation is for data taken from March 26 to April 5, during the steady operating periods. This sorbent fill feeder speed data correlation is shown on Figure 4.5-1. The correlation for the sorbent feeder is:

$$
\text { Sorbent rate }=66.586(\mathrm{RPM})+72.716
$$

The operating period limestone rates are shown on Table 4.5-2 and were from zero to $313 \mathrm{lb} / \mathrm{hr}$. Limestone was not fed to the Transport Reactor during operating periods TC07$6,-19,-21$, and -25 to -29 . 
The operating period steam and nitrogen flow rates are shown in Figure 4.5-2 and on Table 4.5-2. It is estimated that about $500 \mathrm{lb} / \mathrm{hr}$ nitrogen from FI609 does not enter the process but was used to seal valves, pressurized - depressurized feed and ash lock hopper systems, and in the seals for the screw coolers. Values on Table 4.5-2 and Figure 4.5-2 assume that $500 \mathrm{lb} / \mathrm{hr}$ of nitrogen from FI609 does not enter the Transport Reactor. In previous test runs it was assumed that $1,000 \mathrm{lb} / \mathrm{hr}$ of nitrogen was lost, but the assumption of $500 \mathrm{lb} / \mathrm{hr}$ makes the nitrogen balance agree better. It may be that the nitrogen system was improved to decrease nitrogen losses. A small amount of nitrogen $(\sim 200 \mathrm{lb} / \mathrm{hr})$ was added via FI6080 to the Transport Reactor through the coke breeze feed line to keep the line clear between periods of coke breeze feed. This is included in the feed nitrogen. Nitrogen rates were from 9,000 to 5,800 lb/hr during TC07. The nitrogen rates were gradually decreased from $9,000 \mathrm{lb} / \mathrm{hr}$ at hours 168 to 180 to around 7,000 lb/hr from hour 192 to 249 . From hour 263 to the end of TC07, the nitrogen rates were held constant at about $6,400 \mathrm{lb} / \mathrm{hr}$. Decreasing the nitrogen rates increased the synthesis gas heating value as was shown in Figure 4.3-17.

The steam rate to the reactor should be determined by the sum of FI204 (total steam flow to the UMZ), FI727 (steam mixed with the air fed to the LMZ), FI734 (fed into the lower mixing zone), and FI733 (steam fed to a shroud into the LMZ). FI204 read less than zero for all of the TC07 operating periods, and was not used to determine the steam to the reactor. The steam to the reactor was based on the sums of FI727, FI734, and FI733. It is believed that some steam was added to the UMZ and not measured, so there is a good chance that the reported steam rate is low. TC07 began with nearly no steam fed to the reactor from hours 168 to 180 . The steam rate was then 800 to 1,700 lb/hr from hours 192 to 334 . From hour 341 to the end of TC07, the steam rate was again very low. Lower steam rates would tend to increase the synthesis gas LHV as shown in Figure 4.3-17 and decrease the synthesis gas $\mathrm{H}_{2} \mathrm{O}$ content as shown in Figure 4.3-14. Higher steam rates also tend to increase the equilibrium $\mathrm{H}_{2} \mathrm{~S}$ and total reduced sulfur emissions, which can be seen by comparing the steam rates on Figure 4.5-2 with the equilibrium $\mathrm{H}_{2} \mathrm{~S}$ values and the total reduced sulfur emissions on Figure 4.3-25.

The operating period air feed rates are shown on Figure 4.5-3 and listed on Table 4.5-2. The air rate held fairly constant for the first 400 hours of TC07 at about 13,500 lb/hr ( $\pm 500 \mathrm{lb} / \mathrm{hr})$. The air rate was decreased by about $1,000 \mathrm{lb} / \mathrm{hr}$ at hour 400 , and then was increased by about 1,000 lb/hr at the last operating period (hour 446).

\subsubsection{Product Rates}

The operating period synthesis gas rates are shown on Figure 4.5-3 and listed on Table 4.5-2. The synthesis gas rates were taken from FI465.

The synthesis gas rate was checked for all the operating periods using an oxygen balance around the synthesis gas combustor and found to be in excellent agreement with the synthesis gas combustor data for most of the operating periods (see Figure 4.3-20). The synthesis gas rate was constant at about $26,500 \pm 1,000 \mathrm{lb} / \mathrm{hr}$ from the beginning of TC07 to hour 294, when the rate decreased to $23,000 \pm 1,000$ until the end of the run. The synthesis 
gas rate was a strong function of the air rate and lesser function of the steam and nitrogen rates.

The solids flow from the PCD can be determined from two different methods by using:

1. In situ particulate sampling data upstream of the PCD.

2. FD0530 weigh cell data.

The best measurement of the solids flow to the PCD is the in situ PCD inlet particulate determination. Using the synthesis gas-flow rate and the in situ PCD inlet particulate measurement, the solids flow to the PCD can be determined, since the PCD essentially captures all of the solids.

The FD0530 weigh cell data can be used to determine the PCD solids flow only if both the FD0530 feeder and the FD0510 feeder (standpipe solids) are off because FD0520 and FD0510 both feed into FD0530 and FD0530 feeds the sulfator (AFBC). This method assumes that the PCD solids level in the PCD and FD0502 screw cooler are constant, that is the PCD solids level is neither increasing nor decreasing. The results for the first two methods are compared in Figure 4.5-4.

The FD0530 weigh cell measurements had a large scatter. There seemed to be a daily cycle to the variations in FD0520 flow. The in situ samples agreed with the lower range of the weigh cell readings. The PCD fines rate was about 350 to $500 \mathrm{lb} / \mathrm{hr}$ until the iron oxide injection tests after hour 400.

Rates for use in the operating period mass and energy balances were interpolated between the in situ measurements and weigh cell measurements. The interpolated rates used for the operating periods in mass and energy calculations are shown on Table 4.5-2.

Only six of the operating periods had a flow through FD0510. The flow rates from those six periods are shown on Table 4.5-2. The amounts of solids removed from the reactor were determined by differences in the standpipe level using LI339 before and after the FD0206 and FD0510 operation. Since FD0510 was usually not operated for an entire operating period, the values shown on Table 4.5-2 and used in the mass balances have been prorated down from the FD0510 rates determined as if FD0510 had been operating continuously.

The accumulation term is determined by the difference in standpipe and loop seal levels from the beginning and end of each operating period.

\subsubsection{Coal Rates and Carbon Conversion}

In GCT3 and GCT4, both the carbon balance and energy balance were off by 10 to 20 percent. It was speculated that this was due to FD0210 weigh cell data reading about 15 percent too high. Using coal rates determined by FD0210 weigh cell data would have 
produced a TC06 carbon balance that had 10 to 20 percent more carbon entering the Transport Reactor than exiting the Transport Reactor. The other large carbon flows (synthesis gas carbon flow and PCD solids carbon flow) are independently checked, so it is likely that the weigh cell coal rate is in error. The coal rate was determined in TC06 and TC07 by a carbon balance, using the coal carbon, PCD carbon, synthesis gas carbon, standpipe carbon, synthesis gas rate, PCD solids rate, the reactor solids rates, and the reactor carbon accumulation. The results of this calculation are shown in Table 4.5-1, where the Transport Reactor carbon flows are listed for each operating period.

The carbon balance coal-flow rate and FD0210 weigh cells coal rate for the operating periods are compared on Figure 4.5-5. The FD0210 weigh cell coal rates were determined from a spreadsheet which calculated the coal rate for every filling of the FD0210 surge vessel. The carbon balance coal-flow rate is about 80 percent of the FD0210 weigh cell coalflow rate. Also shown on Figure 4.5-5 are the coal rates calculated from the synthesis gas combustor flue gas $\mathrm{CO}_{2}$ analyzer, AI476D, which is similar to how the coal rate was determined in the Transport Reactor combustion mode operation by using the Transport Reactor $\mathrm{CO}_{2}$ analyzer. The coal rate by the syngas combustor (BR0401) carbon balance using the syngas combustor $\mathrm{CO}_{2}$ analyzer was always between the coal rate by the FD0210 weigh cell coal rate and the syngas carbon balance coal rate. The syngas combustor coal rate was always greater than than the syngas coal rate because the syngas combustor flue gas measured $\mathrm{CO}_{2}$ concentration was always higher than the $\mathrm{CO}_{2}$ concentration calculated from the syngas composition. (See Figure 4.3-21.) As the run progressed, the calculated and measured syngas combustor flue gas $\mathrm{CO}_{2}$ compositions slowly got closer together as the syngas and syngas combustor carbon balance coal rates got closer together. The coal rate by the synthesis gas analyzers will be used for all further data analysis in this section.

The carbon balance coal-flow rates for the operating periods are given in Table 4.5-2. The coal rate was fairly steady at 4,100 $\pm 200 \mathrm{lb} / \mathrm{hr}$ for most of TC07 until the iron oxide testing at 400 hours. During the iron oxide testing, the coal rate had a larger variation and was from 3,700 to $4,500 \mathrm{lb} / \mathrm{hr}$.

Carbon conversion is defined as the percent fuel carbon that is gasified to $\mathrm{CO}, \mathrm{CO}_{2}, \mathrm{CH}_{4}$, $\mathrm{C}_{2} \mathrm{H}_{6}$, and higher hydrocarbons. The carbon conversion is the measure of how much carbon is rejected by the gasifier with the PCD and reactor solids. This rejected carbon is typically burned in a less efficient combustor (or disposed) and results in a less efficient use of the original fuel. The carbon conversion is plotted on Figure 4.5-6. The carbon conversions for each operating period are given on Table 4.5-1. The carbon conversion was between 94 and 98 percent (with one outlier) up until the iron oxide injection tests at 400 hours. Carbon conversions were from 90 to 96 percent during the iron oxide injection tests.

The air-to-coal ratio is given on Figure 4.5-6. The air-to-coal ratio was at about $3.35 \pm 0.15$ for the first 365 hours of TC07, until the iron oxide injection tests. The air-to-coal ratio then decreased to $3.1 \pm 0.1$ for the remainder of TC07. The air rate was controlled either manually or automatically to maintain a desired reactor temperature for a set coal rate. Since the desired set point temperature did not change much during TC07, the air-to-coal ratio was constant during TC07. 
The carbon conversion should be a function of reactor temperature, with the carbon conversion increasing as the temperature increases. The TC07 carbon conversions are plotted against riser temperature in Figure 4.5-7. There is a very slight increase of carbon conversion with temperature. A greater range of operating temperatures might demonstrate the temperature dependence better.

\subsubsection{Overall Material Balance}

Material balances are useful in checking the accuracy and consistency of data as well as determining periods of operation where the data is suitable for model development or commercial plant design. Total material balances for each operating period are given on Figure 4.5-8, which shows the relative difference (relative error) of Transport Reactor feeds in minus products out divided by the feeds ( $\{$ In-Out $\} / \mathrm{In})$, and the absolute difference (absolute error) of the feeds and the products (In-Out). The overall material balance was excellent, with most of the relative difference between +1.0 and -4.6 percent $(+271$ to $-1,046$ $\mathrm{lb} / \mathrm{hr}$ for the absolute difference).

The gas composition data in Section 4.3 and the solids composition data in Section 4.4 affect the mass balance through the coal rate determined by carbon balance. The main contributors to the material balance are the synthesis gas rate $(22,000$ to $27,000 \mathrm{lb} / \mathrm{hr})$, air rate $(12,000$ to $15,000 \mathrm{lb} / \mathrm{hr})$, nitrogen rate $(6,000$ to $9,000 \mathrm{lb} / \mathrm{hr})$, and coal rate $(3,800$ to $4,500 \mathrm{lb} / \mathrm{hr})$.

\subsubsection{Nitrogen Balance}

Test periods nitrogen balances are plotted in Figure 4.5-9 and listed in Table 4.5-3. Typical nitrogen flows for TC07-9a are shown in Table 4.5-4. The overall TC07 nitrogen balance was excellent for all of the operating periods within \pm 2 percent $( \pm 200 \mathrm{lb} / \mathrm{hr}$ nitrogen). The first several operating periods had around a +2 percent error, which occurred when the nitrogen rates were high. The nitrogen flows, as shown in Table 4.5-4, are dominated by the air, nitrogen, and synthesis gas flow. None of the solid streams contributes significantly to the nitrogen balance.

Using the ammonia analyzer data, the coal rates and the coal nitrogen concentration, the amount of fuel nitrogen converted to $\mathrm{NH}_{3}$ can be calculated. The amount of fuel nitrogen converted to $\mathrm{NH}_{3}$ is shown on Figure 4.5-10. The amount of fuel nitrogen converted to ammonia varied from 67 to 88 percent. The percent converted increased from hour 173 to a peak of 88 percent between hours 240 and 282, and then gradually decreased to 66 percent by the end of TC07. The ammonia concentrations and percent conversions are probably high based on later gasification tests when this ammonia analyzer was checked against extractive sampling and a different ammonia analyzer. 


\subsubsection{Sulfur Balance and Sulfur Removal}

Sulfur balances for all the TC07 operating periods are given in Figure 4.5-11 and Table 4.5-5. The synthesis gas sulfur compounds were not directly measured, but estimated from syngas combustor $\mathrm{SO}_{2}$ analyzer data and synthesis gas combustor flue gas flow. The sulfur balances are acceptable from hours 150 to 365 where the balances are within \pm 20 percent $( \pm 4 \mathrm{lb} / \mathrm{hr}$ sulfur). There were seven TC07 operating periods with excellent sulfur balances of \pm 10 percent $( \pm 1 \mathrm{lb} / \mathrm{hr}$ sulfur). Most of the operating periods sulfur balances were biased high (similar to TC06). The sulfur balances were not as good during the iron oxide injection tests at the end of TC07. The sulfur mass balance is difficult to close due to the low sulfur content of the PRB coal and PCD fines.

With the errors in the sulfur balances, it is difficult to determine the correct sulfur removal. There are three different methods to determine the Transport Reactor sulfur removal:

1. From synthesis gas sulfur emissions (using the synthesis gas combustor flue gas rate and synthesis gas combustor flue gas $\mathrm{SO}_{2}$ measurement) and the feed sulfur rate (using the feed coal rate and coal sulfur content). (Gas analyses)

2. From PCD solids analysis (using PCD solids flow rate and PCD solids sulfur content) and the feed sulfur rate. (Solids analyses)

3. From the gas analysis data and the PCD solids data. (Product analyses)

The three sulfur removals are plotted on Figure 4.5-12 and given on Table 4.5-5. The sulfur in the fuel is an inaccurate measurement due to the multiplication of a very small number (coal sulfur) by a very large number (coal-feed rate). The low coal sulfur contents (0.24-wt percent sulfur) increase the error in feed sulfur. The gaseous sulfur measurement should be more accurate, although it is also the product of a small number (syngas combustor $\mathrm{SO}_{2}$ ) and a large number (syngas combustor flue gas rate). This is because it is more accurate to measure gas flow rates and compositions and these flows and compositions are measured continuously. The PCD fines sulfur rate may have inaccuracies due to the very low sulfur in the PCD solids. There is no accumulation of sulfur-containing solids in the reactor during TC07 because the standpipe and FD0510 reactor samples contained very small amounts of sulfur. All three sulfur removals inversely followed the steam rate (higher steam rate, less sulfur removal). The sulfur removals by all three methods analyses agreed well for the first four operating periods, when the sulfur balance was very good. The sulfur removals for both the products and solids were less than the gas analyzers for all but one of the operating periods after the first four operating periods.

The synthesis gas combustor $\mathrm{SO}_{2}$ data was used for the sulfur emissions shown in Table-4.5-5. The sulfur emissions based on the gas analyses are from 0.16 to $0.48 \mathrm{lb} \mathrm{SO}_{2}$ per million Btu coal fed. The sulfur emissions were higher and the sulfur removals were lower in TC07 when compared to TC06 due to the higher steam rates in TC07. 
The sulfur removal by the gas analyzers is plotted against the steam rate in Figure 4.5-13, where the trend of increasing steam rate and decreasing sulfur removal is clear. The lower removals are as predicted by thermodynamics since the higher steam rates lead to higher syngas $\mathrm{H}_{2} \mathrm{O}$, which lead to higher equilibrium $\mathrm{H}_{2} \mathrm{~S}$. Higher equilibrium $\mathrm{H}_{2} \mathrm{~S}$ levels prevent high $\mathrm{H}_{2} \mathrm{~S}$ removals.

\subsubsection{Hydrogen Balance}

Hydrogen balances for the operating periods are given in Figure 4.5-14 and Table 4.5-3 with typical values for TC07-9a given on Table 4.5-4. The coal, steam, and synthesis gas streams dominate the hydrogen balance. The hydrogen balances were fairly poor, from 0 to -30 percent ( 0 to $-120 \mathrm{lb} / \mathrm{hr}$ hydrogen), with a consistently low bias. Several operating periods had excellent hydrogen balances at hours 180, 310, 421, and 446. The poor hydrogen balances are possibly due to the steam rate being underreported since it was probable that there was some steam flowing into the UMZ despite a large negative flow reading from FD204.

The steam rate for each operating period can be calculated using a hydrogen balance, which is essentially the difference in hydrogen between the coal-feed and synthesis-gas rate. This comparison is shown on Figure 4.5-15. The two steam rates compare well when the hydrogen balance is excellent, as expected. The steam rate by hydrogen balance is more than the measured steam rate and averages about $500 \mathrm{lb} / \mathrm{hr}$ of steam. This may be an indication of about $500 \mathrm{lb} / \mathrm{hr}$ of steam being fed into the UMZ that is not being measured.

\subsubsection{Oxygen Balance}

Operating period oxygen balances are given in Figure 4.5-16 and Table 4.5-3, with typical values given for TC07-9a on Table 4.5-4. The TC07 operating periods oxygen balances were not very good and had a consistent low bias. The oxygen balance was from -3 to -18 percent (-131 to $-781 \mathrm{lb}$ oxygen/hr). This was very similar to TC06 when there was steam leaking from HX0202 into the reactor. The oxygen balance average was off by about $550 \mathrm{lb}$ oxygen $/ \mathrm{hr}$ (equivalent to $630 \mathrm{lb} / \mathrm{hr}$ steam). The oxygen balance would have been excellent if $630 \mathrm{lb} / \mathrm{hr}$ of unmeasured steam was added to the Transport Reactor. Note the large oxygen contribution of the feed coal since PRB has a high oxygen content (moisture plus elemental oxygen).

\subsubsection{Calcium Balance}

Operating period calcium balances are given in Figure 4.5-17 and Table 4.5-3, with typical values for TC07-9a given on Table 4.5-4. PRB operation is characterized by low sorbent feed rates because of low sulfur in the PRB coal. About half of the inlet calcium comes from fuel, and half from sorbent, when sorbent is fed. The calcium balances were good during about half of the TC07 operating periods, when the calcium balance was from \pm 20 percent $( \pm 20 \mathrm{lb}$ calcium $/ \mathrm{hr})$. The other half of the operating periods had poor calcium balances between +40 to -124 percent, with a negative bias. The poor periods of calcium balances are probably due to the low calcium flows in the system, the inaccuracies of the 
sorbent and coal feeder flows, and because the calcium flow is the result of multiplying a small number (calcium in the coal) by a large number (coal-flow rate). The periods when limestone was not fed to the reactor (operating periods TC07-6, -19, and -25 to -29) had very poor calcium balances since only about half of the typical rate of calcium was fed to the reactor.

The PCD fines calcium is typically not totally calcined as shown in Figure 4.4-10 where the calcium calcination was 70 to 90 percent. The level of sorbent limestone calcination can be calculated by a mass balance, since the sorbent limestone and the coal calcium feed rates are known. The sorbent limestone calcination calculation uses the assumption that the calcium in the coal ash has not recarbonated. Figure 4.5-18 plots the estimate of the limestone calcination for TC07 assuming that the calcium from the coal ash in the PCD solids is neglected. The limestone sorbent calcination was about 50 percent for the first three operating periods (hours 168 to 180) and is 20 to 30 percent less than the PCD calcium calcination. For the operating periods when there is no limestone being fed to the reactor, TC07-6, -19, -21, and -25 to 29 (hours 210, 354, 378, and 421 to 446), the feed limestone calcination was not calculated. There were other operating periods when the PCD solids $\mathrm{CO}_{2}$ was very high, which made the feed limestone calcination less than zero, which are also not plotted (TC07-5 and -24). During TC07-24, the limestone was fed directly to the PCD. From hour 215 to hour 268 the limestone calcination was about 15 percent lower than the PCD solids calcination.

Also plotted on Figure 4.5-18 is the $\mathrm{CaCO}_{3}$ calcination temperature calculated from the synthesis gas $\mathrm{CO}_{2}$ partial pressure. Figure 4.3-15 of the GCT1 Final Report shows a plot of the $\mathrm{CO}_{2}$ partial pressure for the $\mathrm{CaCO}_{3}-\mathrm{CaO}-\mathrm{CO}_{2}$ system. The calcination temperature varied between 1,630 and $1,680^{\circ} \mathrm{F}$, slightly below the mixing zone temperature of 1,700 to $1,800^{\circ} \mathrm{F}$. If $\mathrm{CaCO}_{3}$ is at equilibrium at the mixing zone temperatures, it should all calcine to $\mathrm{CaO}$ and $\mathrm{CO}_{2}$. As $\mathrm{CaO}$ cools, thermodynamic equilibrium predicts that $\mathrm{CaO}$ should recarbonate to $\mathrm{CaCO}_{3}$ at the $\mathrm{PCD}$ temperatures of 700 to $750^{\circ} \mathrm{F}$.

From the data, it can not be determined whether the limestone calcined and then recarbonated as thermodynamics would predict or whether the limestone only partially calcined. It is probably the former since compound decomposition reactions (like limestone calcination) are fast and proceed quickly to completion. The recarbonation reaction is also fast, but is limited by the mass transfer of the $\mathrm{CO}_{2}$ into the PCD fines particle. It is likely that the mass transfer prevents the FD0520 solids sampled from being completely carbonated.

Figure 4.5-19 plots TC07 sulfur emissions (expressed as pounds $\mathrm{SO}_{2}$ emitted per million Btu coal fed), and sulfur removal by products method as a function of calcium-to-sulfur ratio $(\mathrm{Ca} / \mathrm{S})$, based on the coal and sorbent fed to the Transport Reactor. For TC07, the sulfur emissions are independent of the feed $\mathrm{Ca} / \mathrm{S}$, which was not true in TC06. The sulfur emissions and removals are given in Table 4.5-5. Most of the operating periods had feed $\mathrm{Ca} / \mathrm{S}$ ratios in a narrow range of $3.0 \pm 0.2$, which may have masked any trends of feed $\mathrm{Ca} / \mathrm{S}$ with sulfur removal and sulfur emissions. Due to the poor sulfur and calcium balances for much of TC07, the actual trend might not be evident due to the errors in the data. 
Operating periods when there was no sorbent feed to the Transport Reactor (TC07-6, -19, -21 , and -25 to -29$)$ are excluded from Figure 4.5-19.

Figure 4.5-20 plots TC07 sulfur emissions (expressed as pounds $\mathrm{SO}_{2}$ emitted per million Btu coal fed) and sulfur removal by products method as a function of calcium-to-sulfur ratio $(\mathrm{Ca} / \mathrm{S})$ measured in the PCD solids samples from FD0520. The measured PCD solids $\mathrm{Ca} / \mathrm{S}$ ratio is much higher than the feed $\mathrm{Ca} / \mathrm{S}$ because the PRB coal has higher calcium content. The trends in PCD solids Ca/S with sulfur emissions (see Figure 4.5-20) were opposite of what was expected. The sulfur removal should increase with $\mathrm{Ca} / \mathrm{S}$ ratio and the sulfur emissions should decrease with $\mathrm{Ca} / \mathrm{S}$ ratio. Since the steam rate strongly effects sulfur removal and the limestone (and calcium) feed rates were constant, the results shown on Figure 4.5-20 are the results of a simple mass balance. The results seen on Figure 4.5-20 demonstrate that when the PCD solids contain very little sulfur (high $\mathrm{Ca} / \mathrm{S}$ ), the $\mathrm{SO}_{2}$ removals are low and the $\mathrm{SO}_{2}$ emissions are high, which is reasonable by sulfur balance. The calcium sulfation percent is the reciprocal (times 100) of the $\mathrm{Ca} / \mathrm{S}$ ratio based on the PCD fines solids.

\subsubsection{Silica Balance}

Operating periods $\mathrm{SiO}_{2}$ balances are given in Figure 4.5-21, with typical values for TC07-9a given on Table 4.5-4. Table 4.5-3 gives the results of the $\mathrm{SiO}_{2}$ balances for all of the operating periods. The $\mathrm{SiO}_{2}$ balance mainly reflects the coal rate, reactor draw-off rate and PCD-solids rate, since the limestone sorbent typically had only 2.5-percent $\mathrm{SiO}_{2}$. The $\mathrm{SiO}_{2}$ balance is similar to the calcium balance since both are dominated by the coal rate and the PCD solids rates and compositions. The Silicon dioxide balances were poor at \pm 50 percent ( $\pm 80 \mathrm{lb} / \mathrm{hr}$ silicon dioxide), with a positive bias. The $\mathrm{SiO}_{2}$ balance was usually biased positive. A few operating periods do have good $\mathrm{SiO}_{2}$ balances.

The reactor starts the run filled with start-up sand, which is mostly $\mathrm{SiO}_{2}$. During the run the $\mathrm{SiO}_{2}$ is slowly replaced by coal ash and limestone. Due to attrition, the sand particles slowly become small enough to pass through the cyclone and exit the Transport Reactor.

\subsubsection{Energy Balance}

The TC07 Transport Reactor energy balance is given in Figure 4.5-22, with standard conditions chosen to be 1.0 atmosphere pressure and $80^{\circ} \mathrm{F}$ temperature. Table 4.5-6 breaks down the individual components of the energy balance for each operating period. The "energy in" consists of the coal, air, and steam fed to the Transport Reactor. The nitrogen and sorbent fed to the reactor were considered to be at the standard conditions $\left(80^{\circ} \mathrm{F}\right)$ and hence have zero enthalpy. The "energy out" consisted of the synthesis gas and PCD solids. The LHV of the coal and PCD solids were used in order to be consistent with the LHV of the synthesis gas. While the reactor solids sampled from FD0510 flow had no latent heat, there was a small amount of sensible heat in the FD0510 solids. The energy of the synthesis gas was determined at the Transport Reactor cyclone exit. About 1,200 lb $\mathrm{N}_{2} / \mathrm{hr}$ fed to the PCD inlet and outlet particulate sampling trains has been subtracted from the synthesis gas 
rate to determine the actual syngas rate from the cyclone. The sensible enthalpy of the synthesis gas was determined by overall gas heat capacity from the synthesis gas compositions and the individual gas heat capacities. The synthesis gas and PCD solids energy consists of both latent and sensible heat. The heat loss from the Transport Gasifier was estimated to be $1.5 \times 10^{6} \mathrm{Btu} / \mathrm{hr}$, based on a previous combustion test. The assumption of $3.5 \times 10^{6} \mathrm{Btu} / \mathrm{hr}$ heat loss would put all of the TC07 energy balance error to be less than 10 percent, centered on the 0 -percent error line. It is possible that the actual Transport Gasifier heat losses are higher than the $1.5 \times 10^{6} \mathrm{Btu} / \mathrm{hr}$ measured.

The TC07 energy balance was biased high by 2.5 to 8.4 percent ( 0.8 to 3.2 million Btu/hr). This is a better energy balance than if the FD0210 weigh cell data coal-flow rates were used, since the higher coal rates from the FD0210 weigh cell data would make the energy balance have a higher bias than the synthesis gas coal rates. A decrease in coal flow rates by 5 percent would put most of the operating periods in energy balance, but the carbon balance would then be off by 5 percent. A decrease in synthesis gas by about 5 percent or an increase in the reactor heat loss by 2 million Btu/hr would also place the energy balance in better agreement.

\subsubsection{Gasification Efficiencies}

Gasification efficiency is defined as the percent of the feed energy that is converted to potentially useful synthesis gas energy. Two types of gasification efficiencies have been defined - the cold-gas efficiency and the hot gas efficiency. The cold-gas efficiency is the amount of feed energy that is available to a gas turbine as synthesis gas latent heat.

Similar to sulfur removal, the cold-gas efficiency can be calculated at least three different ways. Since the energy balance is off by up to about 4.3 percent, each result could be different. If there were a perfect energy balance, all three calculations would produce the same result. Three calculation methods were performed for cold gasification consistent with the three methods of sulfur removal:

1. Based on the feed energy and the latent heat of the synthesis gas. This assumes that the feed energy and the synthesis gas latent heat is correct. (Gas analyses)

2. Based on the feed energy and the latent heat of the synthesis gas determined by a Transport Reactor energy balance, not the gas analyses. This assumes that the synthesis gas latent heat is incorrect. (Solids analyses)

3. Based on the feed energy determined by Transport Reactor energy balance and the synthesis gas sensible heat. This assumes that the coal feed is in error. (Products analyses)

The cold gas gasification efficiencies for the three calculation methods are plotted in Figure 4.5-23. For all of the operating periods, the products method is between the solids and gas methods. The gas method is lower than the solids method and the products method for all TC07 operating period since all operating period energy balances are biased high. The 
three methods agree with each other whenever the energy balance is perfect. Only the products method is listed on Table 4.5-6 because the products method is probably the most accurate since it does not use the coal rate determined by carbon balance. The products analysis cold gas gasification efficiencies were 54 to 61 percent.

The hot gasification efficiency is the amount of feed energy that is available to a gas turbine plus a heat recovery steam generator. The hot gas efficiency counts both the latent and sensible heat of the synthesis gas. Similar to the cold gasification efficiency and the sulfur removal, the hot gas efficiency can be calculated at least three different ways. The three calculation methods for hot gasification are identical with the three methods of cold gasification efficiency calculation except for the inclusion of the synthesis gas sensible heat into the hot gasification efficiency.

The hot gasification efficiency assumes that the sensible heat of the synthesis gas can be recovered in a heat recovery steam generator, so the hot gasification efficiency is always higher than the cold gasification efficiency. The three hot gasification calculation methods are plotted in Figure 4.5-24 and shown on Table 4.5-6.

For all of the operating periods, the products method was essentially equal to the solids method. This was because the amount of inlet coal heat was about the same as the total synthesis gas heat, and it made little difference whether the synthesis gas heat or the coal heat was corrected. The gas method was lower than the solids and products. The gas method hot gasification efficiency was within 2 to 8 percent of the solids and products method depending on the degree of energy balance closure. The products method hot gasification efficiencies were from 85 to 94 percent. These high efficiencies were a result of the low PCD fines carbon content and low PCD fines rates. As with the cold gasification efficiencies, the hot gasification efficiency by products method should be more accurate than the hot gasification efficiencies by the gas and solids methods.

Two main sources of losses in efficiency are the reactor heat loss and the latent heat of the PCD solids. The reactor heat loss of $1.5 \times 10^{6} \mathrm{Btu} / \mathrm{hr}$ is about 4 percent of the feed coal energy, while the total energy of the PCD solids was between 2 and 10 percent of the feed coal energy. The heat loss percentage will decrease as the reactor size is increased. While the Transport Reactor does not recover the latent heat of the PCD solids, this latent heat could be recovered in a combustor. The heat of the PCD solids can be decreased by decreasing both the PCD solids carbon content (heating value) and the PCD solids rate.

Gasification efficiencies can be calculated from the adiabatic nitrogen corrected gas heating values that were determined in Section 4.3. The adiabatic nitrogen corrected cold gasification efficiencies are plotted on Figure 4.5-25, and the products method corrected cold gasification efficiencies are listed on Table 4.5-6 for all of the operating periods. Only the cold gasification efficiencies based on the products are given in Table 4.5-6 because they are the most representative of the actual gasification efficiencies. The products method adiabatic nitrogen corrected cold gasification efficiencies were between 66 and 73 percent for TC07. The adiabatic nitrogen correction increases the cold gasification efficiencies by about 12 percent for most of the operating periods. The adiabatic nitrogen correction does 
POWER SYSTEMS DEVELOPMENT FACILITY

TEST CAMPAIGN TCO7

TRANSPORT REACTOR

MASS AND ENERGY BALANCES

not increase the hot gasification efficiency because the deleted nitrogen lowers the synthesis gas sensible heat and increases the synthesis gas latent heat. Both changes effectively cancel each other out. 
Table 4.5-1

\section{Carbon Rates}

\begin{tabular}{|c|c|c|c|c|c|c|c|c|c|}
\hline \multirow[b]{2}{*}{$\begin{array}{c}\text { Operating } \\
\text { Period }\end{array}$} & \multirow{2}{*}{$\begin{array}{c}\text { Average } \\
\text { Relative } \\
\text { Hours }\end{array}$} & \multicolumn{3}{|c|}{ Carbon In (Feed) } & \multicolumn{4}{|c|}{ Carbon Out (Products) } & \multirow{2}{*}{\begin{tabular}{|c} 
Carbon \\
Conversion \\
$\%$
\end{tabular}} \\
\hline & & $\begin{array}{l}\text { Coal }^{1} \\
\mathrm{lb} / \mathrm{hr}\end{array}$ & $\begin{array}{c}\text { Sorbent } \\
\mathrm{lb} / \mathrm{hr}\end{array}$ & $\begin{array}{l}\text { Total } \\
\mathrm{lb} / \mathrm{hr}\end{array}$ & $\begin{array}{c}\text { Syngas } \\
\mathrm{lb} / \mathrm{hr}\end{array}$ & $\begin{array}{c}\text { Standpipe }^{2} \\
\mathrm{lb} / \mathrm{hr}\end{array}$ & $\begin{array}{c}\text { PCD Solids } \\
\mathrm{lb} / \mathrm{hr}\end{array}$ & $\begin{array}{l}\text { Total } \\
\mathrm{lb} / \mathrm{hr}\end{array}$ & \\
\hline TC07-1 & 168 & 2,270 & 23 & 2,293 & 2,103 & 0.0 & 189 & 2,293 & 92.7 \\
\hline TC07-2 & 173 & 2,261 & 14 & 2,276 & 2,082 & 0.0 & 194 & 2,276 & 92.0 \\
\hline TC07-3 & 180 & 2,214 & 14 & 2,228 & 2,038 & 0.0 & 190 & 2,229 & 92.1 \\
\hline TC07-4 & 192 & 2,259 & 19 & 2,278 & 2,169 & 0.0 & 108 & 2,278 & 96.0 \\
\hline TC07-5 & 199 & 2,269 & 18 & 2,287 & 2,222 & 0.1 & 66 & 2,287 & 97.9 \\
\hline TC07-6 & 210 & 2,236 & 0 & 2,236 & 2,096 & 0.0 & 140 & 2,236 & 93.7 \\
\hline TC07-7 & 215 & 2,238 & 14 & 2,252 & 2,104 & 0.0 & 148 & 2,252 & 94.0 \\
\hline TC07-8 & 222 & 2,259 & 14 & 2,274 & 2,160 & 0.0 & 114 & 2,274 & 95.6 \\
\hline TC07-9a & 232 & 2,240 & 14 & 2,254 & 2,162 & 0.0 & 93 & 2,254 & 96.5 \\
\hline TC07-9b & 240 & 2,331 & 14 & 2,345 & 2,244 & 0.0 & 101 & 2,345 & 96.3 \\
\hline TC07-9c & 249 & 2,288 & 14 & 2,302 & 2,196 & 0.0 & 106 & 2,302 & 96.0 \\
\hline TC07-10 & 263 & 2,152 & 15 & 2,166 & 2,069 & 0.0 & 97 & 2,166 & 96.2 \\
\hline TC07-11 & 268 & 2,234 & 14 & 2,249 & 2,156 & 0.0 & 93 & 2,249 & 96.5 \\
\hline TC07-12 & 282 & 2,212 & 16 & 2,228 & 2,133 & 0.0 & 94 & 2,228 & 96.4 \\
\hline TC07-13 & 294 & 2,221 & 26 & 2,247 & 2,144 & 0.0 & 104 & 2,247 & 96.5 \\
\hline TC07-14 & 310 & 2,180 & 14 & 2,195 & 2,115 & 0.0 & 80 & 2,195 & 97.0 \\
\hline TC07-15 & 321 & 2,252 & 14 & 2,267 & 2,173 & 0.0 & 93 & 2,267 & 96.5 \\
\hline TC07-16 & 334 & 2,219 & 29 & 2,248 & 2,176 & 0.0 & 72 & 2,248 & 98.0 \\
\hline TC07-17 & 341 & 2,185 & 15 & 2,200 & 2,126 & 0.0 & 74 & 2,200 & 97.3 \\
\hline TC07-18 & 346 & 2,213 & 14 & 2,227 & 2,152 & 0.1 & 75 & 2,227 & 97.3 \\
\hline TC07-19 & 354 & 2,303 & 0 & 2,303 & 2,238 & 0.0 & 65 & 2,303 & 97.2 \\
\hline TC07-20 & 365 & 2,348 & 14 & 2,363 & 2,323 & 0.1 & 40 & 2,363 & 98.9 \\
\hline TC07-21 & 378 & 2,307 & 0 & 2,307 & 2,196 & 0.0 & 110 & 2,307 & 95.2 \\
\hline TC07-22 & 394 & 2,341 & 8 & 2,349 & 2,242 & 0.0 & 107 & 2,349 & 95.8 \\
\hline TC07-23 & 403 & 2,062 & 12 & 2,074 & 1,979 & 0.0 & 94 & 2,074 & 96.0 \\
\hline TC07-24 & 411 & 2,195 & 36 & 2,231 & 2,064 & 0.0 & 167 & 2,231 & 94.0 \\
\hline TC07-25 & 421 & 2,034 & 0 & 2,034 & 1,902 & 0.0 & 133 & 2,034 & 93.5 \\
\hline ТC07-26 & 431 & 2,282 & 0 & 2,282 & 2,109 & 0.0 & 173 & 2,282 & 92.4 \\
\hline TC07-27 & 434 & 2,262 & 0 & 2,262 & 2,062 & 0.0 & 200 & 2,262 & 91.2 \\
\hline TC07-28 & 439 & 2,179 & 0 & 2,179 & 1,952 & 0.0 & 227 & 2,179 & 89.6 \\
\hline TC07-29 & 446 & 2,433 & 0 & 2,433 & 2,241 & 0.0 & 192 & 2,433 & 92.1 \\
\hline
\end{tabular}

Notes:

1. Coal carbon determined by carbon balance.

2. Standpipe carbon flow intermittent. Rate shown is average FD0510 rate during operating period. 
Table 4.5-2 Feed Rates, Product Rates, and Mass Balance

\begin{tabular}{|c|c|c|c|c|c|c|c|c|c|c|c|c|c|c|}
\hline \multirow[b]{3}{*}{$\begin{array}{c}\text { Operating } \\
\text { Period }\end{array}$} & \multirow{3}{*}{$\begin{array}{c}\text { Average } \\
\text { Relative } \\
\text { Hours }\end{array}$} & \multicolumn{6}{|c|}{ Feeds (In) } & \multicolumn{5}{|c|}{ Products (Out) } & \multirow[b]{3}{*}{$\begin{array}{c}\text { In - Out } \\
\mathrm{lb} / \mathrm{hr}\end{array}$} & \multirow[b]{3}{*}{$\begin{array}{c}\text { (In- Out)/In } \\
\%\end{array}$} \\
\hline & & & Sorbent & Air & Nitrogen & & & Syngas & PCD Solids & SP Solids & Reactor & & & \\
\hline & & $\begin{array}{l}\mathrm{Coal}^{2} \\
\mathrm{lb} / \mathrm{hr}\end{array}$ & $\begin{array}{c}\text { FD0220 } \\
\mathrm{lb} / \mathrm{hr}\end{array}$ & $\begin{array}{l}\text { FI205 } \\
\mathrm{lb} / \mathrm{hr}\end{array}$ & $\begin{array}{c}{\text { FI } 609^{1}}^{1} \\
\mathrm{lb} / \mathrm{hr}\end{array}$ & $\begin{array}{c}\text { Steam } \\
\mathrm{lb} / \mathrm{hr}\end{array}$ & $\begin{array}{l}\text { Total } \\
\mathrm{lb} / \mathrm{hr}\end{array}$ & $\begin{array}{l}\text { FI465 } \\
\mathrm{lb} / \mathrm{hr}\end{array}$ & $\begin{array}{c}\text { FD0520 } \\
\mathrm{lb} / \mathrm{hr}\end{array}$ & $\begin{array}{c}\text { FD0510 } \\
\mathrm{lb} / \mathrm{hr}\end{array}$ & $\begin{array}{c}\text { Accumulation } \\
\mathrm{lb} / \mathrm{hr}\end{array}$ & $\begin{array}{l}\text { Total } \\
\mathrm{lb} / \mathrm{hr}\end{array}$ & & \\
\hline \begin{tabular}{|l|} 
TC07-1 \\
\end{tabular} & 168 & 4,152 & 202 & 13,874 & 8,628 & 59 & 26,915 & 26,130 & 532 & \begin{tabular}{|l|}
0 \\
\end{tabular} & \begin{tabular}{|l|}
-18 \\
\end{tabular} & 26,644 & 271 & 1.0 \\
\hline TC07-2 & 173 & 4,137 & 126 & 13,821 & 8,686 & 33 & 26,803 & 26,110 & 531 & 0 & -9 & 26,631 & 171 & 0.6 \\
\hline TC07-3 & 180 & 4,050 & 126 & 13,483 & 8,611 & 33 & 26,302 & 25,602 & 511 & 0 & -14 & 26,098 & 204 & 0.8 \\
\hline TC07-4 & 192 & 4,132 & 164 & 13,900 & 7,098 & 1,306 & 26,599 & 26,224 & 474 & 19 & -4 & 26,714 & -115 & -0.4 \\
\hline TC07-5 & 199 & 4,151 & 158 & 14,490 & 6,975 & 1,166 & 26,941 & 26,937 & 453 & 76 & 67 & 27,534 & -593 & -2.2 \\
\hline TC07-6 & 210 & 4,091 & 0 & 13,457 & 6,844 & 1,031 & 25,423 & 25,229 & 423 & 0 & -21 & 25,630 & -207 & -0.8 \\
\hline TC07-7 & 215 & 4,093 & 127 & 13,610 & 6,940 & 1,124 & 25,893 & 25,577 & 409 & 0 & -15 & 25,971 & -78 & -0.3 \\
\hline TC07-8 & 222 & 4,133 & 127 & 14,388 & 6,984 & 1,620 & 27,251 & 26,872 & 394 & 0 & 2 & 27,268 & -17 & -0.1 \\
\hline TC07-9a & 232 & 4,097 & 126 & 13,929 & 6,827 & 1,614 & 26,593 & 26,236 & 384 & 15 & 18 & 26,652 & -59 & -0.2 \\
\hline TC07-9b & 240 & 4,263 & 127 & 14,334 & 7,058 & 1,709 & 27,491 & 27,292 & 384 & 0 & 4 & 27,679 & -188 & -0.7 \\
\hline \begin{tabular}{|l|} 
TC07-9c \\
\end{tabular} & 249 & 4,184 & 125 & 14,103 & 6,992 & 1,626 & 27,031 & 26,831 & 384 & 0 & -2 & 27,213 & -182 & -0.7 \\
\hline \begin{tabular}{|l|} 
TC07-10 \\
\end{tabular} & 263 & 3,935 & 127 & 12,963 & 6,132 & 1,679 & 24,837 & 24,811 & 396 & 15 & 24 & 25,245 & -408 & -1.6 \\
\hline \begin{tabular}{|l|} 
TC07-11 \\
\end{tabular} & 268 & 4,087 & 126 & 13,728 & 6,054 & 1,644 & 25,638 & 25,849 & 399 & 0 & -2 & 26,246 & -607 & -2.4 \\
\hline TC07-12 & 282 & 4,046 & 137 & 13,497 & 6,398 & 1,662 & 25,740 & 25,678 & 408 & 0 & -10 & 26,076 & -336 & -1.3 \\
\hline TC07-13 & 294 & 4,063 & 226 & 13,384 & 6,089 & 958 & 24,720 & 24,607 & 458 & 0 & -43 & 25,022 & -302 & -1.2 \\
\hline TC07-14 & 310 & 3,988 & 127 & 13,388 & 6,138 & 769 & 24,409 & 24,434 & 514 & 0 & -1 & 24,947 & -538 & -2.2 \\
\hline \begin{tabular}{|l|} 
TC07-15 \\
\end{tabular} & 321 & 4,120 & 127 & 13,407 & 6,040 & 758 & 24,452 & 24,463 & 514 & 0 & 7 & 24,984 & -533 & -2.2 \\
\hline \begin{tabular}{|l|} 
TC07-16 \\
\end{tabular} & 334 & 4,060 & 252 & 13,559 & 6,165 & 842 & 24,878 & 24,855 & 389 & 0 & -49 & 25,195 & -317 & -1.3 \\
\hline \begin{tabular}{|l|} 
TC07-17 \\
\end{tabular} & 341 & 3,997 & 128 & 13,285 & 6,021 & 151 & 23,581 & 24,003 & 389 & 0 & -49 & 24,343 & -761 & -3.2 \\
\hline \begin{tabular}{|l|} 
TC07-18 \\
\end{tabular} & 346 & 4,047 & 127 & 13,505 & 6,002 & 148 & 23,830 & 24,263 & 389 & 28 & 11 & 24,691 & -862 & -3.6 \\
\hline \begin{tabular}{|l|} 
TC07-19 \\
\end{tabular} & 354 & 4,212 & 0 & 13,719 & 6,278 & 179 & 24,389 & 24,670 & 361 & 0 & -5 & 25,025 & -637 & -2.6 \\
\hline \begin{tabular}{|l|} 
TC07-20 \\
\end{tabular} & 365 & 4,295 & 127 & 14,193 & 5,975 & 171 & 24,762 & 25,084 & 350 & 32 & 23 & 25,490 & -729 & -2.9 \\
\hline \begin{tabular}{|l|} 
TC07-21 \\
\end{tabular} & 378 & 4,219 & 0 & 13,345 & 6,245 & 179 & 23,988 & 23,934 & 389 & 0 & 17 & 24,340 & -352 & -1.5 \\
\hline \begin{tabular}{|l|} 
TC07-22 \\
\end{tabular} & 394 & 4,281 & 74 & 13,558 & 5,813 & 15 & 23,741 & 24,069 & 427 & 0 & -11 & 24,484 & -743 & -3.1 \\
\hline \begin{tabular}{|l|}
$\mathrm{TC} 07-23$ \\
\end{tabular} & 403 & 3,771 & 104 & 12,083 & 5,813 & 15 & 21,786 & 22,090 & 520 & 0 & -20 & 22,590 & -804 & -3.7 \\
\hline TC07-24 & 411 & 4,015 & 313 & 12,583 & 5,880 & 18 & 22,810 & 22,945 & 909 & 0 & -23 & 23,832 & $-1,022$ & -4.5 \\
\hline TC07-25 & 421 & 3,721 & 0 & 11,687 & 5,852 & 13 & 21,273 & 21,075 & 700 & 0 & -14 & 21,760 & -487 & -2.3 \\
\hline \begin{tabular}{|l|} 
TC07-26 \\
\end{tabular} & 431 & 4,174 & 0 & 13,006 & 6,041 & 13 & 23,234 & 23,696 & 612 & 0 & -10 & 24,298 & $-1,064$ & -4.6 \\
\hline \begin{tabular}{|l|} 
TC07-27 \\
\end{tabular} & 434 & 4,137 & 0 & 12,641 & 6,076 & 13 & 22,867 & 23,017 & 662 & 0 & -37 & 23,642 & -774 & -3.4 \\
\hline \begin{tabular}{|l|} 
TC07-28 \\
\end{tabular} & 439 & 3,986 & 0 & 11,927 & 5,565 & 13 & 21,490 & 21,506 & 681 & 0 & -85 & 22,102 & -612 & -2.8 \\
\hline \begin{tabular}{|l|} 
TC07-29 \\
\end{tabular} & 446 & 4,451 & 0 & 13,766 & 5,972 & 37 & 24,226 & 24,255 & 566 & 0 & 2 & 24,823 & -597 & -2.5 \\
\hline
\end{tabular}

Notes:

1. Nitrogen feed rate reduced by 750 pounds per hour to account for losses in feed systems and seals.

2. Coal Rate by carbon balance.

3. FD0510 was not always operated during an entire test period. FD0510 flow rates shown have been prorated to account for the actual time of FD0510 operation. 
Table 4.5-3

Nitrogen, Hydrogen, Oxygen, and Silicon Mass Balances

\begin{tabular}{|c|c|c|c|c|c|c|c|c|c|c|c|}
\hline \multirow{3}{*}{$\begin{array}{c}\text { Operating } \\
\text { Period }\end{array}$} & \multirow{3}{*}{$\begin{array}{c}\text { Average } \\
\text { Relative } \\
\text { Hours }\end{array}$} & \multicolumn{2}{|c|}{ Nitrogen } & \multicolumn{2}{|c|}{ Hydrogen } & \multicolumn{2}{|c|}{ Oxygen } & \multicolumn{2}{|c|}{ Calcium $^{2}$} & \multicolumn{2}{|c|}{$\mathrm{SiO}_{2}$} \\
\hline & & $\begin{array}{c}(\text { In- Out }) \\
\text { In }\end{array}$ & In - Out & $\frac{(\text { In- Out) }}{\text { In }}$ & In - Out & $\begin{array}{c}\text { (In- Out) } \\
\text { In }\end{array}$ & In - Out & $\begin{array}{c}(\text { In- Out) } \\
\text { In }\end{array}$ & In - Out & $\begin{array}{c}\text { (In- Out) } \\
\text { In }\end{array}$ & In - Out \\
\hline & & $\%$ & $\mathrm{lb} / \mathrm{hr}$ & $\%$ & $\mathrm{lb} / \mathrm{hr}$ & $\%$ & $\mathrm{lb} / \mathrm{hr}$ & $\%$ & $\mathrm{lb} / \mathrm{hr}$ & $\%$ & $\mathrm{lb} / \mathrm{hr}$ \\
\hline TC07-1 & 168 & 2.1 & 396 & -11.7 & -29 & -4.8 & -229 & 6.3 & 6 & 38.1 & 64 \\
\hline TC07-2 & 173 & 1.8 & 352 & -11.1 & -27 & -5.4 & -251 & -16.8 & -12 & 34.8 & 58 \\
\hline TC07-3 & 180 & 1.2 & 231 & -2.6 & -6 & -2.9 & -131 & -12.0 & -8 & 37.2 & 61 \\
\hline TC07-4 & 192 & 1.8 & 321 & -8.3 & -32 & -7.9 & -459 & -33.7 & -28 & 31.1 & 52 \\
\hline TC07-5 & 199 & 2.0 & 364 & -24.1 & -90 & -13.4 & $\begin{array}{l}-781 \\
\end{array}$ & -74.2 & -60 & 15.7 & 26 \\
\hline TC07-6 & 210 & 0.9 & 153 & -13.4 & -47 & -7.5 & -405 & -108.6 & -36 & 43.4 & 70 \\
\hline TC07-7 & 215 & 0.8 & 131 & -9.3 & -34 & -6.0 & -335 & 23.1 & 16 & 42.4 & 70 \\
\hline TC07-8 & 222 & 0.6 & 100 & -4.1 & -17 & -3.7 & -231 & 8.5 & 6 & 41.5 & 69 \\
\hline TC07-9a & 232 & 1.5 & 269 & -8.8 & -37 & -6.2 & -377 & -7.7 & -5 & 35.1 & 58 \\
\hline TC07-9b & 240 & 0.4 & 79 & -8.4 & -37 & -5.8 & -364 & 3.9 & 3 & 41.6 & 71 \\
\hline TC07-9c & 249 & 0.8 & 140 & -10.7 & -45 & -6.7 & -414 & 5.1 & 4 & 42.2 & 71 \\
\hline TC07-10 & 263 & 0.8 & 136 & -12.4 & -52 & -9.4 & -551 & -6.5 & -5 & 24.4 & 39 \\
\hline TC07-11 & 268 & -0.9 & -143 & -13.2 & -56 & -8.5 & -513 & -3.4 & -2 & 29.5 & 48 \\
\hline TC07-12 & 282 & 0.5 & 78 & -9.9 & -42 & -7.9 & -477 & 16.8 & 12 & 14.0 & 23 \\
\hline TC07-13 & 294 & -0.5 & -88 & -8.4 & -29 & -6.0 & -324 & 22.8 & 23 & 15.3 & 25 \\
\hline TC07-14 & 310 & -1.5 & -249 & -3.0 & -10 & -5.0 & -259 & 3.4 & 2 & -39.8 & -64 \\
\hline TC07-15 & 321 & -0.2 & -31 & -11.7 & -38 & -8.8 & -458 & -42.0 & -30 & 4.4 & 7 \\
\hline TC07-16 & 334 & -1.0 & -159 & -9.9 & -33 & -5.8 & -312 & 25.2 & 27 & 32.6 & 54 \\
\hline TC07-17 & 341 & -1.1 & -180 & -27.4 & -69 & -14.0 & -643 & -12.5 & -9 & 30.7 & 49 \\
\hline TC07-18 & 346 & -1.2 & -190 & -26.8 & -68 & -14.1 & -655 & -14.3 & -10 & 19.8 & 32 \\
\hline TC07-19 & 354 & 0.0 & 8 & -23.7 & -63 & -13.7 & -647 & -55.2 & -19 & 14.0 & 23 \\
\hline ТC07-20 & 365 & -0.9 & -151 & -20.3 & -55 & -11.7 & -577 & 43.0 & 31 & -21.2 & -37 \\
\hline TC07-21 & 378 & 1.9 & 314 & -23.2 & -62 & -14.4 & -668 & 23.1 & 8 & -26.9 & -45 \\
\hline TC07-22 & 394 & -0.1 & -16 & -29.0 & -73 & -16.1 & -744 & 8.9 & 5 & 12.3 & 21 \\
\hline TC07-23 & 403 & -0.8 & -113 & -28.0 & -62 & -14.8 & -607 & 22.2 & 14 & -9.2 & -14 \\
\hline TC07-24 & 411 & -0.8 & -130 & -29.0 & -69 & -14.5 & -639 & -9.8 & -12 & 23.0 & 38 \\
\hline TC07-25 & 421 & 0.2 & 29 & -6.7 & -15 & -7.7 & -304 & -127.1 & -38 & 48.4 & 71 \\
\hline TC07-26 & 431 & -1.0 & -156 & -28.7 & -70 & -17.9 & -787 & -67.5 & -23 & -7.4 & -12 \\
\hline TC07-27 & 434 & -0.3 & -44 & -19.9 & -48 & -14.7 & -636 & -82.3 & -27 & -18.4 & -30 \\
\hline TC07-28 & 439 & -0.4 & -54 & -15.8 & -37 & -12.6 & -517 & -103.8 & -33 & -17.9 & -28 \\
\hline TC07-29 & 446 & -1.0 & -169 & -8.0 & -21 & -9.0 & -424 & -52.8 & -19 & 13.6 & 24 \\
\hline
\end{tabular}

Notes:

1. Nitrogen feed rate reduced by 750 pounds per hour to account for losses in feed systems and seals.

2. Limestone feed off during operating periods TC07-6, -19 , and -25 to -29 , 
Table 4.5-4

Typical Component Mass Balances

\begin{tabular}{|l|c|c|c|c|c|}
\hline \multirow{2}{*}{ Operating Period } & Nitrogen & Hydrogen & Oxygen & Calcium & $\mathrm{SiO}_{2}$ \\
\cline { 2 - 6 } & TC07-9a & TC07-9a & TC07-9a & TC07-9a & TC07-9a \\
\hline Date & $3 / 27 / 2002$ & $3 / 27 / 2002$ & $3 / 27 / 2002$ & $3 / 27 / 2002$ & $3 / 27 / 2002$ \\
\hline Time Start & $07: 45$ & $07: 45$ & $07: 45$ & $07: 45$ & $07: 45$ \\
\hline Time End & $16: 15$ & $16: 15$ & $16: 15$ & $16: 15$ & $16: 15$ \\
\hline Fuel & PRB & PRB & PRB & PRB & PRB \\
\hline Sorbent & OH LS & OH LS & OH LS & OH LS & OH LS \\
\hline Riser Temperature, ${ }^{\circ} \mathrm{F}$ & 1,660 & 1,660 & 1,660 & 1,660 & 1,660 \\
\hline Pressure, psig & 200 & 200 & 200 & 200 & 200 \\
\hline In, pounds/hr & & & & & \\
\hline Fuel & 30 & 239 & 1,357 & 33 & 161 \\
\hline Sorbent & & & 58 & 38 & 3 \\
\hline Air & 10,624 & & 3,228 & & \\
\hline Nitrogen & 6,827 & & & & \\
\hline Steam & & 179 & 1,434 & & \\
\hline Total & 17,481 & 419 & 6,077 & 71 & 165 \\
\hline Synthesis Gas & 17,212 & 454 & 6,409 & & \\
\hline PCD Solids & 0 & 1 & 43 & 74 & 97 \\
\hline Reactor & & & 1 & 2 & 10 \\
\hline Accumulation & & & 1 & 0 & 0 \\
\hline Total & 17,212 & 455 & 6,454 & 76 & 107 \\
\hline Out, pounds/hr & $1.5 \%$ & $-8.8 \%$ & $-6.2 \%$ & $-7.7 \%$ & $35.1 \%$ \\
\hline (In-Out)/In, $\%$ & 269 & -37 & -377 & -5 & 58 \\
\hline (In-Out), pounds per hour & & & & & \\
\hline Note: 1. Feed nitrogen decreased & & & & \\
\hline
\end{tabular}

Note: 1 . Feed nitrogen decreased by 750 pounds per hour. 
Table 4.5-5 Sulfur Balances

\begin{tabular}{|c|c|c|c|c|c|c|c|c|c|c|c|c|c|}
\hline \multirow[b]{2}{*}{$\begin{array}{l}\text { Operating } \\
\text { Period }\end{array}$} & \multirow{2}{*}{$\begin{array}{c}\text { Average } \\
\text { Relative } \\
\text { Hours }\end{array}$} & \multirow{2}{*}{$\begin{array}{c}\text { Feeds (In) } \\
\text { Coal } \\
\mathrm{lb} / \mathrm{hr}\end{array}$} & \multicolumn{5}{|c|}{ Products (Out) } & \multirow[b]{2}{*}{$\begin{array}{l}\text { In - Out } \\
\mathrm{lb} / \mathrm{hr}\end{array}$} & \multirow[b]{2}{*}{$\begin{array}{c}\text { (In- Out)/In } \\
\%\end{array}$} & \multicolumn{3}{|c|}{ Sulfur Removal } & \multirow{2}{*}{$\begin{array}{c}\text { Sulfur } \\
\text { Emissions } \\
\mathrm{lb} \mathrm{SO}_{2} / \mathrm{MMBtu}\end{array}$} \\
\hline & & & $\begin{array}{c}\text { Syngas } \\
\mathrm{lb} / \mathrm{hr}\end{array}$ & $\begin{array}{c}\text { PCD Solids } \\
\mathrm{lb} / \mathrm{hr}\end{array}$ & $\begin{array}{c}\text { Reactor } \\
\mathrm{lb} / \mathrm{hr}\end{array}$ & \begin{tabular}{|c|} 
Accumulation \\
$\mathrm{lb} / \mathrm{hr}$
\end{tabular} & $\begin{array}{l}\text { Total } \\
\mathrm{lb} / \mathrm{hr}\end{array}$ & & & $\begin{array}{c}\text { Gas } \\
\%\end{array}$ & $\begin{array}{c}\text { Products } \\
\%\end{array}$ & $\begin{array}{c}\text { Solids } \\
\%\end{array}$ & \\
\hline \begin{tabular}{|l|} 
TC07-1 \\
\end{tabular} & 168 & 10.0 & 4.1 & 6.4 & 0.0 & 0.0 & 10.5 & -0.5 & -5.1 & 59 & 61 & 64 & 0.21 \\
\hline TC07-2 & 173 & 9.9 & 4.4 & 6.3 & 0.0 & 0.0 & 10.7 & -0.8 & -7.8 & 56 & 59 & 63 & 0.23 \\
\hline TC07-3 & 180 & 9.7 & 3.9 & 5.8 & 0.0 & 0.0 & 9.6 & 0.1 & 1.1 & 60 & 60 & 59 & 0.21 \\
\hline TC07-4 & 192 & 9.9 & 7.7 & 2.1 & 0.0 & 0.0 & 9.7 & 0.2 & 1.8 & 23 & 21 & 21 & 0.40 \\
\hline TC07-5 & 199 & 10.0 & 7.4 & 1.3 & 0.0 & 0.0 & 8.7 & 1.3 & 13.1 & 26 & 15 & 13 & 0.39 \\
\hline TC07-6 & 210 & 9.8 & 7.3 & 1.2 & 0.0 & 0.0 & 8.6 & 1.2 & 12.6 & 25 & 15 & 13 & 0.39 \\
\hline \begin{tabular}{|l|} 
TC07-7 \\
\end{tabular} & 215 & 9.8 & 6.7 & 1.2 & 0.0 & 0.0 & 7.9 & 2.0 & 20.0 & 32 & 15 & 12 & 0.35 \\
\hline \begin{tabular}{|l|} 
TC07-8 \\
\end{tabular} & 222 & 9.9 & 7.6 & 0.7 & 0.0 & 0.0 & 8.4 & 1.6 & 15.7 & 23 & 9 & 7 & 0.40 \\
\hline \begin{tabular}{|l|} 
TC07-9a \\
\end{tabular} & 232 & 9.8 & 7.7 & 0.5 & 0.0 & 0.0 & 8.2 & 1.7 & 16.9 & 22 & 6 & 5 & 0.41 \\
\hline TC07-9b & 240 & 10.2 & 8.2 & 0.5 & 0.0 & 0.0 & 8.7 & 1.5 & 14.9 & 20 & 6 & 5 & 0.42 \\
\hline TC07-9c & 249 & 10.0 & 8.2 & 0.8 & 0.0 & 0.0 & 9.0 & 1.0 & 10.4 & 18 & 9 & 8 & 0.43 \\
\hline \begin{tabular}{|l|} 
TC07-10 \\
\end{tabular} & 263 & 9.4 & 8.7 & 0.5 & 0.0 & 0.0 & 9.2 & 0.2 & 2.4 & 8 & 6 & 5 & 0.48 \\
\hline \begin{tabular}{|l|} 
TC07-11 \\
\end{tabular} & 268 & 9.8 & 8.6 & 0.4 & 0.0 & 0.0 & 9.1 & 0.8 & 7.7 & 12 & 5 & 4 & 0.46 \\
\hline \begin{tabular}{|l|} 
TC07-12 \\
\end{tabular} & 282 & 9.7 & 8.4 & 0.6 & 0.0 & 0.0 & 9.0 & 0.7 & 7.0 & 13 & 7 & 6 & 0.45 \\
\hline \begin{tabular}{|l|} 
TC07-13 \\
\end{tabular} & 294 & 9.8 & 7.3 & 0.9 & 0.0 & 0.0 & 8.3 & 1.5 & 15.3 & 25 & 11 & 10 & 0.39 \\
\hline \begin{tabular}{|l|} 
TC07-14 \\
\end{tabular} & 310 & 9.6 & 6.8 & 0.8 & 0.0 & 0.0 & 7.6 & 2.0 & 20.4 & 29 & 11 & 9 & 0.37 \\
\hline \begin{tabular}{|l|} 
TC07-15 \\
\end{tabular} & 321 & 9.9 & 7.1 & 1.4 & 0.0 & 0.0 & 8.5 & 1.3 & 13.6 & 28 & 17 & 14 & 0.37 \\
\hline \begin{tabular}{|l|} 
TC07-16 \\
\end{tabular} & 334 & 9.7 & 7.4 & 1.3 & 0.0 & 0.0 & 8.7 & 1.0 & 10.4 & 24 & 15 & 13 & 0.40 \\
\hline TC07-17 & 341 & 9.6 & 6.8 & 1.3 & 0.0 & 0.0 & 8.1 & 1.5 & 15.6 & 30 & 17 & 14 & 0.37 \\
\hline \begin{tabular}{|l|} 
TC07-18 \\
\end{tabular} & 346 & 9.7 & 6.9 & 1.3 & 0.0 & 0.0 & 8.2 & 1.5 & 15.2 & 29 & 16 & 14 & 0.37 \\
\hline \begin{tabular}{|l|} 
TC07-19 \\
\end{tabular} & 354 & 10.1 & 7.0 & 1.0 & 0.0 & 0.0 & 8.0 & 2.1 & 20.5 & 31 & 13 & 10 & 0.36 \\
\hline \begin{tabular}{|l|} 
TC07-20 \\
\end{tabular} & 365 & 10.3 & 6.4 & 2.1 & 0.0 & 0.0 & 8.5 & 1.8 & 17.1 & 38 & 25 & 21 & 0.32 \\
\hline TC07-21 & 378 & 10.1 & 6.5 & 0.9 & 0.0 & 0.0 & 7.4 & 2.7 & 26.5 & 36 & 12 & 9 & 0.33 \\
\hline \begin{tabular}{|l|} 
TC07-22 \\
\end{tabular} & 394 & 10.3 & 6.6 & 1.2 & 0.0 & 0.0 & 7.7 & 2.6 & 24.9 & 36 & 15 & 11 & 0.33 \\
\hline \begin{tabular}{|l|} 
TC07-23 \\
\end{tabular} & 403 & 9.1 & 4.7 & 1.1 & 0.0 & 0.0 & 5.9 & 3.2 & 35.3 & 48 & 19 & 12 & 0.27 \\
\hline \begin{tabular}{|l|} 
TC07-24 \\
\end{tabular} & 411 & 9.6 & 5.8 & 1.7 & 0.0 & 0.0 & 7.5 & 2.1 & 21.7 & 40 & 23 & 18 & 0.31 \\
\hline TC07-25 & 421 & 8.9 & 2.8 & 2.9 & 0.0 & 0.0 & 5.6 & 3.3 & 36.8 & 69 & 51 & 32 & 0.16 \\
\hline \begin{tabular}{|l|} 
TC07-26 \\
\end{tabular} & 431 & 10.0 & 5.9 & 2.3 & 0.0 & 0.0 & 8.3 & 1.8 & 17.5 & 41 & 28 & 23 & 0.31 \\
\hline \begin{tabular}{|l|} 
TC07-27 \\
\end{tabular} & 434 & 9.9 & 5.2 & 2.6 & 0.0 & 0.0 & 7.8 & 2.1 & 21.1 & 47 & 33 & 26 & 0.27 \\
\hline \begin{tabular}{|l|} 
TC07-28 \\
\end{tabular} & 439 & 9.6 & 5.1 & 3.0 & 0.0 & 0.0 & 8.1 & 1.5 & 15.5 & 47 & 37 & 31 & 0.28 \\
\hline \begin{tabular}{|l|} 
TC07-29 \\
\end{tabular} & 446 & 10.7 & 4.9 & 2.5 & 0.0 & 0.0 & 7.5 & 3.2 & 30.0 & 54 & 34 & 24 & 0.24 \\
\hline
\end{tabular}

1. Synthesis gas sulfur emissions determined from synthesis gas combustor $\mathrm{SO}_{2}$ analyzer.

2. There was no sorbent feed to the Transport Reactor during operating periods TC07-6, $-19,-21$, and -25 to -29 . 
Table 4.5-6 Energy Balance

\begin{tabular}{|c|c|c|c|c|c|c|c|c|c|c|c|c|c|c|c|}
\hline \multirow[b]{3}{*}{ Operating } & \multirow{3}{*}{$\begin{array}{l}\text { Average } \\
\text { Relative }\end{array}$} & & & & & \multicolumn{5}{|c|}{ Products (Out) } & \multirow[b]{3}{*}{\begin{tabular}{||c} 
In - Out \\
$10^{6} \mathrm{Btu} / \mathrm{hr}$
\end{tabular}} & \multirow[b]{3}{*}{$\begin{array}{c}\text { (In- Out)/In } \\
\%\end{array}$} & \multicolumn{3}{|c|}{ Efficiency } \\
\hline & & \multicolumn{4}{|c|}{ Feeds (In) } & \multirow[b]{2}{*}{$\begin{array}{c}\text { Syngas } \\
10^{6} \mathrm{Btu} / \mathrm{hr}\end{array}$} & \multirow{2}{*}{$\begin{array}{c}\text { PCD } \\
\text { Solids } \\
10^{6} \mathrm{Btu} / \mathrm{hr}\end{array}$} & \multirow{2}{*}{\begin{tabular}{|c|} 
Reactor \\
Solids \\
$10^{6} \mathrm{Btu} / \mathrm{hr}$ \\
\end{tabular}} & \multirow{2}{*}{$\begin{array}{c}\text { Heat } \\
\text { Loss } \\
10^{6} \mathrm{Btu} / \mathrm{hr}\end{array}$} & \multirow[b]{2}{*}{$\begin{array}{c}\text { Total } \\
10^{6} \mathrm{Btu} / \mathrm{hr}\end{array}$} & & & \multicolumn{2}{|c|}{ Raw $^{2}$} & \multirow{2}{*}{$\begin{array}{c}\text { Corrected }^{2,} \\
\text { Cold } \\
\%\end{array}$} \\
\hline & & \begin{tabular}{|c|} 
Coal \\
$10^{6} \mathrm{Btu} / \mathrm{hr}$
\end{tabular} & $\begin{array}{c}\text { Air } \\
10^{6} \mathrm{Btu} / \mathrm{hr}\end{array}$ & \begin{tabular}{|c|} 
Steam \\
$10^{6} \mathrm{Btu} / \mathrm{hr}$
\end{tabular} & \begin{tabular}{|c|} 
Total \\
$10^{6} \mathrm{Btu} / \mathrm{hr}$
\end{tabular} & & & & & & & & $\begin{array}{c}\text { Cold } \\
\%\end{array}$ & $\begin{array}{c}\text { Hot } \\
\%\end{array}$ & \\
\hline TC07-1 & 168 & 36.2 & 0.8 & 0.1 & 37.1 & 31.5 & 3.1 & 0.00 & 1.5 & 36.1 & 1.0 & 2.6 & 54.8 & 87.4 & 67.7 \\
\hline \begin{tabular}{|l|} 
TC07-2 \\
\end{tabular} & 173 & 36.0 & 0.8 & 0.0 & 36.9 & 31.2 & 3.2 & 0.00 & 1.5 & 35.9 & 1.0 & 2.7 & 54.3 & 87.0 & 67.3 \\
\hline \begin{tabular}{|l} 
TC07-3 \\
\end{tabular} & 180 & 35.3 & 0.8 & 0.0 & 36.1 & 30.1 & 3.1 & 0.00 & 1.5 & 34.7 & 1.4 & 4.0 & 54.1 & 86.8 & 67.7 \\
\hline \begin{tabular}{|l|} 
TC07-4 \\
\end{tabular} & 192 & 36.0 & 0.9 & 1.8 & 38.6 & 31.7 & 1.7 & 0.01 & 1.5 & 35.0 & 3.7 & 9.5 & 55.4 & 90.8 & 66.9 \\
\hline \begin{tabular}{|l|} 
TC07-5 \\
\end{tabular} & 199 & 36.1 & 0.9 & 1.6 & 38.6 & 33.1 & 1.0 & 0.03 & 1.5 & 35.6 & 3.0 & 7.8 & 57.2 & 93.0 & 68.5 \\
\hline \begin{tabular}{|l|} 
TC07-6 \\
\end{tabular} & 210 & 35.6 & 0.8 & 1.4 & 37.9 & 32.2 & 2.2 & 0.00 & 1.5 & 36.0 & 1.9 & 5.0 & 56.5 & 89.6 & 67.8 \\
\hline \begin{tabular}{|l} 
TC07-7 \\
\end{tabular} & 215 & 35.6 & 0.8 & 1.5 & 38.0 & 31.7 & 2.4 & 0.00 & 1.5 & 35.6 & 2.4 & 6.3 & 55.3 & 89.0 & 66.6 \\
\hline \begin{tabular}{|l|} 
TC07-8 \\
\end{tabular} & 222 & 36.0 & 0.8 & 2.2 & 39.0 & 32.5 & 1.9 & 0.00 & 1.5 & 35.9 & 3.2 & 8.1 & 54.3 & 90.6 & 65.6 \\
\hline \begin{tabular}{|l|} 
TC07-9a \\
\end{tabular} & 232 & 35.7 & 0.8 & 2.2 & 38.7 & 32.8 & 1.5 & 0.01 & 1.5 & 35.8 & 2.9 & 7.5 & 56.0 & 91.6 & 67.4 \\
\hline TC07-9b & 240 & 37.1 & 0.8 & 2.3 & 40.3 & 34.1 & 1.7 & 0.00 & 1.5 & 37.3 & 3.0 & 7.4 & 56.4 & 91.5 & 67.7 \\
\hline TC07-9c & 249 & 36.4 & 0.8 & 2.2 & 39.5 & 33.4 & 1.7 & 0.00 & 1.5 & 36.7 & 2.8 & 7.1 & 56.1 & 91.2 & 67.3 \\
\hline TC07-10 & 263 & 34.3 & 0.8 & 2.3 & 37.4 & 31.1 & 1.6 & 0.01 & 1.5 & 34.2 & 3.2 & 8.6 & 56.1 & 91.0 & 67.0 \\
\hline \begin{tabular}{|l|} 
TC07-11 \\
\end{tabular} & 268 & 35.6 & 0.8 & 2.3 & 38.7 & 32.6 & 1.5 & 0.00 & 1.5 & 35.6 & 3.1 & 8.0 & 56.8 & 91.6 & 67.6 \\
\hline TC07-12 & 282 & 35.2 & 0.8 & 2.3 & 38.4 & 32.1 & 1.5 & 0.00 & 1.5 & 35.1 & 3.2 & 8.4 & 56.0 & 91.5 & 67.2 \\
\hline \begin{tabular}{|l|} 
TC07-13 \\
\end{tabular} & 294 & 35.4 & 0.8 & 1.3 & 37.5 & 32.0 & 1.7 & 0.00 & 1.5 & 35.2 & 2.3 & 6.2 & 57.7 & 90.9 & 68.9 \\
\hline TC07-14 & 310 & 34.7 & 0.8 & 1.1 & 36.6 & 31.3 & 1.4 & 0.00 & 1.5 & 34.2 & 2.4 & 6.7 & 57.9 & 91.4 & 69.9 \\
\hline TC07-15 & 321 & 35.9 & 0.8 & 1.0 & 37.7 & 32.5 & 1.5 & 0.00 & 1.5 & 35.6 & 2.2 & 5.8 & 58.6 & 91.5 & 69.8 \\
\hline \begin{tabular}{|l|} 
TC07-16 \\
\end{tabular} & 334 & 35.3 & 0.8 & 1.1 & 37.3 & 32.5 & 1.2 & 0.00 & 1.5 & 35.2 & 2.2 & 5.8 & 59.1 & 92.4 & 70.8 \\
\hline \begin{tabular}{|l|} 
TC07-17 \\
\end{tabular} & 341 & 34.8 & 0.8 & 0.2 & 35.8 & 31.9 & 1.2 & 0.00 & 1.5 & 34.6 & 1.2 & 3.4 & 59.3 & 92.1 & 71.3 \\
\hline TC07-18 & 346 & 35.2 & 0.8 & 0.2 & 36.2 & 32.2 & 1.3 & 0.01 & 1.5 & 35.0 & 1.3 & 3.5 & 58.9 & 92.1 & 70.8 \\
\hline \begin{tabular}{|l|} 
TC07-19 \\
\end{tabular} & 354 & 36.7 & 0.8 & 0.2 & 37.7 & 33.9 & 1.1 & 0.00 & 1.5 & 36.5 & 1.2 & 3.2 & 60.5 & 92.9 & 72.3 \\
\hline \begin{tabular}{|l|} 
TC07-20 \\
\end{tabular} & 365 & 37.4 & 0.8 & 0.2 & 38.5 & 34.8 & 0.6 & 0.02 & 1.5 & 36.9 & 1.6 & 4.1 & 61.7 & 94.2 & 73.3 \\
\hline TC07-21 & 378 & 36.7 & 0.8 & 0.2 & 37.8 & 33.2 & 1.1 & 0.00 & 1.5 & 35.8 & 2.0 & 5.4 & 60.9 & 92.7 & 72.3 \\
\hline TC07-22 & 394 & 37.3 & 0.8 & 0.0 & 38.1 & 33.7 & 1.8 & 0.00 & 1.5 & 36.9 & 1.2 & 3.2 & 60.2 & 91.2 & 70.9 \\
\hline TC07-23 & 403 & 32.8 & 0.7 & 0.0 & 33.6 & 29.8 & 1.5 & 0.00 & 1.5 & 32.7 & 0.8 & 2.5 & 59.5 & 91.0 & 71.9 \\
\hline \begin{tabular}{|l|} 
TC07-24 \\
\end{tabular} & 411 & 35.0 & 0.7 & 0.0 & 35.7 & 31.0 & 2.2 & 0.00 & 1.5 & 34.7 & 1.0 & 2.9 & 58.3 & 89.3 & 69.7 \\
\hline TC07-25 & 421 & 32.4 & 0.7 & 0.0 & 33.1 & 28.3 & 2.1 & 0.00 & 1.5 & 31.9 & 1.2 & 3.6 & 58.7 & 88.8 & 71.0 \\
\hline TC07-26 & 431 & 36.3 & 0.8 & 0.0 & 37.1 & 31.6 & 2.9 & 0.00 & 1.5 & 36.0 & 1.1 & 3.1 & 56.7 & 87.8 & 67.6 \\
\hline \begin{tabular}{|l|} 
TC07-27 \\
\end{tabular} & 434 & 36.0 & 0.7 & 0.0 & 36.8 & 30.6 & 3.3 & 0.00 & 1.5 & 35.5 & 1.3 & 3.5 & 56.3 & 86.4 & 67.1 \\
\hline \begin{tabular}{|l|} 
TC07-28 \\
\end{tabular} & 439 & 34.7 & 0.7 & 0.0 & 35.4 & 29.1 & 3.6 & 0.00 & 1.5 & 34.2 & 1.2 & 3.3 & 55.9 & 85.0 & 66.4 \\
\hline \begin{tabular}{|l|} 
TC07-29 \\
\end{tabular} & 446 & 38.8 & 0.8 & 0.0 & 39.6 & 33.1 & 3.1 & 0.00 & 1.5 & 37.7 & 1.9 & 4.8 & 57.9 & 87.9 & 68.3 \\
\hline
\end{tabular}

1. Nitrogen and sorbent assumed to enter the system at ambient temperature and therefore have zero enthalpy.

2. Using coal inlet heat determined from energy balance.

3. Reference conditions are $80^{\circ} \mathrm{F}$ and $14.7 \mathrm{psia}$.

4. Correction is to assume that only air nitrogen is in the synthesis gas and that the reactor is adiabatic. 


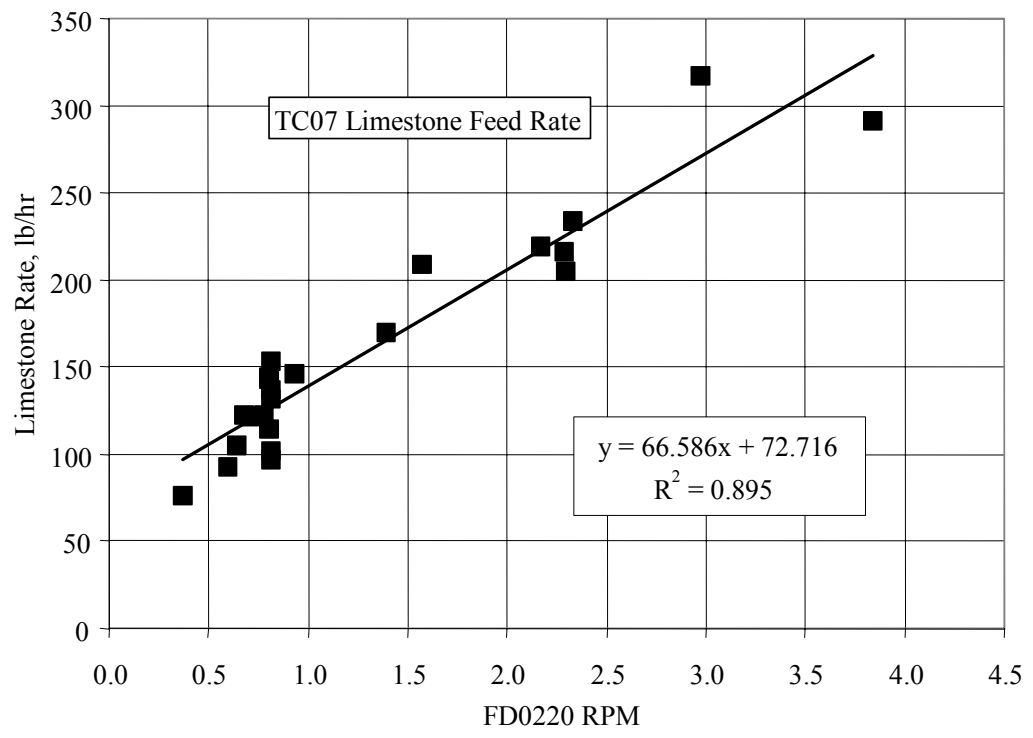

Figure 4.5-1 Sorbent Feeder Correlation

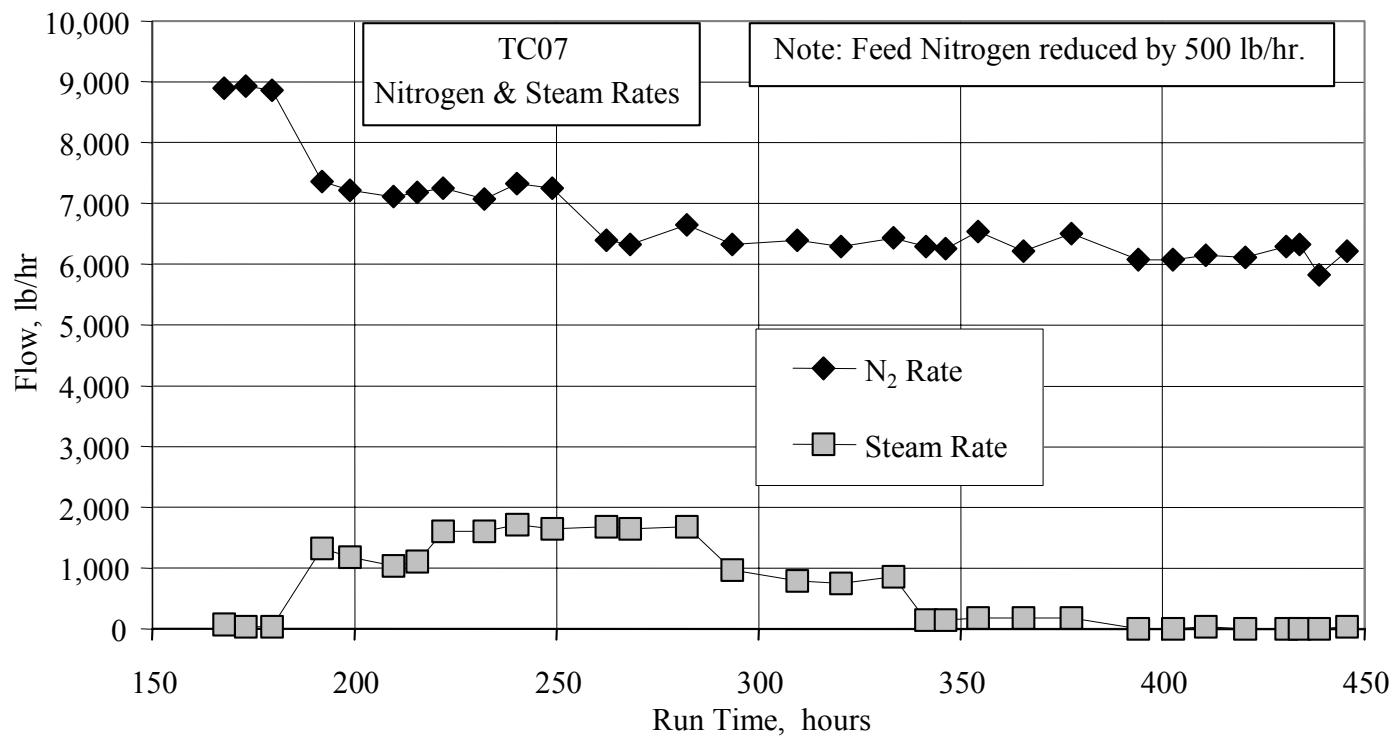

Figure 4.5-2 Nitrogen and Steam Rates 


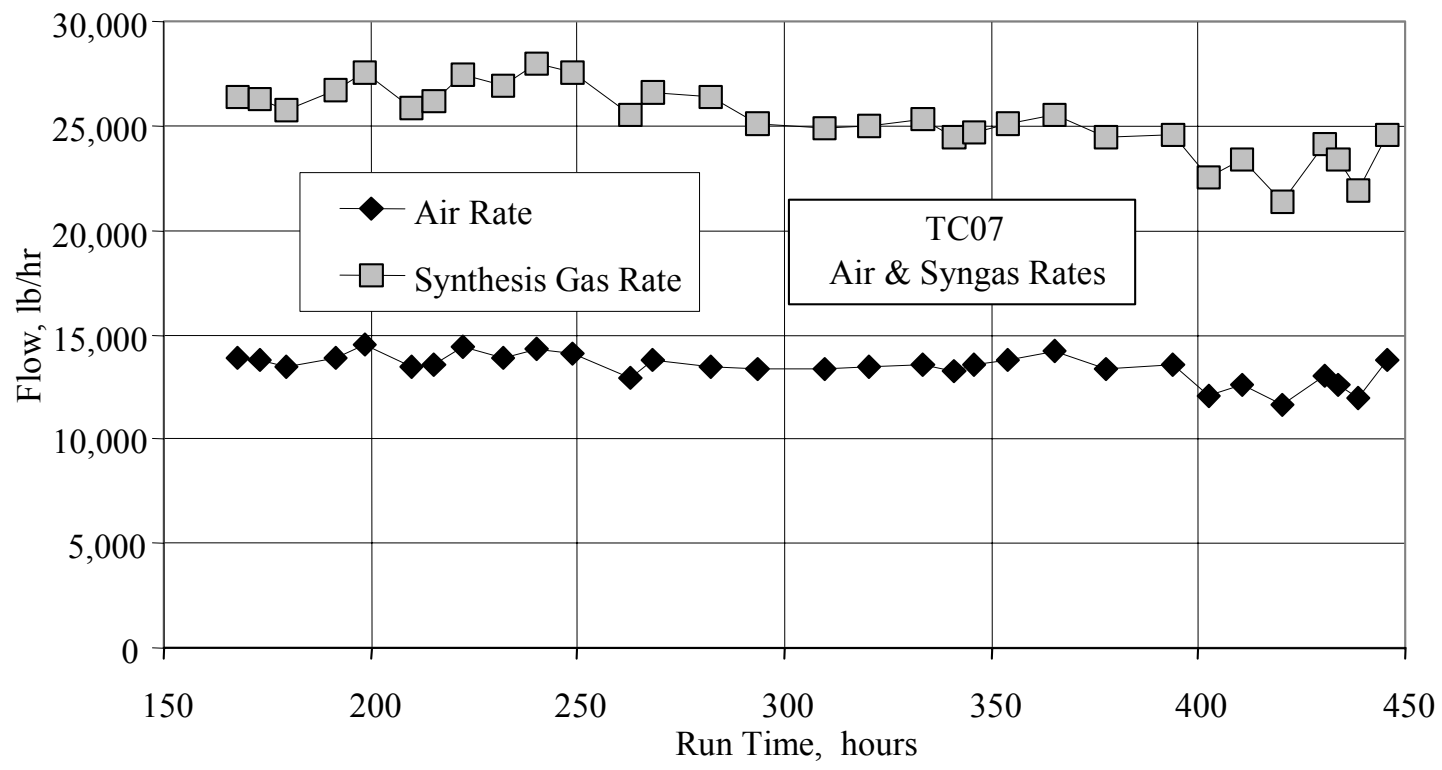

Figure 4.5-3 Air and Synthesis Gas Rates

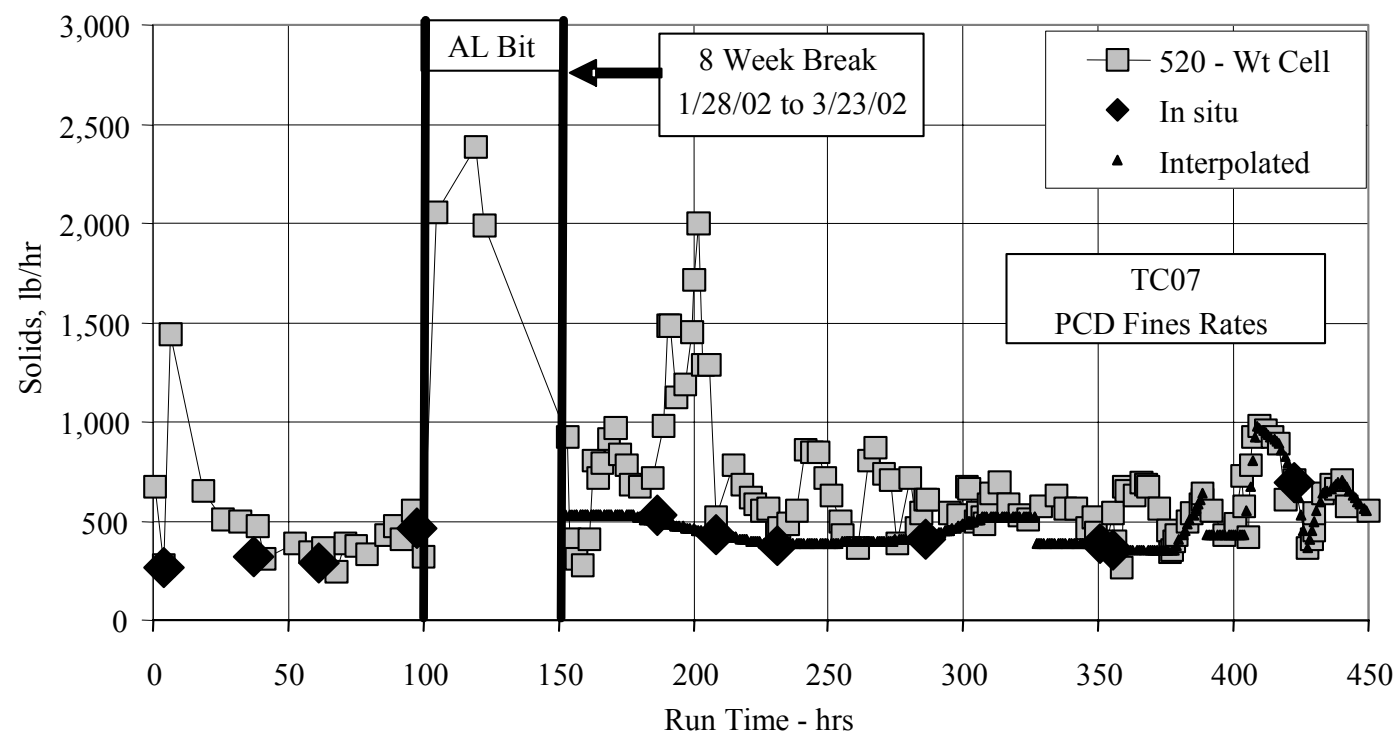

Figure 4.5-4 PCD Fines Rate 


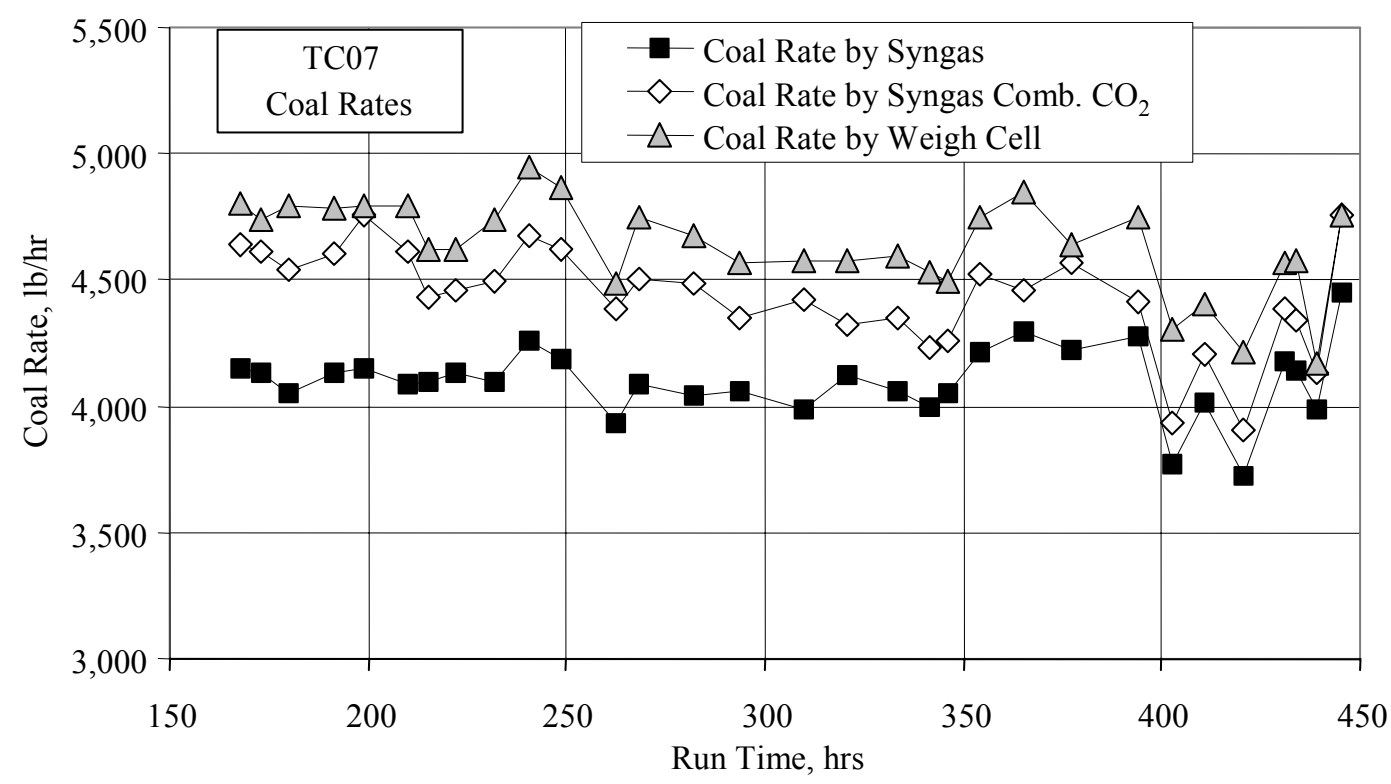

Figure 4.5-5 Coal Rates

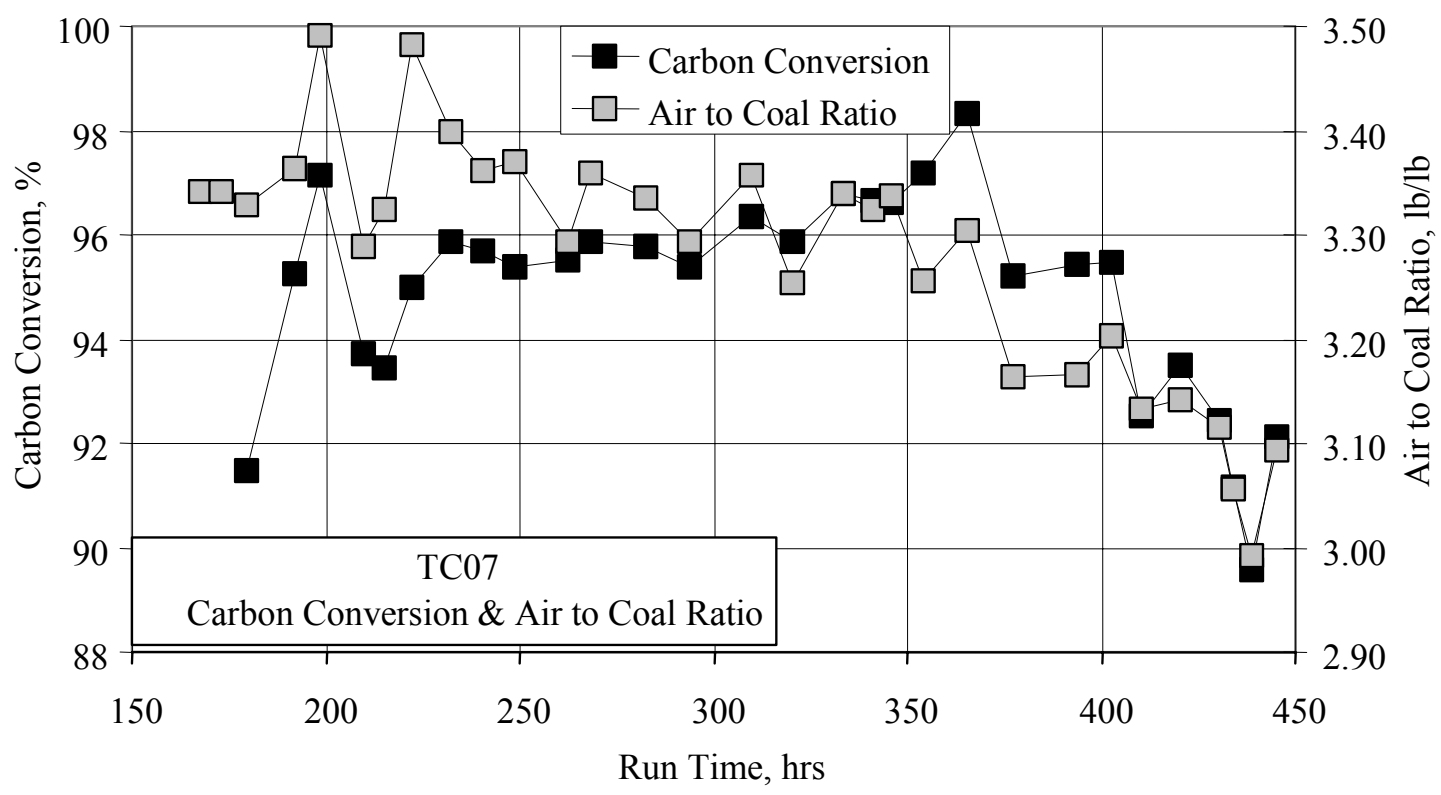

Figure 4.5-6 Carbon Conversion and Air-to-Coal Ratio 


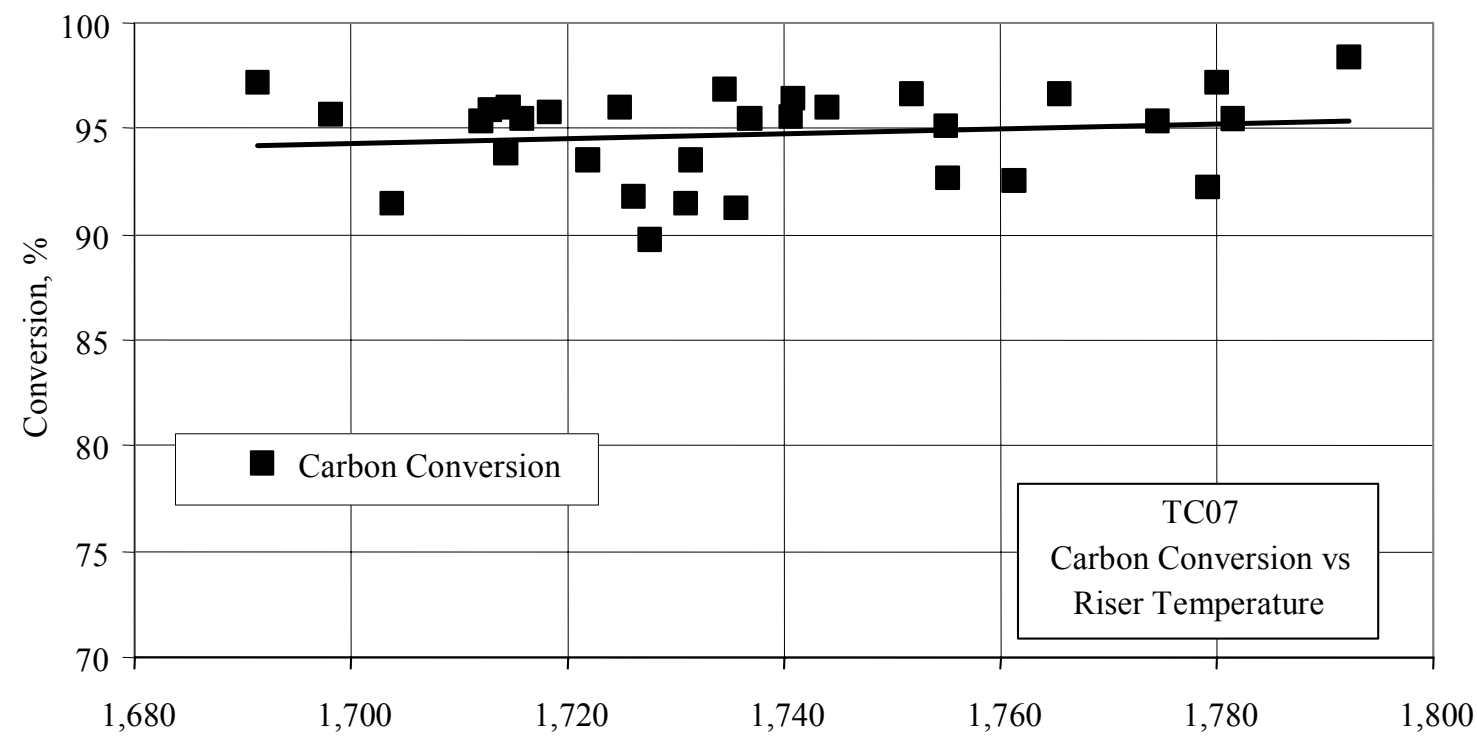

Riser Temperature, $\mathrm{F}$

Figure 4.5-7 Carbon Conversion vs Riser Temperature

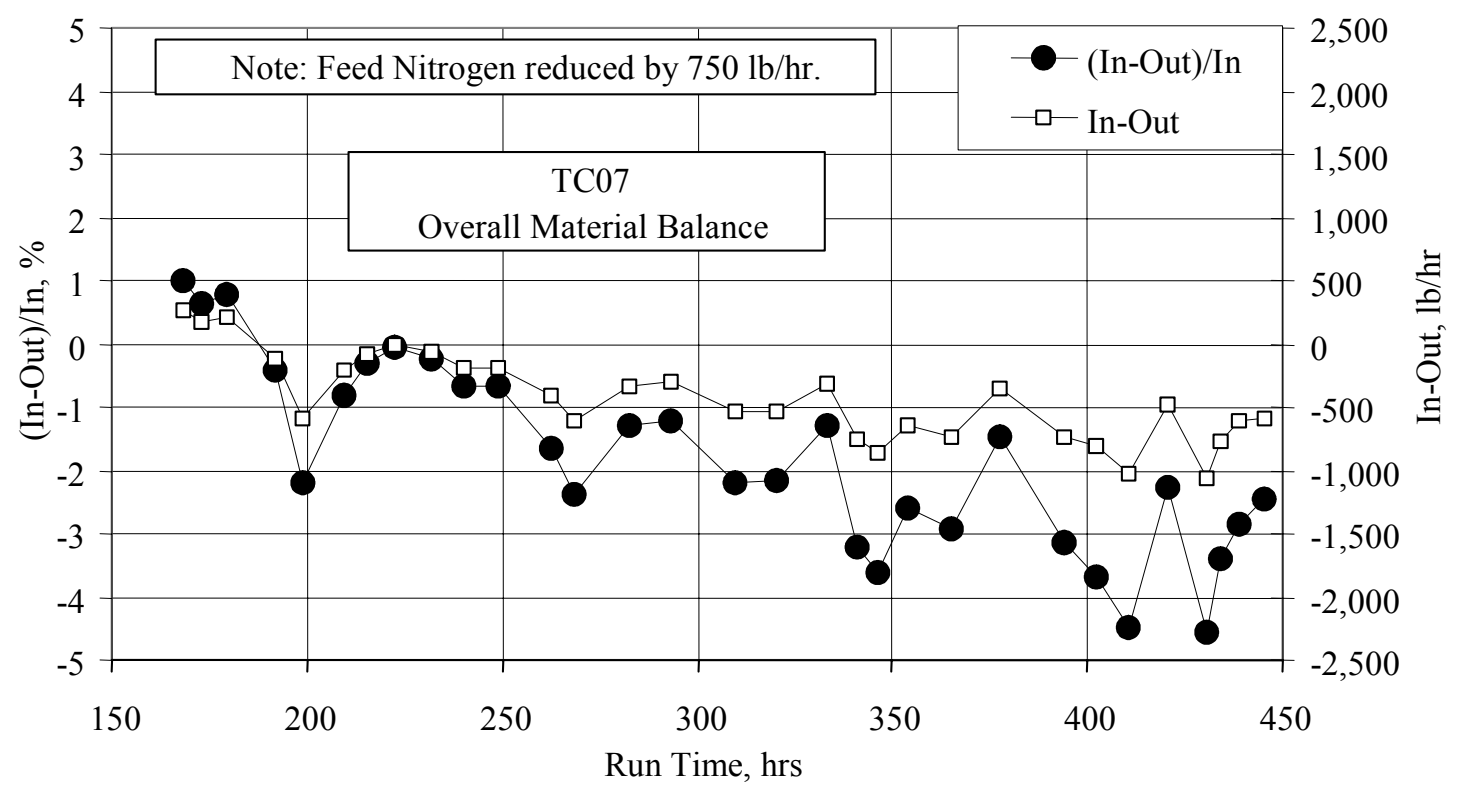

Figure 4.5-8 Overall Material Balance 


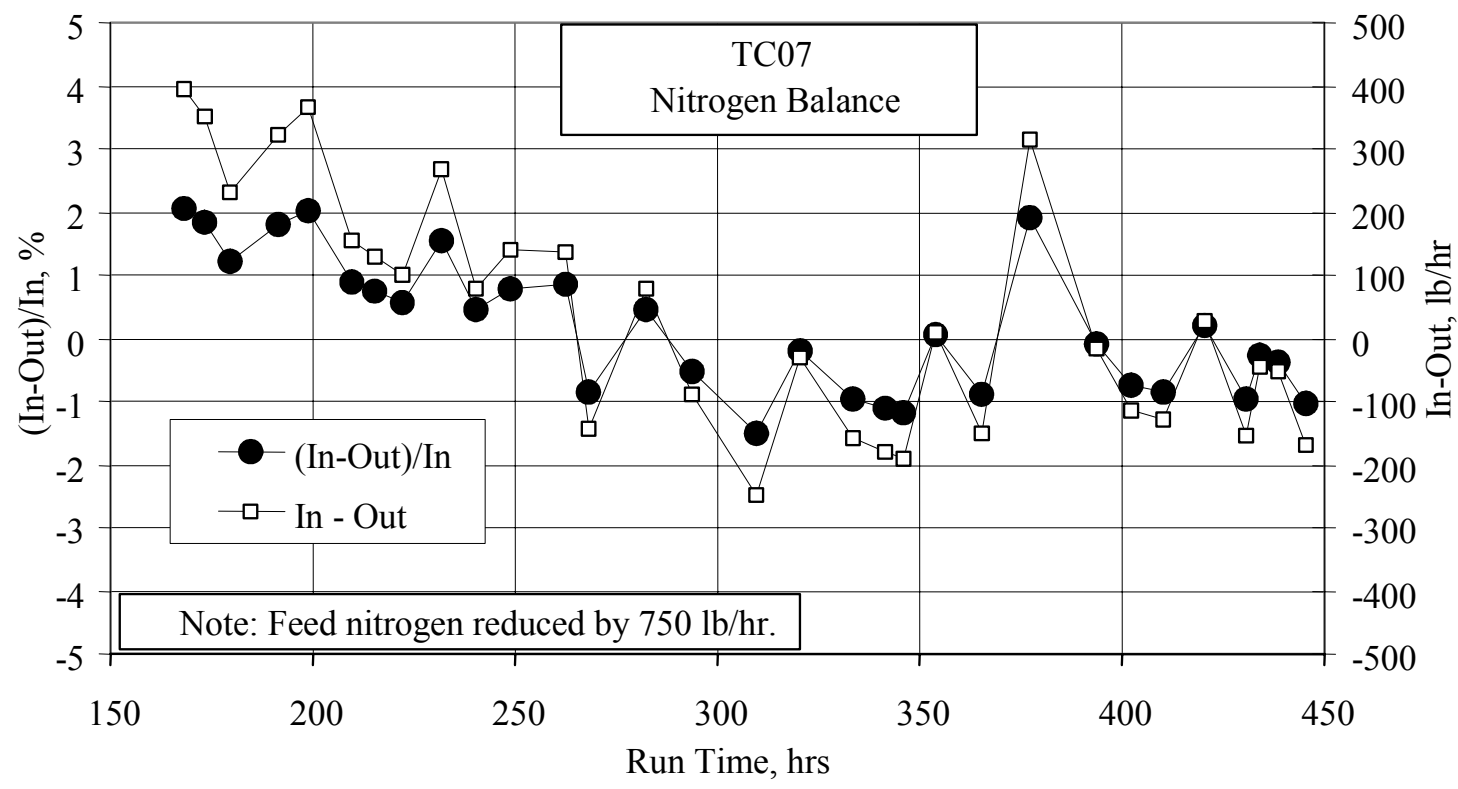

Figure 4.5-9 Nitrogen Balance

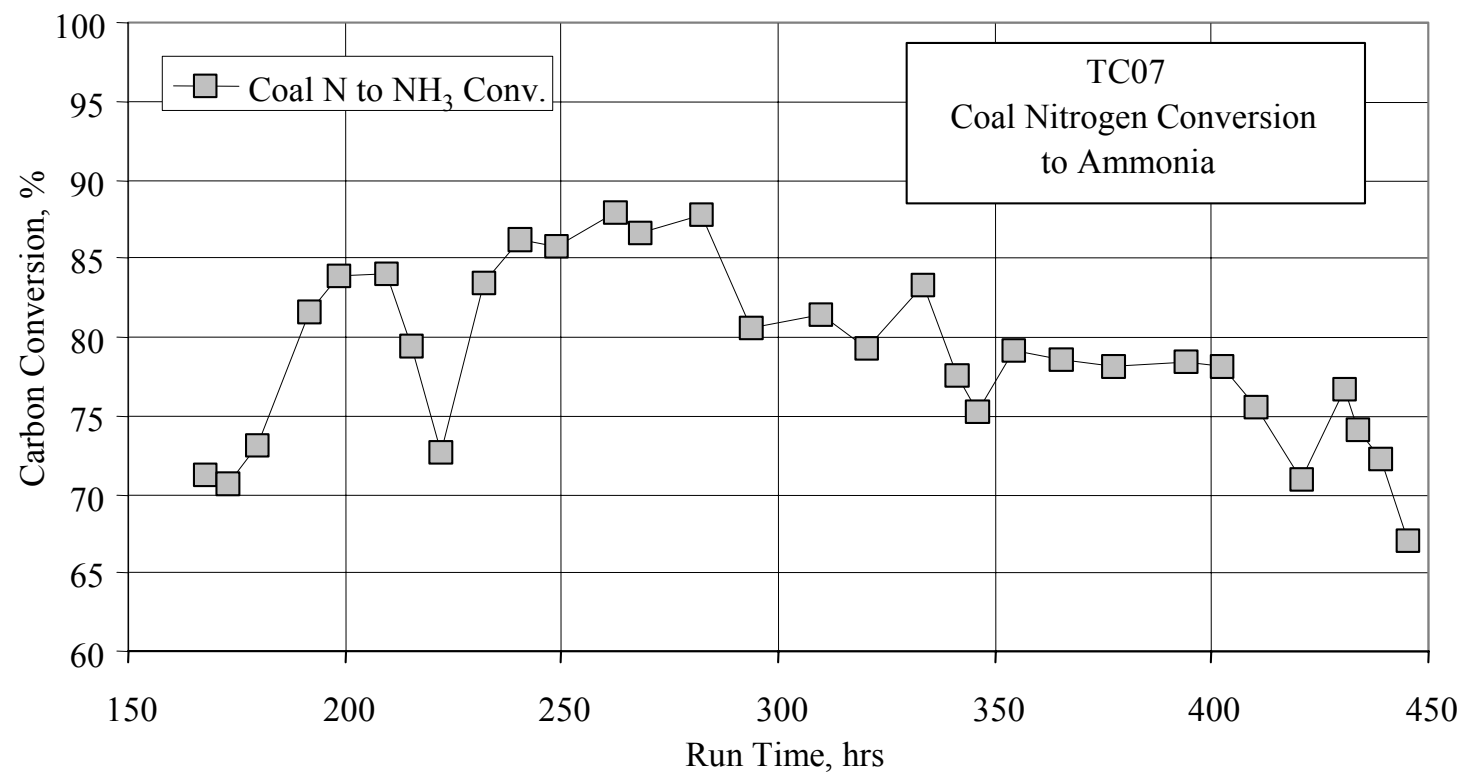

Figure 4.5-10 Coal Nitrogen Conversion to $\mathrm{NH}_{3}$ 


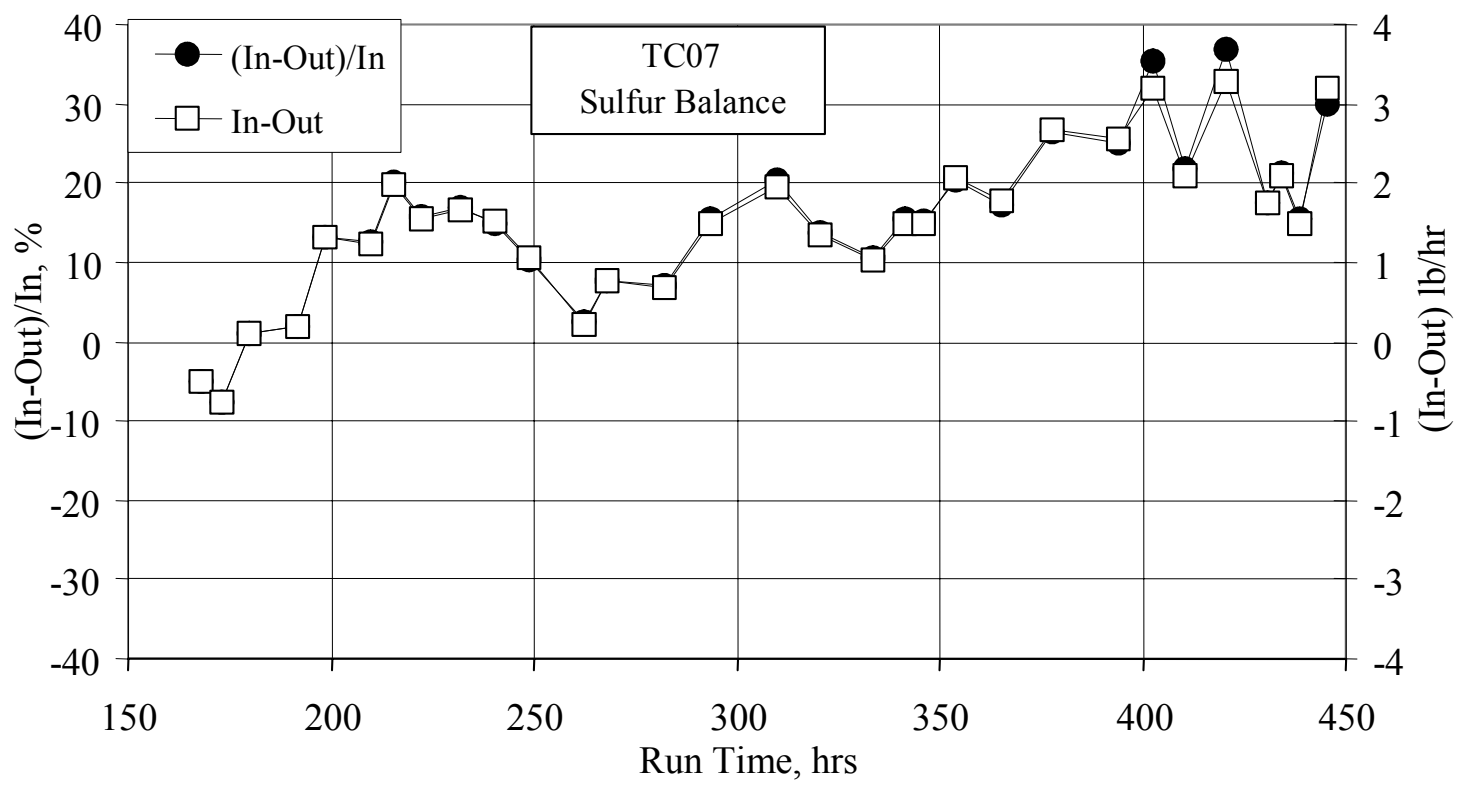

Figure 4.5-11 Sulfur Balance

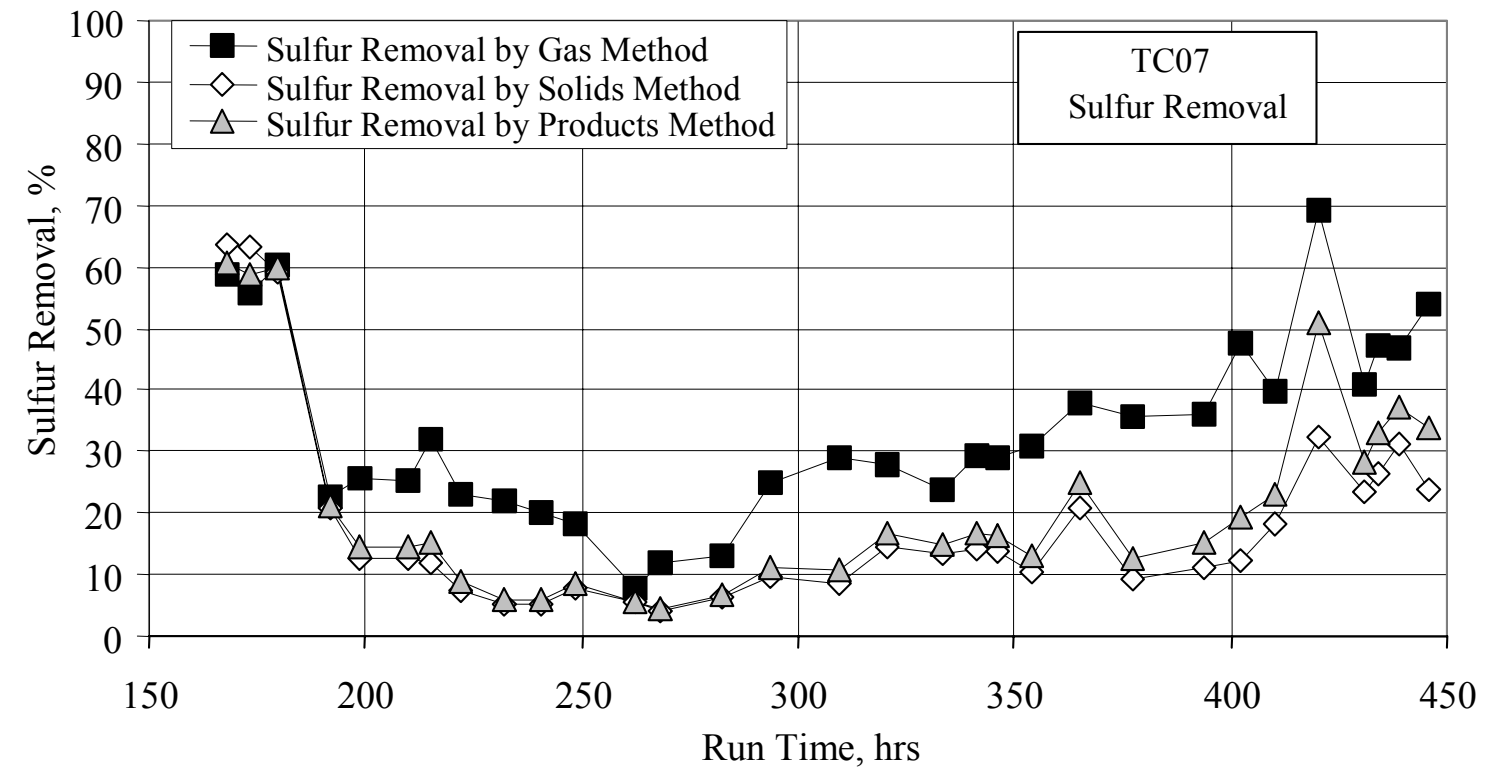

Figure 4.5-12 Sulfur Removal 


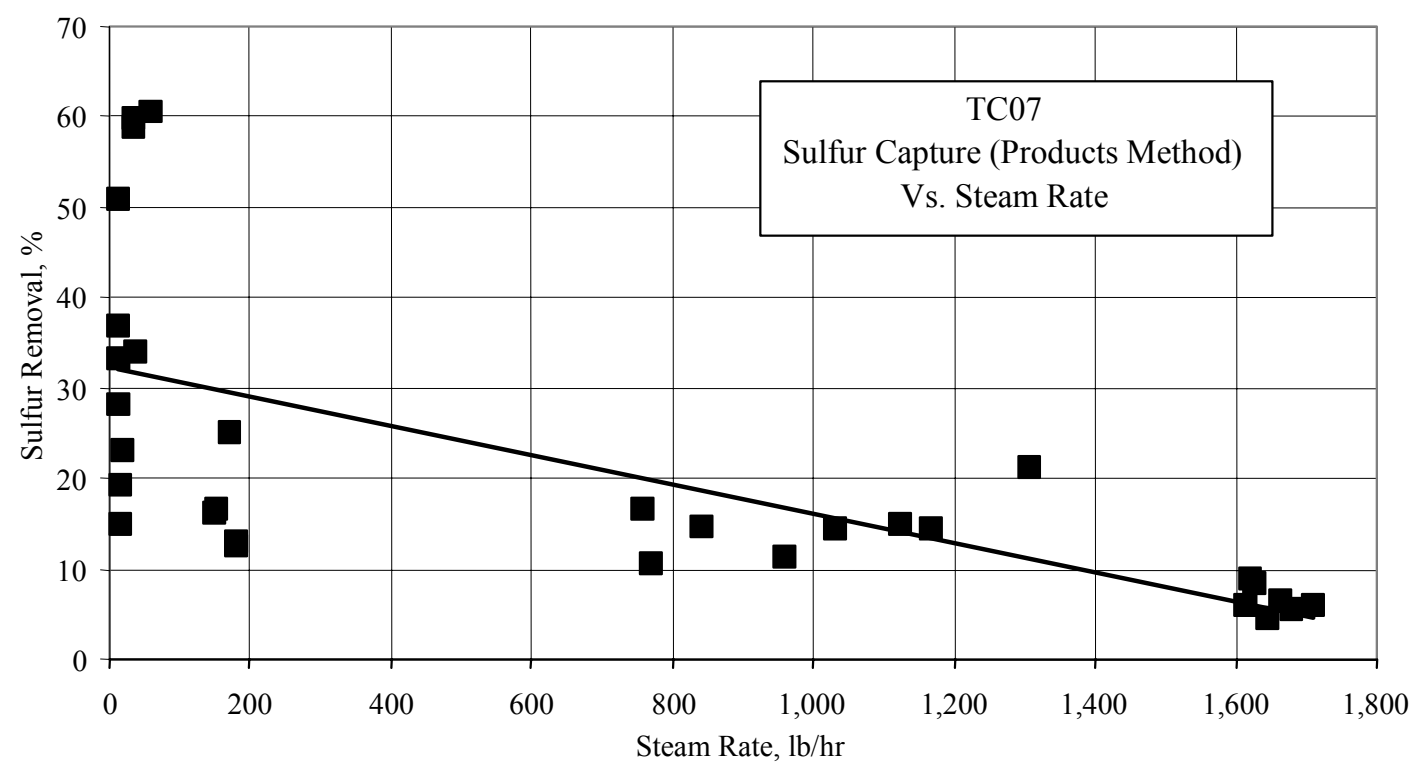

Figure 4.5-13 Sulfur Removal vs Steam Rate

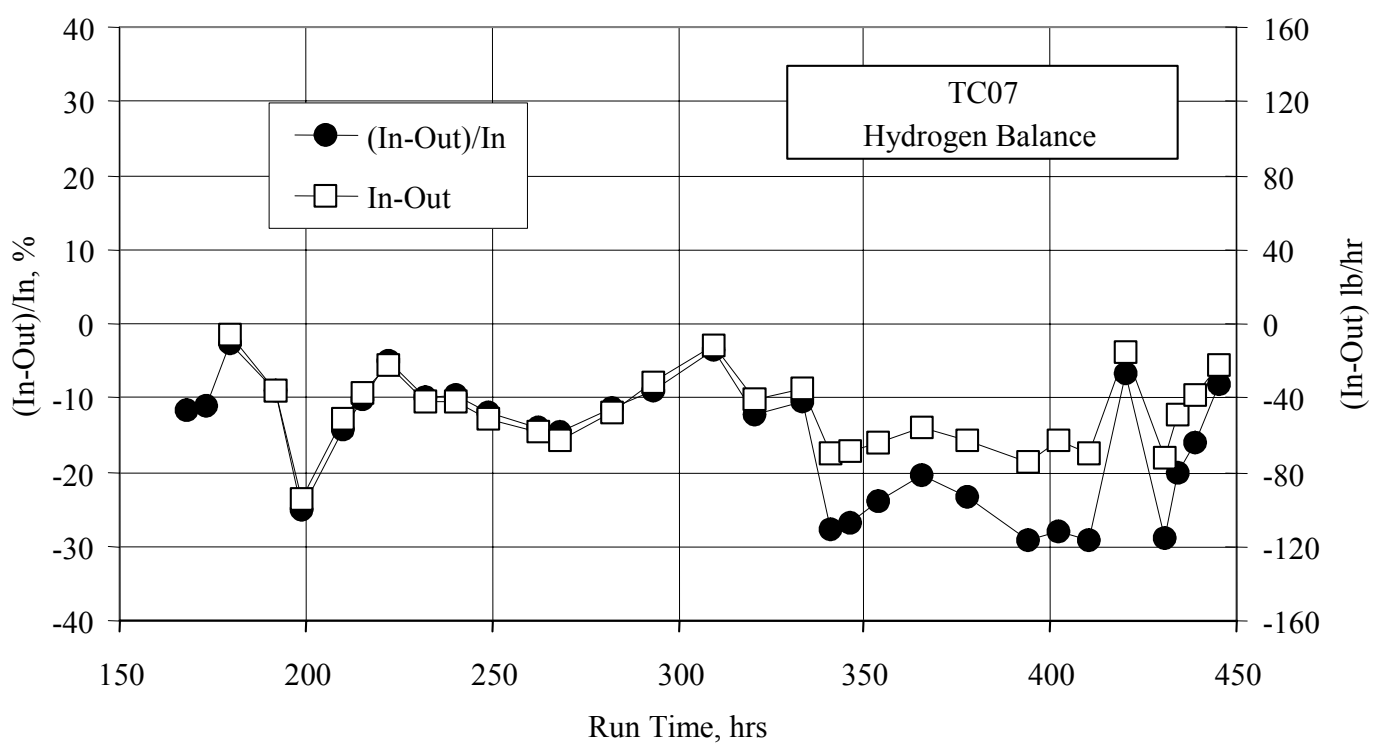

Figure 4.5-14 Hydrogen Balance 


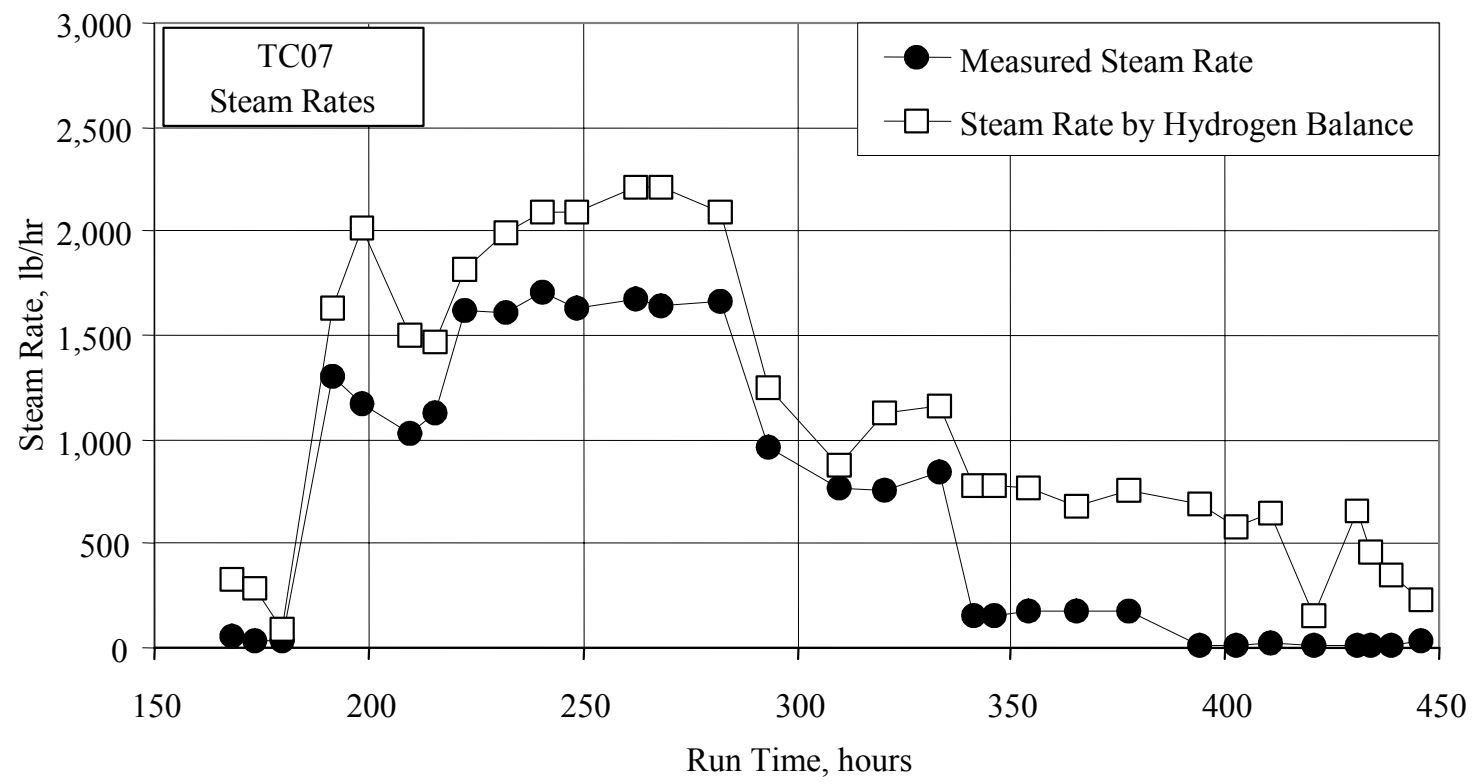

Figure 4.5-15 Steam Rates

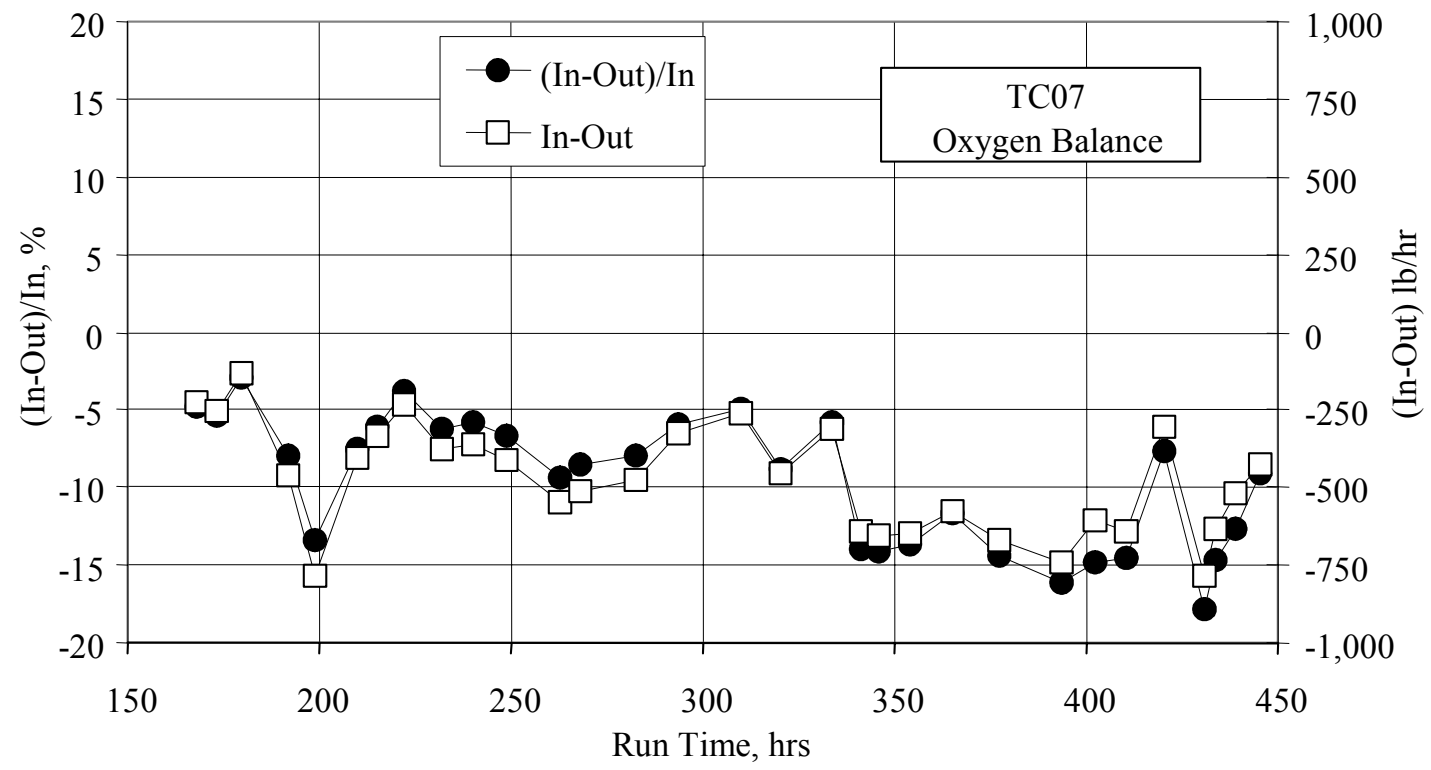

Figure 4.5-16 Oxygen Balance 


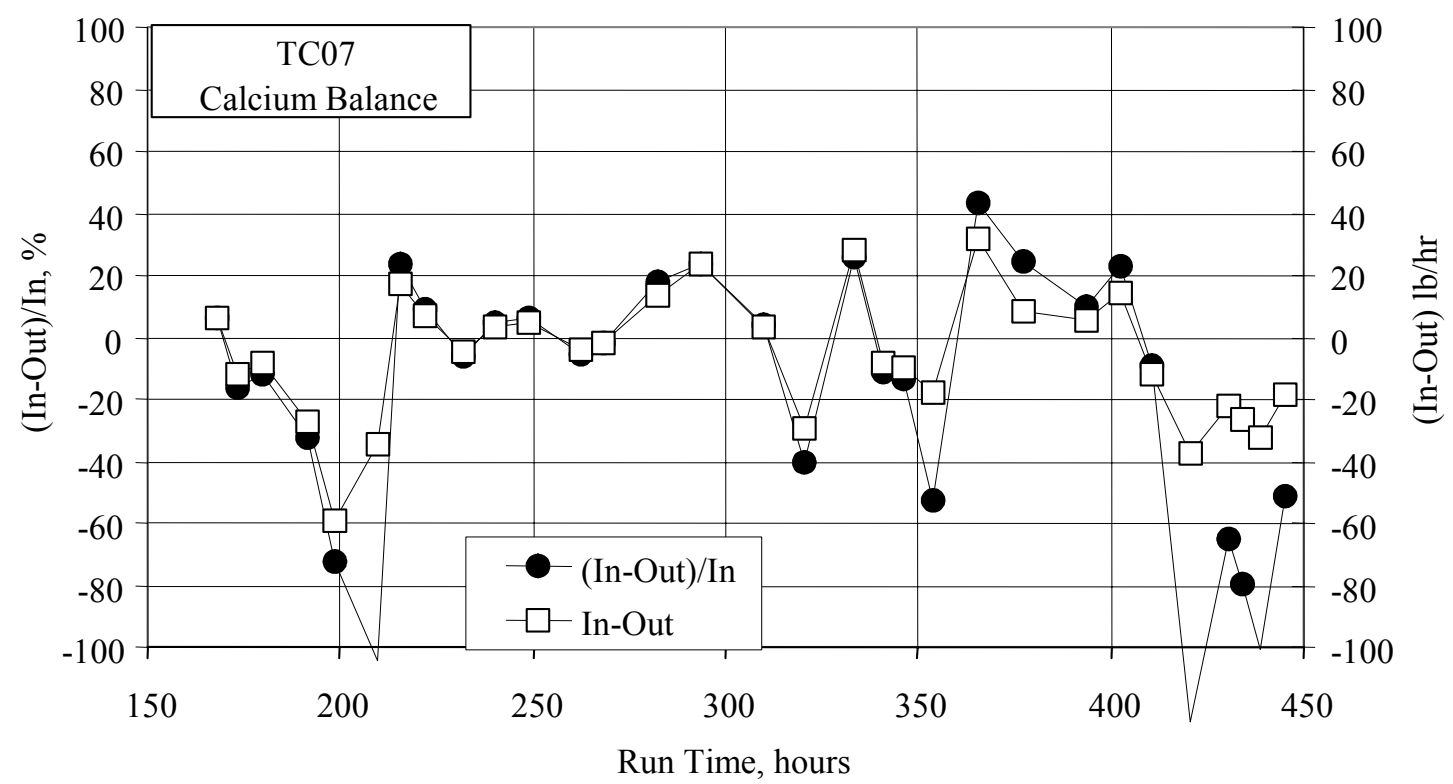

Figure 4.5-17 Calcium Balance

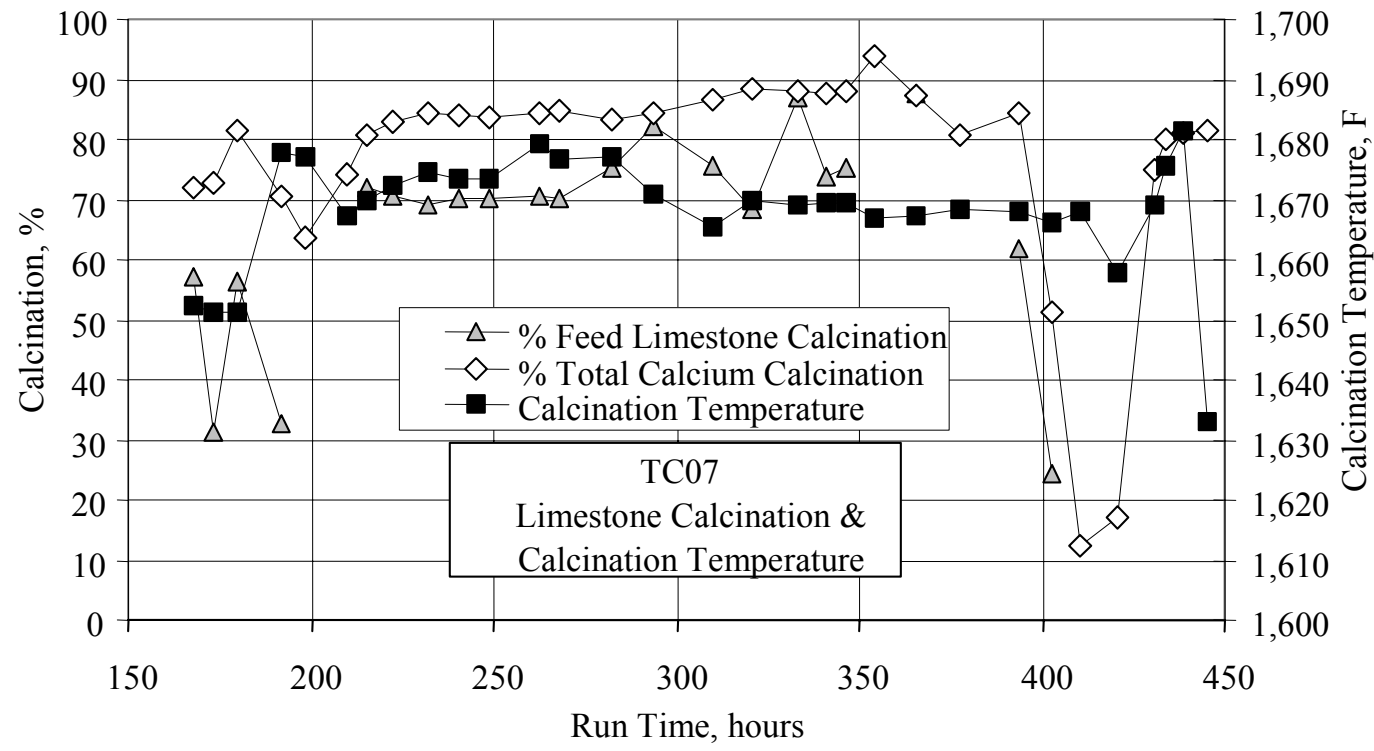

Figure 4.5-18 Calcination and Calcination Temperature 


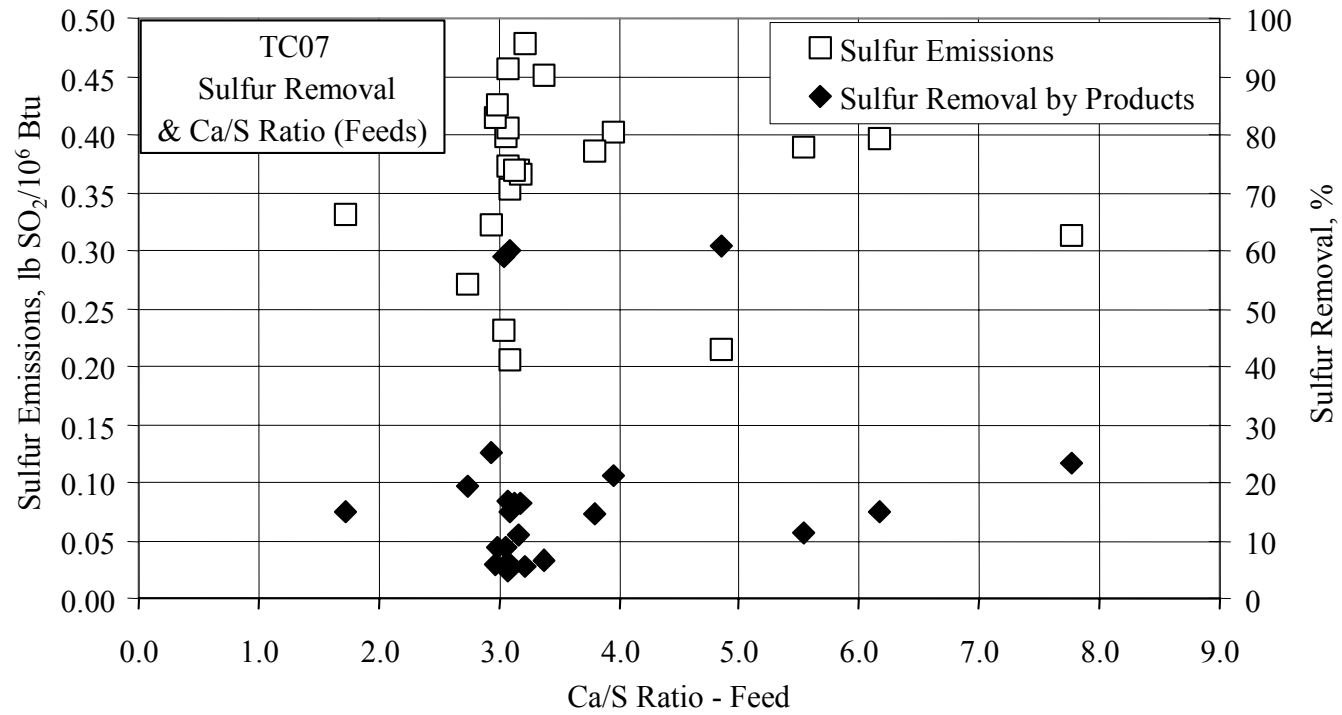

Figure 4.5-19 Sulfur Emissions and Feeds Ca/S Ratio

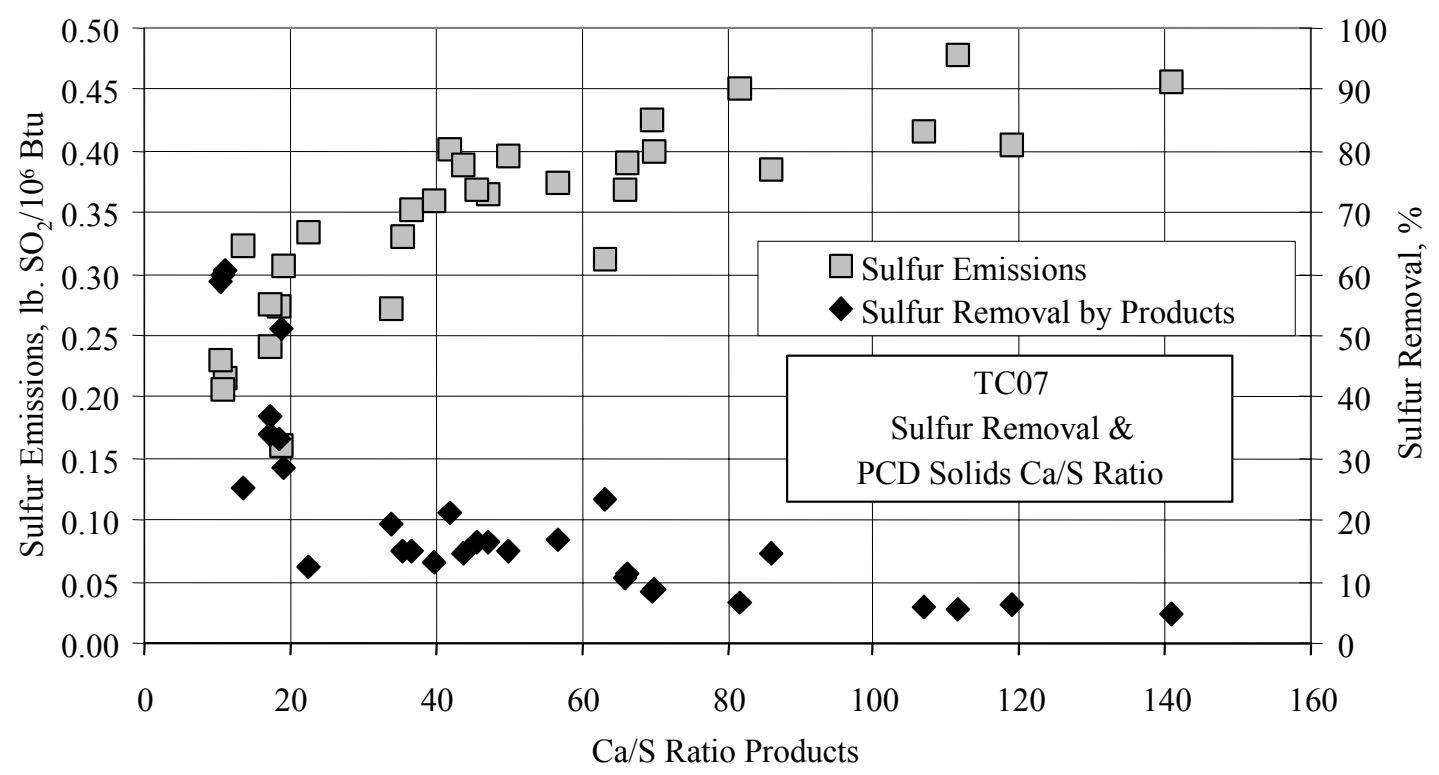

Figure 4.5-20 Sulfur Emissions and PCD Solids Ca/S Ratio 


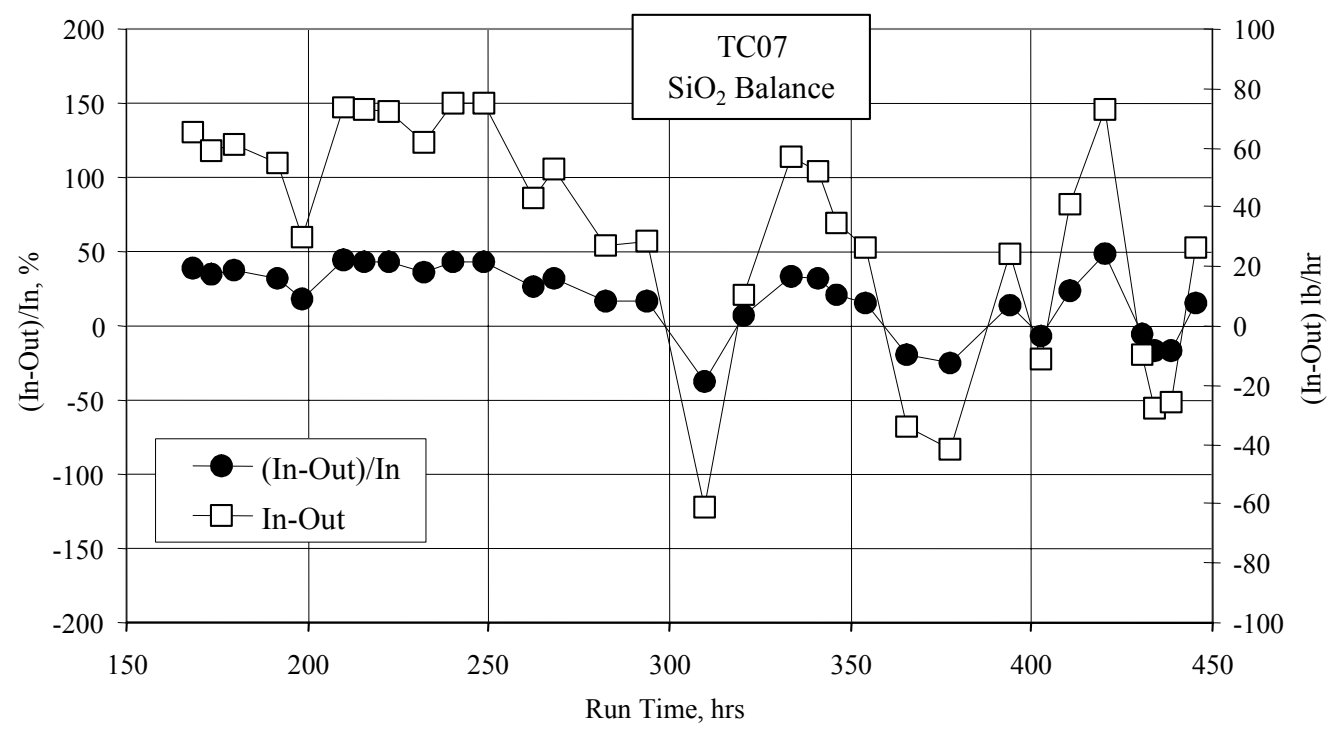

Figure 4.5-21 $\mathrm{SiO}_{2}$ Balance

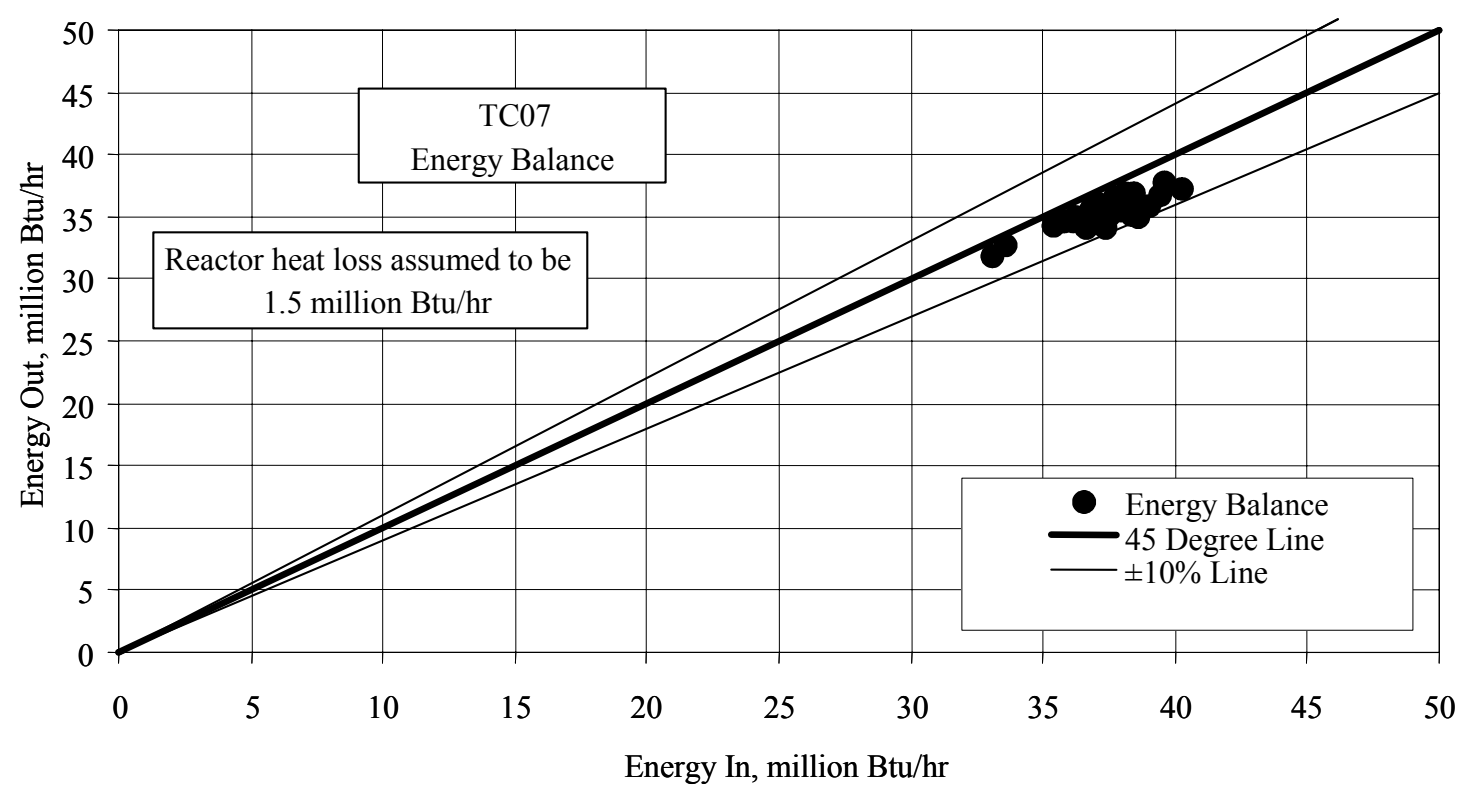

Figure 4.5-22 Energy Balance 


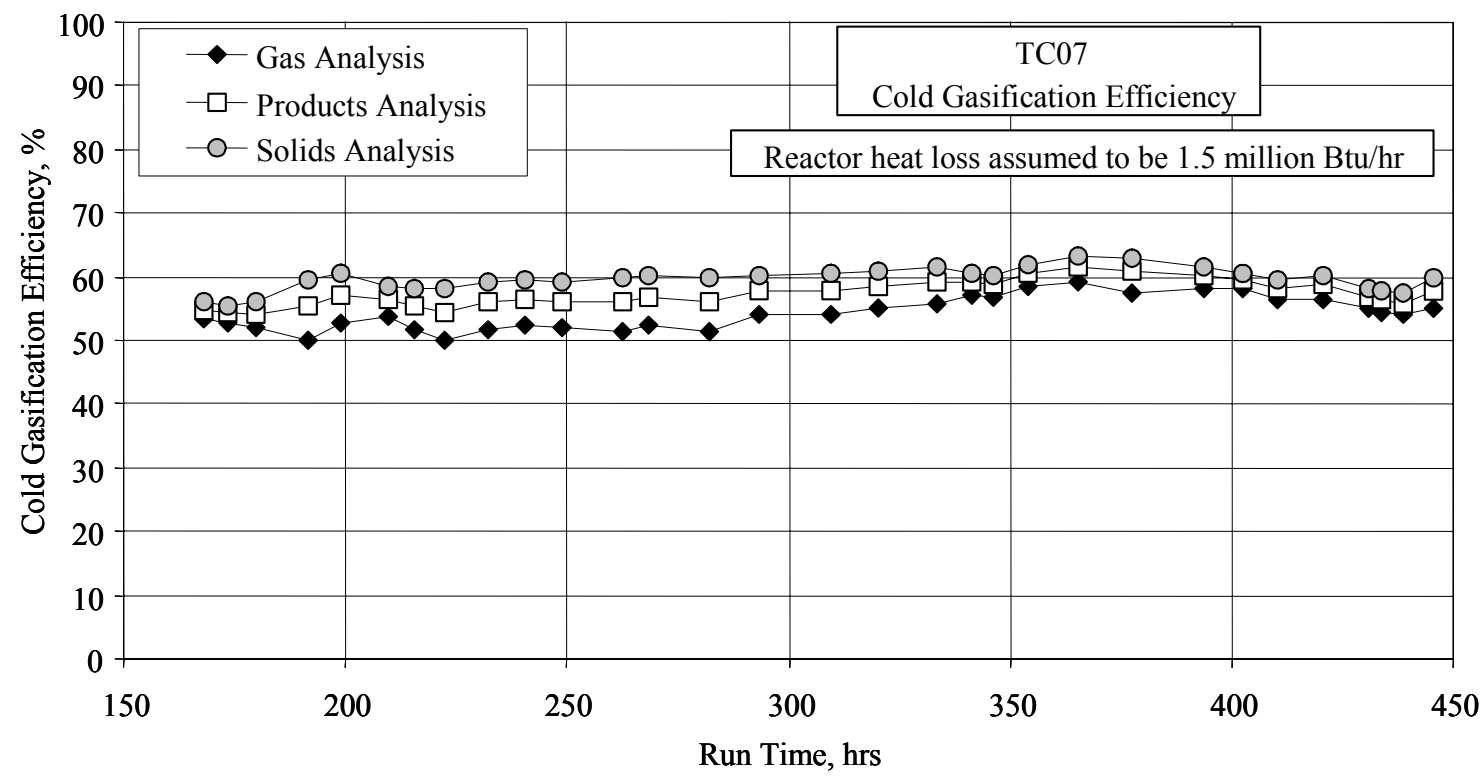

Figure 4.5-23 Cold Gasification Efficiency

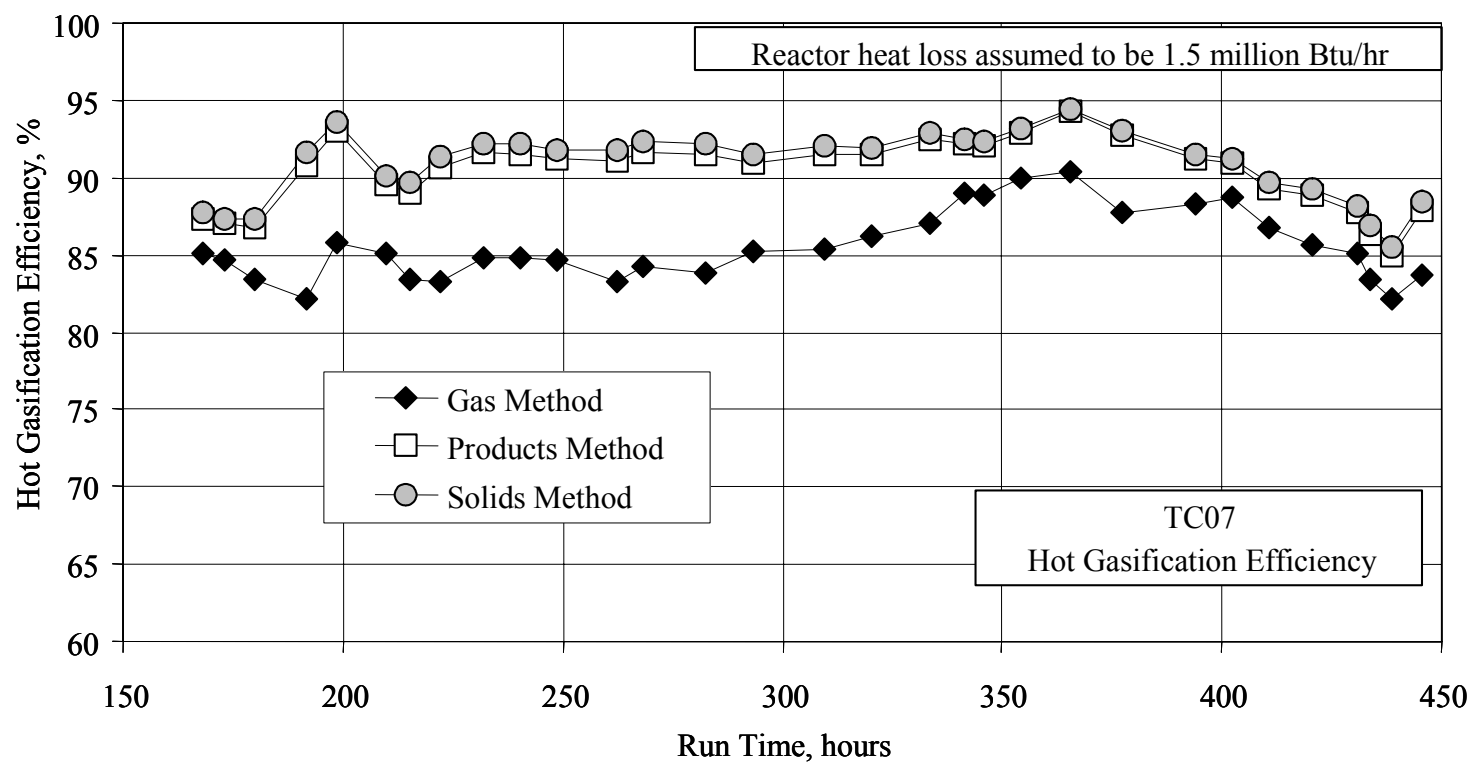

Figure 4.5-24 Hot Gasification Efficiency 


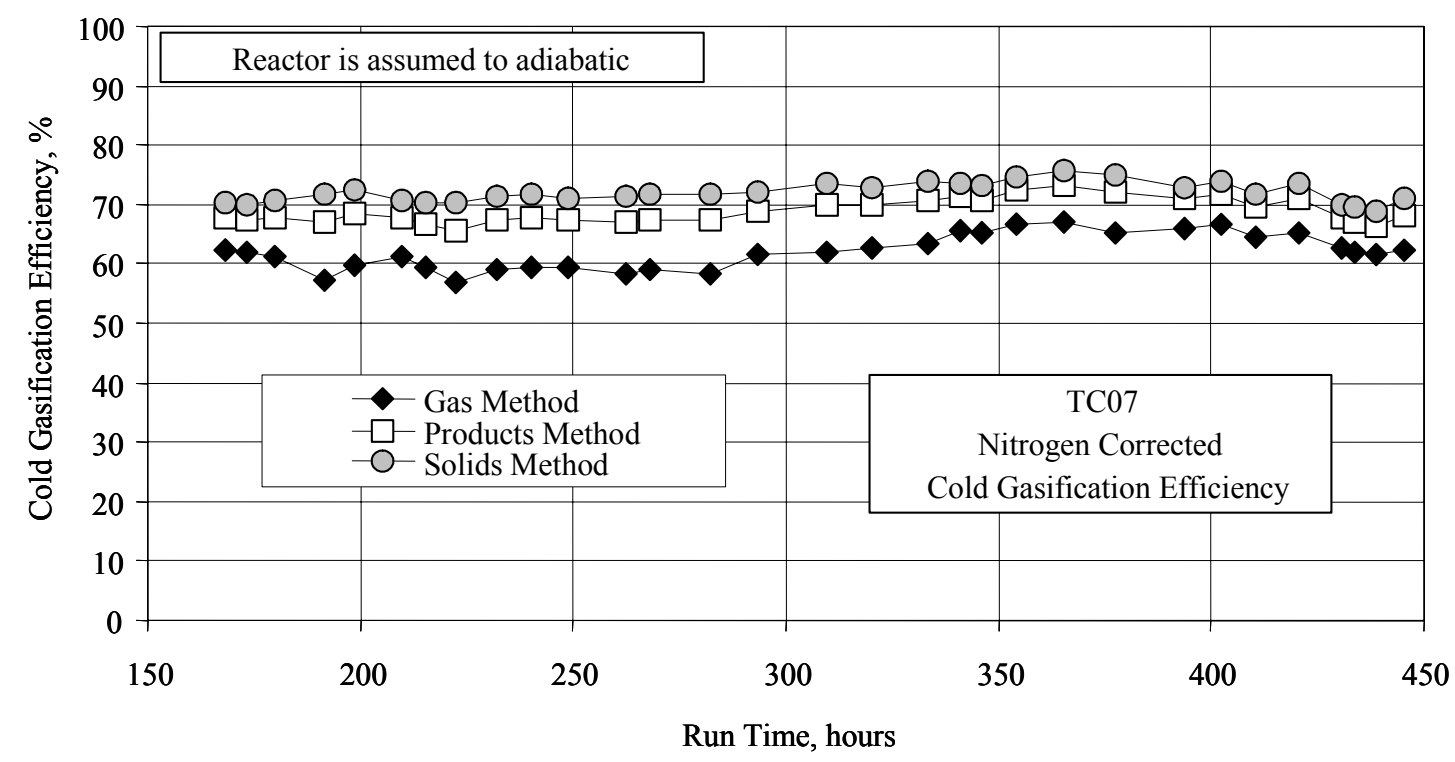

Figure 4.5-25 Nitrogen Corrected Cold Gasification Efficiency 


\subsection{IRON OXIDE INJECTION FOR $\mathrm{H}_{2} \mathrm{~S}$ CONTROL}

\section{$\underline{4.6 .1 \quad \text { Introduction }}$}

A series of iron oxide injection tests were performed to evaluate the effectiveness of the selected iron-based sorbents for removing hydrogen sulfide $\left(\mathrm{H}_{2} \mathrm{~S}\right)$ from the syngas. Seven materials were obtained from the U.S. Steel Corporation in Birmingham, Alabama. These materials are waste by-products from various processes for steel manufacturing. Each sorbent is chemically and physically different and is generated from different processes. Table 4.6-1 lists some of the chemical and physical characteristics of the materials obtained.

The use of iron oxide for removing $\mathrm{H}_{2} \mathrm{~S}$ from industrial gases, especially in the steel industry, has been practiced for several decades. Although these clean-up processes were not without their challenges, greater than 95-percent removal capabilities were realized at the same temperature $\left(750^{\circ} \mathrm{F}\right)$ used in this investigation. ${ }^{1}$

The tests conducted during this investigation were conducted by pneumatically injecting iron oxide into the particle-laden syngas upstream of the particulate collection device (PCD) at roughly 740 to $780^{\circ} \mathrm{F}$, the normal operating temperature of the PCD. The purpose of the tests was to determine if, for the sorbents of interest, the system arrangement provided sufficient time, temperature, and mixing for effective $\mathrm{H}_{2} \mathrm{~S}$ abatement.

A fluidized batch feeder (FD230) was designed, constructed, and installed for this testing. This feeder is capable of holding roughly 7 to 8 cubic feet of material that can be fed at variable rates; however, for these tests, material was fed at roughly 500 to $1,000 \mathrm{lb} / \mathrm{hr}$. The feeder utilizes a metal sintered plate at the bottom of the feeder in which air is directed up through the plate and the material is then removed from the vessel via a small-bore pipe to the process piping upstream of the PCD.

The reaction mechanisms for this system have been investigated by researchers such as Tamhankar and coworkers ${ }^{2}$, Silmane and Abbasian ${ }^{3}$, Oldaker and Gilmore, and others. However, it is unclear as to what the dominant reactions and mechanisms are when these materials are injected into a wet, particle-laden stream with (relatively) short residence times at (relatively) low temperatures.

Based on the findings reported in the literature, the iron is first reduced to either Fe and/or $\mathrm{FeO}$, then these species can react with $\mathrm{H}_{2} \mathrm{~S}$ to form $\mathrm{FeS}_{\mathrm{X}}$, where $\mathrm{x}$ generally ranges between 1 and 1.5. It is believed that these reactions are also applicable to the system configuration used in this investigation, although the extent of reduction (i.e., whether $\mathrm{Fe}$ or $\mathrm{FeO}$ is the dominant reactant) experienced in this study is not known. Rather, the focus of this investigation is the suitability of iron-based sorbents in a transport-reactor configuration, not reaction mechanisms. Therefore, both sets of reactions, partial and complete reduction, will be considered and discussed.

Although the iron-based sorbents used in this investigation did not perform as well as expected-apparently because of the lack of formation of reactive iron oxide sites in 
addition to nonconducive physical properties for sulfidation — iron oxides have favorable thermodynamic properties, favorable kinetics, and a history of success (see reference 1).

Iron, with an atomic number of 26 is located between $\mathrm{Ca}$ (atomic number of 20) and $\mathrm{Zn}$ (atomic number of 30) on the Periodic Table of Elements. Ca-based sorbents have shown great performance in the Transport Reactor-reducing $\mathrm{H}_{2} \mathrm{~S}$ concentrations to, or near, equilibrium values at Transport Reactor temperatures. Zinc-based sorbents, touted as polishing sorbents, are reported in the literature for being highly effective for removing $\mathrm{H}_{2} \mathrm{~S}$, able to reduce $\mathrm{H}_{2} \mathrm{~S}$ levels to below $10 \mathrm{ppmv}^{5}$. Hence, combining all of these factorsfavorable thermodynamics, (relatively) fast kinetics, decades of proven use, "similar" properties of proven sorbents — along with availability, very low cost, and utilization of a waste material from other industries, combine to make iron-based sorbents potentially attractive for $\mathrm{H}_{2} \mathrm{~S}$ abatement.

For example, at $750^{\circ} \mathrm{F}$ the $\mathrm{H}_{2} \mathrm{~S}$ equilibrium concentrations (in ppmv) in the presence of 10 vol-percent $\mathrm{H}_{2} \mathrm{O}$ are as follows:

$\mathrm{FeO} / \mathrm{FeS}: \quad 48$

$\mathrm{CaO} / \mathrm{CaS}: \quad 1$

$\mathrm{ZnO} / \mathrm{ZnS}: \quad 2$

Furthermore, according to Tamhankar and $\mathrm{Wen}^{6}$, the following are the (normalize for surface area) sulfidation rate constants in units of $\mathrm{cm}^{4} / \mathrm{min}$-mole at $750^{\circ} \mathrm{F}$.

$\mathrm{Fe}_{2} \mathrm{O}_{3}: 300$

$\mathrm{CaO}: 0.9$

$\mathrm{ZnO}: 0.7$

Therefore, the successful applications of iron-based sorbents reported in the literature along with favorable chemical properties (capacity as well as rate of reaction) of these materials, suggest that under the right conditions, they could be effectively used in a Transport Reactor configuration for reducing/controlling $\mathrm{H}_{2} \mathrm{~S}$ concentrations.

\subsubsection{Key Reactions}

\section{$\underline{\mathrm{H}}_{2} \underline{\mathrm{S}}$ reaction with $\mathrm{CaO}$ :}

Since $\mathrm{CaO}$ also reacts with $\mathrm{H}_{2} \mathrm{~S}$, the equation below is included since it reduces the number of moles of $\mathrm{H}_{2} \mathrm{~S}$ present in the syngas when the iron-based sorbents are injected. See Section 4.4 for additional discussion on the role of calcium-based sorbents.

$$
\text { Sulfidation Reaction: } \quad \mathrm{CaO}+\mathrm{H}_{2} \mathrm{~S} \leftrightarrow \mathrm{CaS}+\mathrm{H}_{2} \mathrm{O}
$$


POWER SYSTEMS DEVELOPMENT FACILITY

TRANSPORT REACTOR

TEST CAMPAIGN TCO7

IRON OXIDE INJECTION FOR H2S CONTROL

Partial Reduction of $\mathrm{Fe}_{2} \mathrm{O}_{3}$ to $\mathrm{FeO}$ :

Reduction Reaction ${ }^{\mathrm{A}}: \quad \mathrm{Fe}_{2} \mathrm{O}_{3}+1 / 2\left(\mathrm{H}_{2}+\mathrm{CO}\right) \leftrightarrow 2 \mathrm{FeO}+1 / 2\left(\mathrm{H}_{2} \mathrm{O}+\mathrm{CO}_{2}\right)$

Sulfidation Reaction: $\quad \mathrm{FeO}+\mathrm{H}_{2} \mathrm{~S} \leftrightarrow \mathrm{FeS}+\mathrm{H}_{2} \mathrm{O}$

Complete Reduction of $\mathrm{Fe}_{2} \underline{\mathrm{O}_{3}}$ to Fe:

Reduction Reaction ${ }^{\mathrm{A}}: \quad \mathrm{Fe}_{2} \mathrm{O}_{3}+1.5\left(\mathrm{H}_{2}+\mathrm{CO}\right) \leftrightarrow 2 \mathrm{Fe}+1.5\left(\mathrm{H}_{2} \mathrm{O}+\mathrm{CO}_{2}\right)$

Sulfidation Reaction ${ }^{\mathrm{B}}: \quad \mathrm{Fe}+1.1 \mathrm{H}_{2} \mathrm{~S} \leftrightarrow \mathrm{FeS}_{1.1}+1.1 \mathrm{H}_{2}$

${ }^{\text {A }}$ For illustrative purposes, this reaction is written for the reduction of Hematite. Magnetite, $\mathrm{Fe}_{3} \mathrm{O}_{4}$, was also present in the samples and would be reduced via a similar overall reaction.

${ }^{\mathrm{B}}$ Nonstoichiometric compounds, represented as $\mathrm{FeS}_{1+\alpha}$, where $\alpha$ generally ranges from 0 to 0.5 , have been identified with Mossbauer spectroscopic analysis as the dominate iron-sulfur form. Pyrite, $\mathrm{FeS}_{2}$, contains the maximum amount of sulfur for this reaction but is only stable below roughly $675^{\circ} \mathrm{F}$.

One of the key factors common to all of the reduction reactions shown is the potential role of $\mathrm{H}_{2} \mathrm{O}$ for adversely affecting the reduction of Hematite $\left(\mathrm{Fe}_{2} \mathrm{O}_{3}\right)$. Similarly, water vapor can also adversely affect the sulfidation of $\mathrm{CaO}$ and $\mathrm{FeO}$. Since steam is typically used to enhance gasification reactions and moderate temperatures, the role of $\mathrm{H}_{2} \mathrm{O}$ on $\mathrm{H}_{2} \mathrm{~S}$ abatement using these types of sorbents, or any sorbent affected by the partial pressure of water, is an issue that must be considered.

Thermodynamic analyses are used to evaluate the potential influence of factors such as, temperature, pressure, water vapor, or any other reactant or product in the equation of interest. In particular, the role of water vapor will be discussed.

\subsubsection{Run Data}

Figure 4.6-1 shows the concentration of water in the syngas measured upstream of the atmospheric syngas burner (tag number AI475H) and the total reduced sulfur (TRS) concentrations over a 4-day period during which iron-based sorbents were injected. The TRS values were computed from the continuous $\mathrm{SO}_{2}$ measurements downstream of the syngas burner and converted to TRS concentration via a mass balance for the syngas stream. TRS is taken as equivalent to the $\mathrm{H}_{2} \mathrm{~S}$ concentration for this analysis (Section 4.6). The most striking aspect of the graph is how the TRS concentrations closely and consistently track the concentrations of water in the syngas stream. For example, towards the end of the run, the steam to the Transport Reactor was increased rapidly and sufficiently to increase the overall water concentration from roughly 8.3 to $14.1 \mathrm{vol}$ percent ( 70 percent increase) and the TRS concentration correspondingly increased roughly 50 percent from 170 to 250 ppmv. 
Table 4.6-2 provides supplemental information for the iron injection time periods (indicated by the green rectangles) shown in Figure 4.6-1. For the five tests listed, the iron injection tests varied from 30 minutes to 14 hours. Two feeders, FD230, discussed above, and the limestone sorbent feeder (FD220) installed when the plant was constructed for Ca-based sorbents, were both used to feed iron oxide. Both feeders connect to the process piping in the same location (downstream of the primary gas cooler and upstream of the PCD). Decreases in total reduced sulfer (TRS) concentrations ranged from 3 to 37 percent; however, many of these decreases occurred while the water concentration was also decreasing. However, for Run 3, the steam flow rate was minimized prior to starting the iron oxide and was held constant during the testing. Under these conditions, the flue dust removed 13 percent of the TRS using a Fe:S molar ratio of 10:1 (note, the goal was not to optimize, but to see if there was any beneficial effect under any conditions).

Several other runs were conducted, but are not shown because (1) they were very short in duration, (2) the feed was unstable, or (3) the results are similar to the ones highlighted.

The interdependent behavior between the water and TRS concentrations as shown in Figure 4.6-1 is believed to be a result of the corresponding change in the equilibrium concentration of $\mathrm{H}_{2} \mathrm{~S}$ for the $\mathrm{CaO} / \mathrm{H}_{2} \mathrm{~S}$ system. To further investigate this hypothesis, the measured and $\mathrm{CaO}$-based equilibrium concentrations (i.e., from the reaction $\mathrm{CaO}+\mathrm{H}_{2} \mathrm{~S} \leftrightarrow \mathrm{CaS}+\mathrm{H}_{2} \mathrm{O}$ ) of $\mathrm{H}_{2} \mathrm{~S}$ were computed and are shown in Figure 4.6-2. The equilibrium values were computed using the disengager outlet temperature (TI352), the measured water concentration in the syngas, and fundamental thermodynamic principles and data from Perry's Chemical Engineering Handbook. For the 6-hour period wherein the steam was rapidly increased (previously discussed), the actual/measured $\mathrm{H}_{2} \mathrm{~S}$ concentrations were nearly equal to the $\mathrm{CaO}$-based equilibrium values. The biggest deviation occurs while the steam-flow rate was rapidly increased, hence equilibrium was not achieved because of the short, spiking nature of this rapid change.

The equilibrium values for the same system were also computed using the outlet temperature of the PCD (TI439), generally ranging between 470 and $560^{\circ} \mathrm{F}$. Under these conditions, the equilibrium $\mathrm{H}_{2} \mathrm{~S}$ values are less than 1 ppmv (hence not shown in Figure 4.6-2).

Interestingly, this suggests that once the gas and solids exit the cyclone, the partial pressure of $\mathrm{H}_{2} \mathrm{~S}$ is established. Although sufficient cooling of the gas and solids occurs in the primary gas cooler so that the $\mathrm{H}_{2} \mathrm{~S}$ equilibrium values are less than $1 \mathrm{vppm}$, the actual concentrations are much higher, and in fact essentially equal to the equilibrium values under Transport Reactor temperatures - not PCD temperatures.

Although this behavior is not fully understood, it is believed that the lower temperatures, although favorable from a thermodynamic perspective, are so low that the kinetic and diffusion rates are so slow that any benefit(s) of lower-temperature operation are not realized for this system. 
Figure 4.6-3 is a close-up view of Run 3 which shows a 20-minute duration, starting at 13:29 on April 3, 2002, during which flue dust (see Table 4.6-1 for properties) was injected via FD230. This period is highlighted since the partial pressure of water was essentially constant, therefore the decrease in $\mathrm{H}_{2} \mathrm{~S}$ from 176 to $153 \mathrm{ppmv}$ is attributed to injecting the iron-based sorbent. The equilibrium concentration for the $\mathrm{FeO} / \mathrm{FeS}$ system is $42 \mathrm{ppmv}$ under the average conditions shown in Figure 4.6-3. Hence, in an analogous manner, the actual concentration of $\mathrm{H}_{2} \mathrm{~S}$ in the $\mathrm{FeO} / \mathrm{FeS}$ system, like the $\mathrm{CaO} / \mathrm{CaS}$ system, does not approach the equilibrium values at low $\left(<750^{\circ} \mathrm{F}\right)$ temperatures. Plausible reasons for the low reduction of $\mathrm{H}_{2} \mathrm{~S}$ is explained in the next section and illustrated in Figure 4.6-4.

In an attempt to develop a plausible reason for the low TRS removal, the influence of water was investigated. The equilibrium constants for the reduction reactions (already discussed) were computed as a function of temperature. Then, for the conditions used during testing, for example, $\mathrm{H}_{2} / \mathrm{CO}=0.85$, the equilibrium concentrations were calculated and compared to the actual water concentrations.

As shown in Figure 4.6-4, the actual syngas water concentrations were always greater than the equilibrium concentrations. Hence, for the reduction reactions shown, the forward reactions were prohibited by the high partial pressure of water and therefore the formation of the active form of iron, $\mathrm{FeO}$ and $\mathrm{Fe}$, was also thermodynamically prohibited.

Since the sorbent was pneumatically conveyed with dry nitrogen, it is possible that local areas with less than the bulk water concentrations shown in Figure 4.6-4 were present. If such local "pockets" were present, then it is possible that some reduction may have occurred. However, the analysis clearly suggests that the overall conditions were such that the reduction of the original material to form $\mathrm{FeO}$ and/or Fe was not favored, if possible at all.

\subsubsection{Conclusions}

- A variety of iron-based sorbents were successfully fed into the Transport Reactor system. Although attempts were made to limit the amount of steam fed into the system so as to enhance sorbent reactivity, other process requirements (e.g., temperature) restricted how much steam could be removed.

- The data suggests that for both the $\mathrm{CaO} / \mathrm{CaS}$ and the $\mathrm{FeO} / \mathrm{FeS}$ systems, that the $\mathrm{H}_{2} \mathrm{~S}$ concentrations are considerably higher than the equilibrium values at $750^{\circ} \mathrm{F}$. However, at Transport Reactor temperatures (say, above $1,650^{\circ} \mathrm{F}$ ) the $\mathrm{H}_{2} \mathrm{~S}$ concentrations are nearly equal to the equilibrium concentrations for the $\mathrm{CaO} / \mathrm{CaS}$ system. It is suspected that the kinetic and diffusion rates are too slow at the lower temperatures to achieve the equilibrium values.

- Under the conditions used in this investigation, thermodynamic analyses indicate that the partial pressure of water was too high to reduce the iron oxides to the required 
$\mathrm{Fe}$ and/or $\mathrm{FeO}$ state for sulfur removal. Hence, this was one of the primary reasons why so little $\mathrm{H}_{2} \mathrm{~S}$ was removed from the gas stream.

- When other operative phenomena such as heat transfer, particle characterization (e.g., surface area), and reaction kinetics, are factored into the analysis, the rate and extent of reaction will be reduced even further. Since sulfidation kinetics are considerably slower than reduction reaction rates, the results observed in the field are consistent with this theoretical explanation.

- It is imperative that (whenever possible) sorbents are tested in the actual environment of the intended application so that all operative phenomena that affect sorbent performance are present and active.

- Because of the unique history (i.e., derived from different processes during steel manufacturing) of each sorbent used in this investigation, these materials are not representative of all the available iron-based sorbents. Therefore, the results from these tests should be used within their proper context and over-generalizations should be avoided.

\section{$\underline{\text { References }}$}

1. E.C. Oldaker and D.W. Gillmore, Hot Gas Cleanup Process for Removing $\mathrm{H}_{2} \mathrm{~S}$ from Low-Btu Gases Using Iron Oxide Absorbents, ACS Div. Fuel Chem. Prepr. 21, 1976, pp. 79-90

2. S.S. Tamhankar, M. Hasatani, and C.Y. Wen, Kinetic Studies on the Reactions Involved in the Hot Gas Desulfurization Using a Regenerable Iron Oxide Sorbent - I, Chem. Eng. Sci., vol. 36, 1981, pp. 1181-1191.

3. R.B. Slimane and J. Abbasian, Utilization of Metal Oxide-Containing Waste Materials for Hot Coal Gas Desulfurization, Fuel Proc. Tech., 70, 2001, pp. 97-113

4. E.C. Oldaker and D.W. Gillmore, Hot Gas Cleanup Process for Removing $\mathrm{H}_{2} \mathrm{~S}$ from Low-Btu Gases Using Iron Oxide Absorbents, ACS Div. Fuel Chem. Prepr. 21, 1976, pp. 79-90

5. S.S. Tamhankar, C.Y. Wen, High-Temperature Hydrogen Sulfide Removal Using a Regenerable Iron Oxide Sorbent, Industrial Gas Separations, ACS, 1982, pp. 255279

6. Ibid 
Table 4.6-1 Chemical and Physical Properties of Iron-Based Materials

\begin{tabular}{|c|c|c|c|c|c|c|c|c|}
\hline & & $\begin{array}{l}\text { Baghouse } \\
\text { Dust }\end{array}$ & Pellet Fines & Flue Dust & $\begin{array}{l}\text { Blast Furnace } \\
\text { - Baghouse } \\
\text { Fresh }\end{array}$ & Hot Strip & $\begin{array}{l}\text { Pipe Mill } \\
\text { Scale }\end{array}$ & Hot Drip Pit \\
\hline & & AB10030 & AB10032 & AB10033 & AB10035 & AB10036 & AB10037 & AB10038 \\
\hline Sodium Oxide & $\mathrm{NaO}$ & 7.73 & 1.63 & 10.2 & - & - & - & - \\
\hline Magnesium Oxide & $\mathrm{MgO}$ & 22.32 & 7.2 & 6.16 & - & - & - & - \\
\hline Aluminum Oxide & $\mathrm{Al}_{2} \mathrm{O}_{3}$ & 6.97 & 1.73 & 11.63 & 1.03 & 0.63 & 1.02 & 0.83 \\
\hline Silicon Dioxide & $\mathrm{SiO}_{2}$ & 2.26 & 13.75 & 23.62 & 5.22 & 2.04 & 3.2 & 3.22 \\
\hline Sulfur Trioxide & $\mathrm{SO}_{3}$ & 4.41 & 1.12 & 3.09 & 2.98 & - & 2.25 & 0.16 \\
\hline Chloride & & 0.51 & 0.08 & 0.12 & 0.08 & - & - & - \\
\hline Potassium Oxide & $\mathrm{K}_{2} \mathrm{O}$ & 1.16 & 0.12 & 0.81 & 1.44 & - & - & - \\
\hline Calcium Oxide & $\mathrm{CaO}$ & 19.45 & 12.22 & 6.62 & 0.22 & 0.46 & 0.4 & 0.82 \\
\hline Manganese Oxide & $\mathrm{MnO}$ & 0.12 & 0.18 & 0.35 & 0.3 & 0.38 & 1.16 & 0.43 \\
\hline Ferric Oxide ${ }^{A}$ & $\mathrm{Fe}_{2} \mathrm{O}_{3}$ & 35.1 & 62.0 & 37.4 & 88.6 & 96.5 & 91.6 & 94.2 \\
\hline Nickel Oxide & $\mathrm{NiO}$ & - & - & - & 0.1 & - & - & 0.24 \\
\hline Chromium Oxide & $\mathrm{Cr}_{2} \mathrm{O}_{3}$ & - & - & - & - & - & 0.34 & 0.08 \\
\hline Summation & & 100.0 & 100.0 & 100.0 & 100.0 & 100.0 & 100.0 & 100.0 \\
\hline Bulk Density, g/cc & & 0.73 & 2.04 & 1.03 & 0.94 & 2.79 & 2.38 & 2.07 \\
\hline Surface Area, $\mathrm{m}^{2} / \mathrm{g}$ & & 3.34 & - & 10 & 3.1 & 0.2 & 0.1 & 0.1 \\
\hline D50, microns & & $<45$ & 3,046 & 270 & 5 & 773 & 714 & 363 \\
\hline
\end{tabular}

${ }^{A}$ Reporting Basis Only - Other Forms Present but All Recorded as $\mathrm{Fe}_{2} \mathrm{O}_{3}$. 
Table 4.6-2 Iron Oxide Injection Test Results

\begin{tabular}{|c|l|c|c|c|c|}
\hline Ref. No. & Sorbent & $\begin{array}{c}\text { Approx. } \\
\text { Duration }\end{array}$ & Feeder & $\begin{array}{c}\text { \% Decrease in } \\
\text { TRS }\end{array}$ & $\begin{array}{c}\text { \%ecrease in } \\
\text { H2O }\end{array}$ \\
\hline 1 & Caster Scale & $52 \mathrm{~min}$ & FD230 & 15 & 9 \\
\hline 2 & Flue Dust & $30 \mathrm{~min}$ & FD230 & 4 & 13 \\
\hline 3 & Flue Dust & $20 \mathrm{~min}$ & FD230 & 13 & $\sim 0$ \\
\hline $4 \& 5$ & $\begin{array}{l}50 / 50 \text { Mix of Hot Strip Pit } \\
\text { and Pipe Mill Scale + } \\
\text { limestone }\end{array}$ & 14 hour & FD220 & 11,37 & 4,16 \\
\hline
\end{tabular}


POWER SYSTEMS DEVELOPMENT FACILITY

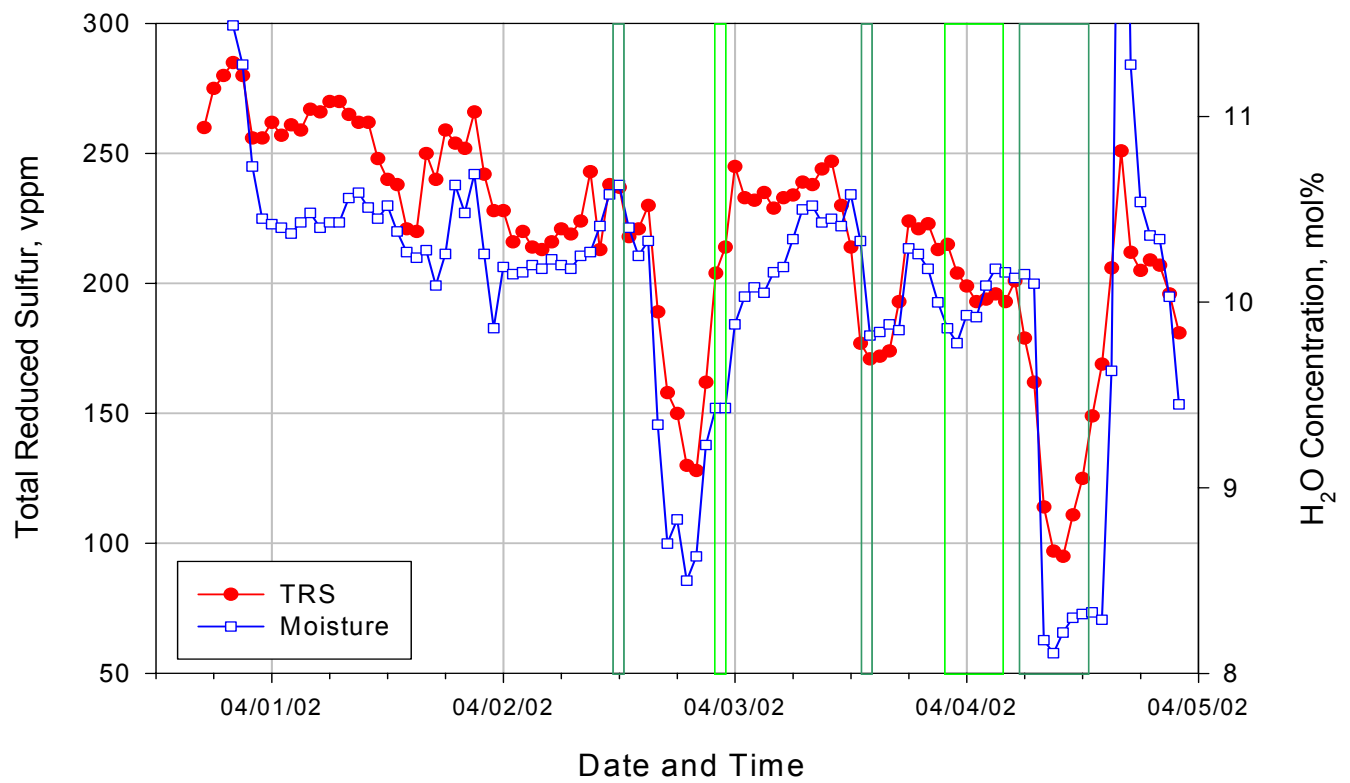

Figure 4.6-1 The Syngas and TRS Concentrations During TCO7D (The highly interdependent behavior between these two gases is emphasized)

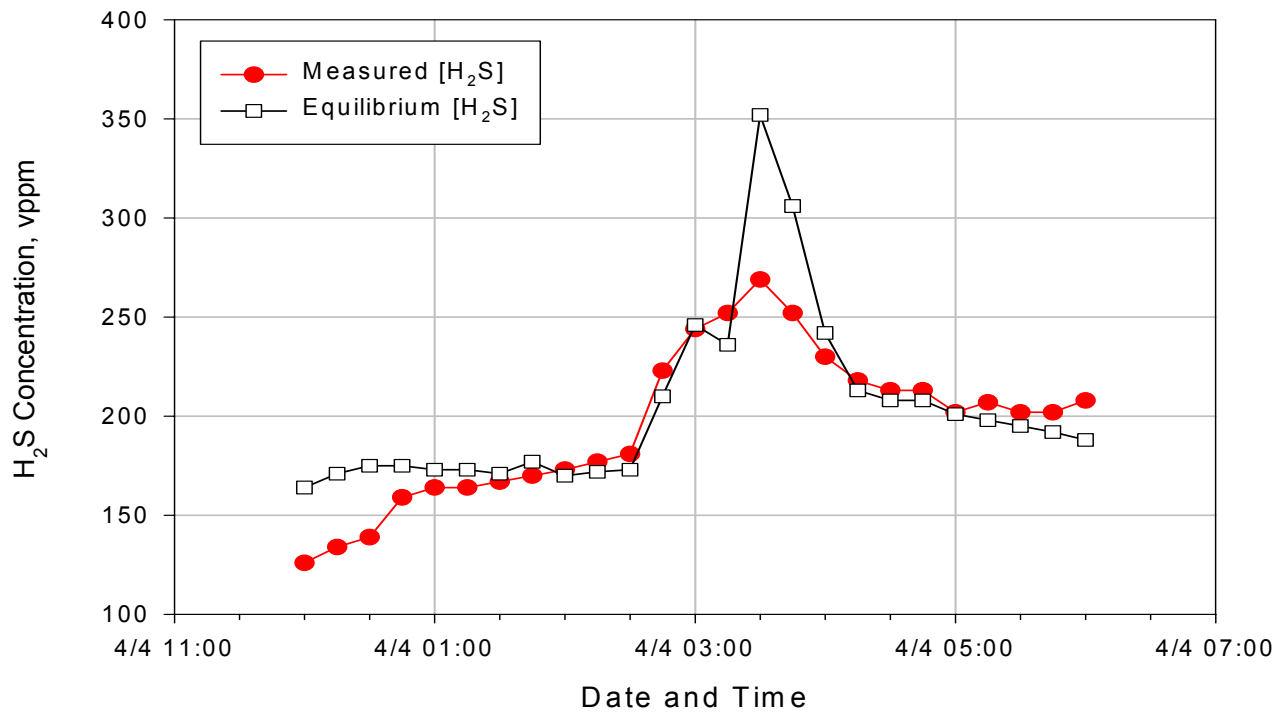

Figure 4.6-2 Actual and CaO-Based Equilibrium Concentrations of $\mathrm{H}_{2} \mathrm{~S}$ 


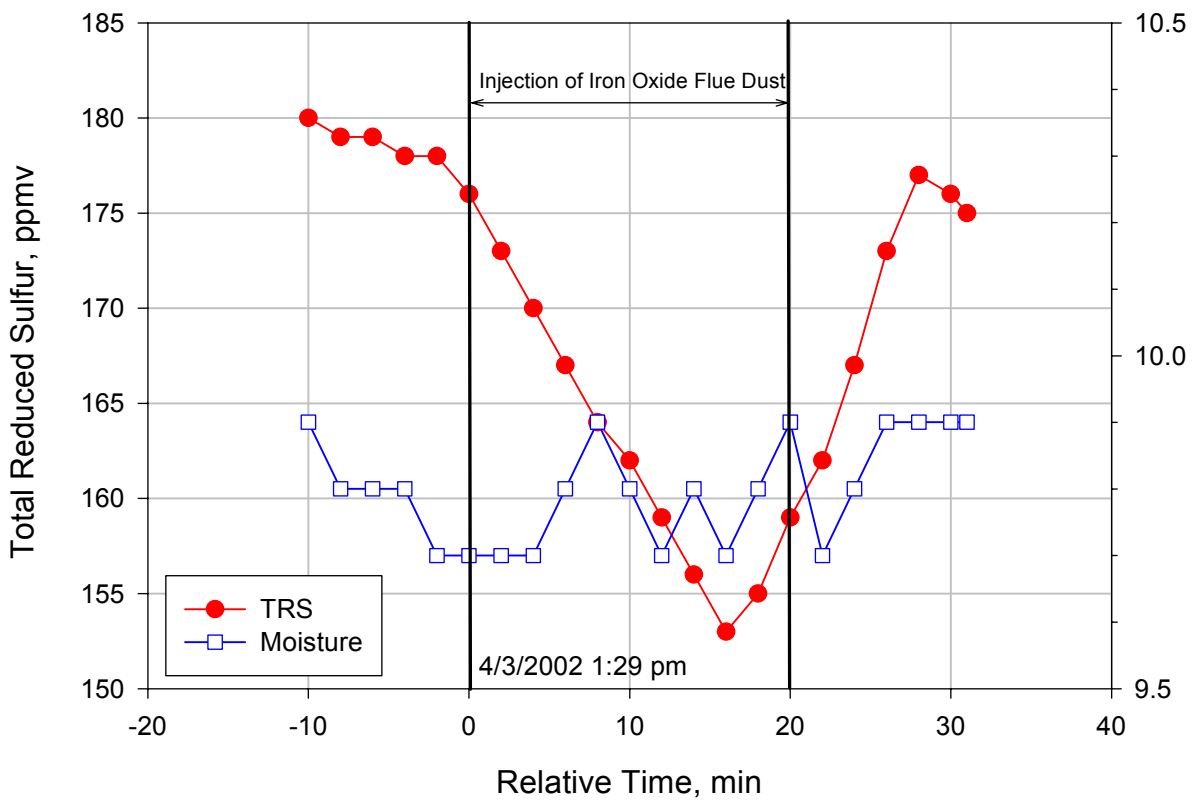

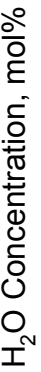

Figure 4.6-3 Effect of Using Flue Dust for Capturing $\mathrm{H}_{2} \mathrm{~S}$

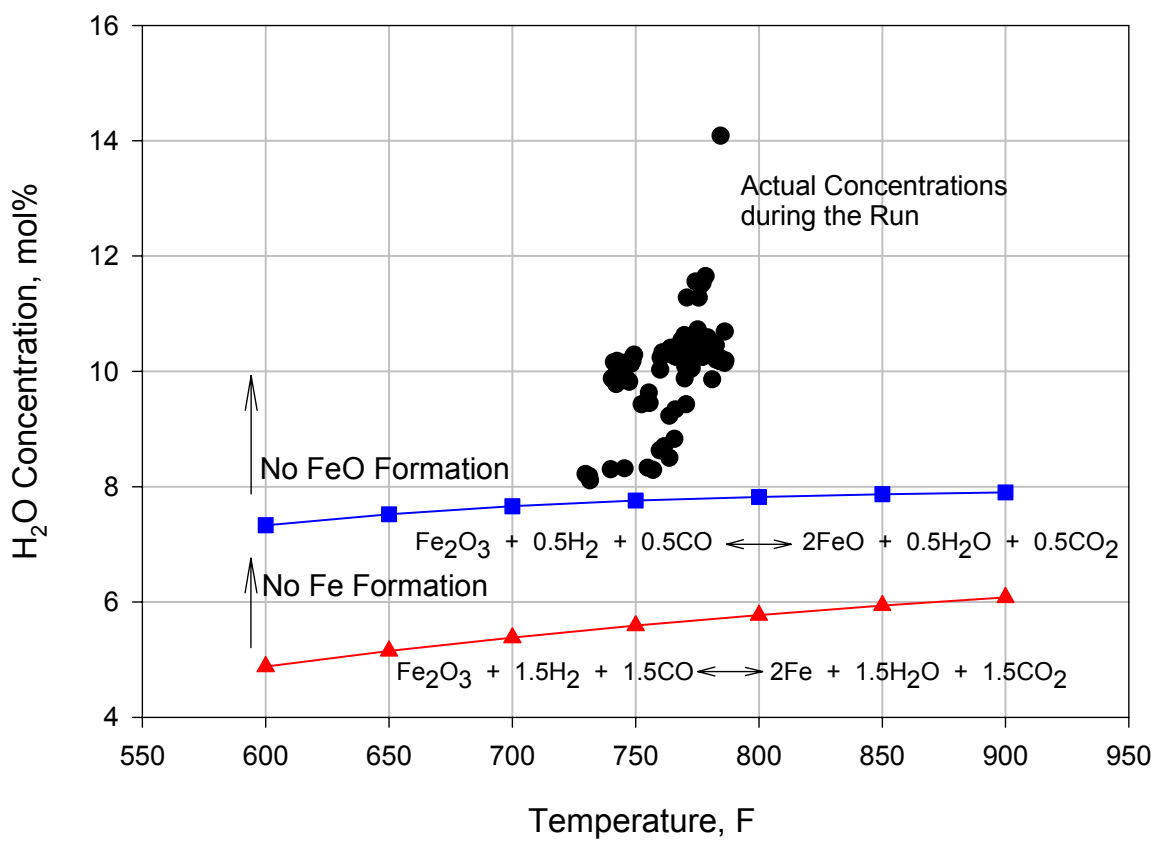

Figure 4.6-4 Actual Concentrations of Water in the Syngas During Iron-0xide Injection Tests Versus Equilibrium Concentrations of Water for Reactions Shown (Note: each reaction is computed using $\mathrm{N}_{2} / \mathrm{CO}=7$ ) 


\subsection{AFBC OPERATIONS}

During TC07, the AFBC was operated for 876 hours and fired PCD fines from the gasifier for a total of 195 hours. The average bed temperature during TC07 was $1,335^{\circ} \mathrm{F}$ which is considerably less than the design temperature of 1,600 to $1,650^{\circ} \mathrm{F}$. The AFBC was operated as high as $1,800^{\circ} \mathrm{F}$. Despite the low operating temperatures, the residence time of material in the AFBC is high enough to still provide high carbon conversion. Figure 4.7-1 shows the carbon content of the feed to the AFBC and of the AFBC ash collected in the baghouse during TC07D.

During TC07, the rate at which material was carried out of the bed was excessive. Normally, the AFBC is started with a bed of sand. Once feed from the gasifier begins, the larger ash particles should collect in the bed, some collected by the cyclone, while the finest particles escape to the baghouse. This problem of bed material carryover has also been seen in previous test runs, but not as severe as in this test run. At the beginning of each test run, the AFBC is charged with around 10 supersacks of sand (about 30,000 lb). During the TC07 test run, it was necessary to add at least an additional 16 bags of sand to maintain bed inventory. The main reason for the bed material carryover is due to the difficulties associated with cyclone dipleg operation.

During early AFBC operations, there had been a problem in which the bed would become progressively less well mixed as refractory fell from walls and interfered with the distribution of the aeration. Before TC06, the lowest 10 feet of the AFBC refractory (where most of the damage was concentrated) was removed and replaced. In addition, the refractory was sprayed with sodium silicate to harden the outer layer. After TC06, the refractory was inspected and showed no signs of new damage. During TC07, the temperature profile, shown in Figure 4.7-2, did not reveal any evidence of fluidization problems. Because of this, the AFBC was not drained and inspected after TC07.

The feed rate of FD0530 (the AFBC feeder) was very difficult to control during TC07. Material in the dispense vessel was able to blow through the rotary feeder through the bare minimum clearances, with the feeder turning at minimum speed or even not turning at all. The feed rate to the AFBC, at times, exceeded the desired feed rate. This led to numerous trips due to low oxygen in the AFBC. The starting and stopping of the feed system during bituminous coal operation also made it difficult to empty the PCD fines from FD0530 as quickly as it was being produced. 


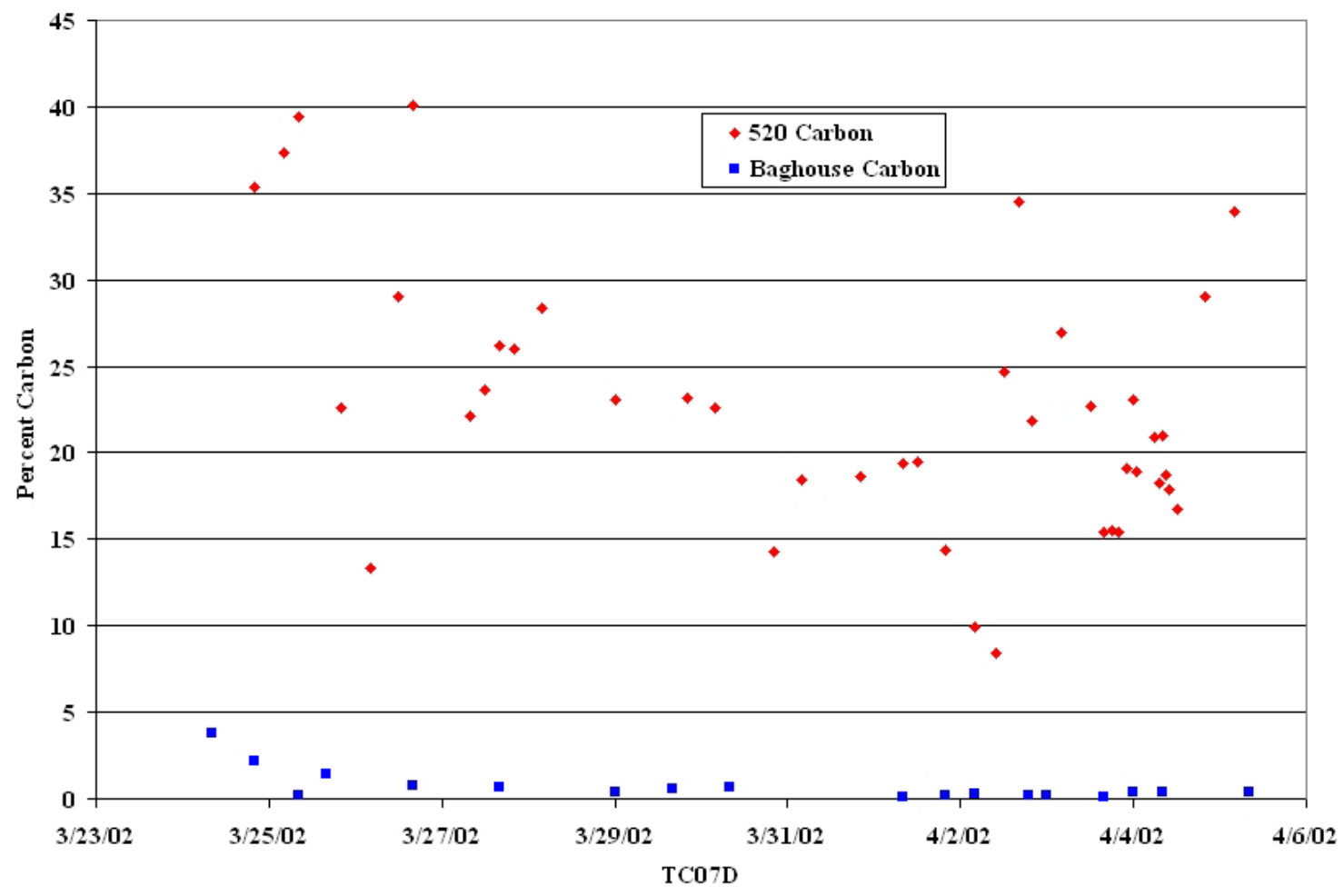

Figure 4.7-1 Carbon in G-ash and Ash

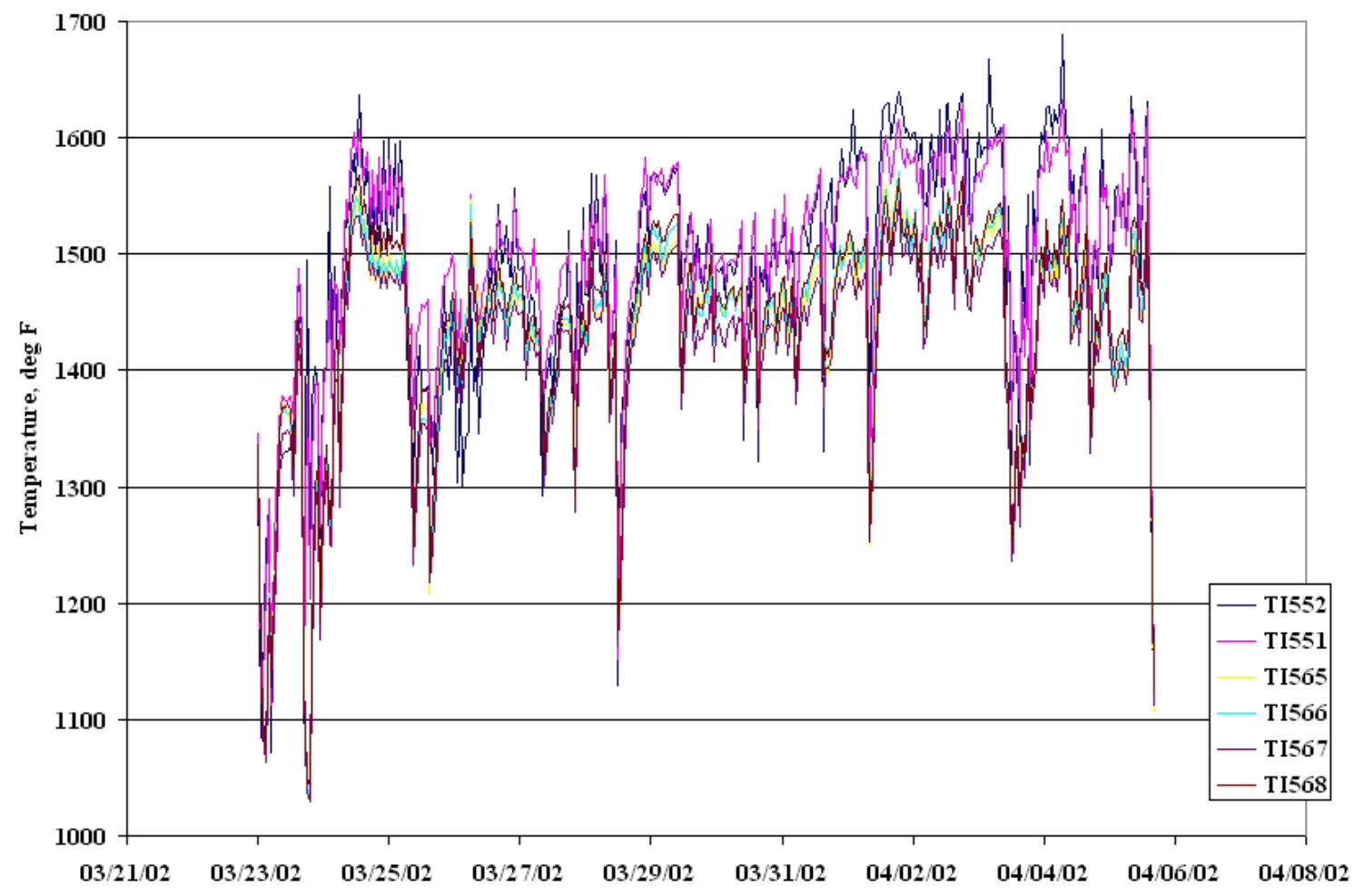

Figure 4.7-2 Temperature Profile of Bed 


\subsection{PROCESS GAS COOLERS}

Heat transfer calculations were performed on the primary gas cooler, HX0202, and the secondary gas cooler, HX0402, to determine if their performance had deteriorated during TC07 due to tar or other compounds depositing on the tubes.

The primary gas cooler, HX0202, is between the Transport Reactor cyclone, CY0201, and the Siemens Westinghouse PCD, FL0301. During TC07, HX0202 was not bypassed, and took the full gas flow from the Transport Reactor. The Primary Gas Cooler is a single flow heat exchanger with hot gas from the Transport Reactor flowing through the tubes and the shell side operating with the plant steam system. The pertinent equations are:

$$
\begin{gathered}
\mathrm{Q}=\mathrm{UA} \Delta \mathrm{T}_{\mathrm{LM}} \\
\mathrm{Q}=\mathrm{c}_{\mathrm{p}} \mathrm{M}\left(\mathrm{T}_{1}-\mathrm{T}_{2}\right) \\
\Delta \mathrm{T}_{\mathrm{LM}}=\frac{\left(\mathrm{T}_{1}-\mathrm{t}_{2}\right)-\left(\mathrm{T}_{2}-\mathrm{t}_{1}\right)}{\ln \frac{\left(\mathrm{T}_{1}-\mathrm{t}_{2}\right)}{\left(\mathrm{T}_{2}-\mathrm{t}_{1}\right)}}
\end{gathered}
$$

Q $=$ Heat transferred, Btu/hour

$\mathrm{U}=$ Heat transfer coefficient, Btu $/ \mathrm{hr} / \mathrm{ft}^{2} /{ }^{\circ} \mathrm{F}$

A $\quad=$ Heat exchanger area, $\mathrm{ft}^{2}$

$\Delta \mathrm{T}_{\mathrm{LM}}=\log$ mean temperature difference, ${ }^{\circ} \mathrm{F}$

$\mathrm{c}_{\mathrm{p}} \quad=$ Gas heat capacity, Btu $/ \mathrm{lb} /{ }^{\circ} \mathrm{F}$

$\mathrm{M} \quad=$ Mass flow of gas through heat exchanger, $\mathrm{lb} / \mathrm{hr}$

$\mathrm{T}_{1} \quad=$ Gas inlet temperature, ${ }^{\circ} \mathrm{F}$

$\mathrm{T}_{2}=$ Gas outlet temperature, ${ }^{\circ} \mathrm{F}$

$\mathrm{t}_{1} \quad=\mathrm{t}_{2}=$ Steam temperature, ${ }^{\circ} \mathrm{F}$

Using equations (1) through (3) and the process data, the product of the heat transfer coefficient and the heat exchanger area (UA) can be calculated. The TC07 HX0202 UA is shown on Figure 4.8-1 as 4-hour averages, along with the design UA of 5,200 Btu/hr $/{ }^{\circ} \mathrm{F}$ and the pressure drop across HX0202. If HX0202 is plugging, the UA should decrease and the pressure drop should increase. The UA deterioration is a better indication of heat exchanger plugging because the pressure drop is calculated by the difference of two pressure transmitters that generally have similar numbers, usually from 150 to 240 psig, resulting in pressure drops of 1 to 3 psi.

The TC07 UA stabilized at about $8,000 \mathrm{Btu} / \mathrm{hr} /{ }^{\circ} \mathrm{F}$ after around 50 hours of operation, which is above the design $\mathrm{UA}$ of $5,200 \mathrm{Btu} / \mathrm{hr} /{ }^{\circ} \mathrm{F}$. The UA of about $8,000 \mathrm{Btu} / \mathrm{hr} /{ }^{\circ} \mathrm{F}$ was 
maintained during the initial PRB testing that lasted about 95 hours. After the transition from PRB to Alabama bituminous coal, the UA initially rose from 8,000 to $9,000 \mathrm{Btu} / \mathrm{hr} /{ }^{\circ} \mathrm{F}$. Over the next 50 hours, the extent of the bituminous testing, the UA steadily fell to 6,000 $\mathrm{Btu} / \mathrm{hr} /{ }^{\circ} \mathrm{F}$. Once the coal feed was changed back to PRB, the UA rose from 6,000 to 8,500 $\mathrm{Btu} / \mathrm{hr} /{ }^{\circ} \mathrm{F}$ in about 50 hours and then held steady until about hour 250. During the remainder of the run the UA fell to $7,500 \mathrm{Btu} / \mathrm{hr} /{ }^{\circ} \mathrm{F}$.

The HX0202 pressure drop held fairly constant during the first 136 hours of TC07 at values from 0.8 to 1.5 psi. The pressure drop then jumped to 2.7 psi and held above 2.0 psi until the end of the bituminous testing. Once returning to PRB, the pressure drop was about 3.0 psi and decreased to 1.7 to 2.8 psi near the end of the test run. In the last several hours, the pressure drop was around 3.0 psi. Though the UA was above the design value for essentially all of TC07, the increased pressure drop combined with the decreasing UA during the bituminous testing indicates that some fouling or plugging of the gas cooler occurred during this time. Indeed, when the cooler was inspected after TC07, deposits on the tubesheet were found to be blocking a significant portion of the tubes.

The pressure drop during TC07 was lower in the early PRB testing and the first part of the bituminous testing than in TC06. Most of TC06 has pressure drops in the range of 1.5 to 2.3 psi. After the bituminous testing, the pressure drop was higher for the rest of TC07 than the pressure drop in TC06. The UA in TC07 was lower for most of the run than the UA for TC06, although both were still well above the design UA.

The secondary gas cooler, HX0402, is a single-flow heat exchanger with hot gas from the PCD flowing through the tubes and the shell side operating with plant steam system. Some heat transfer and pressure drop calculations were done around HX0402 to determine if there was any plugging or heat exchanger performance deterioration during TC07. HX0402 is not part of the combustion gas turbine commercial flow sheet. In the commercial gas turbine flow sheet, the hot synthesis gas from the PCD would be sent directly to a combustion gas turbine. HX0402 would be used commercially if the synthesis gas was to be used in a fuel cell or as a chemical plant feedstock.

Using Equations (1) through (3) and the process data, the product of the heat transfer coefficient and the UA can be calculated. The UA for TC07 testing is shown on Figure 4.8-2 as 2-hour averages, along with the design UA of $13,100 \mathrm{Btu} / \mathrm{hr} /{ }^{\circ} \mathrm{F}$ and the pressure drop across HX0402. If HX0402 is plugging, the UA should decrease and the pressure drop should increase.

The UA was at 13,700 to $14,400 \mathrm{Btu} / \mathrm{hr} /{ }^{\circ} \mathrm{F}$ for the first 94 hours of TC07 during the PRB testing, above the design UA of $13,100 \mathrm{Btu} / \mathrm{hr} /{ }^{\circ} \mathrm{F}$. The UA dropped to about 12,500 $\mathrm{Btu} / \mathrm{hr} /{ }^{\circ} \mathrm{F}$ once the unit transitioned to bituminous coal feed. After returning to PRB coal, the UA increased to $15,200 \mathrm{Btu} / \mathrm{hr} /{ }^{\circ} \mathrm{F}$. The UA held relatively steady for the remainder of the run only decreasing slightly to about $14,300 \mathrm{Btu} / \mathrm{hr} /{ }^{\circ} \mathrm{F}$ by the end of TC07. 
The HX0402 TC07 pressure drop was between 1.7 and 3.0 psi during the initial PRB operation. For most of the bituminous testing, the pressure drop was about 1.5 psi, increasing to around 2.8 psi for the last 30 hours of the bituminous coal operation. Around hour 160, just after returning to PRB coal, the pressure drop increased to 3.6 psi. The pressure drop stayed fairly constant for the next 120 hours and then started to decline to 2.1 psi by the end of the run. The data does not show any evidence of plugging or fouling during TC07. An inspection after the run confirmed that there were no deposits in the cooler although there were substantial tar deposits in the cone below the cooler.

The TC07 UA range of 12,500 to $15,200 \mathrm{Btu} / \mathrm{hr} /{ }^{\circ} \mathrm{F}$, were lower than the range in TC06 of 14,500 to $18,000 \mathrm{Btu} / \mathrm{hr} /{ }^{\circ} \mathrm{F}$, but were still mostly above the design UA of 13,100

$\mathrm{Btu} / \mathrm{hr} /{ }^{\circ} \mathrm{F}$. The 1.7 to 3.6 psi pressure drops across HX0402 for TC07 were slightly less than the corresponding TC06 pressure drops of 2.0 to 4.5 psi. 


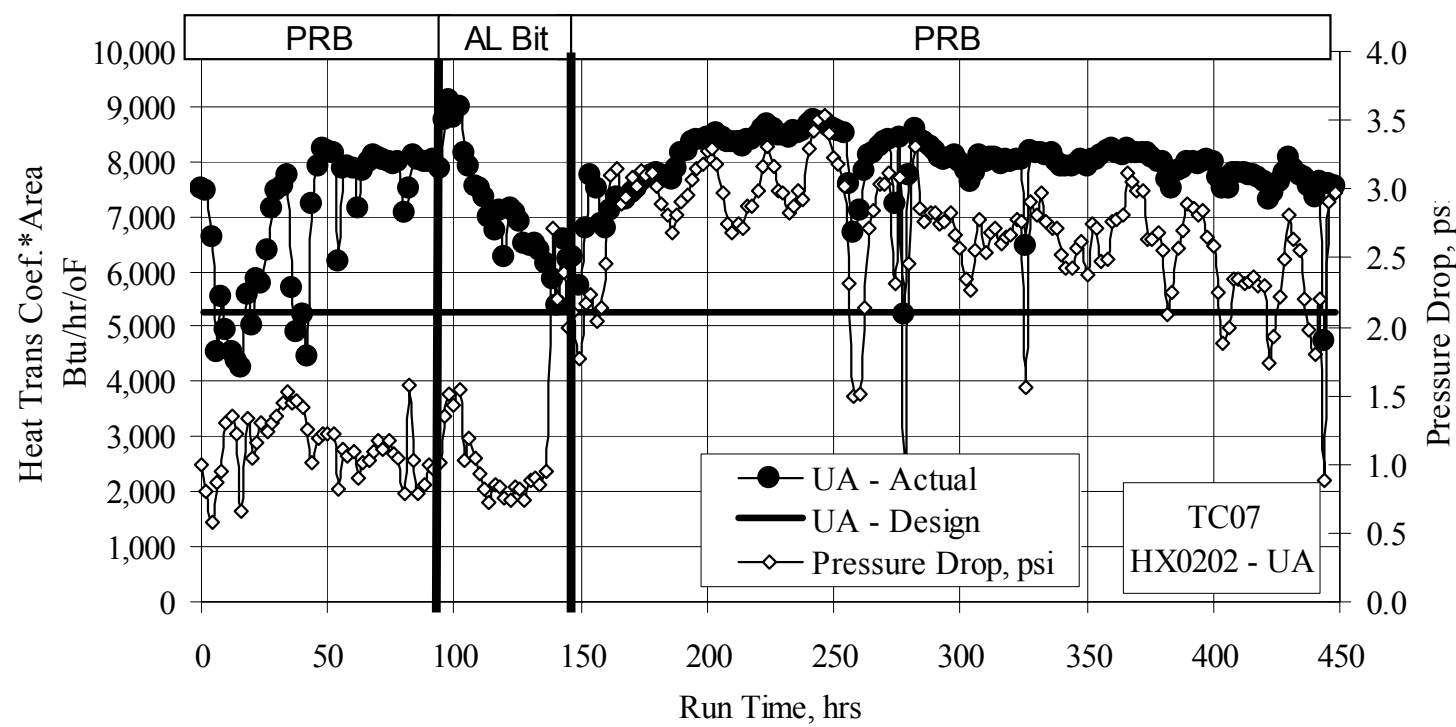

Figure 4.8-1 HX0202 Heat Transfer Coefficient and Pressure Drop

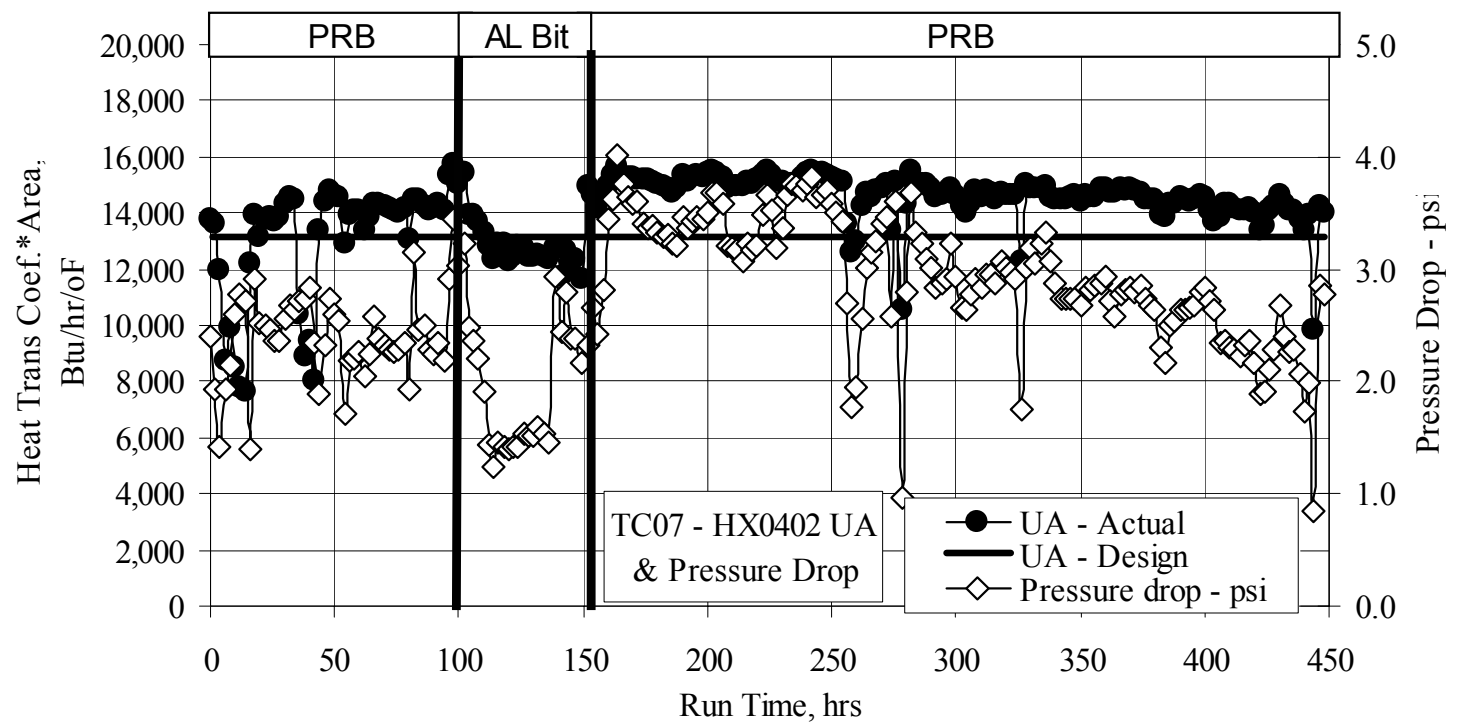

Figure 4.8-2 HXO402 Heat Transfer Coefficient and Pressure Drop 


\section{TERMS}

\section{Listing of Abbreviations}

\begin{tabular}{|c|c|}
\hline AAS & Automated Analytical Solutions \\
\hline ADEM & Alabama Department of Environmental Management \\
\hline $\mathrm{AFBC}$ & Atmospheric Fluidized-Bed Combustor \\
\hline APC & Alabama Power Company \\
\hline APFBC & Advance Pressurized Fluidized-Bed Combustion \\
\hline ASME & American Society of Mechanical Engineers \\
\hline AW & Application Workstation \\
\hline BET & Brunauer-Emmett-Teller (nitrogen-adsorption specific surface technique) \\
\hline BFI & Browning-Ferris Industries \\
\hline BFW & Boiler Feed Water \\
\hline BMS & Burner Management System \\
\hline $\mathrm{BOC}$ & BOC Gases \\
\hline $\mathrm{BOP}$ & Balance-of-Plant \\
\hline BPIR & Ball Pass Inner Race, Frequencies \\
\hline BPOR & Ball Pass Outer Race, Frequencies \\
\hline BSF & Ball Spin Frequency \\
\hline CAD & Computer-Aided Design \\
\hline CAPTOR & Compressed Ash Permeability Tester \\
\hline CEM & Continuous Emissions Monitor \\
\hline CFB & Circulating Fluidized Bed \\
\hline CFR & Code of Federal Regulations \\
\hline $\mathrm{CHE}$ & Combustor Heat Exchanger \\
\hline $\mathrm{COV}$ & Coefficient of Variation (Standard Deviation/Average) \\
\hline $\mathrm{CPC}$ & Combustion Power Company \\
\hline CPR & Cardiopulmonary Resuscitation \\
\hline CTE & Coefficient of Thermal Expansion \\
\hline $\mathrm{DC}$ & Direct Current \\
\hline DCS & Distributed Control System \\
\hline DHL & DHL Analytical Laboratory, Inc. \\
\hline DOE & U.S. Department of Energy \\
\hline DSRP & Direct Sulfur Recovery Process \\
\hline $\mathrm{E} \& \mathrm{I}$ & Electrical and Instrumentation \\
\hline EDS or EDX & Energy-Dispersive X-Ray Spectroscopy \\
\hline EERC & Energy and Environmental Research Center \\
\hline EPRI & Electric Power Research Institute \\
\hline ESCA & Electron Spectroscopy for Chemical Analysis \\
\hline FCC & Fluidized Catalytic Cracker \\
\hline FCP & Flow-Compacted Porosity \\
\hline FFG & Flame Front Generator \\
\hline FI & Flow Indicator \\
\hline FIC & Flow Indicator Controller \\
\hline FOAK & First-of-a-Kind \\
\hline FTF & Fundamental Train Frequency \\
\hline
\end{tabular}




\begin{tabular}{|c|c|}
\hline FW & Foster Wheeler \\
\hline GBF & Granular Bed Filter \\
\hline GC & Gas Chromatograph \\
\hline GEESI & General Electric Environmental Services, Inc. \\
\hline $\mathrm{HHV}$ & Higher Heating Valve \\
\hline $\mathrm{HP}$ & High Pressure \\
\hline HRSG & Heat Recovery Steam Generator \\
\hline HTF & Heat Transfer Fluid \\
\hline НТНР & High-Temperature, High-Pressure \\
\hline $\mathrm{I} / \mathrm{O}$ & Inputs/Outputs \\
\hline ID & Inside Diameter \\
\hline IF\&P & Industrial Filter \& Pump \\
\hline IGV & Inlet Guide Vanes \\
\hline IR & Infrared \\
\hline KBR & Kellogg Brown \& Root, Inc. \\
\hline LAN & Local Area Network \\
\hline LHV & Lower Heating Valve \\
\hline LIMS & Laboratory Information Management System \\
\hline LMZ & Lower Mixing Zone \\
\hline $\mathrm{LOC}$ & Limiting Oxygen Concentration \\
\hline LOI & Loss on Ignition \\
\hline LPG & Liquefied Propane Gas \\
\hline LSLL & Level Switch, Low Level \\
\hline MAC & Main Air Compressor \\
\hline MCC & Motor Control Center \\
\hline MMD & Mass Median Diameter \\
\hline MS & Microsoft Corporation \\
\hline NDIR & Nondestructive Infrared \\
\hline NETL & National Energy Technology Laboratory \\
\hline NFPA & National Fire Protection Association \\
\hline $\mathrm{NO}_{x}$ & Nitrogen Oxides \\
\hline NPDES & National Pollutant Discharge Elimination System \\
\hline NPS & Nominal Pipe Size \\
\hline $\mathrm{OD}$ & Outside Diameter \\
\hline ORNL & Oak Ridge National Laboratory \\
\hline OSHA & Occupational Safety and Health Administration \\
\hline OSI & OSI Software, Inc. \\
\hline P\&IDs & Piping and Instrumentation Diagrams \\
\hline PC & Pulverized Coal \\
\hline PCD & Particulate Control Device \\
\hline PCME & Pollution Control \& Measurement (Europe) \\
\hline PDI & Pressure Differential Indicator \\
\hline PDT & Pressure Differential Transmitter \\
\hline PFBC & Pressurized Fluidized-Bed Combustion \\
\hline PI & Plant Information \\
\hline PLC & Programmable Logic Controller \\
\hline PPE & Personal Protection Equipment \\
\hline
\end{tabular}




\section{TCO7 TECHNICAL PROGRESS REPORT}

$\begin{array}{ll}\text { PRB } & \text { Powder River Basin } \\ \text { PSD } & \text { Particle-Size Distribution } \\ \text { PSDF } & \text { Power Systems Development Facility } \\ \text { AP or DP or dP } & \text { Pressure Drop or Differential Pressure } \\ \text { PT } & \text { Pressure Transmitter } \\ \text { RAPTOR } & \text { Resuspended Ash Permeability Tester } \\ \text { RFQ } & \text { Request for Quotation } \\ \text { RO } & \text { Restriction Orifice } \\ \text { RPM } & \text { Revolutions Per Minute } \\ \text { RSSE } & \text { Reactor Solid Separation Efficiency } \\ \text { RT } & \text { Room Temperature } \\ \text { RTI } & \text { Research Triangle Institute } \\ \text { SCS } & \text { Southern Company Services, Inc. } \\ \text { SEM } & \text { Scanning Electron Microscopy } \\ \text { SGC } & \text { Synthesis Gas Combustor } \\ \text { SGD } & \text { Safe Guard Device } \\ \text { SMD } & \text { Sauter Mean Diameter } \\ \text { SRI } & \text { Southern Research Institute } \\ \text { SUB } & \text { Start-up Burner } \\ \text { TCLP } & \text { Toxicity Characteristic Leaching Procedure } \\ \text { TR } & \text { Transport Reactor } \\ \text { TRDU } & \text { Transport Reactor Demonstration Unit } \\ \text { TRS } & \text { Total Reduced Sulfur } \\ \text { TSS } & \text { Total Suspended Solids } \\ \text { UBP } & \text { Uncompacted Bulk Porosity } \\ \text { UMZ } & \text { Upper Mixing Zone } \\ \text { UND } & \text { University of North Dakota } \\ \text { UPS } & \text { Uninterruptible Power Supply } \\ \text { UV } & \text { Ultraviolet } \\ \text { VFD } & \text { Variable Frequency Drive } \\ \text { VOCs } & \text { Volatile Organic Compounds } \\ \text { WGS } & \text { Water-Gas Shift } \\ \text { WPC } & \text { William's Patent Crusher } \\ \text { XRD } & \text { X-Ray Diffraction } \\ \text { XXS } & \text { Extra, Extra Strong } \\ & \end{array}$




\section{Listing of Units}

\section{UNITS OF MEASURE}

acfm

Btu

${ }^{\circ} \mathrm{C}$

${ }^{\circ} \mathrm{F}$

$\mathrm{ft}$

FPS

gpm

$\mathrm{g} / \mathrm{cm}^{3}$ or $\mathrm{g} / \mathrm{cc}$

$\mathrm{g}$

$\mathrm{GPa}$

hp

hr

in.

inWg (or in Wc)

in.-lb

${ }^{\circ} \mathrm{K}$

$\mathrm{kg}$

$\mathrm{kJ}$

$\mathrm{kPa}$

ksi

$\mathrm{m}$

$\mathrm{MB}$

$\min$

$\mathrm{mm}$

$\mathrm{MPa}$

msi

MW

$\mathrm{m} / \mathrm{s}$

$\mathrm{MBtu}$

$\mathrm{m}^{2} / \mathrm{g}$

$\mu$ or $\mu \mathrm{m}$

$\mathrm{dp}_{50}$

ppm

$\operatorname{ppm}(\mathrm{v})$

ppm (w)

$\mathrm{lb}$

pph

psi

psia

psid

psig

$\Delta \mathrm{P}$

$\mathrm{rpm}$

$\mathrm{s}$ or sec actual cubic feet per minute

British thermal units

degrees Celsius or centigrade

degrees Fahrenheit

feet

feet per second

gallons per minute

grams per cubic centimeter

grams

gigapascals

horsepower

hour

inches

inches, water gauge (inches, water column)

inch pounds

degrees Kelvin

kilograms

kilojoules

kilopascals

thousand pounds per square inch

meters

megabytes

minute

millimeters

megapascals

million pounds per square inch

megawatts

meters per second

Million British thermal units

square meters per gram

microns or micrometers

particle-size distribution at 50 percentile

parts per million

parts per million (volume)

parts per million (weight)

pounds

pounds per hour

pounds per square inch

pounds per square inch absolute

pounds per square inch differential

pounds per square inch gauge

pressure drop

revolutions per minute

seconds 


\section{TCO7 TECHNICAL PROGRESS REPORT}

$\begin{array}{ll}\text { scf } & \text { standard cubic feet } \\ \text { scfh } & \text { standard cubic feet per hour } \\ \text { scfm } & \text { standard cubic feet per minute } \\ \text { V } & \text { volts } \\ \text { W } & \text { watts }\end{array}$

